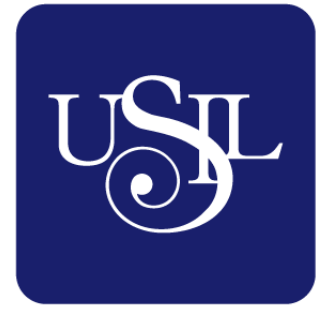

UNIVERSIDAD

SAN IGNACIO

DE LOYOLA

ESCUELA DE POSTGRADO

\title{
PLAN ESTRATÉGICO DE LA UNIDAD ESTRATÉGICA DE NEGOCIOS TUBOS Y ESQUINEROS - CARVIMSA LIMA-PERÚ
} (2018-2021)

Trabajo de Investigación para optar el grado de:

YANINE STEFANY CASANOVA OPORTO

Maestro en Ciencias Empresariales con mención en Gestión Financiera

\section{LENIZA MÁRILYN LLANOS CHÁVEZ}

Maestro en Ciencias Empresariales con mención en Gestión Financiera

ANGELA ANDREA RODRIGUEZ GARCIA

Maestro en Ciencias Empresariales con mención en Gestión Financiera

Asesor:

Carlos Eduardo Ossio Sal y Rosas

Lima - Perú 


\section{Resumen Ejecutivo}

La presente tesis ha sido desarrollada con la finalidad de ayudar a la empresa Cartones Villa Marina S.A. (CARVIMSA) a incrementar las ventas y la participación en el mercado de su Unidad Estratégica de Negocios (UEN) Tubos y Esquinero, para lo cual se ha elaborado un Plan Estratégico para el periodo 2018 a 2021.

La empresa Cartones Villa Marina S.A. (CARVIMSA) inició sus operaciones en el año 1997 implementado la Unidad Estratégica de Negocios (UEN) de Corrugado y Microcorrugado. CARVIMSA identificó que dependía mucho de sus proveedores de materia prima, razón por la cual en el año 2009 implementó la UEN de Papel y Empalmadas a fin de tener un molino de papel propio y tener el $80 \%$ del abastecimiento de materia prima. Al final del año 2010, esta UEN obtuvo una producción acumulada de 21,538 TM; de los cuales el 84\% eran bobinas utilizadas en la UEN de Corrugado y Microcorrugado (Bobinas originales) y un $16 \%$ en saldos de bobinas, denominados Side Roll. Los Side Roll se almacenaron desde abril 2010 hasta febrero 2013, generando un inventario acumulado de 883.18 TM, convirtiéndose en dinero inmovilizado debido a los altos costos de almacenaje en los que se incurría. Es por ello por lo que CARVIMSA, a fin de reducir estos inventarios (Side Roll), desarrolló nuevos productos para atender al mercado nacional en diferentes sectores, tales como: agroindustrial, pesquero, cosméticos, alimenticio e industrial; a través de la creación de la UEN de "Tubos y Esquineros", la cual usa como materia prima estas bobinas de papel de corto ancho (Side Roll).

Del análisis realizado en la presente tesis se ha determinado que un incremento en las exportaciones agrícolas traerá consigo un incremento en la demanda de los esquineros de cartón; ya que estos son necesarios para asegurar la estabilidad de las cajas apiladas; 
garantizando de esta forma que el producto a exportar llegue en óptimas condiciones al consumidor final. Así mismo, con respecto a la demanda de los tubos, se ha determinado que un incremento de las exportaciones textiles ampliará el mercado para este. Por otro lado, debido a los acuerdos contractuales entre CARVIMSA y el cliente Solpack; donde se establece el traslado de la planta de Chile a Perú a inicios del 2018, se ha estimado un crecimiento en la producción de Tubos y Esquineros en 2,892 toneladas anuales.

Con la información obtenida del análisis interno y externo realizado, se elaboraron la Matriz de Evaluación de Factores Internos (EFI), Matriz Evaluación de Factores Externos (EFE) y la Matriz de Perfil Competitivo (MPC), los cuales permitieron desarrollar alternativas de estrategias para la UEN “Tubos y Esquineros”. Así mismo, luego de la evaluación de cada una de las estrategias posibles a través de la matriz de Planeación Estratégica Cuantitativa (MPEC), se seleccionó la estrategia de penetración de mercado debido a que la empresa proyecta un crecimiento sostenido de ventas en un 55\% para el 2018, $27 \%$ para el 2019, 20\% para el 2020 y $11 \%$ para el 2021.

Posteriormente, se realizó la evaluación financiera del Plan Estratégico propuesto para la UEN “Tubos y Esquineros” de la empresa Carvimsa, para lo cual se determinó el Costo Promedio Ponderado de Capital (WACC) y el Costo de Oportunidad (COK) con el Modelo de Valoración de Activos Financieros (CAPM); los cuales constituyen valores necesarios para determinar la viabilidad del proyecto a través de las herramientas Valor Actual Neto (VAN) y Tasa Interna de Retorno (TIR). Finalmente, los valores obtenidos fueron VAN de S/. 4,997,214.02 y una TIR de $151 \%$, los cuales permiten recomendar la implementación del Plan Estratégico Propuesto. 


\section{Tabla de Contenido}

Introducción

Capítulo I. Generalidades

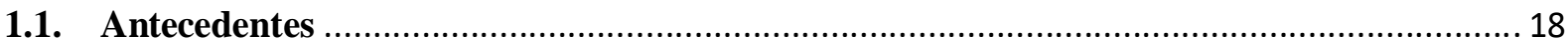

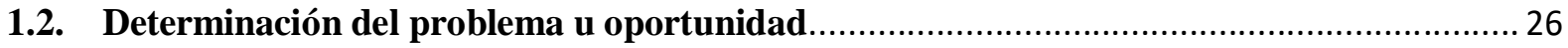

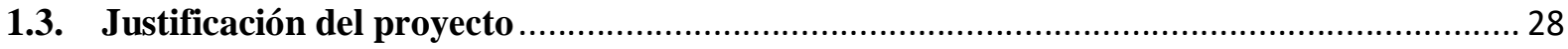

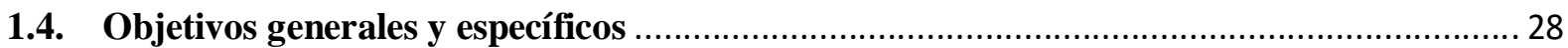

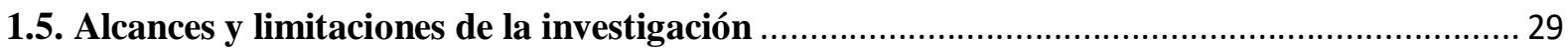

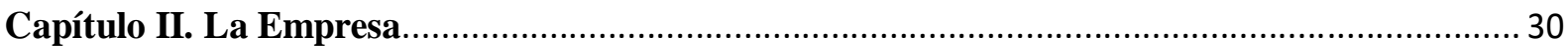

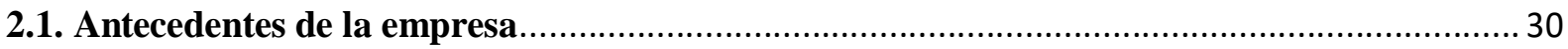

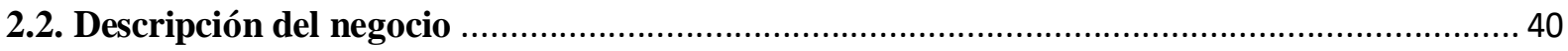

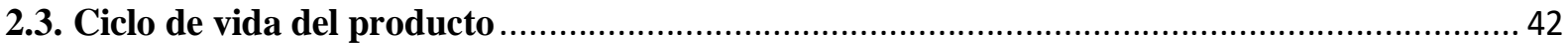

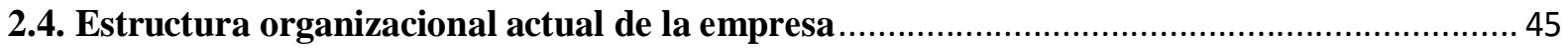

2.5. Situación de mercado y financiera actual de la industria .................................................. 72

Capítulo III. Formulación de visión, misión y valores de la empresa .......................................... 75

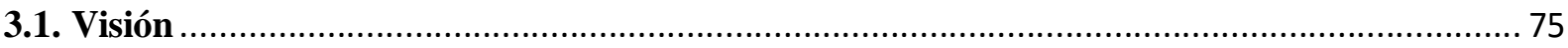

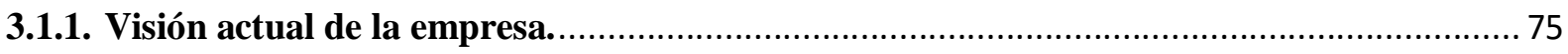

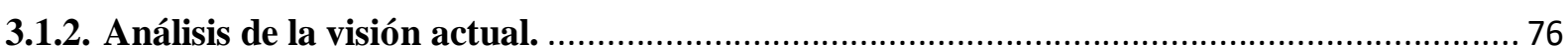

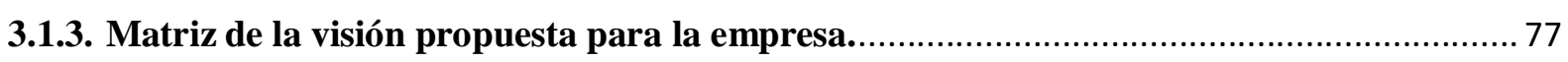

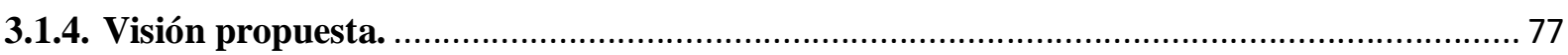

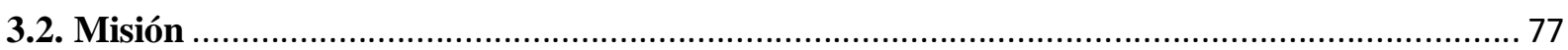

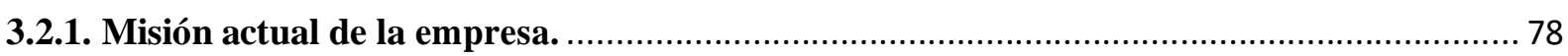

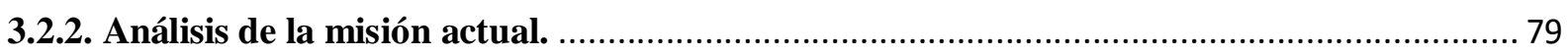

3.2.3. Elementos de la misión propuesta para la empresa............................................................ 80

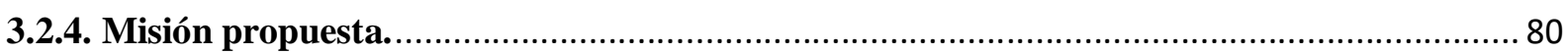

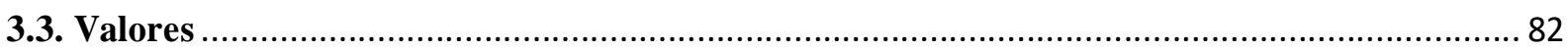

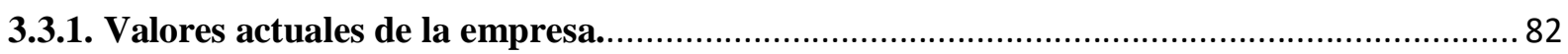

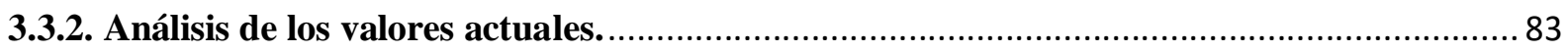

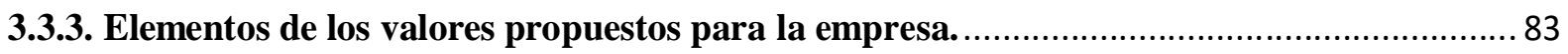

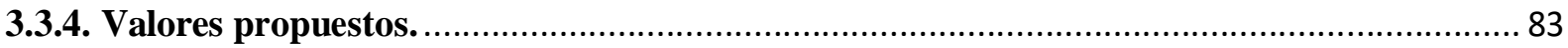

3.4. Alineamiento estratégico de la visión, misión y valores de la UEN Tubos y Esquineros ....... 84

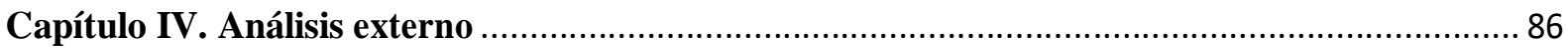

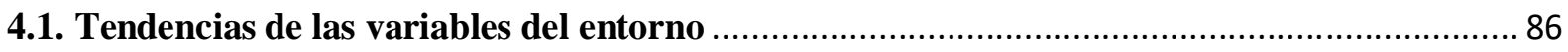

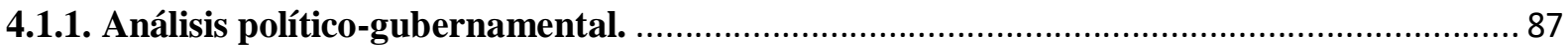

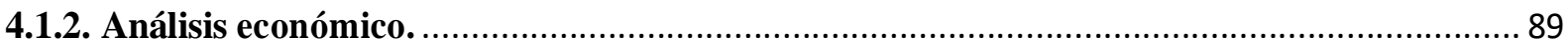




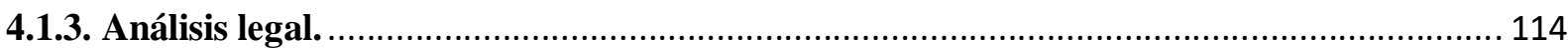

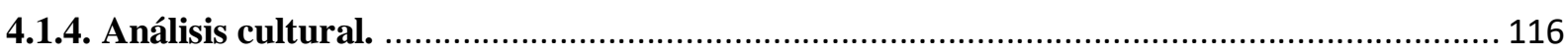

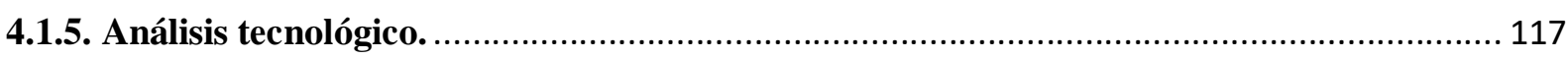

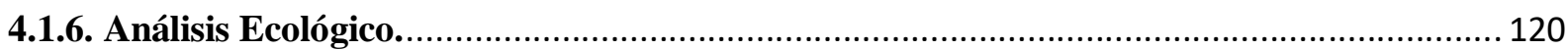

4.2. Impacto en clientes / proveedores de cada una de las variables del entorno ….................... 122

4.3. Efecto en la empresa de cada una de las variables del entorno …....................................... 125

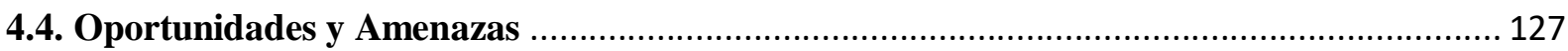

4.5. Matriz de evaluación de los factores externos EFE ............................................................... 130

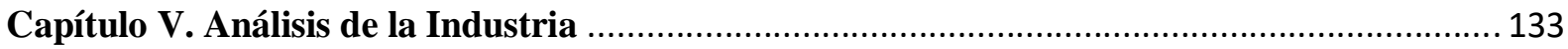

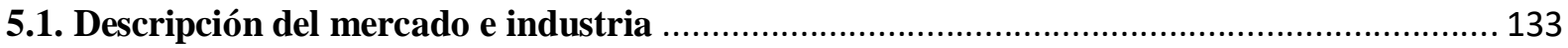

5.2. Descripción de las cinco fuerzas competitivas de la ind ustria .......................................... 144

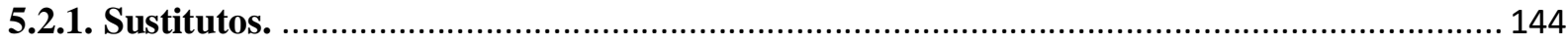

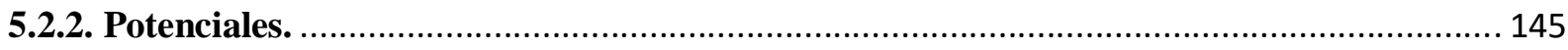

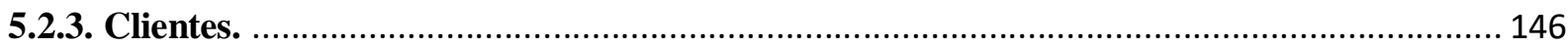

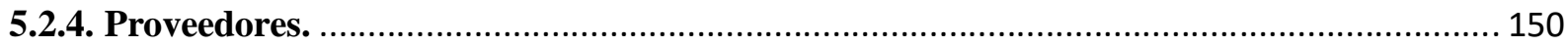

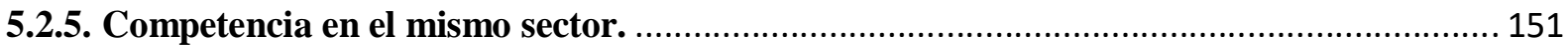

5.3. Matriz de atractividad de cada una de las fuerzas ........................................................... 154

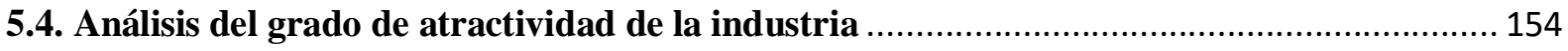

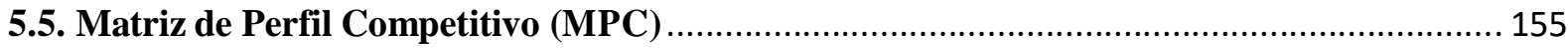

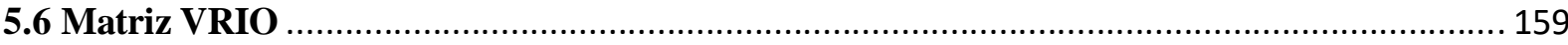

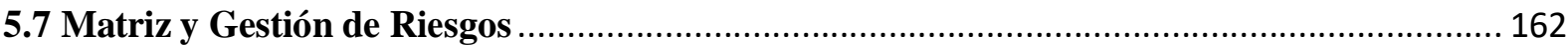

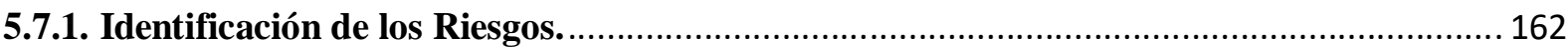

5.7.1.1. Riesgo Moderado de Crecimiento del Mercado ........................................................... 162

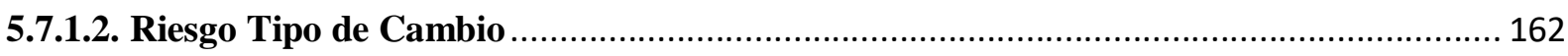

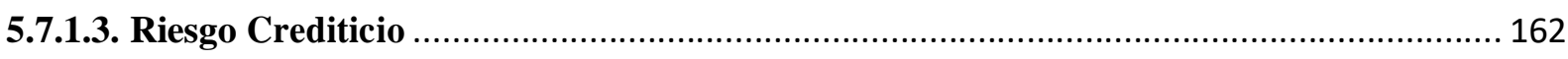

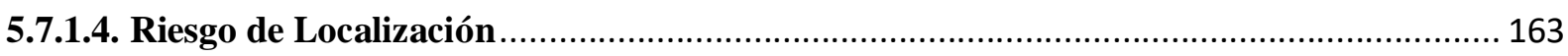

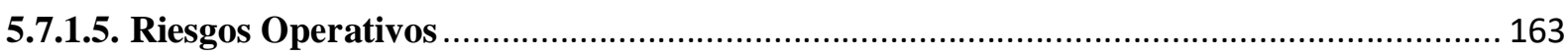

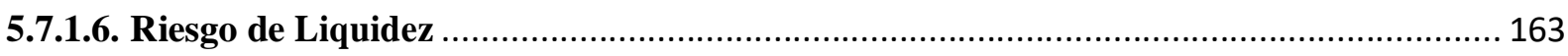

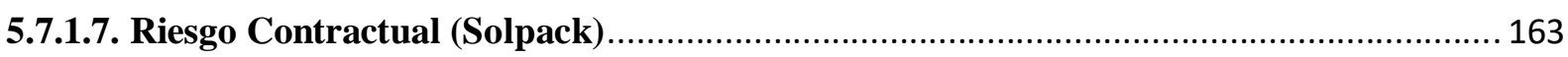

5.7.1.8. Riesgo Volatilidad del Comodity Cartón................................................................. 163

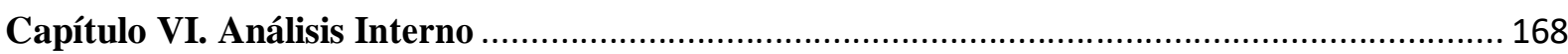

6.1. Descripción de las actividades de la cadena de valor de la empresa, logística interna, operaciones, logística externa, mercadotecnia, servicios, adquisiciones, RR.HH., tecnología e

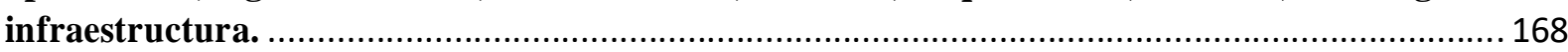

6.2. Indicadores de cada una de las actividades de la cadena de valor ..................................... 188 
6.3. Benchmarking y comparación con los líderes de la industria de cada una de las actividades

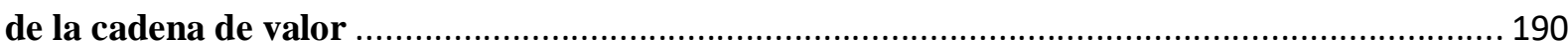

6.4. Determinar las competencias de la empresa ............................................................... 192

6.5. Identificación y determinación de las ventajas competitivas de la empresa ........................ 195

6.6 Matriz de Evaluación de los factores Internos EFI ............................................................. 197

Capítulo VII. Formulación de los Objetivos y Diseño de las Estrategias................................... 199

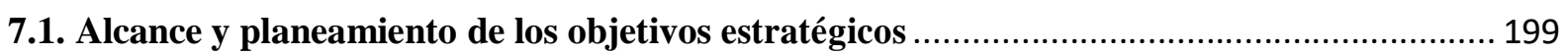

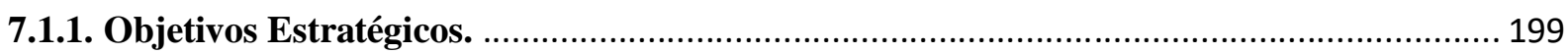

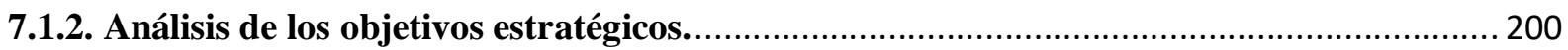

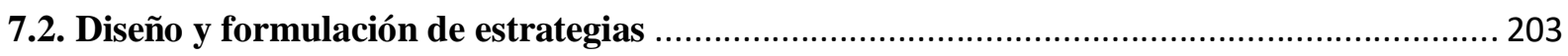

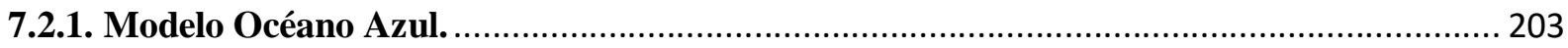

7.2.1.1. Lienzo de la estrategia actual de la empresa .............................................................. 206

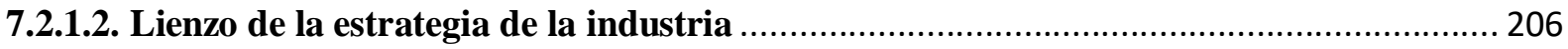

7.2.1.3. Matriz (eliminar, reducir, incrementar, crear) ....................................................... 207

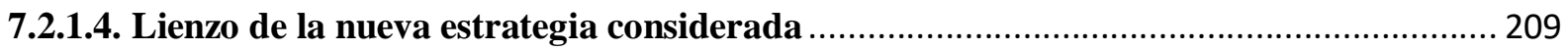

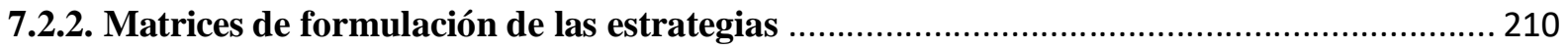

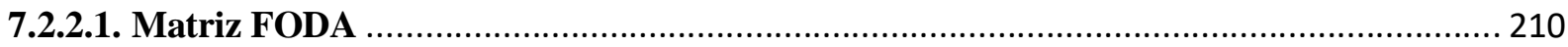

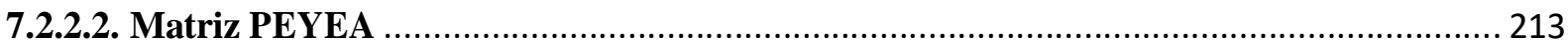

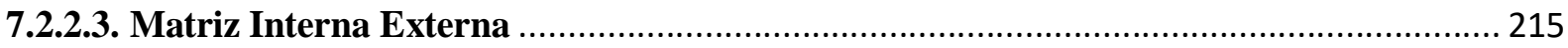

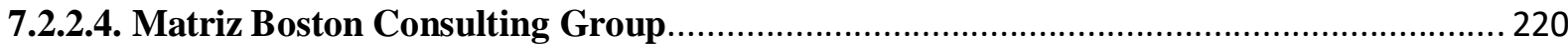

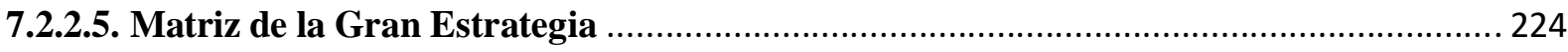

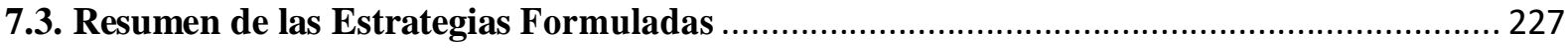

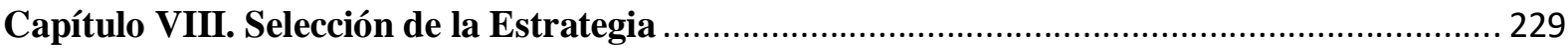

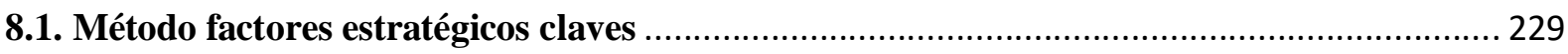

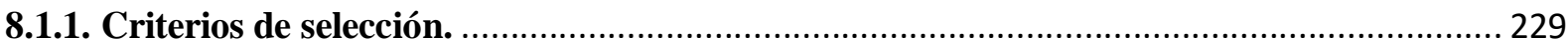

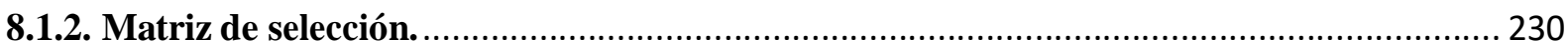

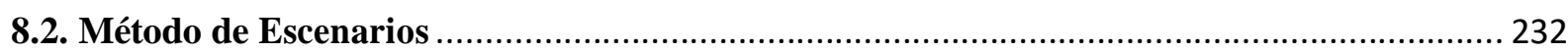

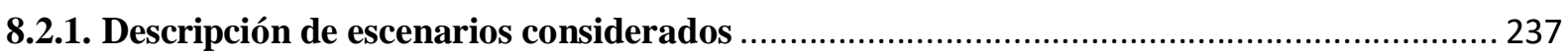

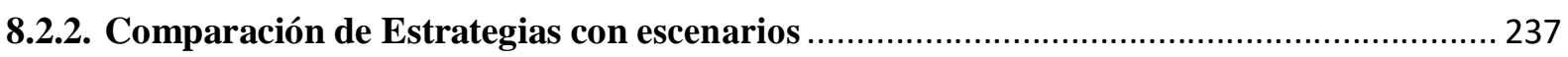

8.3. Matriz de Planeación Estratégica Cuantitativa MPEC .................................................. 239

8.4. Descripción de estrategia seleccionada................................................................. 240

8.5. Descripción de estrategia contingente …..................................................................... 241

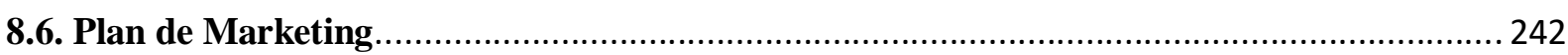

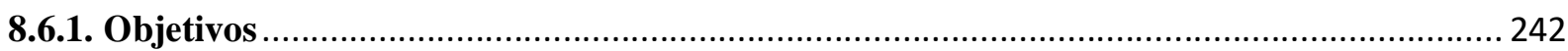

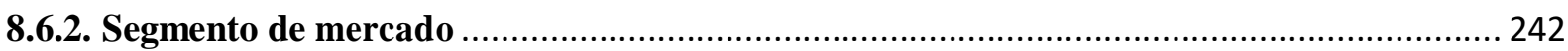

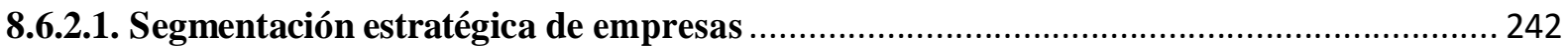




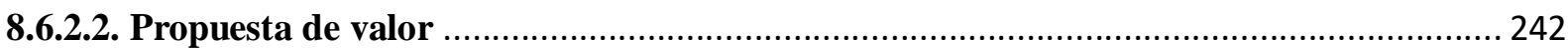

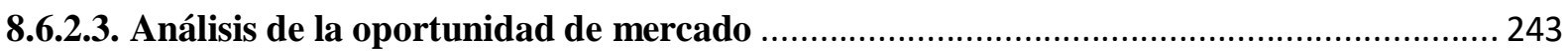

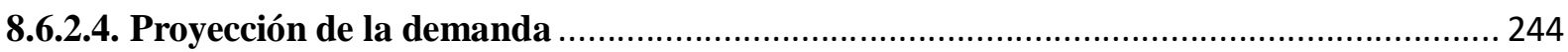

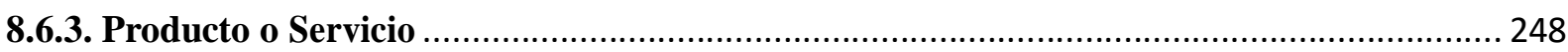

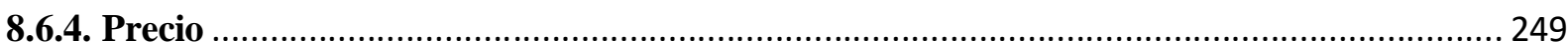

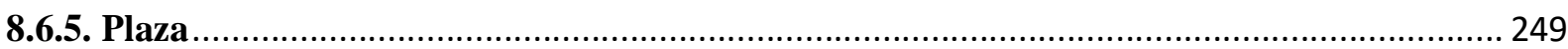

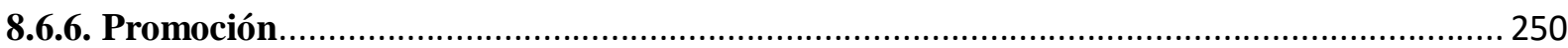

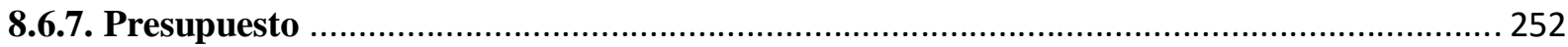

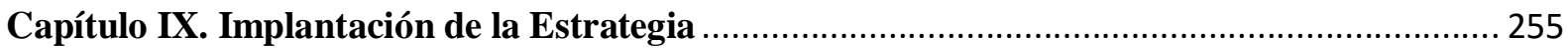

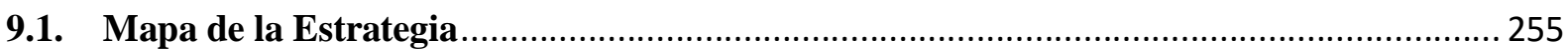

9.2. Objetivos específicos según el mapa de la estrategia ...................................................... 255

9.3. Indicadores para cada uno de los objetivos específicos .................................................. 257

9.4. Metas para cada uno de los objetivos específicos ............................................................ 260

9.5. Iniciativas (acciones a llevar a cabo para cada uno de los objetivos específicos) Estrategias,

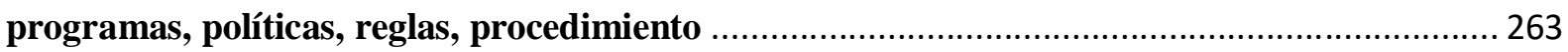

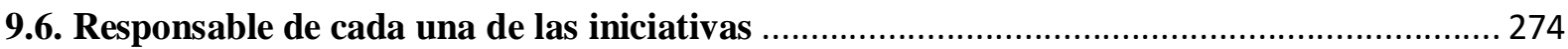

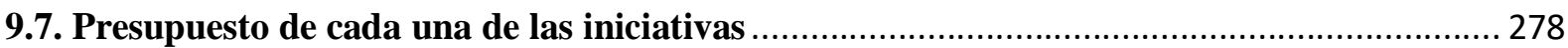

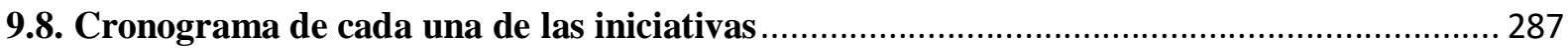

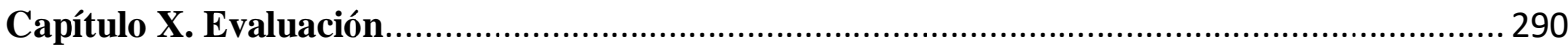

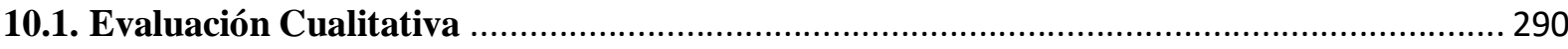

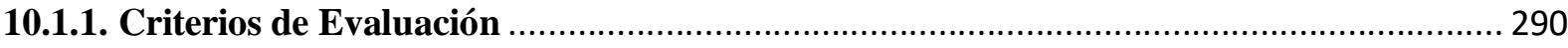

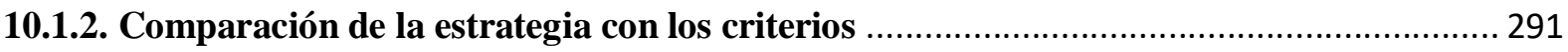

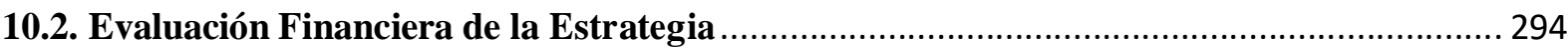

10.2.1. Proyección de estados financieros (situación actual y con la nueva estrategia) .............. 294

10.2.2. Estado de resultados (situación actual y con la nueva estrategia) .................................. 299

10.2.3. Balance general (situación actual y con la nueva estrategia) ....................................... 302

10.2.4. Flujo de efectivo (situación actual y con la nueva estrategia) ......................................... 305

10.2.5. Proyección de flujos (situación actual y con la nueva estrategia) .................................... 305

10.2.6. Evaluación Financiera (VAN, TIR, WACC, COK, PRC y ratios financieras) ................ 308

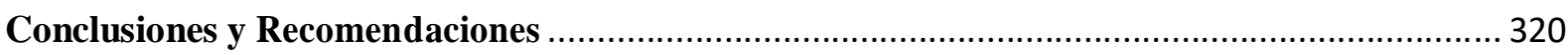

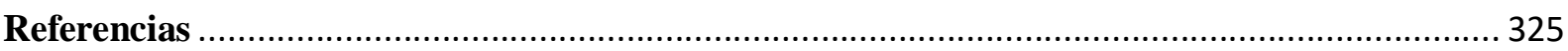

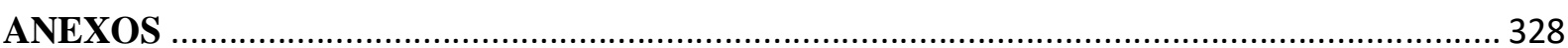




\section{Índice de Figuras}

Figura 01

Figura 02

Figura 03

Figura 04

Figura 05

Figura 06

Figura 07

Figura 08

Figura 09

Figura 10

Figura 11

Figura 12

Figura 13

Figura 14

Figura 15

Figura 16

Figura 17

Figura 18

Figura 19

Figura 20

Figura 21

Figura 22

Figura 23

Figura 24

Figura 24

Figura 26

Figura 27

Figura 28

Figura 29

Figura 30

Figura 31

Figura 32

Figura 33

Figura 34

Figura 35

Figura 36

Figura 37

Figura 38
Moda Victoriana siglo XIX

Sombreros siglo XIX

Patente de Albert L. Jones

Patente de Oliver Long

Patente de Oliver Long

Viviendas emergentes en Kobe

Iglesia en Kobe hasta 1995

Casa de Papel en Japón 1995

Puente en Francia 2007

Caja de cartón corrugado

Tubos de cartón

Esquineros de cartón

Bobinas de papel

Máquina Corrugadora

Ampliación de Máquina Corrugadora

Máquina de papel

34

Construcción de la nave de la planta de papel

Máquina de Papel de Línea de Secado 36

Línea de Tiempo de Historia de CARVIMSA

Máquina Tubera

39

Ciclo de vida de un producto en un mercado

Organigrama de CARVIMSA 46

Puestos de Trabajo de CARVIMSA 47

Puestos de Trabajo de CARVIMSA 48

Resultado del Factor “Comunicación” del periodo 2013 - 2017. Tomado de la Evaluación Anual de Carvimsa.

67

Resultado del Factor "Condiciones de Trabajo" del periodo 2013 - 2017.

Tomado de la Evaluación Anual de Carvimsa.

68

Resultado del Factor "Liderazgo" del periodo 2013 - 2017. Tomado de la

Evaluación Anual de Carvimsa. 69

Resultado del Factor “Capacitación” del periodo 2013 - 2017. Tomado de la

Evaluación Anual de Carvimsa. 70

Resultado del Factor "Identificación y Compromiso" del periodo 2013 - 2017.

Tomado de la Evaluación Anual de Carvimsa. 71

Resultado de Encuesta de Clima Laboral del periodo 2013 - 2017. Tomado de la Evaluación Anual de Carvimsa. 71

Estimación de daños del Fenómeno del Niño Costero (FEN) 201771

Perú: Número de Kilómetros afectados y destruidos de infraestructura agrícola, por departamento (marzo 2017) 73

Perú: Número de hectáreas afectadas y pérdidas de terreno agrícola, por departamento (marzo 2017) 74

Alineamiento Estratégico 85

El entorno externo 86

Índice de Solidez Monetaria 201588

Índice de Libertad Económica del Perú: 2015

Contribuciones a la variación del crecimiento del PIB real, 2016-2017

91 
Figura 39 Comercio internacional y producción industrial (promedio móvil de tres meses: Variación \% anualizada 92

Figura $40 \quad$ PMI de manufacturas (promedio móvil de tres meses; desviaciones respecto de 50) $\quad 92$

Figura 41

Figura 42

Figura 43

Figura 44

Figura 45

Figura 46

Figura 47

Figura 48

Figura 49

Figura 50

Figura 51

Figura 52

Figura 53

Figura 54

Figura 55

Figura 56

Figura 57

Figura 58

Figura 59

Figura 60

Figura 61

Figura 62

Figura 63

Figura 64

Figura 65

Figura 66

Figura 67

Figura 68

Figura 69

Figura 70

Figura 71

Figura 72

Figura 73

Figura 74

Figura 75

Figura 76

Figura 77
Confianza de los consumidores (Índice, 2010=100)

93

Inflación Mundial: Promedio móvil de tres meses; variación porcentual anualizada 94

Variaciones de los tipos de cambio efectivos reales, agosto de 2016 a febrero de 2017 95

PBI Semestral: variación \% real anual 2014 - $2016 \quad 98$

PBI primario y no primario: variación \% real 2013-1026 98

Encuesta de Expectativas Macroeconómicas: Crecimiento del PBI \%

Producción Manufacturera (millones de S/) 101

Manufactura primaria y no primaria (variación \%) 101

Exportaciones manufactureras (millones de US\$) 102

Producción agropecuaria 2012-2018 (variación \%) 103

Exportaciones agrícolas 2012-2018 (millones de US\$) 103

Producción del sector construcción (millones de S/) 104

Empresas Productoras de Papel Según Línea de Producto 105

Evolución de los índices de precios al por mayor de papel 106

Superávit y/o Déficit de la Balanza Comercial expresado en Millones de

Dólares febrero 2016-febrero $2017 \quad 108$

Exportaciones e Importaciones, variación porcentual expresado en Millones de

Dólares febrero 2016-febrero 2017 108

Exportación de maderas, papeles, y manufacturas (millones de US\$ a diciembre 2015) 109

Exportación de Papel y Cartón; Manufacturas de Pasta de Celulosa por País: Valor FOB (Miles de US\$) 109

Importaciones de Papel y Cartón en el periodo 2011-2015 (FOB US\$) 110

Importación de Papel y Cartón; Manufacturas de Pasta de Celulosa por País:

Valor FOB (Miles de US\$) 111

Encuesta de Expectativas Macroeconómicas: Inflación (\%)

Inflación: Variación \% marzo 2014-marzo $2017 \quad 112$

Encuesta de Expectativas Macroeconómicas: Tipo de

Cambio (S/ por US\$)

112

Tipo de cambio e intervención cambiaria del BCRP en el mercado spot

113

Correlación entre el Índice del dólar y el tipo de cambio S/US\$ 113

Máquina para fabricar tubos $\quad 119$

Máquina para fabricar esquineros 119

Producción manufacturera $\quad 135$

Manufactura primaria y no primaria $\quad 135$

Exportaciones manufactureras 136

Exportaciones de papel y cartón 2015 por países de destino 137

Importaciones de papel 2015 por países de origen. Tomado de OEC - Export

Destinations of contenedores de papel from Perú (2015) 138

Participación en el mercado "Tubos y Esquineros de Cartón” 138

Poder de negociación por tipo de empresas de la UEN Tubos y Esquineros 147

Sectores de ventas de la UEN Tubos y Esquineros 148

Matriz de Riesgo de la UEN Tubos y Esquineros 148

La cadena genérica de Valor. Tomado de Ventaja Competitiva 
Figura 78

Figura 79

Figura 80

Figura 81

Figura 82

Figura 83

Figura 84

Figura 85

Figura 86

Figura 87

Figura 88

Figura 89

Figura 90

Figura 91

Figura 92

Figura 93

Figura 94

Figura 95

Figura 96

Figura 97

Figura 98

Figura 99

Figura 100

Figura 101

Figura 102

Figura 103

Figura 104

Figura 105

Figura 106

Figura 107

Figura 108

Figura 109

Figura 110

Figura 111

Figura 112

Figura 113

Figura 114

Figura 115

Figura 116

Figura 117

Figura 118

Figura 119
Flujograma de proceso Venta de la UEN Tubos y Esquineros de Cartón

173

Flujograma de proceso de Fabricación de Tubos de Cartón 174

Flujograma de proceso de Fabricación de Esquineros de Cartón 175

Flujograma de proceso de Despacho de Productos Terminados de la UEN

Tubos y Esquinero de Cartón

176

Máquinas de corte y rebobinado de la UEN Tubos de CARVIMSA

Máquina tubera China de la UEN Tubos de CARVIMSA 178

Corte de la Máquina tubera China de la UEN Tubos de CARVIMSA

178

Máquina tubera casera de la UEN Tubos de CARVIMSA 179

Proceso de curado de tubos de la UEN Tubos de CARVIMSA

179

Salas de horno de tubos de la UEN Tubos de CARVIMSA 180

Despacho de tubos de la UEN Tubos de CARVIMSA $\quad 180$

Tubos de cartón para rollos de tela 181

Proceso de fabricación de esquineros de cartón 181

Cantidad de trabajadores por rango de edad 184

Cantidad de trabajadores por grado de instrucción

Layout de la Planta de Tubos y Esquineros 187

184

Transformación de las actividades en la cadena de valor a ventajas competitivas 191

Identificar la estrategia de una compañía: qué buscar 203

Diagrama del Océano azul para la UEN de Tubos y Esquineros de

CARVIMSA 204

Proceso de Producción de Tubos 205

Lienzo Estratégico de la UEN Tubos y Esquineros de Cartón de

CARVIMSA

206

Lienzo Estratégico de la industria de la UEN Tubos y Esquineros de Cartón

CARVIMSA en comparación con la competencia 207

Matriz ERAC (Eliminar, Reducir, Aumentar y Crear) 208

Lienzo de la nueva estrategia de la UEN Tubos y Esquineros de Cartón -

CARVIMSA 209

Estrategias de la matriz FODA de la nueva estrategia de la UEN Tubos y

Esquineros de Cartón - CARVIMSA

212

Modelo de los cuatros cuadrantes 214

Factores determinantes 214

Matriz PEYEA de la UEN Tubos y esquineros de cartón 215

Modelo de los cuatros cuadrantes 216

Matriz Interna Externa de la UEN Tubos y esquineros de cartón 219

Matriz BCG. Posición de la UEN Tubos y Esquineros de CARVIMSA 223

Matriz MGE. Posición de la Empresa CARVIMSA 227

Criterios de decisión de las Alternativas de estrategias $\quad 230$

Etapa de la planeación de escenarios 232

Ejes de la Planeación de Escenarios de la UEN Tubos y Esquineros de

CARVIMSA

235

Página Web de CARVIMSA 251

Facebook de CARVIMSA 251

Stand de CARVIMSA en la feria Expo alimentaria 2018

252

Mapa de la estrategia de CARVIMSA 255

Capacitaciones Internas a los Ejecutivos de ventas 264

Capacitaciones Externas a los Ejecutivos de ventas 265

Total de Horas Hombre Capacitaciones Ejecutivos de Venta 
Figura 120

Figura 121

Figura 122

Figura 123

Figura 124

Figura 125

Figura 126

Figura 127

Figura 128

Figura 129

Figura 130

Figura 131

Figura 132

Figura 133

Figura 134

Figura 135

Figura 136

Figura 137

Figura 138

Figura 139

Figura 140

Figura 141

Figura 142

Figura 143

Figura 144

Figura 145

Figura 146

Figura 147

Figura 148

Figura 149

Figura 150

Figura 151

Figura 152

Figura 153

Figura 154

Figura 155
Capacitaciones Seguridad y Salud en el Trabajo (SST)

265

Capacitaciones Gestión Ambiental 266

Total de Horas Hombre Capacitaciones Operarios 266

Ficha técnica del Proyecto "Capacitaciones en Gestión ambiental."

267

Ficha técnica del Proyecto "Capacitaciones sobre Seguridad y Salud en el

Trabajo (SST)." 268

Ficha técnica del Proyecto "Capacitaciones sobre conocimiento del producto, la competencia y el cliente." 269

Ficha técnica del Proyecto "Capacitaciones sobre técnicas de ventas" 270

Ficha técnica del Proyecto "Elaboración y ejecución de programas de visitas a clientes" 271

Ficha técnica del Proyecto "Elaboración y ejecución de proyecto Máquina Tubera $N^{\circ} 7$ y 8 " 272

Ficha técnica del Proyecto "Elaboración y ejecución de proyecto Máquina Cámara de Frío." 273

Cronograma de iniciativas de la fuerza de Crecimiento y Aprendizaje de la UEN Tubos y Esquineros - CARVIMSA 288

Cronograma de iniciativas de la fuerza de Procesos Internos de la UEN Tubos y Esquineros - CARVIMSA 288

Cronograma de iniciativas de la fuerza de Clientes de la UEN Tubos y

Esquineros - CARVIMSA 289

Cronograma de iniciativas de la fuerza Financiera de la UEN Tubos y

Esquineros - CARVIMSA 289

Presupuesto de Ventas de la UEN Tubos y Esquineros - CARVIMSA 295

Matriz Consolidada de Estructura de Costos y Gastos de la UEN Tubos y

Esquineros - CARVIMSA 296

Matriz de Tubos de Estructura de Costos y Gastos de la UEN Tubos y

Esquineros - CARVIMSA 297

Matriz de Esquineros de Estructura de Costos y Gastos de la UEN Tubos y Esquineros 298

Fórmula del Cálculo del COK 309

Valores para el cálculo del COK. Valores tomados de SUNAT, Damodaran y BCRP. 309

Fórmula de cálculo del Beta Apalancada 310

Aplicación de los valores para el cálculo del COK

Fórmula del WACC

311

Valores para el cálculo del WACC.

Aplicación de los valores para el cálculo del WACC

Cálculo del VAN $\quad 312$

Cálculo de la TIR 313

Cálculo del PRC 313

Fórmula de Razón corriente $\quad 314$

Fórmula de la prueba ácida $\quad 314$

Fórmula de la prueba defensiva $\quad 315$

Fórmula de la rotación de inventarios

315

Fórmula de la rotación de cuentas por cobrar $\quad 316$

Fórmula de la rotación de cuentas por pagar 316

Fórmula de endeudamiento total 317

Fórmula de deuda a capital 317
311 
Figura 156 Fórmula de margen de utilidad 


\section{Índice de Tablas}

Tabla 01

Listado de Empresas en la Actualidad

22

Tabla 02 Clientes Top por Unidad Estratégica de Negocio Cartón Corrugado y

Microcorrugado 33

Tabla 03 Clientes Top por Unidad Estratégica de Negocio Bobinas de Papel

Tabla 04

Clientes Top por Unidad Estratégica de Negocio de Tubos y Esquineros

Tabla 05

Ventas y Utilidades antes de impuesto por año 43

Tabla 06

Tabla 07

Ventas y Utilidades antes de impuesto por Papel y Empalmadas

Tabla 08

Descripción del puesto del Gerente General

Tabla 09

Descripción del puesto del Gerente Administrativo finan

Tabla 10

Descripción del puesto del Gerente de Planta

49

Tabla 11

Descripción del puesto del Gerente de Ventas 51

Tabla 12

Descripción del puesto del Jefe Administrativo

52

53

Tabla 13

Descripción del puesto del Jefe de Aseguramiento de Calidad

Tabla 14

Descripción del puesto del Jefe de Mantenimiento Eléctric

Tabla 15

Descripción del puesto del Jefe de Mantenimiento Mecánico

55

Tabla 16

Descripción del puesto del Jefe de Producción $\quad 57$

Tabla 17

Descripción del puesto del Jefe de Tesorería $\quad 58$

Tabla 18

Descripción del puesto del Jefe de Créditos y Cobranza 59

Tabla 19

Descripción del puesto del Jefe de Logística

60

Tabla 20

Descripción del puesto del Jefe de Sistemas

61

Tabla 21

Descripción del puesto del Jefe de Almacén Productos Terminados

62

Tabla 22

Descripción del puesto del Jefe de Auditoria

63

Tabla 23

Descripción del puesto del Jefe de Auditoria

64

Tabla 24

Descripción del puesto del Jefe de Servicio al cliente

Tabla 25

Descripción del puesto del Jefe de Ingeniería de

Tabla 26

Características de una declaración de visión

75

Tabla 27

Matriz de la visión propuesta

77

Tabla 28

Características de una declaración de Misión

78

Tabla 29

Cumplimiento de las Características la Misión Actual de CARVIMSA

79

Tabla 30

Tabla 31

Características de una declaración de Misión

80

Tabla 32

Características la misión propuesta 81

Tabla 33

Valores actuales de la empresa CARVIMSA

Valores propuestos para la unidad estratégica de negocio de Tubos y Esquineros 83

Tabla 34 Alineamiento estratégico de la visión, misión y valores propuestos

Tabla 35 Impacto en clientes y proveedores en cada variable del entorno

Tabla 36

Efecto de la empresa en cada variable del entorno 125

Tabla 37

Cinco pasos para la elaboración de la Matriz EFE 131

Tabla 38

Matriz EFE de la UEN Tubos y Esquineros de CARVIMSA

Tabla 39

El mercado Peruano del Sector Cartón

140

Tabla 40 Ventas Históricas y Proyecciones en TM del producto "Tubos de Cartón” de sus principales clientes 141

Tabla 41 Precios Históricos y Proyecciones en Dólares Americanos por TM vendida del producto "Tubos de Cartón" de sus principales clientes 
Tabla 42 Ventas Históricas y Proyecciones en TM del producto "Esquineros de Cartón" de sus principales clientes 143

Tabla 43 Precios Históricos y Proyecciones en Dólares Americanos por TM vendida del producto "Esquineros de Cartón" de sus principales clientes

Tabla 44

Las cinco fuerzas de Porter 144

Tabla $45 \quad$ Factores Determinantes de la Amenaza de Productos Sustitutos 145

Tabla 46 Factores Determinantes de la Amenaza de Nuevos

Competidores Entrantes 146

Tabla 47 Lista de Clientes de la UEN Tubos y Esquineros de CARVIMSA 2016

Tabla 48

Factores Determinantes del Poder de Negociación de los clientes 150

Tabla 49

Factores Determinantes del Poder de Negociación de los proveedores

Tabla 50

Factores Determinantes de la Rivalidad entre los Competidores Existentes 153

Tabla 51

Matriz de atractividad de cada una de las Cinco Fuerzas de Porter 154

Tabla 52

Tabla de Calificaciones de la Matriz MPC

155

Tabla 53

Matriz de Perfil Competitivo

159

Tabla 54

Tabla 55

Tabla 56

Matriz Vrio

160

Recursos Matriz Vrio 161

Tabla 57

Categoría de Riesgo

164

Tabla 58

Tipo de Impacto

164

Tabla 59

Valoración de Impacto y Prioridad de la UEN Tubos y Esquineros

Responsables de Identificación del Riesgo

166

Tabla 60

Estrategia de Respuesta adaptada

166

Tabla 61

Tabla 62

Tabla 63

Tabla 64

Tabla 65

Tabla 66

Tabla 67

Plan de Respuesta Adaptado del Riesgo - UEN Tubos y Esquineros

167

Tabla de Máquinas utilizadas para la fabricación de Tubos de Cartón 185

Tabla 68

Tabla de Máquinas utilizadas para la fabricación de Esquineros de Cartón 186 Indicadores de Recursos Humanos $\quad 188$

Indicadores de Gestión Financiera 189

Indicadores de Ventas y Servicio al Cliente

189

Indicadores de Operaciones $\quad 190$

Tabla 69

Benchmarking

191

Tabla 70

Tabla 71

Cinco pasos para la elaboración de la Matriz EFI 197

Tabla 72

Tabla 73

Tabla 74

Tabla 75

Tabla 76

Tabla 77

Matriz EFI de la UEN Tubos y Esquineros de CAR
Características deseables en los objetivos 199

Objetivos Estratégicos de la UEN Tubos y Esquineros de CARVIMSA 200

Términos de los objetivos estratégicos 200

Proyección de Ventas 2018-2021 201

La estrategia de océano rojo frente a la estrategia de océano azul 204

Estrategias por considerar para el Lienzo actual de la UEN Tubos y Esquineros de cartón-CARVIMSA 206

Tabla 78 Estrategias para considerar para el Lienzo estratégico de la industria de la UEN Tubos y Esquineros de cartón - CARVIMSA 207

Tabla 79 Beneficios de la Matriz (Eliminar, reducir, incrementar, crear) 208

Tabla 80 Estrategias por considerar para el Lienzo de la nueva estrategia de la UEN

Tubos y Esquineros de cartón - CARVIMSA 210

Tabla 81

Estrategias de la matriz FODA 211

Tabla 82 Pasos para la elaboración de la Matriz PEYEA 213

Tabla 83 Puntuación total ponderado de la matriz EFI 216 
Tabla 84

Tabla 85

Tabla 86

Tabla 87

Tabla 88

Tabla 89

Tabla 90

Tabla 91

Tabla 92

Tabla 93

Tabla 94

Tabla 95

Tabla 96

Tabla 97

Tabla 98

Tabla 99

Tabla 100

Tabla 101

Tabla 102

Tabla 103

Tabla 104

Tabla 105

Tabla 106

Tabla 107

Tabla 108

Tabla 109

Tabla 110

Tabla 111

Tabla 112

Tabla 113

Tabla 114

Tabla 115

Tabla 116

Tabla 117

Tabla 118

Tabla 119

Tabla 120

Tabla 121

Tabla 122
Puntuación total ponderado de la matriz EFE

216
Matriz de Factor Interno
217
Matriz de Factor Externo
218

Proyecciones de crecimiento de mercado

221

Participación de mercado 221

Ventas Históricas y Proyecciones en TM del producto “Tubos de Cartón” de sus principales clientes 225

Ventas Históricas y Proyecciones en TM del producto "Esquineros de Cartón" de sus principales clientes 226

Resumen de las estrategias formuladas

227

Matriz de la selección 231

Factores clave y fuerzas ambientales

233

Factores críticos 234

Señales de alerta temprana 236

Comparación de estrategias y escenarios

238

Matriz MPEC de las alternativas de estrategia para CARVIMSA 239

Ventas Históricas y Proyecciones en TM del producto "Tubos de Cartón" 245

Ventas Históricas y Proyecciones en USD del producto "Tubos de Cartón” 246

Ventas Históricas y Proyecciones en TM del producto "Esquineros"

247

Ventas Históricas y Proyecciones en USD del producto "Esquineros"

247

Precio Promedio Tubos y Esquineros de Cartón

Presupuesto de actividades de Marketing 253

Proyección de nuevos activos

256

Indicadores para los Objetivos específicos de Aprendizaje 258

Indicadores para los Objetivos específicos de Procesos Internos

Indicadores para los Objetivos específicos de Clientes 259

Indicadores para los Objetivos específicos de Finanzas 259

Metas para los Objetivos específicos $\quad 260$

Iniciativas para los Objetivos específicos 263

Responsables de cada una de las iniciativas propuestas para la UEN Tubos y

Esquineros de cartón 275

Presupuesto de implementación de la fuerza de aprendizaje y crecimiento 279

Presupuesto de implementación de la fuerza de procesos internos 281

Presupuesto de implementación en la fuerza de clientes 283

Presupuesto de implementación en la fuerza financiera $\quad 284$

Comparación de la estrategia con los criterios 293

Estado de Resultado proyectado Sin Estrategia de la UEN Tubos y Esquineros-

CARVIMSA 300

Estado de Resultado proyectado Con la Nueva Estrategia de la UEN Tubos y

Esquineros-CARVIMSA 301

Balance General proyectado Sin Estrategia de la UEN Tubos y Esquineros-

CARVIMSA 303

Balance General proyectado Con la Nueva Estrategia de la UEN Tubos y

Esquineros-CARVIMSA 304

Estado de Flujos Directo Sin Estrategia de la EN Tubos y Esquineros-

CARVIMSA 305

Estado de Flujos Directo Con Estrategia de la UEN Tubos y EsquinerosCARVIMSA 306 
Tabla 123 Listado de los Activos como inversión de la UEN Tubos y Esquineros CARVIMSA 307

Tabla 124 Estado de Flujos Directo Incrementado de la UEN Tubos y Esquineros CARVIMSA 308

Tabla 125 Resultados de la Razón Corriente 314

Tabla 126 Resultados de la Prueba ácida 314

Tabla 127 Resultados de la Prueba defensiva 315

Tabla 128 Resultados de la rotación de inventarios 315

Tabla 129

Resultados de la rotación de cuentas por cobrar 316

Tabla 130 Resultados de la rotación de cuentas por pagar

Tabla 131

Resultados de endeudamiento total 317

Tabla 132

Resultados de deuda a capital

317

Tabla 133

Resultados de margen de utilidad

318

Tabla 134

Resultados de ROA 319

Tabla 135

Resultados de ROE 319 


\section{Introducción}

Cartones Villa Marina SA (CARVIMSA), es una empresa dedicada a la fabricación de empaques de cartón y derivados de papel a través de sus distintas Unidades Estratégicas de Negocios (UEN). Tubos y Esquineros de Cartón es una unidad que implementó CARVIMSA, la cual tiene un crecimiento vertiginoso y cuenta con la mayor participación de mercado. A pesar de poseer experiencia en el rubro y el respaldo del grupo COMECA hasta la fecha la empresa no ha preparado un Plan Estratégico que fije la dirección y ruta de la UEN.

En este contexto, se ha elaborado el Plan estratégico con visión al 2021 con el objetivo de mejorar la posición competitiva de la unidad y generar mayor rentabilidad para los accionistas. La Gerencia está motivada a implementar las recomendaciones que se proponen en este documento, por lo que se espera que la aplicación de los conocimientos adquiridos en esta maestría beneficie a la UEN, la empresa y al sector cartonero en general.

Con relación al trabajo de investigación, el informe consta de 10 capítulos. El primero está referido a la determinación del problema, así como la justificación del proyecto. En el segundo capítulo, se describe los antecedentes del negocio, la estructura organizacional y la situación de mercado y financiera del sector cartonero. En el tercer capítulo, se analiza la misión, visión y valores actuales de CARVIMSA, a través del análisis se ha logrado realizar una propuesta la cual tuvo gran aceptación por parte de la gerencia general en una entrevista concedida. En los capítulos del cuarto al sexto, se ha utilizado el análisis externo, las cinco fuerzas de Porter, las diferentes matrices y la cadena de valor para realizar el diagnóstico estratégico de la UEN Tubos y Esquineros. En el séptimo capítulo se plantean los objetivos estratégicos y se diseñan las estrategias. El octavo capítulo, consta de la elección de la estrategia principal y la contingente a través del Método de Escenarios. En el noveno y décimo capítulo, se implementa la estrategia y se realiza la evaluación financiera de la estrategia propuesta. 


\section{Capítulo I. Generalidades}

\subsection{Antecedentes}

Según European Federation of Corrugated Board Manufacturers (2017), el origen de la actual caja de cartón corrugado se relaciona con el mundo de la moda de la aristocracia de inicios del siglo XIX y la moda victoriana de mediados del siglo XIX, particularmente en los cuellos y puños plisados, como también en el pliegue de las faldas de las damas y los elegantes sombreros de copa que utilizaban los caballeros ingleses tal como se muestra en la figura 01.

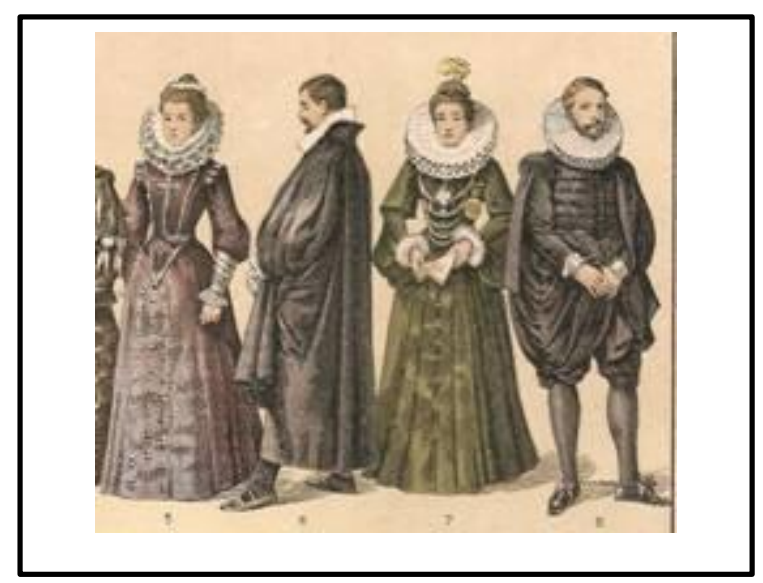

Figura 01. Moda Victoriana siglo XIX. Tomado de Página Web de Academia Colombiana de la Cultura 2017. Recuperado de http://acdlc.ucoz.es/historia_del_traje_siglo_xvii0002.jpg

Por lo antes mencionado, se puede afirmar que la industria textil dio los primeros aportes para el desarrollo del ondulado interno de las cajas corrugadas; pues los primeros equipos para ondular papel eran similares a los utilizados en las lavanderías para planchar las cortinas, los encajes de los cuellos y puños de las camisas.

Para lograr la buena forma y rigidez del sombrero de copa los caballeros, tal como se muestra en la figura 02, Edward G. Healy y Edward E. Allen, patentaron en el año 1856 el uso de papel plisado como refuerzo interior de los mencionados sombreros; ellos obtuvieron el plisado del papel introduciéndole a través de dos rodillos ondulado, dando así origen a lo 
que se conoce hoy en día como la "flauta" o "medium" y es el que le otorga a las cajas corrugadas su resistencia a la compresión, ya que actúa como una estructura interna en forma de curvas y a la vez brinda su bondad de amortiguamiento a los golpes absorbiendo la energía al deformarse.

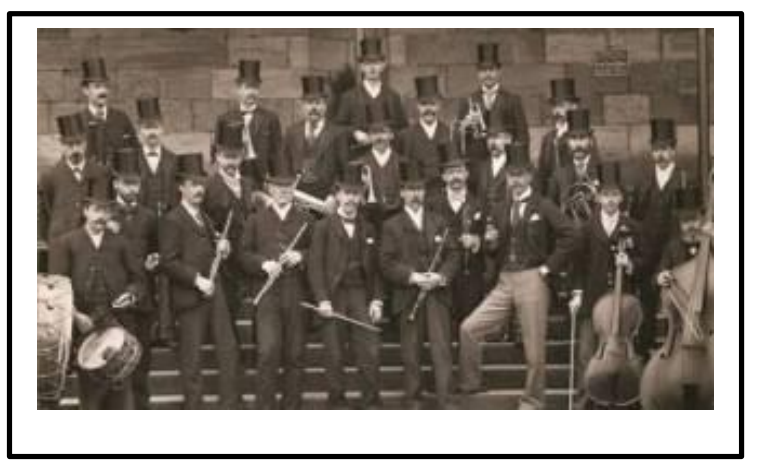

Figura 02. Sombreros siglo XIX. Tomado de Página Web de Skyscraper Dictionary 2017. Recuperado de http://www.skyscraperdictionary.com/wpcontent/uploads/2012/01/tophats.jpg

En el año 1866, Samuel G. Cabell recibió una patente por una lavadora para lino, compuesta esencialmente de un par de rodillos, tubos de bronce perforados que se calentaban introduciéndoles varillas calientes y eran accionados por una manivela. Posteriormente esta máquina fue utilizada para la producción del primer papel corrugado.

En el año1871 Albert L. Jones, un técnico farmaceuta norteamericano dedicado al mundo de la perfumería, y preocupado por las roturas de sus frascos ya que eran envueltas en telas, sustituyó la envoltura de tela por papel; pero evidentemente esto no era suficiente, inspirado en los plisados de las faldas victorianas corrugó el papel con la finalidad de ganar volumen y amortiguación a los golpes propiedad concebida por una "superficie elástica", como lo indica en su patente (Ver figura 3). Es así como nace el concepto de utilizar el papel corrugado como empaque de protección. (European Federation of Corrugated Board Manufacturers, 2017) 


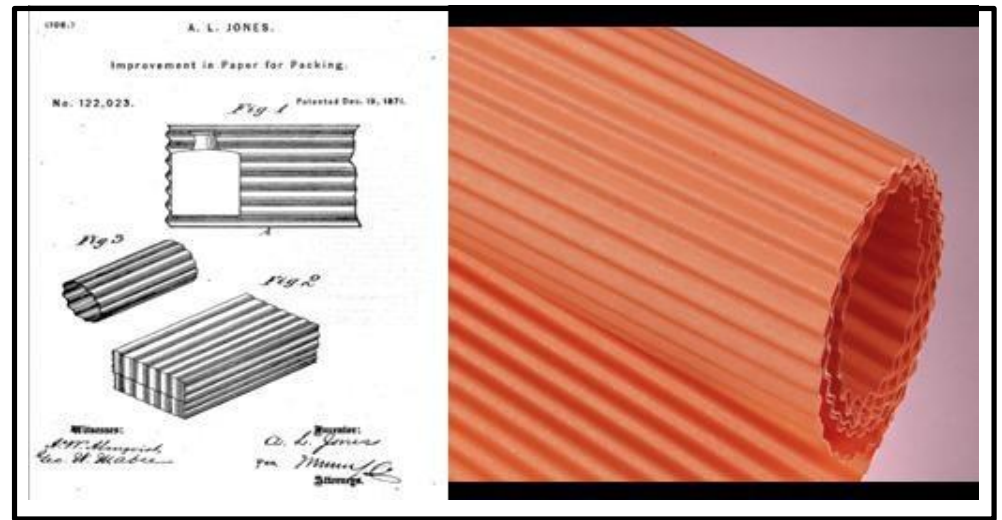

Figura 03. Patente de Albert L. Jones. Tomado de Página Web de A Fine Collection 2017. Recuperado de https://afinecollection.files.wordpress.com/2012/02/dsc0745971.jpg

A pesar de que, con la patente registrada por Albert L. Jones, se había dado inicio al uso de papel corrugado como elemento de empaque protector, este no estaba completo, debido a que el papel no tenía la rigidez suficiente para mantener su forma.

En 1874 el norteamericano Oliver Long (ver figura 04), hace una mejora a la patente de Albert Jones, adhiriendo el papel ondulado inventado por Jones en primer lugar a una lámina de papel plana y luego a dos láminas de papel planas, conocidas hoy en día como los "liners" (ver figura 05) y originando la estructura que hoy conocemos como cartón corrugado.

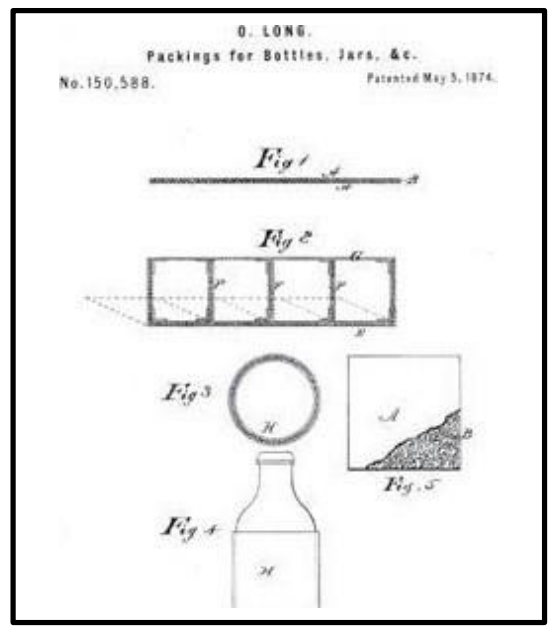

Figura 04. Patente de Oliver Long. Tomado de Página Web de A Fine Collection 2017. Recuperado de https://afinecollection.files.wordpress.com/2012/02/dsc07yh771.jpg 


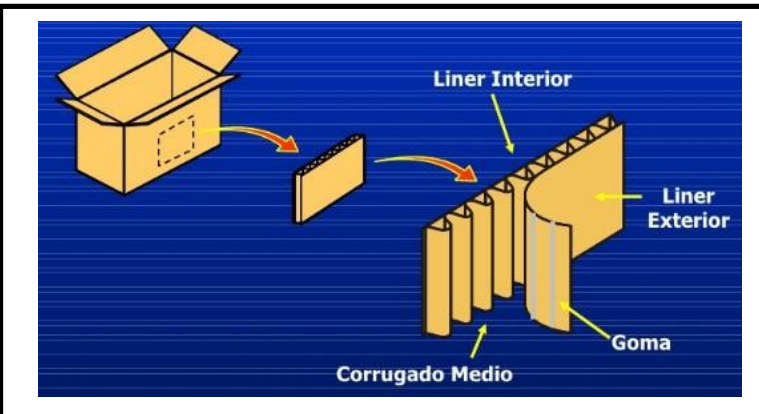

Figura 05. Patente de Oliver Long. Tomado de Página Web de A Fine Collection 2017. Recuperado de https://afinecollection.files.wordpress.com/2012/02/dsc07yh771.jpg

La importancia del invento de Oliver Long radica en las propiedades de resistencia al apilamiento (compresión) y la resistencia al aplastamiento (golpes) que brindan las cajas que se conocen en la actualidad.

Debido a la falta de evidencia histórica del origen de la industria del cartón en Perú, se cree que sus inicios se relacionan con la creatividad y habilidad de los inmigrantes italianos quienes a inicios del siglo XX ya habían iniciado la fabricación de cartones, a través de procesos rudimentarios heredado de Antonio Mazzini, empleando como materia prima la fibra secundaria obtenida a partir de los desechos de papel. Posteriormente la familia Mazzari también de origen italiano, continúa con la fabricación de cartones con un formador de cilindro al cual agregó una serie de ingeniosas ayudas mecánicas económicamente rentable. (Campodónico, 2002)

La segunda fábrica de cartón que se instaló en el Perú fue la de "Piedra Liza" que también empleó como insumo la fibra secundaria, comenzó a operar a partir de 1921 hasta 1987, año en que tuvo una producción de 1375 toneladas entre papel de envolver y cartón de paja. 
El inicio de la fabricación de papel en forma de hoja continua empezó con la creación de la "Papelera Peruana" en 1933, en Chosica, usando como insumos fibrosos pulpa importada a base de madera y fibra secundaria.

Tal como se muestra en la tabla 01, actualmente existen aproximadamente doce empresas posicionadas en el mercado peruano.

Tabla 01

Listado de Empresas en la Actualidad

\section{Empresas Manufactureras del Cartón}

Trupal S.A.

Cartones Villa Marina S.A.

Papelera del Sur S.A.

Sociedad Anónima Papelsa

Peruana de Moldeados S.A.

Molpack del Perú S.A.

Envases y Envolturas S.A.

Ingeniería en Cartones y Papeles S.A.C.

Papelera Inka S.A. Industrias

del Cartón S.A. Cartones del

Pacifico S.A.C. Ceruti

S.A.C.

Otros

Nota. Adaptado de Documentación interna del área de Créditos y Cobranzas, por

CARVIMSA, 2016, Perú, Lima: CARVIMSA. Copyright 2016 por CARVIMSA.

Es preciso indicar que hoy en día la caja de cartón corrugado sigue siendo el embalaje de preferencia para el transporte de mercancías. A pesar de que las formas de comprar han evolucionado con el uso del Internet, lo que ha influido en las formas de transporte, desde las carretas de maderas hasta los aviones; sin embargo, el uso de las cajas de cartón sigue vigente. 


\section{Tubos y Esquineros}

Los tubos de cartón son fabricados en diversas medidas de diámetro, longitudes y espesores de acuerdo a la finalidad de uso según sea para enrollar mallas, stretch films, zunchos, plásticos, polietileno, cubrepisos, cintas adhesivas, etiquetas autoadhesivas, láminas, distintos tipos de papeles, así como textiles. Su uso en el sector construcción se remonta a la década de los 90 gracias al arquitecto Shigeru Ban quien mediante un proceso innovador llevó a la arquitectura a otros niveles gracias a la búsqueda de materiales estructurales alternativos. (Código 2010, 2017)

Este proceso innovador surge en el año 1995, como consecuencia del terremoto en Kobe, Japón, y se trataba de construir a partir de materiales ligeros y económicos. A partir de ello, Shigeru Ban construyó viviendas de emergencia (ver figura 06) e iglesias (ver figura 07) con tubos de cartón.

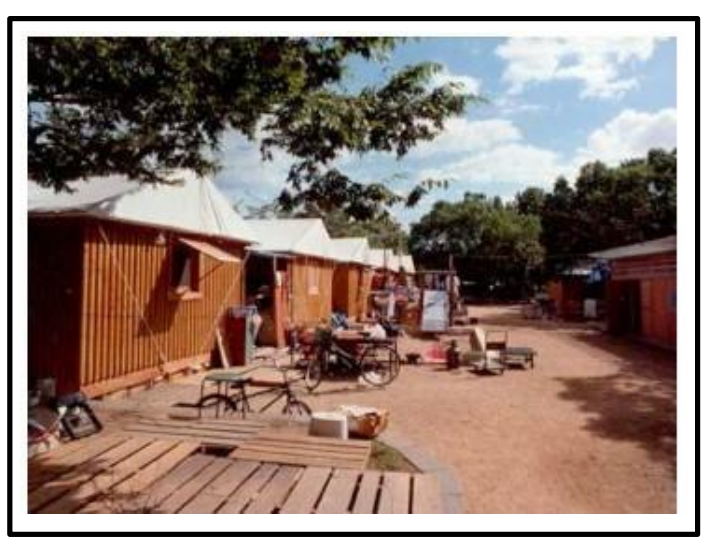

Figura 06. Viviendas emergentes en Kobe. Tomado de Página Web de Código Diez. Recuperado de http://www.codigodiez.mx/textosarquitectoura/shigeruban.html 


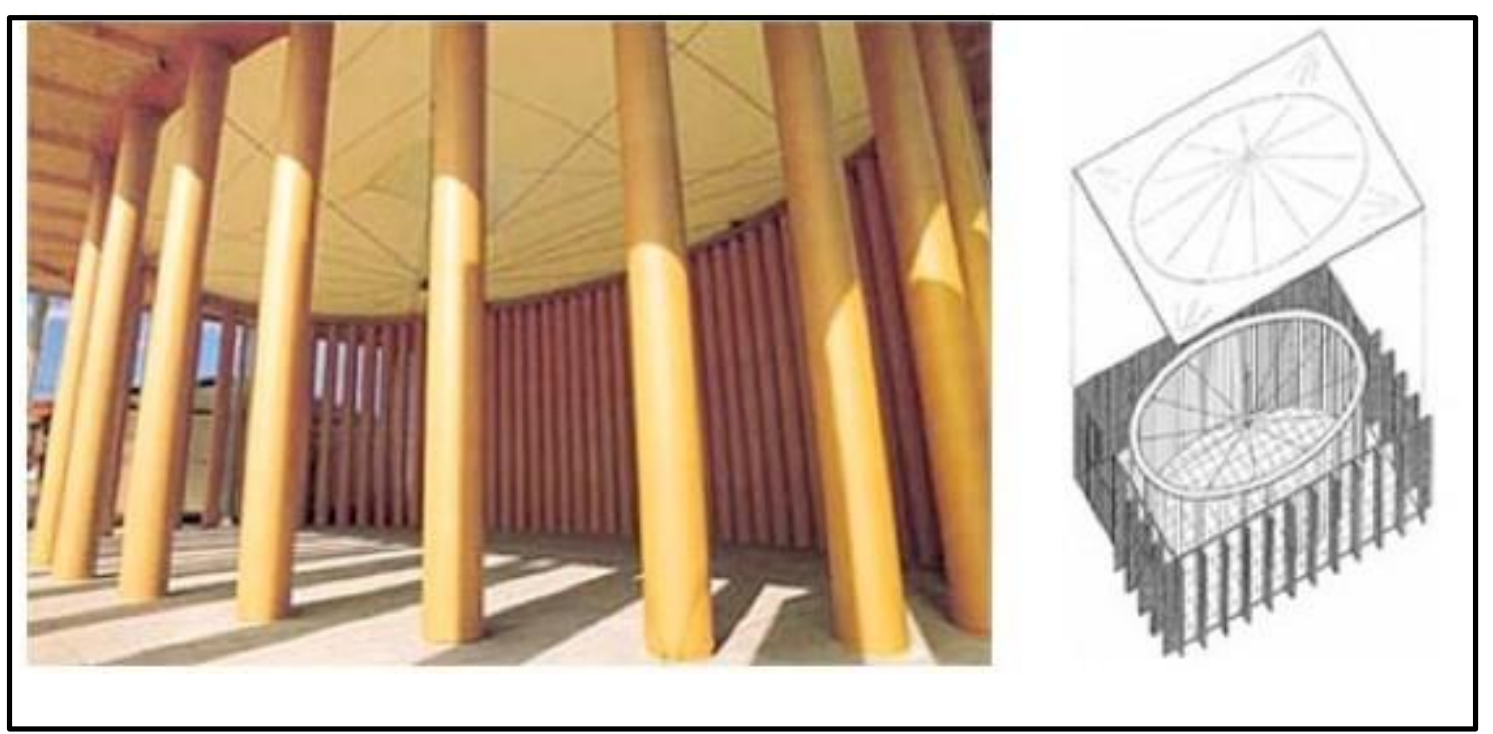

Figura 07. Iglesia en Kobe hasta 1995.Tomado de Página Web de Código Diez. Recuperado de http://www.codigodiez.mx/textosarquitectoura/shigeruban.html

Gracias a estos proyectos que aparte de su sencillez para la fabricación eran ecológicos, llevan a este arquitecto a convertirse en asesor para la Organización de las Naciones Unidas (ONU) para la ejecución de diferentes proyectos en diferentes desastres naturales como los terremotos suscitados en Japón (1995), Turquía (2000), India (2001) y China (2008). En la actualidad se encuentra trabajando en refugios para la gente de Haití.

A partir de esta innovación, el uso de estructuras de tubos de cartón inició su evolución y se creó diferentes proyectos tales como "La casa de papel” en 1995 (ver figura 08), en Japón, formada por 110 tubos de 2.70 metros de alto y 27.50 centímetros de diámetro. Como se puede apreciar en la imagen, los tubos exteriores sirven de soporte para las cargas verticales, mientras que los tubos interiores fueron colocados en forma de la letra "S" para soportar las fuerzas laterales y con la finalidad de mejorar la estructura. Este proyecto fue el primer proyecto autorizado en la que se usaron tubos de cartón como estructura de una edificación permanente, ya que las anteriores habían servido para edificaciones temporales. (Código 2010, 2017) 


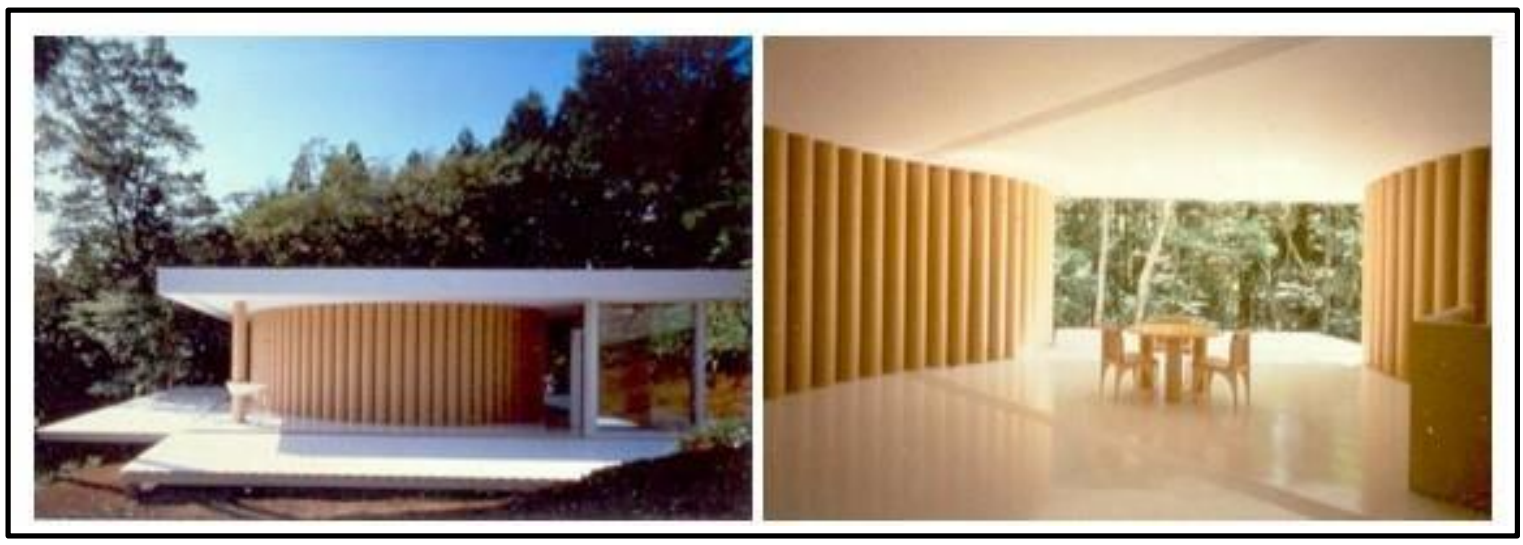

Figura 08. Casa de Papel en Japón 1995.Tomado de Página Web de Código Diez. Recuperado de http://www.codigodiez.mx/textosarquitectoura/shigeruban.html

Luego de la autorización de "La casa de papel" como edificio permanente, se empezaron a usar los tubos de cartón para diferentes construcciones tales como casas, iglesias, librerías particulares, pabellones. Incluso en Francia construyó un puente como parte de un curso de verano dictado por el arquitecto en el año 2007, tal como se muestra en la figura 09. Es preciso indicar que este puente solo se exhibió de forma temporal por meses.
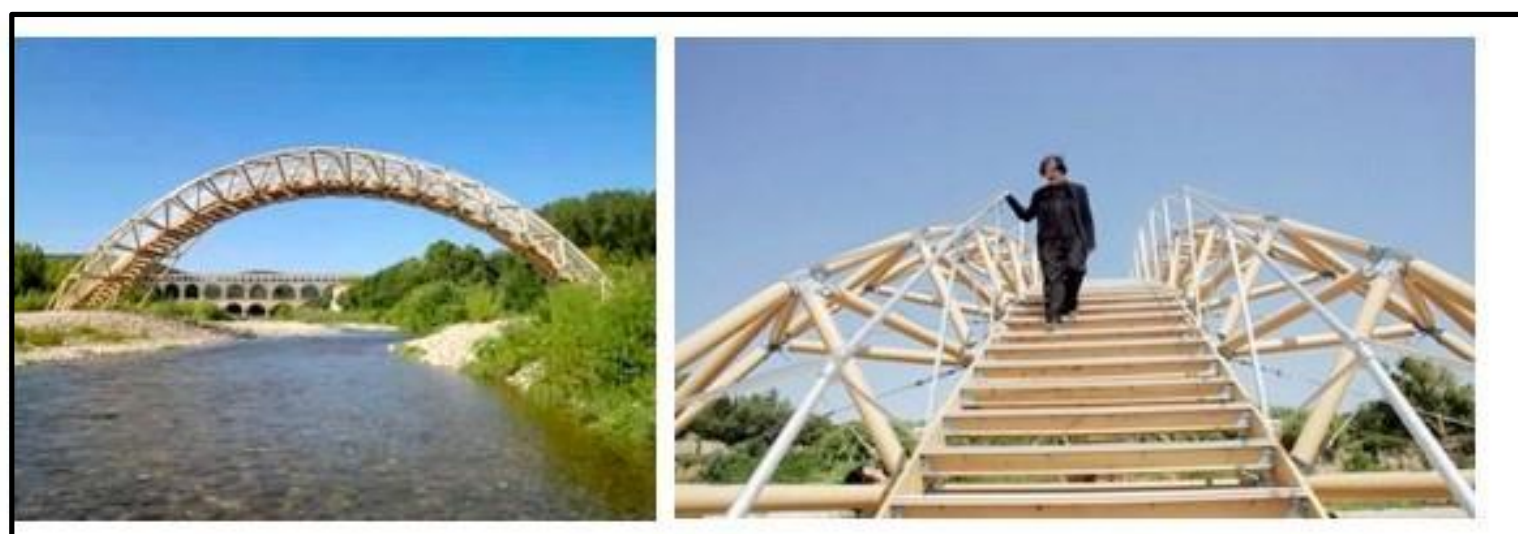

Figura 09. Puente en Francia 2007.Tomado de Página Web de Código Diez. Recuperado de http://www.codigodiez.mx/textosarquitectoura/shigeruban.html

Shigeru Ban se ha convertido, gracias a todas sus creaciones, en una figura líder de la arquitectura del siglo XXI que ha influenciado en la construcción actual. (Diez, T., 2017) 


\subsection{Determinación del problema u oportunidad}

La empresa Cartones Villa Marina S.A.(CARVIMSA) cuenta en la actualidad con tres unidades de negocio como: Unidad de negocios de cajas de cartón Corrugado y Microcorrugado, Unidad de negocios de Papel y Empalmadas y la unidad de negocios de Tubos y Esquineros. CARVIMSA en el año 1997 comenzó sus operaciones con la unidad estratégica de negocio de Corrugado y Microcorrugado (ver figura 10), con una producción promedio 538 TM promedio mes, en el transcurrir de los años, estas dos unidades estratégicas de negocio fueron en aumento, en el año 2007 ya tenían una producción de 2,367 TM promedio mes, es decir unos 340 \% más a su producción inicial, CARVIMSA analizó que dependía muchos de sus proveedores de materia prima (MP), tanto en precios y tiempos de entrega, por ello plantearon crear un molino de papel el cual les permitía tener casi el $80 \%$ de su abastecimiento de materia prima. Realizaron los montajes de la planta en el año 2009, culminándolo en marzo del 2010, su producción promedio de ese año fue de 2,373 TM promedio mes con un total acumulado de 21,538 TM en el año de los cuales el $84 \%$ eran bobinas utilizables para su Corrugadora (Bobinas originales) y un $16 \%$ en saldos de bobinas, denominados Side Roll (SR), estos tipos de bobinas se almacenaron en los inventarios por varios años, desde abril 2010 hasta febrero 2013, haciendo un acumulado de bobinas de 883.18 TM, este stock de inventario es dinero inmovilizado el cual no permite tener mejor flujo de caja operativa, para eso CARVIMSA planteó hacer una integración hacia delante, dando oportunidad de reducir sus inventarios y a su vez el desarrollar nuevos productos en el mercado, para poder utilizar esos side roll crearon la unidad estratégica de negocio de "Tubos y Esquineros" (ver figura 11 y 12), la cual usa como materia prima las bobinas de papel (ver figura 13) de corto ancho resultante del proceso de fabricación de la unidad estratégica de negocio de "Bobinas de papel”. La oportunidad estratégica de negocio surge debido a los altos inventarios en toneladas y los costos de almacenaje que incurría CARVIMSA hasta el 
año 2013. En el 2013, la empresa decide fabricar productos a partir de estas bobinas de papel de corto ancho obteniendo los tubos que sirven para la industria textil y de embalaje, y los esquineros para la industria de exportación. El problema detectado es la falta de un planeamiento estratégico para esta unidad debido al crecimiento vertiginoso, pero sin una estructura adecuada que contribuya a la formalización de dicha unidad estratégica de negocio dentro de CARVIMSA.

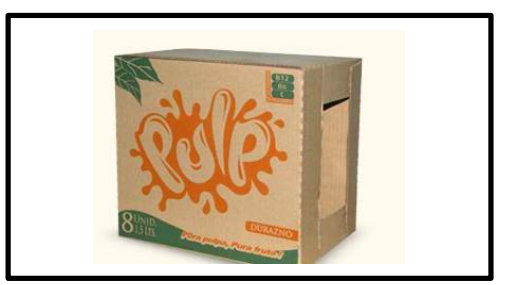

Figura 10. Caja de cartón corrugado. Tomado de Página Web de CARVIMSA 2017. Recuperado de http://www.CARVIMSA.com/division-corrugado.html

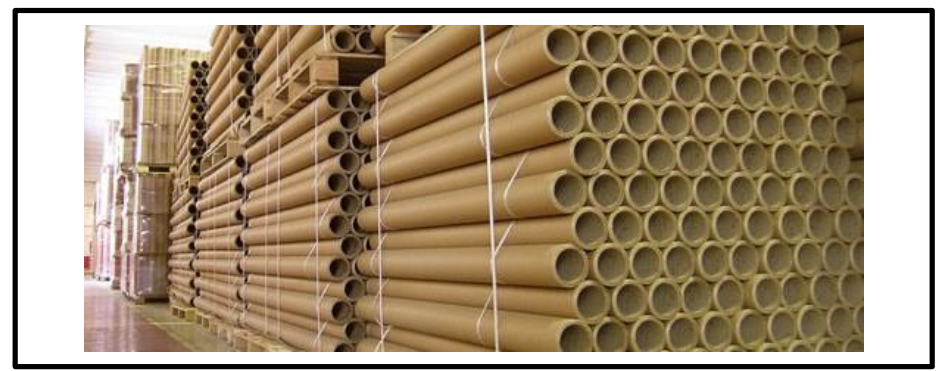

Figura 11. Tubos de cartón. Tomado de logismarketar 2017. Recuperado de https://logismarketar.cdnwm.com/ip/papelera-berazategui-tubo-de-carton-espiralado-tubosproducidos-con-los-mas-variados-materiales-614736-FGR.jpg?imgmax $=800$

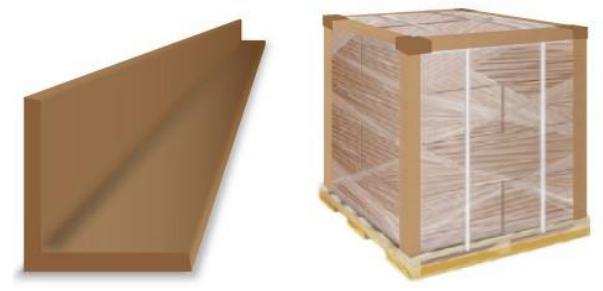

Figura 12. Esquineros de cartón. Tomado de Mx. Recuperado de http://www.mx.all.biz/img/mx/catalog/43361.png 


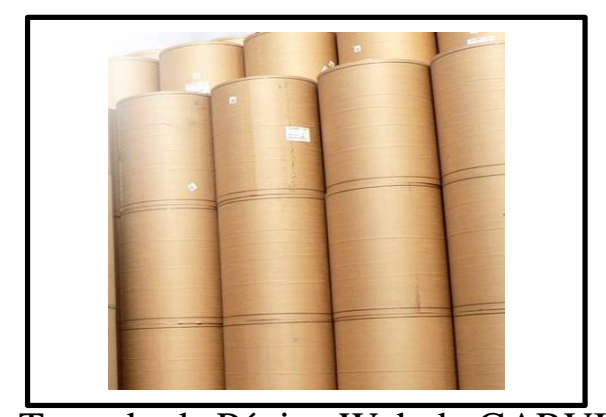

Figura 13. Bobinas de papel. Tomado de Página Web de CARVIMSA 2017. Recuperado de http://www.carvimsa.com/division molino.html

\subsection{Justificación del proyecto}

El proyecto se justifica por:

a) La necesidad de optimizar los procesos productivos para lograr el uso eficiente de los recursos.

b) Y la justificación práctica es dar solución a la falta de un plan estratégico para la UEN Tubos y Esquineros.

c) La necesidad de definir una estructura adecuada que contribuya a su formalización dentro de la organización.

d) Por la iniciativa de aplicar los conocimientos aprendidos en la maestría.

\subsection{Objetivos generales y específicos}

El objetivo general del presente proyecto es ayudar a establecer las principales líneas de acción a seguir en el corto y mediano plazo; a fin de incrementar las ventas, la rentabilidad, participación en el mercado y mejorar el clima organizacional; para lo cual se ha elaborado un Plan Estratégico para la unidad estratégica de negocio (UEN) “Tubos y esquineros" de la empresa Cartones Villa Marina S.A. (CARVIMSA), ubicada en Lurigancho (Lima, Perú) para el periodo 2018 a 2021. 
Los objetivos específicos del proyecto son:

a) Realizar el análisis interno y externo de la unidad estratégica de negocio "Tubos y Esquineros" de la empresa CARVIMSA.

b) Formular los objetivos estratégicos para la unidad estratégica de negocio "Tubos y Esquineros" de la empresa CARVIMSA.

c) Seleccionar y diseñar la estrategia adecuada para la unidad estratégica de negocio

“Tubos y Esquineros" de la empresa CARVIMSA.

d) Determinar la implementación de la estrategia.

e) Realizar la evaluación económico-financiera del proyecto con la nueva estrategia.

\subsection{Alcances y limitaciones de la investigación}

El presente proyecto tiene como alcance el desarrollo de un plan estratégico para la unidad estratégica de negocio "Tubos y esquineros" de la empresa CARVIMSA ubicada en Lote B Fundo Nieveria Lurigancho, Lima, Perú; para el periodo de 2018 a 2021.

Las limitaciones del proyecto en mención son el difícil acceso a la información de la competencia, así como la falta de actualización de los registros históricos del sector papel y cartón. 


\section{Capítulo II. La Empresa}

\subsection{Antecedentes de la empresa}

En el año 1999 el Grupo Comeca, en busca de nuevas oportunidades de negocio, se da cuenta que Perú era el país con menor producción de corrugado per cápita de Latinoamérica, por lo que se decide incursionar en este mercado con la compra, a través de Grupo Cartopel, de la mayoría de las acciones de las empresas Villa Marina EIRL y Gráfica Kuelap, ambas propiedades de la familia Reyna (quienes en la actualidad se mantienen como socios).

Nace así Cartones Villa Marina S.A. (CARVIMSA), el 02 de marzo de 1999 dirigido por su Gerente General y socio Reyna Ciccia, Santiago, con el objeto de dedicarse a la fabricación, importación, exportación, distribución y comercialización al por mayor y menor de cajas de cartón o envases de embalaje hechos de cartón acanalado, corrugado o macizo; cajas de cartón papel plegables o armados, cajas de fibra vulcanizada, envases sanitarios para alimentos, bolsas impresas o no, papeles, tubos y esquineros de cartón, productos y subproductos de los mismos, así como productos afines.

En aquel inicio la capacidad de producción era de 200 TM/mes de cartón corrugado. A partir de entonces dicha capacidad se ha incrementado en varias ocasiones hasta alcanzar hoy en día las 4000 TM/mes con posibilidad de ampliación hasta las 6000 TM/mes de cartón corrugado y las 3,100 TM/mes de papel Kraft.

En el año 2001, se decide ampliar la capacidad de producción a niveles de 1,000 $\mathrm{TM} / \mathrm{mes}$ para ello se adquiere una (01) máquina Corrugadora $\mathrm{S} \& \mathrm{~S}$ (Ver figura 14) y dos (02) impresoras flexo gráficas tipo Hopper y Ward. Asimismo, se decide ampliar la planta y se construye el área de corrugado con inversión de \$1MM adicional. 


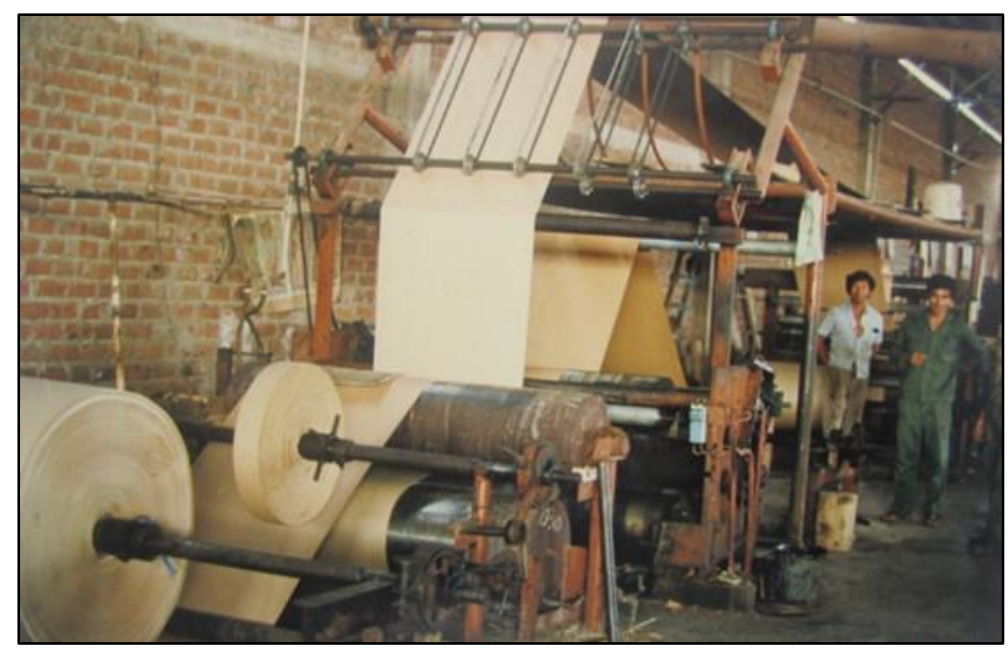

Figura 14. Máquina Corrugadora. Tomado de Galería interna de fotos CARVIMSA.

Posteriormente, en el año 2004 ante una mayor demanda deciden ampliar la capacidad de impresión, por lo que adquieren 2 impresoras flexo gráficas, tipo Ward y TCY, con lo cual la capacidad de producción se incrementa hasta llegar a las 1,800 TM/mes.

Adicionalmente, deciden ampliar la planta construyendo almacenes para productos en proceso y productos terminados. Las inversiones de toda esta ampliación ascendieron a \$3MM.

En el año 2008, deciden nuevamente ampliar la capacidad instalada hasta las 3,000 TM/mes. Para ello se adquirieron 2 nuevas impresoras tipo TCY y Rotary Slotter con una inversión de aproximadamente \$1,5MM. Además, compraron terrenos contiguos cuya inversión, incluyendo la construcción, ascendió a otros \$1.5MM. Estos inmuebles se destinaron a un almacén de materias primas.

Siempre con el objetivo de continuar creciendo y con tal de satisfacer una mayor demanda de mercado deciden, en marzo del 2010, implementar una nueva unidad estratégica de negocio Corrugadora (Ver figura 15). Lo anterior implicó inversiones adicionales por \$5MM en maquinarias con capacidad superior y más eficiente a la que se mantenía, pero que 
por sobre todo pudiera por su compatibilidad de anchos, consumir de manera óptima el papel producido por el Molino.

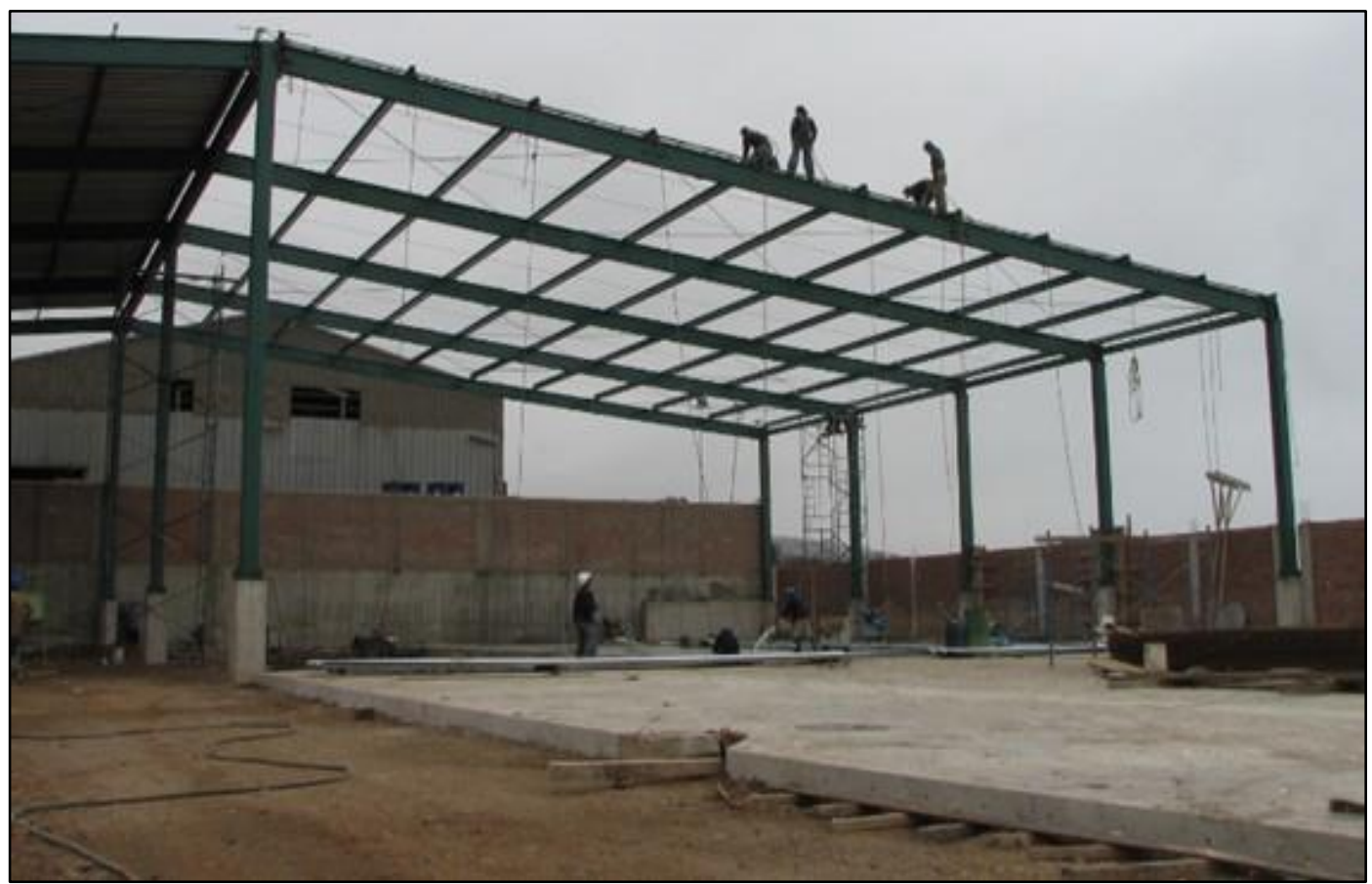

Figura 15. Ampliación de Máquina Corrugadora. Tomado de Galería interna de fotos CARVIMSA.

La unidad estratégica de negocio de cartón corrugado y microcorrugado cuenta en la actualidad con una gran cartera de clientes sólida, en los distintos sectores del mercado:

- Sector Agroindustrial

- Sector Textil

- Sector Cosmético

- Sector Industrial

- Sector Pesca

- Sector Farmacéutico

Su fuerza de ventas está consolidada por sectores, con el fin de tener fuerzas especializadas en el sector y con el conocimiento técnico posible. 
A continuación, la tabla 02 detalla los clientes top de la unidad estratégica de negocio Cartón Corrugado y Microcorrugado de CARVIMSA, los cuales conforman el $80 \%$ de la cartera de clientes actual.

Tabla 02

Clientes Top por Unidad Estratégica de Negocio Cartón Corrugado y Microcorrugado Clientes Top en la actualidad

Panadería San Jorge S. A

Camposol S.A.

Corporación Lindley S.A.

Laive S.A.

Unique

RPM Distripack E.I.R.L

Industrias Teal S.A.

Yobel Supply Chain Management S.A.

Danper Perú S. A

Ajeper S.A.

Nestlé Perú S. A

Molitalia S. A

San Fernando S.A.

San Miguel Industrias Pet S.A.

Snacks América Latina S.R.L.

Gandules Vinculo

Industrias del Espino S. A

Clorox Perú S.A.

Ajinomoto del Perú S. A

Bodegas y Viñedos Tabernero S.A.C.

Nota. Adaptado de los informes de Satisfacción al cliente (p.60), por CARVIMSA, 2016, Perú, Lima: CARVIMSA. Copyright 2016 por CARVIMSA. 
En la actualidad, la capacidad instalada llega a las 4,000 TM/mes con posibilidad de ampliarse hasta las 6,000 TM/mes (Ver figura 16) y sus productos son requeridos en el mercado nacional en diferentes sectores, tales como: agroindustrial, pesquero, cosméticos, alimenticio e industrial. Adicionalmente, también tienen participación en el exterior como en Ecuador y Colombia al cliente Yobel Supply Chain Management S.A.

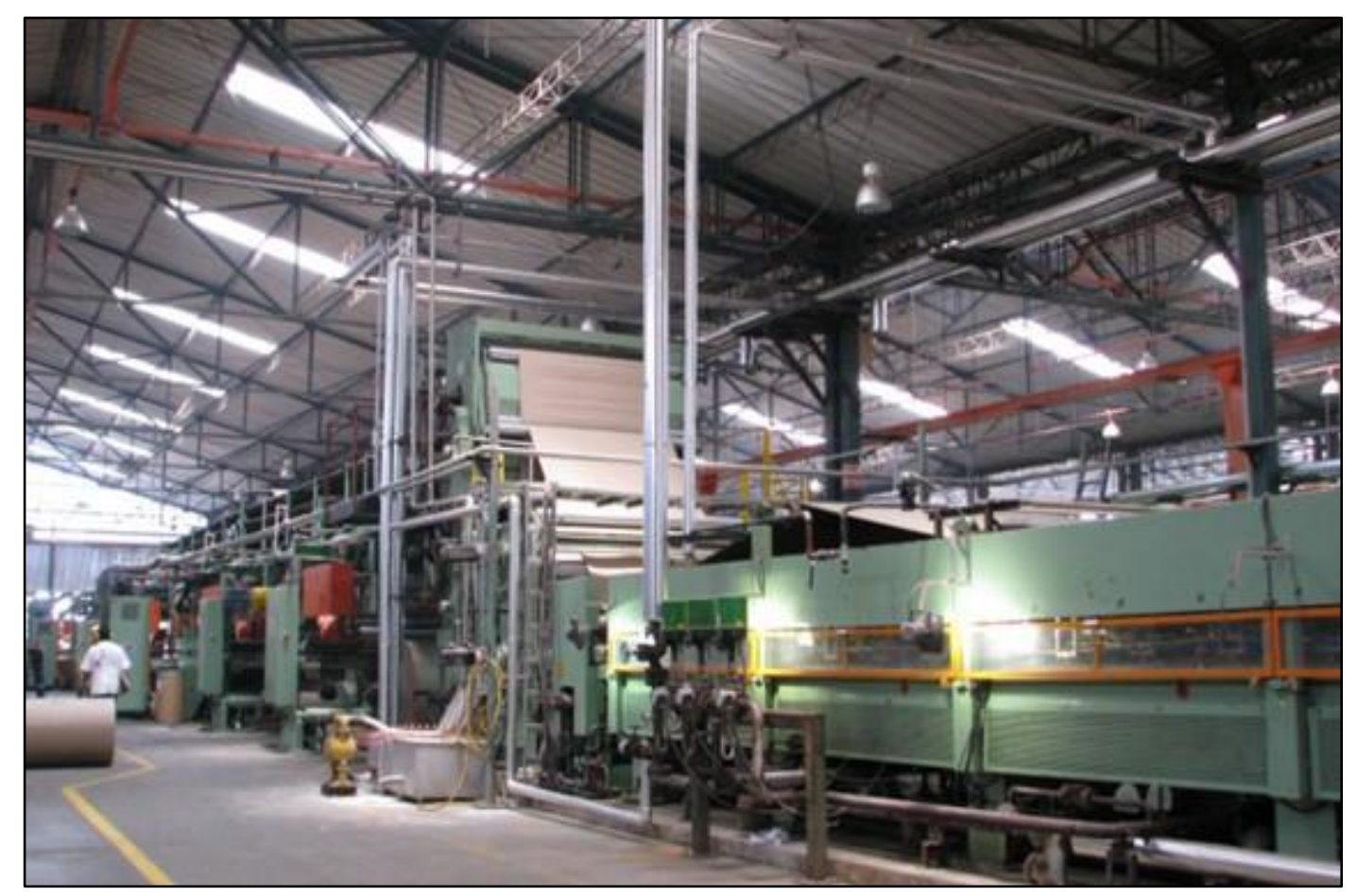

Figura 16. Máquina de papel. Tomado de Galería interna de fotos CARVIMSA.

La planta de la unidad estratégica de negocio de cartón corrugado y microcorrugado cuenta con las certificaciones ISO 9001, BASC y el ISO 14001; asegurando de esta manera un sistema de gestión de calidad en cada proceso, controlando la integridad en el manipuleo de sus productos; y finalmente están comprometidos con la prevención de la contaminación del medio ambiente, respetando los requisitos legales que la industria exige.

A finales del año 2008, CARVIMSA decide emprender el ambicioso proyecto de establecer su propio Molino de Papel. Esto con el objetivo de autoabastecerse, reducir la 
dependencia de proveedores externos y tener un mayor control sobre el costo de la producción.

De acuerdo con el plan estratégico actual que maneja CARVIMSA, tiene planificado que, en un máximo de 5 años, esa unidad estratégica de negocio debería ser capaz de producir papel que pudiera ser consumido por la unidad estratégica de negocio de "Corrugado y Microcorrugado" y por las otras empresas del sector corrugado, tanto del mercado local como internacional. El proyecto comprendía la adquisición de terrenos, la construcción de la nave industrial y la compra, traslado y montaje de la maquinaria. En total, la inversión ascendió aproximadamente a los \$24MM (Ver figura 17 y 18) distribuidos de la siguiente forma:

Maquinaria y equipo: \$19MM, que comprenden todo el complejo industrial, estos Activos Fijos comprenden: \$5MM, que incluyen la adquisición del terreno y la construcción de la nave industrial.

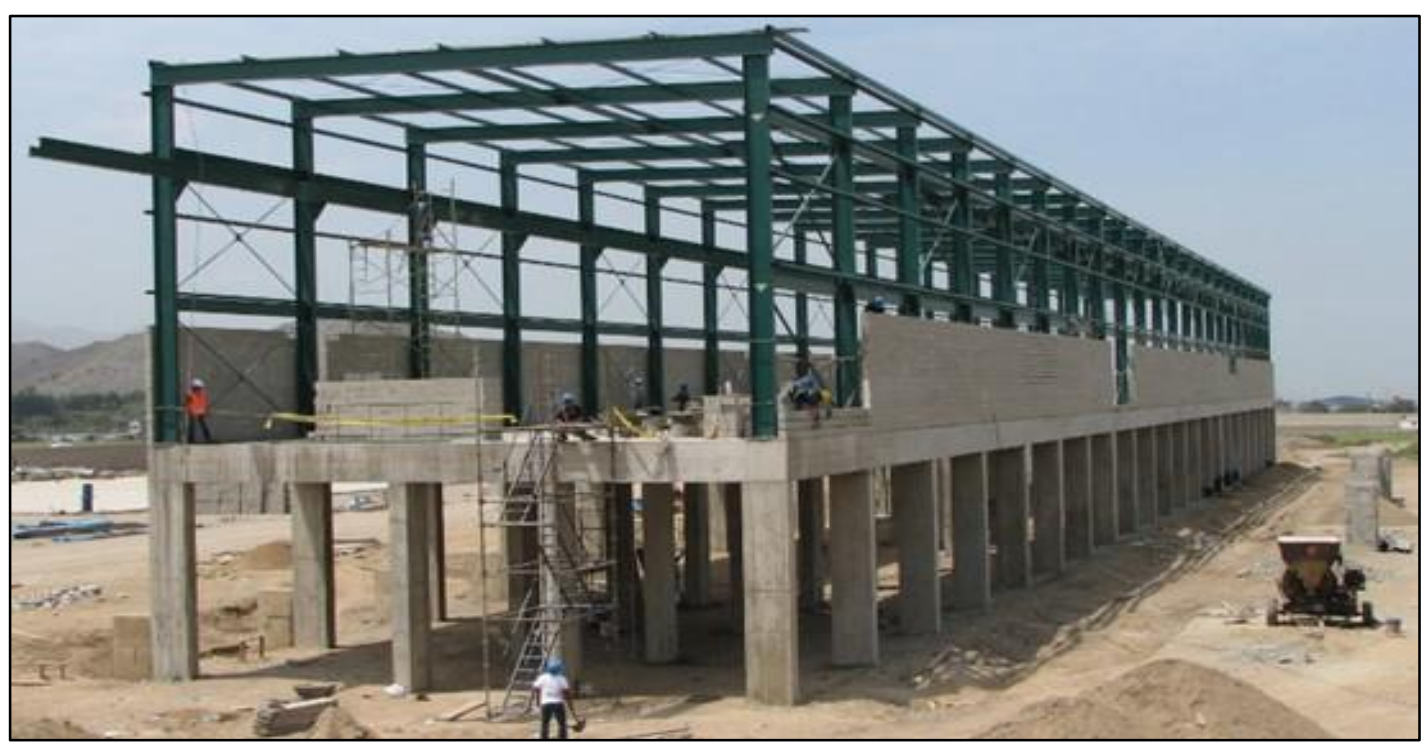

Figura 17. Construcción de la nave de la planta de papel. Tomado de Galería interna de fotos CARVIMSA. 


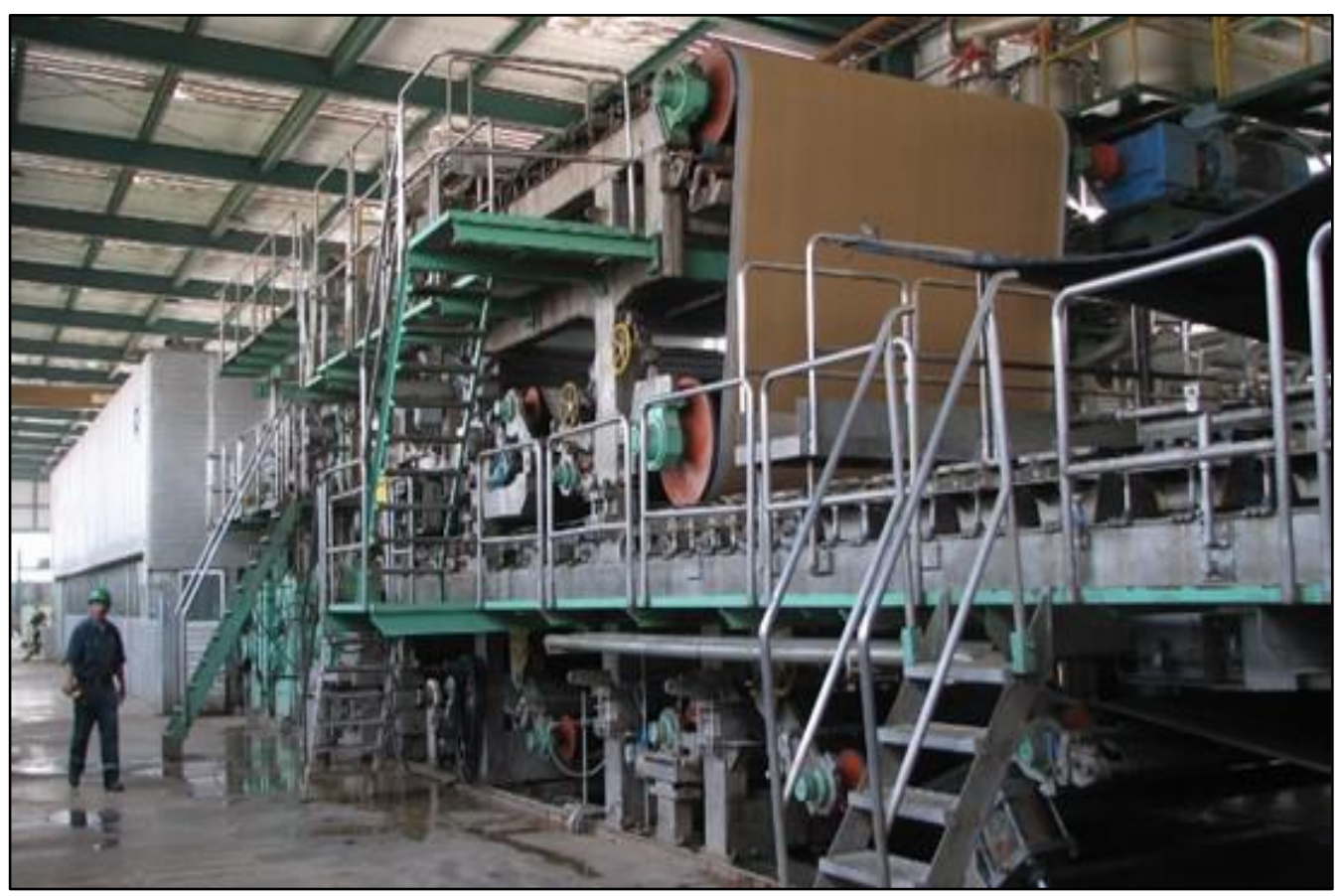

Figura 18. Máquina de Papel de Línea de Secado. Tomado de Galería interna de fotos CARVIMSA.

A partir de abril del 2010 (mucho antes del plazo previsto originalmente)

CARVIMSA empieza a producir papel. Se inició con producciones de 600 TM/mes, las cuales hoy en día alcanzan las 4,700 TM/mes. Este papel es consumido a lo interno por su unidad estratégica de negocio de cartón corrugado y microcorrugado, por el mercado local e incluso por el mercado exterior, exportando a Ecuador, Guatemala; Nicaragua y Costa Rica.

Cuenta con una pequeña cartera de clientes, tanto en el mercado local como del exterior.

A continuación, la tabla 03 detalla los clientes top de la unidad estratégica de negocio Bobinas de Papel de CARVIMSA. 
Tabla 03

Clientes Top por Unidad Estratégica de Negocio Bobinas de Papel

Clientes Top en la actualidad

Sociedad Anónima Papelsa

Ingeniería en Cartones y Papeles Sac

Envases los Pinos Sac

Perucart Eirl

Ceruti Fabrica de envases de cartón S.A.

Volcán

Barnett Corporation Pulp \& Paper

Cartones Nacionales SAI

Empaques San Lucas

Empaques Santa Ana

Industria Cartonera Palmar SA

Nota. Adaptado de los informes de Satisfacción al cliente, por CARVIMSA, 2016, Perú, Lima: CARVIMSA. Copyright 2016 por CARVIMSA.

Asimismo, la unidad estratégica de negocio de Bobinas de Papel recolecta papel y cartón reciclado, los cuales son utilizados en la fabricación de nuevas fibras para la producción de sus papeles. En este proceso, ayudan al medio ambiente evitando la tala de árboles a la vez que reducen la cantidad de desechos que se envían a los rellenos sanitarios y le dan un ahorro al país divisas al no tener que importar papel para la producción de nuevas cajas. Se muestra la evolución de CARVIMSA dese sus inicios hasta el año 2013. (Ver figura 19). 


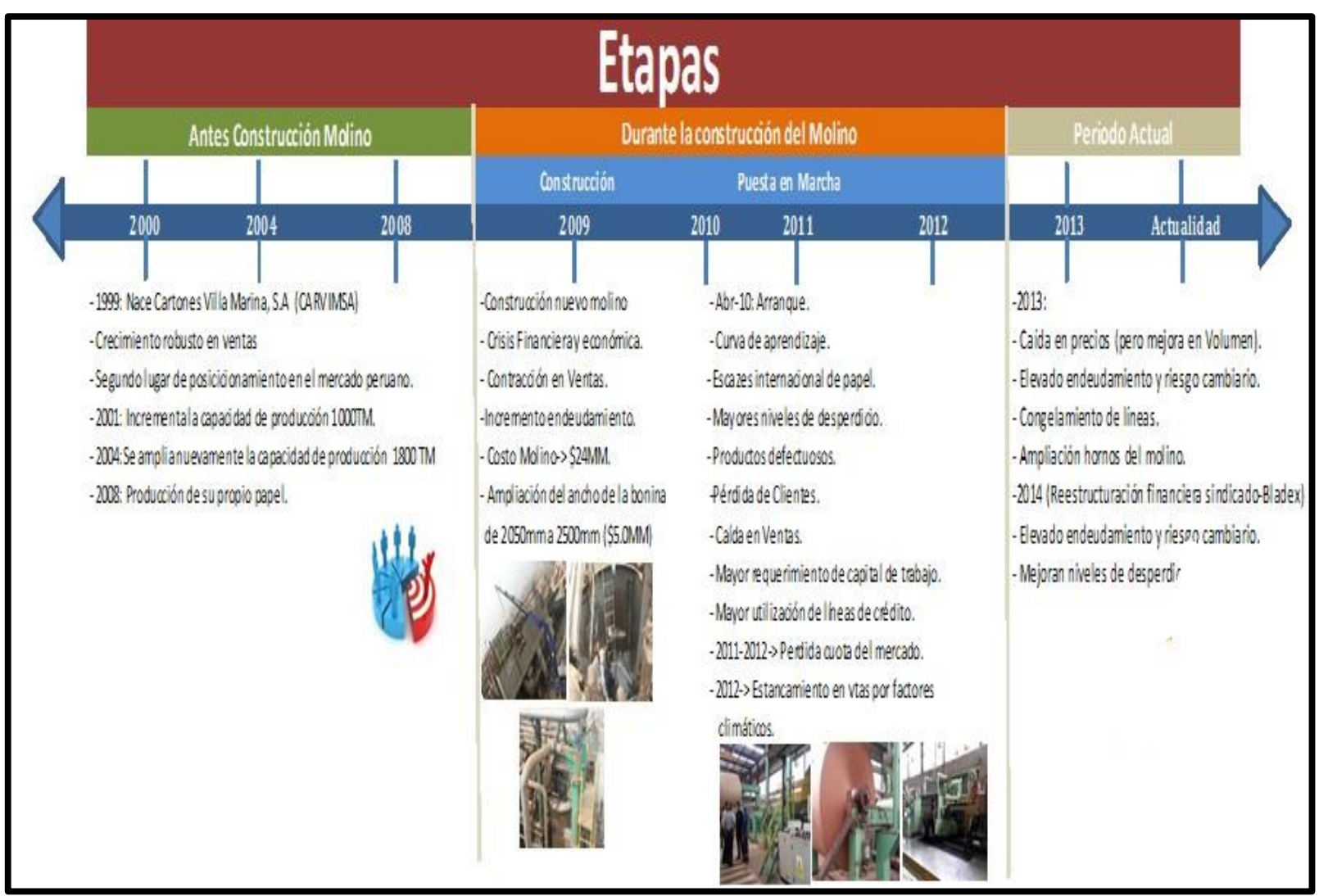

Figura 19. Línea de Tiempo de Historia de CARVIMSA. Tomado de Galería interna de fotos CARVIMSA.

A mediados del año 2013, CARVIMSA decide emprender nuevamente el ambicioso proyecto de establecer su propia unidad estratégica de negocio de "Tubos y Esquineros de cartón”. Esto con el objetivo de reducir los inventarios de side roll que mantiene la unidad estratégica de negocio de bobinas de papel, incursionar en este tipo de productos en el mercado local con el fin de ser reconocidos en el mercado peruano como la primera opción de compra en los envases de tubos y esquineros de cartón, uno de sus principales fines en el corto plazo, es no depender de un inventario acumulado, sino el de pedir pedidos de papeles a la unidad estratégica de negocio de papel, con las especificaciones deseables, reducir los costos de la producción.

De acuerdo con el plan estratégico para el montaje de la planta y maquinarias CARVIMSA, tiene planificado que, en un máximo de 6 meses, esa unidad estratégica de 
negocio debería ser capaz de producir tubos que pudiera ser vendidos al mercado.

Comenzaron con tres máquinas tuberas (Ver figura 20), seis cortadoras de tubos manuales, una maquina Slitter y dos salas de horno para secado.

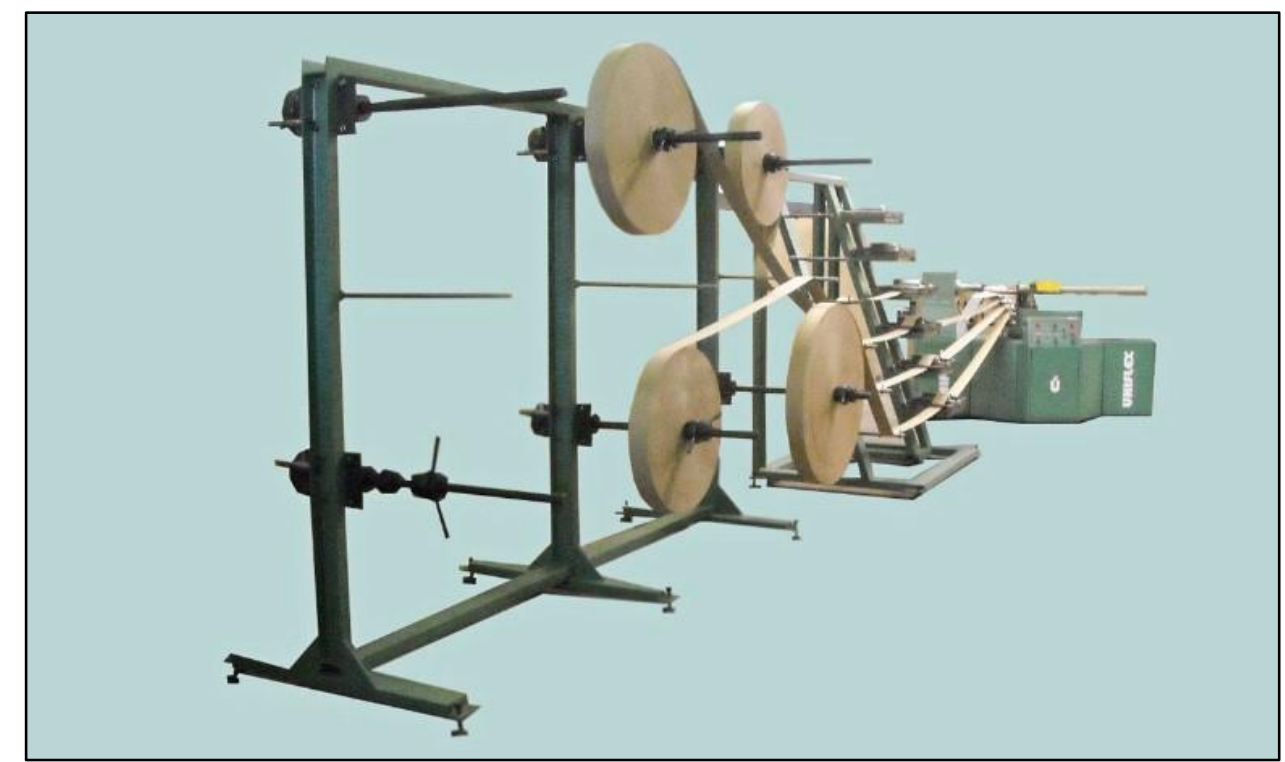

Figura 20. Máquina Tubera. Tomado de Página Web de Uniflex. Recuperado de http://www.uniflex.com.ar/images/formadora_tubos_carton.jpg

Como construcciones, tenían una nave para la producción de tubos y esquineros y un almacén de producto terminado.

Se inició con producciones de $131 \mathrm{TM} / \mathrm{mes}$, las cuales hoy en día alcanzan las 408 $\mathrm{TM} / \mathrm{mes}$. Este tipo de productos son consumidos en el mercado local como del exterior, exportando a Costa Rica.

Cuenta con una gran cartera de clientes, tanto en el mercado local como del exterior. A continuación, la tabla 04 detalla los clientes top de la unidad estratégica de negocio Tubos y Esquineros de CARVIMSA. 
Tabla 04

Clientes Top por Unidad Estratégica de Negocio de Tubos y Esquineros

Clientes Top en la actualidad

\begin{tabular}{l}
\hline Solpack SA \\
\hline Packing \& Plastics Peru S.A. \\
\hline Filmpack S.A.C \\
\hline Peruplast S.A. \\
\hline Tdm Geosinteticos \\
\hline Unión Plast S.A. \\
\hline Envolturas Flexibles Huachipa S.A.C \\
\hline Envases Y Envolturas S.A. \\
\hline Opp Film \\
\hline Sociedad Agrícola Drokasa S.A. \\
\hline Agropacking Export S.A. \\
\hline Línea Plástica Perú S.A. \\
\hline Tal S.A. \\
\hline Gandules Inc. Sac \\
\hline Agrícola Cerro Prieto S.A. \\
\hline Complejo Agroindustrial Beta S.A. \\
\hline Polinplast S.A.C \\
\hline Empacadora Agrícola Del Pacifico S.A. \\
\hline Jayanca Fruits S.A.C. \\
\hline Emusa Perú S.A.C. \\
\hline Danper Trujillo S.A.C. \\
\hline
\end{tabular}

\subsection{Descripción del negocio}

Cartones Villa Marina SA, se identifica con el CIIU 1702-Fabricacion de papel y cartón ondulado y de envases de papel y cartón. Esta CIIU corresponde a la división 17 asignado por el Instituto Nacional de Estadística e Informática (INEI).

Según el INEI 2017, se detalla la conceptualización de la división y clases a la que pertenece CARVIMSA:

- División 17: Fabricación de papel y de productos de papel Esta división comprende la fabricación de pasta de madera, papel y productos de papel. La fabricación de esos productos está agrupada porque abarca una serie de procesos conectados 
verticalmente. Es frecuente que una misma unidad realice más de una de esas actividades. Se trata esencialmente de tres actividades: la fabricación de pasta de madera entraña la separación de las fibras de celulosa de otras impurezas de la madera o el papel usado; la fabricación de papel consiste en el fieltrado de esas fibras hasta convertirlas en una lámina. Los productos de la transformación del papel se realizan con papel y otros materiales mediante diversas técnicas de corte y moldeado, incluidas actividades de revestimiento y laminado. Los artículos de papel pueden estar impresos (papel de empapelar, papel de regalo, etcétera), siempre que la impresión de información no sea el objetivo principal.

- Clase 1702: Fabricación de papel y cartón ondulado y de envases de papel y cartón Esta clase comprende las siguientes actividades: fabricación de papel y cartón ondulado; fabricación de envases de papel o cartón ondulado; fabricación de envases plegables de cartón; fabricación de envases de cartón rígido; fabricación de otros envases de papel y cartón; fabricación de sacos y bolsas de papel; y la fabricación de archivadores de oficina y artículos similares.

La Compañía CARVIMSA se constituyó en el año 1999 y se dedica a la fabricación, importación, exportación, distribución y comercialización al por mayor y menor, de cajas de cartón o envases de embalajes hechos de cartón corrugado y microcorrugado, papeles, tubos y esquineros de cartón. Cabe mencionar, que, en el año 2009, se dedicó ampliar el objeto social de la empresa, con lo cual CARVIMSA puede dedicarse también al transporte de carga de mercancías, nacional e internacional, así como cualquier otro tipo de actividades afines de ella misma.

Para el desarrollo de sus actividades, cuenta con 3 unidades de negocio, las mismas que se detallan a continuación: 
a) Unidad Estratégica de Negocio de "Cajas de Cartón Corrugado y

Microcorrugado: Se dedica a la manufactura y producción de empaques de cartón en las líneas de corrugado y microcorrugado, orientado a los sectores de agro, pesca, textil, farmacéutico, alimentos, cosméticos e industrial.

b) Unidad Estratégica de Negocio de "Papel y Empalmadas": Se dedica a la fabricación de una amplia gama de papeles en distintas composiciones. Asimismo, esta unidad opera recolectando papel y cartón reciclado, los cuales son utilizados en la fabricación de nuevas fibras para la producción.

c) Unidad Estratégica de Negocio de "Tubos y Esquineros": Se dedica a la fabricación de tubos y esquineros de cartón a través de los Side Roll generados de su propio molino de papel.

En la actualidad, CARVIMSA cuenta con dos plantas industriales ubicadas en Villa El Salvador y Huachipa; dedicadas a la elaboración de cajas de cartón corrugado, bobinas de papel, tubos y esquineros para satisfacer tanto al mercado local como externo.

\subsection{Ciclo de vida del producto}

Kotler y Armstrong (2003) afirman que "el ciclo de vida de un producto es el curso de las ventas y utilidades de un producto durante su existencia” (p.373).

El ciclo de vida del producto en CARVIMSA es de la "Etapa de Crecimiento", ya que su participación en el mercado va en aumento y, además está desarrollando nuevos productos. 


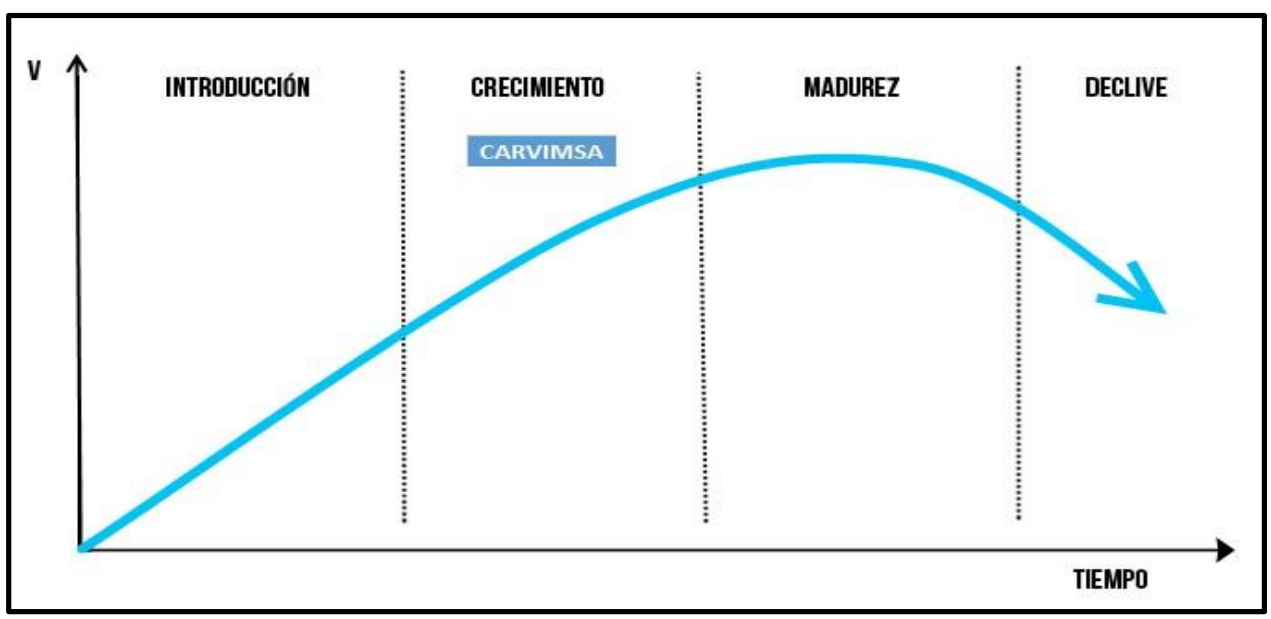

Figura 21. Ciclo de vida de un producto en un mercado.

Ahora se analizará el ciclo de vida por cada unidad estratégica de negocio:

a. Unidad Estratégica de Negocio de "Cajas de Cartón Corrugado y

Microcorrugado: Se dedica a la manufactura y producción de empaques de cartón en las líneas de corrugado y microcorrugado, orientado a los sectores de agro, pesca, textil, farmacéutico, alimentos, cosméticos e industrial. Se analizó los últimos 3 Estados de Ganancias y Pérdidas de esta unidad estratégica de negocio, está en el ciclo de vida "Crecimiento", por mayor participación en el mercado, esto se ve reflejado en las ventas, además al tener mayor volumen de ventas, les ayuda a mejorar sus costos de fabricación, en consecuencia, tener un mejor margen de rentabilidad (Ver tabla 05).

Tabla 05

Ventas y Utilidades antes de impuesto por año

\section{Análisis de Ventas y Utilidad Unidad de Negocios de "Cajas de} cartón Corrugado y Microcorrugado"

\begin{tabular}{llll}
\hline Detalle & $\mathbf{2 0 1 4}$ & $\mathbf{2 0 1 5}$ & $\mathbf{2 0 1 6}$ \\
\hline Ventas en TM & 2,580 & 3,005 & 3,112 \\
\hline $\begin{array}{l}\text { Aumento / Disminución de la } \\
\text { Ventas Anuales }\end{array}$ & $6.5 \%$ & $23.0 \%$ & $9.8 \%$ \\
\hline UAII \% Rentabilidad & $5.1 \%$ & $6.4 \%$ & $9.7 \%$ \\
\hline
\end{tabular}

Nota. Adaptado de los Estados Financieros, por CARVIMSA, 2016, Perú, Lima: CARVIMSA. Copyright 2016 por CARVIMSA. 
b. Unidad Estratégica de Negocio de "Papel y Empalmadas": Se dedica a la fabricación de una amplia gama de papeles en distintas composiciones. Asimismo, esta división opera recolectando papel y cartón reciclado, los cuales son utilizados en la fabricación de nuevas fibras para la producción. Según los EEFF de esta unidad estratégica de negocio está en el ciclo de vida "Crecimiento", y esto se da, porque esta unidad estratégica de negocio se creó para poder abastecer a su unidad estratégica de negocio de cajas de cartón, mas no tanto con el fin de vender a terceros, es por eso que a esta unidad se le debe medir por su productividad mas no por la venta (Ver tabla 06).

Tabla 06

Ventas y Utilidades antes de impuesto por Unidad Estratégica de Negocio

Análisis de Ventas y Utilidad Unidad de Negocios de "Papel y Empalmadas"

\begin{tabular}{lccc}
\hline Detalle & 2014 & 2015 & 2016 \\
\hline Producción en TM & 3,509 & 4,427 & 4,488 \\
\hline Ventas en TM & 1,023 & 1,217 & 894 \\
\hline $\begin{array}{l}\text { Aumento / Disminución de } \\
\text { la Ventas Anuales }\end{array}$ & $49.4 \%$ & $42.5 \%$ & $-38.9 \%$ \\
\hline UAII \% Rentabilidad & $-3 \%$ & $-2 \%$ & $1 \%$
\end{tabular}

Nota. Adaptado de los Estados Financieros, por CARVIMSA, 2016, Perú, Lima: CARVIMSA. Copyright 2016 por CARVIMSA.

c. Unidad Estratégica de Negocio de "Tubos y Esquineros": Se dedica a la fabricación de tubos y esquineros de cartón a través de los Side Roll generados de su propio molino de papel. Esta unidad estratégica de negocio se creó con el fin de poder consumir los inventarios de Side Roll que tenía la unidad estratégica de negocio de papel y empalmadas, pero a su vez poder desarrollar nuevos productos para el mercado. Según los Estados Financieros de esta unidad estratégica de negocio, está en el ciclo de vida de "crecimiento", esto 
es por el aumento de las toneladas vendidas en los últimos 3 años, mejora sus márgenes de rentabilidad (Ver tabla 07).

Tabla 07

Ventas y Utilidades antes de impuesto por Unidad Estratégica de Negocio

\begin{tabular}{lclll}
\hline \multicolumn{2}{c}{ Análisis de Ventas y Utilidad Unidad Estratégica de Negocios Tubos y } \\
$\begin{array}{llll}\text { Esquineros } \\
\text { Detalle }\end{array}$ & $\underline{\mathbf{2 0 1 4}}$ & $\underline{\mathbf{2 0 1 5}}$ & $\underline{\mathbf{2 0 1 6}}$ \\
\cline { 1 - 2 } Ventas en TM & $\underline{\mathbf{2 4 2}}$ & $\underline{\mathbf{3 2 3}}$ & $\underline{\mathbf{3 5 6}}$ \\
\cline { 1 - 2 } $\begin{array}{l}\text { Aumento / Disminución de } \\
\text { la Ventas Anuales }\end{array}$ & $127.8 \%$ & & $44.6 \%$ & $8.5 \%$ \\
\hline UAII \% Rentabilidad & $-1.0 \%$ & $-0.2 \%$ & $0.2 \%$ \\
\hline \hline
\end{tabular}

Nota. Adaptado de los Estados Financieros, por CARVIMSA, 2016, Perú, Lima: CARVIMSA. Copyright 2016 por CARVIMSA.

\subsection{Estructura organizacional actual de la empresa}

Robbins y Judge (2013) sostienen que:

La estructura organizacional es la forma en la cual las actividades del puesto de trabajo se constituyen formalmente. Para diseñar esta estructura los gerentes deben considerar elementos primordiales tales como: Especialización en el trabajo, departamentalización, cadena de mano, extensión de control, centralización y descentralización, y formalización (p.480).

La empresa CARVIMSA para poder tener una estructura bien definida se basó en un elemento primordial de especialización en el trabajo, de modo que en la actualidad existe un gerente para: Gerencia General, Gerencia Administrativa financiera y sistemas, Gerencia de venta, Gerencia de Mantenimiento y Gerencia de Planta. A su vez cada gerencia está conformada por áreas las cuales se han formado tomando en consideración el elemento de Departamentalización, tal como se visualiza en la figura 22. 


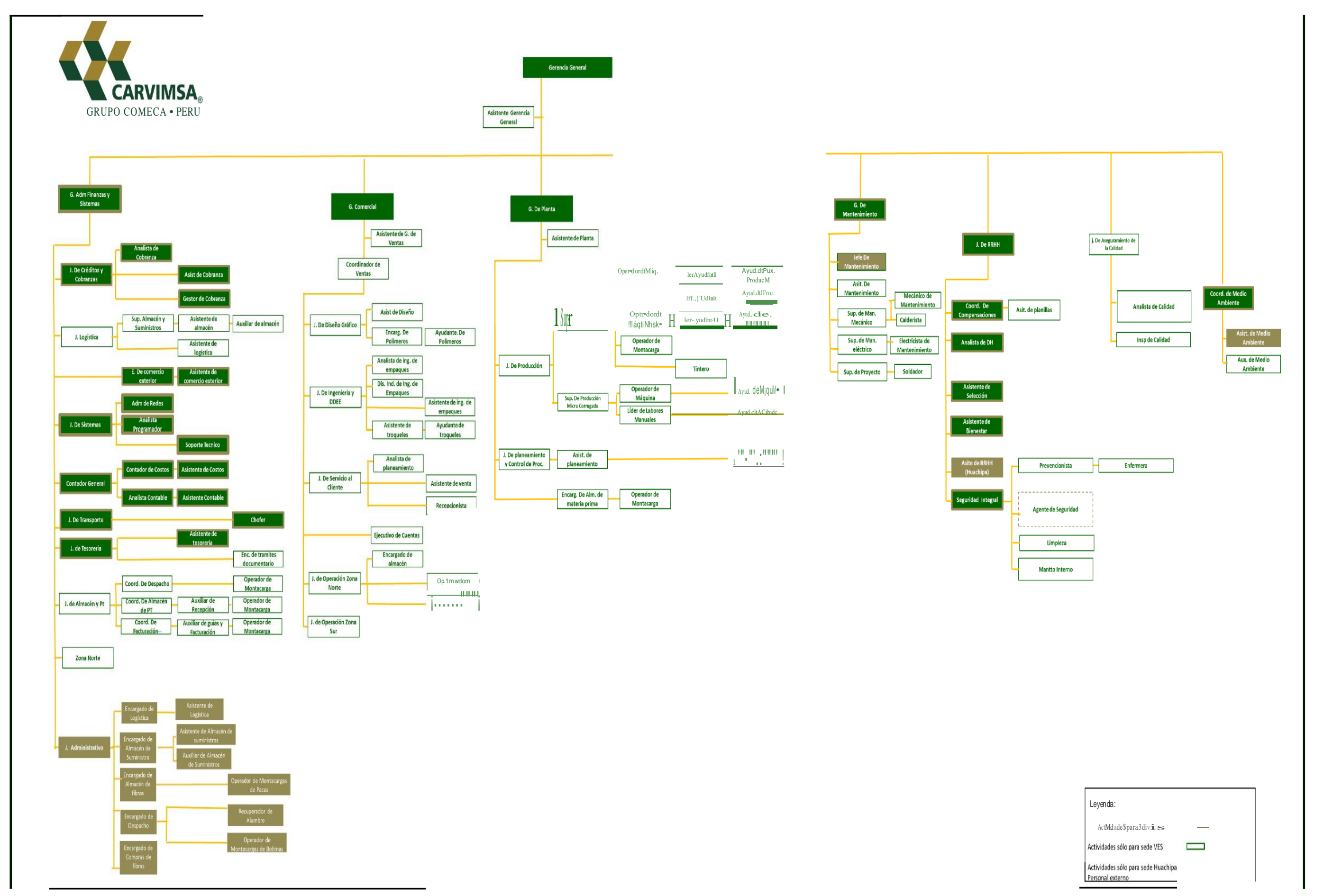

Figura 22. Organigrama de CARVIMSA. Tomado de Manual de Descripción del Puesto de CARVIMSA. 
El resumen de los puestos de trabajo existentes en la actualidad se puede visualizar en las

figuras 23 y 24.

\begin{tabular}{|c|c|c|c|}
\hline Código & GERENCIA GENERAL & Código & ASEGURAMIENTO DE LA CAIIDAD \\
\hline 001 & Gerente General & 036 & Jefe de Aseguramiento de la Calidad \\
\hline 002 & Asistete De Gerencia General & 037 & Analista de Calidad \\
\hline 003 & Asistente Financiero Ger. General & 038 & Inspector de Calidad \\
\hline 004 & Ingeniero Estadista & códizo & MEDIO AMBIENTE \\
\hline Código & ADMINISIRACIÓN Y FINA NZZAS & & \\
\hline 005 & Gerente de Adm. y Finanzas & 039 & $\begin{array}{l}\text { Coordinadora de Medio Amblente } \\
\text { Asistente de Medio Ambiente }\end{array}$ \\
\hline 006 & Jefe de tesorería & 041 & Auxiliar de Medio Ambiente \\
\hline 007 & Asistente de tesorería & & \\
\hline 008 & Encargado de tramites documentario & Código & AUDTIORLA IWTERNA \\
\hline $\begin{array}{l}009 \\
010\end{array}$ & $\begin{array}{l}\text { Contador General } \\
\text { Supervisor Contable }\end{array}$ & 042 & Jefe de Auditoría \\
\hline 011 & $\begin{array}{l}\text { Supervisor contable } \\
\text { Analista contable }\end{array}$ & 043 & Asistente de Auditoría \\
\hline 012 & Asistente contable & & RECURSOS HUMANOS \\
\hline 013 & contadora de costos & Codigo & \\
\hline 014 & Asistente de costos & 044 & coordinadora de Compensaciones \\
\hline 015 & Jefe de Créditos y cobranza & 045 & Auxiliar de Planillas \\
\hline 016 & Analista de Créditos y Cobranza & 046 & Analista de Desarrollo Humano \\
\hline 017 & Asistente de Créditos y cobranza & 047 & Asistenta Social \\
\hline 018 & Gestor de créditos y Cobranza & 048 & Prevencionista de Riesgos \\
\hline 019 & Encargado de comercio exterior & 049 & Enfermera \\
\hline 020 & Asistente de Comercio exterior & & \\
\hline 021 & Jefe de Logistica & Código & VENTAS \\
\hline 022 & Asistente de Logistica & & \\
\hline 023 & Coordinador de Almacén de Suministros & $\begin{array}{l}050 \\
051\end{array}$ & $\begin{array}{l}\text { Gerente de ventas } \\
\text { coordinador de ventas }\end{array}$ \\
\hline Código & SISTEMAS & 052 & Analista de Ventas \\
\hline & & 053 & Asistente de Gerencia de Ventas \\
\hline 025 & $\begin{array}{l}\text { Jefe de Sistemas } \\
\text { Analista programador de sistema }\end{array}$ & 054 & Ejecutivo de cuentas \\
\hline 026 & Administrador de Redes y Servidores & Código & SERVICOO AL CUEENTE \\
\hline 027 & Auxiliar de Soporte Tecnico & 055 & Jefe de Servicio al cliente \\
\hline Código & ALMACEN DE PRODUCTO TERMINADO & 056 & Analista de Planeamiento. \\
\hline 028 & Jefe de Almacén de PT & 057 & Asistente de servicio al cliente \\
\hline 029 & $\begin{array}{l}\text { Jefe de Almacen de PT } \\
\text { coordinador Almacén de Producto Terminado }\end{array}$ & 058 & Recepcionista \\
\hline 030 & Coordinador de Despacho & Código & INGEMIERIA Y EMPPAQUES \\
\hline 031 & Coordinador de Facturación & & \\
\hline 032 & $\begin{array}{l}\text { Auxiliar de Guías y Facturación } \\
\text { Auxiliar de Recepción PT }\end{array}$ & 060 & $\begin{array}{l}\text { Dete de Ingenteria de Empaques } \\
\text { Diseñador Ingeniería de Empaques }\end{array}$ \\
\hline 034 & Operador de Montacargas & 061 & Analista de Ingeniería de Empaques \\
\hline 035 & chofer & 062 & Asistente de Ingeniería de Empaques \\
\hline & & $\begin{array}{l}063 \\
064\end{array}$ & $\begin{array}{l}\text { Asistente de Troqueles } \\
\text { Ayudante de troqueles }\end{array}$ \\
\hline
\end{tabular}

Figura 23. Puestos de Trabajo de CARVIMSA. Tomado de Manual de Descripción del Puesto de CARVIMSA. 


\begin{tabular}{|c|c|c|c|}
\hline & 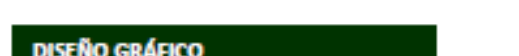 & Código & PRODUCCIÓN MICROCORRUGADO \\
\hline Código & 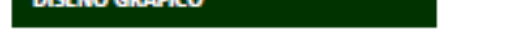 & 087 & Lider de Labores Manuales de Micro \\
\hline 065 & Jefe de Diseño Grafico & 083 & Operador de Máq. Conv Plana y Guillotina \\
\hline 066 & Asistente de Diseño Gráfico & 089 & Operador de Máquina Cortadora de Bobinas \\
\hline 067 & Encargado de Polímeros & 090 & Operador de Máquina Impresora offset \\
\hline 068 & Operario de Polímero & $\begin{array}{l}091 \\
092\end{array}$ & $\begin{array}{l}\text { Operador de Máquina Laminadora } \\
\text { Operador de Máquina Micro corrugado }\end{array}$ \\
\hline & & 093 & Operador de Máquina Troqueladora Plana \\
\hline Código & PRODUCCIONN CORRUGADO & 094 & Ayudante de Proceso Productivo - micro \\
\hline 069 & Gerente de planta & Código & ALMACÉN DE MATERIA PRIMMA \\
\hline $\begin{array}{l}070 \\
071\end{array}$ & Jefe de Producción & & \\
\hline 071 & Jefe de Planeamiento y control de Producción & 095 & Encargada de almacén de Materia prima \\
\hline 072 & Asis de Planeamiento y Control de La Prod & 096 & Operador de Montacargas \\
\hline 073 & Asistente de Gerencia de Planta & & \\
\hline 074 & Supervisor de corrugado & Código & MANTENIMIENTO \\
\hline $\begin{array}{l}075 \\
076\end{array}$ & $\begin{array}{l}\text { Operador de Cabezal corrugador -8HS } \\
\text { Operador de Cabina - corruagador BHS }\end{array}$ & 097 & Jefe de Mantenimiento \\
\hline 077 & Operador de Máquina MQ - Engrampado & 098 & Asistente de Mantenimiento \\
\hline 078 & Operador de Máquina MQ - Flexo & 099 & Planificador de Mantenimiento \\
\hline 079 & Operador de Paletizado - corruagador BHS & 100 & Supervisor de Mantenimiento Eléctrico \\
\hline 080 & Operador de Máquina MQ - Particiones & 101 & Electricista de Mantenimiento lider \\
\hline 081 & Operador de Planta de Adhesivo -BHS & 102 & Electricista de Mantenimiento correctivo \\
\hline 082 & Operador de Stacker - corruagador BHS & 103 & Supervisor de Mantenimiento Mecánico \\
\hline 083 & Operador de Doble Backer - corruagador BHS & 104 & Mecánico de mantenimiento Lider \\
\hline 084 & 1er ayudante & 105 & Mecánico Mantto de correctivo \\
\hline 085 & Ayudante de Proceso Productivo-corrugado & 106 & Mecánico de Montacargas \\
\hline 086 & Líder de Labores Manuales de Corrugado & 107 & Calderista \\
\hline & & 108 & Soldador \\
\hline
\end{tabular}

Figura 24. Puestos de Trabajo de CARVIMSA. Tomado de Manual de Descripción del Puesto de CARVIMSA.

La descripción del puesto de los principales funcionarios de la empresa CARVIMSA se detallan en las siguientes tablas: 
Tabla 08

Descripción del puesto del Gerente General

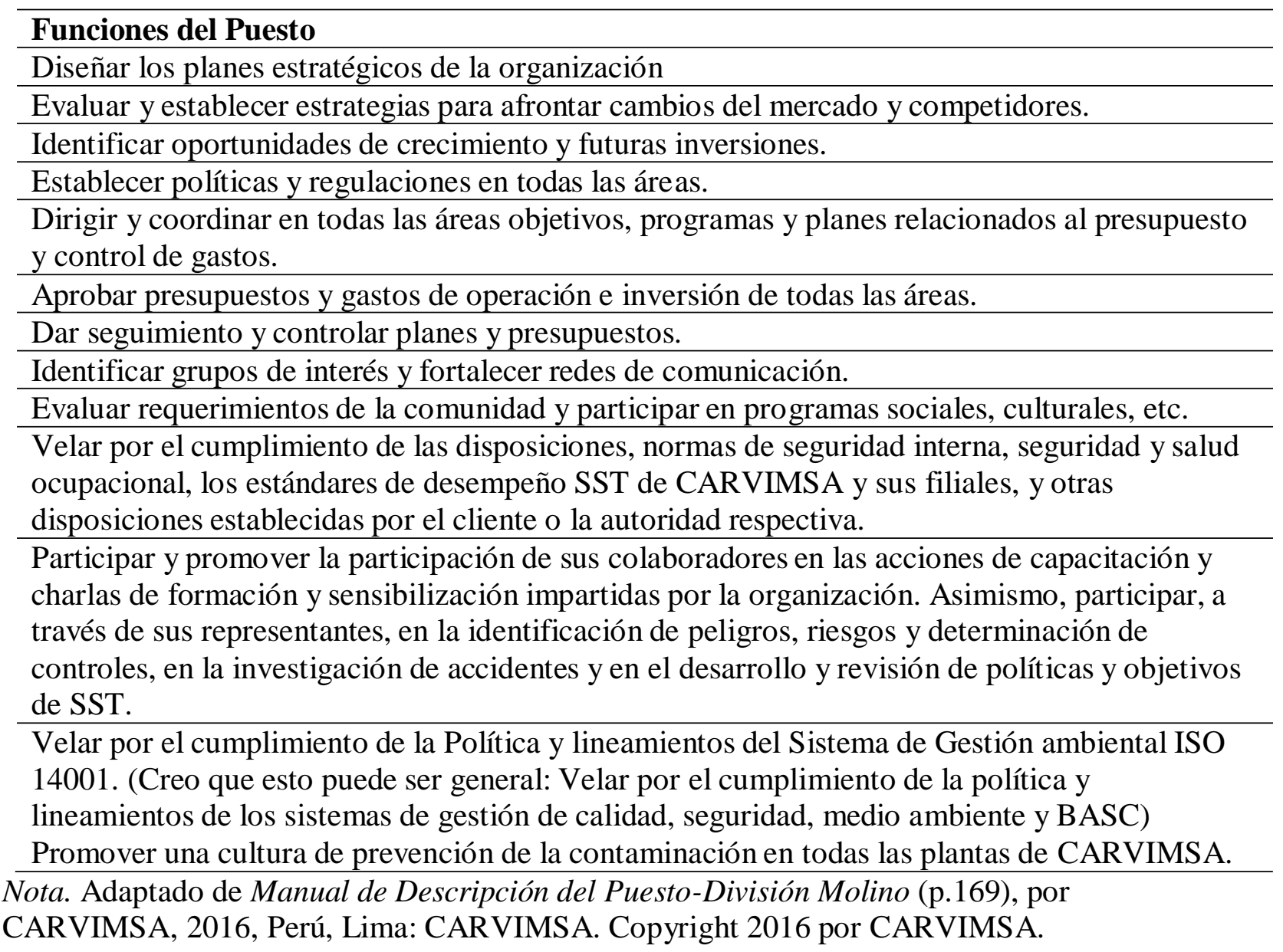


Tabla 09

Descripción del puesto del Gerente Administrativo financiero y sistemas

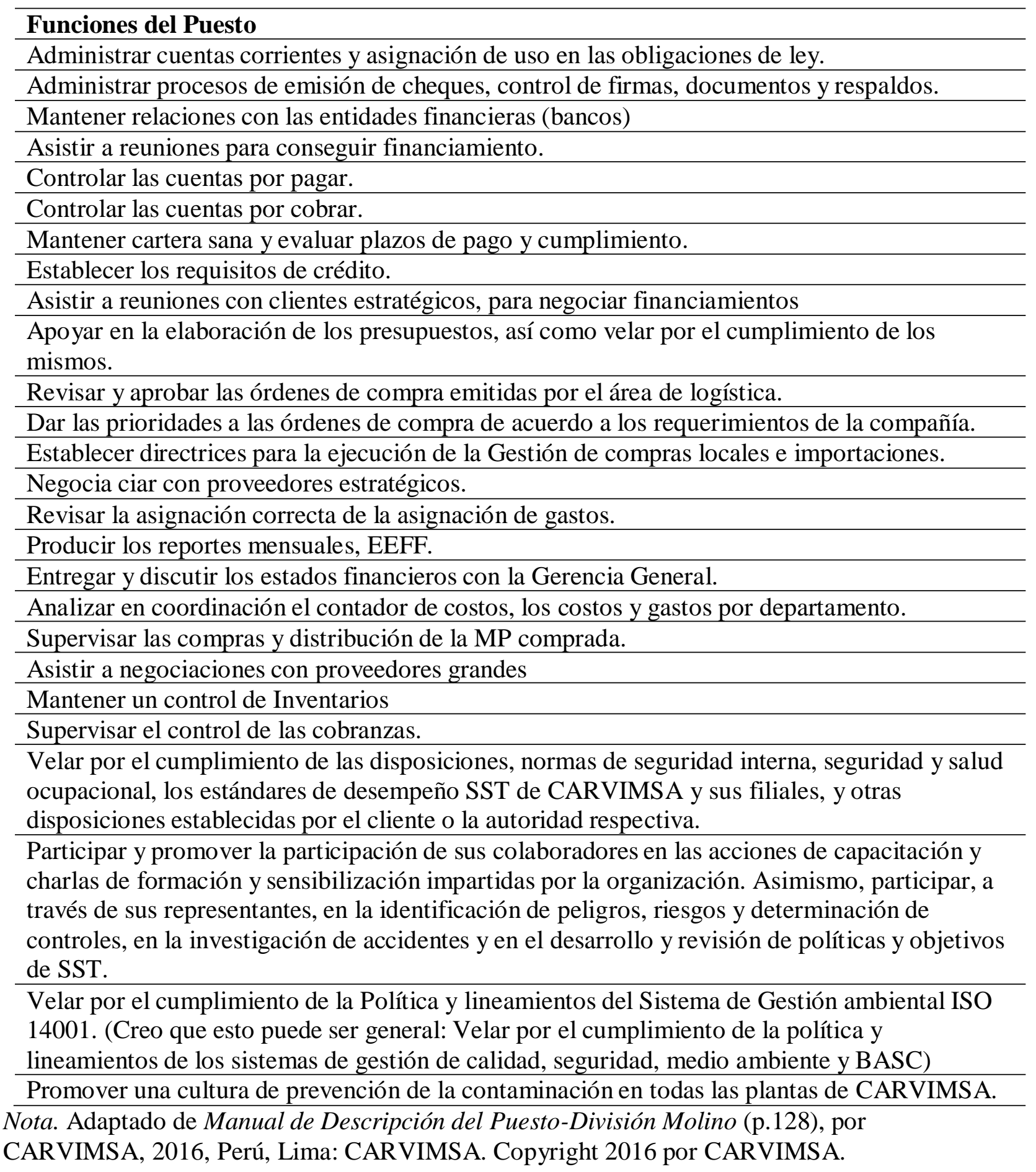


Tabla 10

Descripción del puesto del Gerente de Planta

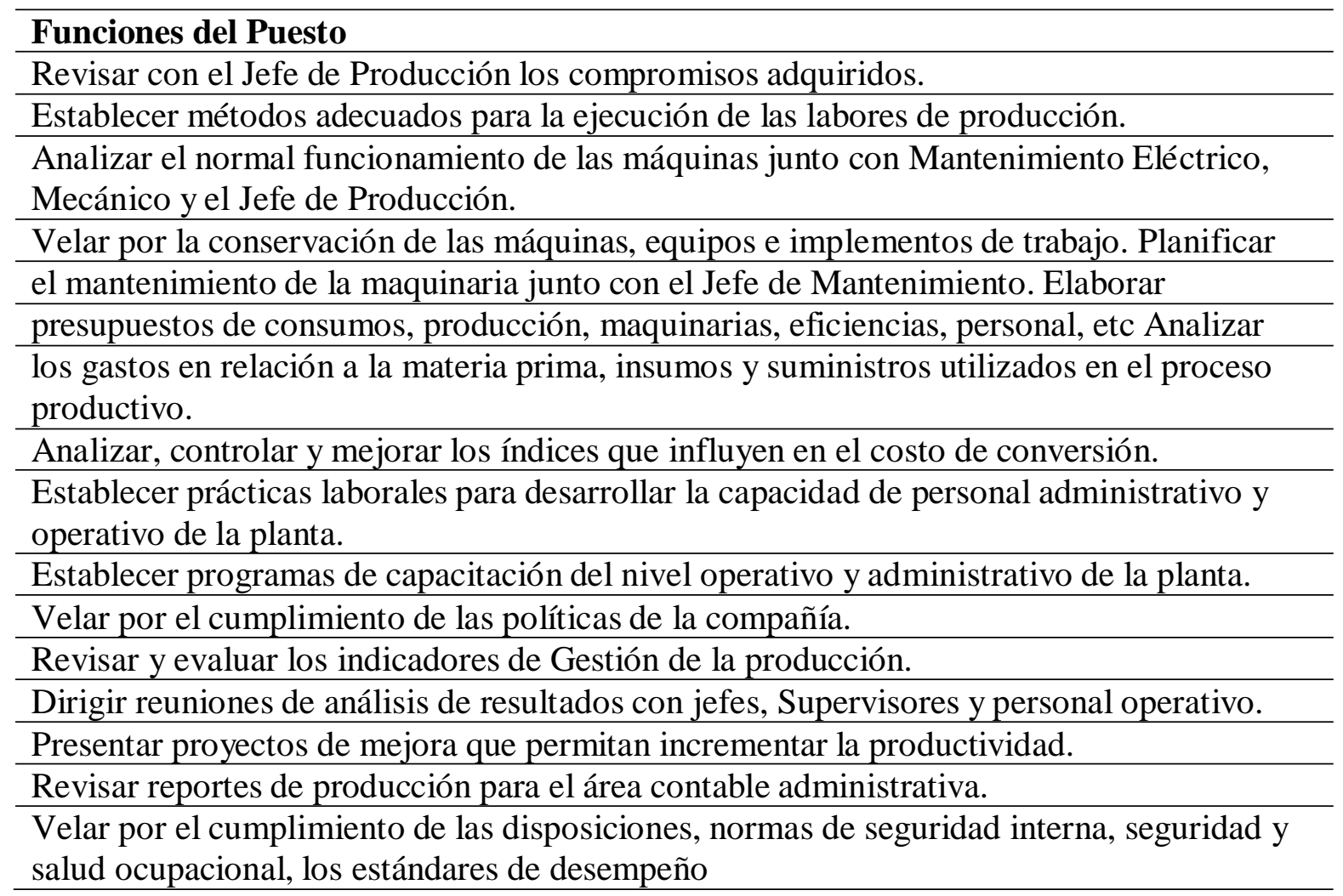

Nota. Adaptado de Manual de Descripción del Puesto-División Corrugado (p.234), por

CARVIMSA, 2016, Perú, Lima: CARVIMSA. Copyright 2016 por CARVIMSA. 
Tabla 11

Descripción del puesto del Gerente de Ventas

\begin{tabular}{l}
\hline Funciones del Puesto \\
\hline Atender a las solicitudes de los clientes top \\
\hline Coordinar con servicio al cliente el ingreso de pedidos urgentes. \\
\hline Aprobar las producciones con cambios test, siempre y cuando ésta no afecte la rentabilidad \\
del pedido. \\
\hline Revisar el control diario de las toneladas despachadas. \\
\hline Revisar el control del inventario de producto terminado y de lenta rotación. \\
\hline Verificar el control de las ventas efectuadas por los ejecutivos de cuentas según proyección \\
de ventas. \\
\hline Realizar visitas diarias a los clientes de las diferentes carteras. \\
\hline Analizar mensualmente los precios de ventas, rentabilidad por pedido, por cliente y por \\
cartera. \\
\hline Dirigir reuniones semanales con todo el equipo de ventas para el seguimiento de las \\
carteras \\
\hline Analizar y presentar los resultados de ventas mensuales a Gerencia General. \\
\hline Analizar los costos y presupuestos presentados por Diseño Gráfico y Diseño Estructural. \\
\hline Aprobar los viáticos. \\
\hline Revisar, analizar y presentar a Gerencia General los presupuestos anuales de ventas. \\
\hline Presentar la proyección de campañas de Agro y Panetones. \\
\hline Velar por el cumplimiento de las disposiciones, normas de seguridad interna, seguridad y \\
salud ocupacional, los estándares de desempeño SST de CARVIMSA y sus filiales, y otras \\
disposiciones establecidas por el cliente o la autoridad respectiva. \\
\hline Participar y promover la participación de sus colaboradores en las acciones de capacitación \\
y charlas de formación y sensibilización impartidas por la organización. Asimismo, \\
participar, a través de sus representantes, en la identificación de peligros, riesgos y \\
determinación de controles, en la investigación de accidentes y en el desarrollo y revisión de \\
políticas y objetivos de SST. \\
\hline Velar por el cumplimiento de la Política y lineamientos del Sistema de Gestión ambiental \\
ISO 14001. (Creo que esto puede ser general: Velar por el cumplimiento de la política y \\
lineamientos de los sistemas de gestión de calidad, seguridad, medio ambiente y BASC) \\
\hline Promover una cultura de prevención de la contaminación en todas las plantas de \\
CARVIMSA. \\
\hline Nota. Adaptado de $M a n u a l$ \\
\hline
\end{tabular}

Nota. Adaptado de Manual de Descripción del Puesto-División Corrugado (p.169), por

CARVIMSA, 2016, Perú, Lima: CARVIMSA. Copyright 2016 por CARVIMSA. 
Tabla 12

Descripción del puesto del Jefe Administrativo

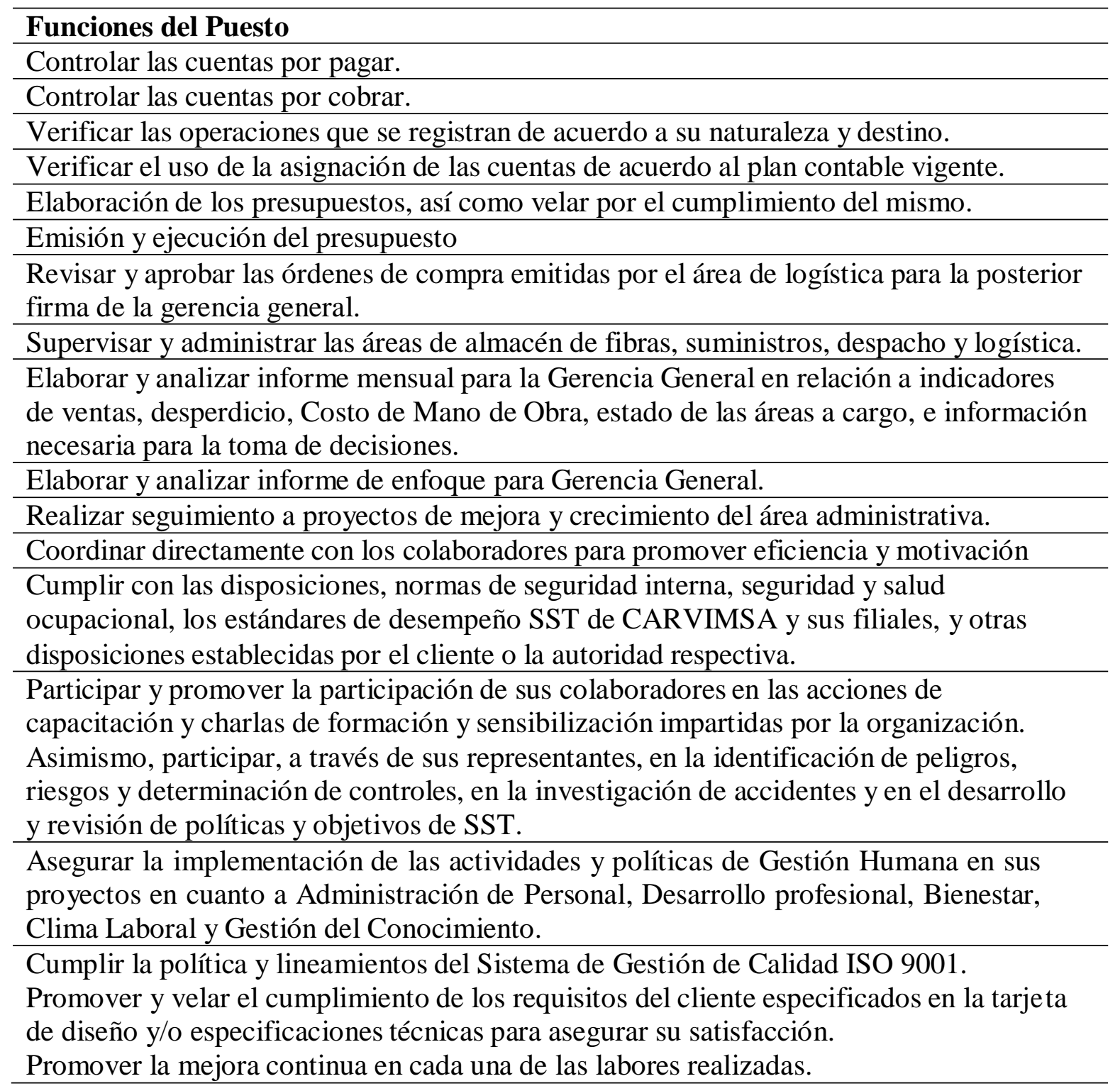

Nota. Adaptado de Manual de Descripción del Puesto-División Corrugado (p.172), por

CARVIMSA, 2016, Perú, Lima: CARVIMSA. Copyright 2016 por CARVIMSA. 
Tabla 13

Descripción del puesto del Jefe de Aseguramiento de Calidad

\section{Funciones del Puesto}

Supervisa y distribuye las actividades del personal a su cargo, elaborando mayas horarias del personal.

Levantamiento de toda la información sistémicamente, concerniente a parámetros principales de control, en concordancia con la administración de planta

Elaborar los estándares de los insumos utilizados para la fabricación del papel

Elaborar los estándares de proceso temporales de control, hasta establecer especificaciones de proceso

Controlar y mantener informado al jefe de Aseguramiento de la Calidad y jefe de producción, sobre los desvíos del proceso en los principales puntos de control

Implementar gráficos de control, atributos de control y demás herramientas en las diferentes secciones del Proceso, en concordancia con la administración de planta

Planificar y ejecutar las inspecciones de calidad en el proceso, en concordancia con el área de producción, desde el pulper, hasta la rebobinadora.

Inspección en la aplicación correcta de los productos químicos en el proceso y mediciones de consumo.

Asistencia al jefe de aseguramiento de la calidad (JAC-RED) en la verificación de no conformidades.

Programación de encuestas de satisfacción al cliente

Apoyo en las auditorías internas e inopinadas al proceso de producción dentro del sistema de gestión de la calidad

Hacer verificaciones y mantener estadística de los formatos de control de variables y atributos implementados en los procesos.

Apoyar a los desarrollos planificados, inspecciones en materia prima, producto terminado, bajo programa de ejecución.

Llevar el control de la producción retenida u observada.

Control de no conformidades del proceso.

Elaboración de certificados de calidad del cliente.

Elaboración de especificaciones técnicas.

Control de los registros de proceso de verificación e inspección.

Cumplir con la Política y normativa relacionada a las condiciones de seguridad y salud en las que se deben llevar a cabo las diversas actividades; estipulada y difundida a través del Reglamento Interno de SST de CARVIMSA

Cumplir la política y lineamientos del Sistema de Gestión de Calidad ISO 9001.

Asegurar el cumplimiento de los requisitos del cliente especificados en la tarjeta de diseño y/o especificaciones técnicas para asegurar su satisfacción.

Practicar la mejora continua en cada una de las labores realizadas

Nota. Adaptado de Manual de Descripción del Puesto-División Corrugado (p.180), por

CARVIMSA, 2016, Perú, Lima: CARVIMSA. Copyright 2016 por CARVIMSA. 
Tabla 14

Descripción del puesto del Jefe de Mantenimiento Eléctrico

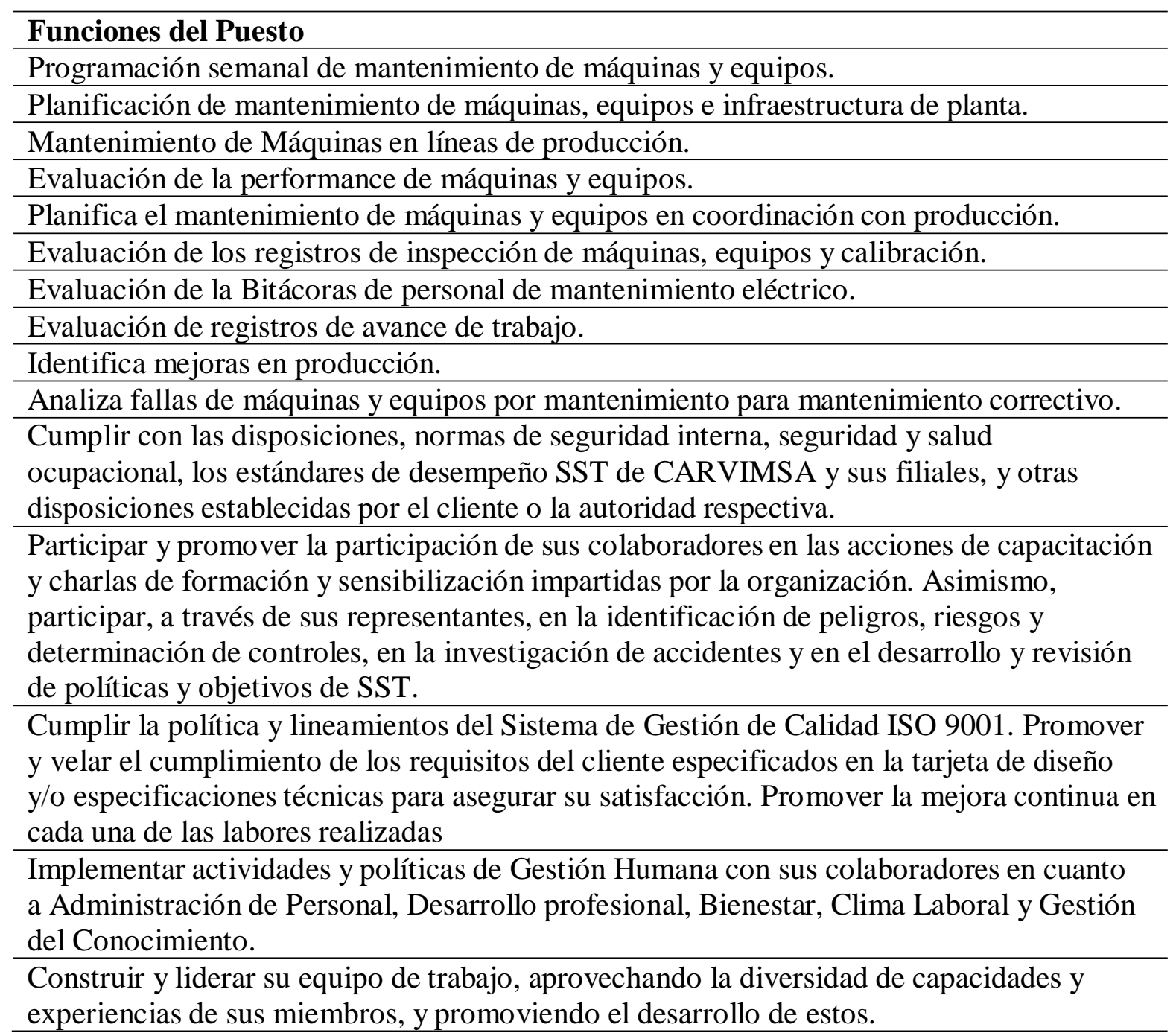

Nota. Adaptado de Manual de Descripción del Puesto-División Corrugado (p.198), por

CARVIMSA, 2016, Perú, Lima: CARVIMSA. Copyright 2016 por CARVIMSA. 
Tabla 15

Descripción del puesto del Jefe de Mantenimiento Mecánico

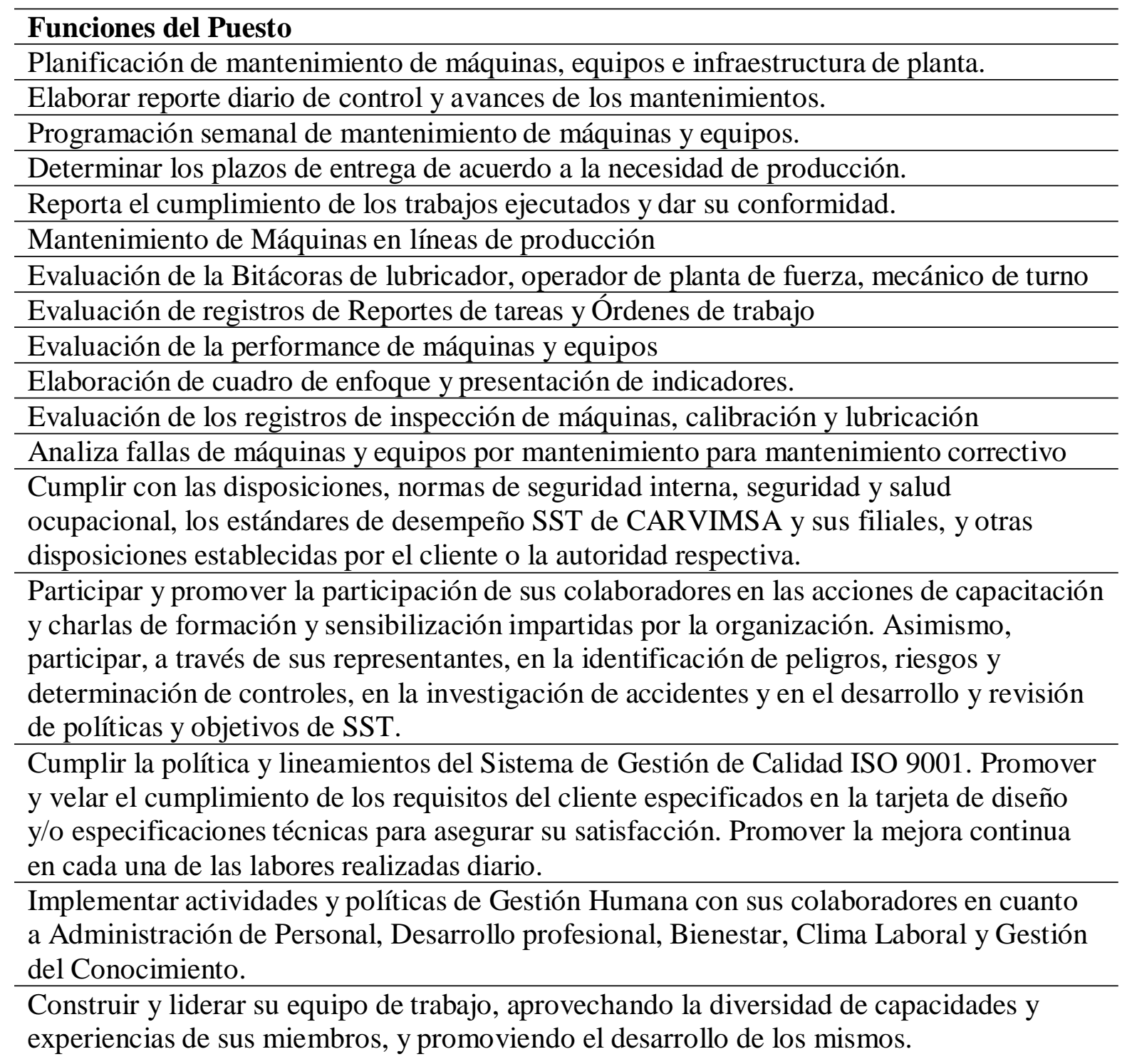

Participar activamente en las actividades de Gestión del Conocimiento de su comunidad, promoviendo los foros de discusión, las lecciones aprendidas y días de conocimiento.

Nota. Adaptado de Manual de Descripción del Puesto-División Corrugado (p.200), por

CARVIMSA, 2016, Perú, Lima: CAR VIMSA. Copyright 2016 por CARVIMSA. 
Tabla 16

Descripción del puesto del Jefe de Producción

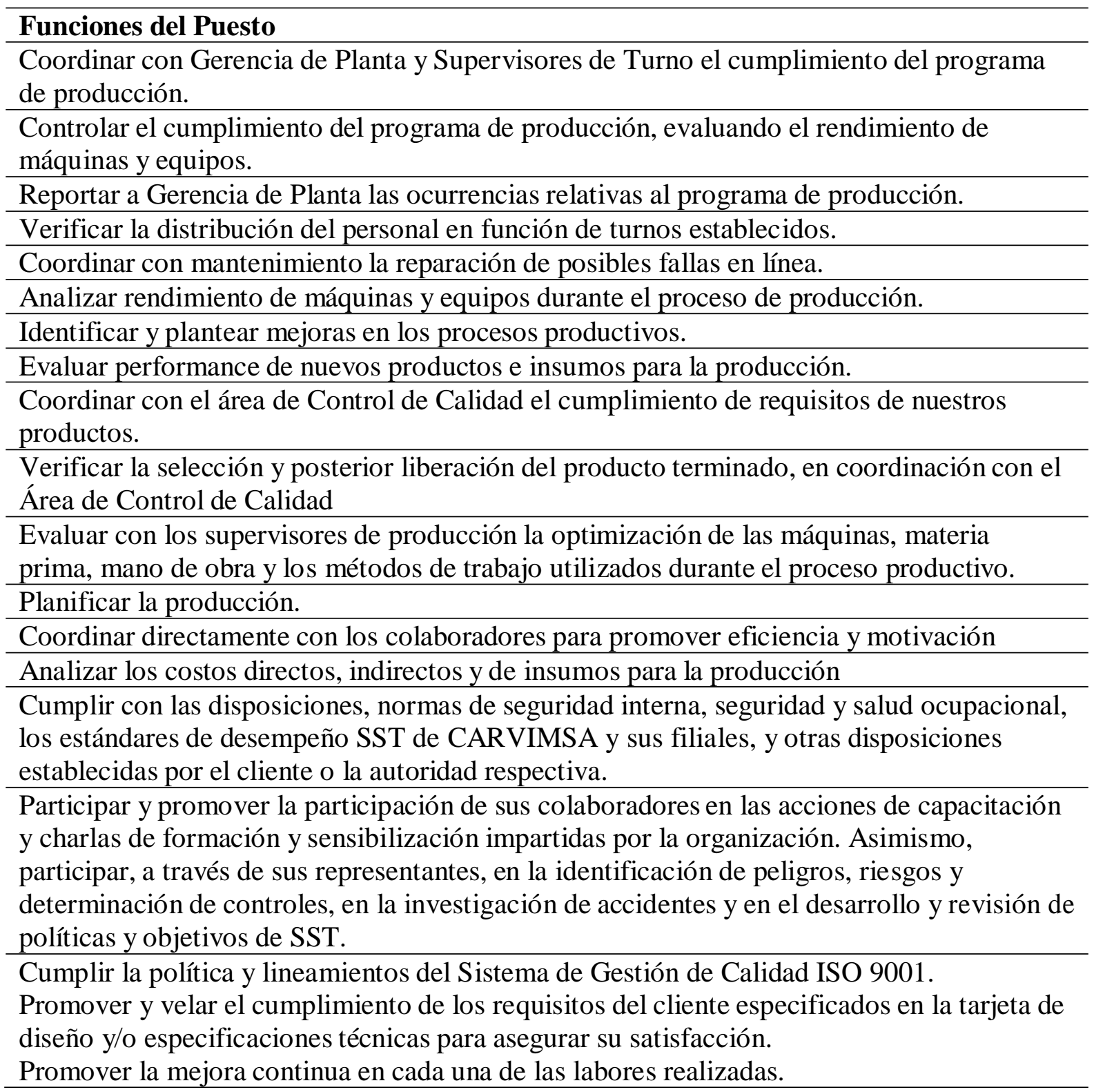

Nota. Adaptado de Manual de Descripción del Puesto-División Corrugado (p.204), por

CARVIMSA, 2016, Perú, Lima: CARVIMSA. Copyright 2016 por CARVIMSA. 
Tabla 17

Descripción del puesto del Jefe de Tesorería

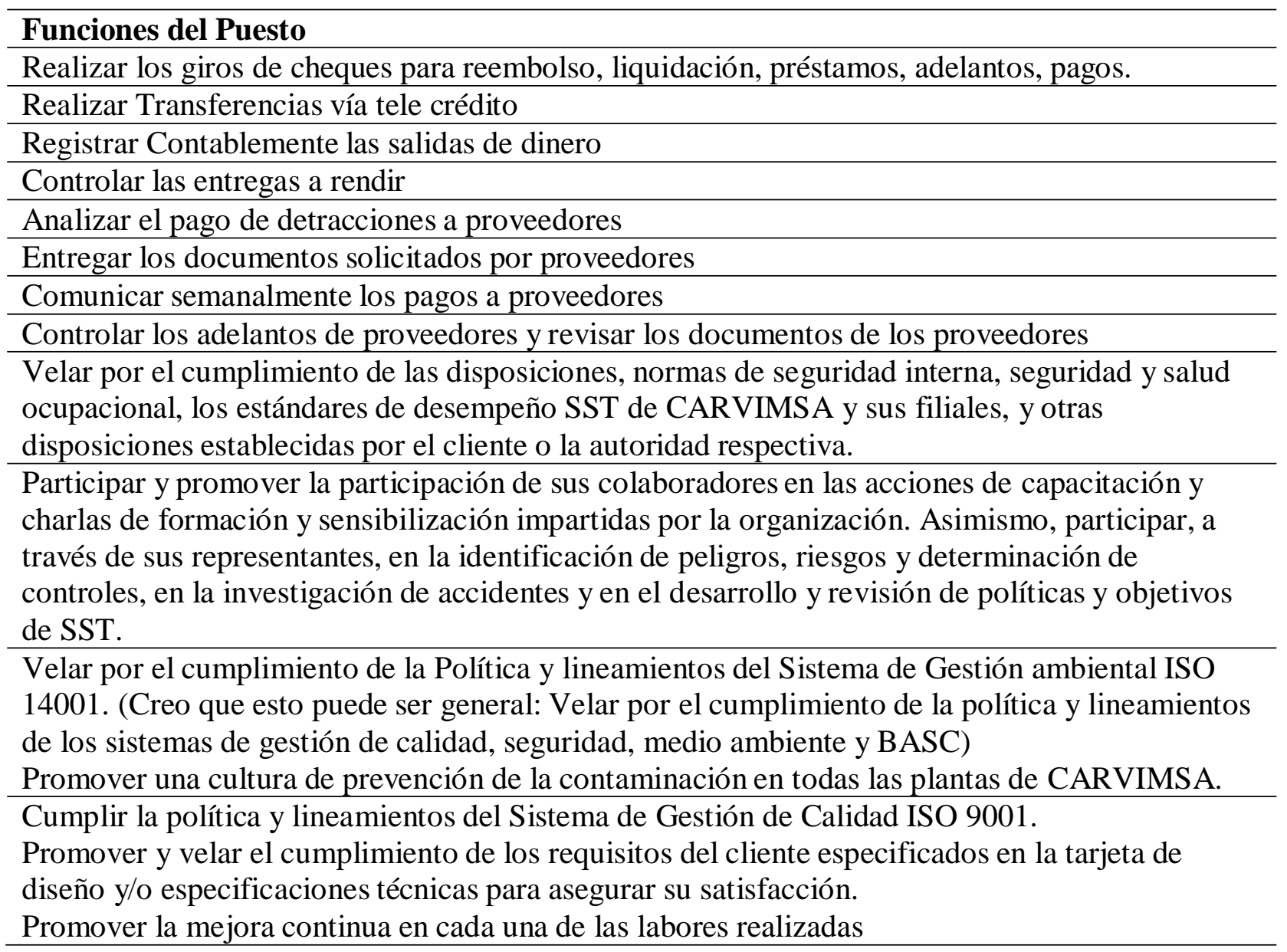

Nota. Adaptado de Manual de Descripción del Puesto-División Corrugado (p.220), por

CARVIMSA, 2016, Perú, Lima: CARVIMSA. Copyright 2016 por CARVIMSA. 
Tabla 18

Descripción del puesto del Jefe de Créditos y Cobranza

\begin{tabular}{l}
\hline Funciones del Puesto \\
\hline Supervisar la evaluación de línea de crédito para clientes nuevos y no frecuentes. \\
\hline Supervisar el Proceso de Emisión de Notas de Crédito y Notas de Débito. \\
\hline Supervisar la gestión de cobranza diaria. \\
\hline Coordinación con el área de facturación \\
\hline Realizar el Proceso de Refinanciación, en coordinación con el área legal \\
\hline Supervisar la correcta ejecución del análisis de la cancelación del título valor para la elaboración \\
de las comisiones de los ejecutivos de cuentas. \\
\hline Coordinar con el área legal los procesos de clientes deudores \\
\hline Velar por el cumplimiento de las disposiciones, normas de seguridad interna, seguridad y salud \\
ocupacional, los estándares de desempeño SST de CARVIMSA y sus filiales, y otras \\
disposiciones establecidas por el cliente o la autoridad respectiva. \\
\hline Participar y promover la participación de sus colaboradores en las acciones de capacitación y \\
charlas de formación y sensibilización impartidas por la organización. Asimismo, participar, a \\
través de sus representantes, en la identificación de peligros, riesgos y determinación de \\
controles, en la investigación de accidentes y en el desarrollo y revisión de políticas y objetivos \\
de SST. \\
\hline Velar por el cumplimiento de la Política y lineamientos del Sistema de Gestión ambiental ISO \\
14001. (Creo que esto puede ser general: Velar por el cumplimiento de la política y lineamientos \\
de los sistemas de gestión de calidad, seguridad, medio ambiente y BASC) \\
Promover una cultura de prevención de la contaminación en todas las plantas de CARVIMSA. \\
\hline Cumplir la política y lineamientos del Sistema de Gestión de Calidad ISO 9001. \\
Promover y velar el cumplimiento de los requisitos del cliente especificados en la tarjeta de \\
diseño y/o especificaciones técnicas para asegurar su satisfacción. \\
Promover la mejora continua en cada una de las labores realizadas
\end{tabular}

Nota. Adaptado de Manual de Descripción del Puesto-División Corrugado (p.222), por

CARVIMSA, 2016, Perú, Lima: CARVIMSA. Copyright 2016 por CARVIMSA. 
Tabla 19

Descripción del puesto del Jefe de Logística

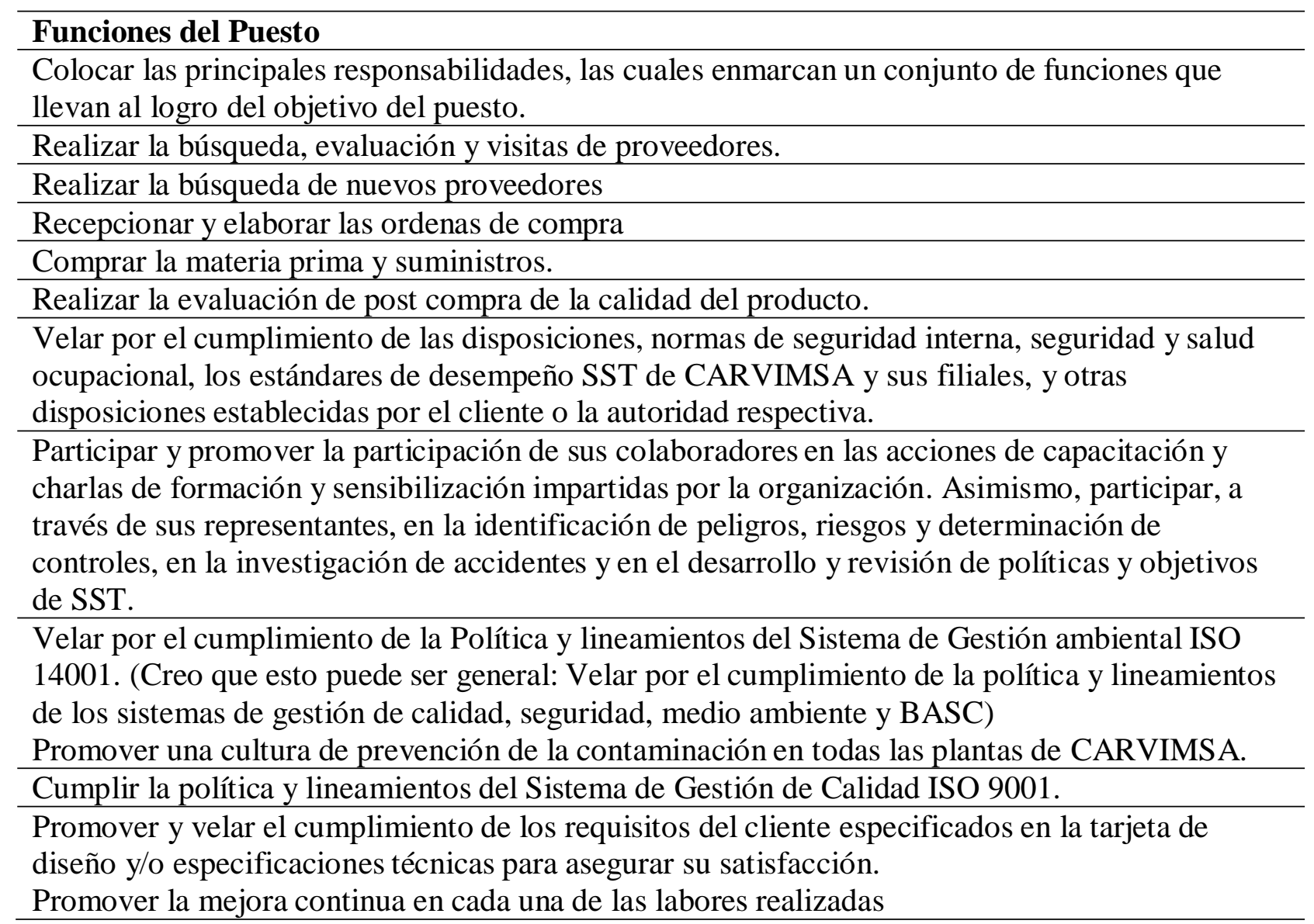

Nota. Adaptado de Manual de Descripción del Puesto-División Corrugado (p.221), por

CARVIMSA, 2016, Perú, Lima: CARVIMSA. Copyright 2016 por CARVIMSA. 
Tabla 20

Descripción del puesto del Jefe de Sistemas

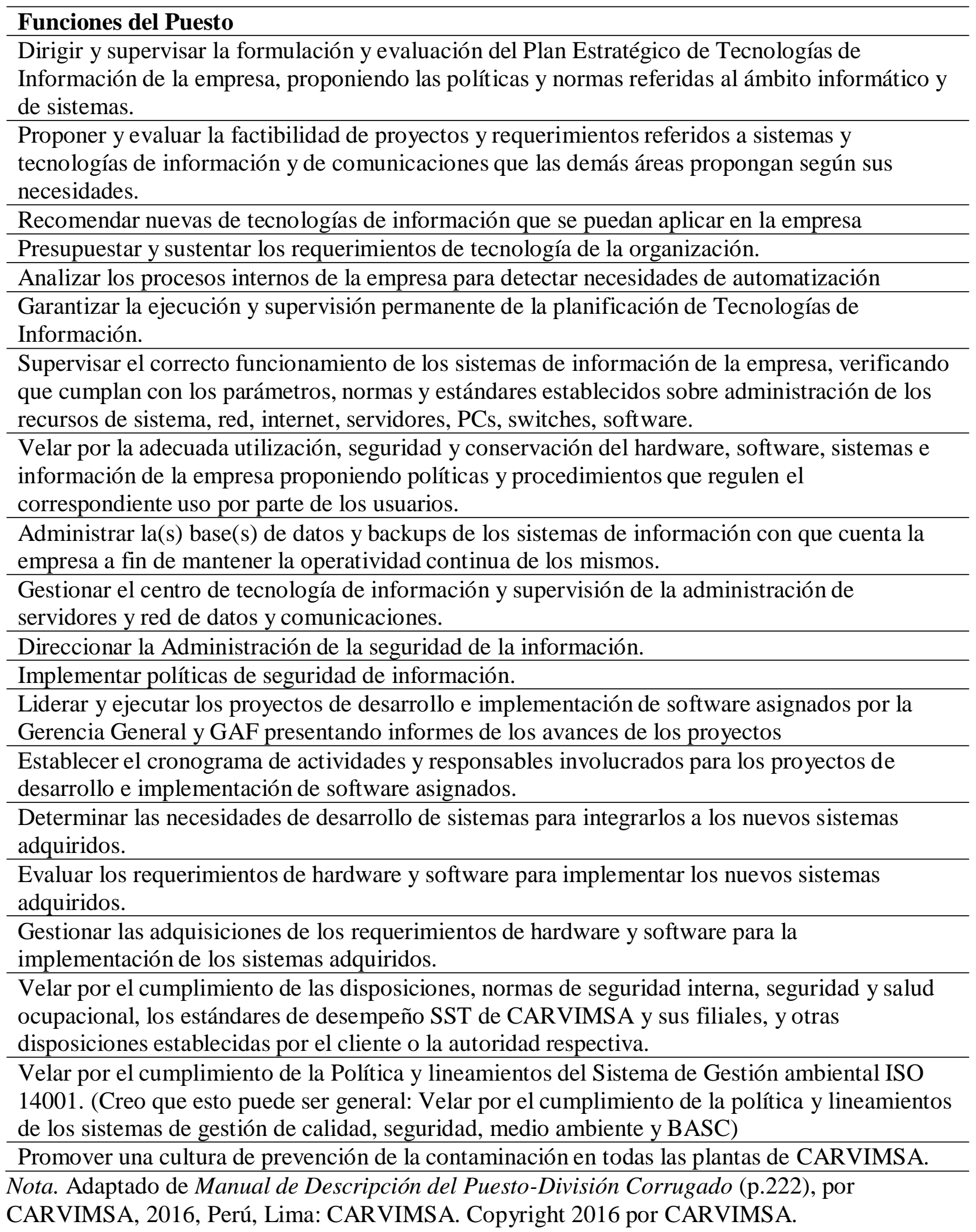


Tabla 21

Descripción del puesto del Jefe de Almacén Productos Terminados

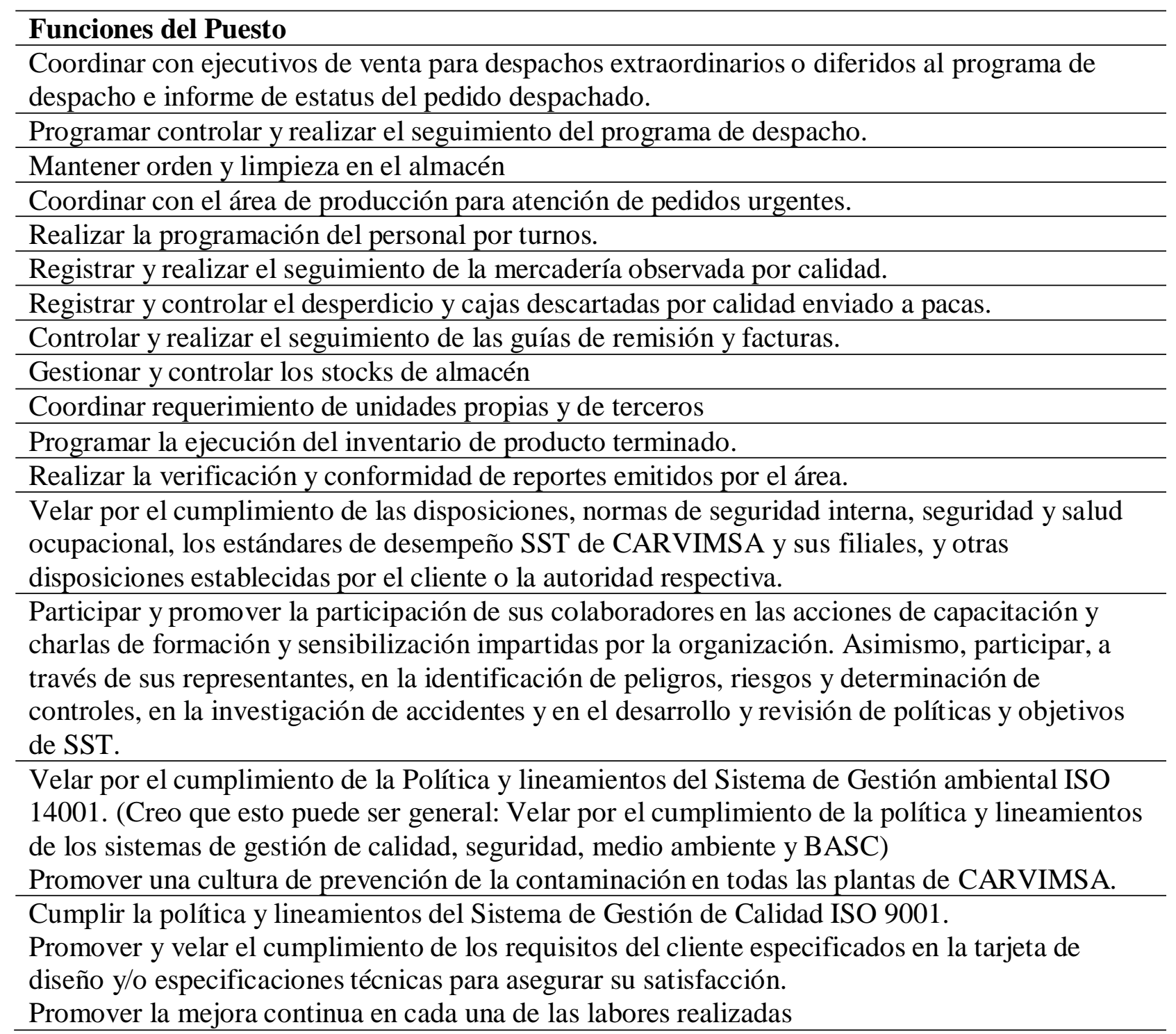

Nota. Adaptado de Manual de Descripción del Puesto-División Corrugado (p.230), por

CARVIMSA, 2016, Perú, Lima: CARVIMSA. Copyright 2016 por CARVIMSA. 
Tabla 22

Descripción del puesto del Jefe de Auditoria

\begin{tabular}{l} 
Funciones del Puesto \\
Elaborar el Plan Anual de Auditoria que contiene las actividades a realizar y la fecha de su \\
ejecución, el cual debe presentar y someter a consideración del Auditor General del Grupo para \\
su respectiva aprobación. \\
\hline Diseñar, organizar y ejecutar con un criterio eminentemente profesional y con apego a las \\
Normas y Programas de Auditoría vigentes: las revisiones, inspecciones, intervenciones y \\
estudios específicos, que se van a aplicar a las diferentes actividades, registros y operaciones de \\
las áreas de la Empresa. \\
\hline Evaluar la correcta aplicación de los controles contables, financieros y de la operación, para \\
determinar y evidenciar el cumplimiento de las disposiciones legales vigentes. \\
\hline Comunicar oportunamente al Auditor General, aquellas situaciones que en el transcurso de una \\
investigación se presenten y se considere que ameriten la intervención inmediata de una \\
auditoría más profunda. \\
\hline Confeccionar, revisar y emitir los Informes de Auditoria en base al programa asignado y de \\
acuerdo al Plan de Auditoria, verificando los procedimientos de control interno implantados. \\
\hline Evaluar de acuerdo con los cuestionarios establecidos y los programas de auditoría, las \\
diferentes áreas y operaciones de la Empresa, con el fin de salvaguardar los activos y otros \\
valores de la misma.
\end{tabular}

Analizar los Estados Financieros y registros contables en cumplimiento de los programas previamente elaborados para tal efecto, y de acuerdo con las Normas de Auditoría, con el fin de colaborar a que los Estados Financieros muestren razonablemente la posición financiera de la Empresa.

Programar en coordinación con el Auditor General, aquellos estudios específicos de índole financiero y operativo que se van a realizar, atendiendo peticiones de la Alta Gerencia o directores, de mayor complejidad y responsabilidad.

Preparar periódicamente un informe resumen que contenga los resultados del estudio realizado y emitirlo al Grupo, que muestre observaciones, conclusiones y recomendaciones.

Velar por el cumplimiento de las disposiciones, normas de seguridad interna, seguridad y salud ocupacional, los estándares de desempeño SST de CARVIMSA y sus filiales, y otras disposiciones establecidas por el cliente o la autoridad respectiva.

Participar y promover la participación de sus colaboradores en las acciones de capacitación y charlas de formación y sensibilización impartidas por la organización. Asimismo, participar, a través de sus representantes, en la identificación de peligros, riesgos y determinación de controles, en la investigación de accidentes y en el desarrollo y revisión de políticas y objetivos de SST.

Velar por el cumplimiento de la Política y lineamientos del Sistema de Gestión ambiental ISO 14001. (Creo que esto puede ser general: Velar por el cumplimiento de la política y lineamientos de los sistemas de gestión de calidad, seguridad, medio ambiente y BASC).

Promover una cultura de prevención de la contaminación en todas las plantas de CARVIMSA.

Cumplir la política y lineamientos del Sistema de Gestión de Calidad ISO 9001.

Nota. Adaptado de Manual de Descripción del Puesto-División Corrugado (p.232), por

CARVIMSA, 2016, Perú, Lima: CARVIMSA. Copyright 2016 por CARVIMSA. 
Tabla 23

Descripción del puesto del Jefe de Auditoría

\begin{tabular}{l}
\hline Funciones del Puesto \\
\hline Supervisar el trabajo que realiza el equipo bajo su cargo \\
\hline Realizar la atención y seguimiento de reclamos u observaciones de los clientes \\
\hline Evaluar el desempeño del equipo de trabajo \\
\hline Presentar el informe mensual de la gestión y estadística del área \\
\hline Presentar informes de enfoque internos del área \\
\hline Planificar de manera semestral la encuesta de servicio al cliente \\
\hline Formular los planes de acción de mejora, de acuerdo con los resultados de la encuesta \\
\hline Coordinar diariamente con producción y despacho para asegurar el cumplimiento de entregas \\
\hline Coordinar las charlas de capacitación a los clientes \\
\hline Cumplir con las disposiciones, normas de seguridad interna, seguridad y salud ocupacional, los \\
estándares de desempeño SST de CARVIMSA y sus filiales, y otras disposiciones establecidas \\
por el cliente o la autoridad respectiva. \\
Participar y promover la participación de sus colaboradores en las acciones de capacitación y \\
charlas de formación y sensibilización impartidas por la organización. Asimismo, participar, a \\
través de sus representantes, en la identificación de peligros, riesgos y determinación de \\
controles, en la investigación de accidentes y en el desarrollo y revisión de políticas y objetivos \\
de SST.
\end{tabular}

Nota. Adaptado de Manual de Descripción del Puesto-División Corrugado (p.234), por

CARVIMSA, 2016, Perú, Lima: CARVIMSA. Copyright 2016 por CARVIMSA. 
Tabla 24

Descripción del puesto del Jefe de Servicio al cliente

\begin{tabular}{l}
\hline Funciones del Puesto \\
\hline Supervisar el trabajo que realiza el equipo bajo su cargo \\
\hline Realizar la atención y seguimiento de reclamos u observaciones de los clientes \\
\hline Evaluar el desempeño del equipo de trabajo \\
\hline Presentar el informe mensual de la gestión y estadística del área \\
\hline Presentar informes de enfoque internos del área \\
\hline Planificar de manera semestral la encuesta de servicio al cliente \\
\hline Formular los planes de acción de mejora, de acuerdo con los resultados de la encuesta \\
\hline Coordinar diariamente con producción y despacho para asegurar el cumplimiento de entregas \\
\hline Coordinar las charlas de capacitación a los clientes \\
\hline Cumplir con las disposiciones, normas de seguridad interna, seguridad y salud ocupacional, los \\
estándares de desempeño SST de CARVIMSA y sus filiales, y otras disposiciones establecidas \\
por el cliente o la autoridad respectiva. \\
\hline Participar y promover la participación de sus colaboradores en las acciones de capacitación y \\
charlas de formación y sensibilización impartidas por la organización. Asimismo, participar, a \\
través de sus representantes, en la identificación de peligros, riesgos y determinación de \\
controles, en la investigación de accidentes y en el desarrollo y revisión de políticas y objetivos \\
de SST.
\end{tabular}

Cumplir la política y lineamientos del Sistema de Gestión Ambiental ISO 14001.

Cumplir y promover la correcta segregación de residuos, el cuidado de las áreas verdes y el consumo responsable de los recursos (agua, energía, materia prima, etc.)

Promover el cumplimiento de los lineamientos del Sistema de Gestión Ambiental del personal a cargo.

Cumplir la política y lineamientos del Sistema de Gestión de Calidad ISO 9001.

Promover y velar el cumplimiento de los requisitos del cliente especificados en la tarjeta de diseño y/o especificaciones técnicas para asegurar su satisfacción.

Promover la mejora continua en cada una de las labores realizadas.

Nota. Adaptado de Manual de Descripción del Puesto-División Corrugado (p.238), por

CARVIMSA, 2016, Perú, Lima: CARVIMSA. Copyright 2016 por CARVIMSA. 
Tabla 25

Descripción del puesto del Jefe de Ingeniería de Empaque

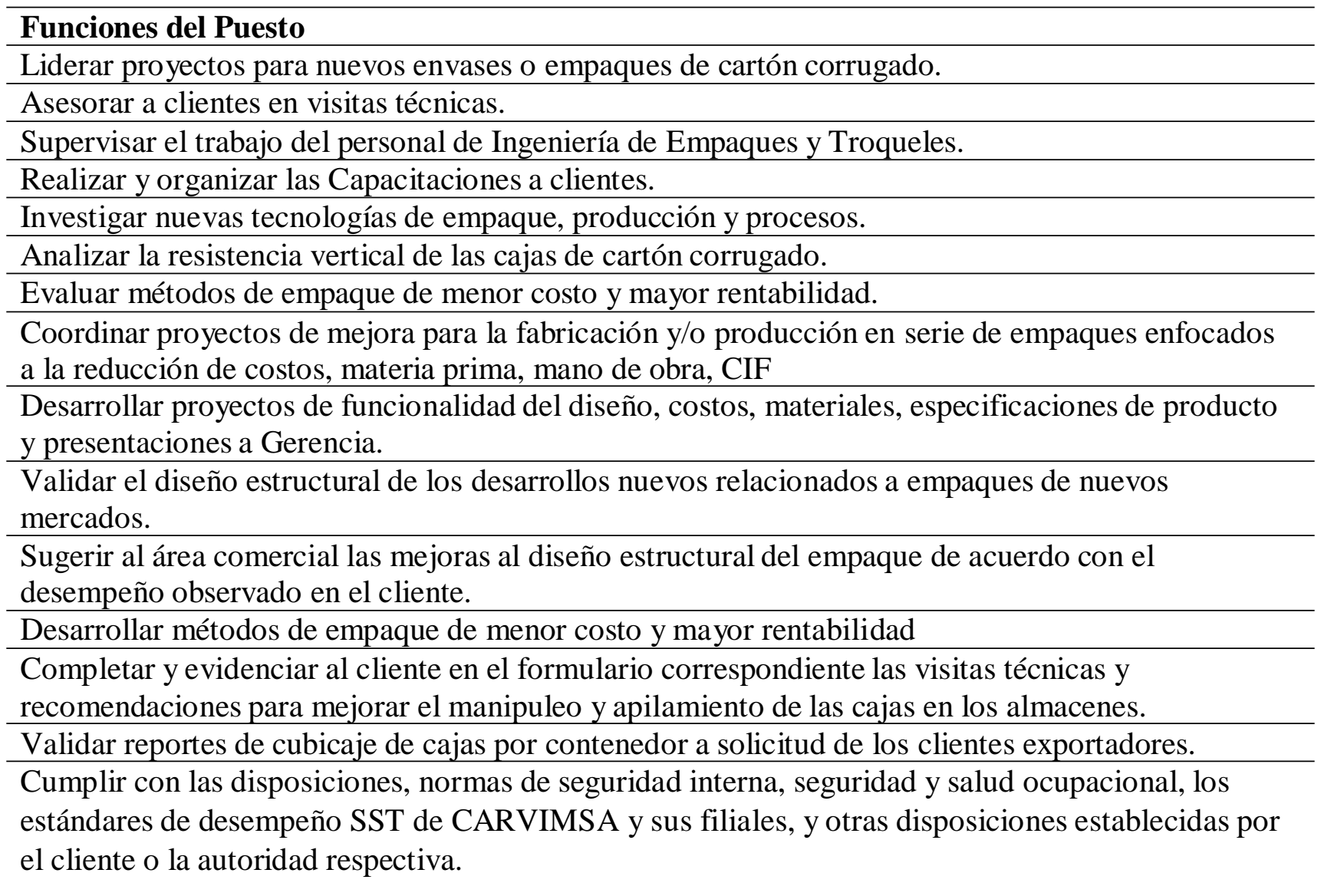

Participar y promover la participación de sus colaboradores en las acciones de capacitación y charlas de formación y sensibilización impartidas por la organización. Así mismo participar, a través de sus representantes, en la identificación de peligros, riesgos y determinación de controles, en la investigación de accidentes y en el desarrollo y revisión de políticas y objetivos de SST.

Cumplir la política y lineamientos del Sistema de Gestión Ambiental ISO 14001.

Cumplir y promover la correcta segregación de residuos, el cuidado de las áreas verdes y el consumo responsable de los recursos (agua, energía, materia prima, etc.)

Promover el cumplimiento de los lineamientos del Sistema de Gestión Ambiental del personal a cargo.

Cumplir la política y lineamientos del Sistema de Gestión de Calidad ISO 9001.

Promover y velar el cumplimiento de los requisitos del cliente especificados en la tarjeta de diseño y/o especificaciones técnicas para asegurar su satisfacción.

Promover la mejora continua en cada una de las labores realizadas

Cumplir la política y lineamientos del Sistema de Gestión de Calidad ISO 9001.

Nota. Adaptado de Manual de Descripción del Puesto-División Corrugado (p.258), por

CARVIMSA, 2016, Perú, Lima: CARVIMSA. Copyright 2016 por CARVIMSA. 
A continuación, se presenta la encuesta realizada a todo el personal de la UEN "Tubos y Esquineros" de Carvimsa, donde los factores analizados fueron: a) Comunicación, b) Condiciones de trabajo, c) Liderazgo, d) Capacitación y e) Identificación y compromiso; los cuales se describen a continuación:

a) Comunicación: Debido a que todo colaborador está constantemente recibiendo instrucciones, entregando información y/o coordinando equipos de trabajo, resulta necesaria la evaluación de este factor ya que permitirá conocer si contribuye de manera eficaz a la productividad de la UEN “Tubos y Esquineros”. Asimismo, el análisis de este factor permitirá evaluar los tipos de comunicación que existen dentro de la UEN “Tubos y Esquineros” y determinar si la información entregada a los colaboradores es suficiente para el cumplimiento de sus funciones y/o responsabilidades.

Del resultado obtenido en la encuesta 2017 con respecto a este factor, se puede observar que la comunicación en la UEN “Tubos y Esquineros" no es la óptima y existen aspectos por mejorar que permitan a los colaboradores contar con información adecuada y oportuna que permita el cumplimiento de sus funciones y/o responsabilidades. A continuación, se muestra los resultados de la evaluación:

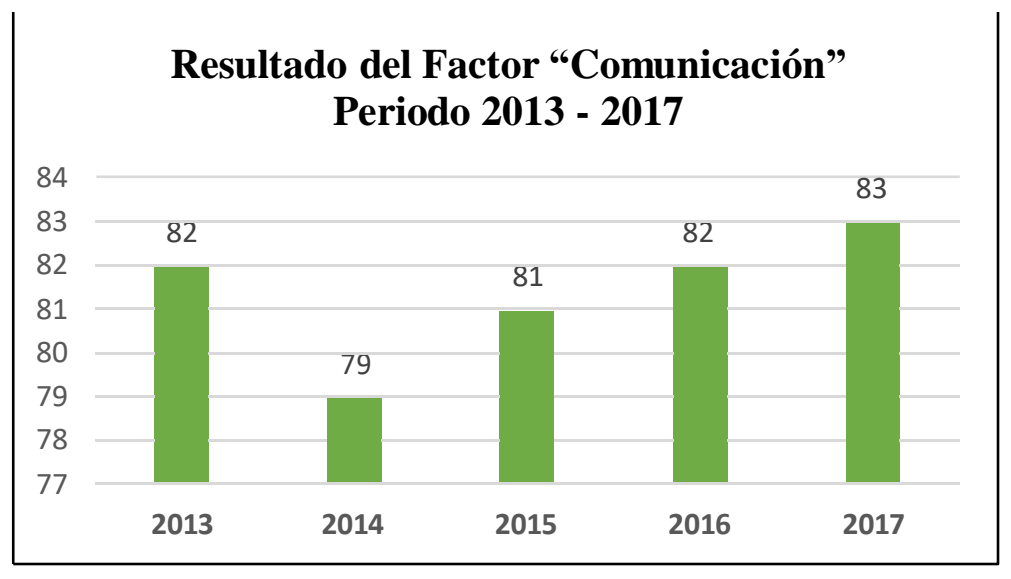

Figura 25. Resultado del Factor "Comunicación” del periodo 2013 - 2017. Tomado de la Evaluación Anual de Carvimsa. 
b) Condiciones de trabajo: El análisis de este factor permite obtener información relacionada con las condiciones de trabajo relacionadas con la seguridad, higiene y ergonomía, a fin de detectar y realizar adecuaciones en los puestos de trabajo, para evitar riesgos e implantar mejoras en las condiciones y acondicionamiento de los espacios de trabajo.

El resultado obtenido del análisis de este factor permite determinar que las condiciones de trabajo en la UEN "Tubos y Esquineros" no son óptimas y se deben implementar mejoras en los espacios de trabajo relacionados con seguridad, higiene y ergonomía a fin de evitar riesgos. A continuación, se muestra los resultados obtenidos:

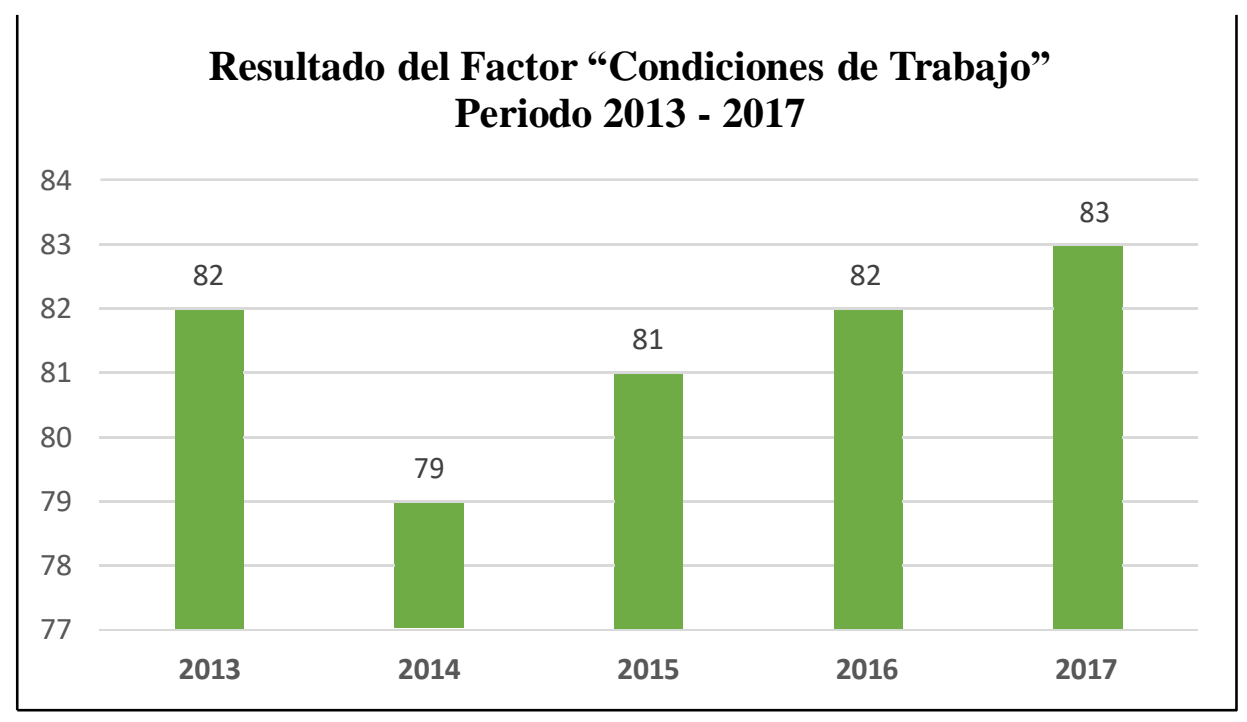

Figura 26. Resultado del Factor "Condiciones de Trabajo" del periodo 2013 - 2017. Tomado de la Evaluación Anual de Carvimsa.

c) Liderazgo: La evaluación de este factor se centra en analizar la gestión directa de personas, la buena comunicación del líder, la accesibilidad hacia el líder, la gestión de conflictos, la coordinación de los equipos, la delegación de tareas y responsabilidades, el reconocimiento y la retroalimentación constante. 
Como se puede observar en la figura 25, la comparación histórica del análisis del factor "Liderazgo" muestra una tendencia a la baja, lo que permite determinar que los colaboradores de la UEN “Tubos y Esquineros” perciben una falta de liderazgo, así como una inadecuada gestión de conflictos y coordinación entre los equipos de trabajo.

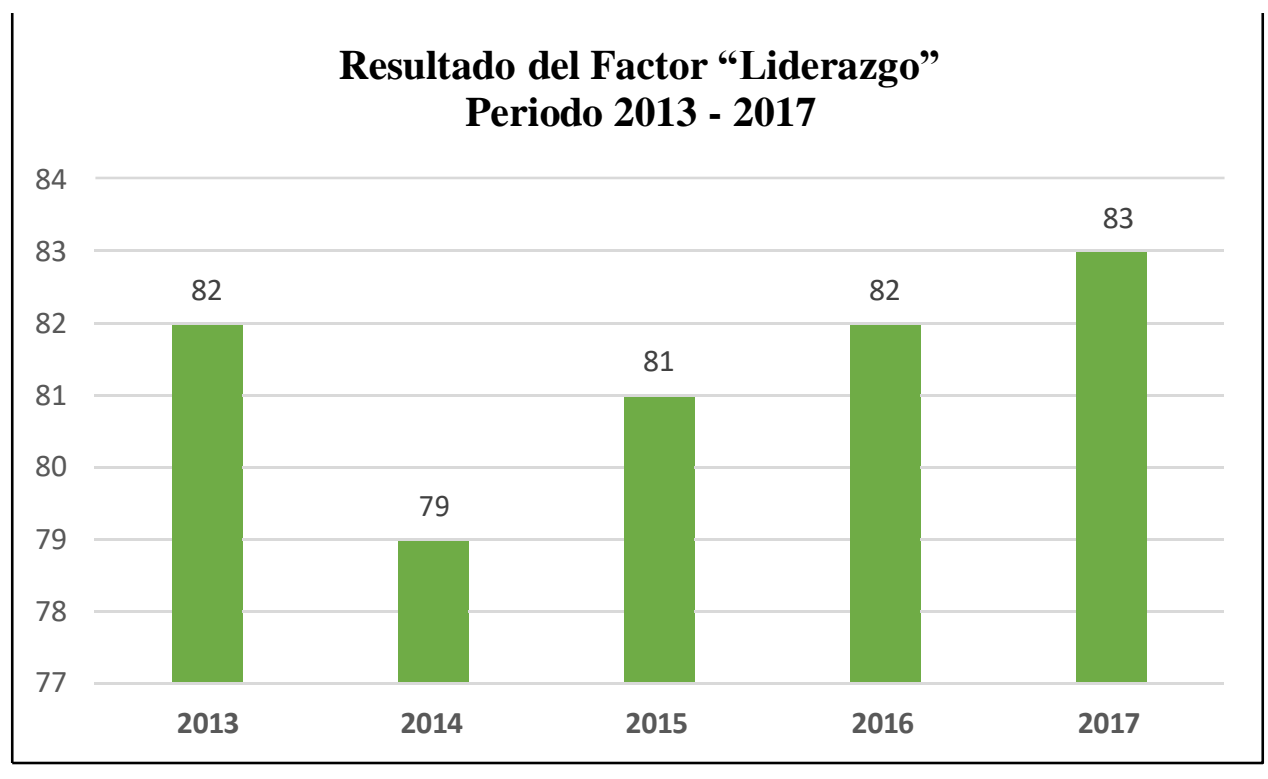

Figura 27. Resultado del Factor "Liderazgo" del periodo 2013 - 2017. Tomado de la Evaluación Anual de Carvimsa.

d) Capacitación: Evaluar este factor aporta información relacionada con los planes de capacitación, la formación básica impartida y las posibilidades de desarrollo de línea de carrera que se ofrecen a los trabajadores de la UEN “Tubos y Esquineros”. A través de esta información se detectan las necesidades de capacitación, la necesidad de implantar otras vías de formación profesional, así como las necesidades de desarrollo de línea de carrera dentro de la UEN.

Como se puede observar, los resultados de la evaluación de este factor revelan que los colaboradores perciben que existe un adecuado plan de capacitación, así como una línea de carrera de les permite desarrollarse profesionalmente. A continuación, se muestran los resultados obtenidos: 


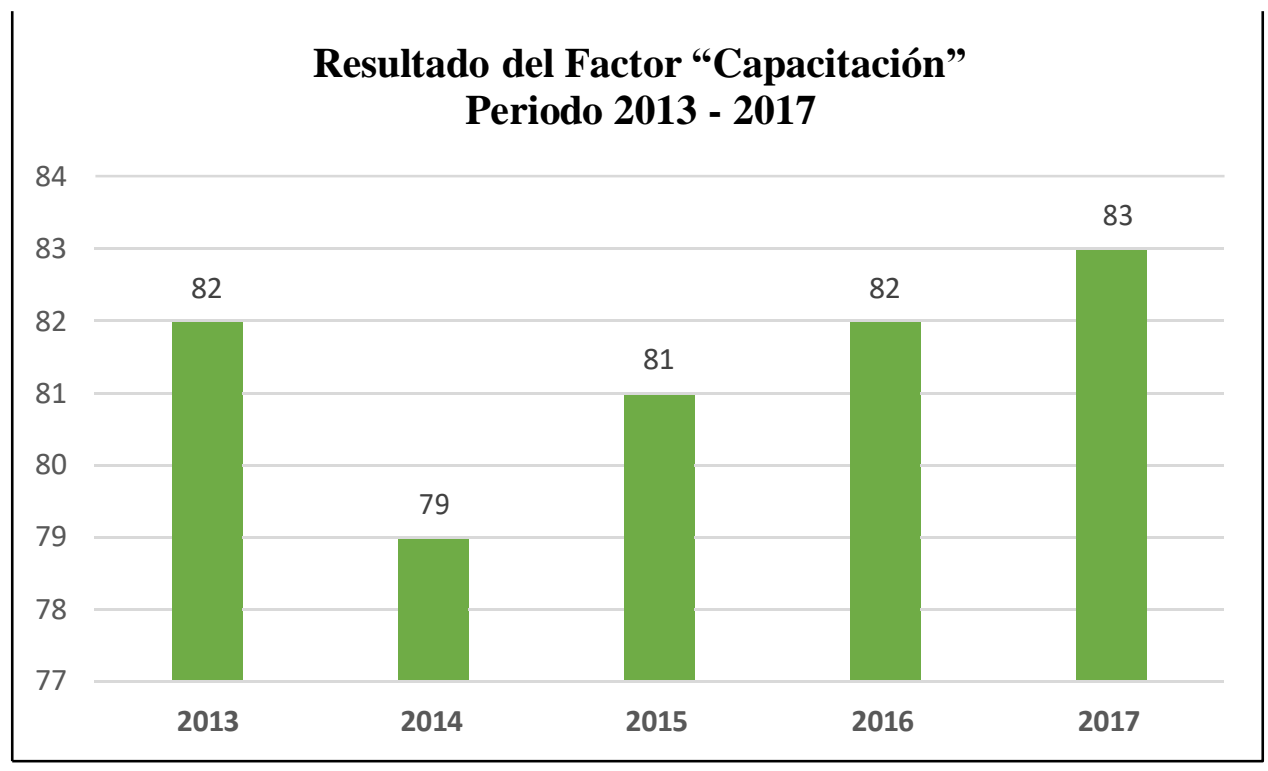

Figura 28. Resultado del Factor "Capacitación" del periodo 2013 - 2017. Tomado de la Evaluación Anual de Carvimsa.

e) Identificación y compromiso: Este factor permite obtener información relacionada con el nivel de identificación y compromiso de los trabajadores con los objetivos de la UEN “Tubos y Esquineros”. También aporta información sobre el nivel de conocimiento de las funciones y responsabilidades relacionadas con su puesto de trabajo por parte de los trabajadores, el nivel de cohesión y pertenencia a un grupo de trabajo.

De los resultados obtenidos, se ha determinado que los trabajadores se encuentran identificados y comprometidos con la UEN “Tubos y Esquineros" pues consideran que la labor desempeñada por cada uno de ellos contribuye al logro de los objetivos de la UEN y esto se ve retribuido en diferentes beneficios otorgados por la empresa. A continuación, se muestran los resultados: 


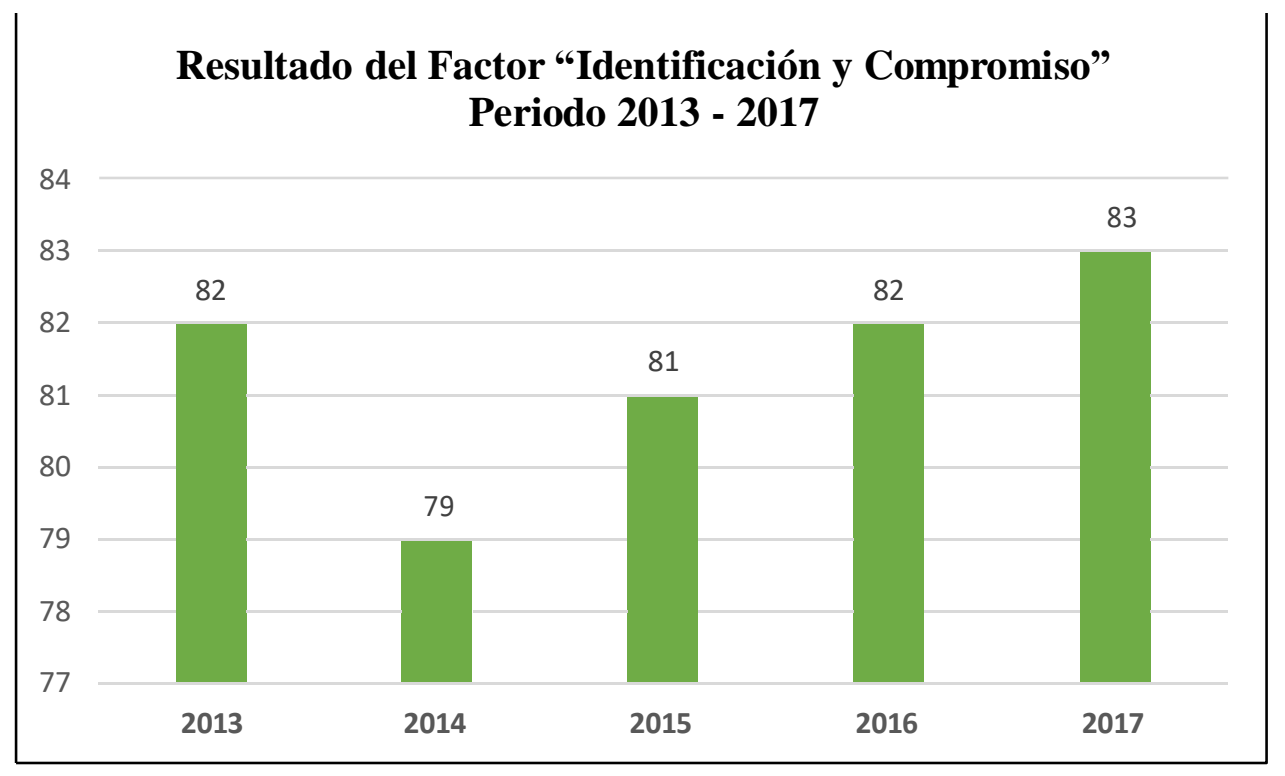

Figura 29. Resultado del Factor "Identificación y Compromiso" del periodo 2013 2017. Tomado de la Evaluación Anual de Carvimsa.

Luego de haber analizado los resultados de cada factor, se muestra el resultado del Clima Laboral en forma general, donde se puede observar que a pesar de que hubo mejora a través de los años, aún se mantiene por debajo de los estándares que la compañía considera óptimo. Por lo tanto, se considerará iniciativas para mejorar ese problema detectado, el cual se está incluyendo en el mapa estratégico. A continuación, se detalla los resultados:

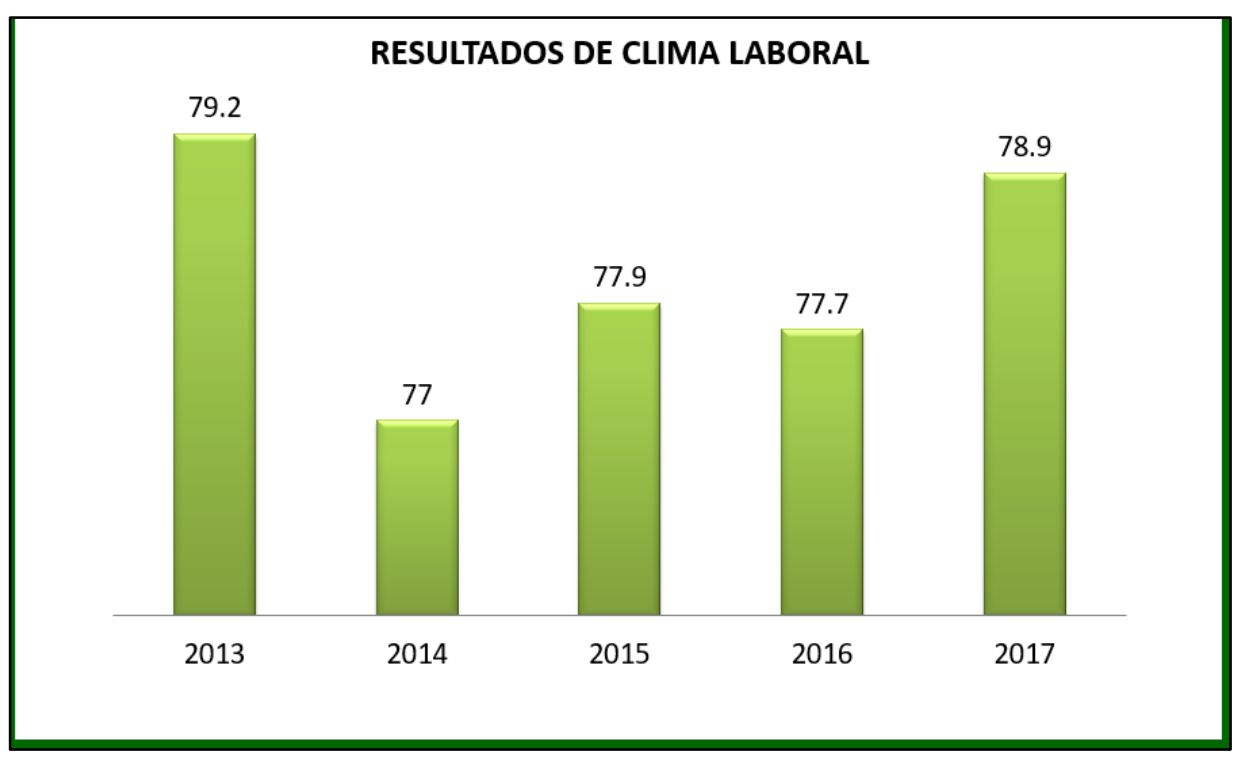

Figura 30. Resultado de Encuesta de Clima Laboral del periodo 2013 - 2017. Tomado de la Evaluación Anual de Carvimsa. 


\subsection{Situación de mercado y financiera actual de la industria}

En los últimos meses el panorama económico ha cambiado radicalmente debido a los desastres naturales que azotan nuestro país, de acuerdo con Maximixe 2017, el balance de las pérdidas suma S/10,809 millones (US\$3,124 millones), lo cual reducirá la capacidad de crecimiento de la economía en el largo plazo, pues se han perdido activos que contribuían a su crecimiento (Ver figura 28).

\begin{tabular}{|c|c|c|}
\hline Rubro dañado & $\begin{array}{c}\text { US\$ } \\
\text { millones }\end{array}$ & $\%$ part. \\
\hline Carreteras & 1,259 & $40 \%$ \\
\hline Viviendas & 1,123 & $36 \%$ \\
\hline Puentes & 253 & $8 \%$ \\
\hline Áreas de cultivo & 243 & $8 \%$ \\
\hline Instituciones educativas & 171 & $5 \%$ \\
\hline Canales de riego & 38 & $1 \%$ \\
\hline Caminos rurales & 31 & $1 \%$ \\
\hline Establecimientos de salud & 7 & $0 \%$ \\
\hline Total nacional & 3,124 & $100 \%$ \\
\hline
\end{tabular}

Figura 31. Estimación de daños del Fenómeno del Niño Costero (FEN) 2017. Tomado de Página Web RPP. Recuperado de http://e.rppnoticias.io/normal/2017/03/24/281828 371628.png

Sin embargo, en el corto plazo los efectos se contrarrestarán pues la reconstrucción contribuirá de manera positiva a la demanda agregada a través de una mayor inversión pública. Los pronósticos para el PBI para el 2017, Macroconsult estimó de 3.5\% a 2.9\% y Maximize estimó $3.8 \%$ a 3.1\%, advierten que podrían bajar hasta $2.4 \%$ si las lluvias continúan hasta mayo.

Ante este panorama, las cifras de las pérdidas en el sector agroindustrial de acuerdo con las cifras del Centro de Operaciones de Emergencia Nacional (COEN) se tiene: 1,909 Km de carreteras y $847 \mathrm{Km}$ de caminos rurales dañados, $600 \mathrm{Km}$ de canales de regadío 
perdidos. De acuerdo con cifras de la Convención Nacional del Agro Peruano (CONVEAGRO) S/ 2,100 millones representa la pérdida para el agro y la ganadería, el 30\% de los cultivos del país, 90 mil hectáreas, se han perdido. Otras 150,000 Hectáreas se encuentran seriamente afectadas y requieren unos S/ 600 millones para la recuperación de los sembríos. (ver figura 29)

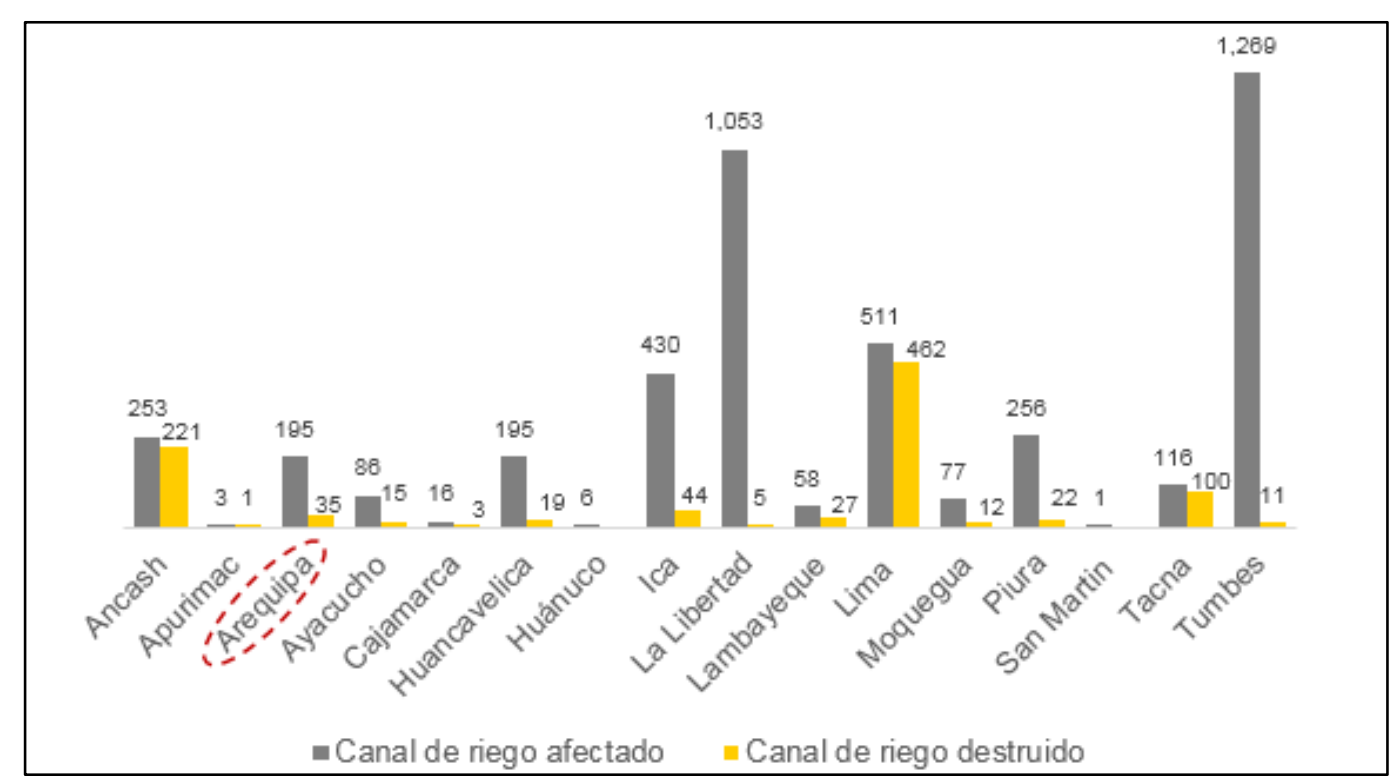

Figura 32. Perú: Número de Kilómetros afectados y destruidos de infraestructura agrícola, por departamento (marzo 2017). Tomado de Página Web de Mercados \& Regiones.

Recuperado de http://mercadosyregiones.com/wpcontent/uploads/2017/03/_d_improd_/1_f_improf_549x349.png

Esto tiene una afectación directa a la industria pues, CARVIMSA es el líder en el sector agroindustrial, de acuerdo con Instituto de Economía y Desarrollo Empresarial (IEDEP) de la Cámara de Comercio de Lima (CCL), las lluvias y el cambio del clima está originando adelantos y retrasos en las cosechas, variaciones en la calidad y rendimientos de producción en el caso del mango y uvas, asimismo, las inundaciones perjudican los cultivos de banano y limón. El sector exportador es el más vulnerable ante las actuales circunstancias. Ante tal panorama es representa una AMENAZA para el sector agroindustrial y CARVIMSA (ver figura 30). 


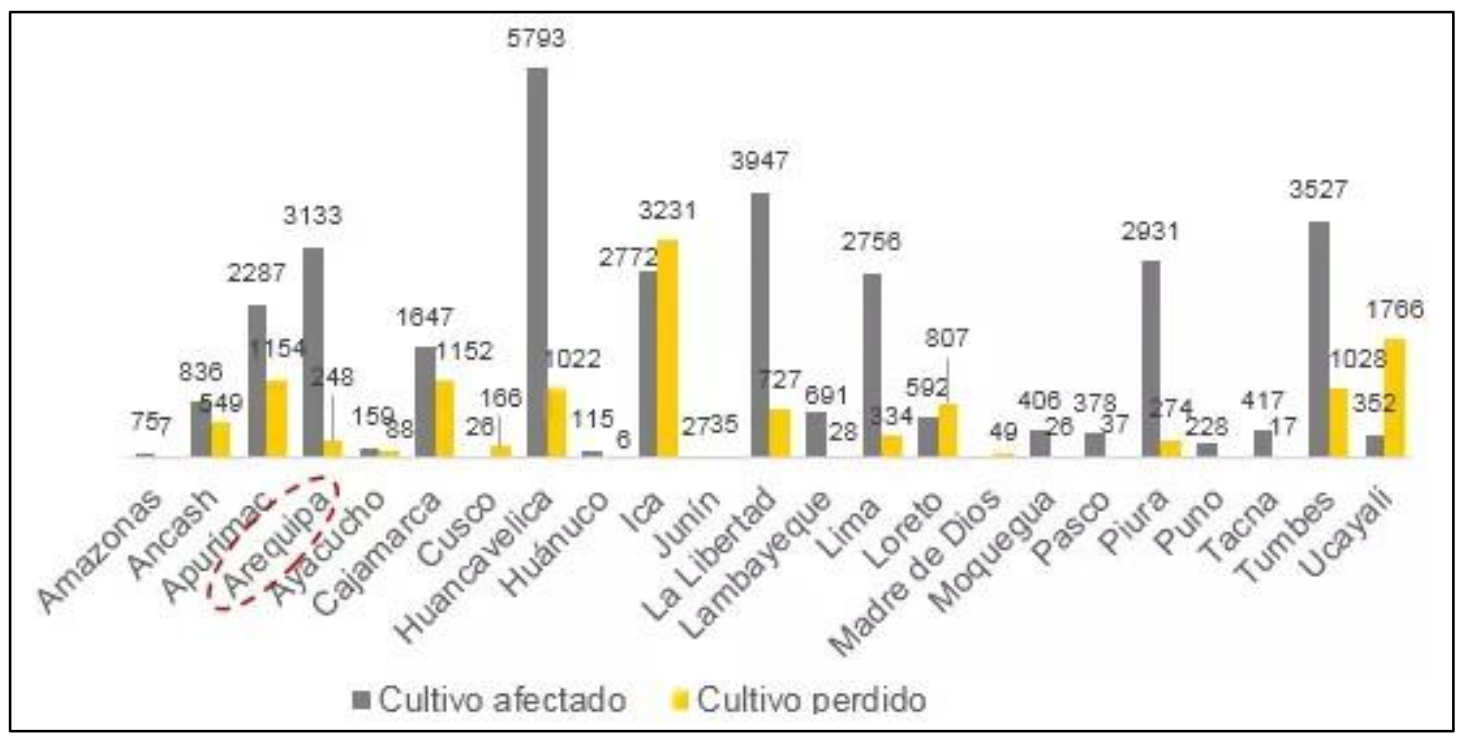

Figura 33. Perú: Número de hectáreas afectadas y pérdidas de terreno agrícola, por departamento (marzo 2017). Tomado de Página Web de Mercados \& Regiones. Recuperado de http://i0.wp.com/mercadosyregiones.com/wp-content/uploads/2017/03/2.png?w=591 


\section{Capítulo III. Formulación de visión, misión y valores de la empresa}

\subsection{Visión}

David (2013) enunció:

Una visión clara sienta las bases para desarrollar una declaración de misión detallada.

La declaración de visión toma en cuenta las siguientes características: Tiene que ser breve, de preferencia de un solo enunciado y contar con la aportación de tantos directivos como sea posible. (p.43)

Tabla 26

Características de una declaración de visión

Características de una declaración de visión

\section{Ser breve.}

\section{Preferencia de un solo enunciado.}

\section{Aportación de tantos directivos como sea posible.}

Nota: Adaptado de "Administración Estratégica," (p.45) por David, 2013, México: Editorial Pearson Education. Copyright 2013 por Prentice Hall.

\subsubsection{Visión actual de la empresa.}

CARVIMSA no ha desarrollado una visión para cada Unidad Estratégica de Negocio, sin embargo, tiene una visión para toda la empresa, la cual ha sido difundida en medios de comunicación interna, así como externas (página web, folletos de presentación para clientes, otros).

A continuación, se detalla la visión de CARVIMSA:

Trabajamos con una visión corporativa de manera que en el plazo de cinco años habremos alcanzado:

- El liderazgo en servicio al cliente y en la solución integral de sus necesidades de envases. 
- Una sólida y creciente presencia en el mercado agroindustrial.

- La consolidación de nuestro crecimiento y participación en el segmento domestico del mercado nacional de envases de cartón corrugado.

\subsubsection{Análisis de la visión actual.}

Para analizar la visión actual de CARVIMSA, es preciso evaluar el cumplimiento de las siguientes características:

a) Ser Breve: Como se puede visualizar en el punto 3.1.1. Visión actual de la empresa, esta es muy extensa e imprecisa. La imprecisión recae en lo referente al periodo pues si bien es cierto determina un plazo de cinco años, este dato no especifica la ubicación actual en el tiempo. Esto último, agregando además que se desconoce la fecha de su publicación, no brinda información sobre la vigencia de esta.

b) Preferencia de un solo enunciado: Como se puede visualizar la visión está compuesta de cuatro enunciados.

c) Aporte de tantos directivos como sea posible: Para la elaboración de la misión han participado los principales funcionarios de la empresa CARVIMSA. 


\subsubsection{Matriz de la visión propuesta para la empresa.}

Tabla 27

Matriz de la visión propuesta

\begin{tabular}{ll}
\hline $\begin{array}{l}\text { Características de una } \\
\text { declaración de visión }\end{array}$ & Descripción \\
\hline Ser breve. & $\begin{array}{l}\text { Ser la empresa líder en el Perú en la fabricación y } \\
\text { distribución de productos de tubos y esquineros de } \\
\text { cartón dándole un valor agregado, concentrándose } \\
\text { especialmente en el sector de embalaje, agroindustrial, } \\
\text { construcción y textil. }\end{array}$ \\
\hline
\end{tabular}

Preferencia de un solo La visión se ha elaborado en un solo enunciado. enunciado.

\begin{tabular}{ll}
\hline $\begin{array}{l}\text { Aportación de tantos } \\
\text { directivos como sea } \\
\text { posible. }\end{array}$ & $\begin{array}{l}\text { La visión propuesta será enviada para su revisión al } \\
\text { gerente general y gerente administrativo. }\end{array}$ \\
\hline
\end{tabular}

\subsubsection{Visión propuesta.}

La visión que se propone en esta sección se refiere a la UEN Tubos y Esquineros, que es objetivo del presente plan estratégico.

A continuación, se describe la visión para la UEN Tubos y Esquineros:

Ser la empresa líder en el Perú en la fabricación y distribución de productos de tubos y esquineros de cartón, concentrándose en los sectores de embalaje, agroindustrial, construcción y textil.

\subsection{Misión}

David (2013) señaló:

La declaración de misión expresa la finalidad que tiene una organización, la cual le permite distinguirse de sus competidores. Así mismo, describe la razón de ser de la organización y responde a la pregunta ¿cuál es nuestro negocio? La misión debe ser clara, para establecer los objetivos y formular estrategia de manera efectiva. Se debe 
tener en cuenta que la misión es el punto de inicio para diseñar el trabajo y la

estructura gerencial. (p.44)

Las características de una declaración de misión se encuentran en la tabla 28.

Tabla 28

Características de una declaración de Misión

\section{Características de una declaración de misión}

1. Tiene amplio alcance, no incluye montos monetarios, cifras, porcentajes, proporciones y objetivos.

2. Su extensión es menor a 250 palabras.

3. Es inspiradoras.

4. Identifica la utilidad de los productos de una empresa.

5. Revela la responsabilidad social de la empresa.

6. Revela la responsabilidad ambiental de la empresa.

7. Toma en cuenta nuevos componentes: clientes, productos o servicios, mercados, tecnología, preocupación por la supervivencia/el crecimiento/la rentabilidad, filosofía, autoconcepto, preocupación por la imagen pública, preocupación por los empleados.

8. Es conciliatoria.

9. Es perdurable.

Nota: Tomado de "Administración Estratégica," (p.52) por David, 2013, México: Editorial Pearson Education. Copyright 2013 por Prentice Hall.

\subsubsection{Misión actual de la empresa.}

CARVIMSA no ha desarrollado una misión para cada UEN, sin embargo, tiene una misión a nivel empresarial, la cual ha sido difundida en medios de comunicación interna, así como externas (página web, folletos de presentación para clientes, otros). 
La misión actual de CARVIMSA es:

Somos una empresa orientada a la solución rentable y personalizada de envases de cartón corrugado para nuestros clientes, sobre la base del desarrollo humano y una actitud positiva frente al cambio.

\subsubsection{Análisis de la misión actual.}

Para analizar la misión actual de la empresa en estudio, se ha tomado en cuenta las características que debe incluir la declaración de misión. La tabla 29 muestra si la misión actual de CARVIMSA cumple con las características.

Tabla 29

Cumplimiento de las Características la Misión Actual de CARVIMSA

\section{Características}

Cumplimiento

Tiene amplio alcance, no incluye montos monetarios, cifras, $\mathrm{Si}$ porcentajes, proporciones y objetivos.

\begin{tabular}{ll}
\hline Su extensión es menor a 250 palabras. & $\mathrm{Si}$ \\
\hline Es inspiradoras. & $\mathrm{Si}$ \\
\hline Identifica la utilidad de los productos de una empresa. & $\mathrm{No}$ \\
\hline Revela la responsabilidad social de la empresa. & $\mathrm{No}$ \\
\hline Revela la responsabilidad ambiental de la empresa. & $\mathrm{No}$ \\
\hline $\begin{array}{l}\text { Toma en cuenta nuevos componentes: clientes, productos o } \\
\text { servicios, mercados, tecnología, preocupación por la } \\
\text { supervivencia/el crecimiento/la rentabilidad, filosofía, autoconcepto, } \\
\text { preocupación por la imagen pública, preocupación por los } \\
\text { empleados. }\end{array}$ & $\mathrm{No}$ \\
\hline Es conciliatoria. & $\mathrm{Si}$ \\
\hline Es perdurable. & $\mathrm{Si}$
\end{tabular}

Nota: Tomado de “Administración Estratégica," (p.52) por David, 2013, México: Editorial Pearson Education. Copyright 2013 por Prentice Hall. 


\subsubsection{Elementos de la misión propuesta para la empresa.}

La misión suele ser la parte más visible y publica de la administración estratégica, es por esta razón que se deben incluir los siguientes componentes:

Tabla 30

Características de una declaración de Misión

\begin{tabular}{|c|c|}
\hline Componentes & Pregunta \\
\hline Clientes & ¿Quiénes son los clientes de la unidad de negocio? \\
\hline Productos o Servicios & $\begin{array}{l}\text { ¿Cuáles son los principales productos o servicios que } \\
\text { ofrece la unidad de negocio? }\end{array}$ \\
\hline Mercados & $\begin{array}{l}\text { ¿En dónde compite la unidad de negocios de tubos y } \\
\text { esquineros? (en términos geográficos) }\end{array}$ \\
\hline Tecnología & $\begin{array}{l}\text { ¿La unidad estratégica de negocio de tubos y esquineros } \\
\text { está al día desde el punto de vida tecnológico? }\end{array}$ \\
\hline $\begin{array}{l}\text { Preocupación por la } \\
\text { supervivencia, } \\
\text { crecimiento y } \\
\text { rentabilidad }\end{array}$ & $\begin{array}{l}\text { ¿La unidad estratégica de negocio de tubos y esquineros } \\
\text { está comprometida con el crecimiento y la solidez } \\
\text { financiera? }\end{array}$ \\
\hline Filosofía & $\begin{array}{l}\text { ¿Cuáles son las creencias, valores, aspiraciones y } \\
\text { prioridades éticas básicos de la unidad estratégica de } \\
\text { negocio de tubos y esquineros? }\end{array}$ \\
\hline Autoconcepto & $\begin{array}{l}\text { ¿Cuál es la competencia distintiva o ventaja competitiva } \\
\text { más importante de la unidad estratégica de negocio de } \\
\text { tubos y esquineros? }\end{array}$ \\
\hline $\begin{array}{l}\text { Preocupación por la } \\
\text { imagen publica }\end{array}$ & $\begin{array}{l}\text { ¿La unidad estratégica de negocio de tubos y esquineros } \\
\text { responde a las preocupaciones sociales, comunitarias y } \\
\text { ambientales? }\end{array}$ \\
\hline $\begin{array}{l}\text { Preocupación por los } \\
\text { empleados }\end{array}$ & $\begin{array}{l}\text { ¿Los empleados son unos activos valiosos para la } \\
\text { unidad estratégica de negocio de tubos y esquineros? }\end{array}$ \\
\hline
\end{tabular}

Nota: Adaptado de "Administración Estratégica," (pp.51-52) por David, 2013, México:

Editorial Pearson Education. Copyright 2013 por Prentice Hall.

\subsubsection{Misión propuesta.}

La misión que se propone en esta sección se refiere a la UEN Tubos y

Esquineros, que es objetivo del presente plan estratégico. 
A continuación, se describe la misión para la UEN Tubos y Esquineros:

Crear valor y seguridad para los clientes de los sectores de embalaje, agroindustrial, construcción y textil del mercado local e internacional, entregando soluciones personalizadas de tubos y esquineros de cartón, empleando tecnología de vanguardia y calidad en el producto, sobre la base del desarrollo del capital humano, generando rentabilidad para los accionistas y manteniendo un compromiso con la comunidad y el medio ambiente.

A continuación, en la tabla 31 se detalla los componentes de la misión propuesta:

Tabla 31

Características la misión propuesta

\begin{tabular}{|c|c|c|}
\hline Componentes & Pregunta & Respuesta \\
\hline Clientes & $\begin{array}{l}\text { ¿Quiénes son los clientes de } \\
\text { la unidad estratégica de } \\
\text { negocio de tubos y } \\
\text { esquineros? }\end{array}$ & $\begin{array}{l}\text { Empresas del sector de } \\
\text { embalaje, agroindustrial, } \\
\text { construcción y textil. }\end{array}$ \\
\hline $\begin{array}{l}\text { Productos o } \\
\text { Servicios }\end{array}$ & $\begin{array}{l}\text { ¿Cuáles son los principales } \\
\text { productos o servicios que } \\
\text { ofrece la empresa? }\end{array}$ & $\begin{array}{l}\text { Envases de tubos y } \\
\text { esquineros de cartón. }\end{array}$ \\
\hline Mercados & $\begin{array}{l}\text { ¿En dónde compite la unidad } \\
\text { estratégica de negocio de } \\
\text { tubos y esquineros? (en } \\
\text { términos geográficos) }\end{array}$ & Perú y Costa Rica. \\
\hline Tecnología & $\begin{array}{l}\text { ¿La unidad estratégica de } \\
\text { negocio de tubos y } \\
\text { esquineros está al día desde } \\
\text { el punto de vida tecnológico? }\end{array}$ & $\begin{array}{l}\text { Emplea tecnología de } \\
\text { vanguardia. }\end{array}$ \\
\hline $\begin{array}{l}\text { Preocupación por la } \\
\text { supervivencia, } \\
\text { crecimiento y } \\
\text { rentabilidad }\end{array}$ & $\begin{array}{l}\text { ¿La unidad estratégica de } \\
\text { negocio de tubos y } \\
\text { esquineros está } \\
\text { comprometida con el } \\
\text { crecimiento y la solidez } \\
\text { financiera? }\end{array}$ & $\begin{array}{l}\text { Crea rentabilidad para los } \\
\text { accionistas. }\end{array}$ \\
\hline
\end{tabular}




\begin{tabular}{|c|c|c|}
\hline Componentes & Pregunta & Respuesta \\
\hline Filosofía & $\begin{array}{l}\text { ¿Cuáles son las creencias, } \\
\text { valores, aspiraciones y } \\
\text { prioridades éticas básicos de } \\
\text { la unidad estratégica de } \\
\text { negocio de tubos y } \\
\text { esquineros? }\end{array}$ & $\begin{array}{l}\text { Crear valor para los clientes, } \\
\text { accionistas, la comunidad y el } \\
\text { medio ambiente. }\end{array}$ \\
\hline Autoconcepto & $\begin{array}{l}\text { ¿Cuál es la competencia } \\
\text { distintiva o ventaja } \\
\text { competitiva más importante } \\
\text { de la empresa? }\end{array}$ & $\begin{array}{l}\text { Entrega soluciones } \\
\text { personalizadas. }\end{array}$ \\
\hline $\begin{array}{l}\text { Preocupación por la } \\
\text { imagen pública }\end{array}$ & $\begin{array}{l}\text { ¿La unidad estratégica de } \\
\text { negocio de tubos y } \\
\text { esquineros responde a las } \\
\text { preocupaciones sociales, } \\
\text { comunitarias y ambientales? }\end{array}$ & $\begin{array}{l}\text { Mantiene un compromiso con } \\
\text { la comunidad y el medio } \\
\text { ambiente. }\end{array}$ \\
\hline $\begin{array}{l}\text { Preocupación por } \\
\text { los empleados }\end{array}$ & $\begin{array}{l}\text { ¿Los empleados son unos } \\
\text { activos valiosos para la } \\
\text { unidad estratégica de negocio } \\
\text { de tubos y esquineros? }\end{array}$ & $\begin{array}{l}\text { La base del desarrollo del } \\
\text { capital humano. }\end{array}$ \\
\hline
\end{tabular}

\subsection{Valores}

Thompson, Peteraf, Gamble y Strickland III (2014) señalaron:

Los valores son los principios de negocio y normas éticas que la administración predica y práctica. Esto es clave para la cultura de la empresa pues las acciones dicen más que las palabras. (p.312)

\subsubsection{Valores actuales de la empresa.}

CARVIMSA no ha desarrollado valores para cada UEN Tubos y Esquineros de Cartón, sin embargo, tiene valores a nivel empresarial, la cual ha sido difundida en medios de comunicación interna (página web - Facebook).

Los valores actuales de CARVIMSA son: 
Tabla 32

Valores actuales de la empresa CARVIMSA.

\begin{tabular}{ll} 
Valor & Comentario \\
\hline $\begin{array}{l}\text { Satisfacción al } \\
\text { Cliente }\end{array}$ & $\begin{array}{l}\text { Velar por la orientación al servicio de nuestros clientes internos y } \\
\text { externos, brindándoles atención de calidad ante sus necesidades. }\end{array}$ \\
\hline Compromiso & $\begin{array}{l}\text { Compromiso con la misión, visión, valores, cultura organizacional y } \\
\text { cumplimiento de objetivos y/o acuerdos. }\end{array}$ \\
\hline Rentabilidad & $\begin{array}{l}\text { Mejorar la productividad reduciendo costos y mejorando los márgenes, } \\
\text { con la finalidad de retornar la inversión que contribuya con los programas } \\
\text { de desarrollo en beneficio de nuestros colaboradores. }\end{array}$ \\
\hline Respeto & $\begin{array}{l}\text { Entre los integrantes de la organización sin importar el nivel que ocupen, a } \\
\text { la vez el respeto por el medio ambiente y prevención de riesgos también } \\
\text { debe ser para todos. }\end{array}$ \\
\hline $\begin{array}{l}\text { Desarrollo } \\
\text { Humano }\end{array}$ & $\begin{array}{l}\text { Desarrollo humano a través del entrenamiento, capacitación permanente y } \\
\text { facilitación de recursos necesarios para su realización personal y profesional }\end{array}$
\end{tabular}

\subsubsection{Análisis de los valores actuales.}

Para analizar los valores actuales de la empresa en estudio, se ha tomado en cuenta las bases que se mencionan según los autores en mención.

\subsubsection{Elementos de los valores propuestos para la empresa.}

Se propone nuevos valores para la UEN de tubos y esquineros de la empresa CARVIMSA, referidos al respeto, trabajo en equipo, ética, mejora continua, compromiso con el medio ambiente, calidad en los productos, liderazgo, innovación y orientación al cliente, con el fin de alcanzar la visión trazada.

\subsubsection{Valores propuestos.}

Tabla 33

Valores propuestos para la unidad estratégica de negocio de Tubos y Esquineros

\begin{tabular}{ll} 
Valor & Comentario \\
\hline Respeto & Hacia sus recursos humanos \\
\hline Trabajo en equipo & $\begin{array}{l}\text { Valor necesario que ayudara a la organización tener alianzas de } \\
\text { trabajo y que aporten a la rentabilidad de la empresa. }\end{array}$ \\
\hline Ética & $\begin{array}{l}\text { Para desarrollar y fortalecer las relaciones comerciales a largo } \\
\text { plazo }\end{array}$ \\
\hline $\begin{array}{l}\text { Compromiso con el } \\
\text { medio ambiente }\end{array}$ & $\begin{array}{l}\text { Valor necesario que permite a prevenir la contaminación en el } \\
\text { mundo. }\end{array}$ \\
\hline
\end{tabular}




\begin{tabular}{ll}
\hline Valor & Comentario \\
\hline $\begin{array}{l}\text { Calidad en los } \\
\text { productos }\end{array}$ & $\begin{array}{l}\text { Valor necesario para elaborar y reforzar nuevos y existentes } \\
\text { productos que ayuden al cliente tener satisfacción. }\end{array}$ \\
\hline Liderazgo & $\begin{array}{l}\text { Valor necesario que permite al colaborador tener confianza en sí } \\
\text { mismo y a su vez transmitirlo a sus subalternos. }\end{array}$ \\
\hline Innovación & $\begin{array}{l}\text { Valor necesario que permite que el producto obtenga mejoras } \\
\text { actuales y que además se desarrollen nuevos productos. }\end{array}$ \\
Orientación al cliente & $\begin{array}{l}\text { Valor que permitirá satisfacer las expectativas que exige el cliente } \\
\text { en la actualidad. }\end{array}$ \\
\hline
\end{tabular}

\subsection{Alineamiento estratégico de la visión, misión y valores de la UEN Tubos y Esquineros}

El alineamiento estratégico de la visión, misión y valores de la UEN Tubos y

Esquineros permite que exista una coherencia entre la estrategia del negocio y todos los

componentes de la organización, a fin de que se cumpla con los objetivos estratégicos

formulados. La tabla 34 muestra como los valores identificados en los componentes de la organización se alinean con la visión y misión; a fin de contribuir con el cumplimiento de la estrategia del negocio.

Tabla 34

Alineamiento estratégico de la visión y misión propuestas para la UEN Tubos y Esquineros y valores propuestos para CARVIMSA

\begin{tabular}{|c|c|c|}
\hline Visión & Misión & Valores \\
\hline \multirow{2}{*}{$\begin{array}{l}\text { Ser la empresa líder } \\
\text { en el Perú en la } \\
\text { fabricación y } \\
\text { distribución de } \\
\text { productos de tubos y } \\
\text { esquineros de cartón, } \\
\text { concentrándose en }\end{array}$} & \multirow{2}{*}{$\begin{array}{l}\text { Crear valor y seguridad } \\
\text { para los clientes de los } \\
\text { sectores de embalaje, } \\
\text { agroindustrial, } \\
\text { construcción y textil del } \\
\text { mercado local e } \\
\text { internacional, }\end{array}$} & Respeto: Hacia sus recursos humanos \\
\hline & & $\begin{array}{l}\text { Trabajo en Equipo: Valor necesario que } \\
\text { ayudara a la organización tener alianzas } \\
\text { de trabajo y que aporten a la rentabilidad } \\
\text { de la empresa. } \\
\text { Ética: Para desarrollar y fortalecer las }\end{array}$ \\
\hline \multirow{2}{*}{$\begin{array}{l}\text { embalaje, } \\
\text { los sectores de }\end{array}$} & \multirow{2}{*}{$\begin{array}{l}\text { personalizadas de tubos } \\
\text { entregando soluciones }\end{array}$} & \\
\hline & & relaciones comerciales a largo plazo. \\
\hline $\begin{array}{l}\text { agroindustrial, } \\
\text { construcción y textil. }\end{array}$ & $\begin{array}{l}\text { y esquineros de cartón, } \\
\text { empleando tecnología }\end{array}$ & $\begin{array}{l}\text { Innovación: Valor necesario que permite } \\
\text { que el producto obtenga mejoras actuales }\end{array}$ \\
\hline
\end{tabular}




\begin{tabular}{lll}
\hline Visión & Misión & Valores \\
\hline $\begin{array}{l}\text { base del desarrollo del } \\
\text { capital humano, } \\
\text { generando rentabilidad } \\
\text { para los accionistas y } \\
\text { manteniendo un } \\
\text { compromiso con la } \\
\text { comunidad y el medio } \\
\text { ambiente. }\end{array}$ & $\begin{array}{l}\text { Calidad en los productos: Valor } \\
\text { necesario para elaborar y reforzar nuevos } \\
\text { cliente tener satisfacción. }\end{array}$ \\
\cline { 2 - 2 } & $\begin{array}{l}\text { Liderazgo: Valor necesario que permite } \\
\text { al colaborador tener confianza en sí } \\
\text { mismo y a su vez transmitirlo a sus } \\
\text { subalternos }\end{array}$ \\
& $\begin{array}{l}\text { Medio Ambiente: Valor necesario que } \\
\text { permite a prevenir la contaminación en el } \\
\text { mundo. }\end{array}$ \\
&
\end{tabular}

El alineamiento estratégico tiene como punto de partida la visión, misión, valores, objetivos y la estrategia del negocio.

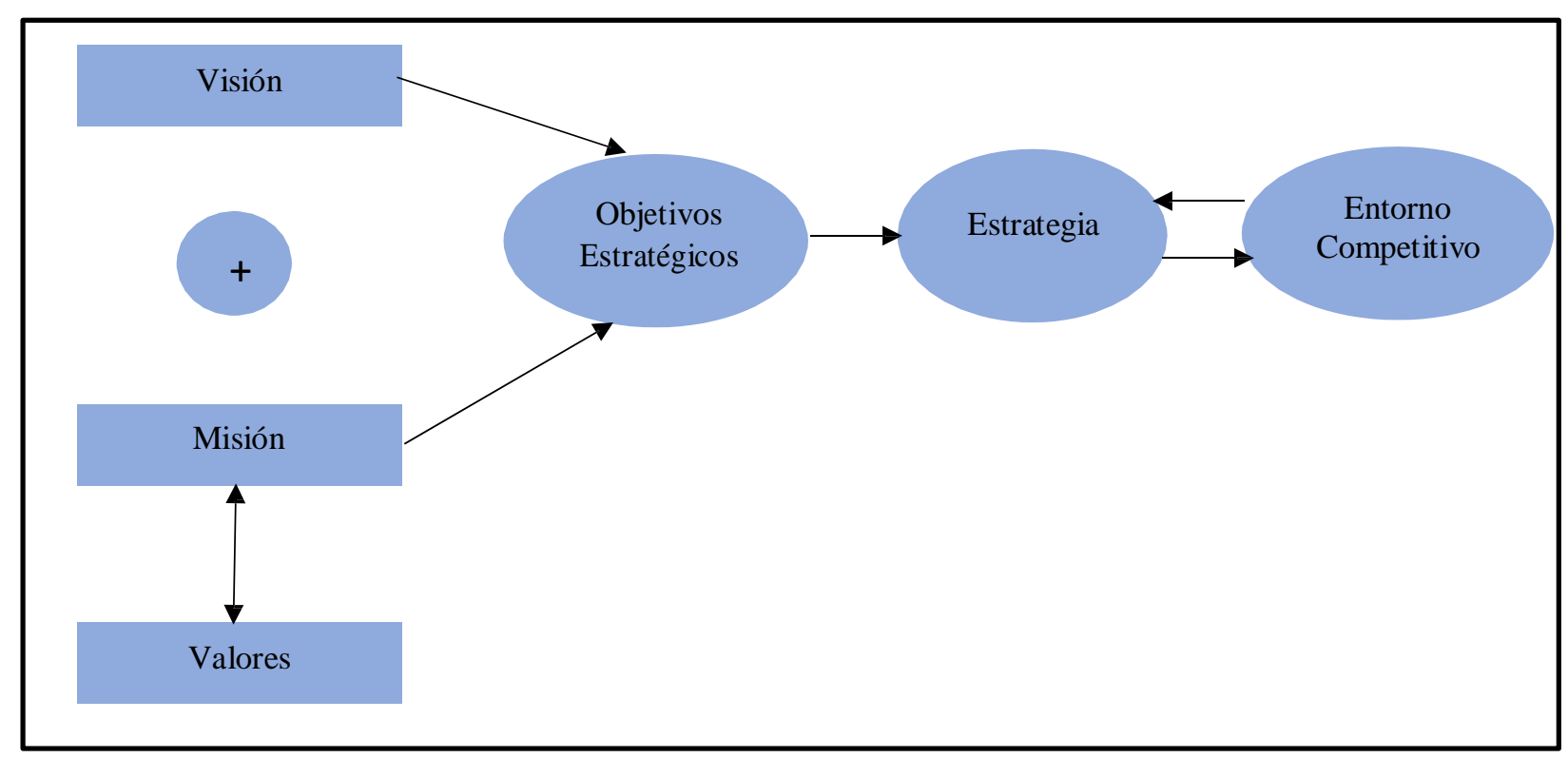

Figura 34. Alineamiento Estratégico

En la unidad de Tubos y Esquineros se han detectado dos tipos de alineamiento: la alineación horizontal y el alineamiento vertical.

Cabe señalar que el alineamiento horizontal es clave, ya que significa la sincronización horizontal que facilitará coordinación a lo largo de las actividades de la 
cadena de valor y de los procesos organizacionales hacia el logro de la estrategia empresarial a fin de crear valor para todos sus stakeholders, los cuales son los clientes, colaboradores, accionistas, la comunidad y el medioambiente.

En cuanto al alineamiento vertical también es clave, ya que se refiere al despliegue vertical que permitirá llevar los objetivos corporativos al plano operativo de manera coherente.

\section{Capítulo IV. Análisis externo}

\subsection{Tendencias de las variables del entorno}

El ambiente externo está conformado por los segmentos de la sociedad que influyen tanto en una actividad industrial determinada como en las empresas que la componen. Dichos segmentos del entorno se consolidan en siete: el demográfico, el económico, el político/legal, el sociocultural, el tecnológico, el global y el físico. (Hitt, Duane \& Hoskisson, 2015)

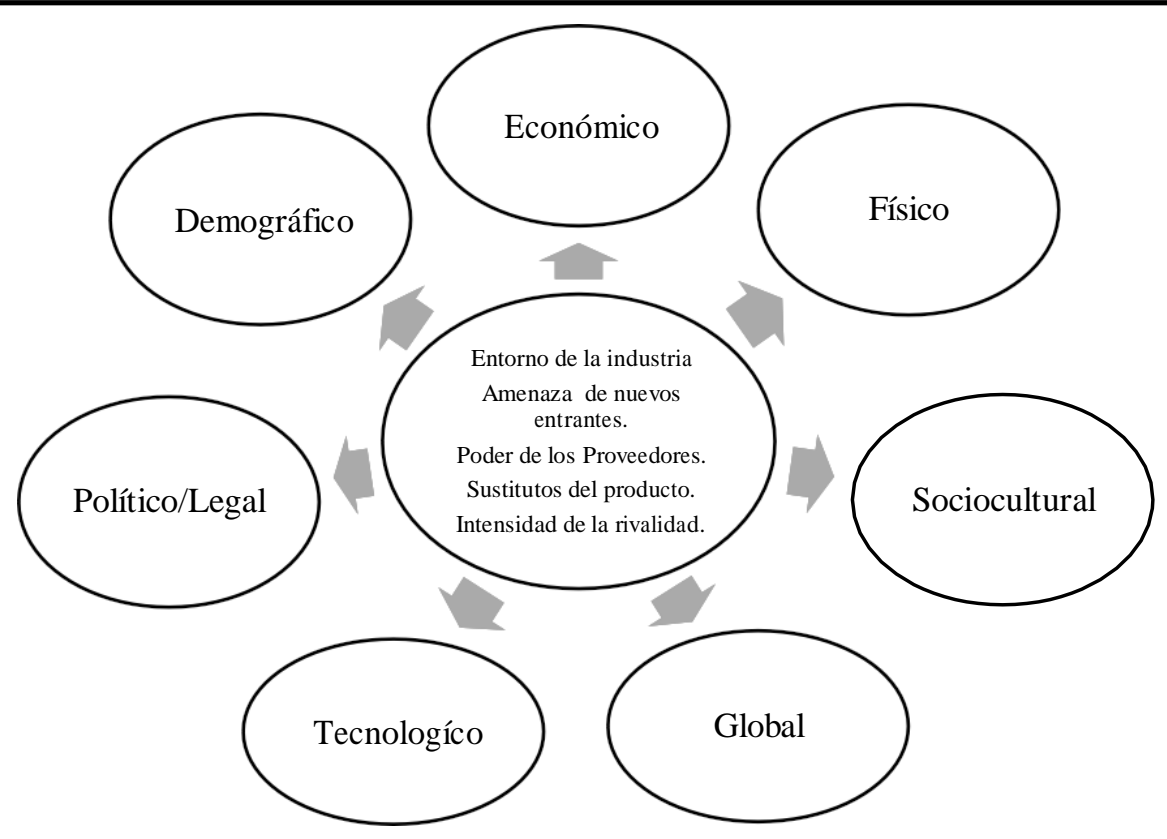

Figura 35. El entorno externo. Adaptado de "Administración Estratégica. Competitividad y globalización: Conceptos y casos Decimo onceava edición”, por Hitt, Duane \& Hoskisson, 2015, p. 68. Editorial: Cergage Learning Editores, SA de CV. 
Es importante entender el entorno en el que una industria y organización se desarrollan, con el fin de medir los impactos positivos y negativos que puede tener sobre la empresa, identificar las oportunidades y amenazas del mercado, y desarrollar un planeamiento estratégico adecuado para tomar las decisiones correctas. A continuación, realizaremos el análisis del entorno para la UEN Tubos y Esquineros de CARVIMSA según las siguientes variables.

\subsubsection{Análisis político-gubernamental.}

El Perú atraviesa una estabilidad política y consistente crecimiento económico desde la última década. Las diferentes reformas políticas y, sobre todo, económicas han puesto al Perú como uno de los países más atractivos en Latinoamérica para invertir.

Perú consiguió un puntaje de 9,56 sobre 10 en el indicador de solidez monetaria en el ranking de Libertad Económica del Fraser Institute del 2015. Cabe resaltar que, la evaluación se realizó entre 159 países y dentro de América Latina, el puntaje obtenido por el Perú está entre los más altos, colocándolo por encima de países como Chile con un puntaje de 9,31, Brasil con 7,97, Colombia con 8,03 y México con 8,14. La principal ventaja la obtuvo por mantener una inflación baja y estable, un crecimiento adecuado del dinero y libertad para obtener cuentas bancarias en moneda extranjera.

Para la medición del índice de Libertad Económica se consideraron factores como el tamaño de gobierno, el sistema legal, la fortaleza monetaria, el libre comercio y la regulación. El Perú obtuvo como puntaje global 7,44 sobre un máximo de 10 consiguiendo un avance respecto al total de 7.26 obtenido en el 2014. (Fraser Institute, 2015). 


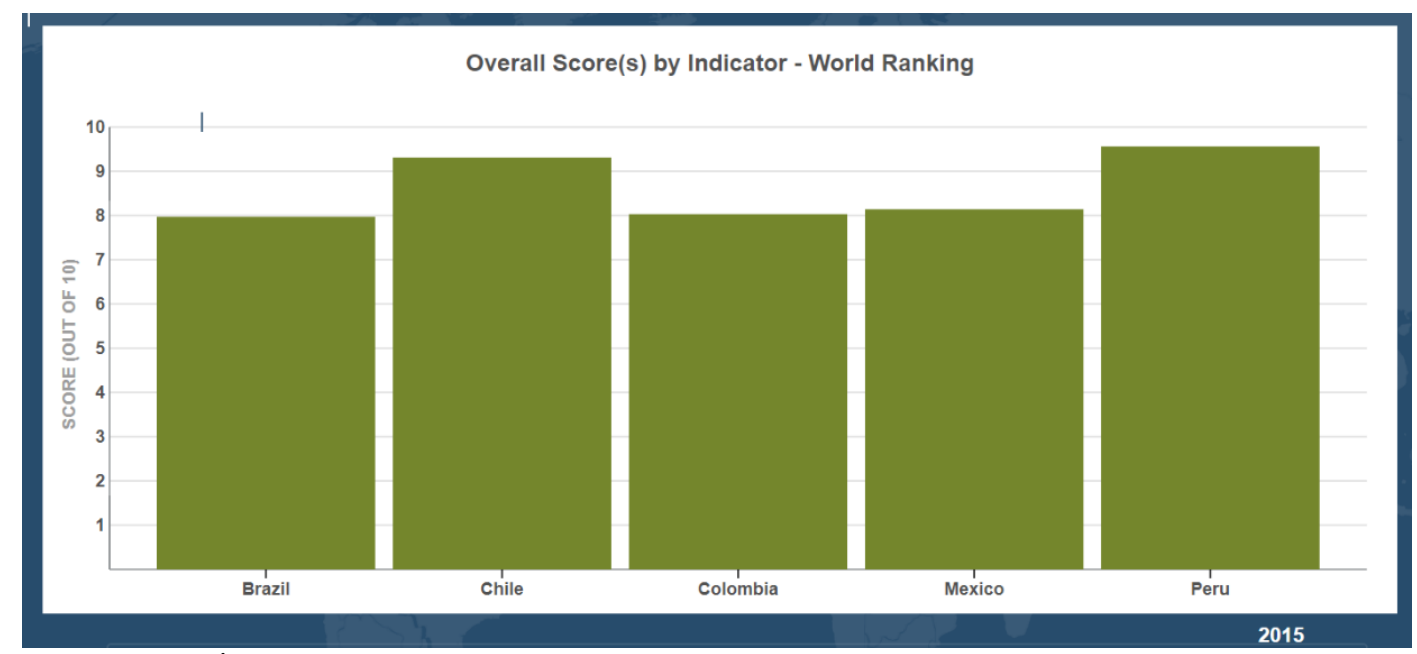

Figura 36. Índice de Solidez Monetaria 2015. Tomado de Fraser Institute. Recuperado de https://www.fraserinstitute.org

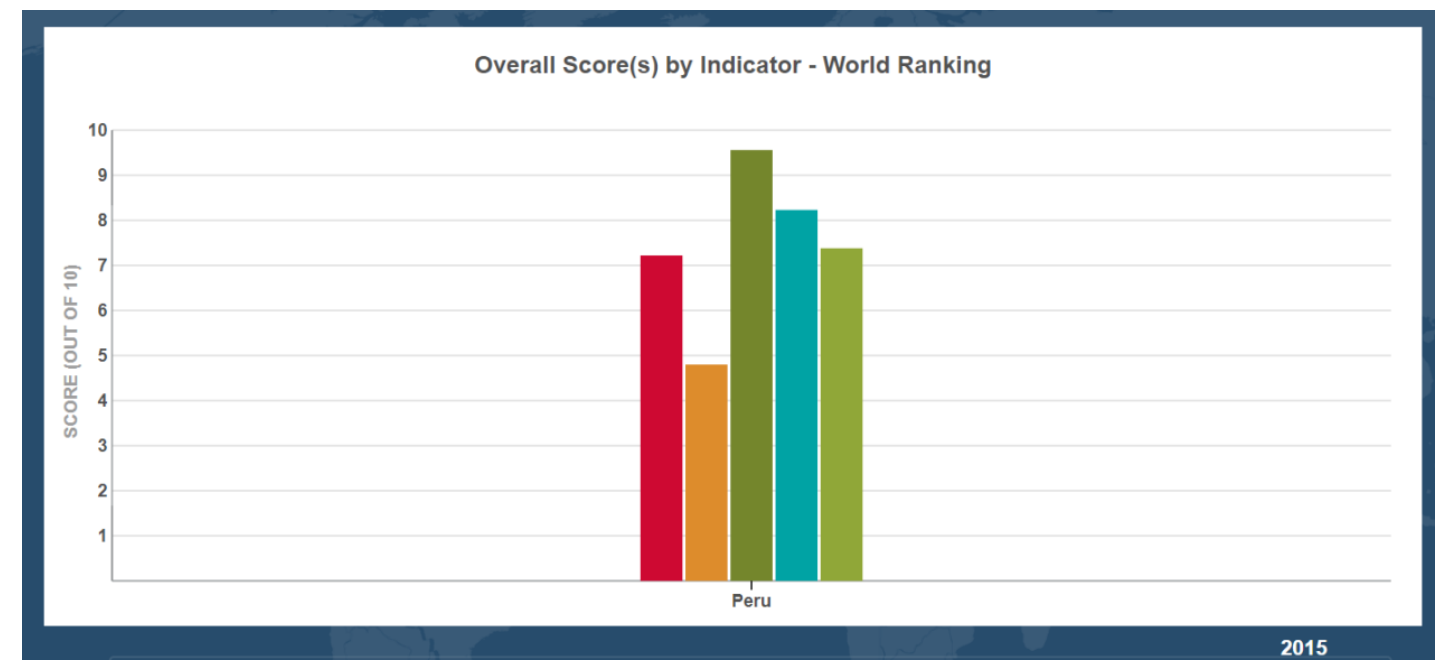

Figura 37. Índice de Libertad Económica del Perú: 2015. Tomado de Fraser Institute. Recuperado de https://www. fraserinstitute.org

El Doing Business del Banco Mundial revalidó al Perú como el tercer mejor país en América Latina para hacer negocios, el primer lugar lo obtiene México y el segundo Chile. Perú conserva el tercer lugar debido a que tiene el mejor ambiente macroeconómico en América Latina, además de ser el cuarto mejor en ambiente corporativo y nivel tecnológico. (Banco Mundial, 2017).

Después de la crisis política en el Perú por la vacancia presidencial a Pedro Pablo Kuczynski y el tema del indulto humanitario para Alberto Fujimori se vieron afectadas las inversiones públicas y privadas, surgió la incertidumbre en la estabilidad política y social, lo 
que podría reducir el PBI estimado para el cierre del año 2018. Por tanto, los primeros pasos que debe adoptar es el fortalecimiento institucional, y asegurar la confianza a la inversión privada que se estaría poniendo en riesgo.

La variable político gubernamental no tiene un impacto negativo para Carvimsa, lo que sí hubiera sido negativo es que se hubiera convocado a nuevas elecciones generales anticipadas, el primer vicepresidente Vizcarra tomó su lugar y esta vez el ruido político y el cambio de mandato estaban ya internalizados, por lo que no ocasionaron volatilidad financiera. Con la normalización de la situación política, las cosas siguen adelante, en este momento el Perú es el único país en la región al que no se le ha reducido la calificación, la crisis política no ha generado riesgo ya que el Perú es considerado el mejor tercer país sudamericano para hacer negocios en el año 2019 y las proyecciones indican que liderará el crecimiento en la región con un 4.2\% lo cual no afectará el nivel de ventas de Carvimsa.

\subsubsection{Análisis económico.}

\section{Panorama mundial}

El crecimiento mundial se consolidó en 2017 logrando alcanzar un nivel de crecimiento del 3,8\%, donde el comercio internacional destacó notablemente debido a (i) la recuperación de la inversión en las economías avanzadas, (ii) el crecimiento ininterrumpido en las economías emergentes del continente asiático, (iii) el notable desempeño de las economías emergentes del continente europeo y (iv) la recuperación en varios exportadores de materias primas. Sin embargo, para el año 2018 y 2019 solo se prevé que el crecimiento mundial aumente ligeramente a 3,9\%, respaldado por el optimismo en los mercados, las condiciones financieras favorables y las repercusiones de la política fiscal expansiva propagada por Estados Unidos. De modo que, la recuperación parcial de los precios de las 
materias primas debería permitir que las condiciones mejoren gradualmente en los países que las exportan. (Fondo Monetario Internacional, 2018).

\section{Economía mundial}

El crecimiento mundial del 2017 fue ligeramente más rápido que en 2016 y el más importante desde 2011. Dos tercios de los países que generan alrededor de tres cuartas partes del producto mundial experimentaron un crecimiento más rápido en 2017 que en el año 2016. Por otro lado, el resurgimiento del gasto en inversión en las economías avanzadas y la interrupción de la caída de la inversión en algunas economías de mercados emergentes y en desarrollo exportadoras de materias primas fueron importantes determinantes del aumento del crecimiento del PIB mundial y la actividad manufacturera. (Fondo Monetario Internacional, 2018).

En las economías avanzadas, el repunte de 0,6 puntos porcentuales observado en el crecimiento de 2017 en comparación con el de 2016 es atribuible casi en su totalidad al gasto en inversión, que se había mantenido débil desde la crisis financiera internacional y fue particularmente atenuado en 2016. Tanto el aumento de la formación bruta de capital fijo como la aceleración de la constitución de stocks contribuyeron al repunte de la inversión; por su parte, la política monetaria acomodaticia, el fortalecimiento de los balances y la mejora de las perspectivas contribuyeron a destrabar la demanda reprimida de bienes de capital.

En las economías de mercados emergentes y en desarrollo, el repunte de 0,4 puntos porcentuales del crecimiento de 2017 puede atribuirse principalmente a la aceleración del consumo privado. Sin embargo, el panorama dentro del grupo es variado. En China e India, el año pasado el crecimiento estuvo respaldado por el resurgimiento de la exportación neta y el vigor del consumo privado, respectivamente, en tanto que el aumento de la inversión perdió fuerza. El fin de la contracción de la inversión fija en las economías exportadoras de materias 
primas que se vieron duramente afectadas por la caída de los precios de las materias primas en 2015-16 (sobre todo Brasil y Rusia, pero también Angola, Ecuador y Nigeria) desempeñaron un papel importante en el repunte del crecimiento en 2017. Asimismo, un aumento más fuerte de la inversión fija (2,3 puntos porcentuales por encima del nivel de 2016) también contribuyó al crecimiento de otras economías de mercados emergentes y en desarrollo, junto con la vigorización del consumo privado. (Fondo Monetario Internacional, 2018).

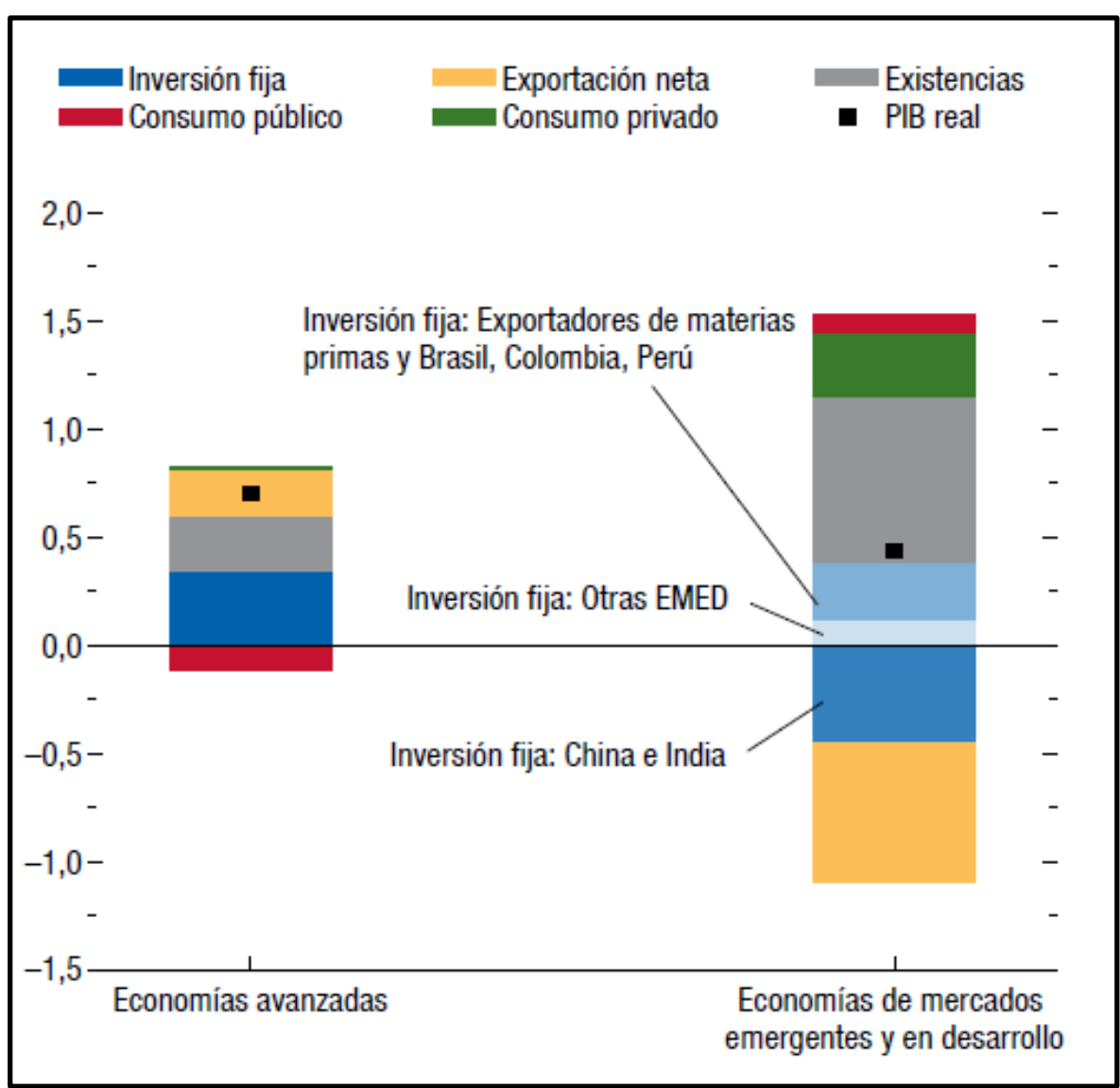

Figura 38. Contribuciones a la variación del crecimiento del PIB real, 2016-2017. Tomado de Perspectivas de la economía mundial (informe WEO) del Fondo Monetario Internacional. Recuperado de https://www.imf.org 


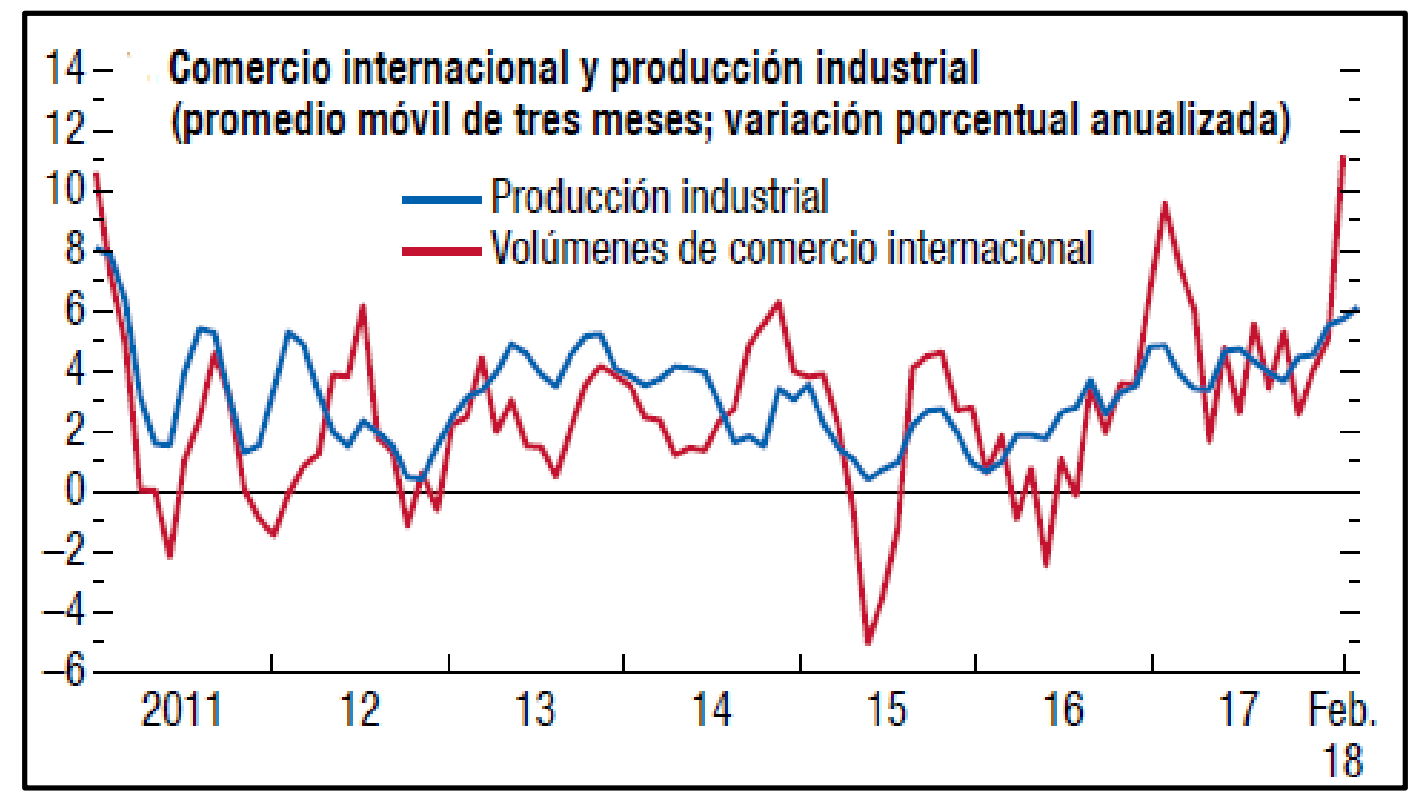

Figura 39. Comercio internacional y producción industrial (promedio móvil de tres meses: Variación \% anualizada. Tomado de Perspectivas de la economía mundial (informe WEO) del Fondo Monetario Internacional. Recuperado de https://www.imf.org

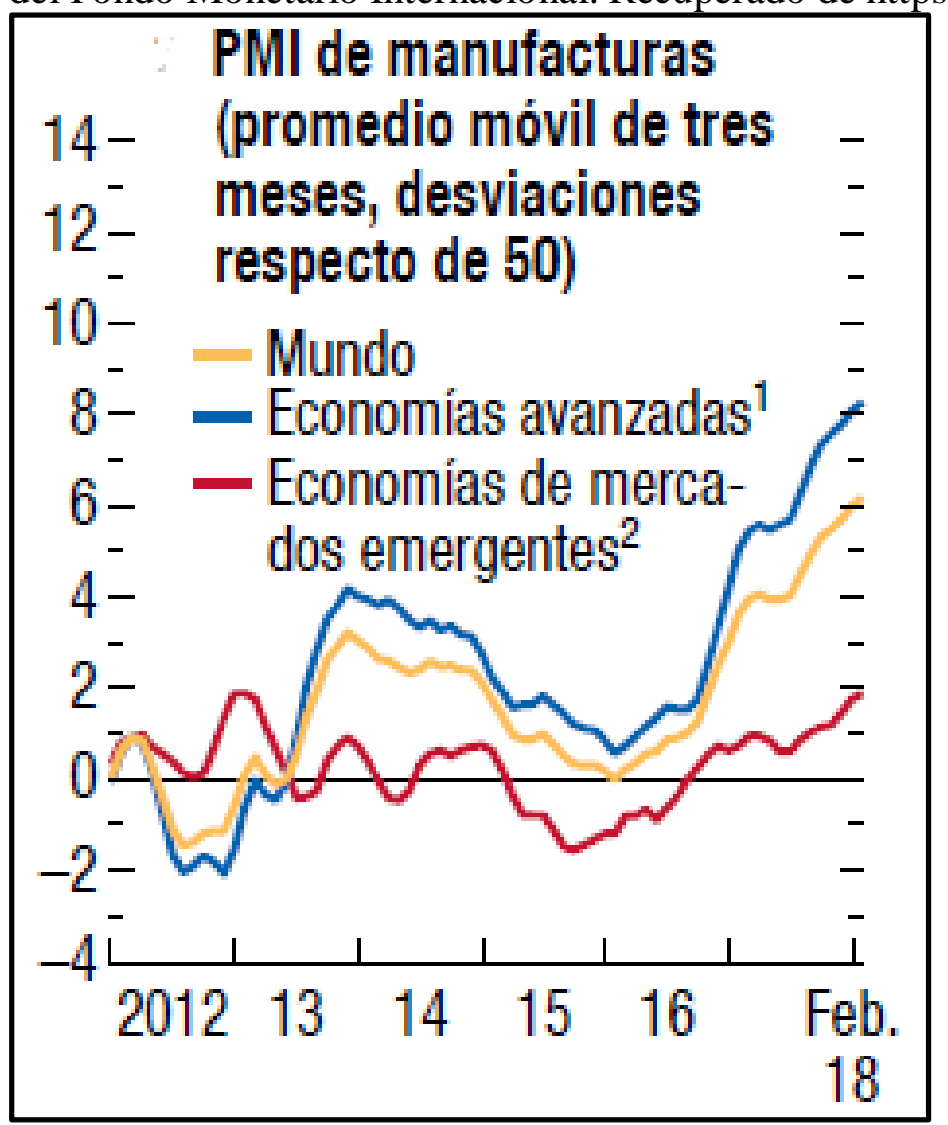

Figura 40. PMI de manufacturas (promedio móvil de tres meses; desviaciones respecto de 50). Tomado de Perspectivas de la economía mundial (informe WEO) del Fondo Monetario Internacional. Recuperado de https://www.imf.org/es 


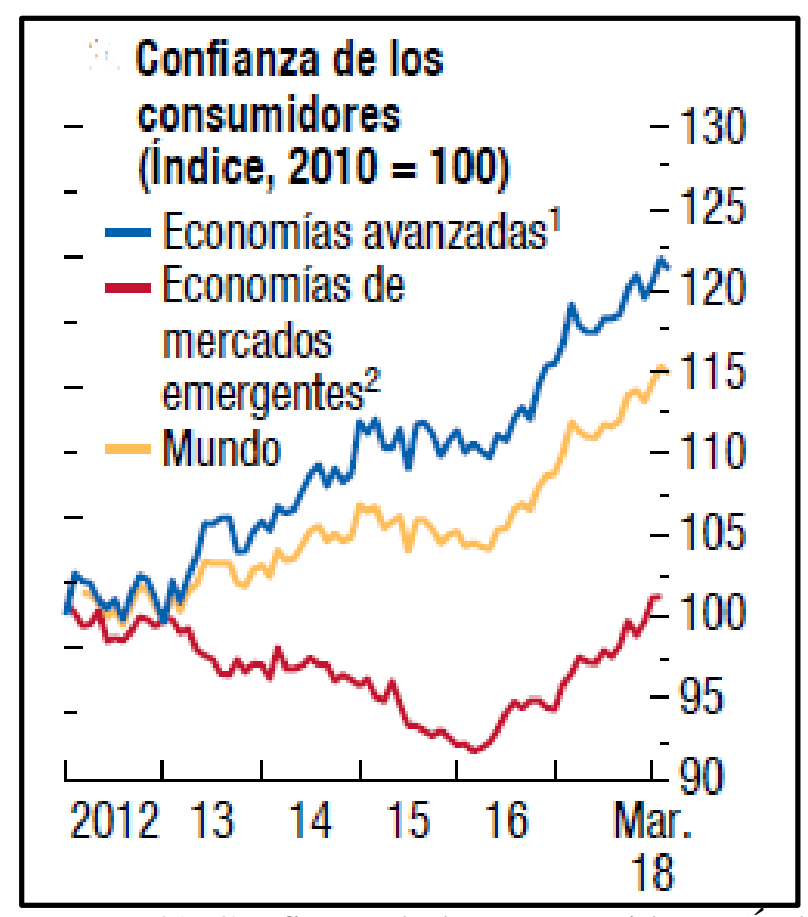

Figura 41. Confianza de los consumidores (Índice, 2010=100). Tomado de Perspectivas de la economía mundial (informe WEO) del Fondo Monetario Internacional. Recuperado de https://www.imf.org

Inflación mundial

Como consecuencia del encarecimiento del petróleo registrado desde septiembre 2017, el nivel general de inflación de precios al consumidor ha repuntado nuevamente. La inflación subyacente (excluye los precios de los combustibles y los alimentos) se mantiene atenuada en términos generales y ha comenzado a dar indicios de recuperación en las economías avanzadas y parece haber tocado fondo en las economías de mercados emergentes y en desarrollo. Así mismo, la debilidad ininterrumpida de la inflación en las economías avanzadas en relación con los años previos a la crisis refleja más que nada servicios no transables al consumidor, tales como atención médica y educación. La inflación de bienes transables se ha mantenido baja, pero no ha disminuido. (Fondo Monetario Internacional, 2018). 


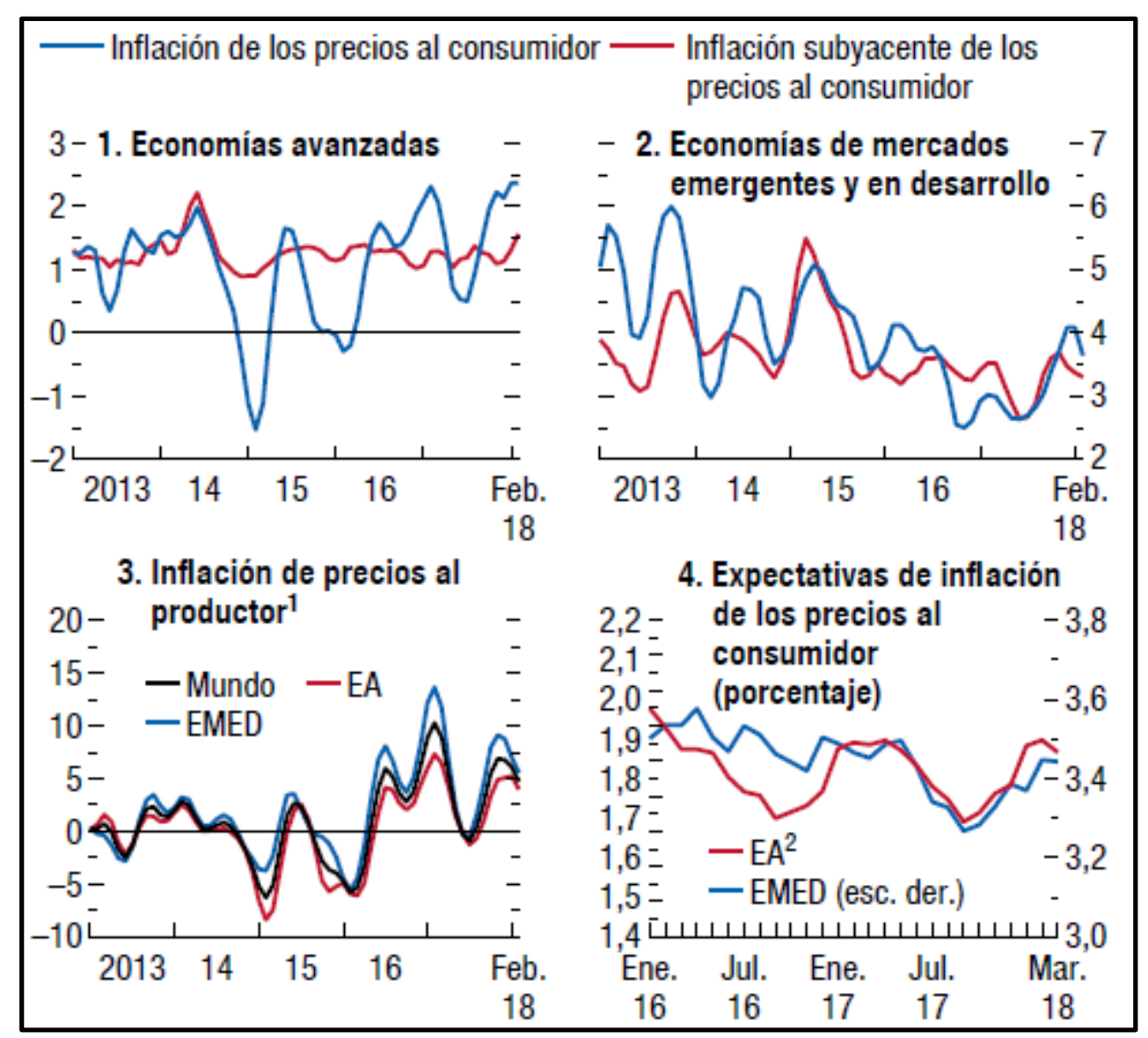

Figura 42. Inflación Mundial: Promedio móvil de tres meses; variación porcentual anualizada. Tomado de Perspectivas de la economía mundial (informe WEO) del Fondo Monetario Internacional. Recuperado de https://www.imf.org

Tipo de cambio mundial

A pesar del aumento de los diferenciales de las tasas de interés, el dólar de EE. UU. se debilitó ligeramente en términos efectivos reales, alrededor de 11/2\% entre agosto de 2017 y fines de marzo de 2018, y es aproximadamente 41/2\% más débil que el promedio de 2017 . El euro se ha apreciado en alrededor de $1 \%$ y es aproximadamente $4 \%$ más fuerte que el promedio de 2017. En lo que respecta a otras monedas, el yen japonés se ha mantenido en términos generales estable, en tanto que la libra esterlina se apreció 5,5\% tras el aumento de las tasas de interés en noviembre por parte del Banco de Inglaterra y expectativas positivas en torno a un acuerdo sobre el brexit. (Fondo Monetario Internacional, 2018). 


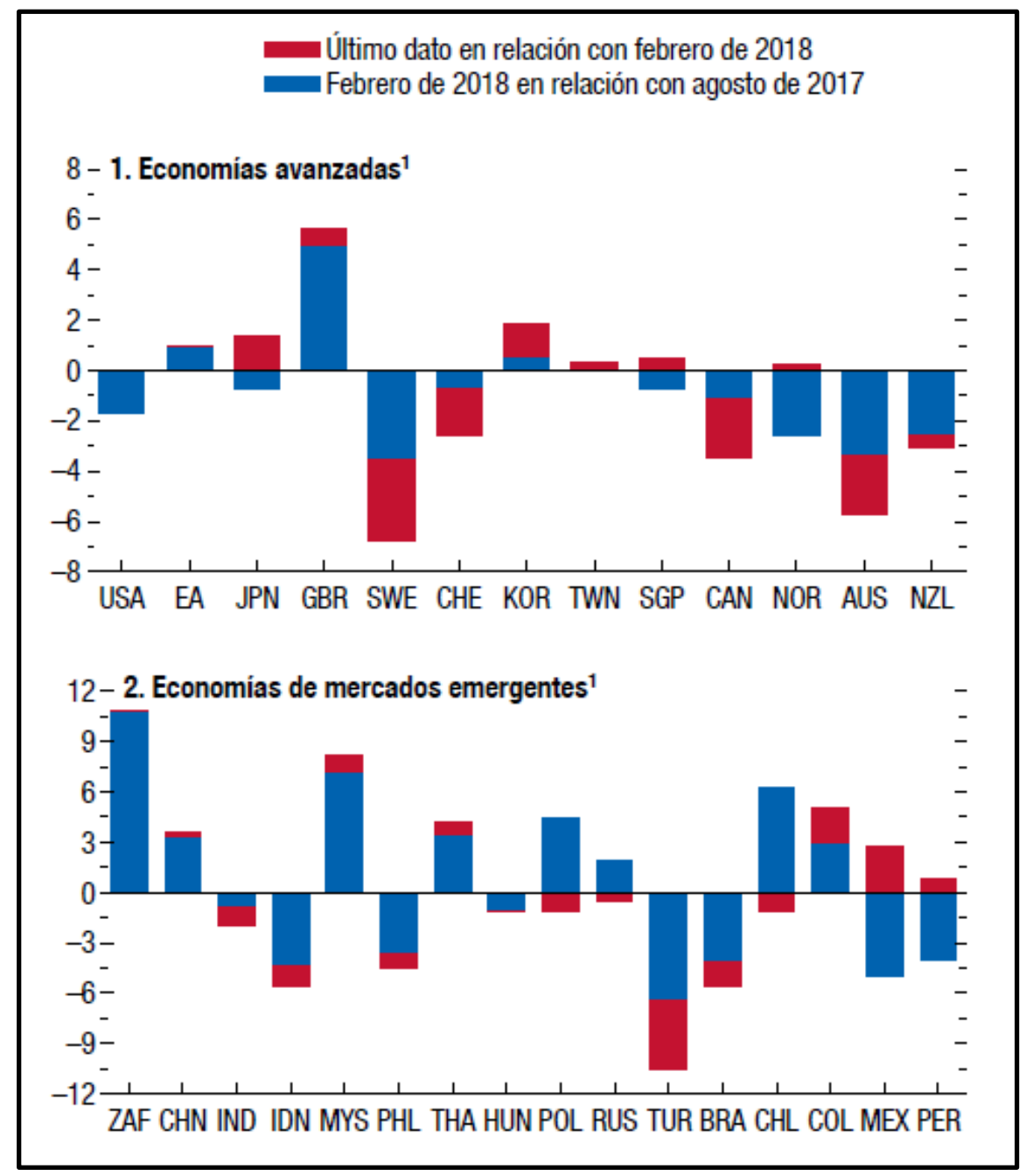

Figura 43. Variaciones de los tipos de cambio efectivos reales, agosto de 2016 a febrero de 2017. Tomado de Perspectivas de la economía mundial (informe WEO) del Fondo Monetario Internacional. Recuperado de https://www.imf.org Perspectivas de la demanda de papel a nivel mundial

En 2017, la producción mundial de papel y cartón aumentó en un 1.5\%, llegando a producir aproximadamente 420 millones de toneladas donde se Japón registró un crecimiento moderado mientras que Estados Unidos mantuvo su estabilidad en comparación al periodo 2016. Por otro lado, se contrajo la producción en Canadá, Corea del Sur e India. China ha crecido a una velocidad mayor que el 2016, Brasil y Rusia también registraron un fuerte crecimiento.

Se espera que la producción de papel periódico, utilizado principalmente para periódicos y diarios, baje alrededor del 5.4\%. La producción de papeles gráficos en otras áreas (revistas y catálogos, correspondencia directa, directorios, etc.) muestra tendencias 
ligeramente diferentes. La producción de papel mecánico recubierto se redujo en un 1\%, mientras que la producción de calidades de madera -pastas mecánicas - recubierta, aumentó en un $2 \%$. La producción de papel mecánico no recubierto disminuyó un $2.1 \%$ y se estima que la producción de calidades sin madera sin recubrimiento, principalmente papel de oficina disminuyó un $1.3 \%$.

En general, esto significa que la producción de papeles gráficos revestidos aumentó un $0.5 \%$, mientras que la producción de calidades sin revestir disminuyó un 1.6\%. La producción de papeles gráficos mostró un ligero aumento del $0.1 \%$, mientras que la producción de papeles gráficos mecánicos disminuyó en un $1.5 \%$.

Por su parte, se estima que la producción de los grados de embalaje aumentó alrededor de un 3.7\% en comparación con 2016. Dentro de los grados de embalaje, los papeles para cajas, principalmente utilizados para el embalaje de transporte y cajas de cartón corrugado, registraron un fuerte aumento del $5 \%$ en la producción. La producción de cartones y otras planchas de empaquetado -como envases pequeños o cubiertas de libros- creció un 1.8\% y la producción de hojas de embalaje, utilizada para la producción de bolsas de papel, mostró un aumento de alrededor del $0.5 \%$.

La producción se ve afectada por la tendencia constante hacia la reducción de peso y la eficiencia de los recursos, ya que se mide en toneladas. La participación de las categorías de envases representó el 51.2\% (50.2\% en 2016) de la producción total de papel y cartón, y los grados gráficos representaron el 36.2\% (37.3\% en 2016). (CEPI, 2017).

\section{Panorama peruano}

A lo largo de la última década, la economía peruana ha sido una de las de más rápido crecimiento en la región, con una tasa promedio de 5.9\% en un contexto de bajo promedio inflación de 2.9\%. La presencia de un entorno externo favorable, políticas macroeconómicas prudentes y reformas estructurales en diferentes áreas crearon un escenario de alto 
crecimiento y baja inflación. El sólido crecimiento en empleo e ingresos redujo considerablemente las tasas de pobreza. La pobreza moderada de US\$4 por día con un Paridad del Poder Adquisitivo (PPA) del 2005 cayó de 45.5\% en el 2005 a 19.3\% en el 2015.

Esto equivale a decir que 6.5 millones de personas salieron de la pobreza durante ese periodo. La pobreza extrema US\$2.5 por día con un PPA del 2005 disminuyó de $27.6 \%$ a 9\% en ese mismo periodo.

La inflación promedio llegó a un 3.6\% en 2016, encima del límite superior de su rango objetivo, debido a que los impactos del lado de la oferta sobre los precios de los alimentos compensaron la débil demanda doméstica.

El Perú enfrentó un déficit fiscal moderado de 2.6\% en el 2016. El mayor déficit proviene de una disminución en los ingresos producto de la desaceleración económica, la reforma fiscal de 2014, y un incremento en los gastos recurrentes durante años recientes, especialmente en el caso de bienes y servicios y salarios. (Banco Mundial, 2017).

\section{PBI}

El Marco Macroeconómico Multianual (MMM) del 2017-2019 señala que la economía peruana creció 4,1\% en la primera mitad del año 2016, impulsada por una mayor oferta minera. Esta dinámica de crecimiento es inestable ya que está sostenida por un motor temporal y sin una clara recuperación de la inversión privada. Sin embargo, persiste una economía a dos velocidades. Por un lado, los sectores primarios han sostenido la recuperación de la actividad económica y, en conjunto, crecieron 8,0\% en el primer semestre del 2016. Por otro lado, los sectores no primarios crecieron $3,2 \%$, ligeramente por encima de lo registrado en el $2015(2,8 \%)$ y por debajo del crecimiento de la economía total por tercer semestre consecutivo. En efecto, la manufactura no primaria cayó alrededor de 2,0\% en la 
primera mitad del año, continuando con la recesión observada en el sector desde el 2014.

(Ministerio de Economía y Finanzas, 2017).

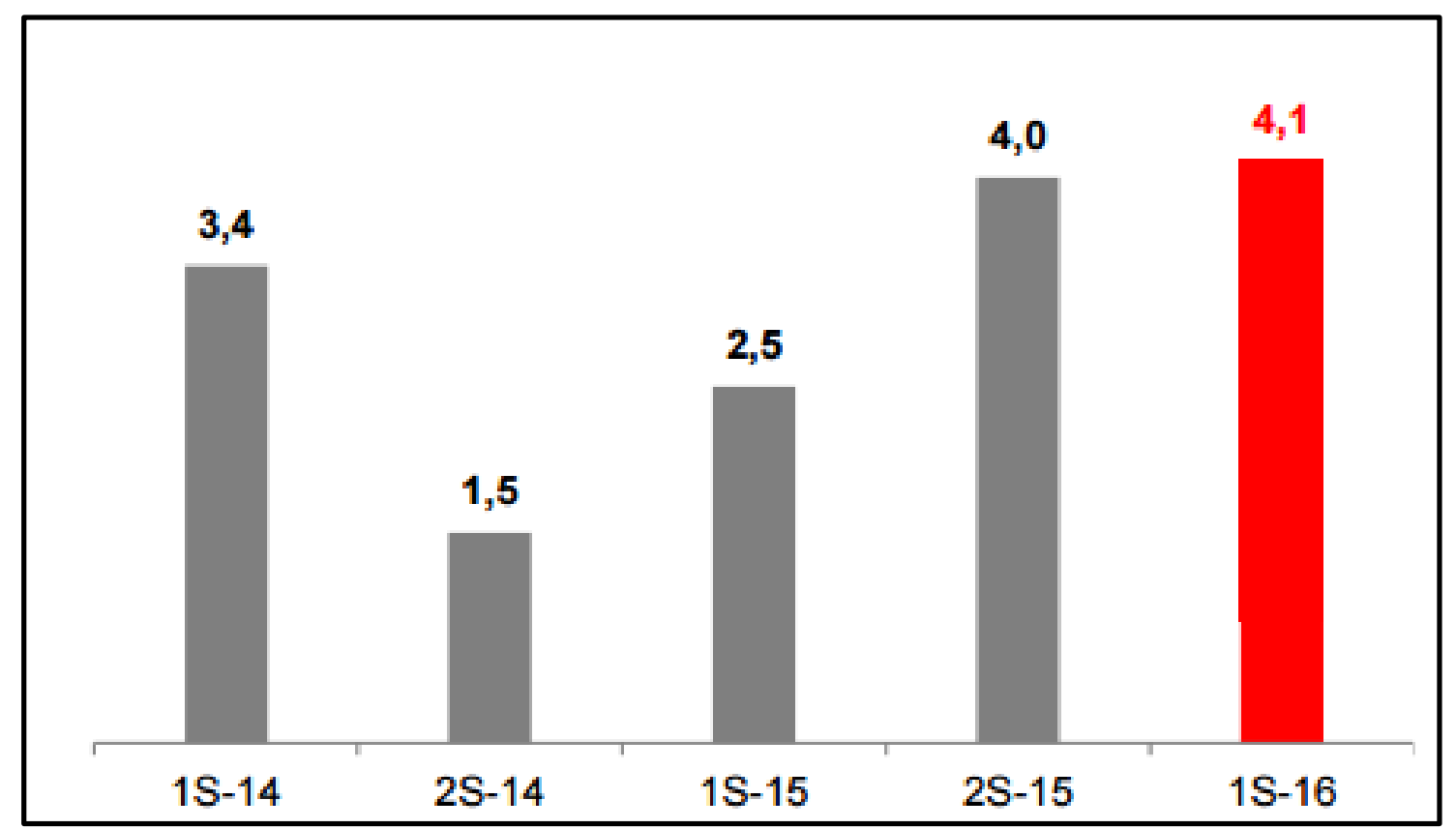

Figura 44. PBI Semestral: variación \% real anual 2014 - 2016. Tomado de Marco

Macroeconómico Multianual 2017-2019. Recuperado de https://www.mef.gob.pe

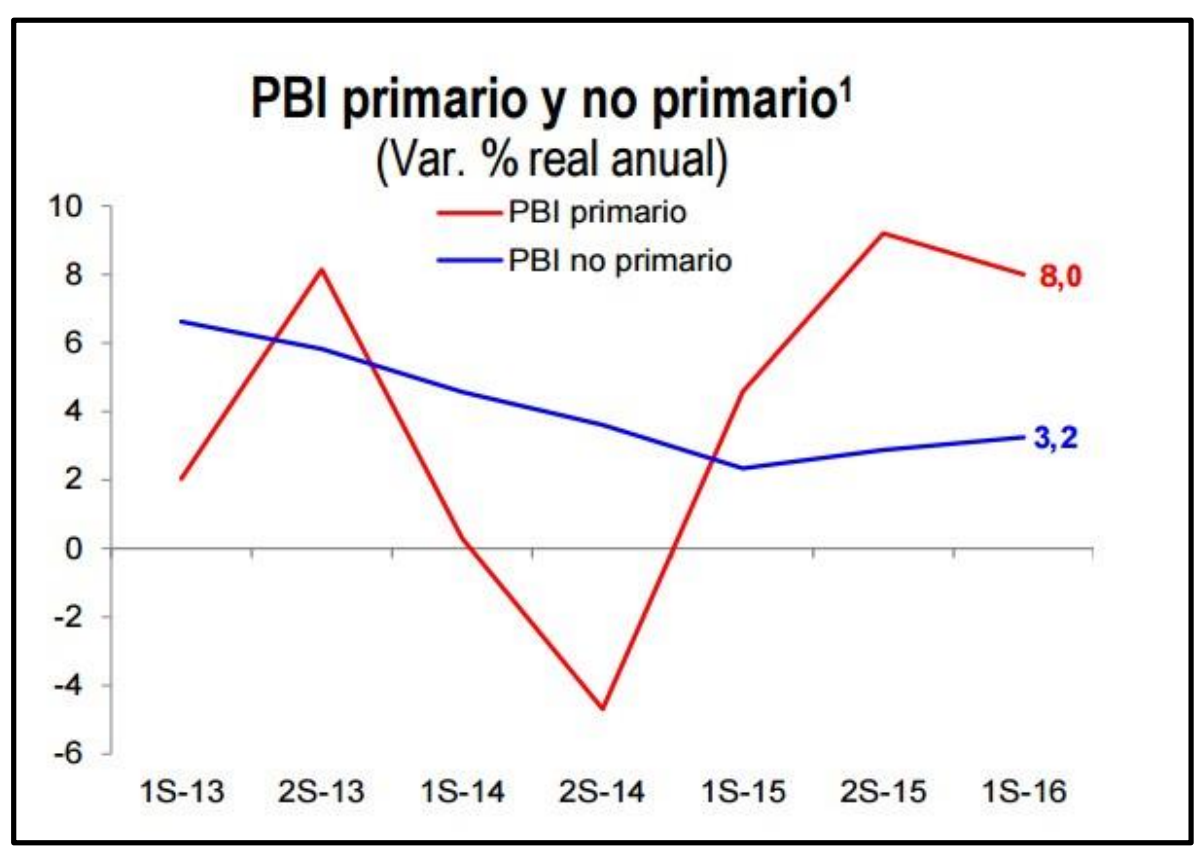

Figura 45. PBI primario y no primario: variación \% real 2013-1026. Tomado de Marco Macroeconómico Multianual 2017-2019. Recuperado de https://www.mef.gob.pe

Para el 2017, se espera que el PBI se desacelere ligeramente debido a la estabilización en el sector minero y una todavía débil inversión privada, ésta última se vio afectada por las 
condiciones globales adversas y la incertidumbre relacionada con los escándalos de corrupción de proyectos firmados en años pasados. Las proyecciones de crecimiento son vulnerables a los impactos externos en relación con precios de productor (commodities), una mayor desaceleración del crecimiento de China, la volatilidad de los mercados de capital, la velocidad del ajuste de la política monetaria en los Estados Unidos. La economía está además expuesta a riesgos naturales, incluyendo fenómenos climáticos recurrentes como El Niño.

Para incrementar el crecimiento se requiere de reformas estructurales y fiscales que liberen la productividad, reduzcan la informalidad, y mejoren la eficiencia de los servicios públicos. (Banco Mundial, 2017).

Las perspectivas de crecimiento económico se moderan para 2017, ubicándose en un rango entre 3,0 y 3,5\% y ascenderían a un rango entre 3,8 y 4,0\% para el año 2018. (Banco Central de Reserva del Perú, 2017).

\begin{tabular}{|c|c|c|c|}
\hline & \multicolumn{3}{|c|}{ Encuesta realizada al: } \\
\hline & 30 Ene.2017 & 27 Feb.2017 & 31 Mar.2017 \\
\hline \multicolumn{4}{|c|}{ Analistas Económicos 1/ } \\
\hline 2017 & 3,8 & 3,5 & 3,0 \\
\hline 2018 & 4,0 & 3,8 & 3,8 \\
\hline 2019 & & 4,0 & 4,0 \\
\hline \multicolumn{4}{|c|}{ Sistema Financiero 2/ } \\
\hline 2017 & 3,8 & 3,5 & 3,3 \\
\hline 2018 & 4,0 & 4,0 & 3,9 \\
\hline 2019 & & 4,0 & 4,0 \\
\hline \multicolumn{4}{|c|}{ Empresas No financieras 3 / } \\
\hline 2017 & 4,0 & 3,8 & 3,5 \\
\hline 2018 & 4,2 & 4,0 & 4,0 \\
\hline 2019 & & 4,2 & 4,1 \\
\hline \multicolumn{4}{|c|}{$\begin{array}{l}\text { 1/ } 16 \text { analistas en enero, } 16 \text { en febrero y } 17 \text { en marzo de } 2017 . \\
\text { 2/ } 19 \text { empresas financieras en enero, } 19 \text { en febrero y } 20 \text { en marzo de } 2017 . \\
\text { 3/ } 371 \text { empresas no financieras en enero, } 328 \text { en febrero y } 335 \text { en marzo de }\end{array}$} \\
\hline
\end{tabular}

Figura 46. Encuesta de Expectativas Macroeconómicas: Crecimiento del PBI \%. Tomado de Resumen Informativo Semanal N ${ }^{\circ} 14$ del Banco Central de Reserva del Perú. Recuperado de https://www.mef.gob.pe 
El mercado de la UEN de tubos y esquineros de CARVIMSA se dirige a los sectores manufactura, agropecuario y construcción. Por ello es importante analizar el comportamiento de dichos sectores para determinar el impacto positivo o negativo que tiene sobre la unidad en mención.

\section{Sector Manufactura}

La Sociedad Nacional de Industrias (SIN) señaló que el sector manufactura crecerá 2,5\% en promedio durante el 2017. Asimismo, la manufactura no primaria, que representa cerca del $75 \%$ de la industria peruana, registrará una expansión de 1,5\%, según cálculos del gremio. La SNI considera que el aumento de la inversión pública que reportó un crecimiento de cerca del 14\% en enero, así como la Línea 2 del Metro de Lima y Callao, las medidas adoptadas para fortalecer a las pymes y ciertos proyectos de inversión (mineros y no mineros), deberían impulsar la industria en el 2017. La manufactura cerró el 2016 con una caída de 1,6\%. En diciembre, creció 6,4\%. Sin embargo, el mayor impulso fue gracias a la industria relacionado a pesca (harina, aceite y conserva de pescado), la cual creció $80 \%$. Menores pedidos de exportación en sectores como textil y metalmecánica, la reducción de la demanda interna y la desaceleración del sector construcción explican el pobre desarrollo de el sector manufactura en el 2016. Las exportaciones no tradicionales durante el año pasado cayeron según se detalla: textiles $(-10 \%)$, madera y papel $(-8,9 \%)$, productos químicos (4,9\%), minerales no metálicos (-8,3\%), metalmecánicas (-15,8\%). (Diario El Comercio, 2017) 


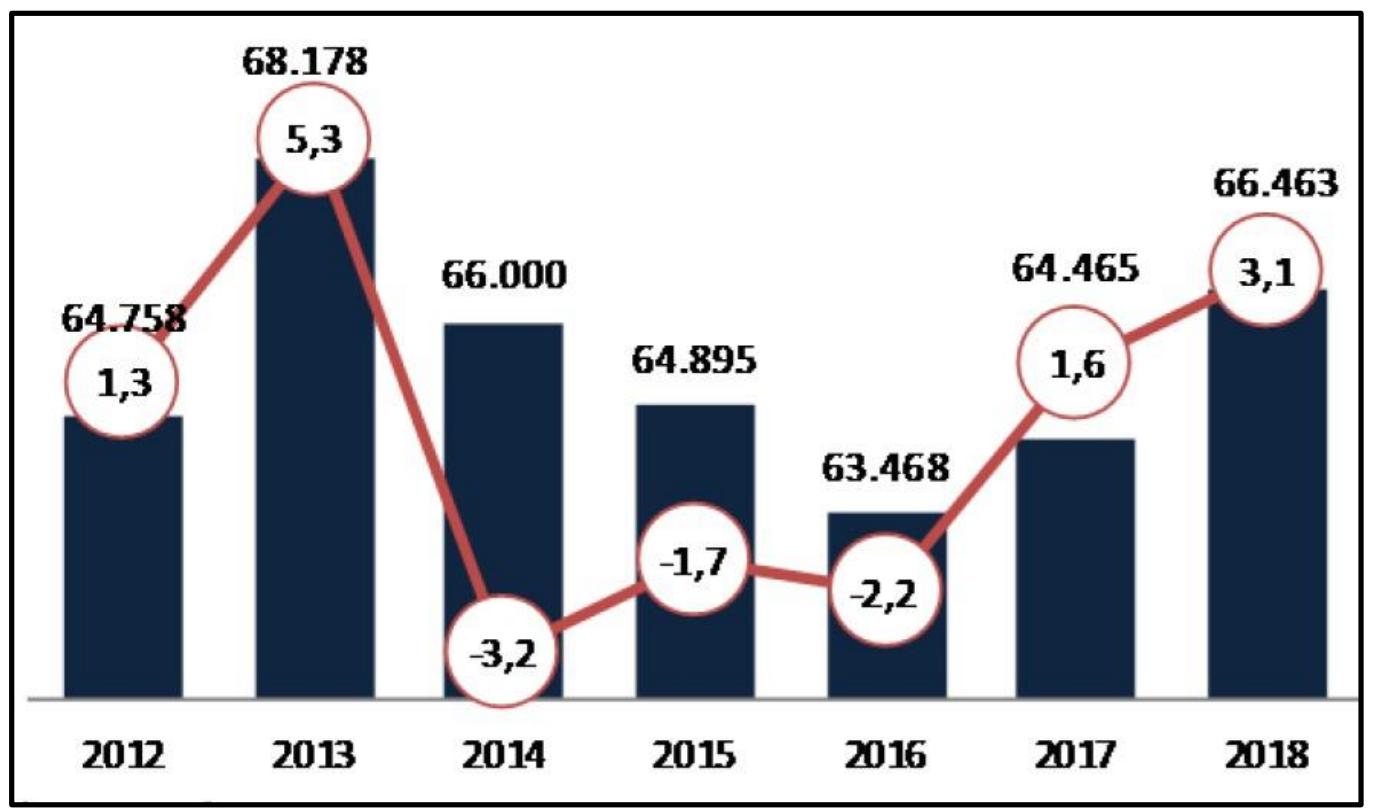

Figura 47. Producción Manufacturera (millones de S/). Tomado de Maximixe. Recuperado de Reporte Perú Proyecciones 2016-2018.

Por el lado de la manufactura no primaria se espera una recuperación en la producción de bienes de consumo (1,5\%), estimulado por la recuperación del consumo privado $(3,5 \%)$, el incremento en el nivel de confianza del consumidor y en menor medida de la recuperación de la demanda externa. De la misma manera, los bienes intermedios $(1,9 \%)$ y de capital $(0,9 \%)$ también impulsarán la reactivación de la manufactura no primaria, dado que la producción de este tipo de bienes depende de la inversión privada, principalmente, la cual se espera que se recupere en el 2017 (alrededor de 3\%). (Maximixe, 2016)

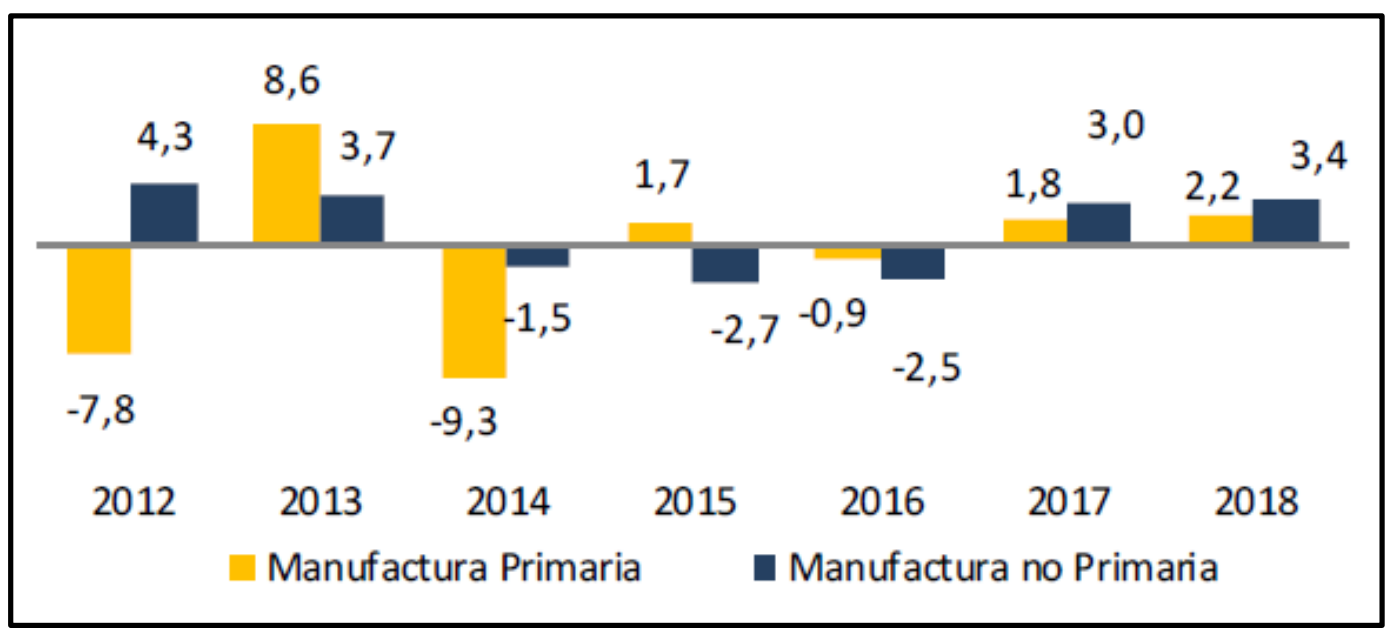

Figura 48. Manufactura primaria y no primaria (variación \%). Tomado de Maximixe. Recuperado de Reporte Perú Proyecciones 2016-2018. 


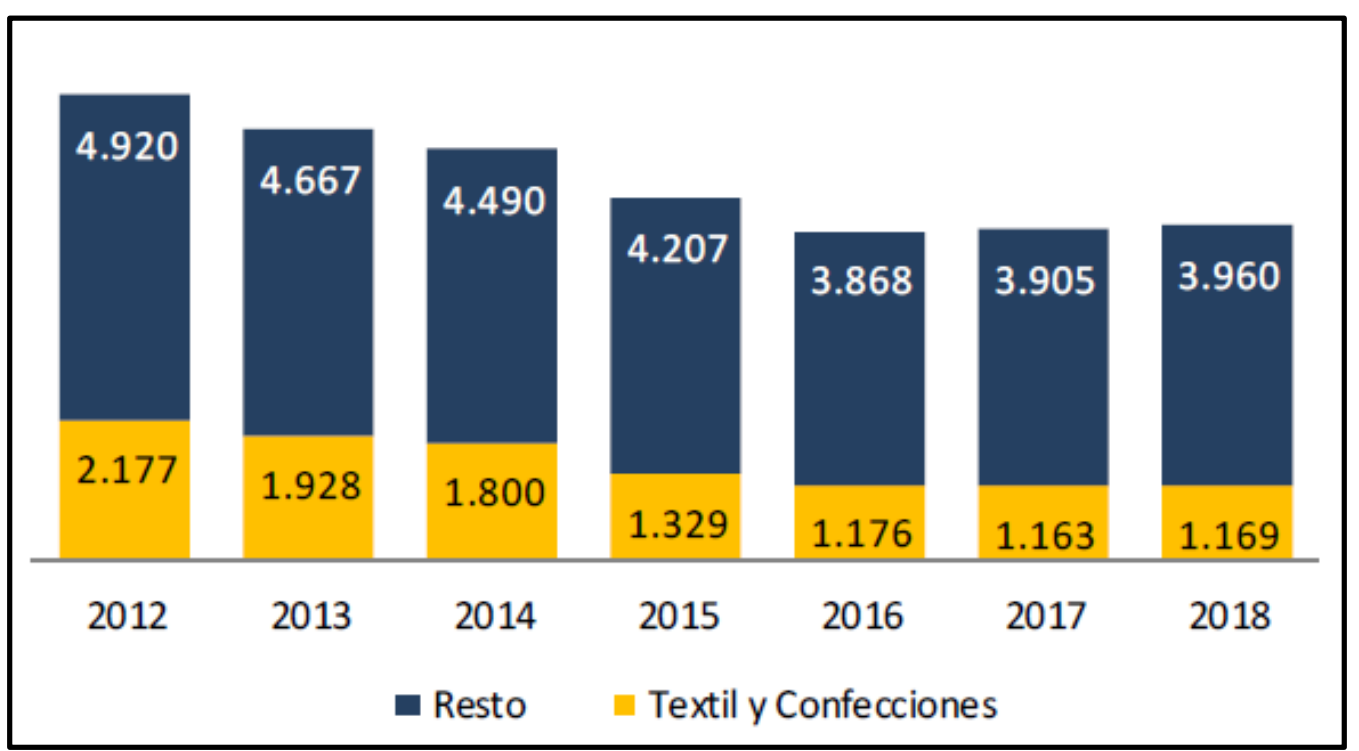

Figura 49. Exportaciones manufactureras (millones de US\$). Tomado de Maximixe. Recuperado de Reporte Perú Proyecciones 2016-2018.

\section{Sector Agropecuario}

En el 2017 el sector agropecuario registraría un crecimiento de 2,9\% anual, a consecuencia de la mayor producción pecuaria $(3,8 \%)$ y agrícola $(3,1 \%)$. Respecto a la actividad agrícola, se espera su recuperación tras la ejecución de programas como Sierra Azul, Serviagro, Agrojoven, programa de semillas mejoradas; y la ampliación de proyectos de irrigación como Majes Siguas II, Chavimochic III, entre otros.

Las exportaciones agropecuarias registrarían un incremento de 1,8\% anual en el 2017 hasta alcanzar los US\$ 5.262 millones, impulsadas por los mayores envíos de productos tradicionales como café, cacao y algodón; y no tradicionales como alcachofa, mandarina, mango, y arándanos, debido a la mayor apertura de mercados como el Reino Unido, Honduras, y los mercados asiáticos que son los más atractivos para la entrada de productos frutícolas. (Maximixe, 2016) 


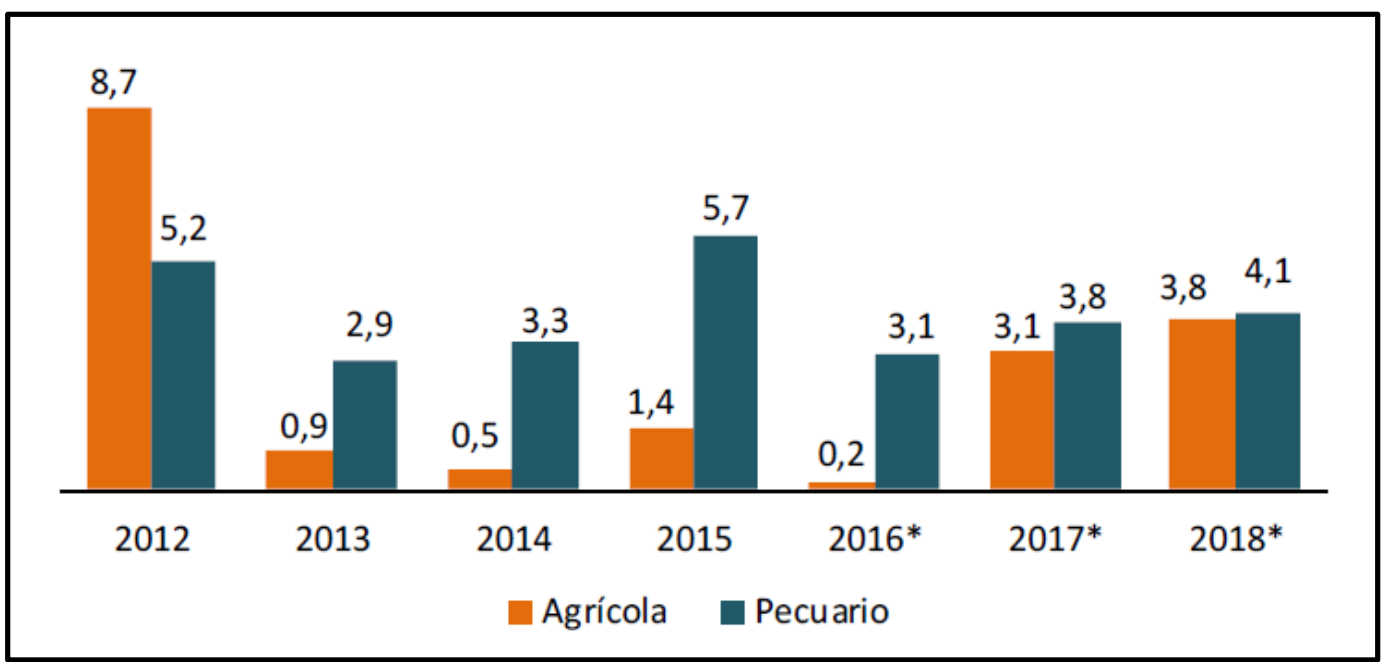

Figura 50. Producción agropecuaria 2012-2018 (variación \%). Tomado de Maximixe. Recuperado de Reporte Perú Proyecciones 2016-2018.

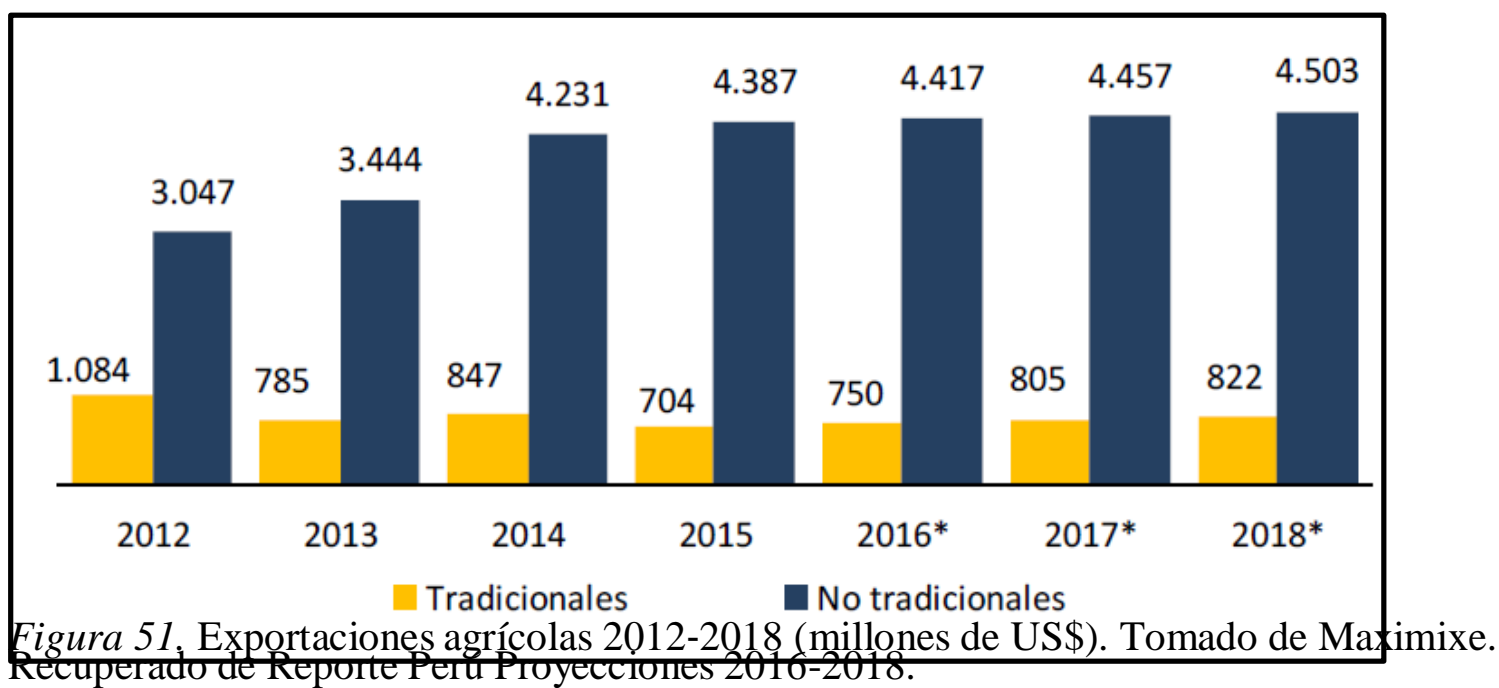

\section{Sector Construcción}

En el 2017 el sector construcción crecerá alrededor de 3,3\% luego de dos años consecutivos de retrocesos (2015 y 2016), debido al impulso de la demanda de cemento en el mercado nacional (1,9\%), gracias al destrabe de megaproyectos tales como la Línea 2 del Metro de Lima y la continuación de la Modernización de la Refinería de Talara. Así mismo, el destrabe de un conjunto de proyectos de inversión pública que impulsarán el avance físico de obras (4,5\%), tales como, la Red Vial 6 (Chincha - Ica), Modernización del Terminal Portuario General de San Martín de Pisco, Autopista del Sol (Trujillo - Sullana), Ampliación 
del Aeropuerto Internacional Jorge Chávez y la Pavimentación de la Red Vial Nacional y las obras para los Juegos Panamericanos 2019. Así mismo, se espera que las obras por impuestos sigan creciendo con mayor fuerza para el 2017 en las regiones del país. (Maximixe, 2016)

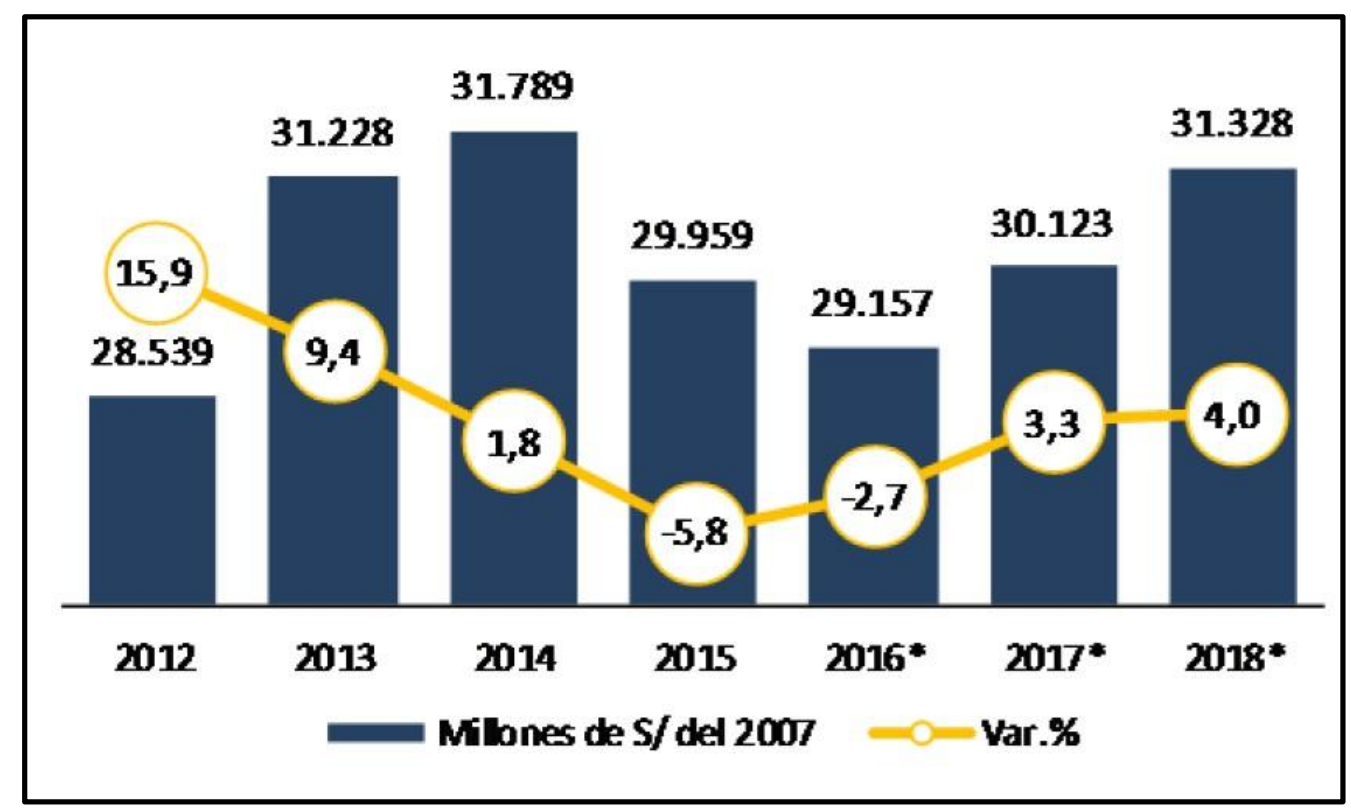

Figura 52. Producción del sector construcción (millones de S/). Tomado de Maximixe. Recuperado de Reporte Perú Proyecciones 2016-2018.

Perspectivas de la demanda de cartón corrugado en el Perú

La figura 49 muestra la división de las empresas que operan dentro de la industria papelera según línea de producto. 


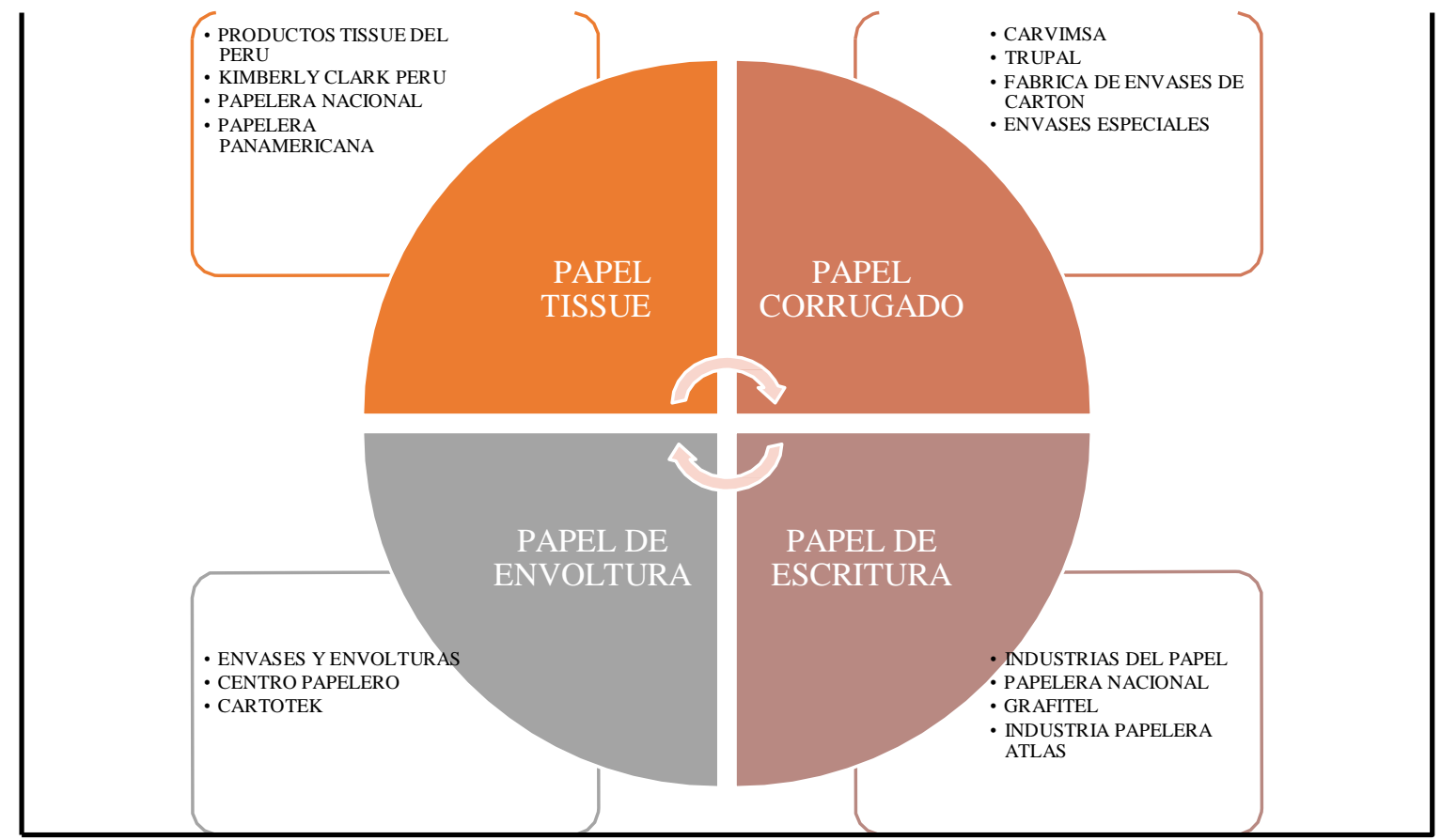

Figura 53. Empresas Productoras de Papel Según Línea de Producto. Tomado de Maximixe. Adaptado de Estudio de Precios de Transferencia por el ejercicio cerrado el 31 de diciembre de 2015, CARVIMSA.

En el ejercicio 2015, diversas empresas compitieron dentro de la industria de papel y productos, siendo importante mencionar que en el sector de envases de cartón operaron siete empresas entre los cuales se encontraron: Trupal S.A., CMPC (grupo Matte), Kimberly Clark, Cartones Villa Marina S.A. (Grupo Comeca) y Envases Especiales.

La producción de papel y cartón corrugado y de envases de papel y cartón registró un crecimiento anual de $7.7 \%$ en el período 2001 - 2013 medido a través del índice de volumen físico. En el caso particular del cartón corrugado, el crecimiento promedio anual de este fue de $11.1 \%$, pasando de 5,700 TM en 2001 a 25,200 TM en 2013. Asimismo, la producción de cartón corrugado registró un incremento de $11.2 \%$ en 2013 con respecto al año anterior al alcanzar un total de 25,235 TM. En este mismo período, se importó papel y cartón corrugado por un total de US\$1,5 millones, en tanto la importación de cajas de papel o cartón corrugado sumaron un total de US\$ 8,9 millones. 
En 2014, el rubro 1702 de la Clasificación Industrial Internacional Uniforme (CIIU), dentro del cual se encuentra la fabricación de papel y cartón corrugado, avanzó en $5.30 \%$ con respecto al 2013 debido a la menor actividad presentada en los sectores construcción, comercio, minero, pesquero y servicios, los cuales demandan productos manufacturados por la industria de papel y cartón corrugado. No obstante, el aumento de los envíos de cultivos agrícolas realizados por el sector agroexportador habría aportado de forma positiva mediante la demanda de cajas de cartón, necesarias para los despachos al exterior.

En este sentido, el desarrollo del sector manufactura estuvo impulsado por el sector fabril primario pese a que sector no primario cayó en $2.6 \%$ debido la menor demanda proveniente tanto de bienes destinados a inversión como la demanda de los socios comerciales de América Latina.

Al fin del año 2015 y a inicios del año 2016, el índice de precios de los principales bienes de consumo se mantiene en un crecimiento constante mensualmente. A continuación, se presenta la evolución de los índices de precios al por mayor de papel y productos de papel:

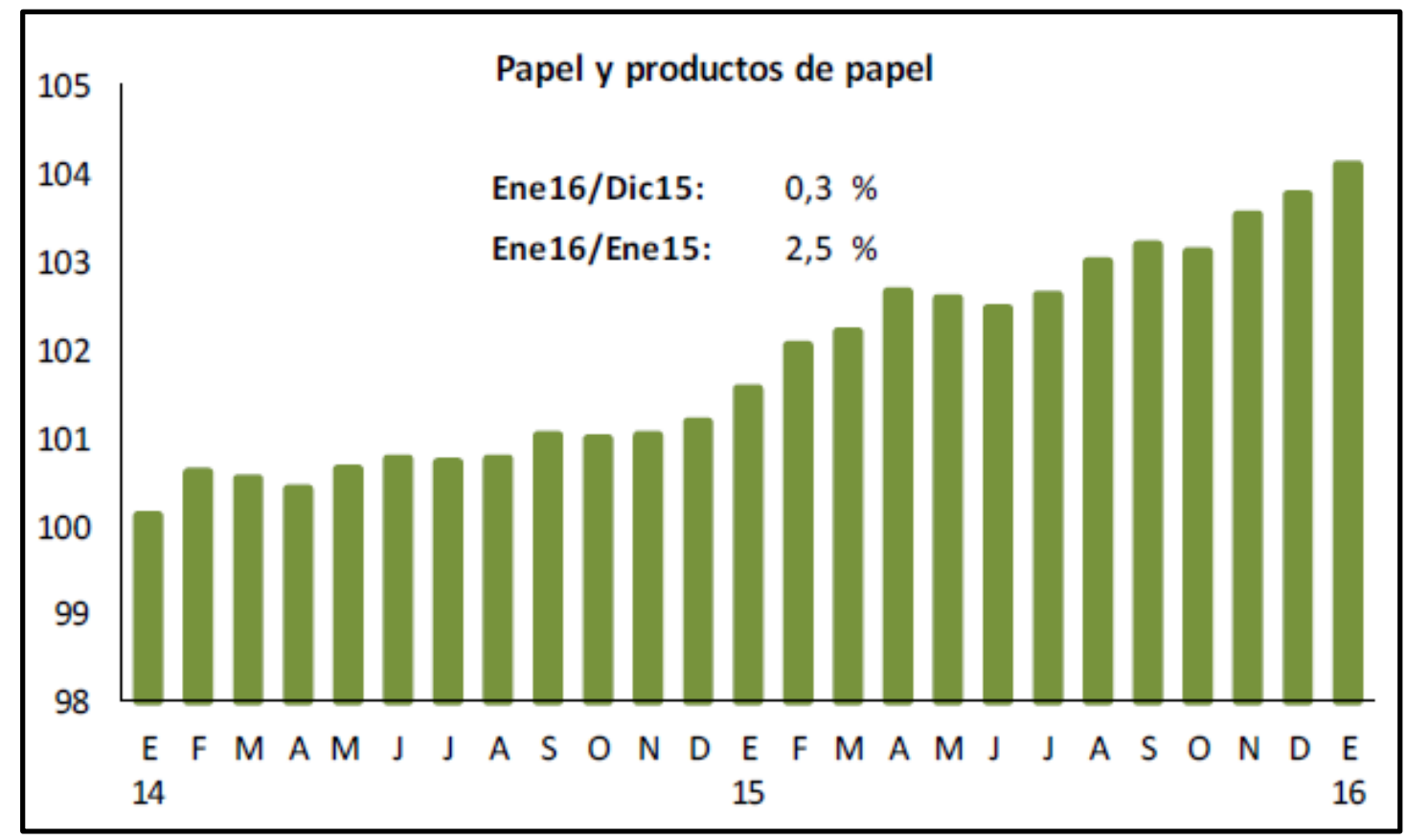

Figura 54. Evolución de los índices de precios al por mayor de papel y productos de papel. Tomado de Maximixe. Recuperado de Estudio de Precios de Transferencia por el ejercicio cerrado el 31 de diciembre de 2015, CARVIMSA. 
Asimismo, el bajo precio de las materias primas y la debilidad del sector manufacturero en China reflejó el descenso de los metales básicos al exterior, así como menores envíos de los principales productos manufactureros como, textiles y químicos. Es así como los envíos del sector cerraron con US\$5.490 millones, equivalente a una caída de 12,5\% anual. Con estos resultados las exportaciones manufactureras en diciembre fueron de US\$ 441 millones (15,1\% interanual).

Por otro lado, cabe mencionar el decrecimiento en $15.6 \%$ de las exportaciones de madera, papeles y manufacturas, donde la caída más representativa de $17.2 \%$ es la exportación de manufactura de papel y cartón de US\$ 174 millones en el 2014 a US\$ 144 en el 2015.

Dentro de las ramas que registraron menor producción, la pulpa, papel y cartón se redujo en un $12.7 \% 25$. Además, cabe resaltar que dentro del sector fabril no primario dentro de la subcategoría bienes de consumo, la manufactura de otros artículos de papel y cartón varió de manera positiva en 13.40\%. (Estudio de Precios de Transferencia CARVIMSA, 2015).

\section{Exportaciones}

La balanza comercial de febrero del 2017 registró un superávit de US\$ 741 millones, con lo que se mantuvo por octavo mes consecutivo el comportamiento positivo observado desde julio de 2016. Esta mejora de US\$ 872 millones frente al déficit de febrero de 2016 se explicó principalmente por el mayor volumen exportado $(21,7 \%)$ y el aumento de los precios promedio de las exportaciones $(19,8 \%)$.

Las exportaciones ascendieron a US\$ 3583 millones (45,8\% de incremento) respecto a febrero de 2016 , por mayores ventas de productos tradicionales (66,5\% de aumento), principalmente cobre, oro, zinc, derivados de petróleo, harina de pescado y gas natural. Por 
su parte, las exportaciones de productos no tradicionales ascendieron a US\$ 808 millones, lo que implicó una expansión anual de $2,1 \%$, por mayores envíos de productos pesqueros (pota congelada y en conserva) y siderometalúrgicos (productos de zinc). Las importaciones se incrementaron US\$ 254 millones $(9,8 \%)$, por mayores compras de insumos. (Banco Central de Reserva del Perú, 2017).

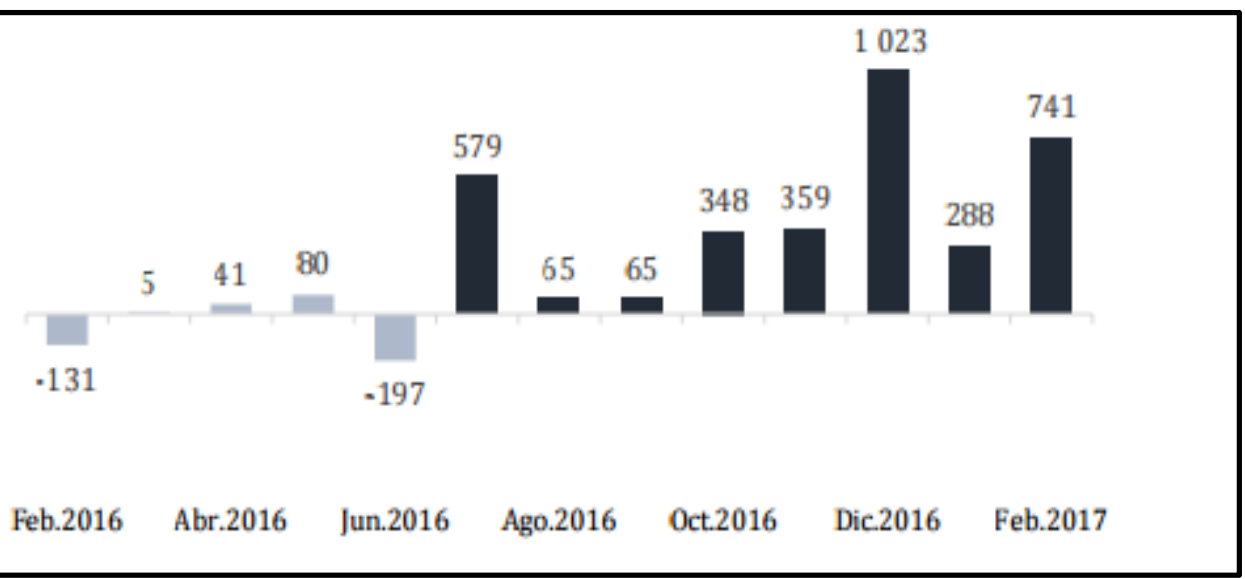

Figura 55. Superávit y/o Déficit de la Balanza Comercial expresado en Millones de Dólares febrero 2016-febrero 2017. Tomado de Resumen Informativo Semanal N ${ }^{\circ} 14$ del Banco Central de Reserva del Perú. Recuperado de www.bcrp.gob.pe

\begin{tabular}{|lrrrr|}
\hline & Feb.2016 & Feb.2017 & Dif. & Var. \% \\
\hline 1. Exportaciones & $\mathbf{2 4 5 8}$ & $\mathbf{3 5 8 3}$ & $\mathbf{1 1 2 5}$ & $\mathbf{4 5 , 8}$ \\
\hline Productos tradicionales & 1661 & $2 \mathbf{7 6 5}$ & 1104 & $\mathbf{6 6 , 5}$ \\
Productos no tradicionales & $\mathbf{7 9 1}$ & $\mathbf{8 0 8}$ & 17 & 2,1 \\
Otros & 6 & 11 & 5 & $\mathbf{8 0 , 1}$ \\
\hline 2. Importaciones & $\mathbf{2 5 8 8}$ & $\mathbf{2 8 4 2}$ & $\mathbf{2 5 4}$ & $\mathbf{9 , 8}$ \\
\hline Bienes de consumo & 663 & 661 & -2 & $-0,2$ \\
Insumos & 1076 & 1394 & 318 & 29,5 \\
Bienes de capital & 841 & $\mathbf{7 8 2}$ & $\mathbf{- 5 9}$ & $\mathbf{- 7 , 0}$ \\
Otros bienes & 8 & 5 & $\mathbf{- 3}$ & $\mathbf{- 3 7 , 2}$ \\
\hline 3. BALANZA comerCIAL & $\mathbf{- 1 3 1}$ & $\mathbf{7 4 1}$ & $\mathbf{8 7 1}$ & \\
\hline
\end{tabular}

Figura 56. Exportaciones e Importaciones, variación porcentual expresado en Millones de Dólares febrero 2016-febrero 2017. Tomado de Resumen Informativo Semanal N 14 del Banco Central de Reserva del Perú. Recuperado de www.bcrp.gob.pe

Por su parte, las exportaciones de papel y cartón alcanzaron un total de US\$ 64,473 miles, lo que representó una reducción de $30.43 \%$ respecto al valor FOB exportado en el 
ejercicio anterior. Ello es explicado por las caídas de exportaciones a Venezuela, Ecuador y Chile por $97.01 \%, 47.92 \%$ y $14.96 \%$, respectivamente. (Estudio de Precios de Transferencia CARVIMSA, 2015).

A continuación, se observa el comportamiento de las exportaciones de papel y cartón en el periodo 2011-2015:

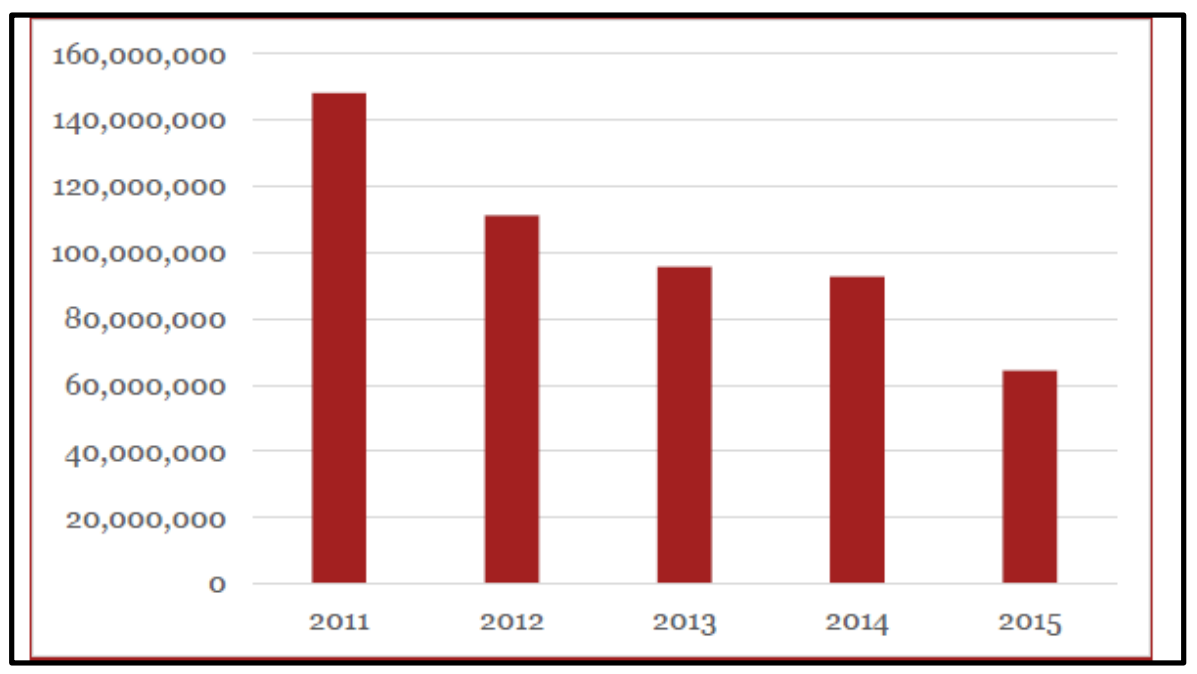

Figura 57. Exportación de maderas, papeles, y manufacturas (millones de US\$ a diciembre 2015). Tomado de Comex. Recuperado de Estudio de Precios de Transferencia por el ejercicio cerrado el 31 de diciembre de 2015, CARVIMSA.

A continuación, se muestra el detalle de las exportaciones de papel y cartón por país de origen en el periodo 2011-2015:

\begin{tabular}{|c|c|c|c|c|c|c|}
\hline País Importador & 2011 & 2012 & 2013 & 2014 & 2015 & Variación 14/15 \\
\hline Chile & 39,777 & 33,038 & 31,813 & 29,426 & 25,023 & $-14.96 \%$ \\
\hline Ecuador & $34,3^{81}$ & 23,686 & 24,886 & 22,310 & 11,620 & $-47.92 \%$ \\
\hline Bolivia & 19,729 & 17,805 & 14,776 & 16,212 & 14,307 & $-11.75 \%$ \\
\hline Venezuela & 23,190 & 10,891 & 6,122 & 11,107 & 332 & $-97.01 \%$ \\
\hline Colombia & 13,910 & 9,802 & 8,795 & 6,388 & $4,73^{8}$ & $-25.83 \%$ \\
\hline Panamá & 1,549 & 1,901 & 1,329 & 1,652 & 1,394 & $-15.62 \%$ \\
\hline Guatemala & 1,971 & 4,263 & 81 & $5^{84}$ & 472 & $-19.16 \%$ \\
\hline Nicaragua & 1,689 & 1,742 & 1,578 & 1,012 & 1,290 & $27.47 \%$ \\
\hline Argentina & 3,105 & 646 & 707 & 731 & 459 & $-37.22 \%$ \\
\hline Honduras & 1,691 & 955 & 1,357 & 491 & 582 & $18.57 \%$ \\
\hline Otros & 7,207 & 6,509 & 4,257 & 2,767 & 4,255 & $53.78 \%$ \\
\hline Total & 148,199 & 111,238 & 95,702 & 92,680 & 64,473 & $-30.43 \%$ \\
\hline
\end{tabular}

Figura 58. Exportación de Papel y Cartón; Manufacturas de Pasta de Celulosa por País: Valor FOB (Miles de US\$). Tomado de Comex. Recuperado de Estudio de Precios de Transferencia por el ejercicio cerrado el 31 de diciembre de 2015, CARVIMSA. 


\section{Importaciones}

Las importaciones de papel y cartón corrugado se han reducido en el último ejercicio, registrando un valor de importación FOB total de US\$ 522,282 miles, lo que representó una reducción de $19.21 \%$ respecto al ejercicio anterior, explicado en su mayoría por la caída de importaciones de papel y cartón de Estados Unidos, Chile y Canadá en 21.93\%, 26.05\% y 39.40\%\%, respectivamente. (Estudio de Precios de Transferencia CARVIMSA, 2015).

A continuación, se observa el comportamiento de las importaciones de papel y cartón en el periodo 2011- 2015:

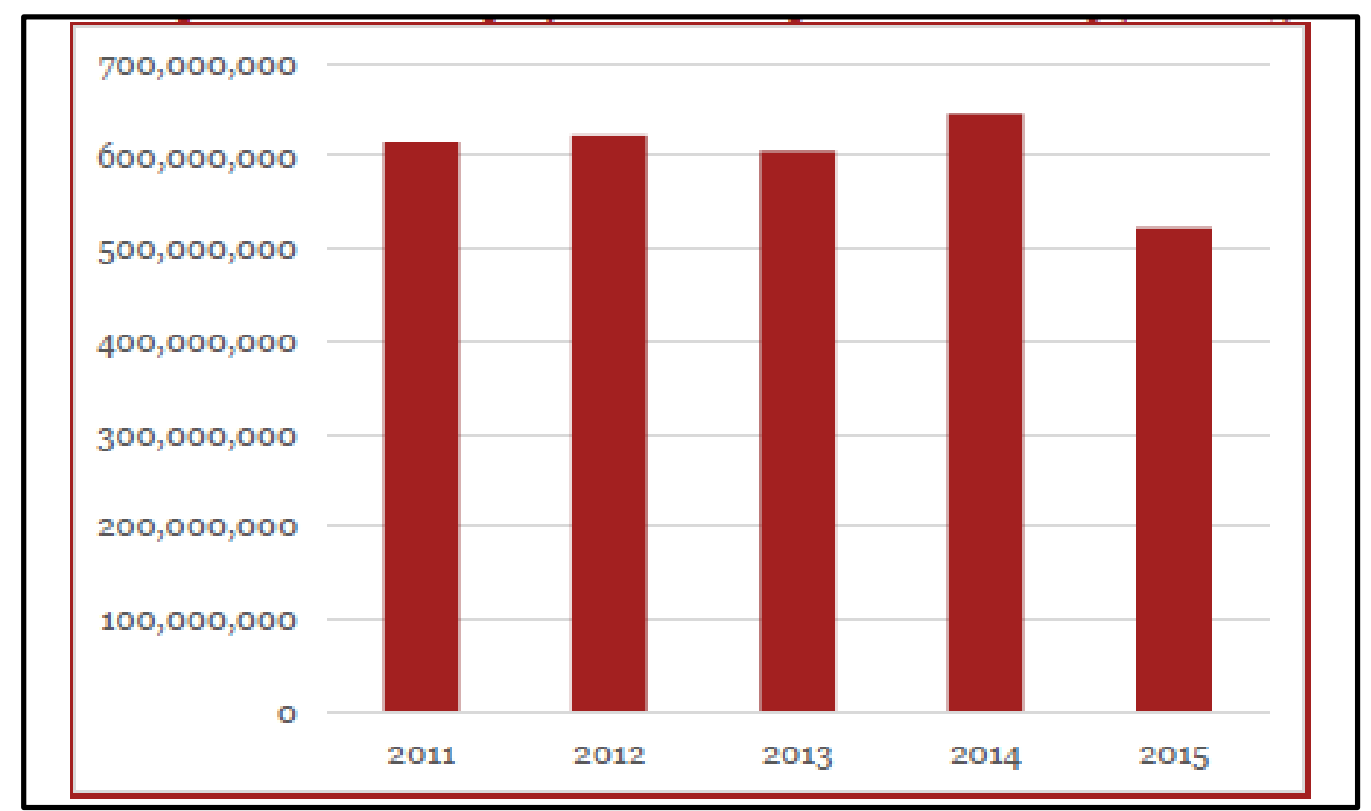

Figura 59. Importaciones de Papel y Cartón en el periodo 2011-2015 (FOB US\$). Tomado de Comex. Recuperado de Estudio de Precios de Transferencia por el ejercicio cerrado el 31 de diciembre de 2015, CARVIMSA.

A continuación, se muestra el detalle de las importaciones de papel y cartón por país de origen en el periodo 2011-2015 (valor FOB): 


\begin{tabular}{|c|c|c|c|c|c|c|}
\hline País Exportador & 2011 & 2012 & 2013 & 2014 & 2015 & Variación 14/15 \\
\hline Estados Unidos & 136,572 & 147,985 & 151,586 & 177,209 & 138,350 & $-21.93 \%$ \\
\hline Chile & 96,720 & 106,971 & 105,479 & 90,472 & 66,900 & $-26.05 \%$ \\
\hline Colombia & 97,877 & 58,184 & 52,285 & 41,047 & 31,967 & $-22.12 \%$ \\
\hline Brasil & 39,973 & 42,429 & 44,881 & 46,323 & 37,024 & $-20.07 \%$ \\
\hline Suiza & 32,422 & 33,009 & 31,707 & 37,332 & 30,994 & $-16.98 \%$ \\
\hline Hong Kong & 21,984 & $29,3^{11}$ & 30,704 & 37,083 & 26,021 & $-29.83 \%$ \\
\hline Finlandia & 30,486 & 32,229 & 25,223 & 26,124 & 25,944 & $-0.69 \%$ \\
\hline Canadá & 19,151 & 21,459 & 22,487 & 35,052 & 21,243 & $-39.40 \%$ \\
\hline Austria & 4,935 & $8,43^{8}$ & 22,673 & 36,803 & 25,024 & $-32.01 \%$ \\
\hline Suecia & 15,391 & 19,318 & 17,207 & 22,257 & 17,777 & $-20.13 \%$ \\
\hline Otros & 119,873 & 123,432 & 100,424 & 96,788 & 101,038 & $4.39 \%$ \\
\hline Total & 615,385 & 622,765 & 604,656 & 646,490 & 522,282 & $-19.21 \%$ \\
\hline
\end{tabular}

Figura 60. Importación de Papel y Cartón; Manufacturas de Pasta de Celulosa por País: Valor FOB (Miles de US\$). Tomado de Comex. Recuperado de Estudio de Precios de Transferencia por el ejercicio cerrado el 31 de diciembre de 2015, CARVIMSA.

\section{Inflación}

En marzo, las expectativas de inflación para 2017 fluctuaron entre 3,0 y 3,2 \%, mientras que para 2018 se ubicaron entre 2,7 y 3,0 \%, dentro del rango meta. (Banco Central de Reserva del Perú, 2017).

\begin{tabular}{|lccc|}
\hline \multicolumn{3}{c}{ Encuesta realizada al: } \\
& 30 Ene.2017 & 27 Feb.2017 & 31 Mar.2017 \\
\hline Analistas Económicos 1/ & & & \\
\hline 2017 & 2,9 & 2,9 & 3,0 \\
2018 & 2,5 & 2,7 & 2,7 \\
2019 & & 2,5 & 2,5 \\
\hline Sistema Financiero 2/ & & 3,0 & 3,1 \\
\hline 2017 & 3,0 & 2,9 & 3,0 \\
2018 & 2,9 & 2,8 & 2,8 \\
\hline 2019 & & & 3,2 \\
Empresas No financieras 3/ & 3,0 & 3,0 & 3,0 \\
\hline 2017 & 3,0 & 3,0 & 3,0 \\
\hline 2018 & & 3,0 & \\
\hline
\end{tabular}

Figura 61. Encuesta de Expectativas Macroeconómicas: Inflación (\%). Tomado de Resumen Informativo Semanal N 14 del Banco Central de Reserva del Perú. Recuperado de www.bcrp.gob.pe 


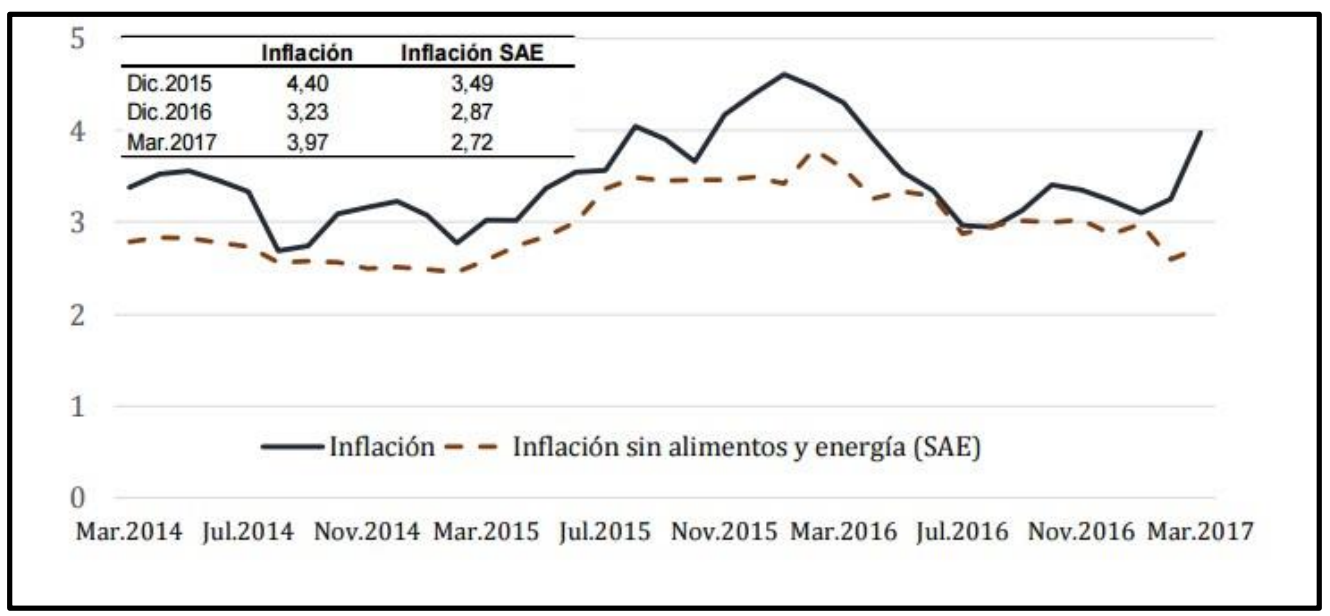

Figura 62. Inflación: Variación \% marzo 2014-marzo 2017. Tomado de Resumen Informativo Semanal N 14 del Banco Central de Reserva del Perú. Recuperado de www.bcrp.gob.pe

\section{Tipo de cambio}

Las expectativas de tipo de cambio para 2017 fluctuaron en un rango de entre S/ 3,35 y S/ 3,40 por dólar y para 2018 se ubicaron en un rango entre S/ 3,40 y S/ 3,47 por dólar. El 5 de abril del 2017, el tipo de cambio venta interbancario cerró en S/ 3,25 por dólar, acumulando una disminución de 3,2 \% con respecto al cierre de diciembre de 2016 y no registra variación en comparación a fines de marzo. (Banco Central de Reserva del Perú, 2017).

\begin{tabular}{|c|c|c|c|}
\hline \multicolumn{4}{|c|}{$\begin{array}{l}\text { Encuesta de Expectativas Macroeconómicas: Tipo de Cambio } \\
\text { (S/ por US\$)* }\end{array}$} \\
\hline & \multicolumn{3}{|c|}{ Encuesta realizada al: } \\
\hline & 30 Ene.2017 & 27 Feb.2017 & 31 Mar.2017 \\
\hline \multicolumn{4}{|c|}{ Analistas Económicos 1/ } \\
\hline 2017 & 3,43 & 3,41 & 3,38 \\
\hline 2018 & 3,48 & 3,45 & 3,45 \\
\hline 2019 & & 3,44 & 3,45 \\
\hline \multicolumn{4}{|c|}{ Sistema Financiero 2/ } \\
\hline 2017 & 3,42 & 3,37 & 3,35 \\
\hline 2018 & 3,47 & 3,40 & 3,40 \\
\hline 2019 & & 3,42 & 3,45 \\
\hline \multicolumn{4}{|c|}{ Empresas No financieras $3 /$} \\
\hline 2017 & 3,47 & 3,40 & 3,40 \\
\hline 2018 & 3,50 & 3,50 & 3,47 \\
\hline 2019 & & 3,50 & 3,50 \\
\hline \multicolumn{4}{|c|}{$\begin{array}{l}1 / 16 \text { analistas en enero, } 16 \text { en febrero y } 17 \text { en marzo de } 2017 . \\
2 / 19 \text { empresas financieras en enero, } 19 \text { en febrero y } 20 \text { en marzo de } 2017 . \\
3 / 371 \text { empresas no financieras en enero, } 328 \text { en febrero y } 335 \text { en marzo de } 2017 . \\
\text { * Tipo de cambio al cierre del año. }\end{array}$} \\
\hline
\end{tabular}

Figura 63. Encuesta de Expectativas Macroeconómicas: Tipo de Cambio (S/ por US\$). Tomado de Resumen Informativo Semanal N 14 del Banco Central de Reserva del Perú. Recuperado de www.bcrp.gob.pe 


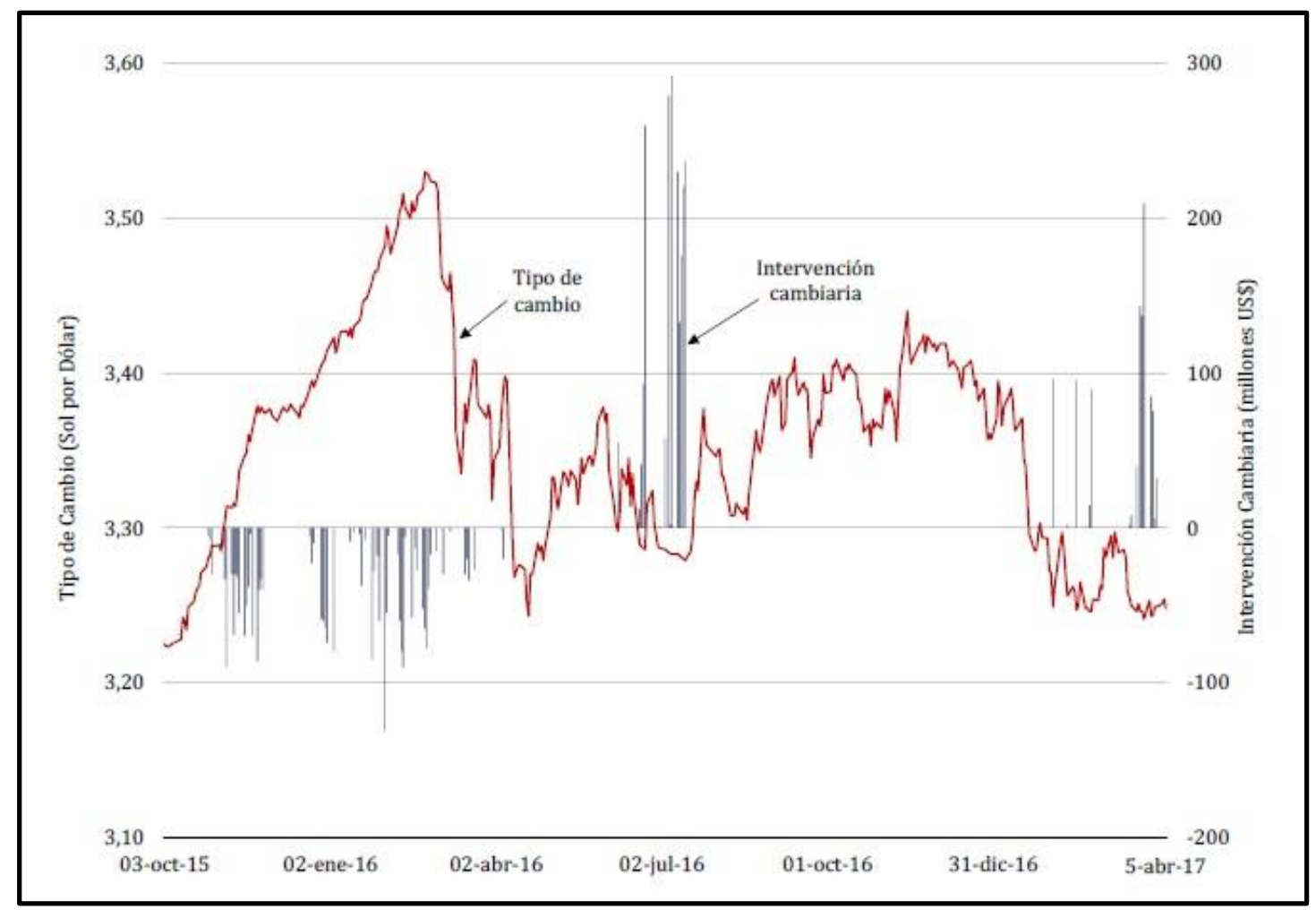

Figura 64. Tipo de cambio e intervención cambiaria del BCRP en el mercado spot. Tomado de Resumen Informativo Semanal N ${ }^{\circ} 14$ del Banco Central de Reserva del Perú. Recuperado de www.bcrp.gob.pe

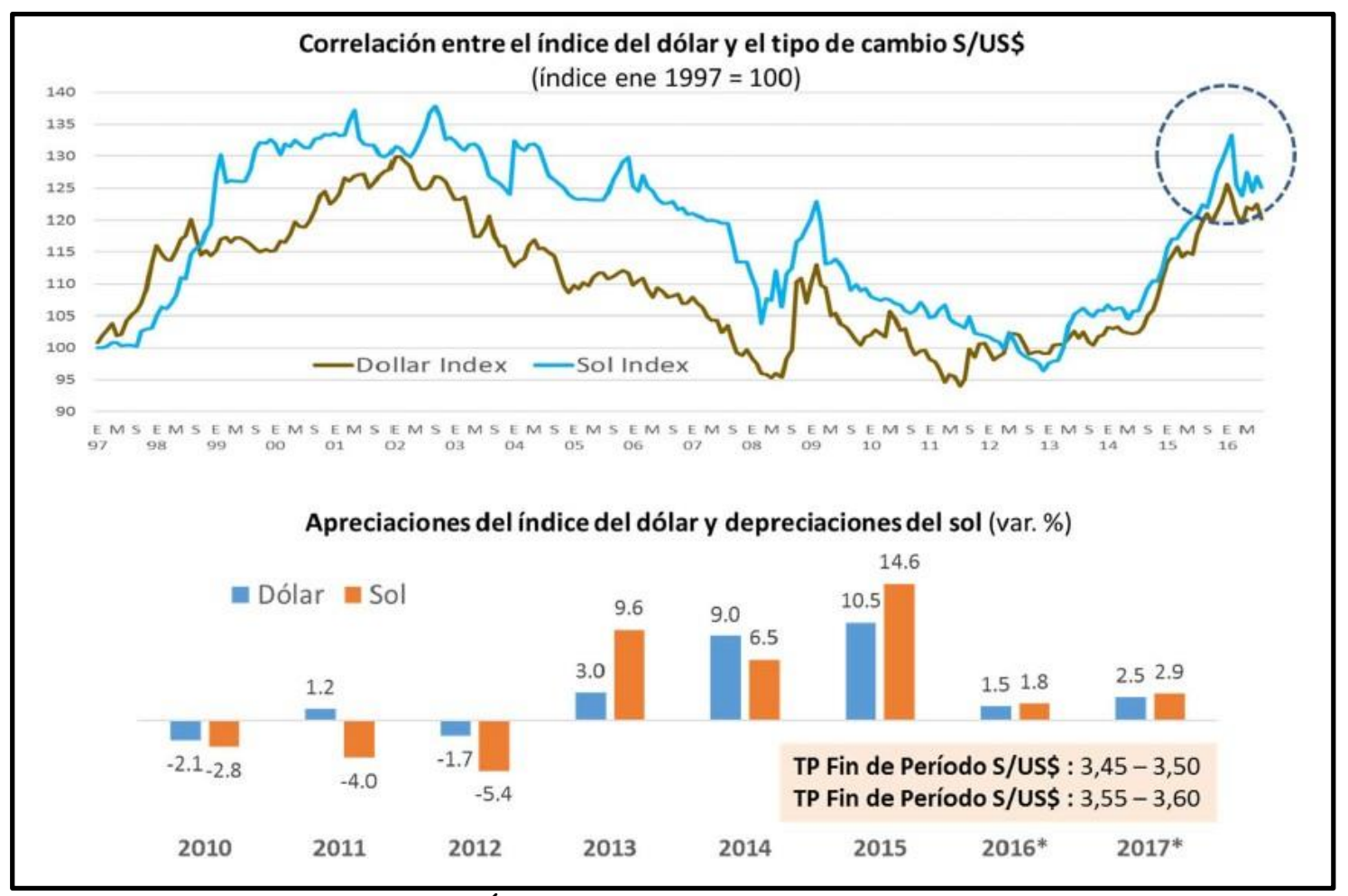

Figura 65. Correlación entre el Índice del dólar y el tipo de cambio S/US\$. Tomado de Maximixe. Recuperado de Reporte Perú Proyecciones 2016-2018. 
Respecto al PBI para el año 2019, las proyecciones son de $4.30 \%$, porcentaje incluso superior al de los últimos cinco años, lo cual tiene un impacto positivo para la industria en general. Los sectores manufactura, agropecuario, textil y construcción mostrarán crecimiento lo cual favorecerá al entorno comercial de Carvimsa. El porcentaje estimado de la inflación para el año 2019 es de $2.40 \%$ lo cual es relativamente bajo. Cabe señalar, que se proyecta para el 2019 un tipo de cambio de 3.43, éste está contemplado dentro de los parámetros de proyección internos de Carvimsa cuyos rangos son 3.40 y 3.47 para el pago de su deuda en dólares proveniente de las importaciones. Por otro lado, el índice de facilidad para hacer negocios, indicador del Banco Mundial, posiciona al Perú con un 82.44, solo detrás de Chile, México y Colombia. Todos estos aspectos proyectan un impacto positivo para Carvimsa dentro de los próximos años.

\subsubsection{Análisis legal.}

\section{La Ley General del Ambiente $N^{\circ} 28611$}

Esta ley es la norma ordenadora del marco normativo legal para la gestión ambiental en el Perú. Establece los principios y normas básicas para asegurar el efectivo ejercicio del derecho a un ambiente saludable, equilibrado y adecuado para el pleno desarrollo de la vida, así como el cumplimiento del deber de contribuir a una efectiva gestión ambiental y de proteger el ambiente, así como sus componentes, con el objetivo de mejorar la calidad de vida de la población y lograr el desarrollo sostenible del país. Organismo de Evaluación y Fiscalización Ambiental (OEFA) encargado de la fiscalización, la supervisión, el control y la sanción en materia ambiental que corresponde. (Ministerio del Ambiente, 2005) 


\section{Reglamento de Gestión Ambiental para la Industria Manufacturera y el Comercio Interno}

A través de este reglamento publicado en el 2015 durante el gobierno de Ollanta Humala, mediante Decreto Supremo Nº 017-2015, el Ministerio de Producción aprobó el Plan Nacional Ambiental del Sector Industrial Manufacturero, cuya finalidad es establecer una estrategia nacional para el desarrollo sostenible de las actividades industriales manufactureras, que permita que la competitividad, la innovación tecnológica y la política ambiental estén debidamente articuladas e involucren la participación concertada y equitativa tanto del sector público como privado. Debido a la diversidad y complejidad de la industria manufacturera, se hace necesario crear nuevos instrumentos ambientales para la evaluación del impacto ambiental complementarios al Sistema de Evaluación de Impacto Ambiental (SEIA). (PRODUCE, 2015)

\section{La Ley de Seguridad y Salud en el Trabajo $N^{\circ} 29783$}

Esta ley publicada el 19 de agosto del 2011, tiene por objetivo promover una cultura de prevención de riesgos laborales, a partir del trabajo conjunto entre empleadores, sindicatos y el Estado. Cabe precisar que la normativa está ideada para establecer las normas mínimas para la prevención de los riesgos laborales. Esto faculta a los empleadores y trabajadores a optar libremente por niveles de protección que mejoren lo previsto en la norma según las particularidades de la actividad empresarial. (Superintendencia Nacional de Fiscalización Laboral, 2018)

El impacto de esta ley es positivo ya que de cumplirse en su totalidad otorga a Carvimsa el estándar mínimo en lo referente a la gestión de Seguridad y Salud en el Trabajo generando la oportunidad de llevar consigo una de las mejores prácticas del mundo, como 
parte de su cultura corporativa, de tal forma que se pueda proyectar hacia el futuro una visión de “cero daños", enfoque practicado por las compañías exitosas.

\subsubsection{Análisis cultural.}

\section{Cultura de Reciclaje de Cartón}

La cultura de reciclaje de cartón en el Perú presenta una tendencia de crecimiento en los siguientes años. Actualmente en el Perú se reciclan 1,500 toneladas de residuos de envases de cartón anuales, cifra que podría duplicarse hasta llegar a un $25 \%$ de residuos si se generaliza la implementación del programa de segregación en la fuente y recolección selectiva de residuos sólidos. (Diario Gestión, 2017)

Un consumidor que tiene una apreciación muy clara del producto o empresa que le está sirviendo es un consumidor que genera una lealtad, algo más importante que alguien que incluso compra a pesar de. Aquí es importante mencionar que la industria cartonera a la cual pertenece Carvimsa presenta un producto verde y eco amigable. Pero no solo eso, sino que también la empresa se inserta en la sociedad para colaborar e introducir elementos de eficiencia ambiental.

\section{Cultura de Consumo de Frutas y Verduras}

Los peruanos presentan un consumo deficiente de frutas y verduras, en promedio el consumo es de 3 a 4 porciones de frutas y verduras por semana, cuando la ingesta de este grupo de alimentos esenciales debería de ser 3 porciones de frutas y 2 de verduras diarias garantizando así un adecuado consumo de fibra alimentaria. Aproximadamente solo el $9.3 \%$ de la población peruana cumple con las recomendaciones de la Organización Mundial de la Salud. (Diario La República, 2018). 
La Estrategia mundial de la Organización Mundial de la Salud (OMS) sobre el régimen alimentario, actividad física y salud hace hincapié en el aumento del consumo de frutas y verduras como una de las recomendaciones a tener en cuenta al elaborar las políticas y directrices dietéticas nacionales tanto para la población como para los individuos. Los investigadores concluyen que las intervenciones centradas en la población para aumentar el consumo de frutas y verduras podrían conducir a millones de años más de vida saludable en todo el mundo.

El mejoramiento de la cultura de los consumidores sobre el consumo de frutas y verduras a nivel mundial aumentaría la exportación de dichos alimentos por lo que el uso de esquineros de cartón donde se colocan generalmente estos dos productos se incrementaría causando un impacto positivo para Carvimsa. De igual manera la cultura de reciclaje, promueve el consumo del cartón en comparación a otro tipo de envases generando una cultura verde en los consumidores.

\subsubsection{Análisis tecnológico.}

Conocimiento, tecnología y capital humano son tres elementos que se conjugan para llevar al mercado de los tubos y esquineros a una mayor competitividad.

La clave del uso eficiente de la tecnología se encuentra en función de los objetivos de negocio y necesidades del personal. Muchas de las nuevas herramientas que están impulsando la productividad, vienen de la mano de beneficios directamente en el trabajo, el orden y la automatización en planta. En este sentido, la industria del corrugado más que nunca se enfoca en el objetivo de poder automatizar y centralizar las principales acciones de negocio, para aprovechar y optimizar mejor los recursos materiales, humanos y de tiempo con la implementación de un software integral de productividad para su planta de producción, con resultados inmejorables. 
Las nuevas tecnologías también están facilitando a las empresas de packaging y logística la búsqueda de nuevas soluciones o proveedores y los puntos de encuentro, como los portales de contratación, intercambio o compra venta. El reto estará en organizar una cadena de suministro que ofrezca las máximas ventajas competitivas. (Revista Oficial de ACCCSA, 2017).

En la actualidad, existen líneas completas para producción de tubos, conos, tambores y envases cilíndricos compuestos de cartón. Líneas automáticas y semiautomáticas para corte y etiquetado de tubos. rebobinadoras, cortadoras rodelas y rollos jumbo. Maquipapel representa a una de las fábricas de Europa Occidental especializadas en la producción de máquinas para fabricar tubos de cartón, con más de 10 años de experiencia en el rubro, exporta a otros países de Europa, Oriente cercano, Latinoamérica y África. (Mundo Papelero, 2017).

A continuación, se detalla las máquinas disponibles en el mercado para la fabricación de tubos y esquineros:

- Recortadora de conos de papel con sistema servo.

- Línea completa de producción de tubos de papel compuestos cartón

- Líneas para producción de tambores de cartón, fibrotambores

- Máquinas para terminación y etiquetado de conos de cartón

- Impresoras flexográficas de 1 a 4 colores

- Rebobinadoras Slitters para rollos jumbo y rodela de papel y cartón

- Máquinas para fabricar esquineros de cartón. (Maquipapel, 2017). 


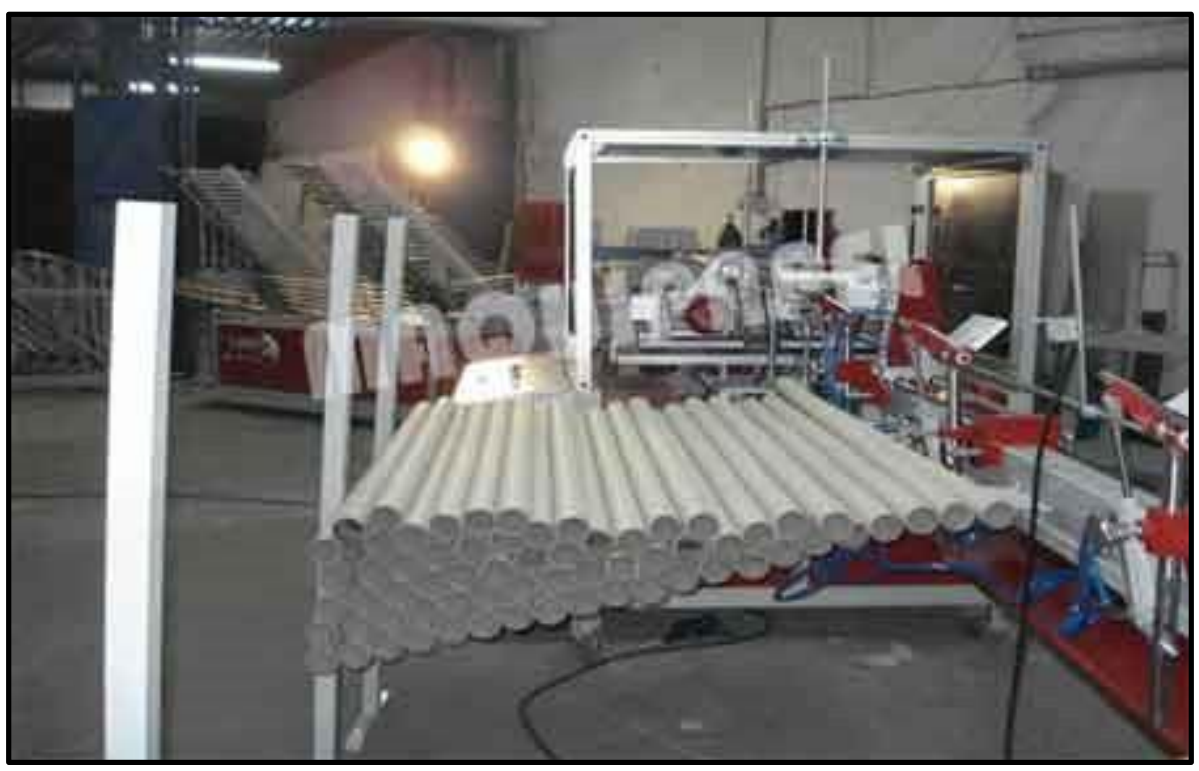

Figura 66. Máquina para fabricar tubos. Tomado de Página Web Mundo papelero. Recuperado de http://www.mundopapelero.com/

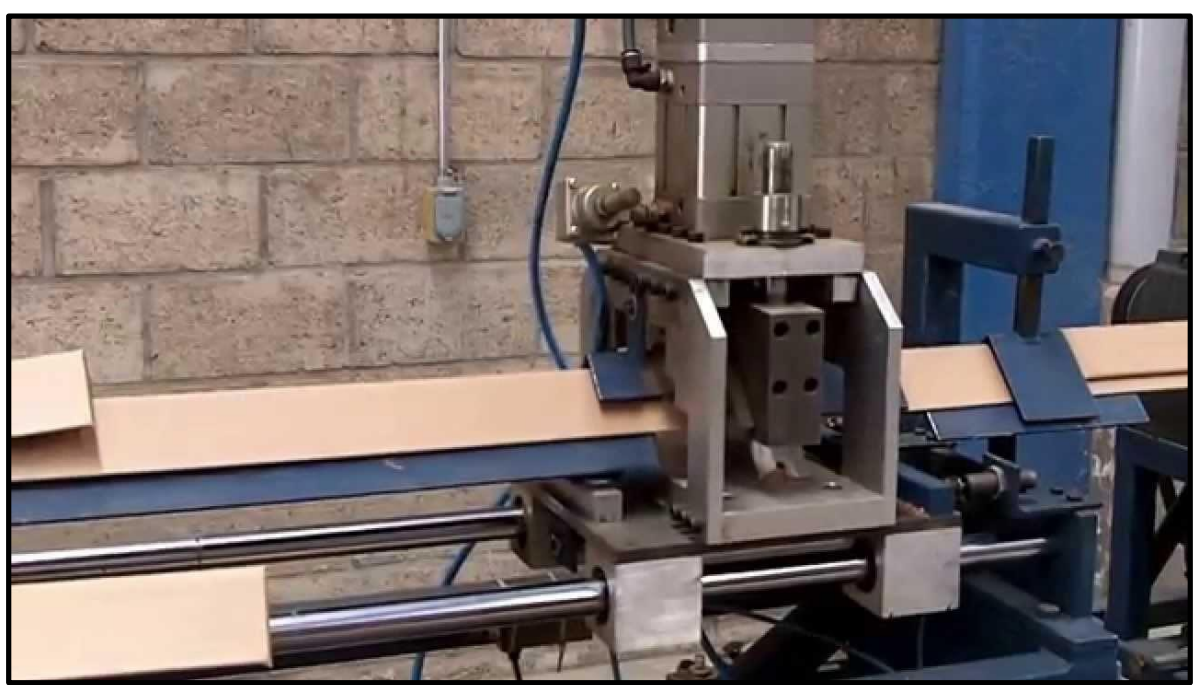

Figura 67. Máquina para fabricar esquineros. Tomado de Página i.ytimg. Recuperado de https://i.ytimg.com/vi/21TjeslZ0YQ/maxresdefault.jpg

El 2016 se convirtió en un año de innovaciones para el sector cartonero. Los avances tecnológicos fueron la principal herramienta de ayuda para que los empresarios anunciaran productos y maquinaria completamente nueva y actual, que fueran funcionales para las diferentes actividades que se deben realizar en plantas corrugadoras o compañías dentro del sector. Este periodo dejó claro que el sector ha crecido de una manera positiva, actualmente 
las empresas se preocupan por innovar con frecuencia y brindar un valor agregado a los clientes añadiendo confianza, seguridad y garantía. (Revista Oficial de ACCCSA, 2017).

La disponibilidad de tecnología para la industria de tubos y esquineros de cartón no está tan desarrollada ya que las máquinas utilizadas son fabricadas por el personal de proyectos de Carvimsa, sin embargo, el avance tecnológico podría contribuir en mejorar aún más los procesos y reducir el factor mano de obra. La máquina de Esquineros es la única máquina tecnológica que tiene Carvimsa la cual fue adquirida en China a la empresa Eberle, el mantenimiento de esta máquina se realiza de manera anual por parte del proveedor para la actualización del software. En general, la variable tecnología tiene un impacto positivo para el desarrollo de Carvimsa.

\subsubsection{Análisis Ecológico.}

Ante un mercado que demanda empaques que deben ser sostenibles, reciclables, pero con impresión de alta calidad, las empresas productoras de tinta buscan ampliar la oferta en esa dirección.

El cambio del modelo económico lineal por uno sostenible y circular ha tomado protagonismo en los últimos años. Los temas relacionados con la defensa del medio ambiente, la escasez de recursos o el cambio climático son hoy los principales problemas a los que se enfrentan gobiernos de todo el mundo.

El año 2015 marcó un punto de inflexión, por una parte, la Organización de las Naciones Unidas (ONU) adoptó la Agenda para el Desarrollo Sostenible, un plan de acción a favor de las personas, el planeta y la prosperidad, que incluía entre otros puntos la adopción de medidas urgentes para proteger el medio ambiente y combatir el cambio climático. Naciones Unidas subrayaba la importancia y el protagonismo de la actividad empresarial, la inversión e innovación privada, como grandes motores de la productividad, el crecimiento 
económico y la creación de empleo. La ONU hacía un llamamiento a que las empresas empleasen su creatividad para resolver los problemas relacionados con el desarrollo sostenible.

Así mismo, en el 2015 cerró un acuerdo histórico contra el cambio climático y hacia un futuro sostenible con bajas emisiones de carbono. El objetivo: descarbonizar la economía y hacerla compatible con los recursos naturales. Precisamente el viernes pasado entró en vigor el Acuerdo de París tras la ratificación por más de 55 partes, entre ellas la Unión Europea (UE), que suman más del $55 \%$ de las emisiones globales de gases de efecto invernadero. Una buena señal política que muestra una clara voluntad y urgencia por combatir el calentamiento global, donde las empresas juegan un papel clave. (Revista Oficial de ACCCSA, 2017).

Apostar por un modelo de desarrollo sostenible y competitivo es una de las prioridades de CARVIMSA. La sostenibilidad se ha convertido en el eje del progreso, la innovación y la excelencia empresarial. Las empresas deben por tanto apostar por la sostenibilidad como valor de marca porque aplicar un modelo empresarial respetuoso, lejos de precisar una mayor inversión, reduce costes y se convierte en una ventaja competitiva. Sostenibilidad y rentabilidad son dos caras de la misma moneda empresarial con vocación de futuro.

La transición hacia la economía circular, la lucha contra el cambio climático o el uso racional de los recursos naturales, generan oportunidades económicas, sociales y ambientales bajo un enfoque de sostenibilidad en toda la cadena de valor empresarial. Es por tanto momento de pasar a la acción. Es el momento de la movilización de todos los estamentos: desde la sociedad, hasta las empresas, pasando por la administración. Hay que utilizar todas las herramientas posibles: normativas, tecnológicas, financieras, culturales y es urgente. 
La responsabilidad social y sostenibilidad empresarial es de aplicación a cualquier tipo de organización y no solo a aquellas cu ya actividad tiene una clara relación con el uso de recursos naturales. Carvimsa cuenta con un molino propio el cual genera bobinas de papel a partir de cartón reciclado en un 95\%, lo cual no genera impactos negativos ya que su actividad no produce efectos adversos en el medio ambiente, por el contrario, integra la gestión ambiental en la gestión de la empresa con el objetivo de eliminar o al menos minimizar y mitigar sus impactos negativos en el medio ambiente y potenciar los positivos.

\subsection{Impacto en clientes / proveedores de cada una de las variables del entorno}

Tabla 35

Impacto en clientes y proveedores en cada variable del entorno

\begin{tabular}{|c|c|c|c|}
\hline \multirow{2}{*}{ Factores } & \multirow{2}{*}{ Variables } & \multicolumn{2}{|c|}{ Impacto (Positivo/Negativo) } \\
\hline & & Proveedor & Cliente \\
\hline Económico & $\begin{array}{l}\text { PBI } \\
\text { Manufactura } \\
\text { Agropecuario } \\
\text { Construcción }\end{array}$ & $\begin{array}{l}\text { El PBI de manufactura y la } \\
\text { confianza de los } \\
\text { consumidores mejoraron } \\
\text { notablemente en las en los } \\
\text { últimos meses de } 2016 \text { y } \\
\text { comienzos de } 2017 \text {, esto } \\
\text { tiene un impacto positivo } \\
\text { para los proveedores ya que } \\
\text { se optimizan los resultados } \\
\text { para la industria a la cual } \\
\text { abastecen. }\end{array}$ & $\begin{array}{l}\text { Para este año se } \\
\text { proyectó una rebaja } \\
\text { de la proyección de } \\
\text { alza del PBI. Aun } \\
\text { así, se estima un } \\
\text { crecimiento } \\
\text { promedio de } 3.3 \% \text {, } \\
\text { para los clientes } \\
\text { tiene un impacto } \\
\text { positivo, pues } \\
\text { produce empleo, } \\
\text { aumento en el } \\
\text { consumo y mejoras } \\
\text { en el bienestar. }\end{array}$ \\
\hline Económico & Tipo de cambio & $\begin{array}{l}\text { El fortalecimiento del tipo de } \\
\text { cambio a favor del dólar } \\
\text { tendría un impacto a favor de } \\
\text { los proveedores de materia } \\
\text { prima en Estados Unidos. }\end{array}$ & $\begin{array}{l}\text { Para los clientes la } \\
\text { depreciación de la } \\
\text { moneda nacional } \\
\text { frente al alza del } \\
\text { dólar tendría un } \\
\text { impacto negativo } \\
\text { ya que los precios } \\
\text { son en soles y es } \\
\text { probable que las }\end{array}$ \\
\hline
\end{tabular}




\begin{tabular}{|c|c|c|c|}
\hline \multirow{2}{*}{ Factores } & \multirow{2}{*}{ Variables } & \multicolumn{2}{|c|}{ Impacto (Positivo/Negativo) } \\
\hline & & Proveedor & Cliente \\
\hline & & & $\begin{array}{l}\text { diferencias en tipo } \\
\text { de cambio en los } \\
\text { costos sean también } \\
\text { transferidas al } \\
\text { precio del producto. }\end{array}$ \\
\hline Tecnológico & $\begin{array}{l}\text { Máquinas para } \\
\text { tubos y } \\
\text { esquineros }\end{array}$ & $\begin{array}{l}\text { La existencia de ferias donde } \\
\text { puedan exponer las } \\
\text { maquinarias de última } \\
\text { tecnología tiene un impacto } \\
\text { positivo para los proveedores } \\
\text { pues se muestran como } \\
\text { nuevas soluciones } \\
\text { ofreciendo las máximas } \\
\text { ventajas competitivas } \\
\text { disponibles en el mercado. }\end{array}$ & $\begin{array}{l}\text { Los clientes están } \\
\text { siempre buscando } \\
\text { algo nuevo, algo } \\
\text { más llamativo, algo } \\
\text { más particular, las } \\
\text { nuevas tecnologías } \\
\text { tienen un impacto } \\
\text { positivo ya que } \\
\text { crean un mercado } \\
\text { de personalización, } \\
\text { y un } \\
\text { posicionamiento } \\
\text { alto basado en } \\
\text { calidad y } \\
\text { flexibilidad. }\end{array}$ \\
\hline Ecológico & $\begin{array}{l}\text { Modelo } \\
\text { Sostenible }\end{array}$ & $\begin{array}{l}\text { El modelo sostenible debe } \\
\text { estar presente en toda la } \\
\text { cadena de valor, los } \\
\text { proveedores convienen } \\
\text { cumplir con los estándares } \\
\text { requeridos de lo contrario } \\
\text { esto tendría un impacto } \\
\text { negativo para su rentabilidad } \\
\text { puesto que la UEN Tubos y } \\
\text { esquineros de CARVIMSA } \\
\text { alinea toda su cadena a su } \\
\text { política medioambiental. }\end{array}$ & $\begin{array}{l}\text { Los clientes } \\
\text { demandan de } \\
\text { envases sostenibles, } \\
\text { reciclables, pero } \\
\text { con impresión de } \\
\text { alta calidad, en este } \\
\text { sentido el modelo } \\
\text { sostenible adoptado } \\
\text { por las compañías } \\
\text { cartoneras como } \\
\text { CARVIMSA tienen } \\
\text { un impacto } \\
\text { positivo. }\end{array}$ \\
\hline Cultural & $\begin{array}{l}\text { Cultura de } \\
\text { Reciclaje y el } \\
\text { Consumo de } \\
\text { Frutas y } \\
\text { Verduras }\end{array}$ & $\begin{array}{l}\text { Las tendencias del reciclaje y } \\
\text { el consumo de frutas y } \\
\text { verduras tienen un impacto } \\
\text { positivo para los proveedores } \\
\text { ya que brinda la oportunidad } \\
\text { de incrementar el uso de } \\
\text { esquineros para la } \\
\text { exportación. }\end{array}$ & $\begin{array}{l}\text { La cultura de } \\
\text { reciclaje y el } \\
\text { consumo de frutas y } \\
\text { verduras } \\
\text { representan un } \\
\text { impacto positivo } \\
\text { para los clientes. }\end{array}$ \\
\hline
\end{tabular}




\begin{tabular}{|c|c|c|c|}
\hline \multirow{2}{*}{ Factores } & \multirow{2}{*}{ Variables } & \multicolumn{2}{|c|}{ Impacto (Positivo/Negativo) } \\
\hline & & Proveedor & Cliente \\
\hline $\begin{array}{l}\text { Político/ } \\
\text { Gubernamental }\end{array}$ & $\begin{array}{l}\text { Estabilidad } \\
\text { Económica } \\
\text { Inclusión } \\
\text { Financiera }\end{array}$ & $\begin{array}{l}\text { El Perú ha gozado en las } \\
\text { últimas dos décadas de un } \\
\text { periodo de estabilidad } \\
\text { económica esto tiene un } \\
\text { impacto positivo para los } \\
\text { proveedores quienes } \\
\text { perciben al Perú como un } \\
\text { escenario confiable. }\end{array}$ & $\begin{array}{l}\text { El Perú tiene un } \\
\text { entorno político } \\
\text { muy favorable para } \\
\text { el desarrollo de la } \\
\text { inclusión financiera } \\
\text { esto tiene un } \\
\text { impacto positivo } \\
\text { para los clientes } \\
\text { pueden usar } \\
\text { mecanismos } \\
\text { digitales como } \\
\text { medio de pago y } \\
\text { acceder a los } \\
\text { servicios } \\
\text { financieros. }\end{array}$ \\
\hline Legal & $\begin{array}{l}\text { Marco } \\
\text { Ambiental } \\
\text { Regulatorio }\end{array}$ & $\begin{array}{l}\text { La mayoría de los } \\
\text { proveedores también tienen } \\
\text { procesos manufactureros y } \\
\text { las nuevas leyes } \\
\text { encaminadas a la protección } \\
\text { del medio ambiente, } \\
\text { representan un impacto } \\
\text { negativo para aquellas } \\
\text { empresas que contaminan } \\
\text { en grandes cantidades, sin } \\
\text { embargo, para otras } \\
\text { representan una oportunidad } \\
\text { de negocio. }\end{array}$ & $\begin{array}{l}\text { La ley general del } \\
\text { Ambiente y el resto } \\
\text { del marco } \\
\text { regulatorio tienen un } \\
\text { impacto positivo } \\
\text { para el cliente ya } \\
\text { que, si CARVIMSA } \\
\text { cumple con los } \\
\text { requerimientos } \\
\text { legales solicitados, } \\
\text { los clientes podrán } \\
\text { hacer uso de un } \\
\text { producto elaborado } \\
\text { bajo un enfoque de } \\
\text { sostenibilidad. }\end{array}$ \\
\hline
\end{tabular}




\subsection{Efecto en la empresa de cada una de las variables del entorno}

Tabla 36

Efecto de la empresa en cada variable del entorno

\begin{tabular}{|c|c|c|}
\hline Factores & Variables & $\begin{array}{l}\text { Impacto en la UEN Tubos y } \\
\text { esquineros de CARVIMSA } \\
\text { (Oportunidad/Amenaza) }\end{array}$ \\
\hline & $\begin{array}{l}\text { PBI } \\
\text { Manufactura } \\
\text { Agropecuario } \\
\text { Construcción }\end{array}$ & $\begin{array}{l}\text { Las expectativas de crecimiento } \\
\text { económico se moderan para } 2017 \text {, en } \\
\text { este sentido el Banco Mundial } \\
\text { estima que el PBI sólo crecerá en un } \\
\text { rango de } 3.0 \% \text { a } 3.5 \% \text {, debido a } \\
\text { factores climáticos como el } \\
\text { fenómeno del niño y otros como la } \\
\text { velocidad del ajuste de la política } \\
\text { monetaria en los Estados Unidos. Si } \\
\text { nos enfocamos a la proyección de la } \\
\text { SIN para el PBI del sector } \\
\text { manufactura el cual es de } 2.5 \% \text { en } \\
\text { promedio, sin duda representa una } \\
\text { oportunidad. }\end{array}$ \\
\hline
\end{tabular}

\begin{tabular}{|c|c|c|}
\hline Economico & Tipo de cambio & $\begin{array}{l}\text { Según el FMI, la propuesta de una } \\
\text { reforma impositiva en Estados } \\
\text { Unidos para favorecer las } \\
\text { exportaciones sobre las } \\
\text { importaciones podría tener un efecto } \\
\text { de derrame sobre las economías } \\
\text { emergentes como el Perú, porque } \\
\text { fortalecería el tipo de cambio a } \\
\text { favor del dólar. Debido a que } \\
\text { Estados Unidos es el principal } \\
\text { proveedor de la materia prima para } \\
\text { CARVIMSA, este aumento del tipo } \\
\text { de cambio del dólar representa una } \\
\text { amenaza. }\end{array}$ \\
\hline Económico & Inflación & $\begin{array}{l}\text { Según el BCRP las expectativas de } \\
\text { inflación para } 2017 \text { fluctuaron entre } \\
3,0 \% \text { y } 3,2 \% \text {, mientras que para } \\
2018 \text { se ubicaron entre } 2,7 \% \text { y } 3,0 \\
\% \text {, está baja proyectada de la } \\
\text { inflación representa una } \\
\text { oportunidad. }\end{array}$ \\
\hline
\end{tabular}


Factores

Variables

Maquinarias para

Tecnológico

fabricación de Tubos y

Esquineros
Impacto en la UEN Tubos y

esquineros de CARVIMSA

(Oportunidad/Amenaza)

Representan una oportunidad como los mejores recursos locales e internacionales en ciencia y tecnología de cartón, estos avances tecnológicos son una principal herramienta de ayuda en cuanto a máquinas, software, servicios, consumibles, etc.

Apostar por un modelo de desarrollo sostenible y competitivo representa una oportunidad para la UEN.

Ecológico

Modelo económico sostenible y circular

Actualmente la empresa cuenta con una sólida Política medioambiental y no tiene antecedentes de contaminación por lo que posee ventaja sobre otros competidores.

Al existir una tendencia al alza del consumo de frutas y verduras a nivel mundial, se incrementará la demanda de los esquineros ya que

Tasa de Reciclaje y

Cultural Tendencia de Consumo de Frutas y Verduras estos son necesarios para la exportación de este tipo de alimentos; representando un impacto positivo para CARVIMSA. De igual manera la cultura de reciclaje, promueve el consumo del cartón en comparación a otro tipo de envases generando una cultura verde en los consumidores.

Este resultado positivo de 9.4 de 10 en el ranking de solidez monetaria de entre 159 países afirman la

\section{Político/Gubernamental Índice de Solidez Monetaria} ventaja de mantener una inflación baja y estable y un crecimiento adecuado del dinero. Para CARVIMSA representa una oportunidad. 


\section{Factores}

Variables
Impacto en la UEN Tubos y esquineros de CARVIMSA

(Oportunidad/Amenaza)

La ratificación del Perú como el tercer mejor país en América Latina

Índice de Libertad para hacer negocios, representa una Económica oportunidad para CARVIMSA ya que le permite operar en un ambiente corporativo y político estable.

\section{Político/Gubernamental}

\section{Legal}

La actual Ley General del Ambiente $\mathrm{N}^{\circ} 28611$ v el Reglamento de Gestión Ambiental para la Industria Manufacturera y el Comercio Interno son el marco normativo legal para gestión ambiental en el Perú, para CARVIMSA no representan una amenaza sino una oportunidad de demostrar a sus stakeholders el desarrollo sostenible de las actividades industriales manufactureras que realiza.

\subsection{Oportunidades y Amenazas}

Una oportunidad es una condición presente en el entorno externo que, en caso de ser debidamente explotada ayudará a la compañía a lograr competitividad estratégica. La mayor parte de las compañías y sin duda las grandes, no cesan de encontrar infinidad de oportunidades y también amenaza. (Hitt, Duane \& Hoskisson, 2015, p. 40).

Una amenaza es una condición del entorno externo que podría entorpecer los esfuerzos de una compañía para lograr la competitividad estratégica. Las compañías recurren a muchas fuentes para analizar el entorno externo por medio de la exploración, el monitoreo, los pronósticos y la evaluación” (Hitt, Duane \& Hoskisson, 2015, p. 41). 


\section{Oportunidades}

a) Crecimiento de los sectores: manufactura, agroindustrial y construcción en el Perú

Las perspectivas de crecimiento económico peruano se moderan para 2017, ubicándose en un rango entre 3,0 y 3,5\%. Los clientes de la UEN Tubos y Esquineros pertenecen a los sectores manufactura, agroindustrial y construcción los cuales tienen una proyección de crecimiento de $1.5 \%, 2.9 \%$ y $3.3 \%$, respectivamente.

\section{b) Nuevas tendencias en la formación académica y profesional}

Una de las claves para mantenerse en un nivel alto de competitividad es saber rodearse de personal calificado, los indicadores positivos presentados por UNESCO muestran oportunidades para la UEN Tubos y esquineros de atraer colaboradores con una amplia capacidad para enfrentar procesos de cambio, con facilidad para la aplicación de nuevas tecnologías y con una sensibilidad mayor hacia los procesos de producción más limpios y amigables con el ambiente

\section{c) Aumento de la demanda de productos biodegradables}

La tendencia de la población y por ende de las empresas al uso de productos biodegradables hace que la UEN Tubos y Esquineros apueste por un modelo de desarrollo sostenible y competitivo.

\section{d) Disponibilidad de Tecnología}

En la actualidad, existen líneas completas para producción de tubos, conos, tambores y envases cilíndricos compuestos de cartón. Líneas automáticas y semiautomáticas para corte y etiquetado de tubos, acceder a estas nuevas tecnologías permitirían reducir costos y desperdicios, y trabajar a economías a escala. 


\section{e) Incremento de exportaciones agrícolas y textiles}

El mercado agrícola es el eje de la nueva visión de CARVIMSA que actualmente lidera esta parte del mercado, un incremento en las exportaciones de este tipo traerá consigo un incremento de los esquineros de cartón para poder dar mayor estabilidad a las cajas apiladas. Por otro lado, un incremento de las exportaciones textiles ampliará el mercado para los tubos como embalaje para las telas.

\section{Amenazas}

\section{a) Precios volátiles, aumento de precios de los commodities (Papel y Cartón)}

CARVIMSA tiene un bajo poder de negociación con los proveedores, la mayor parte de la materia prima que compra es del exterior, el alza de estos insumos en el mercado internacional representa una de las principales amenazas para la UEN Tubos y esquineros.

\section{b) La propuesta de una reforma impositiva en Estados Unidos y el \\ fortalecimiento el tipo de cambio a favor del dólar}

La propuesta de una reforma impositiva en Estados Unidos para favorecer las exportaciones sobre las importaciones podría tener un efecto de derrame sobre las economías emergentes como el Perú, porque fortalecería el tipo de cambio a favor del dólar. Debido a que Estados Unidos es el principal proveedor de la materia prima para la UEN Tubos y Esquineros de CARVIMSA, este aumento del tipo de cambio del dólar representa una amenaza. 


\section{c) Ingreso de importaciones de tubos y esquineros}

La posibilidad de que la necesidad de tubos y esquineros sea suplida por proveedores del exterior está latente. Debido a las economías de escala, empresas con mayor tecnología podrían exportar su producto terminado al Perú y quitar mercado a las empresas ya posicionadas, esto dependerá de los precios y la calidad que manejen.

\section{d) Integración hacia adelante de los proveedores}

Otra amenaza representa los mismos proveedores de insumos que desarrollen el producto y dejen de ser proveedores para pasar a ser competidores pues tendrían la ventaja de conocer el rubro y pueden obtener mejoras en la materia prima.

\section{e) Mayores exigencias ambientales en el Marco Regulatorio que podrían restringir la demanda}

Los tubos y esquineros de CARVIMSA son distribuidos a nivel nacional y también exportados, actualmente cuenta las certificaciones ISO 9001, BASC y el ISO 14001; asegurando de esta manera un sistema de gestión de calidad en cada proceso para prevenir la contaminación del medio ambiente, respetando los requisitos legales que la industria exige. La amenaza es la posibilidad de que surjan nuevas exigencias que tenga que cumplir el producto o mejores estándares internacionales en cuanto a políticas medioambientales.

\subsection{Matriz de evaluación de los factores externos EFE}

David (2013) sostiene que "la Matriz de evaluación de factores externos (EFE) permite que los estrategas resuman y evalúen informaciones económica, social, cultura, demográfica, ambiental, política, gubernamental, legal, tecnológica y competitiva” (p.80) 
Tabla 37

Cinco pasos para la elaboración de la Matriz EFE

Pasos Procedimiento

Paso 1 Elabore una lista de los factores externos clave incluye un total de entre 15 y 20 factores, teniendo en consideración tanto las oportunidades como las amenazas que afectan a la empresa y a la industria en donde ésta opera.

Paso 2 Asigne a cada factor una ponderación que oscile entre 0.0 (No importante) y 1.0
(Muy importante). La ponderación indica la relevancia que tiene este factor para
alcanzar el éxito de la industria en donde participa la empresa. La suma de todas
las ponderaciones asignadas a los factores debe ser igual a 1.0

Paso 3 Asigne a cada factor externo clave una calificación de 1 a 4 puntos para indicar que tan eficazmente responde a las estrategias actuales de la empresa a este factor donde $4=$ la respuesta es superior, $3=$ la respuesta está por encima del promedio, $2=$ la respuesta es promedio y $1=$ la respuesta es deficiente

\begin{tabular}{cl}
\hline Paso 4 & $\begin{array}{l}\text { Multiplique la ponderación de cada factor por su calificación, para determinar } \\
\text { una puntuación ponderada. }\end{array}$ \\
\hline Paso 5 & $\begin{array}{l}\text { Sume las puntuaciones ponderadas cada variable, con el fin de determinar la } \\
\text { puntuación ponderada total para la organización }\end{array}$ \\
\hline
\end{tabular}

Nota: Adaptado de “Administración Estratégica," (pp.80-81) por David, 2013, México: Editorial Pearson Education. Copyright 2013 por Prentice Hall.

Para ponderar y calificar los factores críticos para el éxito se solicitó a los gerentes de Producción, Ventas, Finanzas y Logística juntamente con el Gerente General que coloquen pesos de acuerdo a que factor consideran que tiene mayor poder de influencia en la empresa ya sea de forma positiva como las oportunidades o negativa como las amenazas. Se presentó el análisis de los factores externos y las proyecciones del entorno para que otorguen una calificación actual del factor, de esta manera realizando los cálculos se obtuvieron los resultados mostrados a continuación: 
Tabla 38

Matriz EFE de la UEN Tubos y Esquineros de CARVIMSA

Factores Críticos para el éxito

Peso Calificación

Total

Ponderado

\begin{tabular}{llll}
\hline AMENAZAS & & & \\
\hline 1.Precios volátiles, aumento de precios de los commodities (Papel y Cartón) & 0.15 & 3.00 & 0.45 \\
\hline $\begin{array}{l}\text { 2.La propuesta de una reforma impositiva en Estados Unidos y el } \\
\text { fortalecimiento el tipo de cambio a favor del dólar }\end{array}$ & 0.11 & 2.00 & 0.22 \\
\hline 3.Ingreso de importaciones de tubos y esquineros & 0.04 & 1.00 & 0.04 \\
\hline 4. Integración hacia delante de los proveedores & 0.04 & 2.00 & 0.08 \\
\hline $\begin{array}{l}\text { 5.Mayores exigencias ambientales en el Marco Regulatorio que podrían } \\
\text { restringir la demanda }\end{array}$ & 0.11 & 3.00 & 0.33 \\
\hline TOTAL AMENAZAS & $\mathbf{0 . 4 5}$ & & $\mathbf{1 . 1 2}$ \\
\hline OPORTUNIDADES & & & \\
\hline $\begin{array}{l}\text { 1.Crecimiento de los sectores: manufactura, agroindustrial y construcción } \\
\text { en el Perú }\end{array}$ & 0.06 & 2.00 & 0.12 \\
\hline 2.Nuevas tendencias en la formación académica y profesional & 0.10 & 2.00 & 0.20 \\
\hline 3.Aumento de la demanda de productos biodegradables & 0.16 & 3.00 & 0.48 \\
\hline 4.Disponibilidad de Tecnología & 0.11 & 1.00 & 0.11 \\
\hline 5.Incremento de exportaciones agrícolas y textiles & 0.12 & 3.00 & 0.36 \\
\hline TOTAL OPORTUNIDADES & $\mathbf{0 . 5 5}$ & & $\mathbf{1 . 2 7}$ \\
\hline TOTAL EFE & $\mathbf{1 . 0 0}$ & & $\mathbf{2 . 3 9}$ \\
\hline NOta. ElabOradD en base a entrevistas a los Gerentes Ce CAR
\end{tabular}

Nota. Elaborado en base a entrevistas a los Gerentes de CARVIMSA 


\section{Capítulo V. Análisis de la Industria}

\subsection{Descripción del mercado e industria}

Kottler y Armstrong (2008) afirman que "el mercado es el conjunto en donde tanto compradores y vendedores se reúnen, estos compradores reales y potenciales demuestran que tienen una necesidad, la cual puede satisfacerse mediante el intercambio de productos o servicios que hacen con el vendedor" (p.8).

Para la empresa Cartones Villa Marina S.A de la UEN Tubos y Esquineros, su mercado se da en el territorio nacional e internacional, en donde sus compradores potenciales, tienen la necesidad de adquirir los envases de cartón con el fin de poder satisfacer sus necesidades, ya que sus productos finales deben estar envasados, Cartones Villa Marina les ofrece una diversificación de productos para que el cliente tenga varias opciones a escoger.

Según Maximixe (2016) se prevé que en el 2017 la recuperación de la manufactura en $1.6 \%$, como resultado de la reactivación de la manufactura primaria $(1.8 \%)$ y no primaria (3\%). La recuperación del subsector primario se sustenta en la normalización de las temporadas de pesca, lo cual repercutiría directamente en el crecimiento de la elaboración de harina y aceite de pescado, y la producción de congelados, Por el lado de la manufactura no primaria se espera una recuperación en la producción de bienes de consumo (1.5\%), estimulado por la recuperación del consumo privado (3.5\%), el incremento en el nivel de confianza del consumidor y en menor medida de la recuperación de la demanda externa. De la misma manera, los bienes intermedios (1.9\%) y de capital (0.9\%) también impulsaran la reactivación de la manufactura no primaria, dado que la producción de este tipo de bienes depende de la inversión privada, principalmente, la cual se espera que se recuperen en el 2017 (alrededor del 3\%). 
Se prevé que al finalizar el 2016 el sector manufacturero registre un retroceso de $-2.5 \%$ anual, debido a la ralentización de la manufactura primaria (-0.9\%) y al menor dinamismo de crecimiento del subsector primario se debería a una disminución en la elaboración y conservación de pescado, crustáceos y moluscos, principalmente harina y aceite de pescado, debido al retraso de la maduración de los cardúmenes con lo cual primera temporada, solo se pudo capturar la mitad de los previsto, este deterioro se verá atenuado por crecimiento de la producción de productos primarios de metales preciosos y metales no ferrosos, derivado de una mayor producción de obre de Las Bambas y Cerro Verde. El retroceso del subsector no primario se debería a la desaceleración de la demanda interna, específicamente por la menor demanda de consumo y las tasas de crecimiento negativas de la inversión privada, la cual se espera que cierre el 2016 con una tasa alrededor de -8\%. Estos dos factores afectan directamente a la producción de bienes de consumo (consumo privado) y la elaboración de bienes intermedios y de capital (inversión privada), Los bienes de consumo con mayor desaceleración son los textiles y prendas de vestir (cercano a $-4 \%$ ). Por el lado de los bienes intermedios se observa la desaceleración de la producción de cemento y el decrecimiento de la industria siderúrgica (-3.1\%) y metalmecánica (-5.4\%). (Maximixe 2016). 


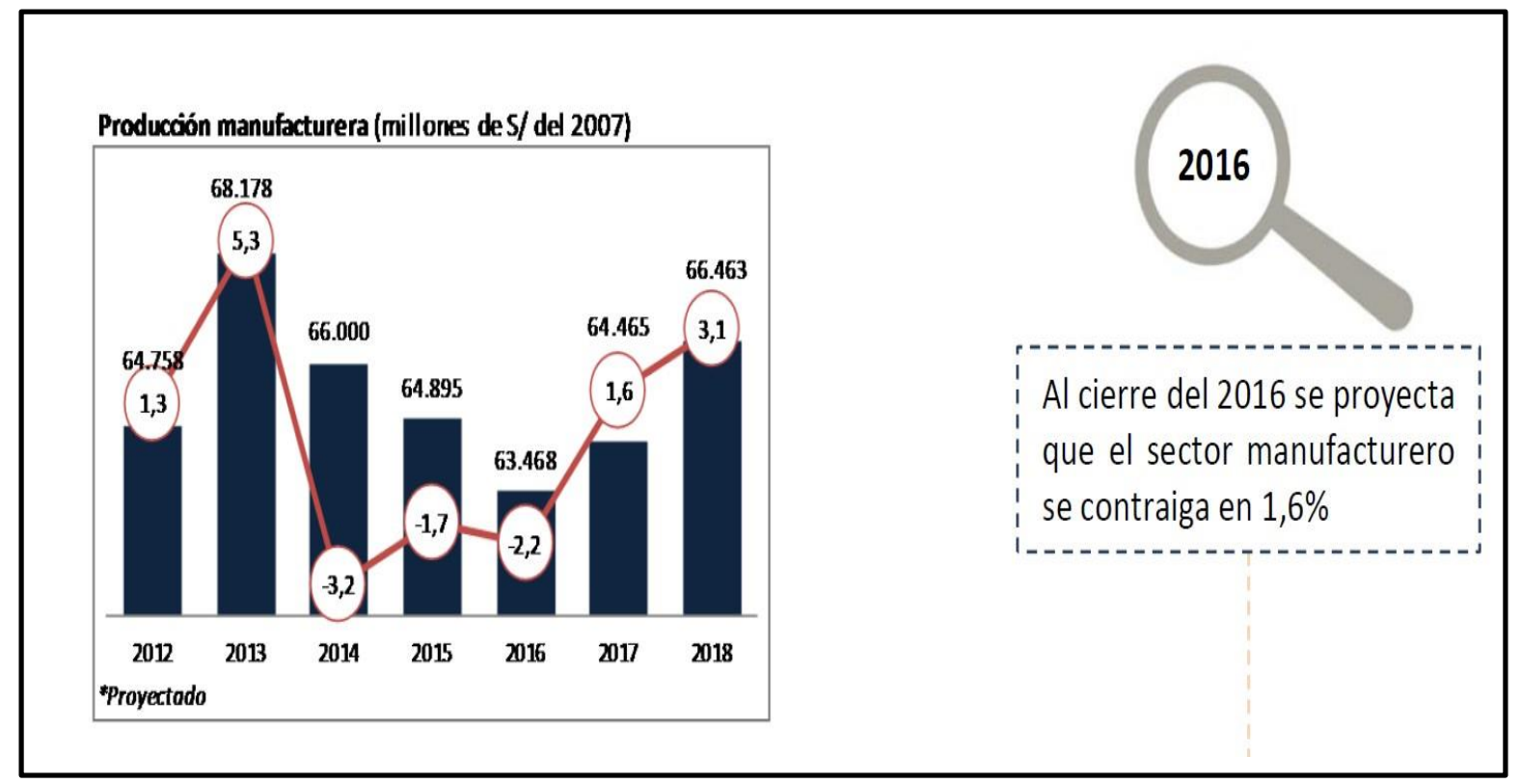

Figura 68. Producción manufacturera. Tomado de "Perú Proyecciones 2016 - 2018 Maximixe".

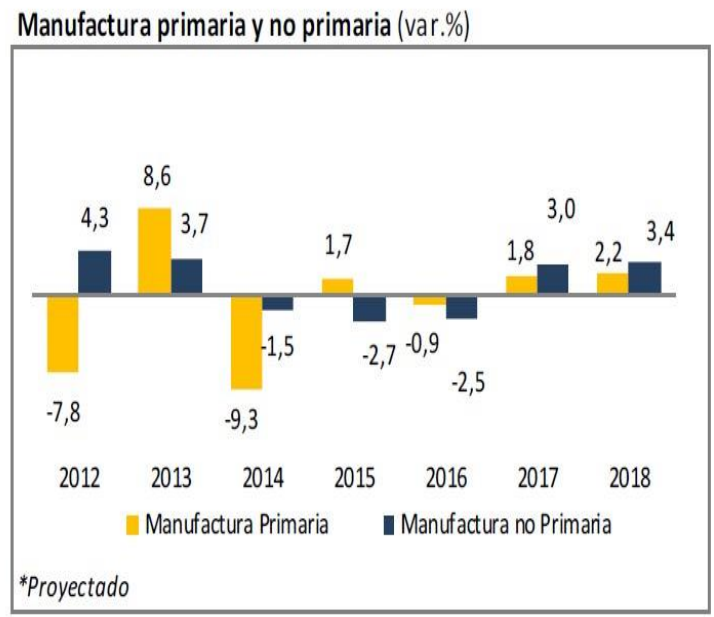

Figura 69. Manufactura primaria y no primaria. Tomado de "Perú Proyecciones 2016 - 2018 Maximixe". 
Exportaciones manufactureras ${ }^{1}$ (millones de US\$)

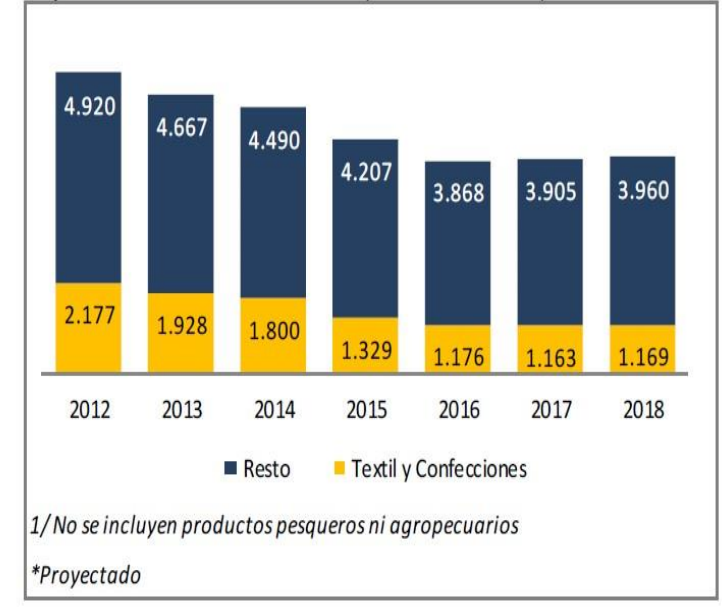

En el 2016, las exportaciones manufactureras retrocederán $-8,9 \%$. Así mismo, las exportaciones de textiles $y$ confecciones se contraerá $11,5 \%$.

Figura 70. Exportaciones manufactureras. Tomado de "Perú Proyecciones 2016 - 2018 Maximixe".

El crecimiento del subsector de papel y cartón se da principalmente por el continuo dinamismo del comercio, construcción, manufactura y sector agrícola.

El comercio sigue impulsando el crecimiento del consumo privado, por mayores ingresos en la fuerza laboral y por mayor acceso a créditos a personas naturales. El sector de manufactura impulsara el crecimiento de los mercados de papel y cartón, el cual impulsara al crecimiento de los subsectores primarios y no primarios.

The Observatory of Economic Complexity (OEC) señala que las importaciones de papel y cartón corrugado ascenderá a unos \$1.9 millones, debido a que esta industria mejorara en la especialización de la producción, mientras que la compras de estas aumentaran en un $7.4 \%$ por tener mayor demanda por parte de los sectores económicos. Por otra parte, las exportaciones de papel y cartón llegarían aumentar en un 2.7\% (\$13.9 millones); estas exportaciones serian sostenidos por la demanda de los países de Ecuador, Chile, Bolivia, Colombia, Panamá y México. 


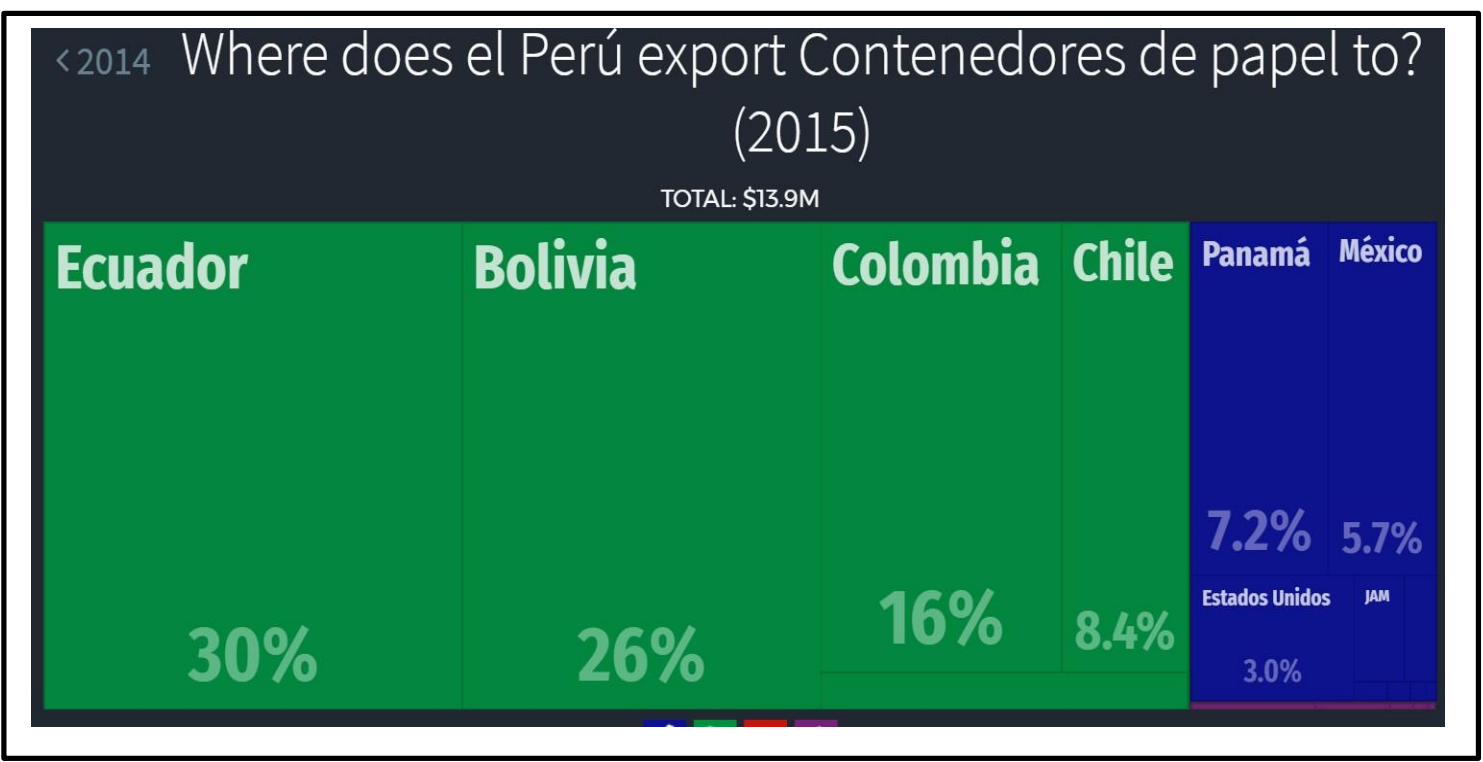

Figura 71. Exportaciones de papel y cartón 2015 por países de destino. Tomado de OEC Export Destinations of contenedores de papel from Perú (2015). Recuperado de http://atlas.media.mit.edu/es/visualize/tree_map/hs92/export/per/show/4819/2015/

\subsubsection{Análisis de la oferta.}

Al definir el sector, se analiza que la producción de los Tubos y Esquineros deben ser complementadas con las importaciones a fin de cubrir con la demanda nacional, ya que las empresas nacionales no utilizan toda la capacidad instalada de sus plantas. Así mismo, las producciones de los diferentes tipos como: papel, cajas, tubos y esquineros de cartón han sufrido variaciones, por la misma coyuntura y por estar íntimamente relacionado con diversos sectores. Un factor que no contribuye al incremento de la producción es el alto precio del papel y pulpa (Fibra corta y larga). 


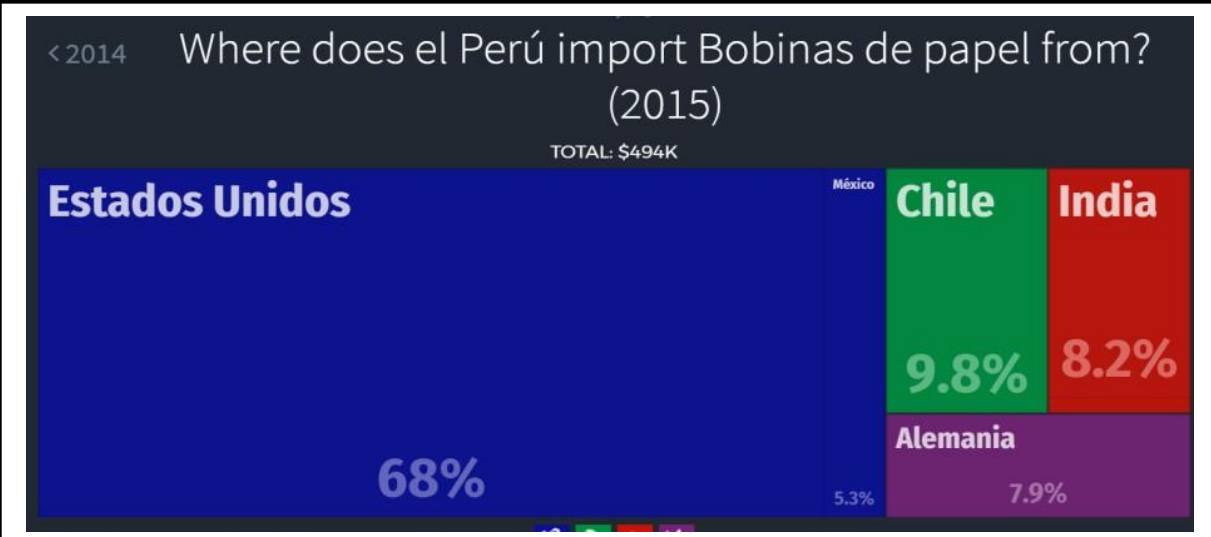

Figura 72. Importaciones de papel 2015 por países de origen. Tomado de OEC - Export Destinations of contenedores de papel from Perú (2015). Recuperado de http://atlas.media.mit.edu/es/visualize/tree_map/hs92/import/per/show/4822/2015/

En el Sector Tubos y Esquineros del mercado peruano se encuentran posicionados cuatro (04) competidores potenciales que abarca todo el mercado nacional. En el siguiente gráfico se puede visualizar la participación del mercado de cada una de ellas.

\section{Participación en el mercado "Tubos y Esquineros de Cartón"}

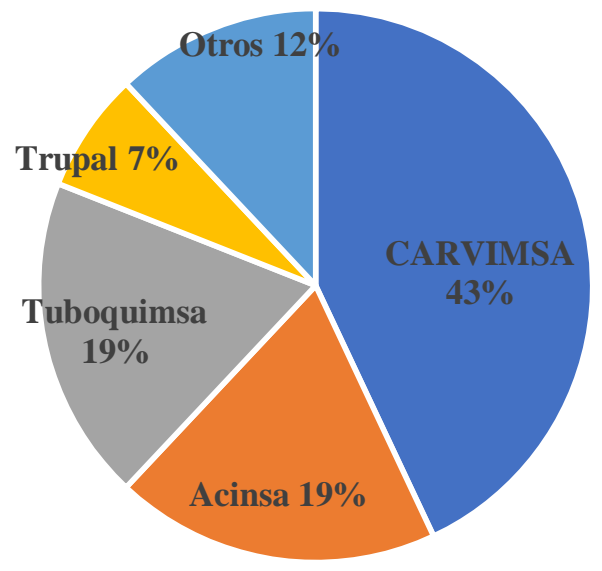

Figura 73. Participación en el mercado "Tubos y Esquineros de Cartón”. Tomado de Documentación Interna de la Gerencia de Ventas CARVIMSA. 
En el Perú, el mercado de "Tubos y Esquineros" es informal y está atomizado con empresas pequeñas que no cuentan con la capacidad de ofrecer un producto de calidad. Es por ello que, en el año 2013, CARVIMS A ingresó a este mercado con la finalidad de ofrecer un producto de calidad. La calidad del producto lo logra gracias al uso de bobinas de anchos pequeños (también conocidos como Side roll), las cuales al tener mayor resistencia mecánica permite obtener un producto superior a lo ofrecido por el mercado.

Actualmente, CARVIMSA atiende al $43 \%$ de este mercado, siendo su principal competidor la empresa Acinsa Tubos, con una participación del 19\% y el 38\% restante lo conforman varias empresas pequeñas.

Por otro lado, CARVIMSA empezó a fabricar y comercializar el producto “Esquineros de Cartón” a partir del año 2015. Este producto está dirigido al sector Agroindustrial, específicamente a las exportaciones. Cabe señalar, que este producto puede ser reemplazado por el "Esquinero de Plástico" cuyo precio es menor que el "Esquinero de Cartón", sin embargo, este último tiene mejor presentación, siendo un factor importante de decisión de compra para algunos clientes. También existen "Esquineros de cartón" importados de Chile y Ecuador, que son fabricados con papel Kraft Liner, brindando mayor resistencia y mejor apariencia al producto final. (Informe Anual CARVIMSA, 2016)

Por lo mencionado en el párrafo anterior, la única forma en la que CARVIMSA pueda competir y aumentar su participación en el mercado nacional e internacional, es brindando un esquinero con mayor espesor, resistencia y más económico.

Se debe tomar en cuenta que la demanda es estacionaria pues varía según la temporada de exportación por producto. Así mismo, puede verse afectado por diferentes factores tales como: desastres naturales, coyuntura política y económica nacional e internacional. 


\subsubsection{Análisis de la demanda.}

En la actualidad los productos reciclados son manufacturados con el fin de crear mercados. La población objetiva es dada en todo el territorio nacional. El consumo de los productos de embalajes de cartón tiene que ver con el poder adquisitivo de las personas, el nivel de educación e industrialización. Se toma en cuenta que el consumo de las cajas, tubos y esquineros de cartón, están relacionadas directamente con el nivel de producción industrial.

Se muestra como está conformado el sector cartón en el mercado peruano:

Tabla 39

El mercado Peruano del Sector Cartón

Mercado Tipo de Papel Consumidores

\begin{tabular}{lll}
\hline & White Top & Empresas que requieren \\
\hline Cajas de Cartón Corrugado & Kraft Liner & Para el sector: Domestico, \\
\hline & Test Liner & Textil, Perfumes, Agro y \\
\hline Corrugado Medium & Pesca. \\
\hline Bobinas de Papel & Fibra Virgen & Empresas que requieren \\
\hline Kraft & Para el sector manufactura \\
\hline Occ & \\
\hline Tubos de cartón & Dkl & Empresas que requieren \\
\hline Kraft Liner & Para el sector: Embalaje, \\
\hline Test Liner & Textil, minería y construcción. \\
\hline Esquineros de cartón & Korrugado Medium & Empresas que requieren \\
\hline & White Top & Para el sector Agro. \\
\hline
\end{tabular}


La empresa CARVIMSA tiene como proyección de ventas por clientes, como principal comprador a Solpack, quien representa un 30\% de su producción. Este cliente en el año 2014 compraba un promedio de 60 TM por mes. En el 2015 aumentó su compra de 60 TM a 80 TM por mes (33\%). La tendencia de venta de este principal cliente muestra un incremento de $50 \%$ más al de la compra del año anterior, según datos históricos proporcionado por el área comercial de CARVIMSA.

Al igual que este cliente, muchos otros han empezado a comprar a CARVIMSA mayores volúmenes. Solo por citar un ejemplo, las ventas mensuales de los tres (03) primeros meses del año 2016 fueron en promedio 300 TM por mes y se tiene proyectado una venta anual de 4,500 TM para el 2017.

Este producto, se proyecta con un crecimiento sostenido de ventas en un $10 \%$ para el año 2017, 2018, 2019 y 2020; conforme se vaya formalizando y volviendo más técnico en la utilización de Tubos de Cartón. Con respecto al precio del producto, con el ingreso de CARVIMSA en este mercado el precio disminu yo llegando a S/. 1.90 por $\mathrm{Kg}(\$ 0.57)$. En la actualidad, CARVIMSA vende este producto a S/ 2.30 por Kg. (\$ 0.69). En el año 2017 pretende incrementar los precios del producto dado la coyuntura del mercado internacional del papel. Este incremento deberá ser paulatino pues los clientes optarán por irse con proveedores de bajos precios aun arriesgando la calidad del producto.

Tabla 40

Ventas Históricas y Proyecciones en TM del producto "Tubos de Cartón” de sus principales clientes

\begin{tabular}{lcccccr}
\hline Cliente & $\mathbf{2 0 1 6}$ & $\mathbf{2 0 1 7}$ & $\mathbf{2 0 1 8}$ & $\mathbf{2 0 1 9}$ & $\mathbf{2 0 2 0}$ & Promedio \\
\hline Solpack S.A.C & 1,300 & 1,430 & 1,573 & 1,730 & 1,903 & 1,587 \\
\hline Filmpack S.A.C & 480 & 528 & 581 & 639 & 703 & 586 \\
\hline Packing \& Plastics Peru S.A. & 480 & 528 & 581 & 639 & 703 & 586 \\
\hline
\end{tabular}




\begin{tabular}{|c|c|c|c|c|c|c|}
\hline Cliente & 2016 & 2017 & 2018 & 2019 & 2020 & Promedio \\
\hline Peruplast S.A. & 510 & 561 & 617 & 679 & 747 & 623 \\
\hline Polytex S.A. & 216 & 216 & 216 & 216 & 216 & 216 \\
\hline Unionplast S.A. & 180 & 180 & 180 & 180 & 180 & 180 \\
\hline Opp Film & 425 & 600 & 720 & 840 & 1,200 & 757 \\
\hline Sector Textil & 80 & 80 & 120 & 130 & 130 & 108 \\
\hline Otros Clientes Tubos & 840 & 840 & 840 & 840 & 840 & 840 \\
\hline & 4,511 & 4,963 & 5,428 & 5,893 & 6,622 & 5,483 \\
\hline
\end{tabular}

Tabla 41

Precios Históricos y Proyecciones en Dólares Americanos por TM vendida del producto "Tubos de Cartón" de sus principales clientes

\begin{tabular}{lccccc}
\hline Cliente & $\mathbf{2 0 1 6}$ & $\mathbf{2 0 1 7}$ & $\mathbf{2 0 1 8}$ & $\mathbf{2 0 1 9}$ & $\mathbf{2 0 2 1}$ \\
\hline Solpack S.A.C. & $\$ 770.00$ & $\$ 808.50$ & $\$ 832.76$ & $\$ 874.40$ & $\$ 874.40$ \\
\hline Filmpack S.A.C. & $\$ 693.64$ & $\$ 728.32$ & $\$ 750.17$ & $\$ 787.68$ & $\$ 787.68$ \\
\hline Packing \& Plastics Peru S.A. & $\$ 685.73$ & $\$ 720.02$ & $\$ 741.62$ & $\$ 778.70$ & $\$ 778.70$ \\
\hline Peruplast S.A. & $\$ 699.73$ & $\$ 734.71$ & $\$ 756.75$ & $\$ 794.59$ & $\$ 794.59$ \\
\hline Polytex S.A. & $\$ 716.76$ & $\$ 752.60$ & $\$ 775.18$ & $\$ 813.94$ & $\$ 813.94$ \\
\hline Union Plast S.A. & $\$ 638.88$ & $\$ 670.82$ & $\$ 690.95$ & $\$ 725.50$ & $\$ 725.50$ \\
\hline Opp Film & $\$ 674.17$ & $\$ 707.88$ & $\$ 729.12$ & $\$ 765.57$ & $\$ 765.57$ \\
\hline Sector Textil & $\$ 760.57$ & $\$ 798.60$ & $\$ 822.56$ & $\$ 863.69$ & $\$ 863.69$ \\
\hline Otros Clientes Tubos & $\$ 760.57$ & $\$ 798.60$ & $\$ 822.56$ & $\$ 863.69$ & $\$ 863.69$ \\
\hline Promedio Precio Por Año & $\$ 711.12$ & $\$ 746.67$ & $\$ 769.07$ & $\$ 807.53$ & $\$ 807.53$ \\
\hline
\end{tabular}

Nota: Recuperado de Documentación Interna de la Gerencia de Ventas CARVIMSA.

En el año 2015, CARVIMSA ha facturado en el mercado nacional 585 TM de “Esquineros de cartón” y 230 TM en el mercado costarricense. En el año 2016 facturaron 873

TM. Debido a la competencia con los esquineros de plásticos y las importaciones de Chile, han visto necesario disminuir el precio a $\$ 751$ por TM. Para el año 2017, CARVIMSA espera recuperar el precio a $\$ 785$ x TM. 
Tabla 42

Ventas Históricas y Proyecciones en TM del producto "Esquineros de Cartón" de sus principales clientes

\begin{tabular}{lcccccc}
\hline Cliente & $\mathbf{2 0 1 6}$ & $\mathbf{2 0 1 7}$ & $\mathbf{2 0 1 8}$ & $\mathbf{2 0 1 9}$ & $\mathbf{2 0 2 0}$ & Promedio \\
\hline Complejo Agroindustrial Beta S.A. & 100 & 110 & 121 & 133 & 146 & 122 \\
\hline Jayanca Fruits S.A.C. & 40 & 45 & 50 & 50 & 50 & 47 \\
\hline Avocado Packing Company S.A.C. & 40 & 40 & 50 & 50 & 60 & 48 \\
\hline Agricola Chapi & 25 & 25 & 30 & 30 & 30 & 28 \\
\hline Agroimex Traiding & 30 & 30 & 36 & 40 & 44 & 36 \\
\hline Cvm-Zona Norte & 40 & 44 & 48 & 53 & 59 & 49 \\
\hline Gandules & 50 & 50 & 60 & 60 & 70 & 58 \\
\hline Líneas Plásticas & 50 & 55 & 60 & 65 & 70 & 60 \\
\hline Tal S.A. & 40 & 40 & 40 & 40 & 40 & 40 \\
\hline Polinplast S.A.C. & 50 & 50 & 50 & 50 & 50 & 50 \\
\hline Otros Clientes Esquineros & 120 & 132 & 145 & 160 & 176 & 147 \\
\hline Total & $\mathbf{5 8 5}$ & $\mathbf{6 2 1}$ & $\mathbf{6 9 0}$ & $\mathbf{7 3 1}$ & $\mathbf{7 9 5}$ & 684 \\
\hline
\end{tabular}

Nota: Recuperado de Documentación Interna de la Gerencia de Ventas CARVIMSA.

Tabla 43

Precios Históricos y Proyecciones en Dólares Americanos por TM vendida del producto "Esquineros de Cartón" de sus principales clientes

\begin{tabular}{lccccc}
\hline Cliente & $\mathbf{2 0 1 6}$ & $\mathbf{2 0 1 7}$ & $\mathbf{2 0 1 8}$ & $\mathbf{2 0 1 9}$ & $\mathbf{2 0 2 1}$ \\
\hline Complejo Industrial Beta S.A. & $\$ 720.41$ & $\$ 756.43$ & $\$ 779.13$ & $\$ 818.08$ & $\$ 818.08$ \\
\hline Jayanca Fruits S.A.C. & $\$ 730.15$ & $\$ 766.66$ & $\$ 789.66$ & $\$ 829.14$ & $\$ 829.14$ \\
\hline Avocado Packing Company S.A.C. & $\$ 730.15$ & $\$ 766.66$ & $\$ 789.66$ & $\$ 829.14$ & $\$ 829.14$ \\
\hline Agricola Chapi & $\$ 730.15$ & $\$ 766.66$ & $\$ 789.66$ & $\$ 829.14$ & $\$ 829.14$ \\
\hline Agroimex Trading & $\$ 730.15$ & $\$ 766.66$ & $\$ 789.66$ & $\$ 829.14$ & $\$ 829.14$ \\
\hline Cliente & $\mathbf{2 0 1 6}$ & $\mathbf{2 0 1 7}$ & $\mathbf{2 0 1 8}$ & $\mathbf{2 0 1 9}$ & $\mathbf{2 0 2 1}$ \\
\hline Cvm - Zona Norte & $\$ 730.15$ & $\$ 766.66$ & $\$ 789.66$ & $\$ 829.14$ & $\$ 829.14$ \\
\hline Gandules & $\$ 730.15$ & $\$ 766.66$ & $\$ 789.66$ & $\$ 829.14$ & $\$ 829.14$ \\
\hline Tal Sa & $\$ 730.15$ & $\$ 766.66$ & $\$ 789.66$ & $\$ 829.14$ & $\$ 829.14$ \\
\hline Líneas Plásticas & $\$ 769.00$ & $\$ 807.45$ & $\$ 831.67$ & $\$ 873.26$ & $\$ 873.26$ \\
\hline Polinplast S.A.C. & $\$ 820.20$ & $\$ 861.21$ & $\$ 887.05$ & $\$ 931.40$ & $\$ 931.40$ \\
\hline Otros Clientes Esquineros & $\$ 800.00$ & $\$ 840.00$ & $\$ 865.20$ & $\$ 908.46$ & $\$ 908.46$ \\
\hline Promedio Precio Por Año & $\$ 747.33$ & $\$ 784.70$ & $\$ 808.24$ & $\$ 848.65$ & $\$ 848.65$ \\
\hline Nota: Recuperado de Documentación Interna de la Gerencia de Ventas CARVIMSA. &
\end{tabular}




\subsection{Descripción de las cinco fuerzas competitivas de la industria}

Porter (2008) sostiene que:

Las cinco fuerzas van a medir el grado de utilidad que tiene cada una y que tanto influye está en el sector como, por ejemplo: los costos, precios, inversiones y el retorno de las inversiones. El poder que pueda tener cada fuerza estará en función del cómo está estructurado la industria, que técnicas de economía se está utilizando (p.22).

Tabla 44

Las cinco fuerzas de Porter

\begin{tabular}{ll}
\hline $\mathbf{N}^{\circ}$ & Fuerzas \\
\hline 1 & Poder de negociación de los clientes \\
\hline 2 & Poder de negociación de los proveedores \\
\hline 3 & Amenaza de nuevos competidores entrantes \\
\hline 4 & Amenaza de productos sustitutos \\
\hline 5 & Rivalidad entre los competidores existentes
\end{tabular}

Nota: Adaptado de "Ventaja Competitiva" por M. Porter, 2008, México. Copyright 2015 por Compañía Editorial Continental S.A. de C.V.

\subsubsection{Sustitutos.}

En esta fuerza se demuestra la propensión del comprador a sustituir, los precios muy bajos de estos, la disponibilidad del producto y una amplia gama de proveedores. (Porter, 2008)

De lo antes expuesto, podemos afirmar que los tubos de cartón son más amigables con el medio ambiente y esto contribuye a que CARVIMSA mantenga e incremente su participación en el mercado ya que la responsabilidad social y la sostenibilidad empresarial son factores muy importantes y valorados por los clientes en la actualidad.

Así mismo, debemos precisar que en la actualidad el producto "Tubos de Cartón” no tiene sustituto. Si bien es cierto existen tubos de plástico, estos son utilizados para otro fin. 
Por otro lado, los “Esquineros de Cartón” si tienen sustitutos, uno de ellos es los “Esquineros de Plástico" que se venden a un precio muy competitivo y se pueden reutilizar.

A continuación, se muestran los factores que determinan la amenaza de nuevos productos sustitutos:

Tabla 45

Factores Determinantes de la Amenaza de Productos Sustitutos

Nivel de

$\mathrm{N}^{\circ}$ Determinantes

Ponderación

Atractividad

Resultado

(Del 1 al 5)

\begin{tabular}{llccc}
\hline 1 & Costes Cambiantes & 0.40 & 2 & 0.80 \\
\hline 2 & Propensión de los clientes a sustituir & 0.60 & 3 & 1.80 \\
\hline
\end{tabular}

Puntuación Final

2.60

La fuerza en promedio es de 2.60 puntos, una fuerza medianamente alta, debido a que se ofrecen sustitutos en cuanto al producto esquineros de cartón en otras entidades que fabrican esquineros de plástico para el sector agrícola y comerciante.

\subsubsection{Potenciales.}

Los factores que determinan la amenaza de los nuevos competidores entrantes se ven reflejados en la economía de escala, diferenciación del producto, inversiones de capital, costos, barreras de entrada y acceso a canales de distribución. (Porter, 2008)

Con relación a los factores determinantes explicados en el párrafo anterior, en el sector de Envases de Cartón (Tubos y Esquineros) ha mostrado un crecimiento de un 3 a $4 \%$ en los últimos años, esto podría ser un estímulo para el ingreso de nuevos competidores, pero se debe tomar en cuenta que en el Perú se tiene un promedio de cuatro (04) empresas grandes que se dedican a la fabricación de envases de cartón (CARVIMSA, Acinsa, Tuboquimsa, Trupal) que imponen una barrera de entrada muy importante. 
Cabe mencionar que Trupal se dedica a la fabricación de Esquineros, pero podría convertirse en un gran potencial en lo que concierne tubos de cartón.

Es preciso señalar que CARVIMSA, cuenta con diversos canales de distribución (Transportes propios, UEN Papel y UEN Cajas de cartón corrugado y micro corrugado), y además con el respaldo del Grupo Comeca, el cual es reconocido por los países de Latinoamérica.

A continuación, se muestran los factores que determinan la amenaza de nuevos competidores entrantes:

Tabla 46

Factores Determinantes de los Amenaza de nuevos competidores entrantes

\begin{tabular}{llll}
\hline & & Nivel de & \\
$\mathrm{N}^{\circ}$ Determinantes & Ponderación & Atractividad & Resultado
\end{tabular}

(Del 1 al 5)

\begin{tabular}{llccc}
\hline 1 & Economías de escala & 0.60 & 5 & 3.00 \\
\hline 2 & Diferenciación de productos & 0.10 & 2 & 0.20 \\
\hline 3 & Identidad de marca & 0.15 & 4 & 0.60 \\
\hline 4 & Acceso a los canales de distribución & 0.15 & 4 & 0.60 \\
\hline & Puntuación Final & & & $\mathbf{4 . 4 0}$ \\
\hline
\end{tabular}

En promedio la fuerza es de 4.40 puntos, por lo que se puede observar es alta, debido a que existe una barrera de ingreso al mercado considerable, esto por el motivo de que se necesita fabricar a economías de escala para que el capital que se requiere para comenzar las actividades en este giro no sea de un monto significativo.

\subsubsection{Clientes.}

Esta teoría se refiere a los factores claves de precio y calidad de los productos, de modo que si el vendedor no transmite de manera adecuada las necesidades que tiene su 
cliente, existirá la posibilidad de que el cliente cambie de proveedor de manera inmediata, por mayor y mejor calidad.

Por consiguiente, al aplicar la fuerza de Porter "Poder de negociación con los clientes", se puede indicar que los principales clientes que atiende CARVIMSA están relacionadas con industrias de consumo de productos terminados e intermedios. Es preciso señalar que la cartera de clientes de CARVIMSA está conformada por empresas pequeñas, medianas y grandes.

Con este enfoque se puede decir que las pequeñas y medianas empresas tienen un poder de negociación bajo, ya que CARVIMSA les ofrece cómodos precios de traslados del producto (fletes) y con altos estándares de calidad, sin embargo, el poder de negociación que tienen los grandes clientes es alta, debido al gran volumen de compra que generan.

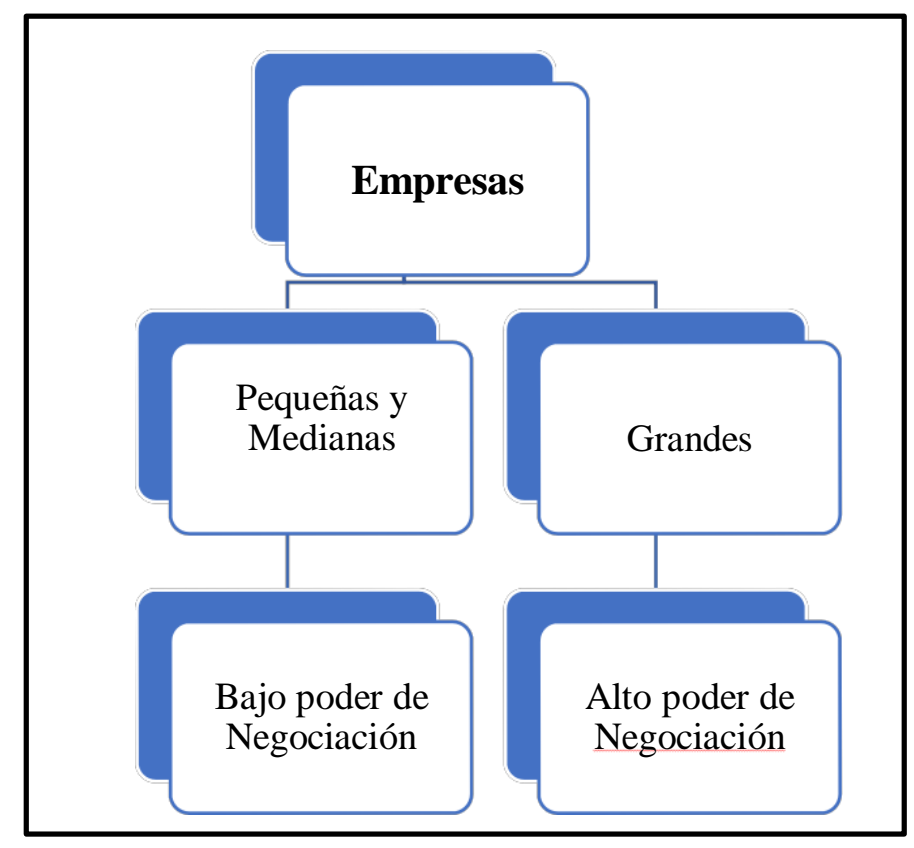

Figura 74. Poder de negociación por tipo de empresas de la UEN Tubos y Esquineros

Otro punto importante es que las grandes empresas tienen acceso a mejores precios de los embalajes de tubos y esquineros, a través de la importación de estas, la mayoría de las importaciones proviene de Chile. 
Es por ello por lo que CARVIMSA si es que quiere seguir atendiendo a estas grandes empresas como: Solpack S.A., Surpack, San Miguel Industrial, Filmpack S.A.C, OPP Film S.A., Peruplast, Envases y Envolturas S.A., etc., debe tomar en cuenta ciertas variables: (i) precios accesibles, (ii) tiempos de entrega, (iii) calidad del producto, (iv) disponibilidad del producto y (v) facilidades de pago. (Francés, 2006)

La UEN Tubos y esquineros atiende a diferentes sectores del mercado manufacturero, el producto Tubos de cartón se dirige a los sectores (i) textil, (ii) Embalaje, (iii) Industrial y (iv) Construcción y minería, mientras que el producto Esquineros de Cartón se dirige al sector agro.

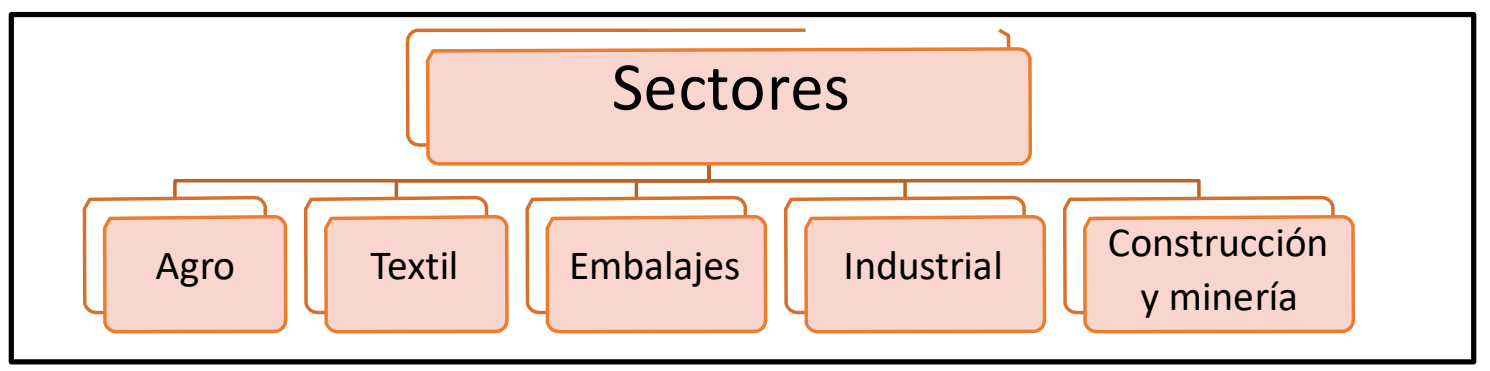

Figura 75. Sectores de ventas de la UEN Tubos y Esquineros

Al cierre del 2016, la UEN Tubos y Esquineros cuenta con 30 clientes aproximadamente. El listado de clientes, el sector al que pertenecen, las ventas en toneladas métricas (tm) así como el porcentaje de éstas, se pueden visualizar en la tabla 47. 
Tabla 47

Lista de Clientes de la UEN Tubos y Esquineros de CARVIMSA 2016.

\begin{tabular}{|c|c|c|c|c|}
\hline LO- & $a \bullet \ldots$, & $\boldsymbol{\square}$ & PnmTa & $\% .1^{\prime-}$ \\
\hline$\overline{12}$ & C-., SAC & "'F' & $<_{13}$ & L:t!!»,. \\
\hline & $\boldsymbol{m} \mathbf{n}<==0 \mathrm{imsaA}$ & "'F' & $2 S: S$ & 4 \\
\hline & & "'F" & $246 \%$ & 4.246 \\
\hline & & & WRN & 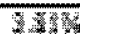 \\
\hline$E$ & $!=\mathbf{A} !=:$ & "'F" & $t: 11$ & $\boldsymbol{U} \mathrm{ti}_{<}$ \\
\hline- & $S \Lambda$ & $\mathrm{I}::: \mathrm{rHJ} x, \mathrm{i}: \mathrm{t}$ & L1SS2 & $2, L$ \\
\hline$\sim$ & a..mte.:i:e.SAC & "'F' & 'rj Jil & UW!í. \\
\hline & mW $-d=: ! ' S E$ & $=10$ & SS<:11 & I W \\
\hline & & & 2414 & $202 \mathrm{~B}_{\mathrm{H}}$ \\
\hline IIIIIIII & $!: A !:=$ & $\& N \|: P$ & $\mathrm{t} ; ! ! \mathrm{G} \mathrm{H}$ & :Xtl.: \\
\hline '!ribcJ & $S A$ & I:::ra.J x,i::t & lis.12it & Ufl'll. \\
\hline l'Um; & $S \Lambda$ & $-j::$ & 14 & Ul'1!. \\
\hline IIIIIII & $r s \ldots c$ & $-\infty$ & $: 11 \mathrm{~A} 8$ & !L！ \\
\hline & & & 2xka & 3.65 \\
\hline & 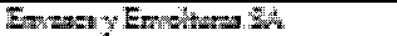 & Erabelsya & $k_{4}$ & 5\% \\
\hline & 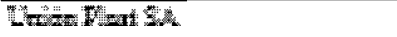 & Entaly & 1506 & D.T. \\
\hline & & & $\operatorname{ls0} 4$ & Z35 \\
\hline & 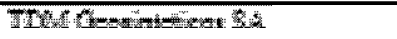 & 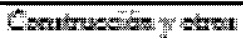 & +34 & Whest \\
\hline & & & 4458 & MEV \\
\hline & & & THe & 965 \\
\hline & & & 5 sast & Iown: \\
\hline
\end{tabular}


Tabla 48

Factores Determinantes del Poder de Negociación de los clientes

\begin{tabular}{llccc}
\hline $\mathrm{N}^{\circ}$ & Determinantes & Ponderación & $\begin{array}{l}\text { Nivel de } \\
\text { Atractividad } \\
\text { (Del 1 al 5) }\end{array}$ & Resultado \\
\hline 1 & Volumen de los clientes & 0.05 & 3 & 0.15 \\
\hline 2 & $\begin{array}{l}\text { Costes cambiantes de los clientes } \\
\text { relación con los de las empresas }\end{array}$ & 0.05 & 2 & 0.10 \\
\hline 3 & Capacidad de integrar hacia atrás & 0.30 & 5 & 1.50 \\
\hline 4 & Producto sustitutivo & 0.10 & 3 & 0.30 \\
\hline 5 & Impacto en la calidad & 0.40 & 5 & 2.00 \\
\hline 6 & Sensibilidad al precio & 0.10 & 3 & 0.30 \\
\hline & Puntuación Final & & 4.35 & \\
\hline
\end{tabular}

En promedio la fuerza es de 4.35 puntos, donde podemos apreciar que es alta, debido a que los clientes pequeños y medianos tendrán una baja influencia sobre la empresa. La fuerza del poder de negociación de los clientes grandes es alta debido a que ellos influyen en la empresa, siempre sentirán la necesidad de comprar el producto y tienen la facilidad de cambiarse de un lugar a otro buscando lo que más les convenga, ya sea por los precios, calidad y puntualidad con la entrega.

\subsubsection{Proveedores.}

Se refiere a una amenaza dada por la industria por parte de los proveedores, a causa del poder que estos disponen ya sea por su grado de concentración, por las características de los insumos que proveen, por el impacto de estos insumos en el costo de la industria, etc. La capacidad de negociar con los proveedores se considera generalmente alta. (Porter, 2008)

De la definición descrita en el párrafo anterior, se puede determinar que el poder de negociación de los proveedores con CARVIMSA es baja, esto se da porque CARVIMSA 
coloca altos volúmenes de compra de manera continua con sus proveedores locales de diversos insumos y otras materias primas necesarias para la fabricación de "Tubos y Esquineros de Cartón”, haciendo que CARVIMSA sea uno de sus principales clientes. Los precios que establecen los proveedores pueden ser variables debido a que CARVIMSA puede negociar para obtener un mejor precio.

A continuación, se muestran los factores que determinan el poder de negociación de los proveedores.

Tabla 49

Factores Determinantes del Poder de Negociación de los proveedores

\begin{tabular}{llccc}
\hline $\mathrm{N}^{\circ}$ & Determinantes & Ponderación & $\begin{array}{l}\text { Nivel de } \\
\text { Atractividad } \\
(\text { Del 1 al 5) }\end{array}$ & Resultado \\
\hline 1 & $\begin{array}{l}\text { Amenaza de integración hacia } \\
\text { adelante }\end{array}$ & 0.10 & 1 & 0.10 \\
\hline 2 & Presencia de productos sustitutivos & 0.10 & 3 & 0.30 \\
\hline 3 & $\begin{array}{l}\text { Costes cambiantes de proveedores y } \\
\text { empresas de la industria }\end{array}$ & 0.40 & 5 & 2.00 \\
\hline 4 & Concentración de proveedores & 0.40 & 5 & 2.00 \\
\hline & Puntuación Final & & & $\mathbf{4 . 4 0}$ \\
\hline
\end{tabular}

En promedio la fuerza es de 4.40 puntos, una ponderación alta, lo que es una buena señal, debido a que en el mercado existen variados proveedores en relación a las adquisiciones de los insumos que utiliza la empresa

\subsubsection{Competencia en el mismo sector.}

La rivalidad define la rentabilidad de un sector porque cuantos menos competidores se encuentren en un sector, normalmente será más rentable y viceversa. Es por ello por lo que 
esta fuerza es considerada la más importante, ya que cuando existe mucha rivalidad en la industria, se puede ver afectada la utilidad de la empresa. (Porter, 2008)

Tomando como referencia lo citado en el párrafo precedente, se puede determinar que en la actualidad existen cuatro (04) empresa que compiten en el mercado de tubos y esquineros de cartón. Así mismo, se tomará en cuenta los siguientes factores que determinarán a un competidor potencial: Infraestructura, tecnología, crecimiento de la empresa, costos fijos, costos variables, diferenciación del producto, barreras de salida y estrategias empresariales.

A continuación, listamos las empresas que compiten en el mercado de tubos y esquineros:

CARVIMSA: Empresa líder en el mercado con un $43 \%$ de participación. Cuenta con máquinas de última generación y una cartera diversificada de productos y clientes.

Acinsa Tubos S.A.: Empresa pionera en el mercado de tubos de cartón, ocupando un posicionamiento en el mercado de un $19 \%$.

Tuboquimsa: Empresa peruana con participación del 19\% en el mercado nacional.

Trupal: Empresa con sólido respaldo financiero del Grupo Gloria, que atiende a diferentes sectores del mercado peruano. Actualmente tiene una participación del 7\%.

Por otro lado, la barrera de salida para CARVIMSA es alta, ya que cuenta con Maquinarias de alta tecnología y además porque tiene un alto apalancamiento financiero a largo plazo.

A continuación, se muestran los factores que determinan la rivalidad entre los competidores existentes: 
Tabla 50

Factores Determinantes de la Rivalidad entre los Competidores Existentes

\begin{tabular}{llccc}
\hline $\mathrm{N}^{\circ}$ & Determinantes & Ponderación & $\begin{array}{l}\text { Nivel de } \\
\text { Atractividad } \\
\text { (Del 1 al 5) }\end{array}$ & Resultado \\
& & 0.10 & 2 & 0.20 \\
\hline 1 & Diferencia de productos & 0.40 & 5 & 2.00 \\
\hline 2 & Costes fijos & 0.30 & 4 & 1.20 \\
\hline 3 & Identidad de Marca & 0.10 & 5 & 0.50 \\
\hline 4 & Diversidad de Competidores & 0.10 & 1 & 0.10 \\
\hline 5 & Barreras de Salida & & & $\mathbf{4 . 0 0}$ \\
\hline & Puntuación Final & &
\end{tabular}

En promedio la fuerza es de 4.00 puntos, esto quiere decir que la cantidad de competidores que existen en el mercado no es grande en número, pero sí es alta potencialmente sobre todo ante la posibilidad de que el competidor Trupal decida involucrarse más en la UEN Tubos y Esquineros ya que actualmente su mayor participación es en cajas de cartón; por lo que para competir fuertemente en el mercado se debe trabajar con alguna diferenciación. 


\subsection{Matriz de atractividad de cada una de las fuerzas}

Tabla 51

Matriz de atractividad de cada una de las Cinco Fuerzas de Porter

\begin{tabular}{llc}
\hline $\mathrm{N}^{\circ}$ & Fuerza de Porter & Nivel de Atractividad \\
\hline 1 & Amenaza de ingreso de productos sustitutos & 2.60 \\
\hline 2 & Amenaza de entrada de competidores potenciales & 4.40 \\
\hline 3 & Poder de negociación de los clientes & 4.35 \\
\hline 4 & Poder de negociación de los proveedores & 4.40 \\
\hline 5 & Rivalidad entre competidores del mismo sector & 4.00 \\
\hline
\end{tabular}

Se concluye que la industria a la cual se enfrenta CARVIMSA es atractiva, debido a que el rubro no se encuentra deteriorado, se observa el grado de importancia que tiene cada una de las fuerzas en el desenvolvimiento de la empresa en el mercado y que para minimizar los riegos a los cuales se puede enfrentar se puede desarrollar variados ajustes para mejorar el negocio, crecimiento, fidelización, reducción de costos, entre otros.

\subsection{Análisis del grado de atractividad de la industria}

Para evaluar la posición competitiva actual de una empresa se puede utilizar diferentes bases tales como, la situación económica financiera obtenida de los estados financieros e indicadores, la valoración de los elementos que forman parte de su ventaja competitiva, la demanda actual en el mercado, la tecnología entre otros. A pesar de existir muchas formas de valorar la posición competitiva de una empresa, siempre se debe incluir un análisis y valorar el entorno donde se desenvuelve el negocio de modo que facilite la compresión ante los cambios que se podrían suscitar originando impacto en la empresa. Todo lo antes mencionado se debe realizar de acuerdo con el sector industrial en el que compite la empresa considerando las características propias e inherentes a la empresa. La finalidad de aplicar este modelo es confirmar el grado de atractividad de la industria en la que la empresa compite. 
Para medir el grado de atractividad de la industria se puede usar diferentes herramientas como las matrices de cartera o el modelo desarrollado por Michael Porter que identifica y valora las fuerzas determinantes de la industria. (David, 2013).

Luego de analizar los factores de la matriz de atractividad de cada fuerza, se ha concluido que el grado de atractividad de la industria es alta debido a que los competidores son pocos y el crecimiento de la industria en relación con los tubos y esquineros muestra una tendencia positiva, gracias al incremento de las exportaciones. Sin embargo, el producto al ser de tipo no diferenciado hace que el nivel de atractividad se reduzca ya que los clientes lo pueden adquirir a otros proveedores.

\subsection{Matriz de Perfil Competitivo (MPC)}

La matriz de perfil competitivo identifica a los principales competidores de la empresa, así como sus fortalezas y debilidades particulares en relación con la posición estratégica de una firma muestra. Los factores críticos de éxito en una MPC incluyen tanto cuestiones externas como internas, las calificaciones se refieren a las fortalezas y amenazas.

(David, 2013).

Tabla 52

Tabla de Calificaciones de la Matriz MPC

\begin{tabular}{cl}
\hline Calificación & Factor crítico de éxito \\
\hline 4 & Fortaleza Principal \\
\hline 3 & Fortaleza Menor \\
\hline 2 & Debilidad Menor \\
\hline 1 & Debilidad Principal
\end{tabular}

Nota: Adaptado de "Administración estratégica" por David, 2013, p. 83. Copyright 2013 por Pearson Education. 
En la matriz MPC las calificaciones y las puntuaciones ponderadas totales para las empresas competidores pueden ser comparadas contra la empresa muestra. Este análisis comparativo arroja importante información estratégica interna. Entre los objetivos principales de la elaboración y análisis de la matriz MPC se encuentran:

- Mantener una ventaja competitiva es el propósito primordial del desarrollo de las listas de oportunidades y amenazas.

- Resaltar los factores importantes, según el rumbo que se quiere dar a la empresa, determinando cómo y por qué estos factores pueden dar como resultado una ventaja competitiva.

- Dejar en claro cómo la empresa puede superar a los competidores o al menos competir con ellas en cuanto a rentabilidad.

- Determinar las razones claves de cómo y por qué la empresa en análisis puede prosperar entre sus competidores.

La matriz MPC refleja la posición de la UEN Tubos y Esquineros de CARVIMSA frente a los principales competidores. Según los resultados de la matriz, CARVIMSA se encuentra en un nivel competitivo alto, frente a sus principales competidores Acinsa Tubos S.A., Tuboquimsa y Trupal, sin embargo, se va a analizar los valores obtenidos por cada factor de éxito.

Materia Prima obtenida del Molino Propio: Como se detalló en el capítulo I, CARVIMSA cuenta con un molino propio, durante el proceso de fabricación de cajas de cartón corrugado, UEN principal, el corte de las bobinas genera una merma denominada Side Roll, lo cual sirve como materia prima para la elaboración de los tubos. La ventaja frente a los competidores es el fácil acceso al insumo principal lo que permite a CARVIMSA no depender al 100\% de la importación de materia prima, sus competidores Acinsa, Tuboquimsa 
no cuentan con molino propio, parte de su materia prima la importan y la otra parte la compran a proveedores locales; ello le da a CARVIMSA la clasificación de "Fortaleza Principal". Sin embargo, Trupal si cuenta con un molino propio pero el mercado de tubos y esquineros no le es atractivo.

Posición Financiera: Si bien es cierto la UEN Tubos y Esquineros no es la que aporta mayores ingresos a CARVIMSA, ha crecido notablemente en los últimos años, ha ganado un segmento diferente de mercado y tiene potencial para incrementar su rentabilidad.

CARVIMSA cuenta con una saludable posición financiera, gracias al respaldo financiero del Grupo Comeca, ello es una "Fortaleza Mayor". Con respecto a Acinsa en los últimos meses ha reducido sus precios lo cual le está generando pérdidas, sin embargo, las otras dos empresas están financieramente consolidadas.

Calidad del Producto: CARVIMSA se encuentra liderando este factor, ya que las bobinas de papel que utiliza, al ser originalmente para cajas de cartón, son de calidad. Esto se refleja en la resistencia a la humedad del producto lo cual está especificado en la ficha técnica. Las otras dos empresas, que no cuentan con molino propio, compran Side Rolls de segunda, por esta razón el valor de la clasificación para CARVIMSA es de "Fortaleza Principal”.

Participación de Mercado: Este factor de éxito es una "Fortaleza Principal" para CARVIMSA que vende al mes 470 toneladas mientras que su principal competidor Acinsa vende 250 toneladas mensuales. CARVIMSA tiene una participación de $43 \%$ en el mercado nacional mientras que su competidor principal solo tiene un aporte de $19 \%$.

Medio Ambiente: CARVIMSA cumple con los estándares requeridos para la protección y cuidado del medio ambiente, es por eso por lo que su clasificación es de 
“Fortaleza Mayor”. Por otro lado, es preciso señalar que la empresa Trupal cuenta con indicios de contaminación ambiental en su planta de Trujillo.

Competitividad de Precios: En este factor CARVIMSA lidera en competitividad de precios porque gracias a sus óptimos costos ha logrado reducir los precios, afectando a Acinsa que frente a esta situación también ha reducido sus precios, pero al parecer no ha optimizado el costo de la materia prima por lo que está generando pérdidas. CARVIMSA tiene poder de fijación de precios, es por eso por lo que se clasifica como "Fortaleza Principal".

Capacidad Tecnológica: CARVIMSA tiene actualmente mejor tecnología respecto a Acinsa y Tuboquimsa. En cuanto a las máquinas tuberas no hay mayor diferencia, pero en lo que respecta a las salas de hornos, estas cuentan con conexión a gas natural haciendo que tenga mayor rapidez y consistencia en el secado, mientras que Acinsa tiene hornos de madera que funcionan con carbón, generando contaminación ambiental. CARVIMSA se encuentra liderando este factor y su calificación es de "Fortaleza principal". 
Tabla 53

Matriz de Perfil Competitivo

\begin{tabular}{|c|c|c|c|c|c|c|c|c|c|}
\hline \multirow{2}{*}{$\begin{array}{l}\text { Factores } \\
\text { importantes para } \\
\text { el éxito }\end{array}$} & \multirow[b]{2}{*}{ Valor } & \multicolumn{2}{|l|}{ CARVIMSA } & \multicolumn{2}{|l|}{ Acinsa } & \multicolumn{2}{|l|}{ Tuboquimsa } & \multicolumn{2}{|l|}{ Trupal } \\
\hline & & Clasificación & Puntaje & Clasificación & Puntaje & Clasificación & Puntaje & Clasificación & Puntaje \\
\hline Molino propio & 0.3 & 4 & 1.2 & 1 & 0.3 & 1 & 0.3 & 4 & 1.2 \\
\hline $\begin{array}{l}\text { Posición } \\
\text { financiera }\end{array}$ & 0.1 & 4 & 0.4 & 1 & 0.1 & 2 & 0.2 & 4 & 0.4 \\
\hline $\begin{array}{l}\text { Calidad del } \\
\text { producto }\end{array}$ & 0.2 & 4 & 0.8 & 2 & 0.4 & 2 & 0.4 & 3 & 0.6 \\
\hline $\begin{array}{l}\text { Participación } \\
\text { de mercado }\end{array}$ & 0.15 & 4 & 0.6 & 3 & 0.45 & 3 & 0.45 & 1 & 0.15 \\
\hline $\begin{array}{l}\text { Medio } \\
\text { ambiente }\end{array}$ & 0.1 & 4 & 0.4 & 2 & 0.2 & 2 & 0.2 & 1 & 0.1 \\
\hline $\begin{array}{l}\text { Competitividad } \\
\text { de precios }\end{array}$ & 0.05 & 4 & 0.2 & 2 & 0.1 & 2 & 0.1 & 3 & 0.15 \\
\hline $\begin{array}{l}\text { Capacidad } \\
\text { tecnológica }\end{array}$ & 0.1 & 4 & 0.4 & 2 & 0.2 & 2 & 0.2 & 4 & 0.4 \\
\hline Total & 1 & & 4.00 & & 1.75 & & 1.85 & & 3.00 \\
\hline
\end{tabular}

Nota. Obtenido de Entrevista con el Gerente General y de las Entrevistas realizadas a los clientes de

CARVIMSA y clientes de la competencia.

\subsection{Matriz VRIO}

El análisis Valor, Raro, Imitable y Organización (VRIO) fue desarrollado para ayudar a evaluar qué recursos internos proporcionan ventaja competitiva, cuáles se debe considerar como vitales y aquéllos que son más prescindibles. Las organizaciones han de ser conscientes de que la base de sus ventajas competitivas se cimienta en los recursos con los que cuentan y en el correcto uso que hacen de ellos. Estos recursos internos pueden ser financieros, humanos, materiales y no materiales (de conocimiento, información, cultura). 
Tabla 54

Matriz Vrio

Tipo de Recurso

\section{Descripción}

\begin{tabular}{ll}
\hline Valor & $\begin{array}{l}\text { El concepto de Valor de un recurso viene } \\
\text { dado por su capacidad para aprovechar una } \\
\text { oportunidad de mercado o minimizar una } \\
\text { amenaza. }\end{array}$ \\
\hline \multirow{3}{*}{ Raro } & $\begin{array}{l}\text { Un recurso Raro es aquel de acceso } \\
\text { reducido, que no está al alcance de todos o } \\
\text { que es limitado. Representa un alto valor } \\
\text { para la organización, aunque puede ser un } \\
\text { recurso difícil de conseguir. }\end{array}$ \\
\hline \multirow{3}{*}{ Imitable } & $\begin{array}{l}\text { Cuando un producto o servicio tiene éxito, } \\
\text { los competidores querrán imitarlo y } \\
\text { ofrecerlo a los clientes mucho más barato, } \\
\text { para superar la imagen de marca ya creada }\end{array}$ \\
& $\begin{array}{l}\text { Se deben organizar todos sus sistemas de } \\
\text { gestión para alcanzar el pleno potencial de } \\
\text { estos recursos, capturando y generando } \\
\text { valor para el cliente. El resultado será una } \\
\text { ventaja competitiva perdurable }\end{array}$ \\
\hline
\end{tabular}

Nota: Adaptado de "El análisis Vrio y la Ventaja Competitiva" por David, 2013, p. 83.

Copyright 2013 por Pearson Education. 
Tabla 55

Recursos Matriz Vrio

\begin{tabular}{|c|c|c|c|c|c|}
\hline Recursos & Valioso & Raro & $\begin{array}{l}\text { Difícil } \\
\text { de } \\
\text { Imitar }\end{array}$ & $\begin{array}{c}\text { Organizació } \\
\text { n alineada } \\
\text { con recursos }\end{array}$ & Resultado \\
\hline $\begin{array}{l}\text { Ausencia de un área funcional de } \\
\text { mercadotecnia y gerente de } \\
\text { producción }\end{array}$ & No & & & & $\begin{array}{l}\text { Desventaja } \\
\text { Competitiva }\end{array}$ \\
\hline Posición financiera fuerte & Sí & No & & & Igualdad Competitiva \\
\hline Competitividad de precios & $\mathrm{Si}$ & No & & & Igualdad Competitiva \\
\hline Prontitud en la entrega & Sí & No & & & Igualdad Competitiva \\
\hline Área de servicio al cliente & Sí & No & & & Igualdad Competitiva \\
\hline Innovación de procesos & Sí & No & & & Igualdad Competitiva \\
\hline $\begin{array}{l}\text { Sin antecedentes de contaminación } \\
\text { ambiental }\end{array}$ & $\mathrm{Si}$ & Sí & No & & $\begin{array}{l}\text { Ventaja Competitiva } \\
\text { Temporal }\end{array}$ \\
\hline Hornos con conexión a gas natural & $\mathrm{Si}$ & Sí & No & & $\begin{array}{l}\text { Ventaja Competitiva } \\
\text { Temporal }\end{array}$ \\
\hline Servicio Técnico y post venta & Sí & Sí & No & & $\begin{array}{l}\text { Ventaja Competitiva } \\
\text { Temporal }\end{array}$ \\
\hline Alta capacidad tecnológica & Sí & Sí & Sí & No & $\begin{array}{l}\text { Ventaja Competitiva } \\
\text { por Explotar }\end{array}$ \\
\hline $\begin{array}{l}\text { Materia prima obtenida del Molino } \\
\text { propio }\end{array}$ & Sí & Sí & Sí & $\mathrm{Si}$ & $\begin{array}{l}\text { Ventaja Competitiva } \\
\text { Sostenible }\end{array}$ \\
\hline Calidad y especificaciones técnicas & Sí & $\mathrm{Si}$ & Sí & Sí & $\begin{array}{l}\text { Ventaja Competitiva } \\
\text { Sostenible }\end{array}$ \\
\hline
\end{tabular}

Nota. Obtenido de Entrevista con los Gerentes de CARVIMSA.

Se puede concluir, que la UEN Tubos y Esquineros tiene 2 grandes ventajas competitivas sostenibles en el tiempo; la primera es la materia prima que proviene del molino propio que es la UEN Papel y Empalmadas y la segunda es la calidad que tienen los productos ya que las bobinas de papel son para elaboración de cajas de cartón con mayor resistencia en comparación con las que los competidores usan. Adicionalmente la calidad está ligada a que CARVIMSA cuenta con un área de especificaciones técnicas para asesorar al cliente antes de la fabricación realizando pruebas y muestras para que el cliente de su visto con el objetivo de que al final se lleve un producto que encaje mejor con su necesidad. 


\subsection{Matriz y Gestión de Riesgos}

\subsubsection{Identificación de los Riesgos.}

El objetivo del proceso de Identificar los Riesgos es conseguir un registro de riesgos lo más completo y fiable posible.

Se ha establecido el listado de riesgos teniendo como base el análisis FODA

\subsubsection{Riesgo Moderado de Crecimiento del Mercado}

La economía está en constantes cambios y se mueve por ciclos económicos, ya sean de recesión o expansión, el riesgo que los sectores económicos relacionados a la UEN no crezcan de acuerdo a las proyecciones consideradas podría afectar el crecimiento del mercado.

\subsubsection{Riesgo Tipo de Cambio}

La UEN paga a sus proveedores del exterior en moneda extranjera para lo cual ha considerado las proyecciones del tipo de cambio establecidas por el BCRP, un cambio brusco en dichas cifras podría afectar la liquidez de la empresa para cumplir con sus obligaciones.

\subsubsection{Riesgo Crediticio}

Según la proyección de los EEFF, el ratio de cuentas por cobrar está a la baja, por lo que posibles cambios en la economía o factores exógenos podrían comprometer la posición financiera de los clientes de UEN generando un riesgo de incumplimiento de pagos. Los clientes actuales de la UEN Tubos son clientes sólidos financieramente sin antecedentes de problemas crediticios, por otro lado, firman letras de cambio lo cual es una herramienta para negociar con bancos. Respecto a los clientes de la línea de esquineros sí podrían traer riesgo ya que son del sector agroexportación y por posibles desastres naturales que se den en el país 
podrían acogerse a los beneficios de no pago que brinda el estado y eso perjudicaría a la UEN.

\subsubsection{Riesgo de Localización}

Los costos por fletes para enviar los productos a los clientes son altos debido a la localización de las plantas, por ello existe un riesgo actual de incurrir en sobrecostos.

\subsubsection{Riesgos Operativos}

La falta de capacitación y ausencia de procedimientos de trabajo generan un riesgo de que los operarios cometan errores humanos que se trasladen al proceso productivo por ende generen costos y gastos variables.

\subsubsection{Riesgo de Liquidez}

Aunque la probabilidad de este tipo de riesgo es baja, se considera debido que existe un riesgo crediticio ya que en mayor porcentaje finanzas depende de los ingresos de clientes pero por otro tiene el respaldo financiero del grupo.

\subsubsection{Riesgo Contractual (Solpack)}

El riesgo de que Solpack no cumpla con el contrato establecido de incremento del volumen de ventas es casi mínimo ya que existen cláusulas de penalidades por incumplimiento en el contrato.

\subsubsection{Riesgo Volatilidad del Comodity Cartón}

Aunque no es un riesgo directo para esta unidad sino para la Unidad de Bobinas de papel y cartón un incremento en los costos significaría un incremento en el reciclado del side roll sobre costeando la materia prima como principal variable para la UEN Tubos y Esquineros. 
Se determinó si el riesgo es una amenaza o una oportunidad, adicionalmente se clasificó por categoría.

Tabla 56

Categoría de Riesgo

Riesgo

Tipo de Riesgo

Categoría de Riesgo

Amenaza Oportunidad

\begin{tabular}{|c|c|c|}
\hline Riesgo Moderado crecimiento del mercado & $\mathrm{x}$ & Económico \\
\hline Riesgo de Tipo de Cambio & $\mathrm{x}$ & Económico \\
\hline Riesgo Crediticio & $\mathrm{x}$ & Clientes \\
\hline Riesgo de Localización & $\mathrm{x}$ & Otros \\
\hline Riesgo Operativo & & Equipo de trabajo \\
\hline Riesgo de Liquidez & $\mathrm{x}$ & Financiero \\
\hline Riesgo Contractual (Solpack) & & Clientes \\
\hline Riesgo Volatilidad del Comodity Cartón & $x$ & Proveedores \\
\hline
\end{tabular}

Nota. Obtenido de Entrevista con los Gerentes de CARVIMSA.

Se asignó el tipo de objetivo del proyecto, así como también si el impacto es directo o indirecto.

Tabla 57

Tipo de Impacto

Riesgo

Objetivo de proyecto afectado

Tipo de Impacto

Alcance Tiempo Costo Calidad Directo Indirecto

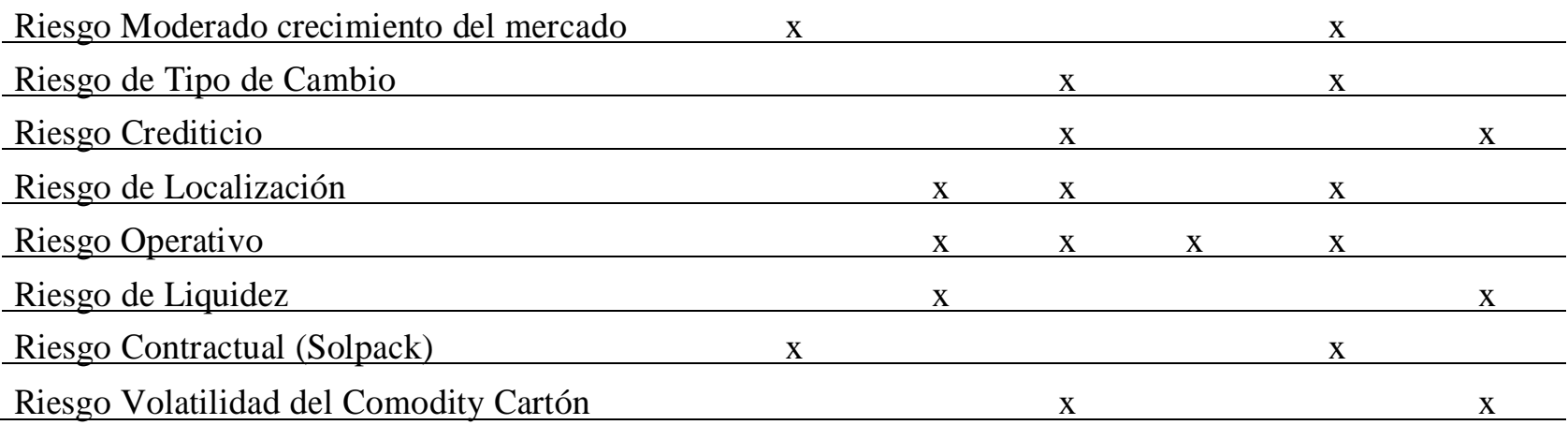

Nota. Obtenido de Entrevista con los Gerentes de CARVIMSA. 
Los expertos de las áreas involucradas valorizaron la probabilidad y el impacto de cada riesgo, obteniendo los siguientes resultados.

Tabla 58

Valoración de Impacto y Prioridad de la UEN Tubos y Esquineros

\begin{tabular}{lcccccccc}
\multicolumn{1}{c}{ Riesgo } & Probabilidad & & \multicolumn{2}{c}{ Valoración de Impacto } & $\begin{array}{c}\text { Valoración } \\
\text { Global del } \\
\text { Riesgo }\end{array}$ & Prioridad \\
\hline & & Alcance & Tiempo & Costo & Calidad & & \\
\hline $\begin{array}{l}\text { Riesgo Moderado } \\
\text { crecimiento del mercado }\end{array}$ & 0.40 & 1.00 & 0.10 & - & - & 0.07 & Baja \\
\hline $\begin{array}{l}\text { Riesgo de Tipo de } \\
\text { Cambio }\end{array}$ & 0.10 & 0.20 & - & 0.20 & - & 0.00 & Baja \\
\hline $\begin{array}{l}\text { Riesgo Crediticio } \\
\text { Riesgo de Localización }\end{array}$ & 0.40 & 1.00 & 1.00 & 1.00 & 1.00 & 0.40 & Media \\
\hline $\begin{array}{l}\text { Riesgo Operativo } \\
\text { Riesgo de Liquidez }\end{array}$ & 0.70 & 0.60 & 0.80 & 0.80 & - & 0.49 & Media \\
\hline $\begin{array}{l}\text { Riesgo Contractual } \\
\text { (Solpack) }\end{array}$ & 0.50 & 1.00 & 1.00 & 1.00 & 1.00 & 0.50 & Media \\
\hline $\begin{array}{l}\text { Riesgo Volatilidad del } \\
\text { Comodity Cartón }\end{array}$ & 0.10 & - & 0.10 & - & - & 0.01 & Baja \\
\hline
\end{tabular}

\section{Matriz de Riesgo}

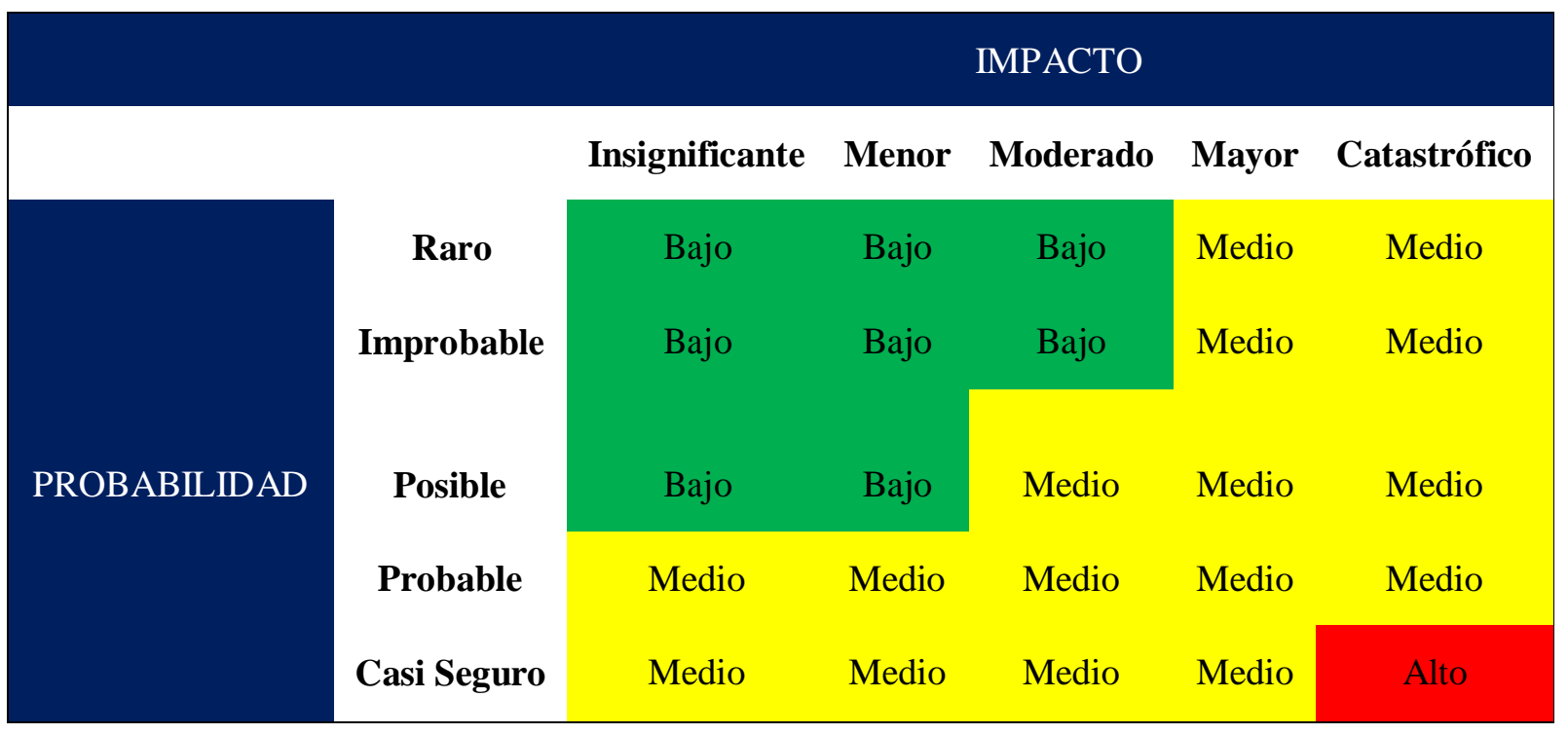

Figura 76. Matriz de Riesgo de la UEN Tubos y Esquineros 


\section{Gestión del Riesgo}

Se procedió a identificar a los responsables de alertar sobre la existencia del riesgo y su probabilidad de ocurrencia, así como el impacto que tendría cada uno de ellos en la UEN.

Tabla 59

Responsables de Identificación del Riesgo

Riesgo

Riesgo Moderado crecimiento del mercado

Riesgo de Tipo de Cambio

Riesgo Crediticio

Riesgo de Localización

Riesgo Operativo

Riesgo de Liquidez

Riesgo Contractual (Solpack)

Riesgo Volatilidad del Comodity Cartón

\section{Responsable}

Jefatura de Ventas

Gerencia de Finanzas Jefatura de Créditos Jefatura de despachos Jefatura de Planta Gerencia de Finanzas Jefatura de Ventas Jefatura de Logística

Nota. Obtenido de Entrevista con los Gerentes de CARVIMSA.

Como segundo paso, se determina la estrategia de respuesta adaptada dependiendo si el riesgo es una amenaza o una oportunidad.

Tabla 60

Estrategia de Respuesta adaptada

Riesgo
Estrategia de Respuesta adaptada Mitigar Aceptar Evitar Aceptar Explotar Evitar Explotar Aceptar

\begin{tabular}{lc} 
Riesgo Moderado crecimiento del mercado & Mitigar \\
Riesgo de Tipo de Cambio & Aceptar \\
Riesgo Crediticio & Evitar \\
\hline Riesgo de Localización & Aceptar \\
\hline Riesgo Operativo & Explotar \\
Riesgo de Liquidez & Evitar \\
Riesgo Contractual (Solpack) & Explotar \\
Riesgo Volatilidad del Comodity Cartón & Aceptar
\end{tabular}

Nota. Obtenido de Entrevista con los Gerentes de CARVIMSA. 
Luego de establecer la estrategia se determina el plan de respuesta adaptado, el cual ayudará a la UEN a mitigar, evitar, explotar o disminuir el impacto en caso de que la estrategia sea la aceptación del riesgo.

Tabla 61

Plan de Respuesta Adaptado del Riesgo - UEN Tubos y Esquineros

\section{Riesgo}

\section{Plan de Respuesta adaptado}

\begin{tabular}{ll}
$\begin{array}{l}\text { Riesgo Moderado } \\
\text { crecimiento del mercado }\end{array}$ & Penetración de Mercado \\
\hline Riesgo de Tipo de Cambio & EEFF incluyen Proyección por Diferencias de Cambio \\
\hline Riesgo Crediticio & $\begin{array}{l}\text { Seleccionar Clientes con bajo riesgo crediticio } \\
\text { Establecer políticas más exigentes para evaluación de créditos }\end{array}$ \\
\hline Riesgo de Localización & Mejorar la planificación de rutas de distribución \\
\hline Riesgo Operativo & $\begin{array}{l}\text { Capacitaciones } \\
\text { Plasmar procedimientos de trabajo }\end{array}$ \\
\hline & $\begin{array}{l}\text { Deriva de evitar el riesgo crediticio ya que la mayor parte de } \\
\text { ingresos viene de clientes }\end{array}$ \\
Riesgo de Liquidez & No financiamiento con bancos sino respaldo del Grupo Comeca \\
\hline & $\begin{array}{l}\text { Cumplir con los plazos de entrega según contrato establecido } \\
\text { con el fin de ampliar las ventas }\end{array}$ \\
Riesgo Contractual (Solpack) & Contar con stock balanceado y stock de seguridad con el fin de \\
Riesgo Volatilidad del & que el impacto sea menor \\
Comodity Cartón & Nota. Obtenido de Entrevista con los Gerentes de CARVIMSA.
\end{tabular}




\section{Capítulo VI. Análisis Interno}

La realización del análisis interno permite identificar y evaluar las fortalezas y debilidades de la UEN Tubos y Esquineros de CARVIMSA en sus áreas funcionales tales como administración, marketing, finanzas y contabilidad, producción y operaciones, investigación y desarrollo, así como los sistemas de administración de información. (David, 2013)

El proceso empleado ayudó a determinar las relaciones entre las áreas funcionales analizando la cadena de valor (ACV) para identificar qué actividades de la UEN Tubos y Esquineros generan valor a sus clientes; seguidamente se midió el desempeño de aquellas actividades empleando indicadores de gestión para luego comparar el desempeño alcanzado en las actividades con el desempeño que presentan actividades similares de competidores de la industria; en base a los resultados obtenidos de la comparación se pudo obtener si la empresa cuenta con fortalezas o si muestra debilidades con relación a sus competidores más relevantes.

\subsection{Descripción de las actividades de la cadena de valor de la empresa, logística interna, operaciones, logística externa, mercadotecnia, servicios, adquisiciones, RR.HH., tecnología e infraestructura.}

La mejor forma de describir el negocio de una empresa es como una cadena de valor, en la cual los ingresos totales menos los costos totales de todas las actividades emprendidas para desarrollar y comercializar un producto o servicio producen valor. El análisis de la cadena de valor $(\mathrm{ACV})$ se refiere al proceso por el cual una empresa determina el costo asociado con actividades de la organización, desde la compra de la materia prima hasta la fabricación del producto y comercialización (Porter, 2008). 


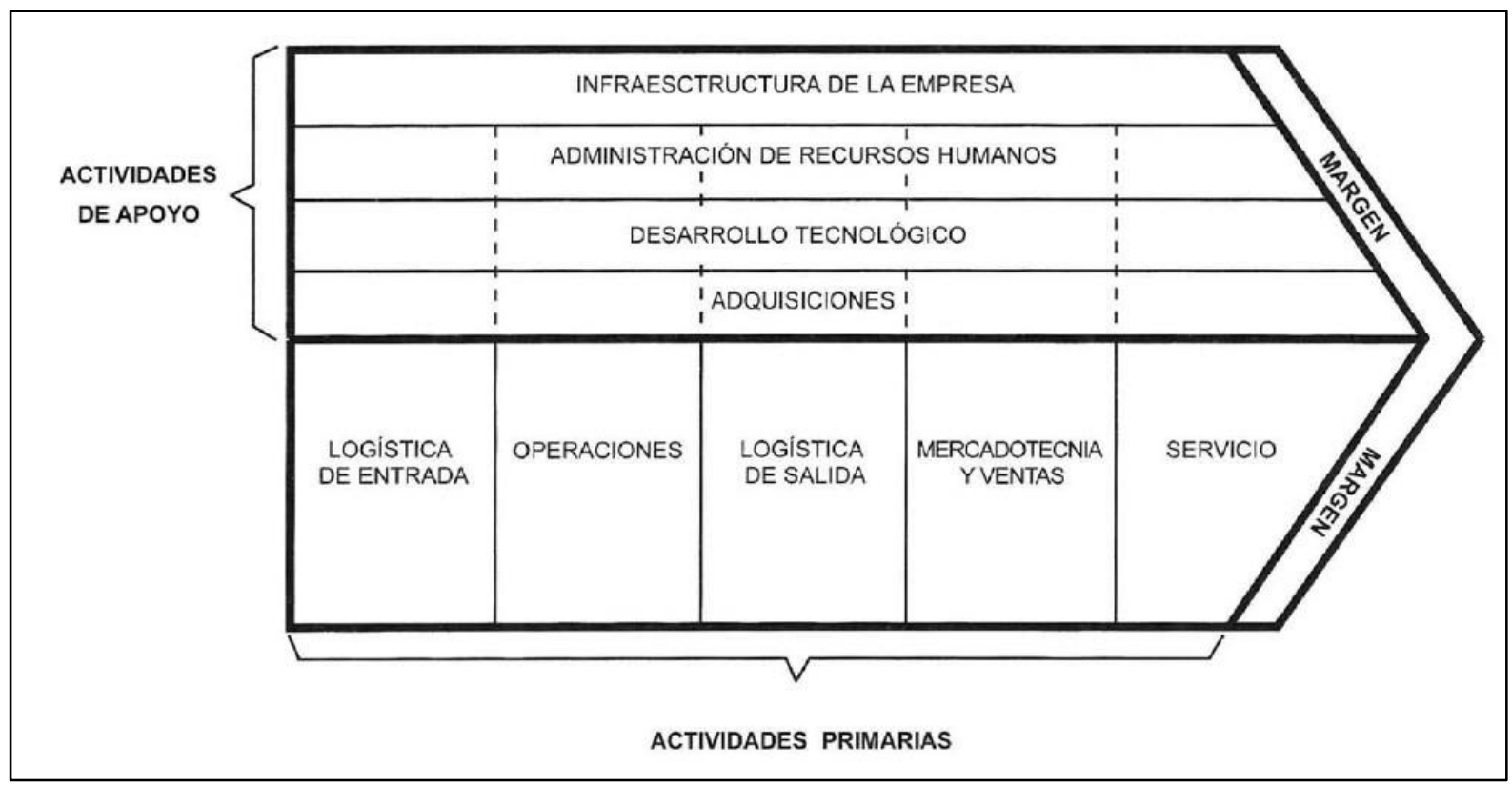

Figura 77. La cadena genérica de Valor. Tomado de Ventaja Competitiva. Porter

A continuación, se describirán las operaciones de la cadena de valor de la UEN Tubos y Esquineros de CARVIMSA lo cual permitirá identificar mejor las fortalezas y debilidades, en relación con el ACV de su principal competidor Acinsa SA.

\section{Logística Interna}

La importancia de este eslabón de la cadena de valor radica en la preparación para cubrir las expectativas y necesidades de los clientes actuales y de los clientes potenciales, para ello se debe tener un correcto entendimiento del cliente. Los ejecutivos de ventas se reúnen con los clientes para determinar sus necesidades y requerimientos, se le presenta la serie de presentaciones de los productos que ofrece la UEN Tubos y Esquineros.

Las especificaciones solicitadas por los clientes están en función a tres puntos: la resistencia, la consistencia a la humedad y la fractura del tubo. Los clientes proporcionan las medidas del diámetro, el espesor y el largo del tubo. Dependiendo de dichas especificaciones técnicas y del volumen de la venta es que se realiza la cotización. 
El personal que se desempeña en esta UEN debe de contar con equipos de protección al personal para minimizar y eliminar los accidentes de trabajos originados por malas prácticas y por falta de conocimiento técnico operativo. Para ello, CARVIMSA cuenta con un área de Seguridad Industrial que programa capacitaciones y auditorias de cumplimiento del uso de sus Equipos de protección al personal (EPP). Los EPP se renuevan dos veces al año con la finalidad de que los operarios tengan herramientas en óptimas condiciones.

La certificación con la que cuenta actualmente es Business Alliance for Secure Commerce o Alianza Empresarial para un Comercio Seguro (BASC).

Con respecto a las técnicas utilizadas para el almacenamiento de materia prima, insumo y productos terminados, se debe considerar los siguientes puntos:

- Espacio de almacenamiento por zonas

- Optimización de rutas para el traslado del producto

- Técnicas de almacenamiento y procesos a ejecutar

- Codificar los productos ya sea por lotes o por fechas de vencimiento

El almacenamiento dependerá mucho de las dimensiones de la característica de los productos, ya sea por un buen espacio disponible por los tipos de materiales, el número de artículos y velocidad d atención necesaria. (Brenes, 2015)

A continuación, se lista las principales técnicas del proceso:

Técnica de proceso de carga unitaria, está constituida por embalajes de transporte que acondiciona una cierta cantidad de material para posibilitar su manipulación y almacenamiento. Esta puede variar dependiendo de la necesidad. (Brenes, 2015) 
Técnica del proceso de apilamiento, corresponde a una variación del almacenamiento de tubos y esquineros para aprovechar el máximo del espacio vertical ya que estos productos ocupan más volumen que peso por ende los apilamientos deben ser en orden vertical. (Brenes, 2015)

\section{Operaciones}

En el caso de producción de los tubos, se realiza el espiralado de varias capas de papel, unidas con adhesivos especiales. La cantidad de capas puede variar según las exigencias a que será sometido el tubo. Asimismo, dependiendo de la cantidad de capas de papel utilizadas para realizar un determinado tubo, se obtendrán distintos espesores y distintas resistencias.

El cartón utilizado para tubos debe tener un gramaje de 200 gramos como mínimo, con ello se pueden fabricar tubos de a partir de $2 \mathrm{~mm}$ de espesor con cuatro o cinco capas de cartón hasta tubos de 10 mm que tienen 30 capas. El gramaje del cartón es un aspecto importante ya que a mayor gramaje el cartón da menos vueltas en la máquina tubera y esto representa menos consumo de pegamento. La primera cinta y la última cinta deben ser las de menos gramaje, particularmente la última cinta es la que debe de procurar formar el menor surco posible en el cierre final del proceso de espiral o fabricación del tubo, muchas veces se utiliza incluso papel bond en esta sección.

Otro aspecto de importancia dentro de la producción de los tubos es la concentración de humedad del cartón, el cartón menos húmedo representa menos tiempo en el horno. Como en el caso de la fabricación de las cajas de cartón corrugado, en la fabricación de tubos de cartón también se manejan combinaciones de papeles. En el caso de la UEN Tubos y 
Esquineros de CARVIMSA obtiene la materia prima de su propio molino, cabe resaltar, que no todos los molinos tienen el mismo calibre y resistencia.

Respecto a los competidores, en ocasiones pueden hacer un mix de proveedores de cartón o en otros casos precisamente trabajan con un solo proveedor, en el caso de Acinsa combina su materia prima la cual compra de Trupal, CARVIMSA, Papelera del Sur e Industrias del Papel.

La materia prima la componen el cartón y el pegamento PVA, dentro de lo que es el cartón se necesita cartón para el forro (175 -180 gramos) y cartón para el tubo (200 gramos a más). En el caso de CARVIMSA, el cartón ingresa a la planta en forma de bobinas obtenidas del molino, es por ello por lo que hay que hacer un proceso de corte y rebobinado, en otros casos en que el cartón se adquiere en forma de cintas se destina directamente a producción. En relación al pegamento, los principales proveedores son Indusquimica, Química Industrial Amec y Vencedor, siendo el último el de mayor costo.

En las siguientes figuras se puede observar los flujogramas del proceso de venta, fabricación y despacho de la UEN Tubos y Esquineros de Cartón: 


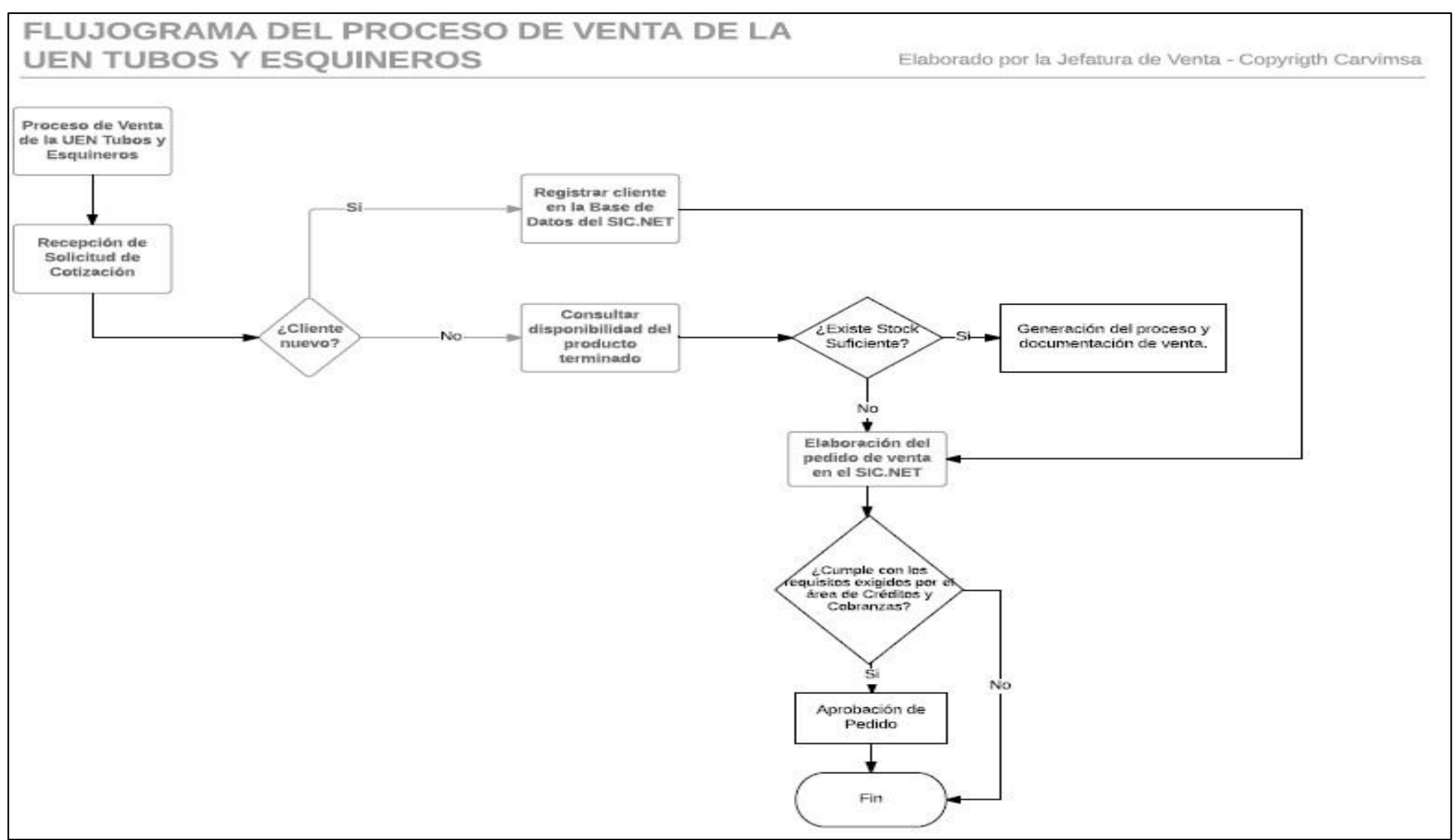

Figura 78. Flujograma de proceso de Venta de la UEN Tubos y Esquineros de Cartón. 


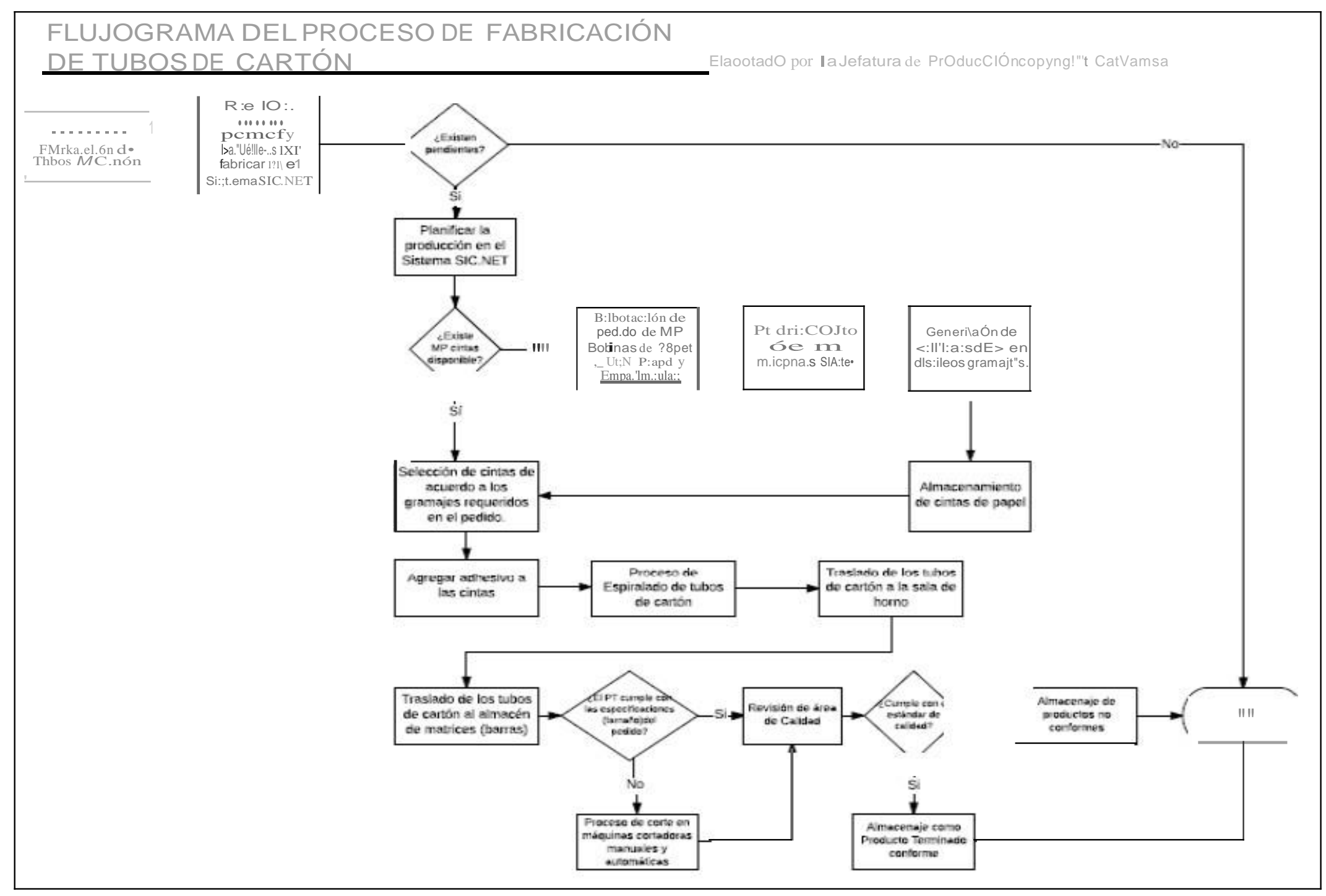

Figura 79. Flujograma de proceso de Fabricación de Tubos de Cartón. 


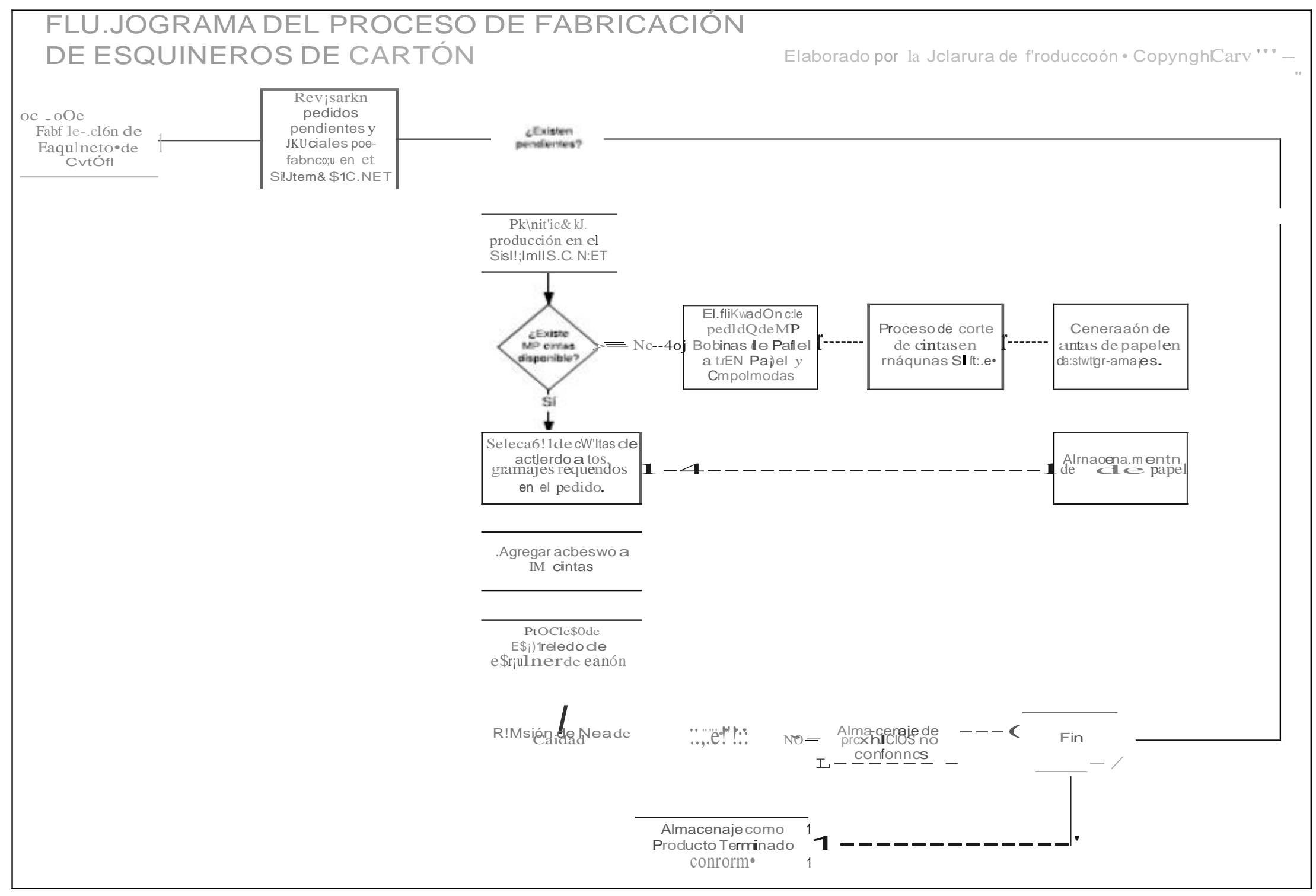

Figura 80. Flujograma de proceso de Fabricación de Esquineros de Cartón. 


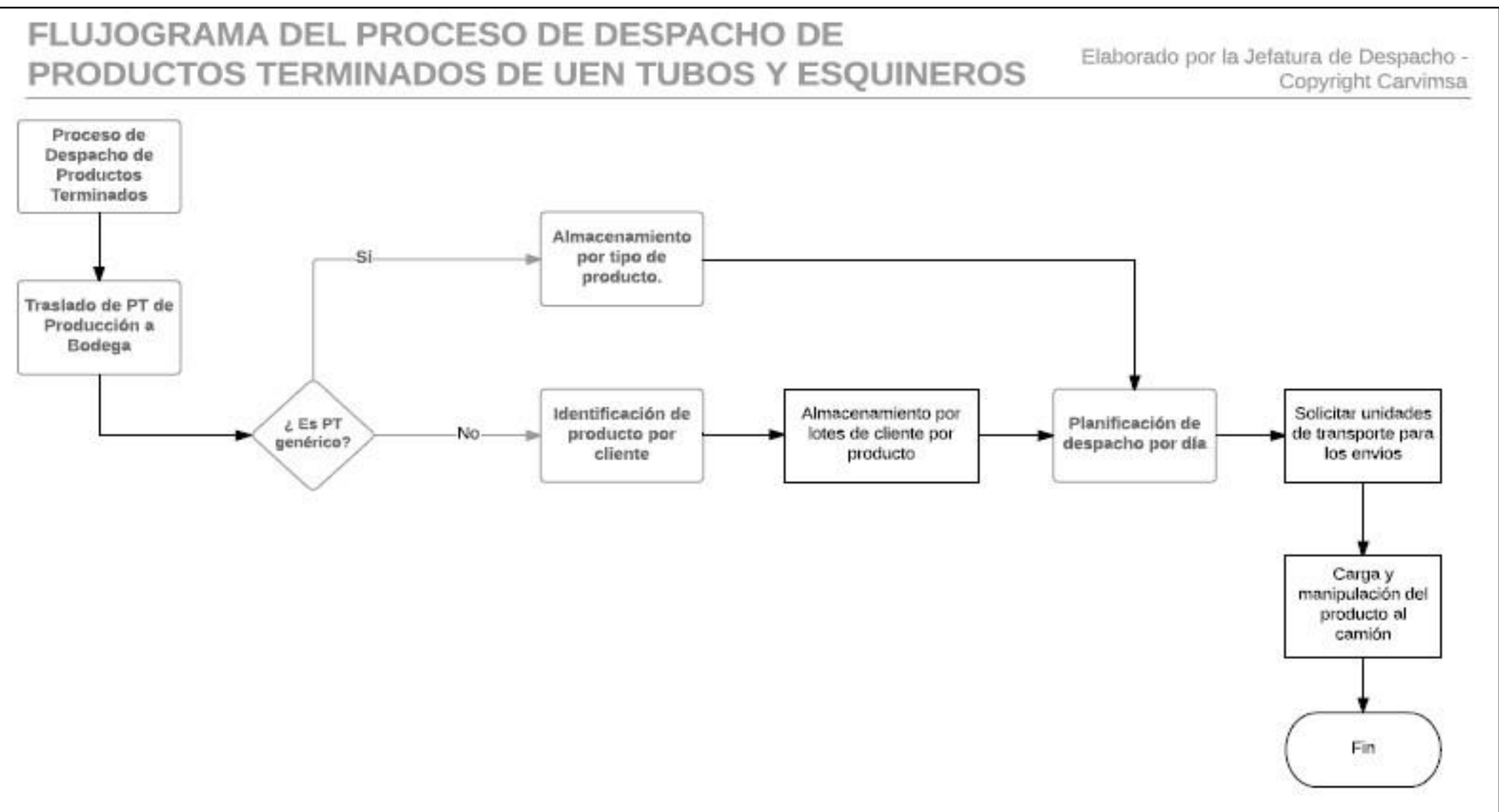

Figura 81. Flujograma de proceso de Despacho de Productos Terminados de la UEN Tubos y Esquinero de Cartón. 
A continuación, se detalla el proceso de fabricación de los tubos de cartón:

a) El proceso de corte y rebobinado, consiste en convertir una bobina en cintas o bobinas de menor ancho necesarias para la fabricación del tubo en espiral. Si la UEN Tubos de CARVIMSA continua con el crecimiento de su producción, va a necesitar más cartón del que merma el molino y tendrá que comprar su materia prima, hay que tener en cuenta que el precio del cartón en forma de cintas es más elevado. El corte y rebobinado de una bobina de una bobina de $80 \mathrm{~cm}$ se realiza en anchos de $10 \mathrm{~cm}$, en teoría debería de alcanzar para 8 cintas. Para el proceso de conversión exacto, las cintas tienen que tener ancho ascendente, la primera $10 \mathrm{~cm}$ y las siguientes 10.1, 10.2, 10.3, 10.4, 10.5 (máximo $10.5 \mathrm{~cm}$ ). Un caso especial es el corte de $12 \mathrm{~cm}$ para tubos de 12 pulgadas, aquí se genera una merma en los extremos, en promedio es de $1 \mathrm{~cm}$ por cada lado. en promedio representaría $2.5 \%$ de desperdicio. Los costos que se incurren en este proceso son mano de obra, depreciación, electricidad y merma del proceso. CARVIMSA cuenta con tres máquinas de corte y rebobinado, las tres máquinas son caseras, a comparación de Acinsa que tiene máquinas de corte y rebobinado, una de ellas es fabricación casera y la otra es más moderna de procedencia China.

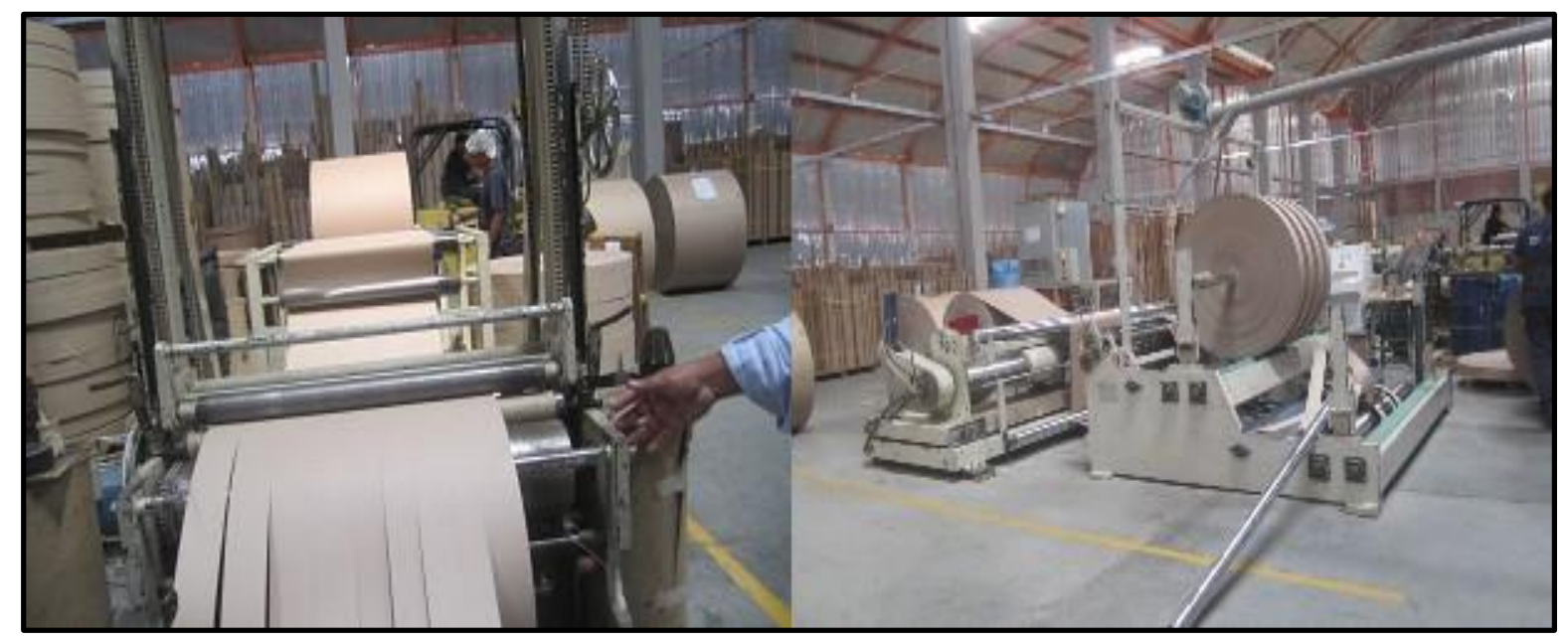

Figura 82. Máquinas de corte y rebobinado de la UEN Tubos de CARVIMSA 
b) El proceso de fabricación del tubo, dependerá del espesor y gramaje del cartón utilizado, todo en relación con qué tipo de tubo se quiere llegar a fabricar. El gramaje del tubo también tiene una variación +/- 5\%. Después de habilitadas las cintas, se pasa a la máquina de fabricación de tubos, los recursos que se utilizan son pegamento, electricidad, mano de obra, suministros (aceites, rodamientos, motores) y las máquinas para fabricar tubos también son conocidas como máquinas de espirales o máquinas tuberas. CARVIMSA cuentan con seis máquinas tuberas, dos de ellas son de procedencia China y las otras cuatro fueron adaptadas por CARVIMSA siguiendo el modelo de las anteriores. Acinsa cuenta con tres máquinas una taiwanesa, una china y una máquina nacional casera.

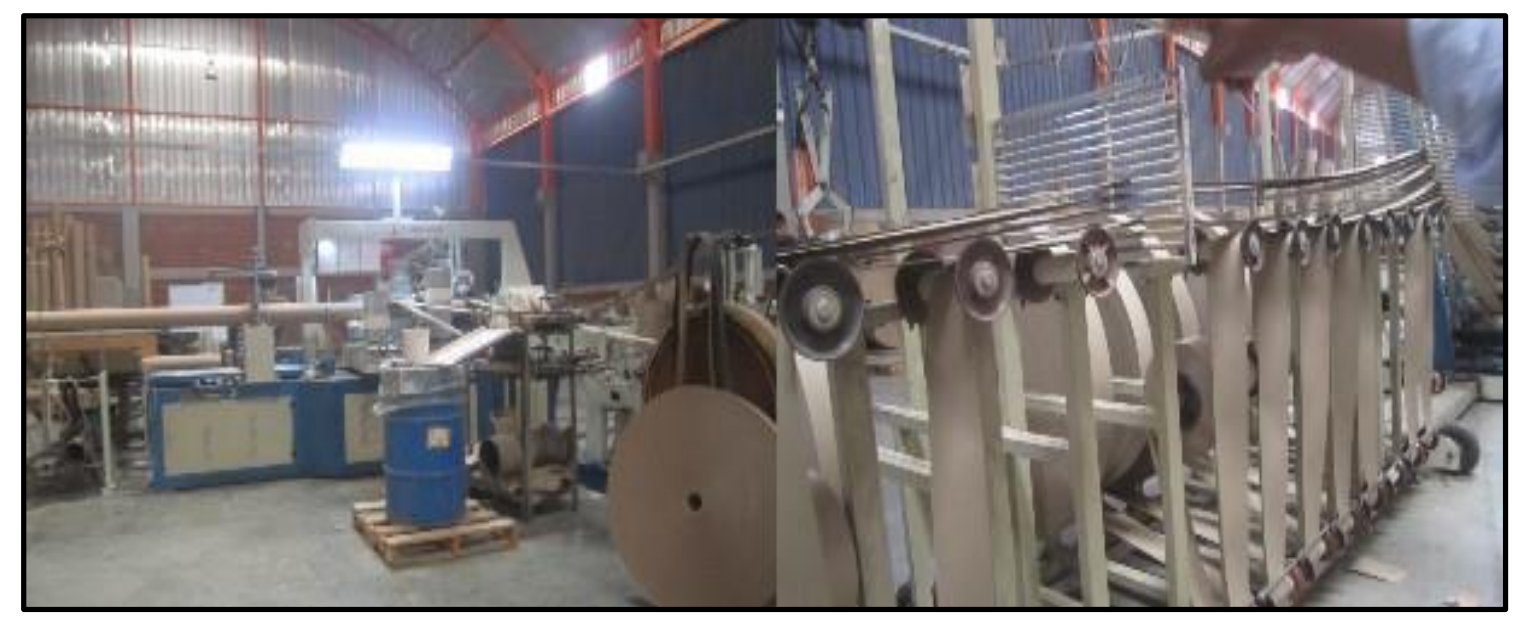

Figura 83. Máquina tubera China de la UEN Tubos de CARVIMSA

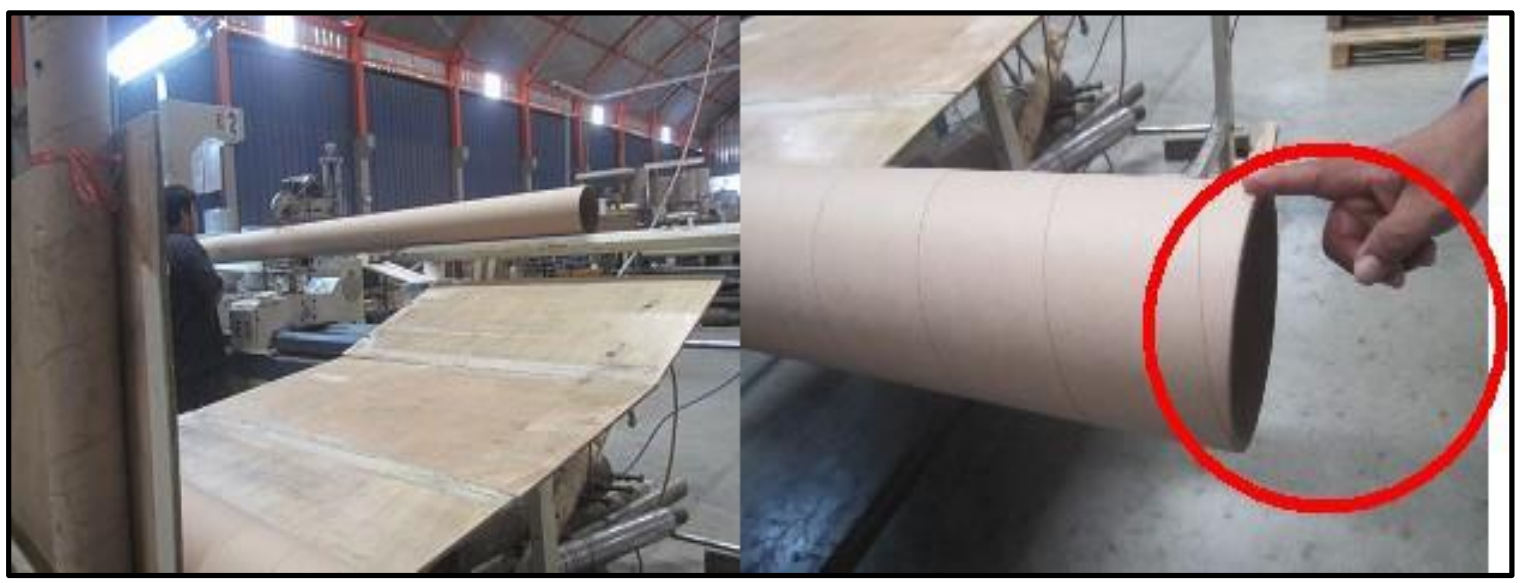

Figura 84. Corte de la Máquina tubera China de la UEN Tubos de CARVIMSA 


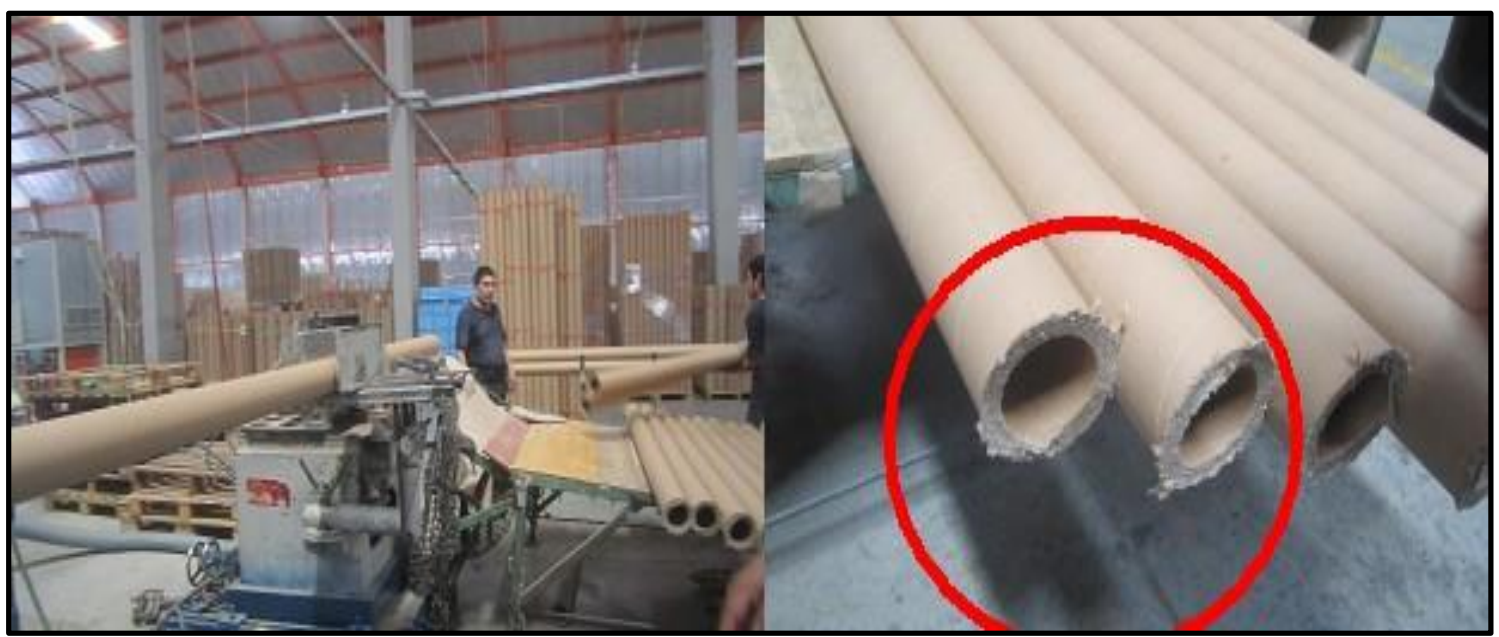

Figura 85. Máquina tubera casera de la UEN Tubos de CARVIMSA

c) El proceso de curado de tubos, también conocido como oreado puede tomar ocho horas. Si se ingresa de inmediato al horno, sin optar por el curado, los tubos tienden a doblarse. La zona de curado lo ocupa la zona previa a la sección de hornos.

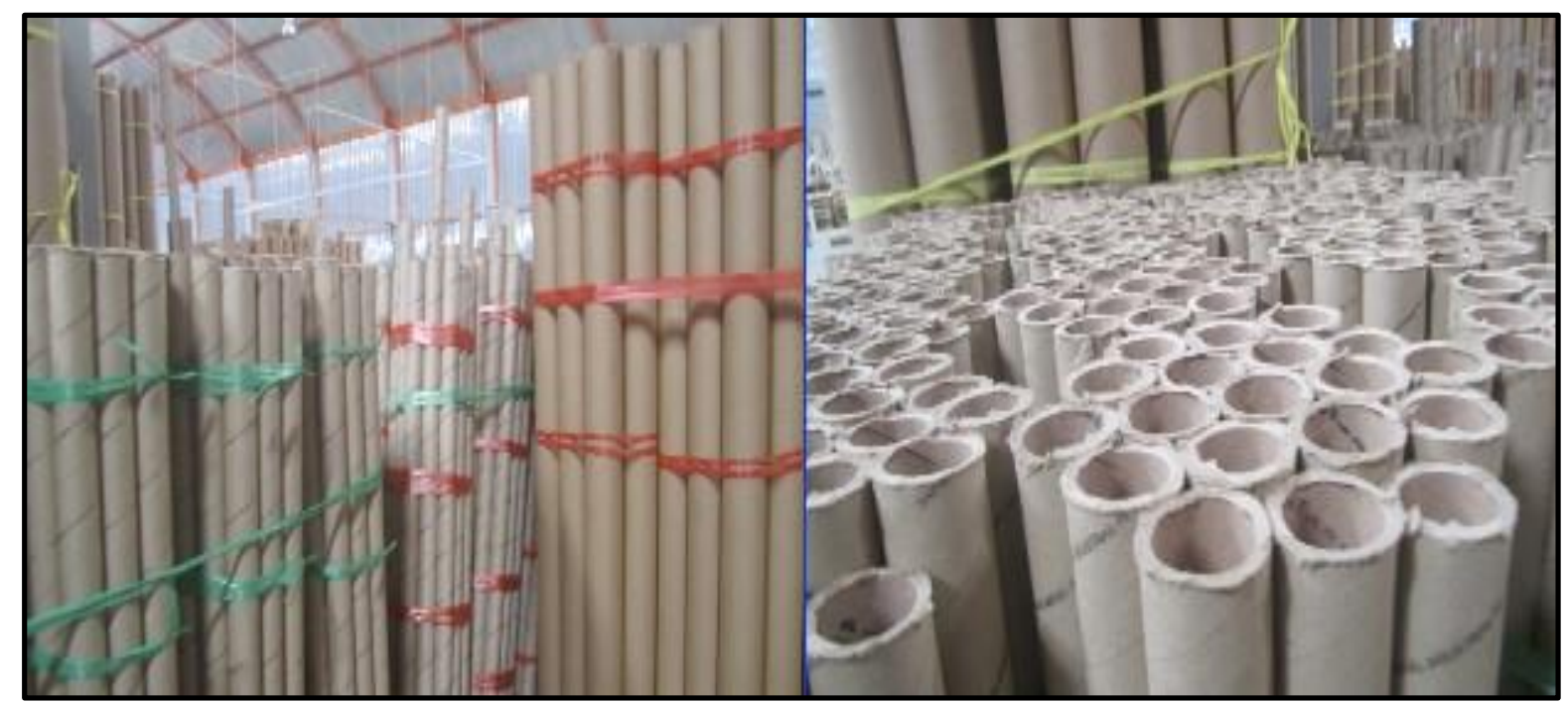

Figura 86. Proceso de curado de tubos de la UEN Tubos de CARVIMSA

d) La UEN cuenta con tres salas de hornos que son de fabricación casera, dos de ellas funcionan a carbón y un horno ya se encuentra funcionando a gas natural desde el mes de mayo del 2017 que se ha instalado un caldero, el proyecto también pretende convertir los otros dos hornos a gas natural. El costo de instalar un horno es de $\$ 8,000$. Toma entre 12 a 36 horas dependiendo de la materia prima. Se necesita una temperatura constante de 52 a 55 
grados centígrados, a mayor temperatura los tubos se doblan. Acinsa al igual que

CARVIMSA cuenta con tres hornos caseros, pero éstos demandan de energía eléctrica.

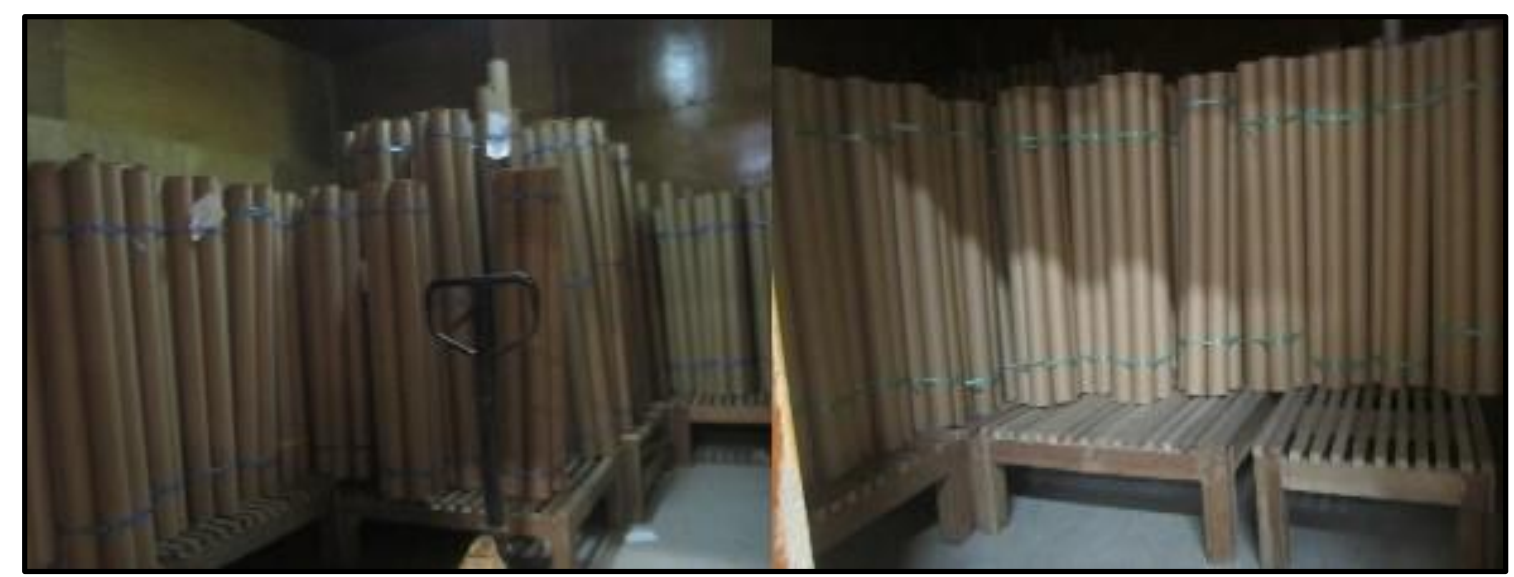

Figura 87. Salas de horno de tubos de la UEN Tubos de CARVIMSA

e) El proceso de corte de tubos es la etapa final y tiene destino directo el despacho.

Este proceso se puede cancelar si las seis máquinas de espiral manejasen corte con cuchilla plana pero como no es el caso se debe de cambiar el sistema de corte. CARVIMSA cuenta con 12 máquinas de corte manuales donde el operador tiene que definir el corte y funcionan de forma eléctrica y dos máquinas automáticas donde se configura el corte a una medida específica. El principal competidor Acinsa tiene solo cuatro máquinas de corte, de las cuales dos son automáticas y las otras dos son mecánicas (utilizan pedales).

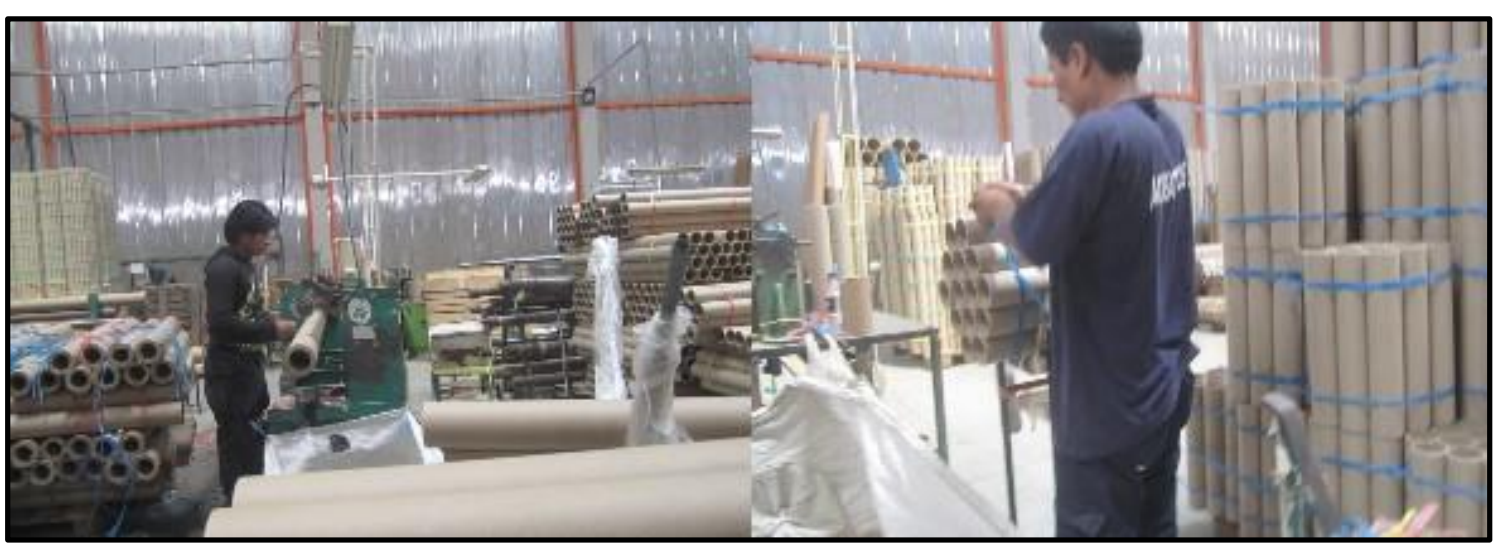

Figura 88. Despacho de tubos de la UEN Tubos de CARVIMSA 
La UEN de Tubos de CARVIMSA no fabrica conos de hilo para el área textil solo tubos para rollos de telas, en el caso de Acinsa si lo fabrica por ello necesita un proceso extra denominado reborde para lo cual cuenta con tres máquinas.

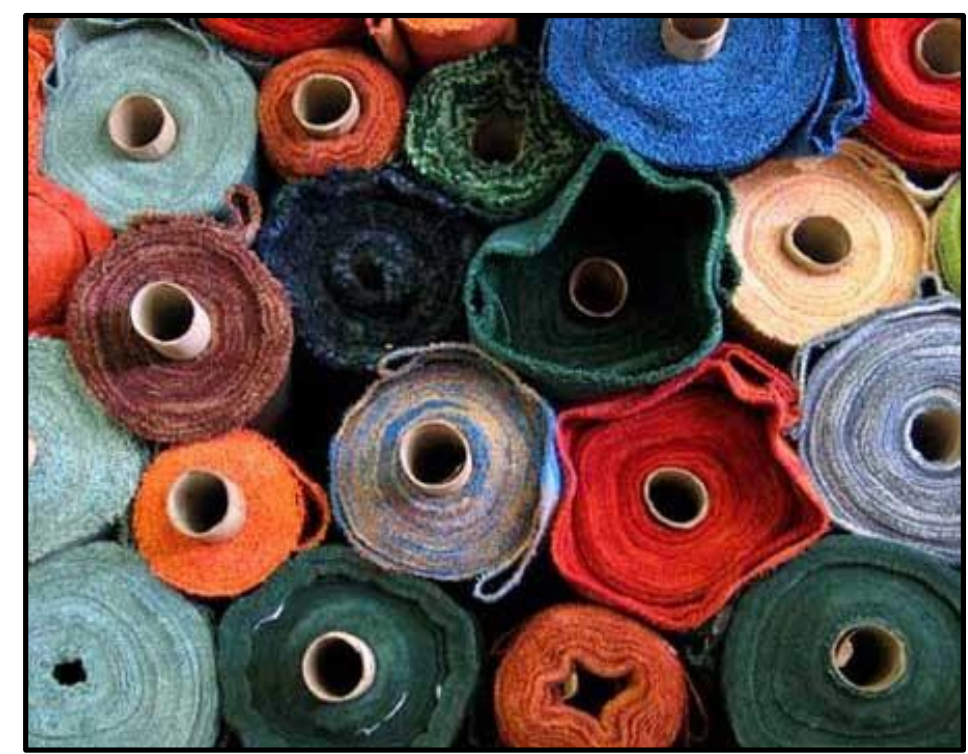

Figura 89. Tubos de cartón para rollos de tela. Recuperado de http://www.lr21.com.uy/wpcontent/uploads/2012/02/telas-e.jpg

Con respecto al proceso de fabricación de esquineros de cartón, es preciso señalar que este producto es fabricado solo con una máquina. El método de producción empleado es lineal. A continuación, se muestra la máquina con la que se produce los esquineros de cartón:

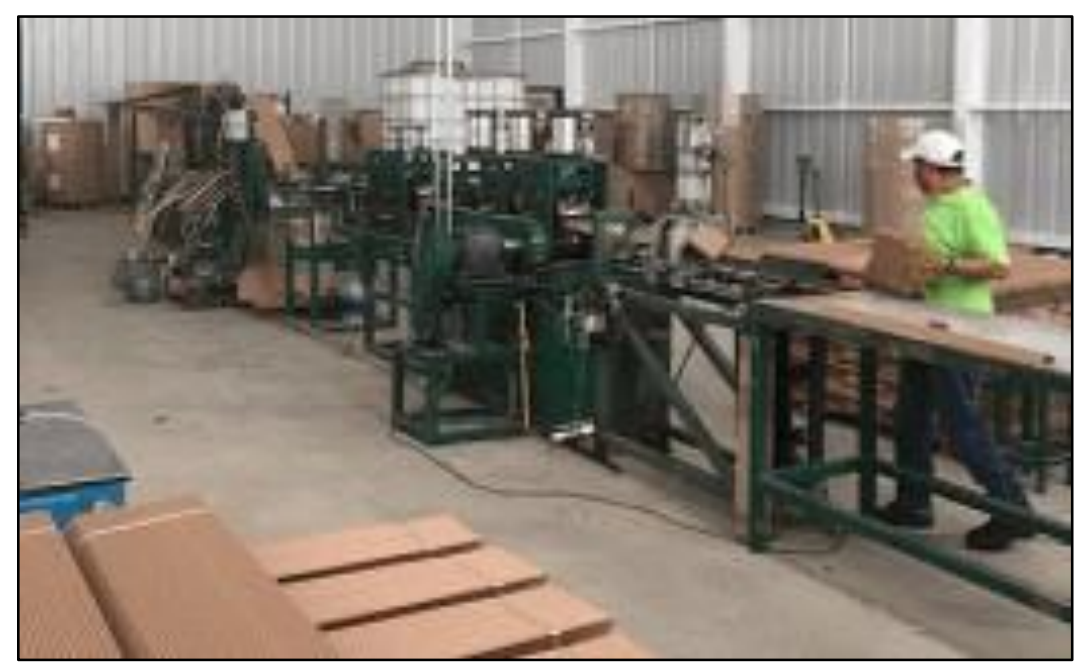

Figura 90. Proceso de fabricación de esquineros de cartón. Recuperado de http://teckpack.mx 


\section{Logística externa}

Una vez que culmina la etapa de producción, el producto está listo para ser despachado dependiendo de los tiempos de entrega pactados con el cliente. Todos los días la persona encargada de despacho planifica los despachos de producto terminado, dependiendo del tipo de producto y cantidades separa los camiones por tema de capacidad del camión. Cada camión tiene rutas por zonas y la UEN cuenta con cinco camiones disponibles de los once camiones que posea CARVIMSA los cuales también alquila sólo para el servicio de transporte. El flete es considerado gasto de venta y se cotiza aparte cuando el cliente es pequeño, pero para los clientes grandes CARVIMSA lo asume como un gasto y no se le cobra al cliente.

\section{Mercadotecnia}

Actualmente la UEN Tubos y Esquineros de CARVIMSA no tiene un área funcional de mercadotecnia por ello no consolida el servicio al cliente ni monitorea el mercado. Existe dos vendedores dedicados

\section{Recursos Humanos}

D’Alessio (2015) sostiene que el activo con mayor valor son los recursos humanos, puesto que depende de las personas que toda la empresa funcione y cumpla sus objetivos, a través de la agilización de los recursos intangibles y tangibles.

La parte operativa de la UEN está conformada por 76 trabajadores, el área administrativa lo conforman cuatro jefaturas: el jefe de producción, el jefe de calidad, el jefe de despacho y el jefe de ventas todos a nivel de jefaturas, actualmente no existen gerencias para la UEN. Para el mes de setiembre del 2017 hay un proyecto que apunta a crear el puesto 
de Gerente de Producción de la UEN Tubos y Esquineros, debido a que actualmente quien se encarga de esta UEN es el Gerente de producción de la UEN "Papel y Empalmadas".

CARVIMSA, tiene sumo cuidado en el proceso de selección, sus filtros son rigurosos dado la industria en la que opera y el nivel de competencia existente; la diferencia entre el producto que provee una empresa y otras la marca el en gran parte el personal y sus calificaciones, tanto psicológicas como físicas, y la experiencia.

El área de recursos humanos exige un plan de capacitación anual a cada jefatura a fin de planificar las capacitaciones con algunas instituciones. Adicionalmente se programan capacitaciones de seguridad industrial, en cuanto a la fuerza de ventas actualmente no existen capacitaciones ya que el área recién se está formando.

CARVIMSA al contratar un colaborador de manera formal, lo ingresa a planilla y reciben beneficios sociales y el Seguro Complementario de trabajo de riesgo (SCRT), con el fin de que puedan tener la seguridad de prestaciones de salud y económicas por accidentes de trabajo y enfermedades.

Tal como se puede evidenciar en los siguientes gráficos, la concentración de trabajadores se encuentra en el rango de edad de 26 a 33 años. En un menor porcentaje, se encuentran los trabajadores entre un rango de edad de 42 años a más. Así mismo, en esta UEN, la mayoría de los trabajadores no cuentan con estudios superiores. Es por ello por lo que las capacitaciones son constantes y están orientadas a desarrollar habilidades duras como manipulación de máquinas y habilidades blandas tales como planificación familiar y valores en el trabajo y la familia. 


\section{CANTIDAD DE TRABAJADORES POR RANGO DE EDAD}

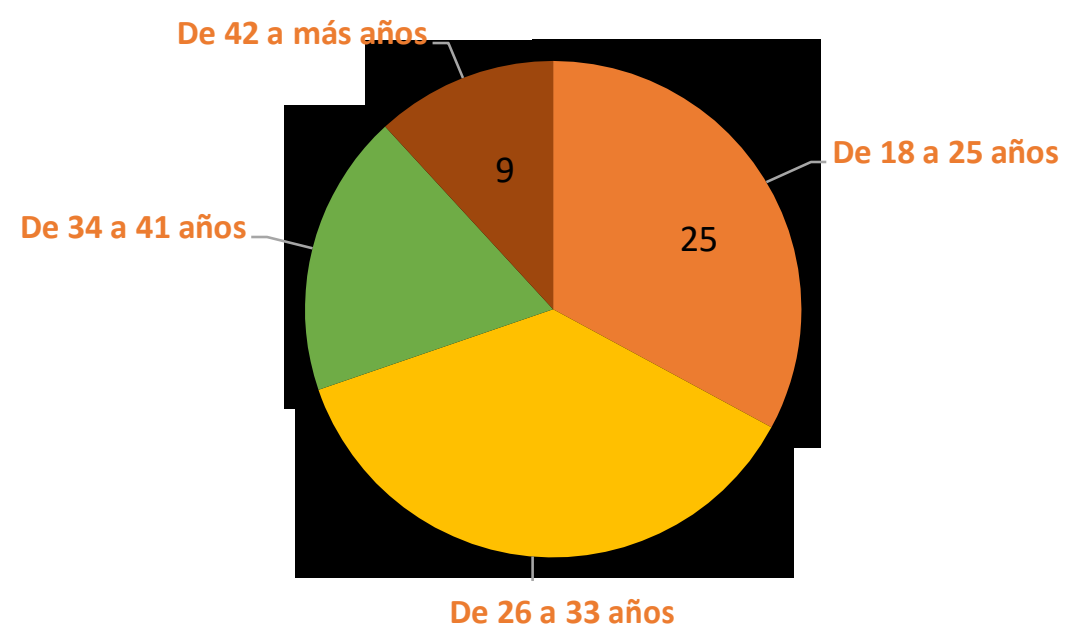

Figura 91. Cantidad de trabajadores por rango de edad. CARVIMSA.

\section{CANTIDAD DE TRABAJADORES POR GRADO DE INSTRUCCIÓN}

- Secundaria Completa - Sin Educación Formal = Técnica Completa घ Universitario Completa

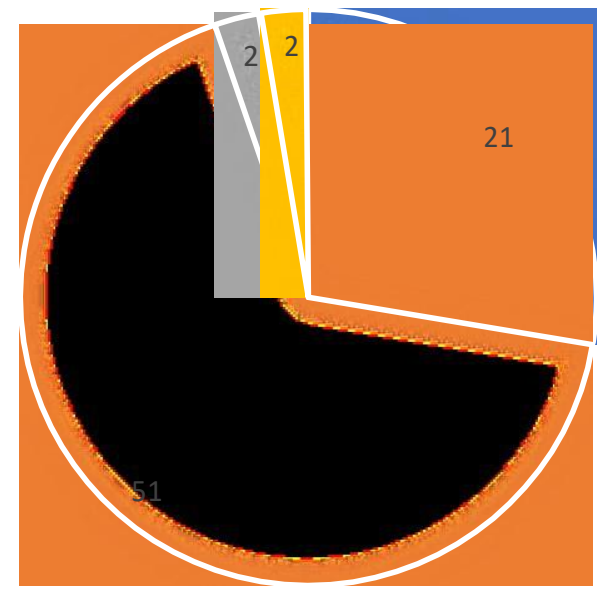

Figura 92. Cantidad de trabajadores por grado de instrucción. CARVIMSA. 


\section{Tecnología}

En el 2017, se ha iniciado la implementación del Sistema de Planificación de Recursos Empresariales o Enterprise Resource Planning (ERP) denominado EPICOR, el cual al ser un sistema de gestión integral permitirá mejorar la gestión y el control de todos los procesos de la empresa.

Con respecto a las maquinarias, éstas ya se encuentran implementadas y no hay planes de nuevas adquisiciones por el momento. En mayo de 2017, se instaló el horno a gas natural y existe un proyecto para continuar con la instalación de los dos (02) hornos faltantes.

A continuación, se muestra la tabla con las características principales de las máquinas disponibles en la UEN Tubos y Esquineros:

Tabla 62

Tabla de Máquinas utilizadas para la fabricación de Tubos de Cartón

\begin{tabular}{|c|c|c|c|c|c|c|}
\hline Código & Equipo & Fabricante & Origen & Función & $\begin{array}{c}\text { Capacidad } \\
\text { de Tubo }\end{array}$ & Velocidad \\
\hline & & CARVIMS & & \multirow{9}{*}{$\begin{array}{l}\text { Fabricación de } \\
\text { Tubos de } \\
\text { rapeı }\end{array}$} & & \\
\hline $\mathrm{T} 1$ & Máquina Tubera 1 & A & Perú & & 3" - 6" & 1800rpm \\
\hline $\mathrm{T} 2$ & Máquina Tubera 2 & $\mathrm{~S} / \mathrm{D}$ & Perú & & 3" - 4" & 1800rpm \\
\hline T3 & Máquina Tubera 3 & Takano & China & & $3^{\prime \prime}-4^{\prime \prime}$ & 1800rpm \\
\hline $\mathrm{T} 4$ & Máquina Tubera 4 & $\mathrm{~S} / \mathrm{D}$ & Perú & & $3 "-4 "$ & 1800rpm \\
\hline \multirow{3}{*}{$\mathrm{T} 5$} & & CARVIMS & & & & \\
\hline & Máquina Tubera 5 & A & Perú & & 3" - 16" & 1800rpm \\
\hline & & CARVIMS & & & & \\
\hline T6 & Máquina Tubera 6 & A & Perú & & 3"-6" & 1800rpm \\
\hline S11 & Sliter 1 & Takano & China & \multirow{3}{*}{$\begin{array}{l}\text { Cortadora de } \\
\text { Cintas de } \\
\text { Papel }\end{array}$} & 1500 & 1800rpm \\
\hline S 12 & Sliter 2 & $\begin{array}{l}\text { CARVIMS } \\
\text { A }\end{array}$ & Perú & & 1500 & 1800rpm \\
\hline $\mathrm{S} 13$ & Sliter 3 & $\begin{array}{l}\text { CARVIMS } \\
\text { A }\end{array}$ & Perú & & 820 & 1800rpm \\
\hline
\end{tabular}

Nota: Tomado de Documentación Interna por CARVIMSA. Copyright 2016 por

CARVIMSA. 
Tabla 63

Tabla de Máquinas utilizadas para la fabricación de Esquineros de Cartón

\begin{tabular}{ccccccc}
\hline Código & Equipo & Fabricante & Origen & Función & Capacidad de Tubo & Velocidad \\
\hline E1 & Esquinero & Eberle & Francia & $\begin{array}{c}\text { Fabricación de } \\
\text { ángulo de Papel }\end{array}$ & $2 "$ & $1800 \mathrm{rpm}$ \\
\hline
\end{tabular}

Nota: Tomado de Documentación Interna por CARVIMSA. Copyright 2016 por

CARVIMSA.

\section{Infraestructura}

Ampliación de la planta de la UEN Tubos y Esquineros conocida como "la nave" y los almacenes de producto terminado y productos en proceso. La planta actual tiene una dimensión de 2,500 $\mathrm{m}^{2}$. La nave está dividida en tres zonas:

- Zona de Maquinarias: Contiene las salas de horno, las tuberas, cortadoras, las slitters o rebobinadoras.

- Zona de Almacenaje: Se subdivide en tres almacenes; Productos Terminados, Materias Primas y Productos en Procesos.

- Zona de Caldero: Se tiene un solo caldero para que pueda distribuir a las tres salas de horno.

Se ha requerido al área de proyectos de CARVIMSA y será entregado para el 28 de junio. A continuación, se muestra el layout de la planta de tubos: 


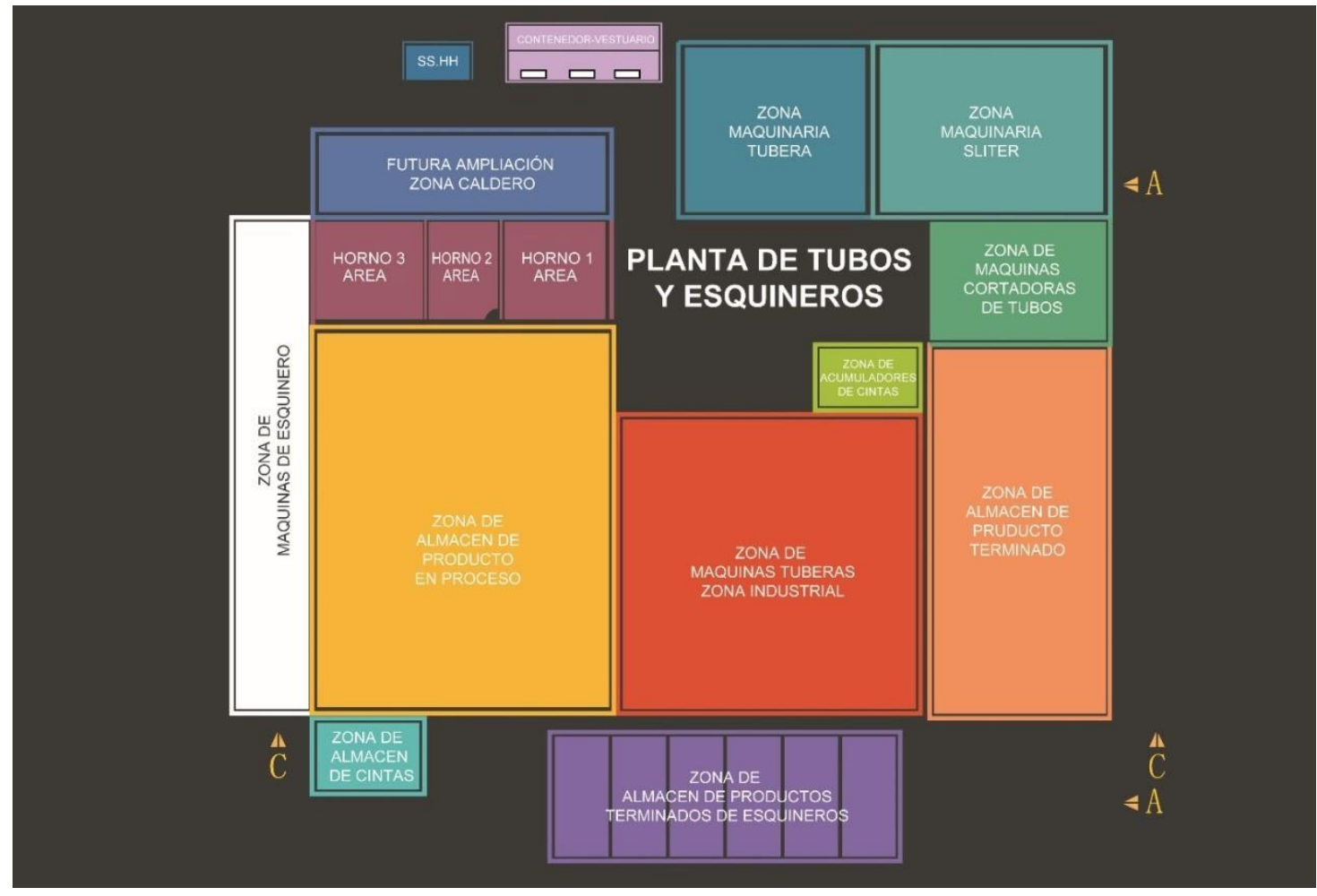

Figura 93. Layout de la Planta de Tubos y Esquineros. 


\subsection{Indicadores de cada una de las actividades de la cadena de valor}

A continuación, presentamos los indicadores de desempeño de la cadena de valor, los cuales los hemos dividido en:

Tabla 64

Indicadores de Recursos Humanos

\begin{tabular}{|c|c|c|c|}
\hline \multirow{2}{*}{ Objetivos } & \multirow{2}{*}{ Indicador } & \multicolumn{2}{|c|}{ Años } \\
\hline & & 2015 & 2016 \\
\hline \multirow{4}{*}{$\begin{array}{l}\text { Reducir el tiempo } \\
\text { Promedio en alcanzar } \\
\text { objetivos }\end{array}$} & $\begin{array}{l}\mathrm{N}^{\circ} \text { de horas de capacitación a } \\
\text { ejecutivos / año }\end{array}$ & \multicolumn{2}{|c|}{20 horas 30 horas } \\
\hline & $\begin{array}{l}\mathrm{N}^{\circ} \text { de horas de capacitación a } \\
\text { operarios / año }\end{array}$ & \multicolumn{2}{|c|}{80 horas 92 horas } \\
\hline & $\begin{array}{l}\text { \% de objetivos logrados exitosamente } \\
\text { / objetivos solicitados }\end{array}$ & $\mathrm{s} / \mathrm{d}$ & $90 \%$ \\
\hline & $\begin{array}{l}\text { Porcentaje de trabajadores } \\
\text { capacitados / año }\end{array}$ & $78 \%$ & $79 \%$ \\
\hline \multirow{4}{*}{$\begin{array}{l}\text { Mejorar el clima } \\
\text { organizacional }\end{array}$} & Porcentaje de trabajadores satisfechos & $77 \%$ & $78 \%$ \\
\hline & $\begin{array}{l}\mathrm{N}^{\circ} \text { de solicitudes atendidas / } \mathrm{N}^{\circ} \\
\text { solicitudes }\end{array}$ & $62 \%$ & $65 \%$ \\
\hline & $\begin{array}{l}\mathrm{N}^{\circ} \text { de trabajadores satisfechos con el } \\
\text { trato / Total de trabajadores }\end{array}$ & $72 \%$ & $76 \%$ \\
\hline & $\begin{array}{l}\text { Porcentaje de aprobación de los } \\
\text { proyectos realizados por la empresa }\end{array}$ & $81 \%$ & $85 \%$ \\
\hline $\begin{array}{l}\text { Incrementar el } \\
\text { porcentaje de } \\
\text { trabajadores que usan } \\
\text { tecnología }\end{array}$ & $\mathrm{N}^{\circ}$ trabajadores usando tecnología & $88 \%$ & $90 \%$ \\
\hline
\end{tabular}

Nota. Adaptado de los Documentación interna, por CARVIMSA, 2016, Perú, Lima: CARVIMSA. Copyright 2016 por CARVIMSA. 
Tabla 65

Indicadores de Gestión Financiera

\begin{tabular}{|c|c|c|c|}
\hline \multirow{2}{*}{ Objetivos } & \multirow{2}{*}{ Indicadores } & \multicolumn{2}{|c|}{ Años } \\
\hline & & 2015 & 2016 \\
\hline $\begin{array}{l}\text { Incrementar el retorno sobre la } \\
\text { inversión }\end{array}$ & Utilidad/ Ventas & $-4 \%$ & $3 \%$ \\
\hline Reducir los gastos operativos & $\begin{array}{l}\text { Gastos operativos/ } \\
\text { Ventas }\end{array}$ & $0.84 \%$ & $0.97 \%$ \\
\hline \multirow{4}{*}{ Optimizar el uso de activos } & $\begin{array}{l}\text { Rotación de } \\
\text { inventarios }\end{array}$ & 3 días & 5 días \\
\hline & \multirow{3}{*}{$\begin{array}{l}\text { Capacidad } \\
\text { utilizada/capacidad } \\
\text { instalada }\end{array}$} & $337 / 400$ & $372 / 400$ \\
\hline & & Toneladas & Toneladas \\
\hline & & 0.58 & 0.82 \\
\hline \multirow{2}{*}{$\begin{array}{l}\text { Incremento y diversificación de } \\
\text { ingresos }\end{array}$} & TM Vendidas & 337 TM & $372 \mathrm{TM}$ \\
\hline & $\begin{array}{l}\text { Ratio de cuentas } \\
\text { por cobrar }\end{array}$ & 45 días & 45 días \\
\hline
\end{tabular}

Nota. Adaptado de los Documentación interna, por CARVIMSA, 2016, Perú, Lima:

CARVIMSA. Copyright 2016 por CARVIMSA.

Tabla 66

Indicadores de Ventas y Servicio al Cliente

\begin{tabular}{|c|c|c|c|}
\hline \multirow{2}{*}{ Objetivos } & \multirow{2}{*}{ Indicadores } & \multicolumn{2}{|c|}{ Años } \\
\hline & & 2015 & 2016 \\
\hline \multirow{4}{*}{$\begin{array}{l}\text { Ser percibido como el proveedor } \\
\text { líder en el sector agroindustrial }\end{array}$} & Participación en el mercado (\%) & $22 \%$ & $50 \%$ \\
\hline & Ventas anuales (TM) & 1,173 & 1134 \\
\hline & \multirow{2}{*}{ Nuevos clientes (\#-\%) } & 123 & 169 \\
\hline & & $5 \%$ & $37 \%$ \\
\hline & Incremento del volumen de Compr & $31 \%$ & $41 \%$ \\
\hline
\end{tabular}

Fidelizar a los Clientes estratégicos

Valoración del producto

$82 \% \quad 87 \%$

Incrementar el porcentaje de satisfacción de clientes

Satisfacción de Clientes

$82 \% \quad 87 \%$

Nota. Adaptado de los Documentación interna, por CARVIMSA, 2016, Perú, Lima: CARVIMSA.

Copyright 2016 por CARVIMSA. 
Tabla 67

Indicadores de Operaciones

\begin{tabular}{|c|c|c|c|}
\hline \multirow{2}{*}{ Objetivos } & \multirow{2}{*}{ Indicadores } & \multicolumn{2}{|l|}{ Años } \\
\hline & & 2015 & 2016 \\
\hline \multirow{4}{*}{$\begin{array}{l}\text { Mejorar el } \\
\text { uso de } \\
\text { recursos }\end{array}$} & \% consumo papel propio/ total papel consumido. & $82 \%$ & $86 \%$ \\
\hline & $\%$ de tubos y esquineros malos/ Totales & $8 \%$ & $7 \%$ \\
\hline & M3/TM producidas & $\mathrm{s} / \mathrm{d}$ & $\mathrm{s} / \mathrm{d}$ \\
\hline & Unidades Reclamadas x cada 1000 & 10.36 & 7.63 \\
\hline \multirow{4}{*}{$\begin{array}{l}\text { Optimizar los } \\
\text { procesos } \\
\text { productivos }\end{array}$} & \% total horas trabajadas/ total horas presupuestadas & $62.50 \%$ & $58.70 \%$ \\
\hline & Mts. Lineales (8 horas) & 26,200 & 25,729 \\
\hline & $\%$ de pedidos producidos/ total pedidos del mes. & $68.25 \%$ & $87.28 \%$ \\
\hline & $\%$ de Desperdicio/TM Tubos y Esquineros & $6.94 \%$ & $6.91 \%$ \\
\hline \multirow{3}{*}{$\begin{array}{l}\text { Reducir el } \\
\text { tiempo de } \\
\text { parada de } \\
\text { máquinas } \\
\end{array}$} & $\%$ (Tiempo de Paro/Tiempo Disponible) & $9.38 \%$ & $9.46 \%$ \\
\hline & $\%$ (Tiempo de Paro /Tiempo Disponible) & $4.67 \%$ & $3.89 \%$ \\
\hline & $\%$ de Pedidos Cumplidos & $76.96 \%$ & $84.29 c$ \\
\hline
\end{tabular}

Nota. Adaptado de los Documentación interna, por CARVIMSA, 2016, Perú, Lima:

CARVIMSA. Copyright 2016 por CARVIMSA.

\subsection{Benchmarking y comparación con los líderes de la industria de cada una de las}

actividades de la cadena de valor

Según David (2013) el Benchmarking es una herramienta analítica empleada para

determinar si las actividades de la cadena de valor de una empresa son competitivas en

comparación con las de sus rivales y así favorecer la victoria en el mercado. El benchmarking

implica la medición de los costos de las actividades de la cadena de valor en una industria

para determinar las "mejores prácticas" entre las empresas competidoras, con la finalidad de

imitar o mejorar tales prácticas. La parte más difícil del benchmarking es tener acceso a las

actividades de la cadena de valor de otras empresas con sus costos asociados. 


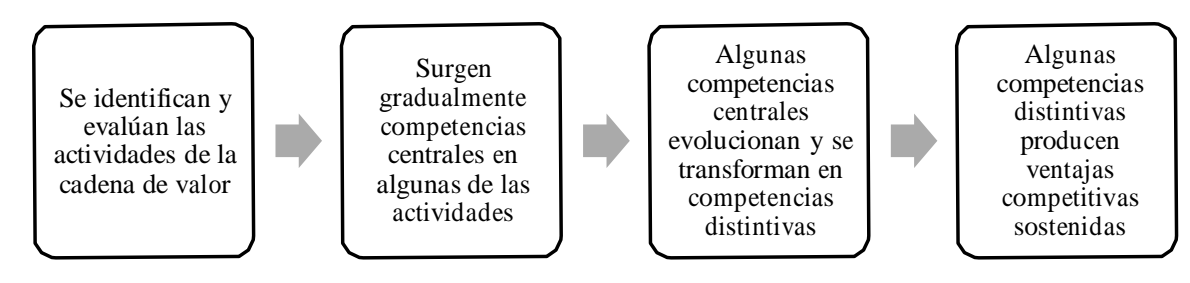

Figura 94. Transformación de las actividades en la cadena de valor a ventajas competitivas. Adaptado de "Administración Estratégica", por David, 2013, p. 121. Editorial: Pearson Education.

El análisis comparado con el principal competidor de CARVIMSA en la industria del sector manufacturero de tubos de cartón, permite identificar brechas positivas y negativas como base para mejorar los aspectos evaluados en la cadena de valor. Los resultados obtenidos en las encuestas realizadas se muestran en la tabla 61.

Tabla 68

Benchmarking

\begin{tabular}{lll}
\hline Actividades en la cadena de valor & $\begin{array}{l}\text { Ponderación } \\
\text { CARVIMSA }\end{array}$ & $\begin{array}{l}\text { Ponderación } \\
\text { Acinsa }\end{array}$ \\
\hline Marketing y ventas & 2 & 1 \\
\hline Servicio de Post Venta & 2 & 3 \\
\hline
\end{tabular}

\begin{tabular}{lll}
\hline Abastecimiento: & 3 & \\
\hline - Calidad de producto & 2 & 3 \\
\hline - Fecha de entrega & 3 & 2 \\
\hline - Control de Inventario & & \\
\hline Tecnología: & 3 & 2 \\
\hline - Sistemas de seguridad & 2 & 1 \\
\hline - Sistemas de Información integrados & 3 & 2 \\
\hline - Maquinaria de última generación & 3 & 0 \\
\hline - Cuidado del Medio Ambiente & \\
\hline Gestión de Recursos Humanos: & 2 \\
\hline - Clima Organizacional & 3 & 1 \\
\hline - Programa de incentivos & & \\
\hline Infraestructura: & 3 & \\
\hline
\end{tabular}




\begin{tabular}{lll}
\hline Actividades en la cadena de valor & $\begin{array}{l}\text { Ponderación } \\
\text { CARVIMSA }\end{array}$ & $\begin{array}{l}\text { Ponderación } \\
\text { Acinsa }\end{array}$ \\
\hline - Capacidad de producción & 2 & 2 \\
\hline Puntos Totales & 31 & 21 \\
\hline
\end{tabular}

0 = No lo consideran, $1=$ Lo consideran

eventualmente, 2 = Lo consideran, pero

necesita mejorar, 3 = Muy bien

implementado

Nota. Obtenido de las Entrevistas realizadas a los clientes de CARVIMSA y Acinsa - Anexo 1 y 2

\subsection{Determinar las competencias de la empresa}

Para determinar las competencias de la empresa se tiene como herramienta el análisis de áreas funcionales que integran el ciclo operativo de la organización, las cuales son:

a) Administración y gerencia: En el proceso operativo, el permanente objetivo de la administración es aumentar la productividad.

b) Marketing, ventas e investigación de mercado: Manejo de la organización en relación con sus mercados, cómo vende, cuál es la satisfacción de sus clientes.

c) Operaciones, logística e infraestructura: Aborda lo que es la gestión de operaciones productivas, logística integrada y la infraestructura adecuada.

d) Finanzas y contabilidad: Su propósito es medir y calificar la asertividad de la toma de decisiones relacionadas con la posición económica financiera de la compañía y su apoyo a las estrategias que se adopten.

e) Recursos humanos y cultura: Involucra aspectos como la cultura y el clima organizacional.

f) Sistema de información y comunicaciones: Está relacionado con el uso de los sistemas de información y comunicaciones en apoyo al proceso de la toma de 
decisiones gerenciales, al soporte del trabajo en equipo y como elementos de apoyo al registro y control organizacional.

g) Tecnología e investigación y desarrollo: Orienta sus esfuerzos a la innovación tecnológica e invención científica dentro del contexto de la era del conocimiento.

En cada una de estas áreas, se deben evaluar las competencias distintivas de la organización. (D’Alessio, 2013)

A continuación, se hace un listado de las variables distintivas que posee CARVIMSA para cada área funcional.

Tabla 69

Tabla de competencias distintivas de las áreas funcionales de CARVIMSA

\begin{tabular}{|c|c|}
\hline Área funcional & Variables críticas \\
\hline \multirow{5}{*}{$\begin{array}{l}\text { Administración } \\
\text { y gerencia }\end{array}$} & $\begin{array}{l}\text {-Efectividad y utilización de los sistemas de toma de decisiones y } \\
\text { control gerencial }\end{array}$ \\
\hline & -Prácticas de gobierno corporativo y responsabilidad social \\
\hline & -Calidad y experiencia del equipo directivo y de los directores \\
\hline & -Estilos de liderazgo usados en los niveles gerenciales \\
\hline & -Imagen y prestigio de la organización \\
\hline
\end{tabular}

-Mix de productos

Marketing, -Política de precios: flexibilidad y descuentos

ventas $e$

investigación de Red de ventas y gestión de los canales de distribución: cantidad, mercado cobertura control, transporte y distribución

-Conocimientos de las necesidades del consumidor 


\begin{tabular}{|c|c|}
\hline Área funcional & Variables críticas \\
\hline \multirow{7}{*}{$\begin{array}{l}\text { Operaciones, } \\
\text { logística e } \\
\text { infraestructura }\end{array}$} & -Costos de fabricación en relación con la industria y los competidores \\
\hline & -Suministros de materiales \\
\hline & -Sistemas de control de inventarios y rotación \\
\hline & -Eficiencia técnica \\
\hline & -Capacidad de producción \\
\hline & $\begin{array}{l}\text {-Efectividad de los procesos en el control de la cantidad, de la } \\
\text { cantidad, de la calidad, del diseño y de los costos }\end{array}$ \\
\hline & -Seguridad e higiene laboral \\
\hline \multirow{6}{*}{$\begin{array}{l}\text { Finanzas } y \\
\text { contabilidad }\end{array}$} & -Situación financiera \\
\hline & -Nivel de apalancamiento financiero y operativo \\
\hline & -Costo de capital \\
\hline & -Estructura de costos \\
\hline & $\begin{array}{l}\text {-Eficiencia y efectividad de los sistemas contables, de costeo y de } \\
\text { presupuesto }\end{array}$ \\
\hline & -Situación tributaria \\
\hline \multirow{7}{*}{$\begin{array}{l}\text { Recursos } \\
\text { humanos y } \\
\text { cultura }\end{array}$} & -Competencias y calificaciones profesionales \\
\hline & -Capacitación y desarrollo del personal \\
\hline & -Disponibilidad y calidad de la mano de obra \\
\hline & -Costos laborales en relación con la industria y los competidores \\
\hline & -Calidad del clima organizacional \\
\hline & -Cultura organizacional \\
\hline & -Valores \\
\hline \multirow{3}{*}{$\begin{array}{l}\text { Sistema de } \\
\text { información y } \\
\text { comunicaciones }\end{array}$} & $\begin{array}{l}\text {-Sistemas orientados al usuario: capacidad del personal de utilizar la } \\
\text { información }\end{array}$ \\
\hline & -Redes y su administración \\
\hline & -Sistemas de seguridad \\
\hline \multirow{3}{*}{$\begin{array}{l}\text { Tecnología e } \\
\text { investigación y } \\
\text { desarrollo }\end{array}$} & -Desarrollo de nuevos procesos antes que la competencia \\
\hline & -Mejorar la calidad de los productos y procesos \\
\hline & -Conseguir automatizaciones y sistemas modernos de gestión \\
\hline
\end{tabular}




\subsection{Identificación y determinación de las ventajas competitivas de la empresa}

La ventaja nace de muchas actividades discretas que ejecuta al diseñar, fabricar, comercializar, entregar y apoyar su producto. Cada una de ellas contribuye a su posición relativa en coses y sienta las bases de la diferenciación. Para analizar las fuentes de la ventaja competitiva se necesita un método de examinar todas las actividades que se realizan y su manera de interactuar. La cadena de valor permite dividir la empresa en sus actividades estratégicamente relevantes a fin de entender el comportamiento de los costes, se logra ventaja competitiva realizándolas mejor o con menor coste que los competidores. (Porter, 2010).

\section{Tipos de ventaja competitiva}

a) Ventaja en costes: Es uno de los tipos de ventaja competitiva que posee una empresa, el coste tiene además importancia vital para las estrategias de diferenciación, porque para aplicarlas es necesario mantenerse cerca de los competidores en este aspecto.

b) Diferenciación: La diferenciación es uno de los dos tipos de ventaja competitiva que pueden poseerse. La medida que permite a los competidores de un sector industria distinguirse entre ellos.

c) Segmentación: Las industrias no son homogéneas, con frecuencia la presión de las cinco fuerzas competitivas difiere entre las partes de una industria. Los segmentos contienen además distintas cadenas de valor.

Luego de haber realizado las entrevistas a los principales clientes de la UEN Tubos y Esquineros, y analizado cada una de las respuestas obtenidas, se ha determinado las siguientes ventajas competitivas: 


\section{a) Disponibilidad de materia prima}

El hecho de que la UEN Tubos y esquineros pueda utilizar los Side roll del molino como materia prima principal, como es parte de la misma empresa, hace que la materia prima se obtenga a precio muy competitivo y además le permite hacer un producto. Por ejemplo, si no se utilizaría el papel se trasladaría un costo de mandarlo nuevamente al reproceso lo que es 200 dólares, en cambio al producir los tubos se está sacando al mercado a 700 dólares, eso es un gran aporte.

\section{b) Resistencia de más de $30 \%$ que la competencia}

Los tubos de CARVIMSA tienen una ventaja, están hechos de Side roll, pedazos de bobina, esos Side roll son papeles que van a producción de cajas de exportación, entonces tienen una resistencia y calidad superior a la que hace la competencia, especialmente la competencia hace un papel para tubos, CARVIMSA no hace un papel para tubos, toma lo que les sobra, entonces le da al mercado un producto que es $30 \%$ más resistente.

\section{c) Valor agregado para el cliente al reducir el espesor}

Si el tubo es $30 \%$ más resistente que el de la competencia y la competencia está acostumbrada a usar un determinado diámetro, entonces CARVIMSA puede reducir el espesor porque tiene más resistencia, si se reduce el espesor, el cliente puede poner más material en el tubo, y si el cliente exporta está aprovechando el flete, los clientes estarían dando más producto pagando el mismo flete, entonces CARVIMSA otorga un beneficio adicional, un valor agregado, porque su producto permite darle eso. 


\section{d) Eficiente servicio del área técnica}

Tiene un área técnica bastante buena que le permite desarrollar productos que tienen una diferencia importante con respecto a los del mercado. El servicio técnico, facilita al cliente desarrollo de nuevos productos, un gran servicio pre y post venta, un gran servicio de atención al cliente porque hacer tubos lo puede hacer cualquiera. El área de servicio es grande porque justamente necesita que los clientes estén bien atendidos con respecto a sus solicitudes entonces el servicio es importante, la innovación también, porque las fechas de entrega y el precio y otras cosas más son replicables, el servicio y la innovación no porque eso es cultural, eso es de una organización. Precio cualquiera lo baja, producir un tipo de tubo de una manera también, haces la formulación, el tipo de papel, el tipo de pegamento y sale el tubo, pero el servicio no.

\subsection{Matriz de Evaluación de los factores Internos EFI}

La matriz de evaluación de factores internos (EFI) es una síntesis dentro del proceso de auditoría interna de la administración estratégica. Esta herramienta para la formulación de estrategia sintetiza y evalúa las fortalezas y debilidades más importantes encontradas en las áreas funcionales de una empresa y también constituye la base para identificar y evaluar las relaciones entre áreas. (David, 2013).

Tabla 70

Cinco pasos para la elaboración de la Matriz EFI

\begin{tabular}{cl}
\hline Pasos & \multicolumn{1}{c}{ Procedimiento } \\
\hline Paso 1 & $\begin{array}{l}\text { Haga una lista de los factores internos clave que se } \\
\text { identificaron en el proceso de auditoría interna. Emplee } \\
\text { un total de } 10 \text { a } 20 \text { factores internos, e incluya tanto } \\
\text { fortalezas como debilidades }\end{array}$ \\
& Asigne a cada factor una ponderación que oscile entre \\
& 0.0 (Sin importancia) y 1.0 (Muy importante). La \\
\hline
\end{tabular}


Pasos

\section{Procedimiento}

ponderación indica la importancia con respecto al éxito de la empresa en la industria.

Paso 3

Asigne a cada factor externo clave una calificación de

1 a 4 puntos para indicar si representa una debilidad importante (calificación=1), una debilidad menor (calificación=2), una fortaleza menor (calificación=3) o una fortaleza importante (calificación=4).

Paso 4

Multiplique la ponderación de cada factor por su calificación, para determinar una puntuación ponderada.

Paso 5 el fin de determinar la puntuación ponderada total para la organización

Nota: Adaptado de “Administración Estratégica," (pp.122) por David, 2013, México: Editorial Pearson Education. Copyright 2013 por Prentice Hall.

Tabla 71

Matriz EFI de la UEN Tubos y Esquineros de CARVIMSA

Factores Críticos para el éxito

Peso Calificación

Total Ponderado

\begin{tabular}{llll}
\hline FORTALEZAS & & & \\
\hline 1. Materia prima obtenida del Molino propio & 0.20 & 4 & 0.80 \\
\hline 2. Competitividad de precios & 0.09 & 3 & 0.27 \\
\hline 3. Mayor participación del mercado & 0.15 & 4 & 0.60 \\
\hline 4. Sin antecedentes de contaminación ambiental & 0.13 & 4 & 0.52 \\
\hline 5. Hornos con conexión a gas natural & 0.12 & 3 & 0.36 \\
\hline TOTAL FORTALEZAS & $\mathbf{0 . 6 9}$ & & $\mathbf{2 . 5 5}$ \\
\hline DEBILIDADES & & & \\
\hline 1. Poco tiempo de la UEN en el mercado & 0.03 & 2 & 0.06 \\
\hline 2. Ausencia de un área funcional de mercadotecnia & 0.06 & 2 & 0.12 \\
\hline 3. Ausencia de un gerente de producción para la UEN & 0.13 & 2 & 0.26 \\
\hline 4. Falta de investigación de mercados & 0.05 & 2 & 0.10 \\
\hline 5. Sobrecostos en fletes internos entre plantas (Ubicación: Villa el & & & \\
Salvador- Huachipa) & 0.04 & 1 & 0.04 \\
\hline TOTAL DEBILIDADES & $\mathbf{0 . 3 1}$ & $\mathbf{0 . 5 8}$ \\
\hline TOTAL EFI & $\mathbf{1 . 0 0}$ & $\mathbf{3 . 1 3}$ \\
\hline NOta
\end{tabular}

Nota. Obtenido de las respuestas de los cuestionarios a los gerentes de CARVIMSA. 


\section{Capítulo VII. Formulación de los Objetivos y Diseño de las Estrategias}

\subsection{Alcance y planeamiento de los objetivos estratégicos}

David (2013) señaló:

La mejor forma de conservar una ventaja competitiva a largo plazo consiste en perseguir sin tregua los objetivos estratégicos que fortalezca la posición de la empresa frente a sus rivales. Si la organización se enfoca en primer lugar y más que nada en lograr los objetivos estratégicos que mejoren su competitividad y su fortaleza en el mercado, también podrá alcanzar sus objetivos financieros. (p.134)

\subsubsection{Objetivos Estratégicos.}

Los objetivos estratégicos representan los resultados que se esperan obtener al implementar ciertas estrategias. Las estrategias son las acciones que deben emprenderse para el logro de los objetivos estratégicos. El marco temporal para la implementación de estrategias y el logro de objetivos deber ser congruente, desarrollando por lo general en un periodo de dos a cinco años. (David, 2013)

Tabla 72

Características deseables en los objetivos

\begin{aligned} & \hline 1. Cuantitativos \\ & \hline 2. Medibles \\ & \hline 3. Realistas \\ & \hline 4. Comprensibles \\ & \hline 5. Desafiantes \\ & \hline 6. Jerárquicos \\ & \hline 7. Alcanzables \\ & \hline 8. $\begin{array}{l}\text { Congruentes a través de todos los } \\ \text { departamentos }\end{array} \\ &$\hline\end{aligned}

Nota: Tomado de “Administración Estratégica,” (pp.133) por David, 2013, México: Editorial Pearson Education. Copyright 2013 por Prentice Hall. 
A continuación, se presenta los objetivos estratégicos, los cuales se dividen en:

Tabla 73

Objetivos Estratégicos de la UEN Tubos y Esquineros de CARVIMSA

\begin{tabular}{ll}
\hline \multicolumn{1}{c}{ Indicador } & \multicolumn{1}{c}{ Objetivo Estratégico } \\
\hline Crecimiento en Ventas & Incrementar el volumen de ventas de la UEN Tubos y Esquineros. \\
\hline Rentabilidad & Incrementar la utilidad neta sobre las ventas proyectadas. \\
\hline Participación en el & Incrementar la participación en el mercado de la UEN Tubos y \\
mercado & Esquineros. \\
\hline
\end{tabular}

\subsubsection{Análisis de los objetivos estratégicos.}

Los objetivos deben estar asociados con un horizonte de tiempo, y entre otros, en términos a:

Tabla 74

Términos de los objetivos estratégicos

1. Crecimiento de activos

2. Crecimiento de las ventas

3. Beneficios / rentabilidad

4. Participación en el mercado

5. Diversificación

6. Integración

7. Ganancias por acción

8. Responsabilidad social

Nota: Tomado de "El proceso estratégico: un enfoque de gerencia," (pp.220) por D'Alessio, 2008, México: Editorial Pearson Education de México S.A. de C.V. Copyright 2008 por Prentice Hall.

Los objetivos estratégicos que se propone para la UEN Tubos y Esquineros son las siguientes: 


\section{Crecimiento en las ventas}

La UEN Tubos y Esquineros - CARVIMSA tiene como proyección para los años 2018 al 2021 el aumento de sus ventas, esto se da por mayor captación de clientes y por el crecimiento del mercado. Este aumento se realizará progresivamente, gracias a las iniciativas que se implementarán como campañas publicitarias, capacitaciones a los ejecutivos de ventas y la elaboración y ejecución de programas de visitas a clientes. Para mayor detalle se ha elaborado un plan de marketing que se detalla posteriormente.

Tabla 75

Proyección de Ventas 2018-2021

\begin{tabular}{|c|c|c|c|c|c|c|c|c|c|}
\hline Clientes & 2017 & 2018 & Var\% & 2019 & Var\% & 2020 & Var\% & 2021 & Var\% \\
\hline Solpack S.A. & 1425 & 2,400 & $68 \%$ & 3430 & $43 \%$ & 4459 & $3 \%$ & 4949 & $11 \%$ \\
\hline Surpack & 840 & 600 & $-29 \%$ & 630 & $5 \%$ & 630 & $0 \%$ & 680 & $8 \%$ \\
\hline Filmpack S.A.C. & 360 & 360 & $0 \%$ & 400 & $11 \%$ & 760 & $15 \%$ & 511 & $11 \%$ \\
\hline Peruplast S.A. & 360 & 510 & $42 \%$ & 638 & $25 \%$ & 733 & $15 \%$ & 814 & $11 \%$ \\
\hline TDM Geosintéticos & 216 & 240 & $11 \%$ & 288 & $20 \%$ & 331 & $15 \%$ & 358 & $8 \%$ \\
\hline $\begin{array}{l}\text { Envolturas Flexibles Huachipa } \\
\text { S.A.C. }\end{array}$ & 180 & 300 & $67 \%$ & 360 & $20 \%$ & 414 & $15 \%$ & 447 & $8 \%$ \\
\hline Unión Plast S.A. & 168 & 144 & $-14 \%$ & 180 & $25 \%$ & 207 & $15 \%$ & 230 & $11 \%$ \\
\hline Opp Film S.A. & 425 & 1,050 & $147 \%$ & 1550 & $48 \%$ & 1938 & $25 \%$ & 2199 & $14 \%$ \\
\hline Megapack Group S.A.C. & 0 & 60 & & 70 & $17 \%$ & 77 & $10 \%$ & 85 & $11 \%$ \\
\hline Resinplast S.A. & 0 & 120 & & 140 & $17 \%$ & 154 & $10 \%$ & 166 & $8 \%$ \\
\hline Línea Plástica Perú S.A. & 85 & 120 & $41 \%$ & 134 & $12 \%$ & 148 & $10 \%$ & 160 & $8 \%$ \\
\hline $\begin{array}{l}\text { Peruana De Papeles Y } \\
\text { Cartones S.A.C. }\end{array}$ & 0 & 60 & & 80 & $33 \%$ & 88 & $10 \%$ & 95 & $8 \%$ \\
\hline Polinplast S.AC. & 35 & 60 & $71 \%$ & 70 & $17 \%$ & 77 & $10 \%$ & 85 & $11 \%$ \\
\hline $\begin{array}{l}\text { Avocado Packing Company } \\
\text { S.A.C. }\end{array}$ & 0 & 380 & & 400 & $5 \%$ & 480 & $20 \%$ & 533 & $11 \%$ \\
\hline Procesadora Laran S.A.C. & 0 & 120 & & 140 & $17 \%$ & 168 & $20 \%$ & 186 & $11 \%$ \\
\hline Huaral Fruit Export S.A.C. & 0 & 84 & & 90 & $7 \%$ & 108 & $20 \%$ & 120 & $11 \%$ \\
\hline $\begin{array}{l}\text { Sociedad Agrícola Drokasa } \\
\text { S.A }\end{array}$ & 80 & 85 & $6 \%$ & 180 & $112 \%$ & 216 & $20 \%$ & 240 & $11 \%$ \\
\hline Agro Victoria S.A.C & 0 & 60 & & 80 & $33 \%$ & 96 & $20 \%$ & 107 & $11 \%$ \\
\hline
\end{tabular}




\begin{tabular}{|c|c|c|c|c|c|c|c|c|c|}
\hline Procesadora Torre Blanca S.A. & 0 & 96 & & 116 & $21 \%$ & 128 & $10 \%$ & 142 & $11 \%$ \\
\hline Agrícola Cerro Prieto S.A. & 0 & 40 & & 60 & $50 \%$ & 66 & $10 \%$ & 73 & $11 \%$ \\
\hline Sociedad Anónima Papelsa & 0 & 120 & & 140 & $17 \%$ & 154 & $10 \%$ & 171 & $11 \%$ \\
\hline Clientes & 2017 & 2018 & Var\% & 2019 & Var\% & 2020 & Var\% & 2021 & Var\% \\
\hline Tal S.A. & 56 & 60 & $7 \%$ & 80 & $33 \%$ & 88 & $10 \%$ & 98 & $11 \%$ \\
\hline Sub - Total $(86.20 \%)$ & 4230 & 7,069 & $67 \%$ & 9256 & $31 \%$ & 11219 & $21 \%$ & 12449 & $11 \%$ \\
\hline Resto de Clientes (13.80\%) & 1032 & 1,085 & $5 \%$ & 1096 & $1 \%$ & 1205 & $10 \%$ & 1338 & $11 \%$ \\
\hline Total & 5262 & 8,154 & $55 \%$ & 10352 & $27 \%$ & 12424 & $20 \%$ & 13787 & $11 \%$ \\
\hline
\end{tabular}

\section{a) Rentabilidad}

A nivel de utilidad neta, los márgenes de contribución de la UNE Tubos y Esquineros de Cartón - CARVIMSA, para el periodo 2016 y lo que viene transcurriendo el presente año sobre la base de un estado de resultados proyectado, son atractivos. Actualmente se tiene un EBITDA promedio de 2.5\%. Al cierre del año 2021 la empresa se ha propuesto mejorar sus indicadores producto del aumento de la participación de mercado, reducción en los costos operativos y optimización de sus gastos operativos.

\section{b) Participación en el mercado}

La UEN Tubos y Esquineros tiene como objetivo a corto plazo de incrementar su participación en el mercado a finales del año 2021. En la actualidad esta unidad tiene una participación de un 43\%. Para el logro de estos objetivos llevaran a cabo cambios de forma como organizacionales, como el generar un área comercial, el cual se dedique a realizar el análisis del mercado, ver la cartera de clientes, contar con un área de servicio al cliente, tener una Gerencia de producción, el cual permitirá tener una planificación de las producciones, administración de sus recursos, reducción de costos, con el fin de generar la productividad deseada. 


\subsection{Diseño y formulación de estrategias}

La estrategia de una empresa es su plan de acción para desempeñarse mejor que sus competidores y obtener una mayor rentabilidad. De hecho, representa un compromiso de la dirección respecto a una serie de decisiones sobre cómo competir. (Thompson, 2015)

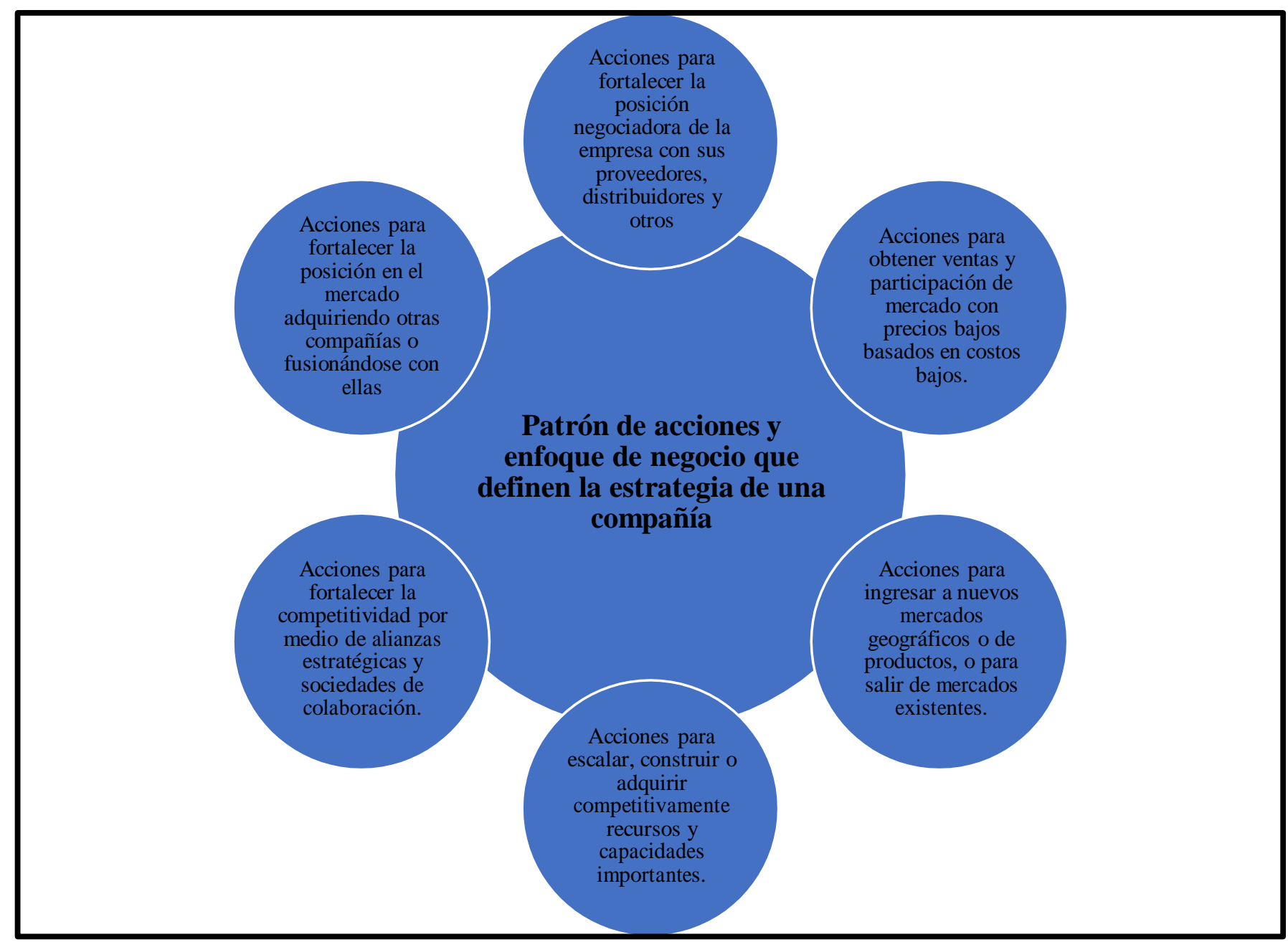

Figura 95. Identificar la estrategia de una compañía: qué buscar. Adaptado de "Administración

estratégica. (19a.ed.)”, por Thompson, 2015, p. 5. Editorial: C McGraw-Hill Interamericana.

\subsubsection{Modelo Océano Azul.}

Los océanos rojos representan a todas las industrias existentes en la actualidad, es el espacio conocido del mercado. Los océanos azules representan a todas las industrias que no existen actualmente, es el espacio desconocido del mercado. (Chan \& Mauborgne, 2005) 
Tabla 76

La estrategia de océano rojo frente a la estrategia de océano azul

\begin{tabular}{ll}
\hline Estrategia del océano rojo & Estrategia del océano azul \\
\hline $\begin{array}{l}\text { Competir en el espacio existente en el } \\
\text { mercado }\end{array}$ & $\begin{array}{l}\text { Crear un espacio sin competencia en el } \\
\text { mercado }\end{array}$ \\
\hline Vencer a la competencia & $\begin{array}{l}\text { Hacer que la competencia pierda toda } \\
\text { importancia }\end{array}$ \\
\hline $\begin{array}{l}\text { Explotar la demanda existente en el } \\
\text { mercado }\end{array}$ & Crear y capturar nueva demanda \\
\hline Elegir entre la disyuntiva de valor o costo & Romper la disyuntiva de valor o costo \\
\hline $\begin{array}{l}\text { Alinear todo el sistema de las actividades de } \\
\text { una empresa con la decisión estratégica de }\end{array}$ & $\begin{array}{l}\text { Alinear todo el sistema de las actividades de } \\
\text { una empresa con el propósito de lograr } \\
\text { diferenciación y bajo costo. }\end{array}$ \\
\hline
\end{tabular}

Nota: Tomado de "La estrategia del océano azul," (pp.25) por Chan \& Mauborgne, 2005,

Colombia: Grupo Editorial Norma. Copyright 2005 para América Latina por Editorial Norma SA.

La UEN de Tubos y Esquineros de cartón aplica la siguiente estrategia de océano azul:

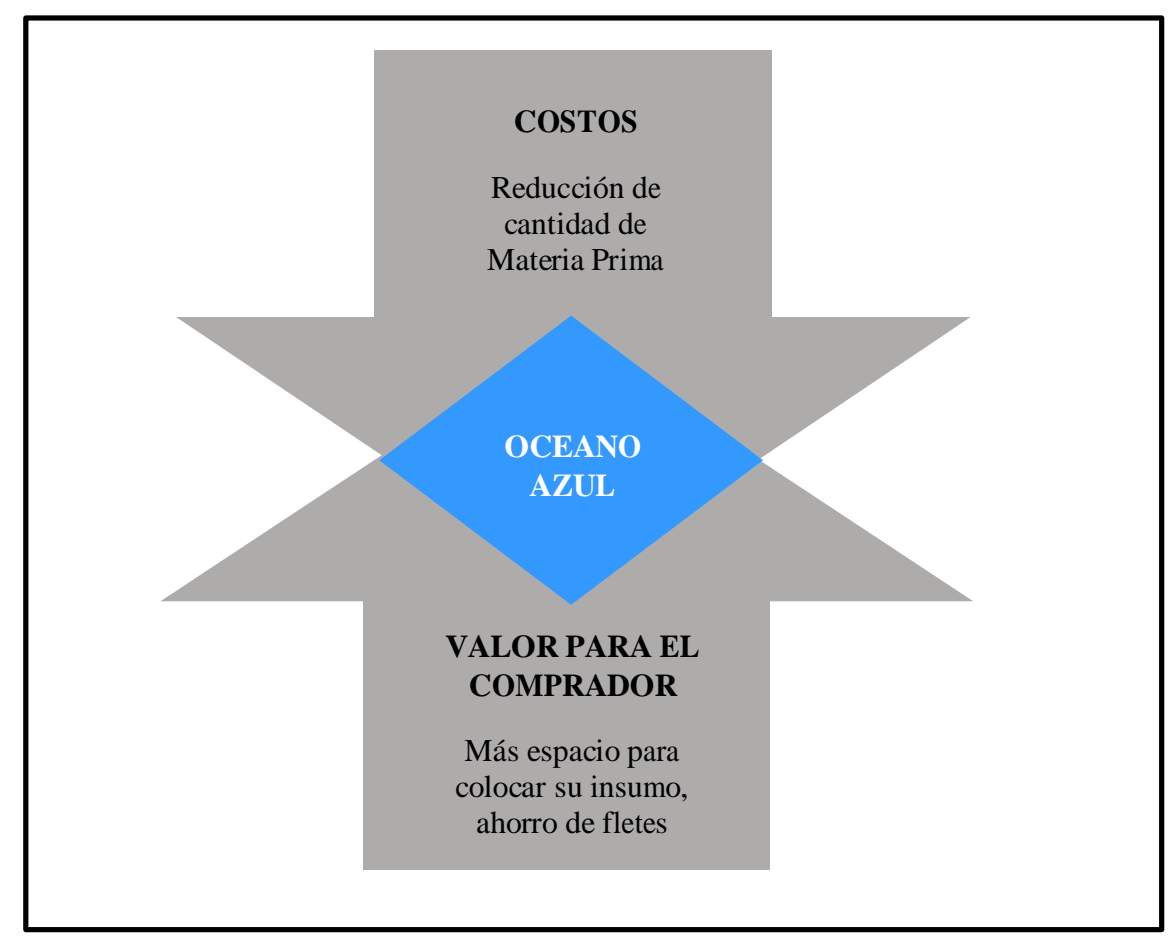

Figura 96. Diagrama del Océano azul para la UEN de Tubos y Esquineros de CARVIMSA. Adaptado de "Harvard Business Review" (pp.8) por Chan \& Mauborgne, 2004. 
En el mercado de tubos el producto es homogéneo, posee las mismas características físicas que hacen que a la vista del cliente se trate del mismo producto. El aspecto que diferencia los tubos de CARVIMSA de los tubos de la competencia parte de la resistencia de los materiales, mientras que CARVIMSA toma como materia prima bobinas de papel que sirven para la elaboración de cajas de cartón para el sector de agro, nos referimos a bobinas especiales porque tienen mayor resistencia a la humedad y especificaciones técnicas por encima de las que utiliza la competencia. Al fabricar un tubo de mayor resistencia no necesita que el diámetro sea muy grueso, lo cual deriva en una reducción de costos ya que necesitas menos materia prima y al obtener menor grosos beneficia al cliente permitiéndole colocar más insumo como film, tela, envoltura. Si nos imaginamos al cliente transportando su mercadería en grandes camiones u otro tipo de fletes, al dar más vuelta sobre el más delgado diámetro del tubo obtiene mayor espacio para transportar más tubos y también optimiza costos.

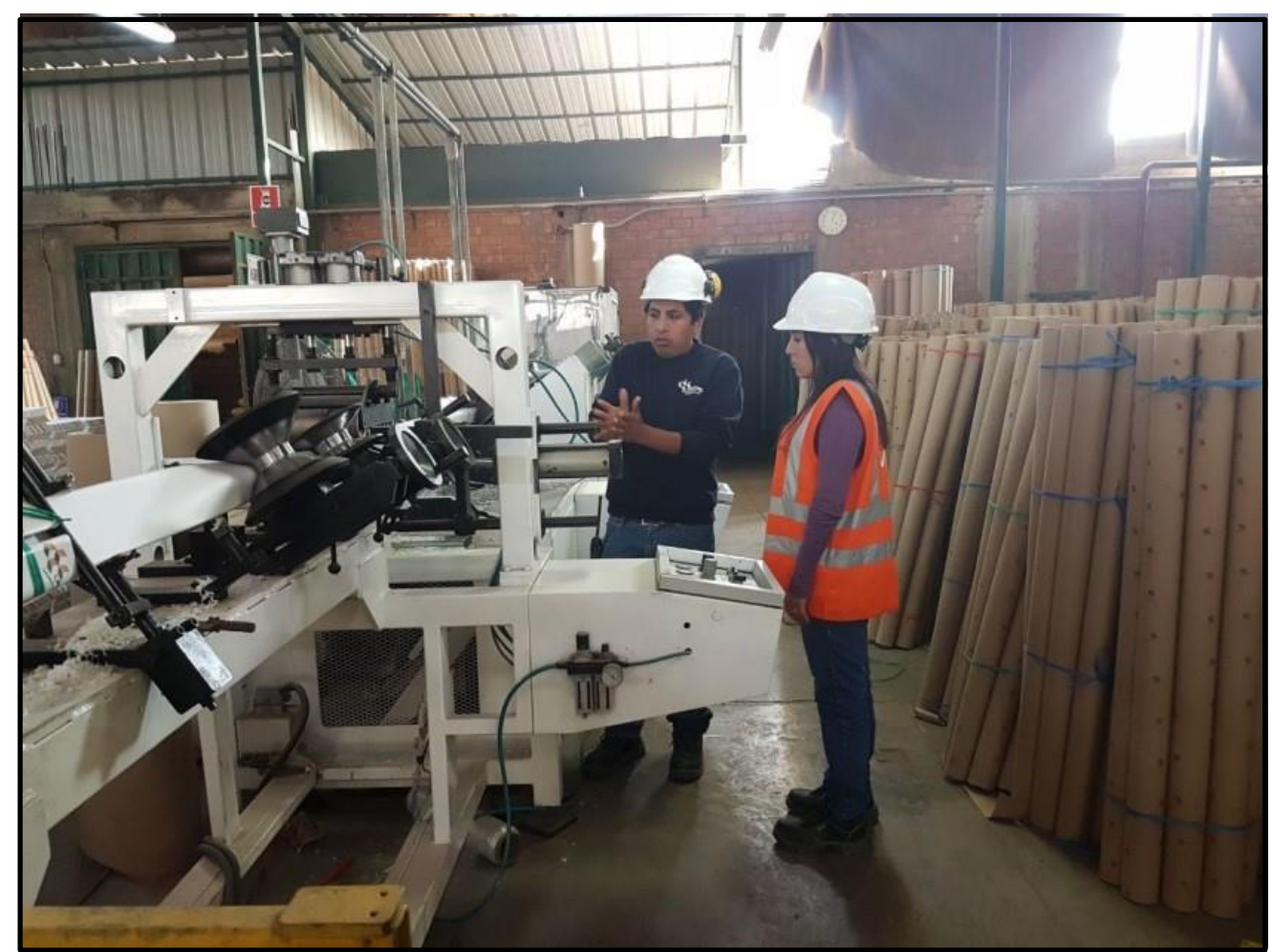

Figura 97. Proceso de Producción de Tubos. Tomado de Galería de fotos durante la visita a la planta de CARVIMSA en Huachipa. 2017. 


\subsubsection{Lienzo de la estrategia actual de la empresa}

La UEN Tubos y Esquineros presenta siete estrategias a seguir:

5
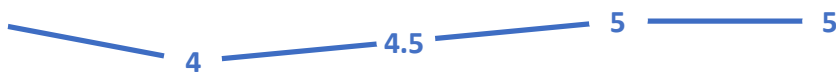

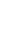
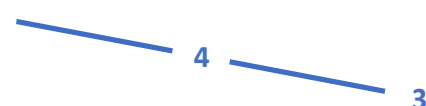

Figura 98. Lienzo Estratégico de la UEN Tubos y Esquineros de Cartón de CARVIMSA

Tabla 77

Estrategias por considerar para el Lienzo actual de la UEN Tubos y Esquineros de cartónCARVIMSA

Molino Posición Calidad del Participación Medio Competitividad Capacidad Propio Financiera Producto del Mercado Ambiente de precios Tecnológica

\begin{tabular}{lllllll}
\hline 5 & 4 & 4.5 & 5 & 5 & 4 & 3 \\
\hline
\end{tabular}

El gráfico muestra que la UEN Tubos y Esquineros de cartón necesita aún más mejorar la calidad del producto y la capacidad tecnológica, este resultado se da por los pocos años que tiene en el sector de Tubos y Esquineros. Para ello se implementarán estrategias a corto y mediano plazo, que permitirá mejorar la calidad de los productos e incrementar la capacidad tecnológica.

\subsubsection{Lienzo de la estrategia de la industria}

La UEN Tubos y Esquineros en comparación con la competencia, presenta siete estrategias a seguir: 
5

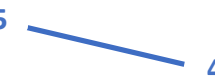

4

2

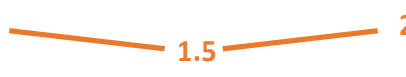

2
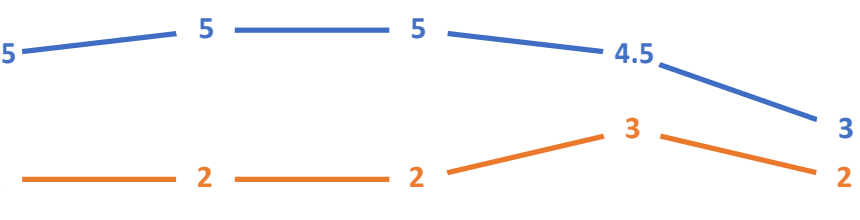

Molino Propio

$$
\begin{gathered}
\text { Posición } \\
\text { Financiera }
\end{gathered}
$$

\section{Calidad del
Producto}

Participación de Mercado

- - Carvimsa
Medio Competitividad Capacidad Ambiente de Precios Tecnológica

Figura 99. Lienzo Estratégico de la industria de la UEN Tubos y Esquineros de Cartón CARVIMSA en comparación con la competencia.

Tabla 78

Estrategias para considerar para el Lienzo estratégico de la industria de la UEN Tubos y

\begin{tabular}{|c|c|c|c|c|c|c|}
\hline $\begin{array}{l}\text { Molino } \\
\text { Propio }\end{array}$ & $\begin{array}{l}\text { Posición } \\
\text { Financiera }\end{array}$ & $\begin{array}{l}\text { Calidad } \\
\text { del }\end{array}$ & $\begin{array}{c}\text { Participación } \\
\text { del Mercado }\end{array}$ & $\begin{array}{c}\text { Medio } \\
\text { Ambiente }\end{array}$ & $\begin{array}{c}\text { Competitividad } \\
\text { de precios }\end{array}$ & $\begin{array}{l}\text { Capacidad } \\
\text { Tecnológica }\end{array}$ \\
\hline
\end{tabular}
Esquineros de cartón - CARVIMSA

\begin{tabular}{lccccccc}
\hline Carvimsa & 5 & 4 & 4.5 & 5 & 5 & 4 & 3 \\
\hline Industria & 2 & 1.5 & 2 & 2 & 2 & 3 & 2 \\
\hline
\end{tabular}

La competencia no se encuentra bien posicionado bajo los siete objetivos mostrados, ya que la mayoría de las empresas de este sector son empresas medianas y pequeñas, e incluso informales, las cuales no tienen un molino propio ni cuentan con respaldo financiero a diferencia de la empresa Carvimsa, que cuenta con posición financiera gracias al respaldo del grupo Comeca. Por otro lado, estas empresas tienen antecedentes de contaminación ambiental.

\subsubsection{Matriz (eliminar, reducir, incrementar, crear)}

La matriz "eliminar-reducir-incrementar-crear" es una herramienta fundamental para crear océanos azules. Esta matriz estimula a las compañías a actuar a fin de crear una nueva curva de valor. Al llenar la matriz con las acciones de eliminar, reducir, incrementar y crear, las compañías obtienen los siguientes cuatro beneficios. (Chan \& Mauborgne, 2005) 
Tabla 79

Beneficios de la Matriz (Eliminar, reducir, incrementar, crear)

1. Se obligan a buscar simultáneamente la diferenciación y el bajo costo

2. Pueden identificar inmediatamente si están orientados sólo a incrementar y crear, elevando su estructura de costos y exagerando en la ingeniería de sus productos y servicios, problema que suele afligir a muchas.

3. Sus gerentes de cualquier nivel pueden comprenderla fácilmente, lo cual facilita su compromiso a la hora de aplicarla.

4. Como la tarea de llenar la matriz es exigente, las obliga a examinar a fondo cada una de las variables alrededor de las cuales compite la industria y así descubrir la gama de suposiciones implícitas que se hacen a la hora de competir.

Nota: Adaptado de "La estrategia del océano azul," (pp.51) por Chan \& Mauborgne, 2005, Colombia: Grupo Editorial Norma. Copyright 2005 para América Latina por Editorial Norma SA.

A continuación, se presenta la matriz aplicada a la UEN Tubos y Esquineros de CARVIMSA:

\begin{tabular}{|c|c|}
\hline Reducir & Aumentar \\
\hline \multicolumn{1}{|c|}{ El diámetro de los tubos de cartón } & \multicolumn{2}{|c|}{ La participación de mercado. } \\
\hline Eliminar & Crear \\
\hline $\begin{array}{l}\text { El uso de hornos a base de carbón } \\
\text { industrial como parte del proceso de } \\
\text { secado de los tubos. }\end{array}$ & \multicolumn{2}{|c|}{$\begin{array}{l}\text { Un área de calidad y } \\
\text { especificaciones técnicas. }\end{array}$} \\
\hline
\end{tabular}

Figura 100. Matriz ERAC (Eliminar, Reducir, Aumentar y Crear)

\section{Reducir: El diámetro de los tubos de cartón}

Los tubos de CARVIMSA son 30\% más resistentes que los de la competencia, por ello se puede hacer el tubo con menos espesor reduciendo el diámetro de éste, con ello propone a sus clientes más resistencia y al mismo tiempo más espacio para colocar el material que va en el tubo aprovechando los fletes.

\section{Aumentar: La participación de mercado}

CARVIMSA pretende aumentar la participación en el mercado. Actualmente CARVIMSA tiene una participación del $43 \%$ y debido a los acuerdos contractuales con el 
cliente Solpack S.A., que establece el traslado de la planta de Chile a Perú a inicios del 2018, se prevé un incremento 2,892 toneladas anuales.

Eliminar: El uso de hornos a base de carbón industrial como parte del proceso de secado de los tubos

Actualmente CARVIMSA cuenta con dos hornos a gas, los demás miembros de la competencia no lo tienen, el uso de carbón trae consigo daños medioambientales, por ello se considera que debe eliminarse, además de mitigar la contaminación medioambiental, el tiempo de secado con hornos a gas es menor.

\section{Crear: Un área de calidad y especificaciones técnicas}

Se proponen auditorias por parte del Ministerio de la Producción para que exijan a que cada empresa cuente con un área de calidad que éstas muestren los certificados otorgados a los clientes ya que existen casos en los que ofrecen bajos precios a cambio de un producto que no cumple los estándares de calidad.

\subsubsection{Lienzo de la nueva estrategia considerada}

La UEN Tubos y Esquineros en comparación con la competencia presenta siete estrategias a seguir:

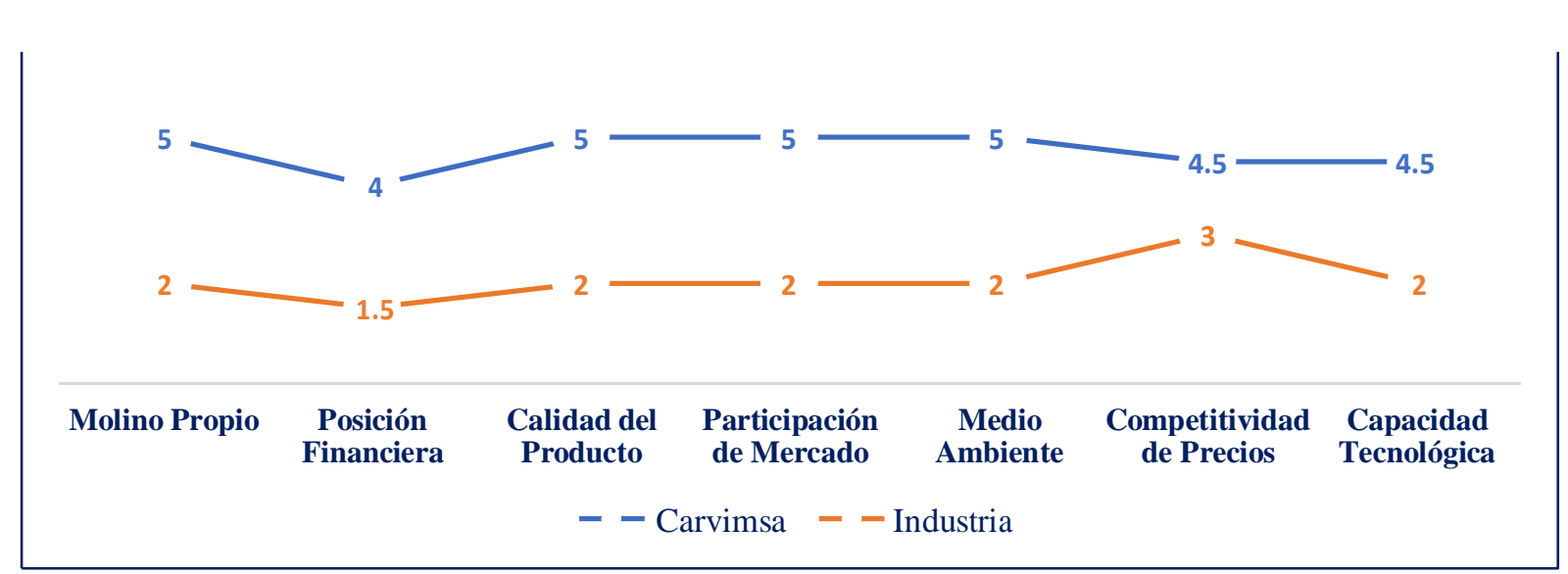

Figura 101. Lienzo de la nueva estrategia de la UEN Tubos y Esquineros de Cartón CARVIMSA 
Tabla 80

Estrategias por considerar para el Lienzo de la nueva estrategia de la UEN Tubos y Esquineros de cartón-CARVIMSA

$\begin{array}{ccccccc}\text { Molino } & \text { Posición } & \text { Calidad } & \text { Participación } & \text { Medio } & \text { Competitividad } & \text { Capacidad } \\ \text { Propio Financiera } & \text { Producto } & \text { del Mercado } & \text { Ambiente } & \text { de precios } & \text { Tecnológica }\end{array}$

\begin{tabular}{lccccccc}
\hline Carvimsa & 5 & 4 & 5 & 5 & 5 & 4.5 & 4.5 \\
\hline Industria & 2 & 1.5 & 2 & 2 & 2 & 3 & 2 \\
\hline
\end{tabular}

\subsubsection{Matrices de formulación de las estrategias}

Dentro de la etapa de formulación de la estrategia, la elección de estrategias externas e internas se constituye en la parte más importante y se soporta en la intuición estratégica, ya que no existen reglas, sino matrices que ayudan, y exigen del gerente o gerentes el uso de sus propias cualidades creativas, inspiradoras, y de presentimientos para obtener resultados exitosos. (D'Alessio, 2008).

\subsubsection{Matriz FODA}

La matriz de fortalezas, oportunidades, debilidades y amenazas (FODA) es una importante herramienta de adecuación que ayuda a los directivos a desarrollar cuatro tipos de estrategias: estrategias FO (fortalezas-oportunidades), estrategias DO (debilidadesoportunidades), estrategias FA (fortalezas-amenazas) y estrategias DA (debilidadesamenazas). Adecuar los factores internos y externos clave es la parte más difícil en el desarrollo de la matriz FODA. (David, 2013) 
Tabla 81

Estrategias de la matriz FODA

\begin{tabular}{ll}
\hline $\begin{array}{l}\text { Las estrategias } \\
\text { FO }\end{array}$ & $\begin{array}{l}\text { Utilizan las fortalezas internas de la empresa para aprovechar las } \\
\text { oportunidades externas. }\end{array}$ \\
\hline $\begin{array}{l}\text { Las estrategias } \\
\text { DO }\end{array}$ & $\begin{array}{l}\text { Buscan superar las debilidades internas aprovechando las oportunidades } \\
\text { externas. }\end{array}$ \\
\hline $\begin{array}{l}\text { Las estrategias } \\
\text { FA }\end{array}$ & $\begin{array}{l}\text { Utilizan las fortalezas de la empresa para evitar o reducir el impacto de } \\
\text { las amenazas externas. }\end{array}$ \\
\hline $\begin{array}{l}\text { Las estrategias } \\
\text { DA }\end{array}$ & $\begin{array}{l}\text { Son tácticas defensivas cuyo propósito es reducir las debilidades internas } \\
\text { y evitar las amenazas externas. }\end{array}$
\end{tabular}

Nota: Tomado de “Administración Estratégica," (pp.176) por David, 2013, México:

Editorial Pearson Education. Copyright 2013 por Prentice Hall.

Para construir la matriz FODA se copia directamente en esta las oportunidades y amenazas registradas en la matriz EFE, así como las fortalezas y debilidades registradas en la matriz EFI; con esto se crean las cuatro entradas para los cuatro cuadrantes (FO, DO, FA, DA) y se generan principalmente estrategias externas y eventualmente internas. (D'Alessio, 2008). 


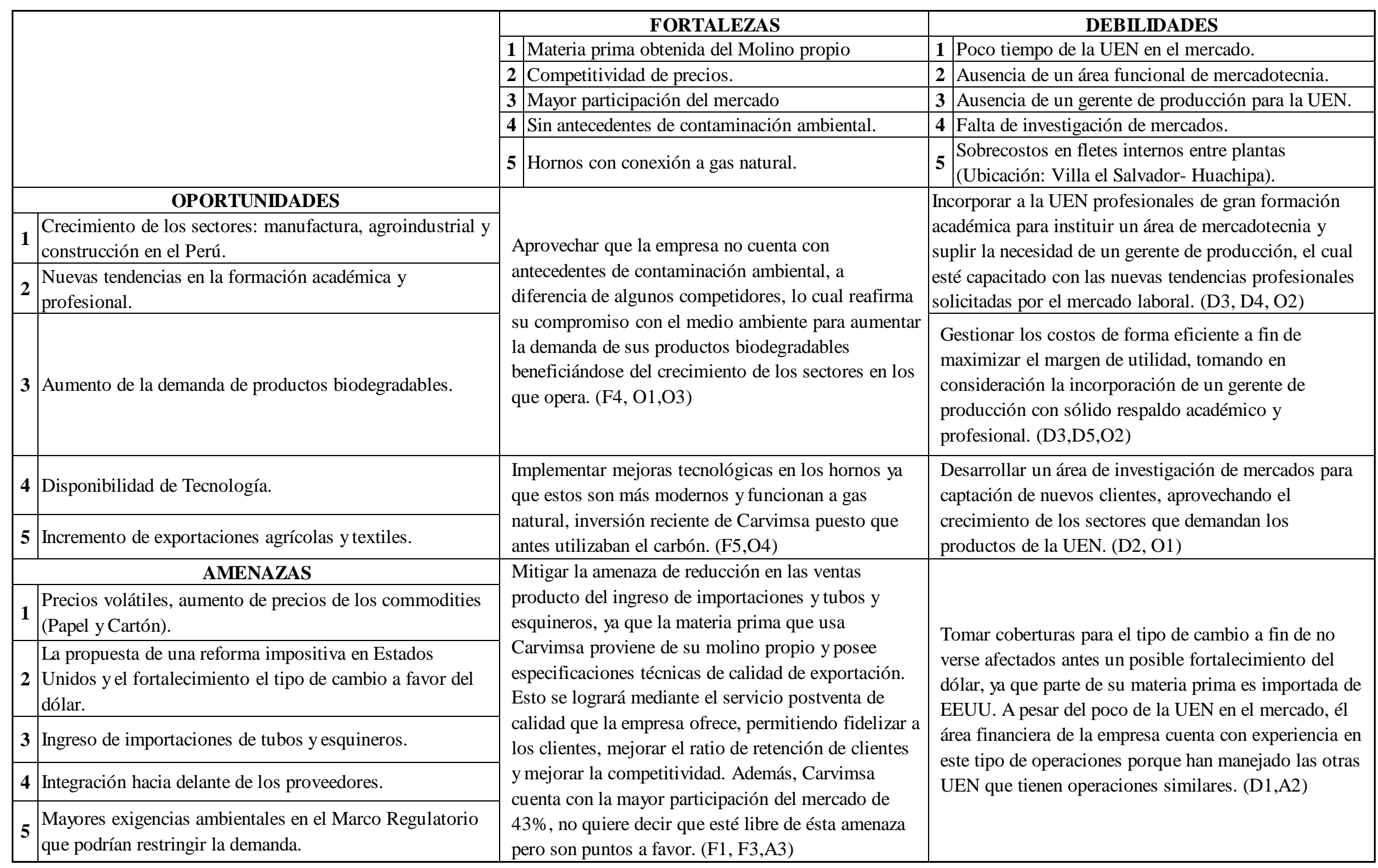

Figura 102. Estrategias de la matriz FODA de la nueva estrategia de la UEN Tubos y Esquineros de Cartón - CARVIMSA 


\subsubsection{Matriz PEYEA}

David (2013) señaló:

La matriz PEYEA se ilustra en cuatro cuadrantes que indica cuáles son las estrategias más adecuadas para una organización determinada: agresivas, conservadoras, defensivas o competitivas. Los ejes de la matriz representan dos dimensiones internas: (la fuerza financiera (FF) y la ventaja competitiva (VC)) y dos dimensiones externas (la estabilidad del entorno (EE) y la fuerza de la industria (FI). Es posible que estos cuatro factores constituyan los determinantes más importantes de la posición estratégica de una organización. (p.178)

Tabla 82

Pasos para la elaboración de la Matriz PEYEA

\section{Pasos Procedimiento}

Paso 1 Seleccionar un conjunto de variables para definir la fuerza financiera (FF), la ventaja competitiva (VC), la estabilidad del entorno (EE), y la fuerza de la industria (FI).

Paso 2 Asignar un valor numérico de más uno (la peor) a más siete (la mejor) a cada una de las variables que integran las dimensiones FF y FI. Asignar un valor numérico de menos uno (la mejor) a menos siete (la peor) a cada una de las variables que integran las dimensiones EE y VC. En los ejes FF y VC, hacer una comparación con los competidores. En los ejes FI y EE, hacer una comparación con otras industrias.

Paso 3 Calcular la puntuación promedio FF, VC, FY y EE sumando los valores otorgados a las variables en cada dimensión, y dividiendo el resultado entre el número de variables incluidas en la dimensión respectiva.

Paso 4 Graficar las puntuaciones promedio FF, FI, EE y VC sobre el eje correspondiente de la matriz PEYEA.

Paso 5 Sumar las dos puntuaciones del eje x y trazar el punto resultante en X. Sumar las dos puntuaciones del eje y trazar el punto resultante en Y. Trazar la intersección del nuevo punto xy.

Paso 6 Trazar un vector direccional que vaya desde el origen de la matriz PEYEA hasta el punto de intersección. Este sector indica el tipo de estrategias recomendadas para la organización: agresiva, competitiva, defensiva o conservadora.

Nota: Adaptado de "Administración Estratégica," (pp.179) por David, 2013, México: Editorial Pearson Education. Copyright 2013 por Prentice Hall. 


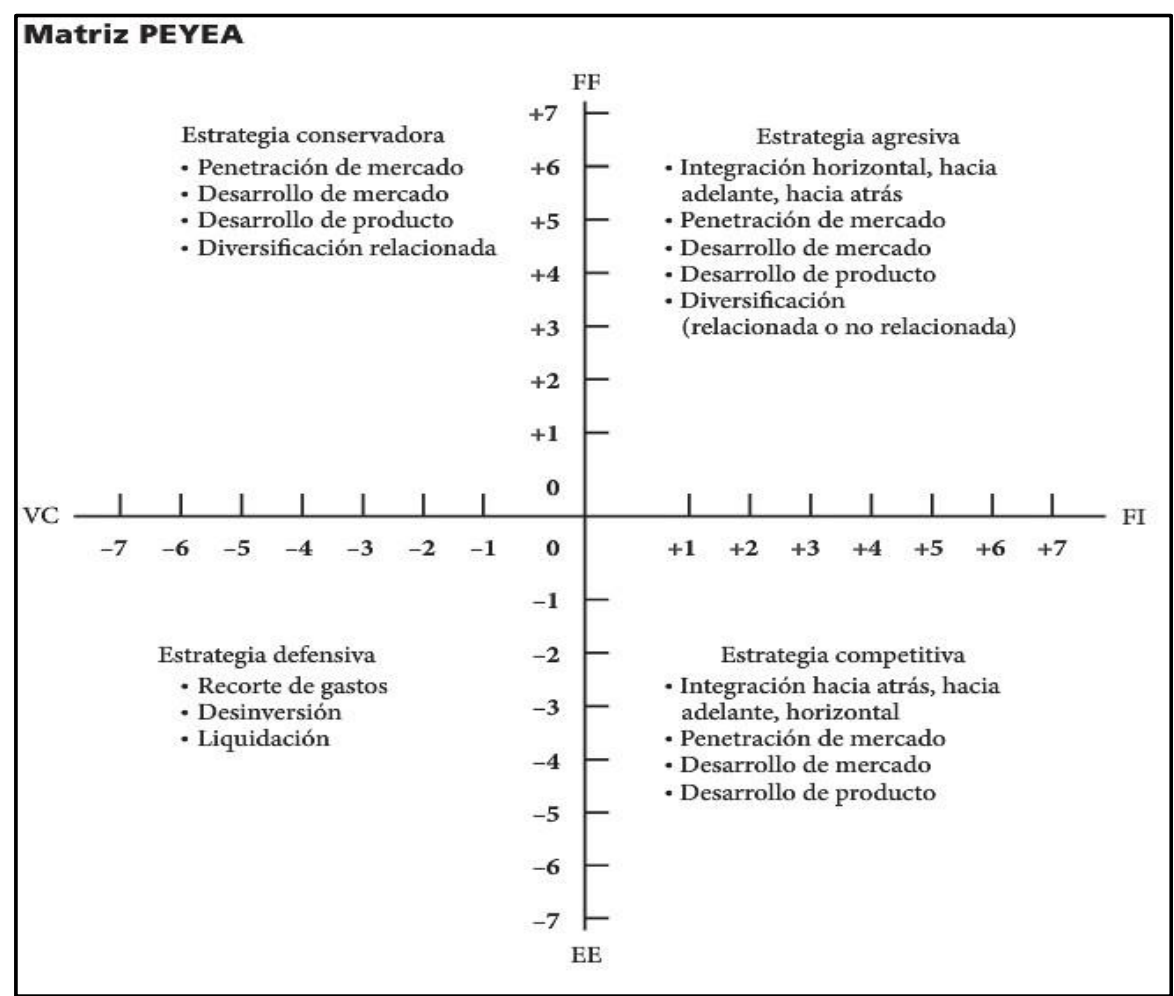

Figura 103. Modelo de los cuatros cuadrantes. Adaptado de "Administración estratégica. (14a.ed.)”, por David, 2013, p. 178. Editorial Pearson Education.

En la figura 99, se muestran los factores determinantes de la posición estratégica interna y externa empleados para la elaboración de la matriz PEYEA.

\begin{tabular}{|c|c|c|c|c|c|}
\hline \multicolumn{3}{|c|}{$\begin{array}{r}\text { Posición Estratégica Interna } \\
\end{array}$} & \multicolumn{3}{|c|}{ Posición Estratégica Externa } \\
\hline \multicolumn{3}{|c|}{ Factores determinantes de la Fortaleza Financiera } & \multicolumn{3}{|c|}{ Factores determinantes de la Ventaja Competitiva } \\
\hline Nro. & Factor & Puntuación & Nro. & Factor & Puntuación \\
\hline 1 & Liquidez & 1 & & Cambios Tecnológicos & 5 \\
\hline 2 & Endeudamiento & 3 & & Tasa de inflación & 5 \\
\hline 3 & Rotación Cuentas por Cobrar & 2 & & Variabilidad de la demanda & 5 \\
\hline 4 & Rotación de Inventarios & 4 & & Rango de precios de productos competitivos & 4 \\
\hline 5 & Rotación Cuentas por Pagar & 6 & & Barreras de entrada al Mercado & 5 \\
\hline 6 & Rentabilidad & 3 & & Rivalidad/presión competitiva & \\
\hline \multirow[t]{3}{*}{7} & Capital de Trabajo & 1 & & Elasticidad precio demanda & \\
\hline & & & & Presión de los productos sustitutos & 5 \\
\hline & Promedio: & 286 & & Promedio & -138 \\
\hline \multicolumn{3}{|c|}{ Factores determinantes de la Ventaja Competitiva } & \multicolumn{3}{|c|}{ Factores determinantes de la Fortaleza de la Industria } \\
\hline Nro. & Factor & Puntuación & Nro. & Factor & Puntuación \\
\hline 1 & Participación del Mercado & 5 & 1 & Potencial Crecimiento & 5 \\
\hline 2 & Calidad del producto & 6 & 2 & Estabilidad Financiera & 4 \\
\hline 3 & Ciclo de vida del producto & 4 & 3 & Conocimiento Tecnológico & 5 \\
\hline 4 & Ciclo de reemplazo del producto & 2 & 4 & Utilización de recursos & 6 \\
\hline 5 & Lealtad del consumidor & 3 & 5 & Facilidad de entrada al mercado & 5 \\
\hline 6 & Utilización de la capacidad de los competidores & 4 & 6 & Productividad/Utilización de la capacidad & 2 \\
\hline 7 & Conocimiento Tecnológico & 6 & 7 & Poder de negociación de los productores & 5 \\
\hline 8 & Integración Vertical & 6 & & & \\
\hline 9 & Velocidad de introducción de nuevos productos & 3 & & & \\
\hline & Promedio: & -1.67 & & Promedio: & 4.57 \\
\hline
\end{tabular}

Figura 104. Factores determinantes 
En la figura 100, se muestra la matriz PEYEA de la UEN Tubos y Esquineros:

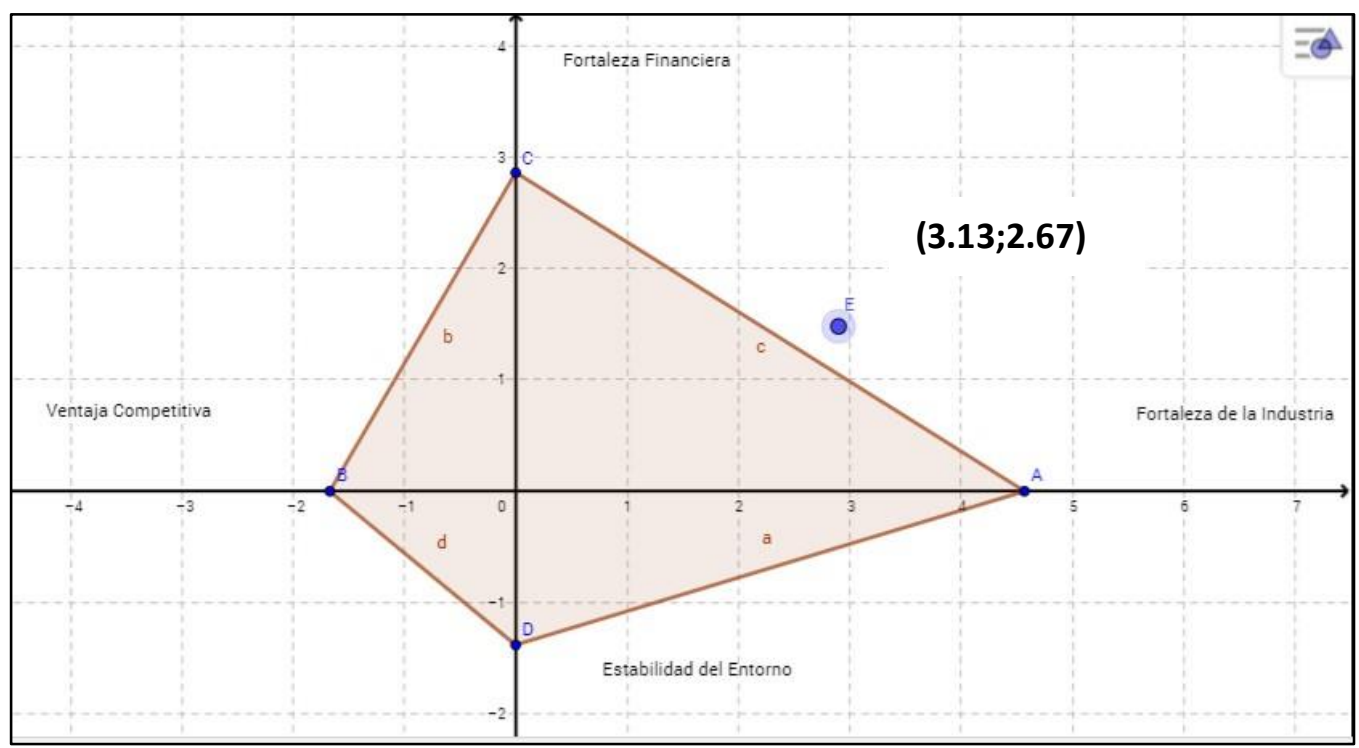

Figura 105. Matriz PEYEA de la UEN Tubos y esquineros de cartón

\subsubsection{Matriz Interna Externa}

David (2013) señaló:

La matriz Interna Externa representa (IE), muestra las diferentes divisiones de una organización en un modelo de nueve casillas. Esta matriz es similar a la matriz BCG en cuento a que en ambas herramientas las divisiones de la organización se muestran en un diagrama esquemático; esta es la razón de que ambas matrices reciban el nombre de "matrices de cartera". Asimismo, tanto en la matriz IE como en la BCG el tamaño de cada circulo representa el porcentaje de ventas que aporta cada división y las tajadas que hay en el interior de estos revelan el porcentaje de utilidades que aporta cada división. La matriz IE se basa en dos dimensiones clave: los puntajes totales ponderados de EFI en el eje $\mathrm{x}$ y los puntajes totales ponderados de EFE en el eje y. (p.186) 
Tabla 83

Puntuación total ponderado de la matriz EFI

Posición interna débil Del puntaje 1.0 a 1.99

Posición interna promedio Del puntaje 2.0 a 2.99

Posición interna fuerte Del puntaje 3.0 a 4.

Nota: Tomado de "Administración Estratégica," (pp.188) por David, 2013, México:

Editorial Pearson Education. Copyright 2013 por Prentice Hall.

Tabla 84

Puntuación total ponderado de la matriz EFE

\begin{tabular}{ll}
\hline Posición externa bajo & Del puntaje 1.0 a 1.99 \\
\hline Posición externa medio & Del puntaje 2.0 a 2.99 \\
\hline Posición externa alto & Del puntaje 3.0 a 4.
\end{tabular}

Nota: Tomado de “Administración Estratégica,” (pp.188) por David, 2013, México:

Editorial Pearson Education. Copyright 2013 por Prentice Hall.

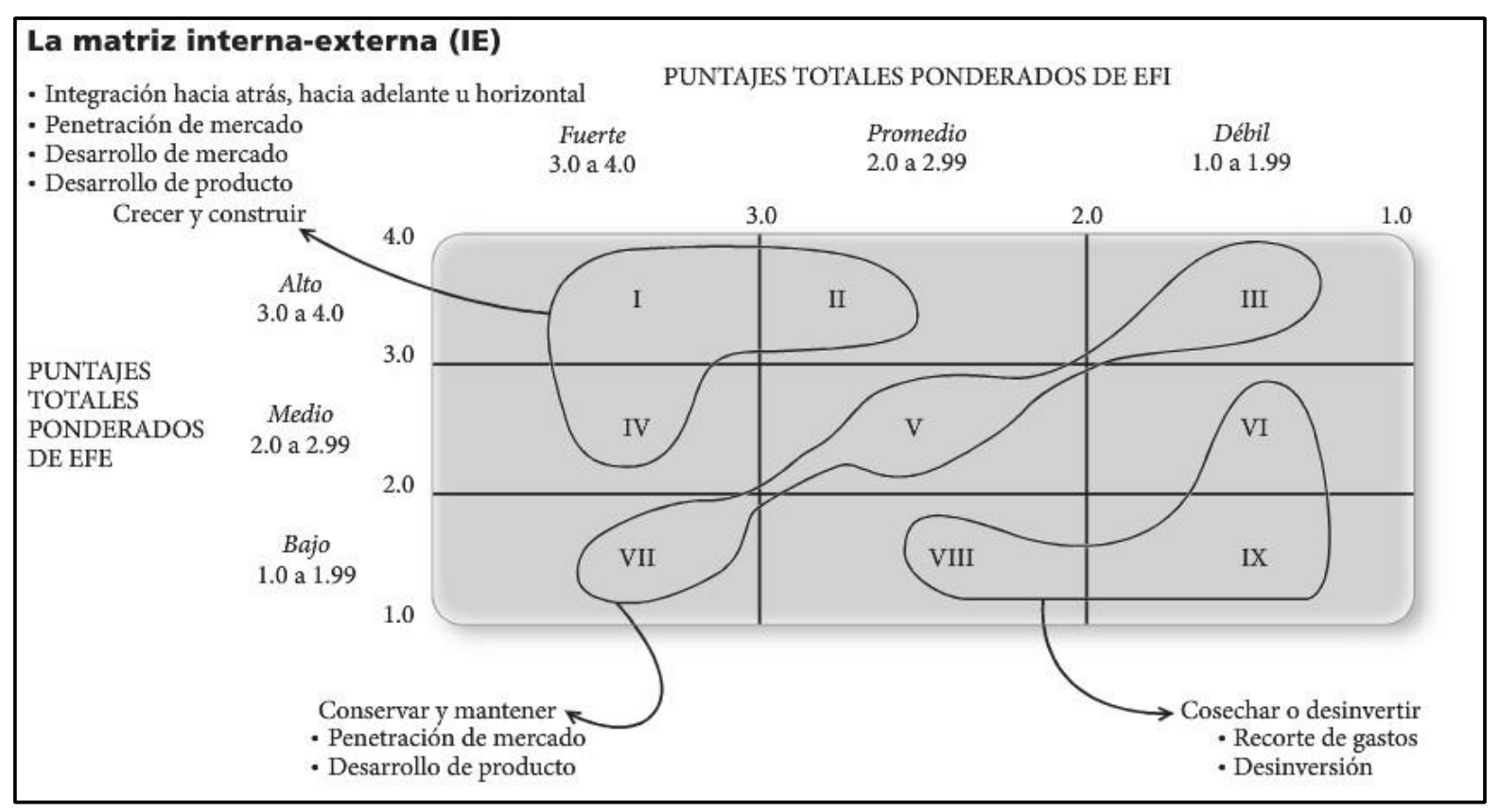

Figura 106. Modelo de los cuatros cuadrantes. Adaptado de "Administración estratégica. (14a.ed.)”, por David, 2013, p. 187. Editorial Pearson Education. 


\section{Matriz de Factor Interno}

Para elaborar la matriz de Factor Interno se determinaron los factores clave, es decir, las fortalezas y debilidades de la UEN Tubos y Esquineros, se otorgó una ponderación de acuerdo con la importancia de cada factor y una calificación según la percepción actual de los gerentes de las cuatro áreas representativas de la empresa: Finanzas, Ventas, Logística y Producción además de realizar la consulta a Gerencia General. A continuación, se muestran los resultados obtenidos.

Tabla 85

Matriz de Factor Interno

Factor clave interno

Ponderación Calificación Resultado

\begin{tabular}{llll}
\hline 1. Materia prima obtenida del Molino propio & 0.20 & 4 & 0.80 \\
\hline 2. Competitividad de precios & 0.09 & 3 & 0.27 \\
\hline 3. Mayor participación del mercado & 0.15 & 4 & 0.60 \\
\hline 4. Sin antecedentes de contaminación ambiental & 0.13 & 4 & 0.52 \\
\hline 5. Hornos con conexión a gas natural & 0.12 & 3 & 0.36 \\
\hline 6. Poco tiempo de la UEN en el mercado & 0.03 & 2 & 0.06 \\
\hline 7. Ausencia de un área funcional de mercadotecnia & 0.06 & 2 & 0.12 \\
\hline $\begin{array}{l}\text { 8. Ausencia de un gerente de producción para la } \\
\text { UEN }\end{array}$ & 0.13 & 2 & 0.26 \\
\hline $\begin{array}{l}\text { 9. Falta de investigación de mercados } \\
\text { 10. Sobrecostos en fletes internos entre plantas } \\
\text { (Ubicación: Villa el Salvador- Huachipa) }\end{array}$ & 0.05 & 2 & 0.10 \\
\hline Total & 0.04 & 1 & 0.04 \\
\hline
\end{tabular}

Nota. Elaborado en base a entrevistas a funcionarios de CARVIMSA

\section{Matriz de Factor Externo}

De igual manera, para la elaboración de la matriz externa se determinaron los factores clave, en este caso las oportunidades y amenazas y se procedió con la misma mecánica. 
Tabla 86

Matriz de Factor Externo

\begin{tabular}{lccc}
\hline Factor clave externo & Ponderación & Calificación & Resultado \\
\hline $\begin{array}{l}\text { 1.Precios volátiles, aumento de precios de los } \\
\text { commodities (Papel y Cartón) }\end{array}$ & 0.15 & 2 & 0.30 \\
\hline $\begin{array}{l}\text { 2.La propuesta de una reforma impositiva en } \\
\text { Estados Unidos y el fortalecimiento el tipo de } \\
\text { cambio a favor del dólar }\end{array}$ & 0.11 & 2 & 0.22 \\
\hline $\begin{array}{l}\text { 3.Ingreso de importaciones de tubos y } \\
\text { esquineros }\end{array}$ & 0.04 & 1 & 0.04 \\
\hline $\begin{array}{l}\text { 4. Integración hacia delante de los proveedores } \\
\text { 5.Mayores exigencias ambientales en el Marco } \\
\text { Regulatorio que podrían restringir la demanda }\end{array}$ & 0.04 & 2 & 0.11 \\
\hline $\begin{array}{l}\text { 6.Crecimiento de los sectores: manufactura, } \\
\text { agroindustrial y construcción en el Perú }\end{array}$ & 0.06 & 2 & 0.22 \\
\hline $\begin{array}{l}\text { 7.Nuevas tendencias en la formación } \\
\text { académica y profesional }\end{array}$ & 0.10 & 4 & 0.24 \\
\hline $\begin{array}{l}\text { 8.Aumento de la demanda de productos } \\
\text { biodegradables }\end{array}$ & 0.16 & 3 & 0.40 \\
\hline 9.Disponibilidad de Tecnología & 0.11 & 3 & 0.33 \\
\hline $\begin{array}{l}\text { 10.Incremento de exportaciones agrícolas y } \\
\text { textiles }\end{array}$ & 0.12 & 3 & 0.36 \\
\hline Total & $\mathbf{1 . 0 0}$ & & $\mathbf{2 . 6 7}$ \\
\hline Nota. Elaborado en base a entrevistas a funcionarios & $\mathrm{CARVIMSA}$ & & \\
\hline
\end{tabular}

Nota. Elaborado en base a entrevistas a funcionarios de CARVIMSA

\section{Matriz Interna Externa}

Los índices obtenidos en las matrices anteriores se grafican en la Matriz Interna

Externa, la cual consta de 9 cuadrantes. El resultado obtenido de los factores internos es 3.13 mientras que el resultado de los factores externos es 2.67, en la gráfica se puede observar que la UEN Tubos y Esquineros de cartón de CARVIMSA, se ubica en el cuadrante IV, donde se deben implementar estrategias para "crecer y construir". 


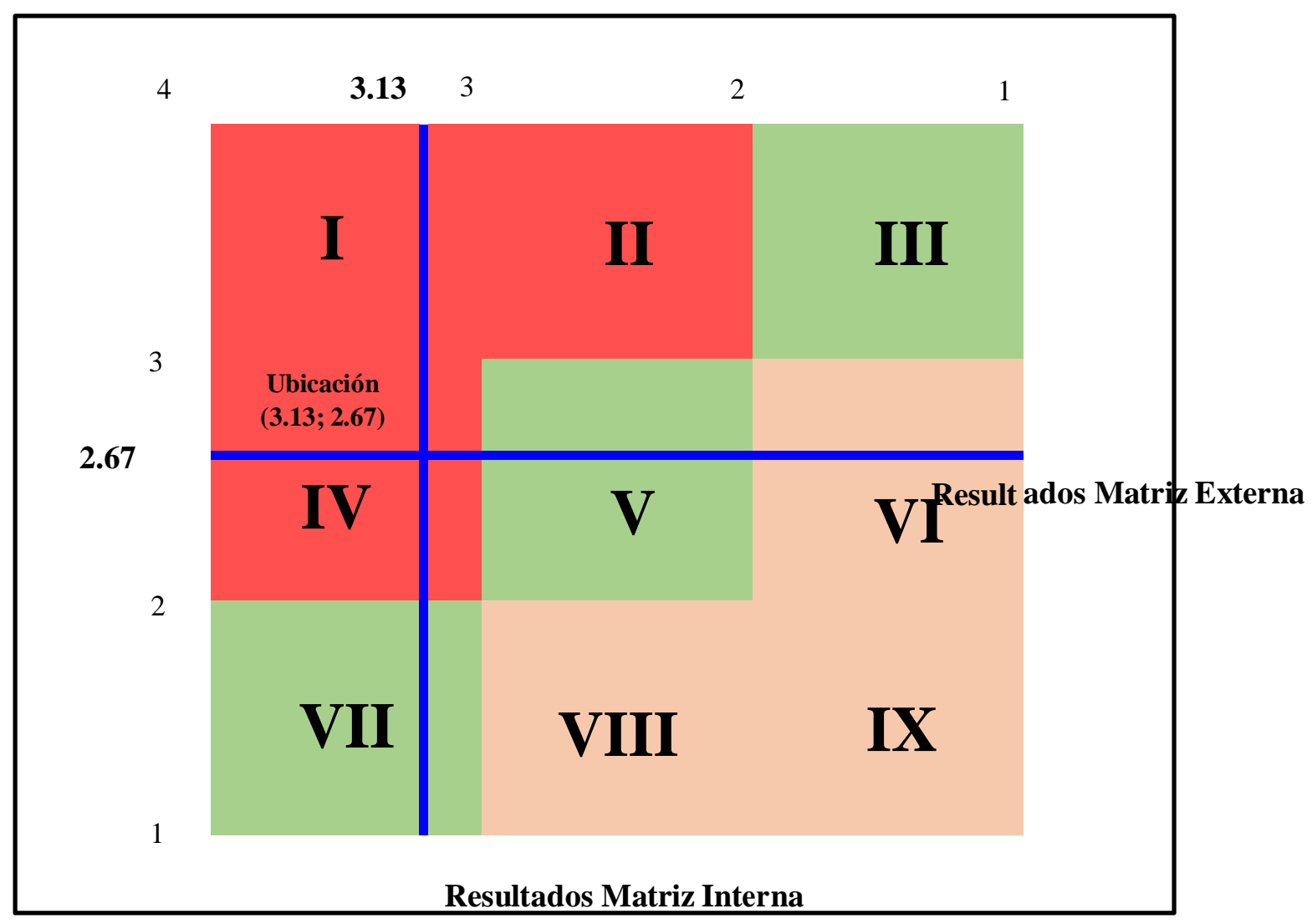

Figura 107. Matriz Interna Externa de la UEN Tubos y esquineros de cartón

Las estrategias intensivas resultantes de la matriz son tres: la penetración de mercado, el desarrollo de mercado y el desarrollo de producto. Se recomienda para la UEN Tubos y Esquineros de CARVIMSA abordar la estrategia de penetración de mercados mediante el incentivo de un mayor consumo de los productos en los mercados que ya existen a través del aumento de ventas a clientes actuales con gran potencial como Solpack S.A.C, ganando clientes de la competencia como OPP Film S.A. y quitándoles participación de mercado a sus competidores. Teniendo en cuenta las proyecciones de crecimiento de los sectores, otra estrategia es la de desarrollo de mercado en cuanto a esquineros la posibilidad de buscar mercados en el exterior es una opción para considerar con la creación del área de investigación de mercados y mercadotecnia. Por último, la gerencia general de CARVIMSA enfatizó mucho el tema del desarrollo de producto mediante el valor de la innovación. 


\subsubsection{Matriz Boston Consulting Group}

La matriz Boston Consulting Group (BCG), desarrollada por el grupo consultor del mismo nombre, relaciona las divisiones, subsectores o productos, a partir de su posición en la participación de mercado y generación de efectivo, y de la tasa de crecimiento de ventas en la industria y uso de efectivo. De esta forma, se forman cuatro cuadrantes con la finalidad de monitorear el ciclo de vida de las divisiones, subsectores o productos, y ajustar las estrategias cuando estas cambian de cuadrante. Estos cuadrantes son: (i) Interrogantes, para una baja participación de mercado y alto crecimiento en ventas; (ii) Estrellas, para una alta participación de mercado y alto crecimiento en ventas; (iii) Vacas lecheras, para una alta participación de mercado y bajo crecimiento en ventas; y (iv) Perros, para una baja participación de mercado y bajo crecimiento en ventas. (D’Alessio, 2008)

A continuación, emplearemos la matriz BCG matriz de tasa del crecimiento de mercado y participación relativa en el mercado como metodología gráfica para el análisis de la UEN Tubos y Esquineros de cartón de CARVIMSA.

\section{Crecimiento del mercado}

Son varios los factores que explican esta tendencia. En primer lugar, el conjunto de la economía mundial que bajo los efectos de la globalización está propiciando cambios estructurales en la demanda, en la logística y en el proceso de compra. Este crecimiento ha impulsado cambios importantes en la industria, a pesar del alza del precio del papel en el mercado internacional, la industria de cartón corrugado lograría este año un crecimiento de 5,3\% impulsado por el continuo dinamismo del sector construcción, manufactura y el sector agrícola. 
Tabla 87

Proyecciones de crecimiento de mercado

Las proyecciones para finalizar el 2017 son de $3,5 \%$ mientras que el pronóstico para 2018 se

Crecimiento Mundial mantiene en $3,6 \%$.

FMI, 2017

Las perspectivas de crecimiento económico se ubican en un rango entre 3,0 y $3,5 \%$ y BCRP, ascenderían a un rango entre 3,8 y 4,0\% para el 2017 año 2018.

Sector Manufactura: $3.0 \%$

Crecimiento de los sectores involucrados

Sector Construcción: $3.3 \%$

BCRP,

Sector Agropecuario: $2.9 \%$

\section{Participación relativa del mercado}

En la actualidad existen cuatro empresas que compiten en el mercado de tubos y esquineros de cartón. Para calcular la participación relativa de mercado se dividió la participación de mercado de CARVIMSA del $43 \%$ entre la participación de la empresa de mayor porcentaje que en este caso también es CARVIMSA obteniendo el puntaje de 1.

\section{Tabla 88}

Participación de mercado

\section{Empresa \\ Porcentaje de participación de mercado}

CARVIMSA Empresa líder en el mercado con un $43 \%$ de participación. Cuenta con máquinas de última generación y una cartera diversificada de productos y clientes

Acinsa Tubos Empresa pionera en el mercado de tubos de cartón, ocupando un posicionamiento en el mercado de un $19 \%$.

Tuboquimsa Empresa peruana con participación del 19\% en el mercado nacional.

Trupal Empresa con sólido respaldo financiero del Grupo Gloria, que atiende a diferentes sectores del mercado peruano. Actualmente tiene una participación del 7\%. 
Para proceder a la determinación del cuadrante de la UEN Tubos y Esquineros, se ubica en el eje "x" el porcentaje de participación relativa de mercado que tiene, es decir, el $43 \%$ entre $43 \%$, por ello se considera 1 . En el eje "y" que va de $-20 \%$ a $+20 \%$ siendo 0.0 el punto medio, la empresa se encuentra en una tasa de crecimiento de $5.3 \%$.

Para tener un enfoque a nivel corporativo, se realizará el procedimiento para las UEN Cajas de cartón para el sector doméstico y agroindustrial, no se considera a las Bobinas de papel ya que esta unidad sirve de uso interno dentro de la cadena de abastecimiento de las otras tres unidades.

Respecto a la UEN Cajas de cartón para el sector doméstico se ubica en el eje "x" el porcentaje de participación relativa de mercado que es el $35 \%$ entre $40 \%$ que es la participación del líder, por ello se considera 0.88 . En el eje “y” que va de $-20 \%$ a $+20 \%$ siendo 0.0 el punto medio, la empresa se encuentra en una tasa de crecimiento de $-5 \%$.

En el caso de la UEN Cajas de cartón para el sector agroindustrial se ubica en el eje "x" el porcentaje de participación relativa de mercado que es el 54\% entre 54\%, por ello se considera 1. En el eje "y" que va de $-20 \%$ a $+20 \%$ siendo 0.0 el punto medio, la empresa se encuentra en una tasa de crecimiento de $5 \%$. 
(-) PARTICIPACION RELATIVA DEL MERCADO (+)

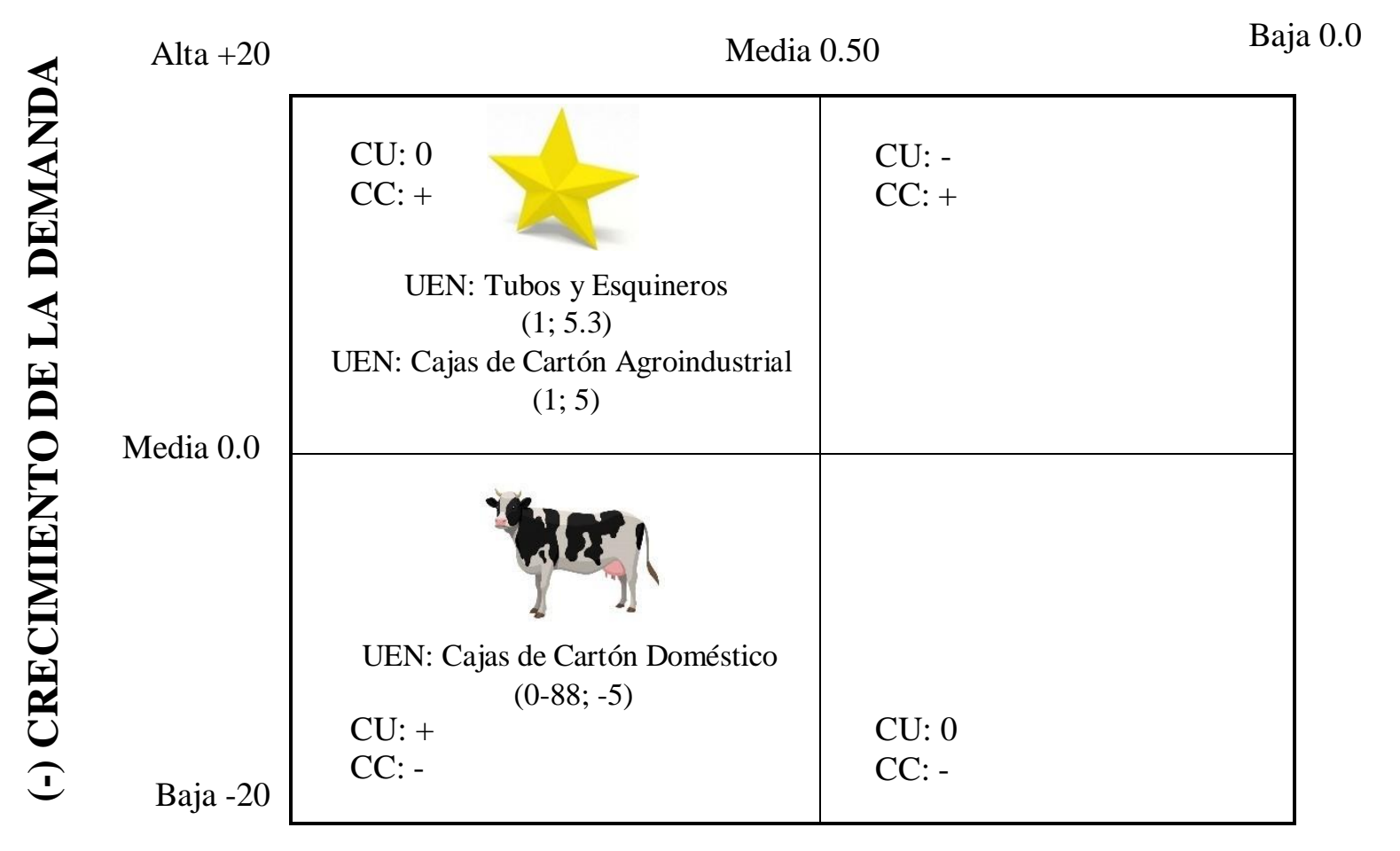

Figura 108. Matriz BCG. Posición de la UEN Tubos y Esquineros de CARVIMSA

La UEN Tubos y Esquineros se ubica en el cuadrante de la "Estrella" ya que su cuota de mercado sobrepasa el 50\% de las ventas de la industria, al ser la empresa con mayor participación de mercado, seguido del competidor Acinsa con 19\% de participación, debe aprovechar el rápido crecimiento como potencial para ganar aún más cuota de mercado a través de captación de mayores volúmenes de ventas o nuevos clientes.

En este cuadrante también se ubica la UEN de cajas de cartón para el sector agroindustrial que es considerada la mayor fuente de ingresos de la compañía puesto que opera en una industria de alto crecimiento y con una elevada cuota de mercado, pero no obtiene el primer lugar en participación de mercado siendo éste para su competidor Trupal que en la UEN Tubos y Esquineros se ubica con una participación de 7\%. 
La UEN Cajas de Cartón para el uso doméstico se ubica en el cuadrante vaca, es un producto que CARVIMSA ha decidido mantener en el mercado, aunque ya no esté en su mejor momento, poco a poco se está reduciendo la cantidad de clientes para darle más énfasis al sector agroindustrial, el cual es de mayor rentabilidad. Cabe resaltar que CARVIMSA no tiene intenciones de crecimiento para esta UEN.

\subsubsection{Matriz de la Gran Estrategia}

Según D’Alessio (2008), la matriz de la Gran Estrategia (GE) define la situación de un negocio o industria de acuerdo con dos factores: (i) crecimiento del mercado y (ii) su posición competitiva en dicho mercado, de modo que se generan cuatro cuadrantes, donde cada una sugiere diferentes alternativas de estrategia ordenados de acuerdo con su atractividad.

A continuación, se describe el análisis realizado a cada factor que interviene en el desarrollo de la Matriz de la Gran Estrategia:

\section{- Crecimiento del mercado}

La empresa CARVIMSA proyecta un crecimiento sostenido de ventas en un $10 \%$ para el año 2017, 2018, 2019 y 2020, tal como se puede visualizar en las tablas 83 y 84 . La proyección se sustenta en los siguientes criterios:

a) Crecimiento Mundial: Las proyecciones para finalizar el 2017 son de 3,5\% mientras que el pronóstico para 2018 se mantiene en 3,6\%. (FMI, 2017)

b) Crecimiento del Perú: Las perspectivas de crecimiento económico se ubican en un rango entre 3,0 y 3,5\% y ascenderían a un rango entre 3,8 y 4,0\% para el año 2018. (BCRP, 2017) 
c) Crecimiento de los sectores involucrados: El sector Manufactura, construcción y agropecuario experimentarán un crecimiento del $3.0 \%, 3.3 \%$ y $2.9 \%$, cada uno respectivamente.

Tabla 89

Ventas Históricas y Proyecciones en TM del producto "Tubos de Cartón” de sus principales clientes

\begin{tabular}{lrrrrr}
\hline \multicolumn{1}{c}{ Clientes } & $\mathbf{2 , 0 1 7}$ & $\mathbf{2 , 0 1 8}$ & $\mathbf{2 , 0 1 9}$ & $\mathbf{2 , 0 2 0}$ & $\mathbf{2 , 0 2 1}$ \\
\hline Solpack S.A. & 1,425 & 2,400 & 3,430 & 4,459 & 4,949 \\
\hline Surpack & 840 & 600 & 630 & 630 & 680 \\
\hline Filmpack S.A.C. & 360 & 360 & 400 & 460 & 511 \\
\hline Peruplast S.A. & 360 & 510 & 638 & 733 & 814 \\
\hline TDM Geosinteticos & 216 & 240 & 288 & 331 & 358 \\
\hline Envolturas Flexibles Huachipa S.A.C. & 180 & 300 & 360 & 414 & 447 \\
\hline Unión Plast S.A. & 168 & 144 & 180 & 207 & 230 \\
\hline Opp Film S.A. & 425 & 1,050 & 1,550 & 1,938 & 2,199 \\
\hline Megapack Group S.A.C. & - & 60 & 70 & 77 & 85 \\
\hline Resinplast S.A. & - & 120 & 140 & 154 & 166 \\
\hline Línea Plástica Perú S.A. & 85 & 120 & 134 & 148 & 160 \\
\hline Peruana De Papeles Y Cartones S.A.C. & & 60 & 80 & 88 & 95 \\
\hline Polinplast S.AC. & 35 & 60 & 70 & 77 & 85 \\
\hline Sub - Total (86.20\%) & $\mathbf{4 , 0 9 4}$ & $\mathbf{6 , 0 2 4}$ & $\mathbf{7 , 9 7 0}$ & $\mathbf{9 , 7 1 6}$ & $\mathbf{1 0 , 7 7 9}$ \\
\hline Resto de Clientes (13.80\%) & $\mathbf{1 , 0 3 2}$ & $\mathbf{1 , 0 8 5}$ & $\mathbf{1 , 0 9 6}$ & $\mathbf{1 , 2 0 5}$ & $\mathbf{1 , 3 3 8}$ \\
\hline Total & $\mathbf{5 , 1 2 6}$ & $\mathbf{7 , 1 0 9}$ & $\mathbf{9 , 0 6 6}$ & $\mathbf{1 0 , 9 2 1}$ & $\mathbf{1 2 , 1 1 7}$ \\
\hline
\end{tabular}

Nota: Recuperado de Documentación Interna de la Gerencia de Ventas CARVIMSA. 
Tabla 90

Ventas Históricas y Proyecciones en TM del producto "Esquineros de Cartón" de sus principales clientes

\begin{tabular}{lrrrrr}
\hline \multicolumn{1}{c}{ Clientes } & $\mathbf{2 , 0 1 7}$ & $\mathbf{2 , 0 1 8}$ & $\mathbf{2 , 0 1 9}$ & $\mathbf{2 , 0 2 0}$ & $\mathbf{2 , 0 2 1}$ \\
\hline Avocado Packing Company S.A.C. & - & 380 & 400 & 480 & 533 \\
\hline Procesadora Laran S.A.C. & - & 120 & 140 & 168 & 186 \\
\hline Huaral Fruit Export S.A.C. & - & 84 & 90 & 108 & 120 \\
\hline Sociedad Agrícola Drokasa S.A. & 80 & 85 & 180 & 216 & 240 \\
\hline Agro Victoria S.A.C & - & 60 & 80 & 96 & 107 \\
\hline Procesadora Torre Blanca S.A. & - & 96 & 116 & 128 & 142 \\
\hline Agrícola Cerro Prieto S.A. & - & 40 & 60 & 66 & 73 \\
\hline Sociedad Anónima Papelsa & - & 120 & 140 & 154 & 171 \\
\hline Tal S.A. & 56 & 60 & 80 & 88 & 98 \\
\hline \multicolumn{1}{c}{ Total } & $\mathbf{1 3 6}$ & $\mathbf{1 , 0 4 5}$ & $\mathbf{1 , 2 8 6}$ & $\mathbf{1 , 5 0 4}$ & $\mathbf{1 , 6 6 9}$
\end{tabular}

Nota: Recuperado de Documentación Interna de la Gerencia de Ventas CARVIMSA.

\section{Posición competitiva en el mercado}

Actualmente CARVIMSA tiene una participación del $43 \%$ en el mercado nacional mientras que Acinsa Tubos, Tuboquimsa y Trupal tienen 19\%, 19\% y 7\%, cada uno respectivamente. El porcentaje restante lo conforman empresas informales.

Finalmente, de los resultados obtenidos en el análisis de los dos factores, se concluye que la UEN “Tubos y Esquineros” se sitúa en el cuadrante I porque tiene una posición competitiva fuerte debido a las ventajas competitivas determinadas por su i) disponibilidad de materia prima (side roll) obtenido del molino principal, ii) mayor resistencia del producto frente a la competencia, gracias a la calidad del Side roll empleados en la fabricación de cajas de exportación y iii) la eficiencia del servicio del área técnica al permitir el desarrollo de productos que tienen una diferencia importante con respecto a la competencia. 
Por otro lado, los tres principales competidores se sitúan en el cuadrante II, dado que, aunque la industria donde se posicionan se encuentra en crecimiento rápido, estos han disminuido sus ventas y como consecuencia su participación de mercado. Por lo antes mencionado, la posición competitiva de estas empresas es débil.

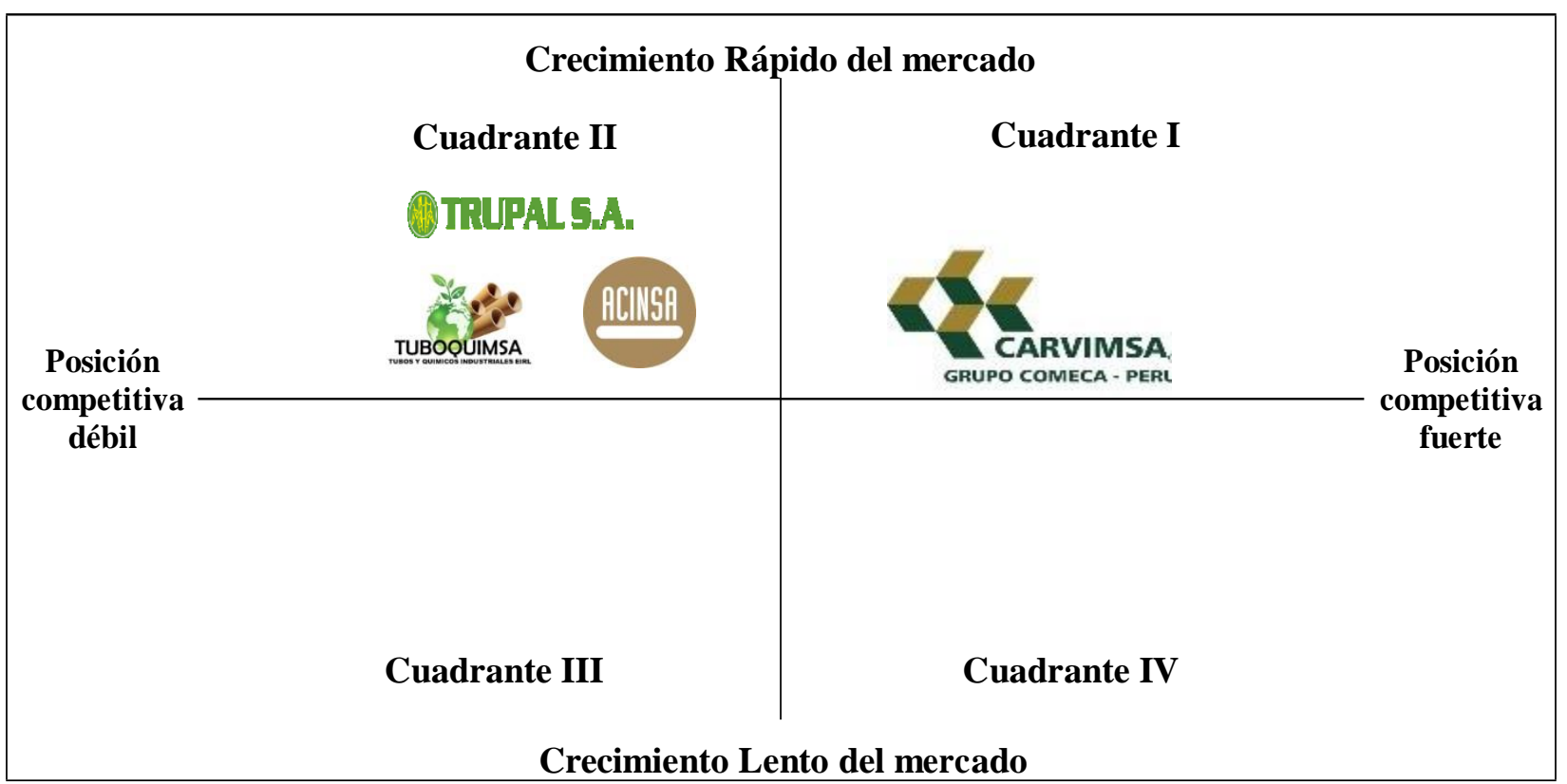

Figura 109. Matriz MGE. Posición de la Empresa CARVIMSA.

\subsection{Resumen de las Estrategias Formuladas}

A continuación, en la tabla 85, se describe el resumen de las estrategias formuladas de acuerdo con las matrices desarrolladas previamente.

Tabla 91

Resumen de las estrategias formuladas

\begin{tabular}{|c|c|c|}
\hline Estrategia & Descripción & Matriz \\
\hline \multirow{4}{*}{$\begin{array}{l}\text { Integración } \\
\text { Horizontal }\end{array}$} & \multirow{4}{*}{$\begin{array}{l}\text { CARVIMSA debe buscar su consolidación en } \\
\text { el mercado mediante la reducción del número } \\
\text { de empresas participantes con la finalidad de } \\
\text { incrementar su productividad, rentabilidad y } \\
\text { competitividad. Por lo antes mencionado, se } \\
\text { debe promover la integración horizontal de las } \\
\text { empresas que conforman el mercado, a través } \\
\text { de la adquisición de estas. }\end{array}$} & Matriz PEYEA \\
\hline & & Matriz IE \\
\hline & & Matriz BCG \\
\hline & & $\begin{array}{l}\text { Matriz de la Gran } \\
\text { Estrategia }\end{array}$ \\
\hline
\end{tabular}




\begin{tabular}{|c|c|c|}
\hline Estrategia & Descripción & Matriz \\
\hline $\begin{array}{l}\text { Penetración de } \\
\text { mercado }\end{array}$ & $\begin{array}{l}\text { Actualmente CARVIMSA cuenta con el 43\% } \\
\text { de participación del mercado nacional, el } \\
\text { segundo es Acinsa con el 19\% al igual que } \\
\text { Tuboquimsa. Hay un gran porcentaje que está } \\
\text { divido en empresas pequeñas e informales y el } \\
\text { mercado tiene una proyección de crecimiento } \\
\text { de } 5.3 \% \text {, por todo lo expuesto CARVIMSA } \\
\text { tiene grandes oportunidades de ampliar su } \\
\text { participación a pesar de no tener muchos años } \\
\text { en el mercado ya que posee fortalezas que } \\
\text { hacen que su posición sea fuerte. }\end{array}$ & $\begin{array}{l}\text { Matriz PEYEA } \\
\text { Matriz IE Matriz } \\
\text { BCG Matriz de la } \\
\text { Gran } \\
\text { Estrategia }\end{array}$ \\
\hline $\begin{array}{l}\text { Desarrollo del } \\
\text { producto }\end{array}$ & $\begin{array}{l}\text { Ya que el producto es homogéneo en cuanto a } \\
\text { estructura física, se debe generar valor } \\
\text { agregado mediante la innovación, CARVIMSA } \\
\text { debe realizar varias encuestas con el fin de } \\
\text { conocer cuál es la opinión que tienen los } \\
\text { clientes de la UEN con base en este producto, } \\
\text { qué es lo que más valoran para explotar ese } \\
\text { recurso ya que el producto viene acompañado } \\
\text { de un servicio como la garantía post venta, las } \\
\text { capacitaciones o la atención al cliente. }\end{array}$ & $\begin{array}{l}\text { Matriz PEYEA } \\
\text { Matriz IE } \\
\text { Matriz BCG } \\
\text { Matriz de la Gran } \\
\text { Estrategia }\end{array}$ \\
\hline $\begin{array}{l}\text { Exploración de } \\
\text { nuevos mercados }\end{array}$ & $\begin{array}{l}\text { Adicional a la oportunidad de incrementar su } \\
\text { participación en el mercado local, CARVIMSA } \\
\text { tiene opciones de ampliar su cartera de clientes } \\
\text { en otros países ya que cuenta con el respaldo } \\
\text { del Grupo Comeca. }\end{array}$ & $\begin{array}{l}\text { Matriz PEYEA } \\
\text { Matriz IE } \\
\text { Matriz BCG } \\
\text { Matriz de la Gran } \\
\text { Estrategia }\end{array}$ \\
\hline Inversión & $\begin{array}{l}\text { Invertir en mejoras en los procesos, tecnología, } \\
\text { maquinaria, y contratación de personal } \\
\text { calificado para las áreas que aún no tiene } \\
\text { implementadas, le servirá a la UEN para crecer } \\
\text { internamente y consolidarse en el mercado, } \\
\text { protegiendo y no dejando caer su posición } \\
\text { competitiva. }\end{array}$ & Matriz BCG \\
\hline
\end{tabular}




\section{Capítulo VIII. Selección de la Estrategia}

\subsection{Método factores estratégicos claves}

\subsubsection{Criterios de selección.}

Luego de haber obtenido las estrategias a desarrollar de acuerdo con los resultados de las matrices: i) FODA, ii) PEYEA, iii) Interna-Externa, iv) BCG y v) Gran Estrategia, se deberá elegir la estrategia que CARVIMSA implementará a fin de cumplir con los objetivos estratégicos. Es por ello por lo que se ha considerado que CARVIMSA deberá adoptar una de las siguientes estrategias:

- Integración Horizontal: Actualmente existen tres competidores principales, quienes han detenido su participación en el mercado y tienen una tendencia a la baja por lo que CARVIMSA podría aumentar su participación mediante la adquisición de estas empresas.

- Penetración de mercado: Como se ha podido determinar en capítulos anteriores, el mercado de "Tubos y Esquineros" tiene una proyección de crecimiento del 5.3\%. CARVIMSA deberá incrementar su participación, debido a que actualmente representa el 43\% del mercado. A pesar de que la UEN “Tubos y Esquineros” es relativamente nueva, cuenta con el respaldo de la UEN “Cajas de cartón”, cuya presencia en el mercado es ampliamente, conocido y valorado.

- Desarrollo del producto: La innovación debe ser de forma continua y permanente ya que el producto es homogéneo, para ello CARVIMSA deberá realizar encuestas a fin de conocer las características más valoradas por los clientes.

- Exploración de nuevos mercados: El respaldo financiero del Grupo Comeca, le permite a CARVIMSA la posibilidad de incursionar en mercados internacionales, de modo que su participación no solo se limitaría al mercado local. 
- Inversión: Se deberá desarrollar un plan de inversión para incrementar la productividad de esta UEN. Esta inversión debe incluir mejoras en los procesos, tecnología y maquinaria. Así mismo, dado que actualmente la UEN no cuenta con gerente de producción, se deberá contratar personal calificado que contribuya a gestionar eficientemente los costos a fin de incrementar los márgenes de utilidad.

En la figura 105, se muestran los criterios de decisión adoptados para seleccionar las alternativas de estrategias obtenidas de las matrices i) FODA, ii) PEYEA, iii) InternaExterna, iv) BCG y v) Gran Estrategia.

\begin{tabular}{|c|c|c|c|c|c|c|c|c|c|c|c|}
\hline \multirow[b]{2}{*}{ Criterios de decisión } & \multirow[b]{2}{*}{ Peso } & \multicolumn{10}{|c|}{ Alternativas de estrategias } \\
\hline & & $\begin{array}{l}\text { Integración } \\
\text { Horizontal }\end{array}$ & Ponderado & $\begin{array}{l}\text { Penetración } \\
\text { de mercado }\end{array}$ & Ponderado & $\begin{array}{l}\text { Desarrollo } \\
\text { del producto }\end{array}$ & Ponderado & $\begin{array}{l}\text { Exploración } \\
\text { de nuevos } \\
\text { mercados }\end{array}$ & Ponderado & Inversión & Ponderado \\
\hline Utilidad prevista & 0.20 & 9 & 1.8 & 9 & 1.80 & 8 & 1.60 & 3 & 0.60 & 8 & 1.60 \\
\hline Disponibilidad de recursos financieros & 0.20 & 6 & 1.2 & 9 & 1.80 & 8 & 1.60 & 6 & 1.20 & 5 & 1.00 \\
\hline Riesgo & 0.10 & 8 & 0.8 & 8 & 0.80 & 8 & 0.80 & 2 & 0.20 & 5 & 0.50 \\
\hline Tiempo de entrega & 0.10 & 5 & 0.5 & 9 & 0.90 & 7 & 0.70 & 2 & 0.20 & 6 & 0.60 \\
\hline Facilidad de implantación & 0.20 & 5 & 1 & 8 & 1.60 & 6 & 1.20 & 2 & 0.40 & 7 & 1.40 \\
\hline Satisfacción prevista del cliente & 0.20 & 5 & 1 & 9 & 1.80 & 5 & 1.00 & 3 & 0.60 & 7 & 1.40 \\
\hline Suma de pesos & 1.00 & & & & & & & & & & \\
\hline Califación de Fortaleza General & & & 6.30 & & 8.70 & & 6.90 & & 3.20 & & 6.50 \\
\hline
\end{tabular}

Figura 110. Criterios de decisión de las Alternativas de estrategias

\subsubsection{Matriz de selección.}

Para efectos de la selección de la estrategia se han identificado los planes o acciones a seguir para la implementación de las estrategias que más se repiten como resultado de las matrices desarrolladas anteriormente, las estrategias de penetración de mercado, desarrollo de productos y desarrollo de mercado o también llamada exploración de nuevos mercados.

Se realizó la ponderación de las acciones por estrategia, obteniendo el resultado de 11.55 para la estrategia de penetración de mercado, la cual se perfila como estrategia principal ante la posibilidad de ampliar la cantidad de toneladas vendidas al principal cliente 
Solpack S.A.C. se planea también aumentar el volumen de ventas al cliente OPP Film S.A. cliente que anteriormente era atendido por la competencia. Para poder llevar a cabo la estrategia de penetración de mercado existen supuestos que se tienen que cumplir como la inversión para crear un área de mercadotecnia propia de la UEN Tubos y Esquineros, al igual que realizar investigaciones de mercado a los sectores donde actualmente se tiene participación como en los sectores en los cuales CARVIMSA aún no incursiona.

Como segunda estrategia se encuentra la de desarrollo de producto con un puntaje de 10.05 enfocada en mejorar aspectos físicos y técnicos de los productos, para ello también se debe cumplir la recomendación de contratación de un gerente de producción y la ampliación del área de servicio al cliente.

La tercera estrategia con un puntaje de 9.15 es la estrategia de exploración de nuevos mercados orientada a la exportación de esquineros, ya que en el caso de tubos los costos por fletes son muy elevados.

Tabla 92

Matriz de la selección

\begin{tabular}{|c|c|c|c|c|c|c|c|c|}
\hline $\begin{array}{c}\text { Estrategia } \\
\text { General }\end{array}$ & Estrategias Especificas & Peso & $\begin{array}{l}\text { Pen } \\
\text { de }\end{array}$ & $\begin{array}{l}\text { ración } \\
\text { ercado }\end{array}$ & & $\begin{array}{l}\text { Irrollo } \\
\text { lel } \\
\text { ducto }\end{array}$ & & $\begin{array}{l}\text { oración } \\
\text { nuevos } \\
\text { cados }\end{array}$ \\
\hline \multirow{4}{*}{$\begin{array}{l}\text { Danntmanión da } \\
\text { mercado }\end{array}$} & $\begin{array}{l}\text { Aumento de ventas a } \\
\text { clientes actuales }\end{array}$ & 0.15 & 10 & 1.50 & 5 & 0.75 & 4 & 0.60 \\
\hline & $\begin{array}{l}\text { Captar clientes de los } \\
\text { mmnotidnnar }\end{array}$ & 0.10 & 10 & 1.50 & 4 & 0.60 & 3 & 0.45 \\
\hline & $\begin{array}{l}\text { Aprovechar el } \\
\text { crecimiento del mercado } \\
\text { local }\end{array}$ & 0.05 & 10 & 1.50 & 3 & 0.45 & 8 & 1.20 \\
\hline & $\begin{array}{l}\text { Creación de un área de } \\
\text { mercadotecnia e } \\
\text { investigación de mercados }\end{array}$ & 0.10 & 10 & 1.50 & 8 & 1.20 & 9 & 1.35 \\
\hline \multirow[t]{2}{*}{$\begin{array}{l}\text { Desarrollo del } \\
\text { producto }\end{array}$} & $\begin{array}{l}\text { Innovación en los } \\
\text { procesos de producción y } \\
\text { distribución }\end{array}$ & 0.10 & 5 & 0.75 & 10 & 1.50 & 4 & 0.60 \\
\hline & $\begin{array}{l}\text { Reducción del espesor y } \\
\text { diámetro de los tubos }\end{array}$ & 0.15 & 7 & 1.05 & 10 & 1.50 & 5 & 0.75 \\
\hline
\end{tabular}




\begin{tabular}{|c|c|c|c|c|c|c|c|c|}
\hline \multirow[t]{3}{*}{$\begin{array}{c}\text { Estrategia } \\
\text { General }\end{array}$} & \multirow{2}{*}{$\begin{array}{l}\text { Estrategias Especificas } \\
\text { Conservar y mejorar el } \\
\text { estándar del servicio al } \\
\text { cliente }\end{array}$} & \multirow{2}{*}{$\begin{array}{l}\text { Peso } \\
0.10\end{array}$} & \multicolumn{2}{|c|}{$\begin{array}{l}\text { Penetración } \\
\text { de mercado }\end{array}$} & \multicolumn{2}{|c|}{$\begin{array}{l}\text { Desarrollo } \\
\text { del } \\
\text { producto }\end{array}$} & \multicolumn{2}{|c|}{$\begin{array}{l}\text { Exploración } \\
\text { de nuevos } \\
\text { mercados }\end{array}$} \\
\hline & & & 9 & 1.35 & 10 & 1.50 & 5 & 0.75 \\
\hline & $\begin{array}{l}\text { Contratación de un } \\
\text { gerente de producción }\end{array}$ & 0.05 & 3 & 0.45 & 10 & 1.50 & 3 & 0.45 \\
\hline \multirow[t]{3}{*}{$\begin{array}{l}\text { Exploración de } \\
\text { nuevos } \\
\text { mercados } \\
\end{array}$} & $\begin{array}{l}\text { Incursionar en otros } \\
\text { sectores del mercado para } \\
\text { tubos }\end{array}$ & 0.10 & 7 & 1.05 & 3 & 0.45 & $\begin{array}{l}1 \\
0\end{array}$ & 1.50 \\
\hline & $\begin{array}{l}\text { Ventas de esquineros a } \\
\text { mercados del exterior }\end{array}$ & 0.10 & 6 & 0.90 & 4 & 0.60 & $\begin{array}{l}1 \\
0\end{array}$ & 1.50 \\
\hline & Suma de ponderados & 1.00 & & 11.55 & & $\mathbf{1 0 . 0 5}$ & & 9.15 \\
\hline
\end{tabular}

\subsection{Método de Escenarios}

La planificación de escenarios es un proceso que estimula el pensamiento imaginativo y creativo para mejorar la preparación de una organización para el futuro. Consiste en investigar para entender las fuerzas mayores que podrían mover el mundo en diferentes direcciones para luego establecer un mapa de un pequeño número de posibles futuros alternativos llamados escenarios. Posteriormente se describen estos escenarios, y desarrollan opciones para que la organización pueda gestionar dentro de estos mundos futuros. (Harvard Business School, 2006)

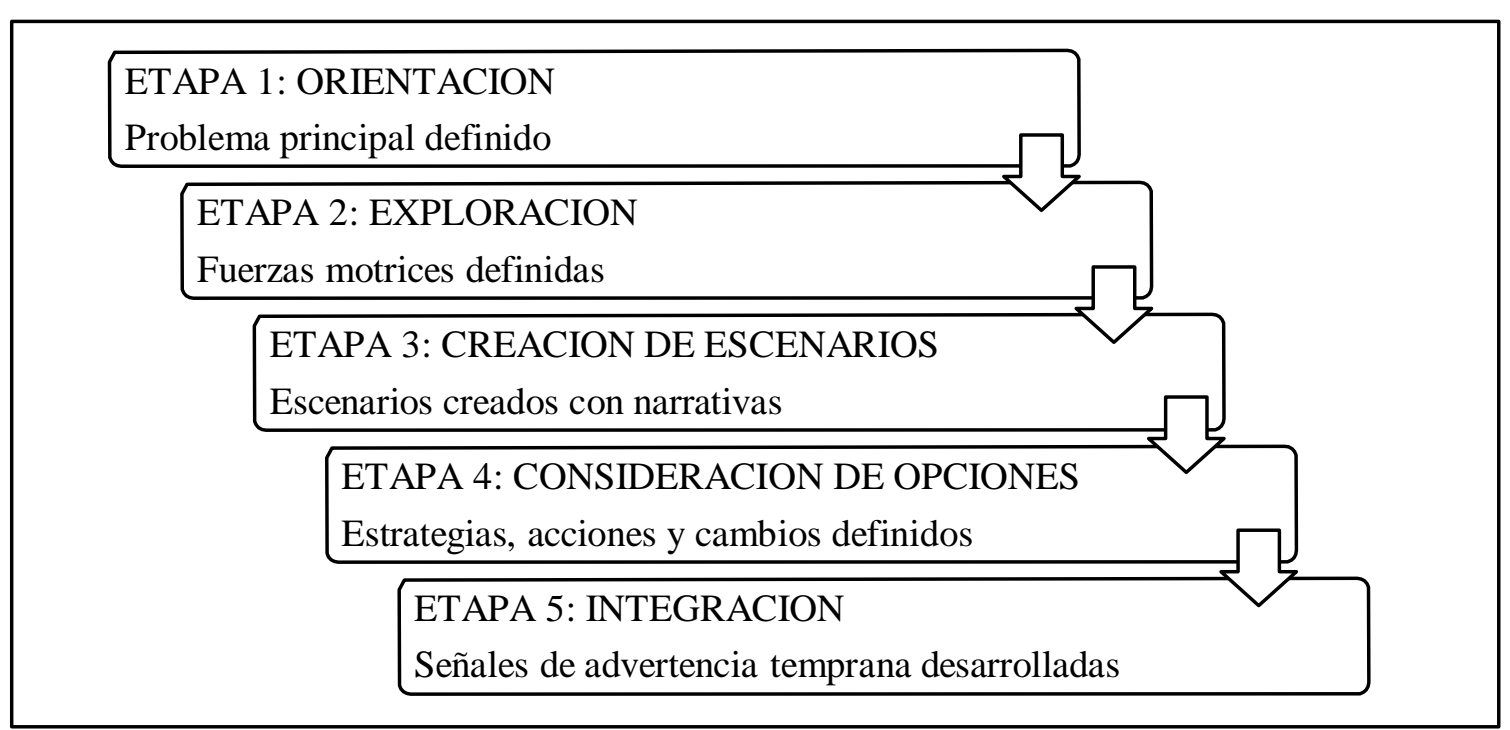

Figura 111. Etapa de la planeación de escenarios. 


\section{-Etapa 1: Orientación}

Después de haber realizado la matriz de la selección de la estrategia, el tema central clave es corroborar que estrategia: penetración de mercado, desarrollo de producto o exploración de nuevos mercados es la más adecuada, simulando posibles escenarios en base a fuerzas críticas que pueden influir positiva o negativamente en la implementación de la estrategia.

\section{-Etapa 2: Exploración}

En esta etapa se va a identificar las fuerzas impulsoras del macroentorno que impactan en el éxito o fracaso de la estrategia para la UEN Tubos y Esquineros. A continuación, se lista algunas de las fuerzas identificadas:

Tabla 93

Factores clave y fuerzas ambientales

Crecimiento económico de los sectores involucrados

Incremento del tipo de cambio

Marco regulatorio ambiental más exigente

Aumento de participación de mercado del competidor Trupal SA

Mayor volumen de toneladas vendidas al cliente Solpack SAC

Aumento de participación de mercado del competidor Acinsa SA

En la tabla 88, se puede apreciar algunas de las fuerzas que pueden impactar en los diversos escenarios, de esta lista se ha considerado tres fuerzas críticas las cuales son el crecimiento económico, la participación de mercado de Trupal SA y el incremento del volumen de ventas a Solpack SAC. 
No se ha considerado el posible incremento del tipo de cambio ya que la perspectiva de CARVIMSA según comentó el gerente general en una entrevista es que el molino propio produzca directamente la materia prima a la UEN Tubos y Esquineros y que ya no solo se fabrique los tubos de los Side roll, sino que se haga una planificación de la producción, por ello el volumen de materia prima importado sería menor. Tampoco se ha considerado el tema del marco regulatorio medioambiental para las industrias ya que el Perú cuenta con una normativa bastante exigente alineada a la legislación de la Unión Europea. Una posible mejora en la posición competitiva del cliente Acinsa es muy poco probable lo que descarta la estrategia de orientación horizontal al plantear una posible compra de Acinsa ya que no tiene algún elemento que genere valor agregado a CARVIMSA, por el contrario, uno de sus principales clientes OPP Film SA ha empezado a comprar a CARVIMSA.

Tabla 94

Factores críticos

Crecimiento económico de los sectores involucrados

Aumento de participación de mercado del competidor Trupal SA

Mayor volumen de toneladas vendidas al cliente Solpack SAC

\section{-Etapa 3: Creación de Escenarios}

Esta etapa está compuesta por dos pasos, la selección del marco del escenario y la creación de la narración del escenario. En este caso se ha considerado un escenario donde el crecimiento económico es favorable ubicado en el cuadrante alto del factor y un crecimiento desfavorable en cuanto a las proyecciones estimadas ubicado en el cuadrante bajo. El otro factor es la participación de mercado de Trupal SA. si se imagina una participación superior al 7\% actual y que podría amenazar la posición en el mercado de CARVIMSA éste se ubica en el cuadrante alto del factor, por otro lado si Trupal decide no invertir más en su UEN Tubos y 
Esquineros y enfocarse en su UEN Cajas de Cartón corrugado para permanecer su liderazgo el escenario sería bajo, en este caso CARVIMSA concreta el contrato con su cliente Solpack SAC que traerá su planta del Chile al Perú lograría un aumento en su participación de mercado.

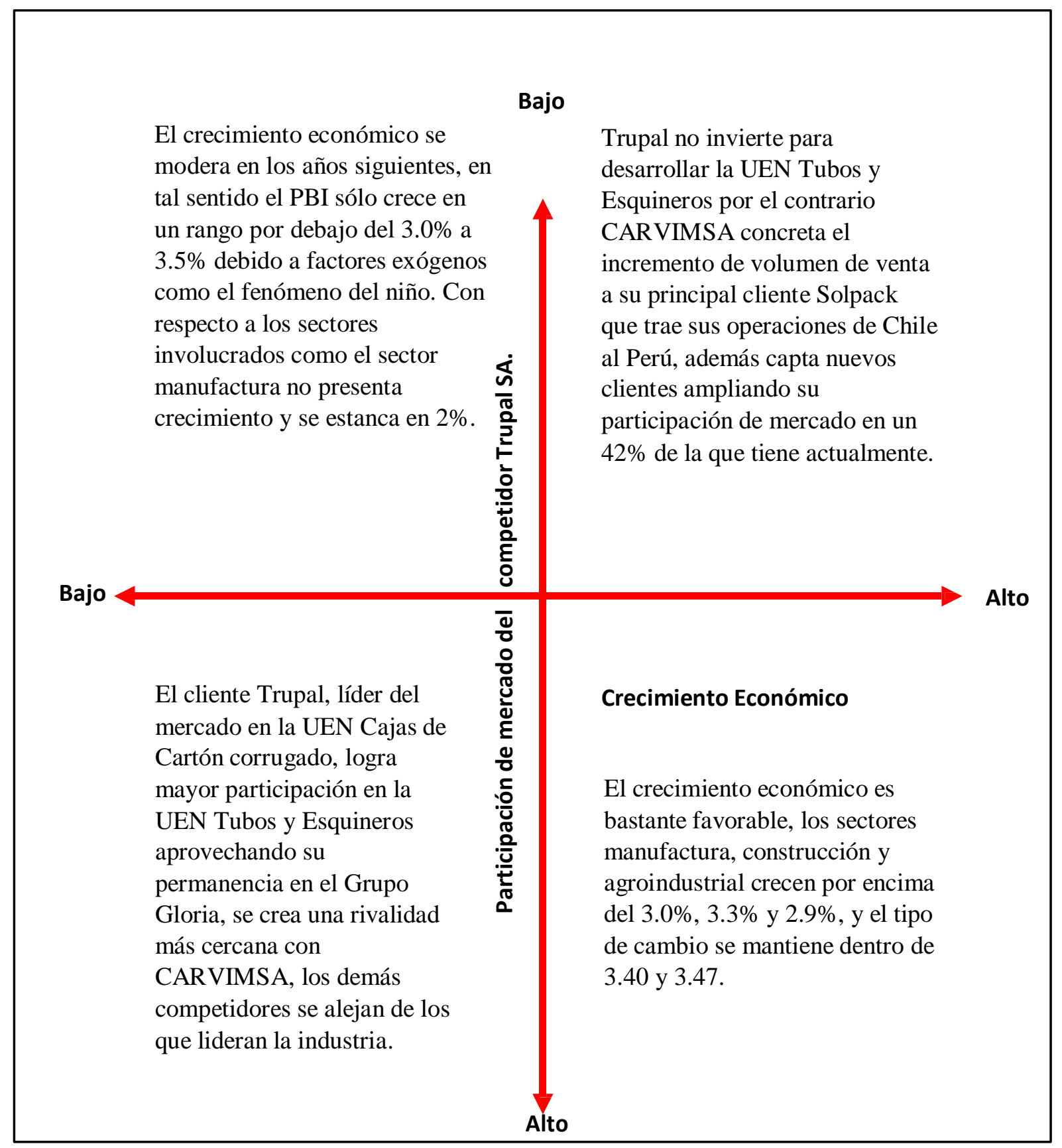

Figura 112. Ejes de la Planeación de Escenarios de la UEN Tubos y Esquineros de CARVIMSA 


\section{-Etapa 4: Consideración de opciones}

Se pueden apreciar los escenarios planteados, dentro de un escenario optimista se consideran las opciones de crecimiento económico favorable que mantenga o supere las proyecciones de los sectores manufactura, construcción y agroindustria, donde Trupal no amplíen considerablemente su participación de mercado y CARVIMSA pueda concretar el aumento de toneladas vendidas a su cliente más grande Solpack S.A.C, esto implica que se realice la inversión para casi duplicar las 500 toneladas producidas actualmente y poder abastecer la demanda.

Dentro de un escenario pesimista se considera las opciones de un menor crecimiento de la economía por debajo de las proyecciones estimadas y una mayor presencia en el mercado de Trupal con respaldo del grupo Gloria.

\section{Etapa 5: Integración}

En esta etapa se detectan señales de alerta temprana que pueden apuntar a que la probabilidad de aparición de un escenario en lugar de otros sea mayor.

Tabla 95

Señales de alerta temprana

Tendencia de crecimiento del PBI de los sectores manufactura, construcción y agroindustria

Conversaciones entre las gerencias de CARVIMSA y

Solpack para la firma del contrato

El cliente OPP Film SA ha dejado de comprar a Acinsa para pasar a ser cliente de CARVIMSA 


\subsubsection{Descripción de escenarios considerados}

El escenario optimista presenta condiciones económicas más favorables, el tipo de cambio se mantiene dentro de las proyecciones del BCRP, el crecimiento de los sectores involucrados también es positivo para CARVIMSA. Por el lado de la industria no se presenta crecimientos considerables de la participación de mercado de las demás empresas, lo que permitiría a CARVIMSA concretar el aumento de volumen de ventas a Solpack SAC y OPP Film S.A. cliente anteriormente atendido por uno de los rivales. Este escenario implica que se cumplan los lineamientos como la contratación del gerente de producción y la creación del área de mercadotecnia éstas dos acciones ayudarían con las estrategias desarrollo de producto y penetración de mercado respectivamente.

El escenario tendencial no contempla un crecimiento del mercado, éste mantiene los niveles actuales, en cuanto a la participación de los competidores podría elevarse o mantenerse sin afectar el liderazgo que mantiene CARVIMSA.

El escenario pesimista implica que Trupal aumente su participación de mercado buscando convertirse también en líder en la UEN Tubos y Esquineros y que no se presente crecimiento favorable para la economía ni estabilidad de los demás factores económicos como el tipo de cambio, la inflación y las tasas de interés.

\subsubsection{Comparación de Estrategias con escenarios}

En el caso del escenario optimista, se puede implementar la estrategia de penetración de mercado, al aumentar el volumen de ventas al cliente Solpack S. A.C. lo cual implicaría una producción adicional de 300 toneladas y además se proyecta un aumento de 200 toneladas adicionales para captación de nuevos clientes ya que el mercado muestra tendencias de crecimiento. Para ello se debe invertir en la fabricación de más máquinas tuberas. En este 
caso la estrategia de penetración de mercado es propicia en sus tres modalidades: el incentivo de un mayor consumo de los productos en los mercados que ya existen a través del aumento de ventas a clientes actuales con gran potencial, quitándoles participación de mercado a sus competidores y aprovechar el crecimiento para atraer a nuevos clientes.

En el escenario pesimista la estrategia ideal es la de exploración de nuevos mercados, mercados en el exterior a los cuales CARVIMSA pueda exportar aprovechando el estándar de calidad de sus productos, las certificaciones técnicas y el prestigio limpio de escándalos medioambientales, en este escenario la competencia aumenta su participación de mercado, también se aplicaría la estrategia de desarrollo de producto a través de potenciar el área de servicio al cliente y buscar mayores cualidades físicas sobre todo de resistencia y espesor del producto, con ello se puede recuperar a los clientes que dejaron de comprar a CARVIMSA para comprar a la competencia.

Cae resaltar que la estrategia de integración horizontal quedó descartada en la primera etapa, ya que el competidor Acinsa no presenta variables que CARVIMSA no tenga como para sustentar la compra.

En la tabla 89 se observa las estrategias que se utilizarían en cada uno de los escenarios. Se ha realizado una valoración de cómo las estrategias ayudan a afrontar los escenarios en una escala del 1 al 5, siendo 1 si la estrategia que va muy en contra del escenario, 3 si no afecta al escenario, y 5 si es muy propicia para el desarrollo del escenario

Tabla 96

Comparación de estrategias y escenarios

\begin{tabular}{lcc}
\hline Escenarios / Estrategias & Escenario Optimista & Escenario Pesimista \\
\hline Penetración de mercado & 5 & 2 \\
\hline Desarrollo de producto & 5 & 5 \\
\hline Exploración de nuevos mercados & 4 & 5
\end{tabular}




\subsection{Matriz de Planeación Estratégica Cuantitativa MPEC}

La matriz de Planeación Estratégica Cuantitativa (MPEC) utiliza la información inicial obtenida de las matrices EFI, EFE y MPC con la finalidad de evaluar objetivamente las alternativas de estrategias posibles identificadas en las matrices FODA, PEYEA, IE, BCG y de la Gran Estrategia. La MPEC muestra el grado relativo de atracción de las alternativas de estrategias, de modo que proporciona criterios objetivos que permitirá a los estrategas, evaluar estrategias específicas con objetividad. David (2013)

El desarrollo de la matriz MPEC de las alternativas de estrategia para CARVIMSA se encuentran en la tabla 90.

Tabla 97

Matriz MPEC de las alternativas de estrategia para CARVIMSA

\begin{tabular}{|c|c|c|c|c|c|c|c|}
\hline \multirow[t]{2}{*}{ Factores Críticos para el éxito } & \multirow[t]{2}{*}{ Peso } & \multicolumn{2}{|c|}{$\begin{array}{r}\text { Penetración } \\
\text { de mercado }\end{array}$} & \multicolumn{2}{|c|}{$\begin{array}{c}\text { Desarrollo } \\
\text { de } \\
\text { producto }\end{array}$} & \multicolumn{2}{|c|}{$\begin{array}{c}\text { Exploración } \\
\text { de nuevos } \\
\text { mercados }\end{array}$} \\
\hline & & PA & PTA & $\mathbf{P A}$ & PTA & $\mathbf{P A}$ & PTA \\
\hline \multicolumn{8}{|l|}{ Oportunidades } \\
\hline $\begin{array}{l}\text { 1.Crecimiento de los sectores: manufactura, } \\
\text { agroindustrial y construcción en el Perú. }\end{array}$ & 0.06 & 4 & 0.24 & 3 & 0.18 & 2 & 0.12 \\
\hline $\begin{array}{l}\text { 2. Nuevas tendencias en la formación académica } \\
\text { y profesional. }\end{array}$ & 0.10 & 1 & 0.10 & 4 & 0.40 & 1 & 0.10 \\
\hline $\begin{array}{l}\text { 3.Aumento de la demanda de productos } \\
\text { biodegradables. }\end{array}$ & 0.16 & 4 & 0.64 & 4 & 0.64 & 4 & 0.64 \\
\hline 4.Disponibilidad de Tecnología. & 0.11 & 4 & 0.44 & 3 & 0.33 & 3 & 0.33 \\
\hline $\begin{array}{l}\text { 5.Incremento de exportaciones agrícolas y } \\
\text { textiles. }\end{array}$ & 0.12 & 4 & 0.48 & 4 & 0.48 & 3 & 0.36 \\
\hline \multicolumn{8}{|l|}{ Amenazas } \\
\hline $\begin{array}{l}\text { 1.Precios volátiles, aumento de precios de los } \\
\text { commodities (Papel y Cartón). }\end{array}$ & 0.15 & 2 & 0.30 & 1 & 0.15 & 1 & 0.15 \\
\hline $\begin{array}{l}\text { 2.La propuesta de una reforma impositiva en } \\
\text { Estados Unidos y el fortalecimiento el tipo de } \\
\text { cambio a favor del dólar. }\end{array}$ & 0.11 & 2 & 0.22 & 2 & 0.22 & 2 & 0.22 \\
\hline $\begin{array}{l}\text { 3.Ingreso de importaciones de tubos y } \\
\text { esquineros. }\end{array}$ & 0.04 & 1 & 0.04 & 1 & 0.04 & 1 & 0.04 \\
\hline 4. Integración hacia delante de los proveedores. & 0.04 & 2 & 0.08 & 2 & 0.08 & 2 & 0.08 \\
\hline $\begin{array}{l}\text { 5.Mayores exigencias ambientales en el Marco } \\
\text { Regulatorio que podrían restringir la demanda. }\end{array}$ & 0.11 & 2 & 0.22 & 2 & 0.22 & 1 & 0.11 \\
\hline
\end{tabular}




\begin{tabular}{|c|c|c|c|c|c|c|c|}
\hline \multirow[t]{2}{*}{ Factores Críticos para el éxito } & \multirow[t]{2}{*}{ Peso } & \multicolumn{2}{|c|}{$\begin{array}{l}\text { Penetración } \\
\text { de mercado }\end{array}$} & \multicolumn{2}{|c|}{$\begin{array}{c}\text { Desarrollo } \\
\text { de } \\
\text { producto }\end{array}$} & \multicolumn{2}{|c|}{$\begin{array}{c}\text { Exploración } \\
\text { de nuevos } \\
\text { mercados }\end{array}$} \\
\hline & & PA & PTA & $\mathbf{P A}$ & PTA & $\mathbf{P A}$ & PTA \\
\hline \multicolumn{8}{|l|}{ Fortalezas } \\
\hline 1. Materia prima obtenida del Molino propio. & 0.20 & 4 & 0.80 & 4 & 0.80 & 3 & 0.60 \\
\hline 2. Competitividad de precios. & 0.09 & 3 & 0.27 & 2 & 0.18 & 1 & 0.09 \\
\hline 3. Mayor participación del mercado. & 0.15 & 4 & 0.60 & 3 & 0.45 & 3 & 0.45 \\
\hline 4. Sin antecedentes de contaminación ambiental. & 0.13 & 4 & 0.52 & 2 & 0.26 & 2 & 0.26 \\
\hline 5. Hornos con conexión a gas natural. & 0.12 & 4 & 0.48 & 3 & 0.36 & 2 & 0.24 \\
\hline \multicolumn{8}{|l|}{ Debilidades } \\
\hline 1. Poco tiempo de la UEN en el mercado. & 0.03 & - & - & - & & - & - \\
\hline $\begin{array}{l}\text { 2. Ausencia de un área funcional de } \\
\text { mercadotecnia. }\end{array}$ & 0.06 & 3 & 0.18 & 4 & 0.24 & 2 & 0.12 \\
\hline $\begin{array}{l}\text { 3. Ausencia de un gerente de producción para la } \\
\text { UEN. }\end{array}$ & 0.13 & 2 & 0.26 & 2 & 0.26 & 2 & 0.26 \\
\hline 4. Falta de investigación de mercados. & 0.05 & 2 & 0.10 & 1 & 0.05 & 1 & 0.05 \\
\hline $\begin{array}{l}\text { 5. Sobrecostos en fletes internos entre plantas } \\
\text { (Ubicación: Villa el Salvador- Huachipa). }\end{array}$ & 0.04 & 1 & 0.04 & 1 & 0.04 & 1 & 0.04 \\
\hline $\begin{array}{l}\text { Suma del puntaje total del grado de atracción } \\
\text { (SPTA) }\end{array}$ & & & 6.01 & & 5.20 & & 4.14 \\
\hline
\end{tabular}

\subsection{Descripción de estrategia seleccionada}

Luego, del análisis realizado al puntaje obtenido en la matriz MPEC para cada una de las alternativas de estrategias, y tomando en consideración las necesidades identificadas para la empresa CARVIMSA, se seleccionó la estrategia de penetración de mercado. Esto debido a que, la empresa CARVIMSA proyecta un crecimiento sostenido de ventas en un 55\% para el $2018,27 \%$ para el 2019, 20\% para el 2020 y $11 \%$ para el 2021, sustentado en el crecimiento mundial, el crecimiento del mercado peruano, así como el crecimiento de los sectores involucrados. Es por ello por lo que se debe consolidar las actividades tales como mercadotecnia, publicidad, relaciones con los clientes y el servicio post venta, las cuales están relacionadas intrínsecamente con las ventas; con la finalidad de que la estrategia sea 
eficiente, de modo que se incremente la participación de mercado, que actualmente representa el 43\%. Así mismo, es preciso mencionar que la selección de esta estrategia está amparada en las fortalezas que actualmente respaldan a CARVIMSA tales como: i) materia prima obtenida del Molino propio, ii) competitividad de precios, iii) mayor participación del mercado, iv) sin antecedentes de contaminación ambiental y v) hornos con conexión a gas natural. Por otro lado, para lograr resultados con esta estrategia es necesario tomar acciones para hacer frente a las amenazas y debilidades. Es por ello, que resulta necesario la contratación de un gerente de producción que se encargue de gestionar los costos de forma eficiente a fin de maximizar el margen de utilidad. También se deberá considerar la incorporación de profesionales de gran formación académica para crear un área de mercadotecnia

\subsection{Descripción de estrategia contingente}

La estrategia contingente, de acuerdo con los resultados obtenidos en la MPEC, la cual considera los factores claves e internos, es el desarrollo de mercado. Con esta estrategia, se busca incrementar las ventas mediante la mejora de los productos actuales o el desarrollo de nuevos productos, permitiendo mejorar la posición competitiva de CARVIMSA. El sustento de la selección radica principalmente en que CARVIMSA compite en una industria de rápido crecimiento. También se han considerado las fortalezas de la empresa

CARVIMSA, la cual se encuentra respaldada financieramente por el grupo Comeca. En adición a lo mencionado, es conveniente señalar que actualmente existe disponibilidad de tecnología que permita mejorar los productos que actualmente ofrece o, incluso, crear nuevos productos para satisfacer la demanda requerida por los clientes; sin embargo, esto implica grandes gastos en investigación y desarrollo. 
Así mismo, es preciso destacar que a pesar de que la UEN Tubos y Esquineros, no tiene mucho tiempo en el mercado; cuenta con el prestigio de las otras UEN, las cuales son ampliamente reconocidas en el mercado por la calidad de sus productos.

\subsection{Plan de Marketing}

El presente plan de marketing se desarrolló con la finalidad de implementar la estrategia de penetración de mercado.

\subsubsection{Objetivos}

- Incrementar las ventas de tubos y esquineros en un 55\% para el 2018, 27\% para el 2019, 20\% para el 2020 y $11 \%$ para el 2021.

- Aumentar la participación de mercado de la UEN Tubos y Esquineros en $61 \%$ para el 2018, 75\% para el 2019, 80\% para el 2020 y 80\% para el 2021.

\subsubsection{Segmento de mercado}

\subsubsection{Segmentación estratégica de empresas}

Con respecto al producto “Tubo de Cartón” está orientado a las empresas que pertenecen al sector (i) textil, (ii) Embalaje, (iii) Industrial y (iv) Construcción y minería. Asimismo, el producto "Esquineros de Cartón" se orienta a empresas que pertenecen al sector agroexportador.

\subsubsection{Propuesta de valor}

CARVIMSA ofrece la siguiente propuesta de valor a sus clientes:

a. Calidad: La materia prima utilizada para la fabricación de los tubos y esquineros son los Side Roll, pedazos de bobina, que se utilizan para la elaboración de cajas de 
cartón de exportación, es decir son de buena calidad lo que se traduce en un producto de $30 \%$ de mayor resistencia que la competencia.

b. Reducción del espesor del producto: Al tener un producto más resistente, el cliente puede reducir su espesor, de modo que puede colocar más material en el tubo, y si el cliente exporta podría generar reducción de costos asociado al flete.

c. Eficiencia del Servicio del área técnica: CARVIMSA ofrece servicio técnico pre y post venta. Con respecto al servicio pre-venta, facilita al cliente el diseño y desarrollo de nuevos productos, de modo que sus requerimientos se vean reflejados en el producto final. Y con respecto al servicio post-venta, CARVIMSA ofrece un seguimiento y asesoría sobre la entrega oportuna y la correcta manipulación de los productos.

\subsubsection{Análisis de la oportunidad de mercado}

En el Perú, el mercado de "Tubos y Esquineros" es informal y está atomizado con empresas pequeñas que no cuentan con la capacidad de ofrecer un producto de calidad. Es por ello por lo que, en el año 2013, CARVIMS A ingresó a este mercado con la finalidad de ofrecer un producto de calidad. La calidad del producto lo logra gracias al uso de bobinas de anchos pequeños (también conocidos como Side roll), las cuales al tener mayor resistencia mecánica permite obtener un producto superior a lo ofrecido por el mercado.

Actualmente, CARVIMSA atiende al $43 \%$ de este mercado, siendo su principal competidor la empresa Acinsa Tubos, con una participación del 19\% y el $38 \%$ restante lo conforman varias empresas pequeñas.

Por otro lado, CARVIMSA empezó a fabricar y comercializar el producto “Esquineros de Cartón” a partir del año 2015. Este producto está dirigido al sector 
Agroindustrial, específicamente a las exportaciones. Cabe señalar, que este producto puede ser reemplazado por el "Esquinero de Plástico" cuyo precio es menor que el "Esquinero de Cartón”, sin embargo, este último tiene mejor presentación, siendo un factor importante de decisión de compra para algunos clientes. También existen "Esquineros de cartón” importados de Chile y Ecuador, que son fabricados con papel Kraft Liner, brindando mayor resistencia y mejor apariencia al producto final. (Informe Anual CARVIMSA, 2016)

Por lo mencionado en el párrafo anterior, la única forma en la que CARVIMSA pueda competir y aumentar su participación en el mercado nacional e internacional, es brindando un esquinero con mayor espesor, resistencia y más económico.

Se debe tomar en cuenta que la demanda es estacionaria pues varía según la temporada de exportación por producto. Así mismo, puede verse afectado por diferentes factores tales como: desastres naturales, coyuntura política y económica nacional e internacional.

\subsubsection{Proyección de la demanda}

En la actualidad los productos reciclados son manufacturados con el fin de crear mercados. La población objetiva se encuentra direccionada en todo el territorio nacional. El consumo de los productos de embalajes de cartón tiene que ver con el poder adquisitivo de las personas, el nivel de educación e industrialización. Se toma en cuenta que el consumo de las cajas, tubos y esquineros de cartón, están relacionadas directamente con el nivel de producción industrial.

La empresa CARVIMSA tiene como proyección de ventas por clientes, como principal comprador a Solpack, quien representa un 30\% de su producción. Este cliente 
en el año 2014 compraba un promedio de 60 TM por mes y en el 2015 aumentó su compra de $60 \mathrm{TM}$ a $80 \mathrm{TM}$ por mes (33\%). La tendencia de venta de este principal cliente muestra un incremento de 50\% más al de la compra del año anterior, según datos históricos proporcionado por el área comercial de CARVIMSA.

$\mathrm{Al}$ igual que este cliente, muchos otros han empezado a comprar a CARVIMSA en mayores volúmenes. Solo por citar un ejemplo, las ventas mensuales de los tres (03) primeros meses del año 2016 fueron en promedio 300 TM por mes y se tiene proyectado una venta anual de 4,500 TM para el 2017.

Este producto, se proyecta con un crecimiento sostenido de ventas en un $10 \%$ para el año 2017, 2018, 2019 y 2020; conforme se vaya formalizando y volviendo más técnico en la utilización de Tubos de Cartón.

Tabla 98

Ventas Históricas y Proyecciones en TM del producto "Tubos de Cartón” de sus principales clientes

\begin{tabular}{lcccccr}
\hline Cliente & $\mathbf{2 0 1 6}$ & $\mathbf{2 0 1 7}$ & $\mathbf{2 0 1 8}$ & $\mathbf{2 0 1 9}$ & $\mathbf{2 0 2 0}$ & Promedio \\
\hline Solpack S.A.C & 1,300 & 1,430 & 1,573 & 1,730 & 1,903 & 1,587 \\
\hline Filmpack S.A.C & 480 & 528 & 581 & 639 & 703 & 586 \\
\hline Packing \& Plastics Peru S.A. & 480 & 528 & 581 & 639 & 703 & 586 \\
\hline Peruplast S.A. & 510 & 561 & 617 & 679 & 747 & 623 \\
\hline Polytex S.A. & 216 & 216 & 216 & 216 & 216 & 216 \\
\hline Unión Plast S.A. & 180 & 180 & 180 & 180 & 180 & 180 \\
\hline Opp Film & 425 & 600 & 720 & 840 & 1,200 & 757 \\
\hline Sector Textil & 80 & 80 & 120 & 130 & 130 & 108 \\
\hline Otros Clientes Tubos & 840 & 840 & 840 & 840 & 840 & 840 \\
\hline
\end{tabular}




\begin{tabular}{|c|c|c|c|c|c|c|}
\hline Cliente & 2016 & 2017 & 2018 & 2019 & 2020 & Promedio \\
\hline & 4,511 & 4,963 & 5,428 & 5,893 & 6,622 & 5,483 \\
\hline
\end{tabular}

Tabla 99

Precios Históricos y Proyecciones en Dólares Americanos por TM vendida del producto

"Tubos de Cartón” de sus principales clientes

\begin{tabular}{lccccc}
\hline Cliente & $\mathbf{2 0 1 6}$ & $\mathbf{2 0 1 7}$ & $\mathbf{2 0 1 8}$ & $\mathbf{2 0 1 9}$ & $\mathbf{2 0 2 1}$ \\
\hline Solpack S.A.C. & $\$ 770.00$ & $\$ 808.50$ & $\$ 832.76$ & $\$ 874.40$ & $\$ 874.40$ \\
\hline Filmpack S.A.C. & $\$ 693.64$ & $\$ 728.32$ & $\$ 750.17$ & $\$ 787.68$ & $\$ 787.68$ \\
\hline Packing \& Plastics Peru S.A. & $\$ 685.73$ & $\$ 720.02$ & $\$ 741.62$ & $\$ 778.70$ & $\$ 778.70$ \\
\hline Peruplast S.A. & $\$ 699.73$ & $\$ 734.71$ & $\$ 756.75$ & $\$ 794.59$ & $\$ 794.59$ \\
\hline Polytex S.A. & $\$ 716.76$ & $\$ 752.60$ & $\$ 775.18$ & $\$ 813.94$ & $\$ 813.94$ \\
\hline Unión Plast S.A. & $\$ 638.88$ & $\$ 670.82$ & $\$ 690.95$ & $\$ 725.50$ & $\$ 725.50$ \\
\hline Opp Film & & & & & \\
\hline Sector Textil & $\$ 674.17$ & $\$ 707.88$ & $\$ 729.12$ & $\$ 765.57$ & $\$ 765.57$ \\
\hline Otros Clientes Tubos & $\$ 760.57$ & $\$ 798.60$ & $\$ 822.56$ & $\$ 863.69$ & $\$ 863.69$ \\
\hline Promedio Precio Por Año & $\$ 760.57$ & $\$ 798.60$ & $\$ 822.56$ & $\$ 863.69$ & $\$ 863.69$ \\
\hline Nota: Recuperado de Documentación Interna de la Gerencia de Ventas CARVIMSA. & & & & & \\
\hline
\end{tabular}

En el año 2015, CARVIMSA ha facturado en el mercado nacional 585 TM de “Esquineros de cartón” y 230 TM en el mercado costarricense. En el año 2016 facturaron 873 TM. Debido a la competencia con los esquineros de plásticos y las importaciones de Chile, han visto necesario disminuir el precio a \$751 por TM. Para el año 2017, CARVIMSA espera recuperar el precio a $\$ 785$ x TM. 
Tabla 100

Ventas Históricas y Proyecciones en TM del producto "Esquineros de Cartón” de sus principales clientes

\begin{tabular}{lcccccc}
\hline Cliente & $\mathbf{2 0 1 6}$ & $\mathbf{2 0 1 7}$ & $\mathbf{2 0 1 8}$ & $\mathbf{2 0 1 9}$ & $\mathbf{2 0 2 0}$ & Promedio \\
\hline Complejo Agroindustrial Beta S.A. & 100 & 110 & 121 & 133 & 146 & 122 \\
\hline Jayanca Fruits S.A.C. & 40 & 45 & 50 & 50 & 50 & 47 \\
\hline Avocado Packing Company S.A.C. & 40 & 40 & 50 & 50 & 60 & 48 \\
\hline Agricola Chapi & 25 & 25 & 30 & 30 & 30 & 28 \\
\hline Agroimex Traiding & 30 & 30 & 36 & 40 & 44 & 36 \\
\hline Cvm-Zona Norte & 40 & 44 & 48 & 53 & 59 & 49 \\
\hline Gandules & 50 & 50 & 60 & 60 & 70 & 58 \\
\hline Líneas Plásticas & 50 & 55 & 60 & 65 & 70 & 60 \\
\hline Tal S.A. & 40 & 40 & 40 & 40 & 40 & 40 \\
\hline Polinplast S.A.C. & 50 & 50 & 50 & 50 & 50 & 50 \\
\hline Otros Clientes Esquineros & 120 & 132 & 145 & 160 & 176 & 147 \\
\hline Total & $\mathbf{5 8 5}$ & $\mathbf{6 2 1}$ & $\mathbf{6 9 0}$ & $\mathbf{7 3 1}$ & $\mathbf{7 9 5}$ & 684 \\
\hline
\end{tabular}

Nota: Recuperado de Documentación Interna de la Gerencia de Ventas CARVIMSA.

Tabla 101

Precios Históricos y Proyecciones en Dólares Americanos por TM vendida del producto "Esquineros de Cartón" de sus principales clientes

\begin{tabular}{lccccc}
\hline Cliente & $\mathbf{2 0 1 6}$ & $\mathbf{2 0 1 7}$ & $\mathbf{2 0 1 8}$ & $\mathbf{2 0 1 9}$ & $\mathbf{2 0 2 1}$ \\
\hline Complejo Industrial Beta S.A. & $\$ 720.41$ & $\$ 756.43$ & $\$ 779.13$ & $\$ 818.08$ & $\$ 818.08$ \\
& & & & & \\
\hline Jayanca Fruits S.A.C. & $\$ 730.15$ & $\$ 766.66$ & $\$ 789.66$ & $\$ 829.14$ & $\$ 829.14$ \\
& & & & & \\
\hline Avocado Packing Company S.A.C. & $\$ 730.15$ & $\$ 766.66$ & $\$ 789.66$ & $\$ 829.14$ & $\$ 829.14$ \\
& & & & & \\
\hline Agricola Chapi & $\$ 730.15$ & $\$ 766.66$ & $\$ 789.66$ & $\$ 829.14$ & $\$ 829.14$
\end{tabular}




\begin{tabular}{lrrrrr}
\hline Cliente & $\mathbf{2 0 1 6}$ & $\mathbf{2 0 1 7}$ & $\mathbf{2 0 1 8}$ & $\mathbf{2 0 1 9}$ & $\mathbf{2 0 2 1}$ \\
\hline Agroimex Trading & $\$ 730.15$ & $\$ 766.66$ & $\$ 789.66$ & $\$ 829.14$ & $\$ 829.14$ \\
\hline Cliente & $\mathbf{2 0 1 6}$ & $\mathbf{2 0 1 7}$ & $\mathbf{2 0 1 8}$ & $\mathbf{2 0 1 9}$ & $\mathbf{2 0 2 1}$ \\
\hline Cvm - Zona Norte & $\$ 730.15$ & $\$ 766.66$ & $\$ 789.66$ & $\$ 829.14$ & $\$ 829.14$ \\
\hline Gandules & $\$ 730.15$ & $\$ 766.66$ & $\$ 789.66$ & $\$ 829.14$ & $\$ 829.14$ \\
\hline Tal Sa & $\$ 730.15$ & $\$ 766.66$ & $\$ 789.66$ & $\$ 829.14$ & $\$ 829.14$ \\
\hline Líneas Plásticas & $\$ 769.00$ & $\$ 807.45$ & $\$ 831.67$ & $\$ 873.26$ & $\$ 873.26$ \\
\hline Polinplast S.A.C. & $\$ 820.20$ & $\$ 861.21$ & $\$ 887.05$ & $\$ 931.40$ & $\$ 931.40$ \\
\hline Otros Clientes Esquineros & $\$ 800.00$ & $\$ 840.00$ & $\$ 865.20$ & $\$ 908.46$ & $\$ 908.46$ \\
\hline Promedio Precio Por Año & $\$ 747.33$ & $\$ 784.70$ & $\$ 808.24$ & $\$ 848.65$ & $\$ 848.65$ \\
\hline Nota: Recuperado de Documentación Interna de la Gerencia de Ventas CARVIMSA.
\end{tabular}

\subsubsection{Producto o Servicio}

- Tubo de Cartón: Los tubos se utilizan para enrollar papel, plástico, telas y en general cualquier producto que necesite ser enrollado. El tubo se obtiene mediante el espiralado de varias capas de papel, unidas con adhesivos especiales. Dependiendo de la cantidad de capas de papel utilizadas para realizar un determinado tubo, se obtendrán distintos espesores y distintas resistencias. CARVIMSA fabrica tubos para diversos sectores industriales en diferentes medidas de diámetro y longitudes de acuerdo con las necesidades del cliente

- Esquinero de Cartón: Son accesorios de embalaje, utilizados para reforzar la resistencia de la carga, fabricados mediante la unión de varias capas de papel, unidas 
con adhesivos especiales. Con los esquineros, la carga queda mejor protegida al utilizarse como refuerzo estructural para el apilamiento de cajas, ya sea sobre pallets u otra superficie de apilado, permitiendo que la carga soporte mejor las oscilaciones durante el transporte y la manipulación. CARVIMSA fabrica los esquineros de cartón en una amplia gama de medidas, configuración de ángulos y opciones de papel que permitan cumplir con las especificaciones del cliente.

\subsubsection{Precio}

Debido a que los tubos y esquineros de cartón son productos fabricados de acuerdo con la necesidad de cada cliente, los precios pueden variar. Otro factor que puede influir en el precio es el volumen de compra del cliente. A continuación, se detalla el precio promedio de cada producto:

Tabla 102

Precio Promedio Tubos y Esquineros de Cartón

\begin{tabular}{lcc}
\hline Producto & Unidad & Precio \\
\hline Tubo de Cartón & 1 & $\$ 0.80$ \\
\hline Esquinero de Cartón & 1 & $\$ 1.20$
\end{tabular}

\subsubsection{Plaza}

- Ubicación del Mercado Meta: Es importante resaltar que la mayoría de los clientes de la UEN Tubos y Esquineros, se encuentran ubicados en Huachipa, lo que facilita la entrega de los productos debido a que los productos terminados se almacenan en la planta ubicada en el mismo distrito. La ubicación de la planta es en una zona 
estratégica ya que colinda con rutas de fácil acceso hacia la avenida Panamericana Sur, lo que también facilita la atención a otros clientes ubicados en diferentes puntos de Lima.

- Recursos de la empresa: Una vez que culmina la etapa de producción, el producto está listo para ser despachado dependiendo de los tiempos de entrega pactados con el cliente. Todos los días la persona encargada de despacho planifica los despachos del producto terminado, considerando el tipo de producto y el volumen del pedido. Cada camión tiene rutas por zonas y la UEN cuenta con cinco camiones disponibles de los once camiones que posee CARVIMA. Por otro lado, los productos terminados son distribuidos en su mayoría por CARVIMSA (80\%). El 20\% restante los clientes, prefiere recoger el producto en las instalaciones de CARVIMSA.

\subsubsection{Promoción}

Los medios con los que cuenta CARVIMSA a fin de que la marca y sus productos sean reconocidos son:

- Página Web: La página se actualiza constantemente con información relacionada a la participación de ferias y noticias relevantes del Grupo Comeca. Así mismo, cuenta con una sección de "Contáctenos" donde los clientes actuales y potenciales pueden solicitar información relacionada a los productos que ofrece la empresa. 


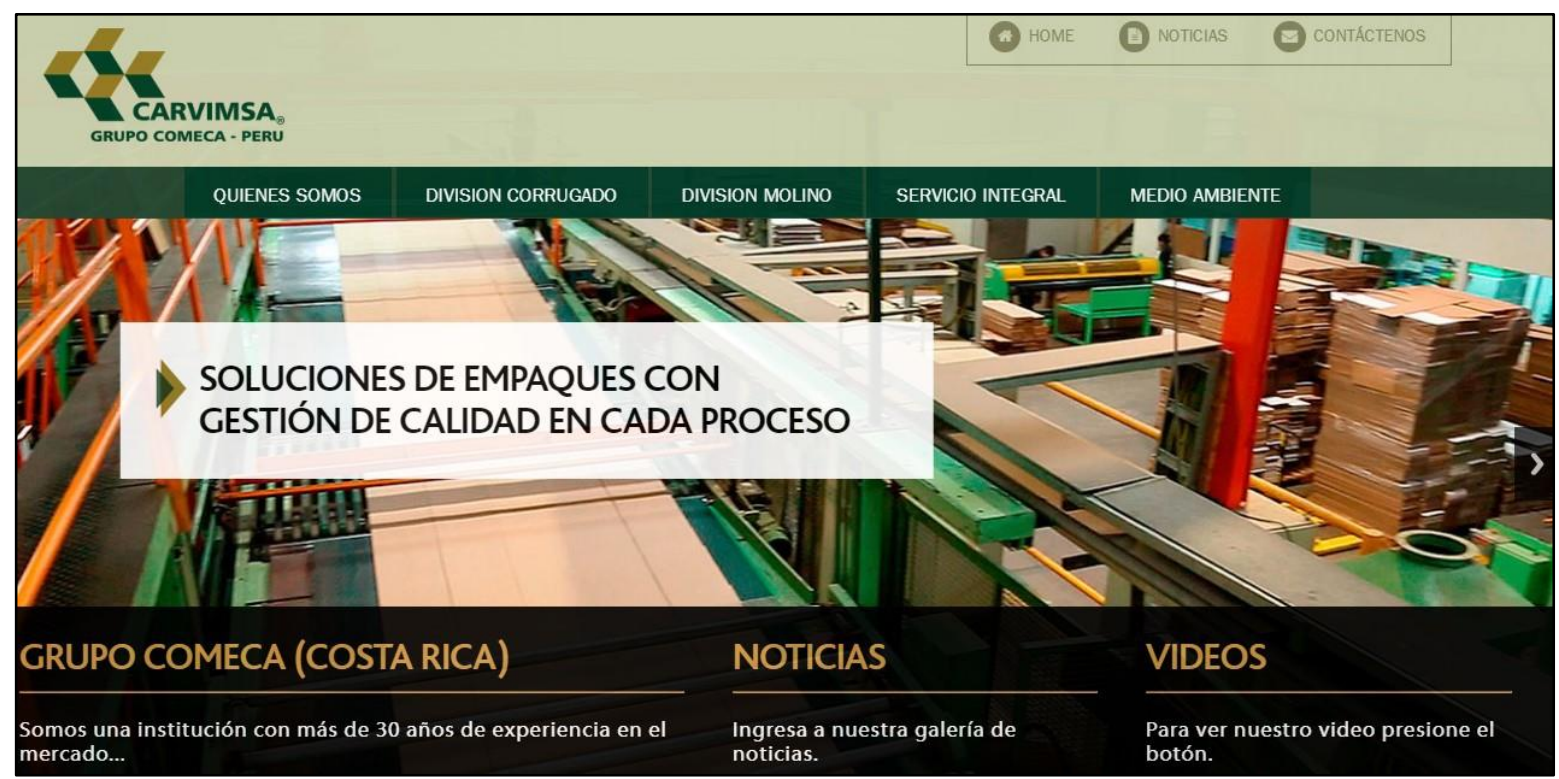

Figura 113. Página Web de CARVIMSA.

- Facebook: La cuenta de Facebook cuenta con 1,575 seguidores y es actualizada constantemente con información relacionada a capacitaciones, eventos, participación de la empresa en ferias y noticias relevantes para sus seguidores.

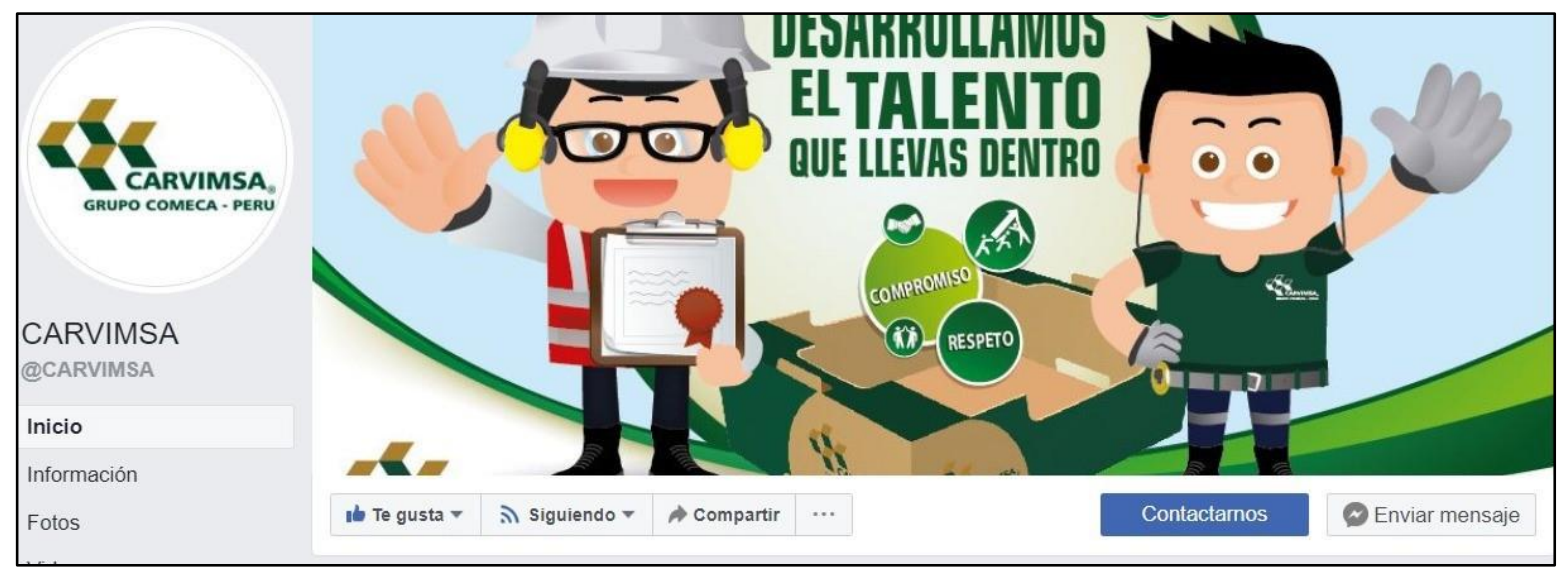

Figura 114. Facebook de CARVIMSA.

- Participación en Eventos a nivel nacional: CARVIMSA participa activamente en eventos a nivel nacional a fin de promocionar la marca y sus productos. 


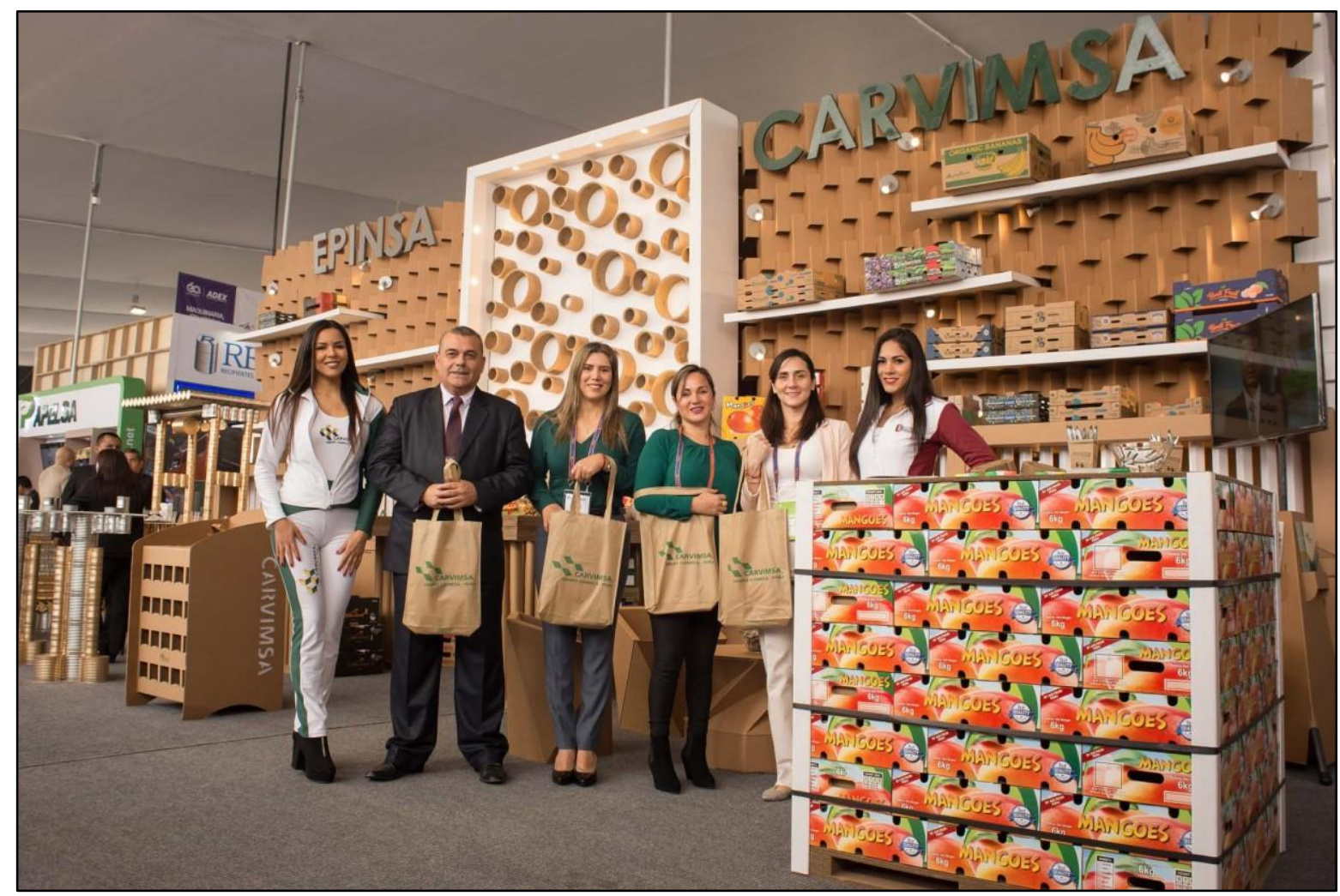

Figura 115. Stand de CARVIMSA en la feria Expo alimentaria 2018

\subsubsection{Presupuesto}

En la siguiente tabla, se detallan los presupuestos anuales asignados para la UEN Tubos y Esquineros para cada una de las iniciativas de marketing que serán realizadas a fin de cumplir con los objetivos establecidos. 
Tabla 103

Presupuesto de actividades de Marketing

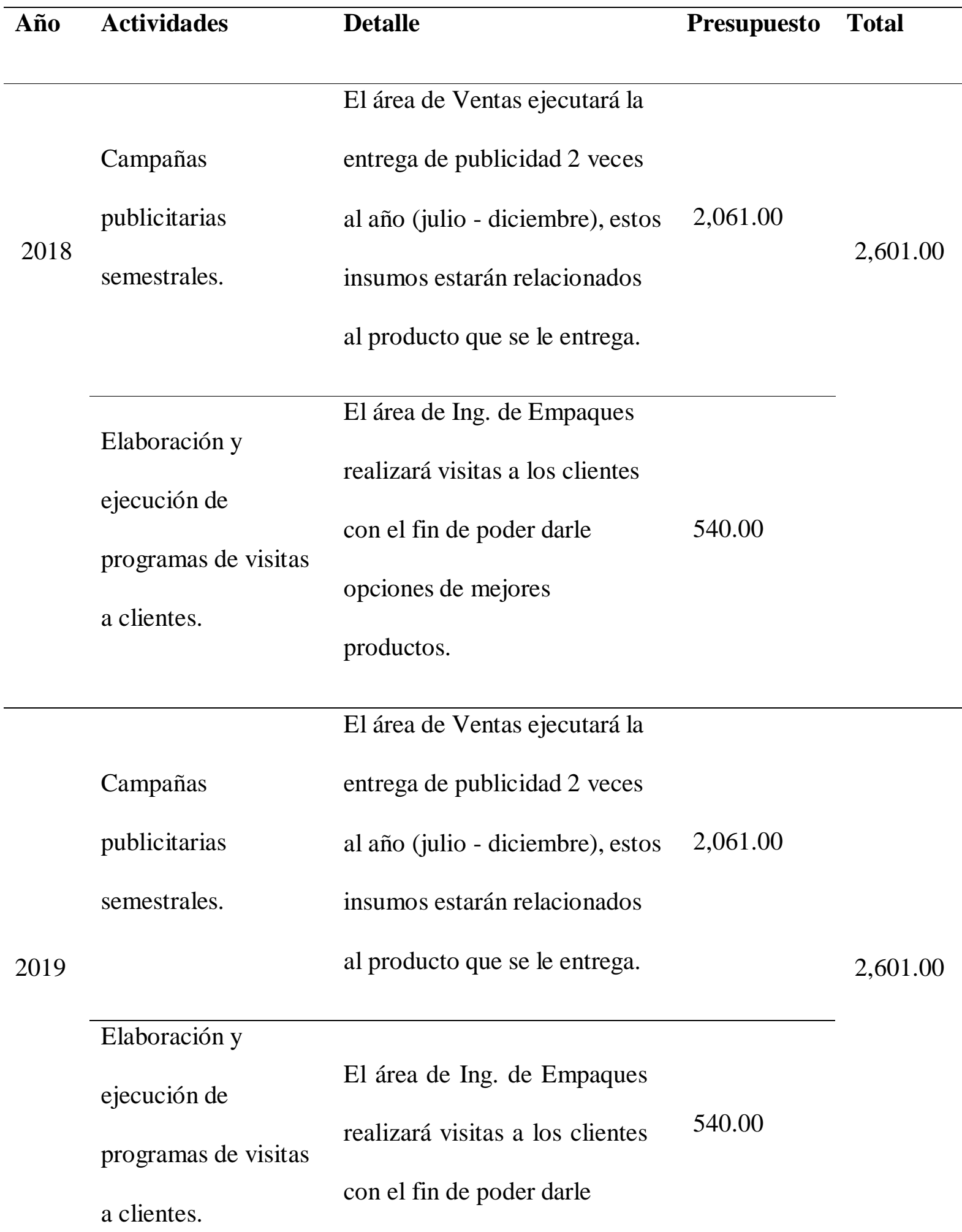




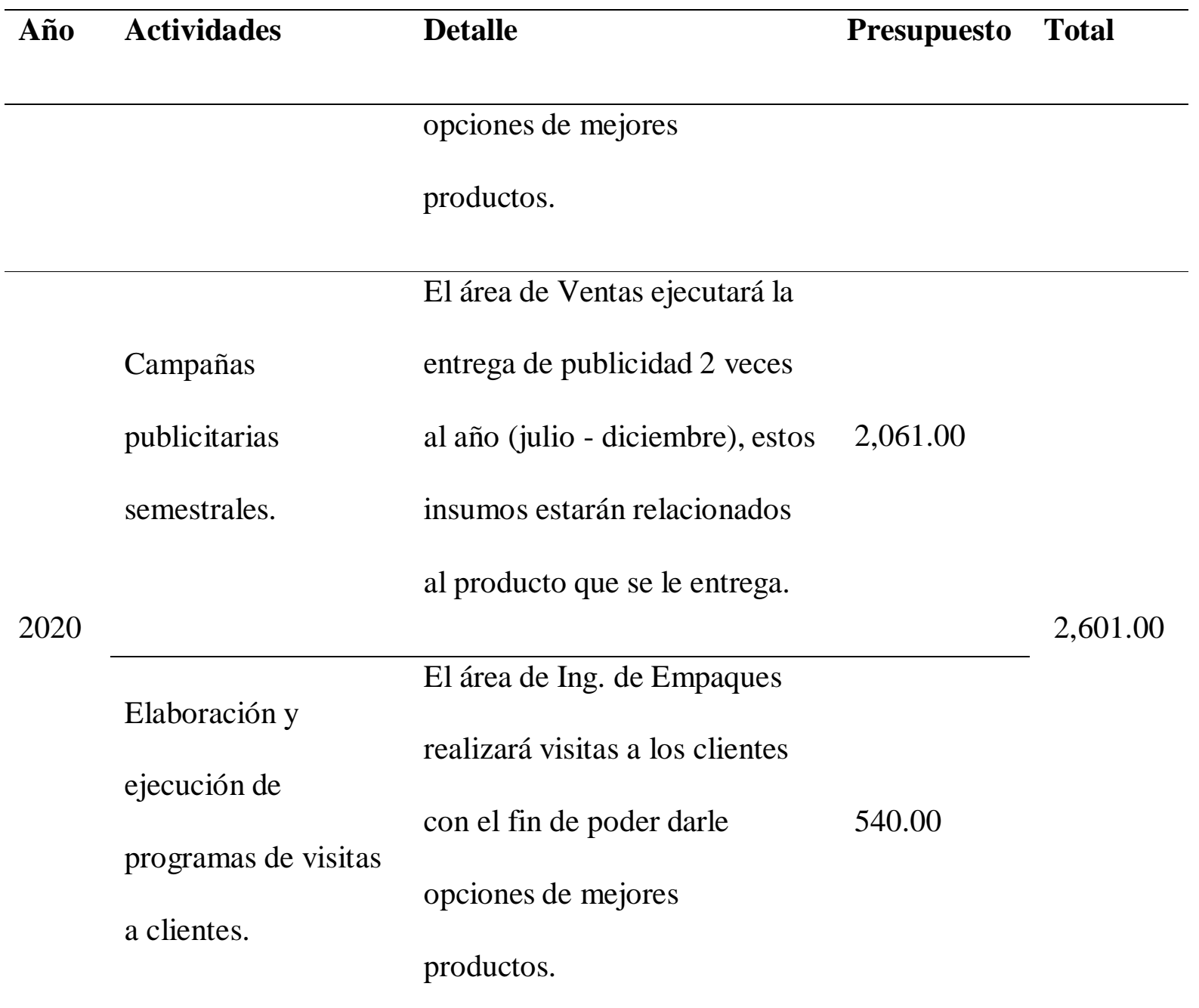

\section{El área de Ventas ejecutará la}

Campañas entrega de publicidad 2 veces

publicitarias al año (julio - diciembre), estos $\quad 2,061.00$

semestrales. insumos estarán relacionados

al producto que se le entrega.

Elaboración y

ejecución de

programas de visitas

a clientes.
El área de Ing. de Empaques

realizará visitas a los clientes

con el fin de poder darle

opciones de mejores

productos. 


\section{Capítulo IX. Implantación de la Estrategia}

\subsection{Mapa de la Estrategia}

Kaplan y Norton (2004) sostienen que el mapa de la estrategia permite a las empresas describir los vínculos entre los activos intangibles y la creación de valor. Así mismo, afirman que el aspecto más crítico de la estrategia es la implantación, pues de ella dependerá la creación de valor sostenido en el tiempo. Para ello es necesario enfocarse en la gestión de cuatro procesos internos clave: operaciones, relaciones con los clientes, innovación y procesos regulatorios y sociales. De esta manera, cualquier organización puede seguir para alinear procesos, personas y tecnología de la información para un rendimiento superior.

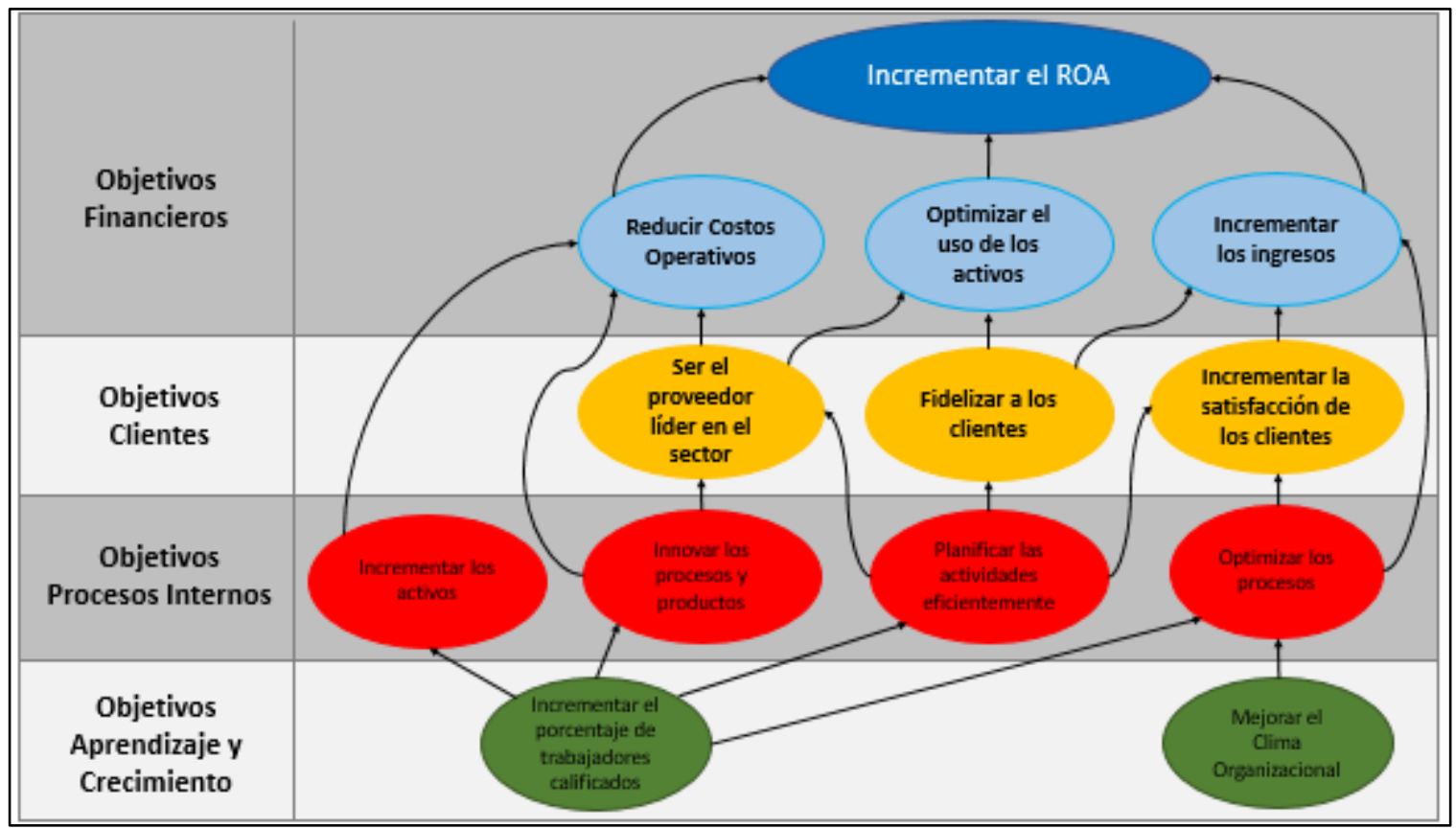

Figura 116. Mapa de la estrategia de CARVIMSA

\subsection{Objetivos específicos según el mapa de la estrategia}

- Objetivos de Aprendizaje y Crecimiento: Los objetivos están enfocados en estrategias de recursos humanos basados en la formación, motivación y calidad en el trabajo. Es por ello por lo que se establecen los siguientes objetivos:

a) Incrementar el porcentaje de trabajadores calificados 
b) Mejorar el clima organizacional

- Objetivos de Procesos Internos: Estos objetivos permiten mejorar y optimizar la calidad, productividad y tecnología. Para ello se han determinado los siguientes objetivos:
a) Incrementar los activos
b) Innovar los procesos y productos
c) Planificar las actividades eficientemente
d) Optimizar los procesos

Con respecto al objetivo de incrementar los activos, es preciso mencionar que la UEN Tubos y Esquineros - CARVIMSA tiene como proyección para los años 2018, 2019, 2020 y 2021 el aumento de sus activos, con la finalidad de poder cubrir toda la demanda que requiera el sector, en la actualidad esta unidad cuenta con un $43 \%$ de participación en el mercado y desea aumentar su participación en un promedio de $42 \%$ hasta el 2021. Para que logre este objetivo, tendrá que aumentar la capacidad instalada en su planta, tanto en terrenos como en maquinarias.

Tabla 104

Proyección de Nuevos Activos
Tipo de Activo Descripción del Activo
Cantidad

$\begin{array}{lll}\text { Construcción } & \text { Ampliación Nave de Planta } & 1\end{array}$

\begin{tabular}{lll}
\hline Construcción & Ampliación Almacén de Producto en Proceso & 1
\end{tabular}

Construcción $\quad$ Ampliación Almacén de Materias Primas 1

Construcción $\quad$ Ampliación Almacén de Sub Productos 1

Construcción $\quad$ Ampliación Almacén de Producto Terminado Tubos 1

Construcción $\quad$ Ampliación Almacén de Producto Terminado Esquineros 1


Tipo de Activo

Construcción $\quad$ Sala de Horno $\mathrm{N}^{\circ} 4$ 1

Maquinarias $\quad$ Tuberas $\mathrm{N}^{\circ} 7 \mathrm{y} \mathrm{N}^{\circ} 8$ 2

Maquinarias $\quad$ Cortadoras Automáticas $\mathrm{N}^{\circ} 3 \mathrm{y} \mathrm{N}^{\circ} 4$

2

Maquinarias Cortadoras Manuales

4

Maquinarias $\quad$ Slitter $\mathrm{N}^{\circ} 4$

1

- Objetivos de Clientes: Estos objetivos se relacionan con el cumplimiento de las expectativas de los clientes. Los objetivos identificados son:

a) Ser el proveedor líder en el sector

b) Fidelizar a los clientes

c) Incrementar la satisfacción de los clientes

- Objetivos Financieros: El objetivo financiero global más importante es aumentar la rentabilidad, es decir maximizar el valor del ROA.
a) Incrementar el ROA
b) Reducir Costos operativos
c) Optimizar el uso de los activos
d) Incrementar los ingresos

\subsection{Indicadores para cada uno de los objetivos específicos}

Los objetivos específicos han sido divididos en cuatro áreas principales de la cadena de valor: aprendizaje, procesos internos, clientes y finanzas. Dentro del área de aprendizaje, se orienta a reforzar la calidad profesional de los colaboradores y el clima organizacional. Se 
han identificado los siguientes indicadores que se utilizarán para medir los objetivos específicos de aprendizaje.

Tabla 105

Indicadores para los Objetivos específicos de Aprendizaje

\begin{tabular}{|c|c|}
\hline Objetivos Específicos & Indicadores \\
\hline \multirow{4}{*}{$\begin{array}{l}\text { Incrementar el porcentaje de trabajadores } \\
\text { calificados }\end{array}$} & $\mathrm{N}^{\circ}$ de horas de capacitación a ejecutivos / Mes \\
\hline & $\mathrm{N}^{\circ}$ de horas de capacitación a operarios / Mes \\
\hline & Porcentaje de trabajadores capacitados / Año \\
\hline & $\begin{array}{l}\mathrm{N}^{\circ} \text { trabajadores usando tecnología / Total de } \\
\text { trabajadores }\end{array}$ \\
\hline \multirow{4}{*}{ Mejorar el clima organizacional } & Porcentaje de trabajadores satisfechos / Año \\
\hline & $\mathrm{N}^{\circ}$ de solicitudes atendidas / $\mathrm{N}^{\circ}$ solicitudes \\
\hline & $\begin{array}{l}\mathrm{N}^{\circ} \text { de trabajadores satisfechos con el trato / } \\
\text { Total de trabajadores }\end{array}$ \\
\hline & $\begin{array}{l}\text { Porcentaje de aprobación de los proyectos } \\
\text { realizados por la empresa }\end{array}$ \\
\hline
\end{tabular}

Para el área de procesos internos, se consideran los siguientes indicadores para cuantificar los avances hacia los objetivos específicos de optimización de procesos, planificación de actividades y la innovación de procesos y dentro del producto mismo.

Tabla 106

Indicadores para los Objetivos específicos de Procesos Internos

\begin{tabular}{|c|c|}
\hline Objetivos Específicos & Indicadores \\
\hline \multirow{4}{*}{ Innovar los procesos y productos } & $\%$ consumo bobinas de papel propio/ Total consumido \\
\hline & $\%$ de tubos y esquineros malos/ Total producido \\
\hline & M3/TM producidas \\
\hline & Unidades Reclamadas x cada 1000 Unidades \\
\hline \multirow{4}{*}{ Optimizar los procesos } & $\%$ total horas trabajadas/ Total horas presupuestadas \\
\hline & Metros Lineales 8 horas. \\
\hline & $\%$ de pedidos producidos/ Total pedidos del mes \\
\hline & $\%$ de Desperdicios /TM bobinas de Papel \\
\hline \multirow{2}{*}{$\begin{array}{l}\text { Planificar las actividades } \\
\text { eficientemente }\end{array}$} & $\%$ (Tiempo de Paro/Tiempo Disponible) \\
\hline & $\%$ de Pedidos cumplidos \\
\hline
\end{tabular}

Para el área comercial orientada a los clientes, los objetivos específicos son incrementar la satisfacción al cliente, fidelizar al cliente y convertirse en el proveedor líder 
del mercado. Los indicadores que permitirán realizar el monitoreo de avance hacia el cumplimiento de los objetivos son los siguientes.

Tabla 107

Indicadores para los Objetivos específicos de Clientes

\begin{tabular}{ll}
\hline \multicolumn{1}{c}{ Objetivos Específicos } & \multicolumn{1}{c}{ Indicadores } \\
\hline \multirow{2}{*}{ Ser el proveedor líder } & Porcentaje de participación de mercado \\
\cline { 2 - 2 } & Ventas anuales expresado en toneladas métricas \\
\cline { 2 - 2 } Fúmero de nuevos clientes \\
\hline $\begin{array}{ll}\text { Incrementar la satisfacción de } \\
\text { clientes }\end{array}$ & Volumen de Compra \\
& Vuloración del producto \\
\hline
\end{tabular}

En cuanto al área financiera, se plantean los objetivos de incremento de ingresos, optimización del uso de activos y reducción de costos operativos. Los indicadores se presentan a continuación.

Tabla 108

Indicadores para los Objetivos específicos de Finanzas

\begin{tabular}{ll}
\hline \multicolumn{1}{c}{ Objetivos Específicos } & \multicolumn{1}{c}{ Indicadores } \\
\hline Reducir los costos operativos & Costos operativos/ Ventas \\
\hline \multirow{2}{*}{ Optimizar el uso de activos } & Rotación de inventarios \\
\cline { 2 - 2 } Incrementar los ingresos & Capacidad utilizada/capacidad instalada \\
\cline { 2 - 2 } & TM Vendidas \\
\hline
\end{tabular}




\subsection{Metas para cada uno de los objetivos específicos}

Tabla 109

Metas para los Objetivos específicos

\begin{tabular}{|c|c|c|c|c|c|c|c|c|}
\hline $\begin{array}{c}\text { Objetivos } \\
\text { Específicos }\end{array}$ & Indicadores & 2015 & 2016 & 2017 & $\begin{array}{l}\text { Meta } \\
2018\end{array}$ & $\begin{array}{l}\text { Meta } \\
2019\end{array}$ & $\begin{array}{l}\text { Meta } \\
2020\end{array}$ & $\begin{array}{l}\text { Meta } \\
2021\end{array}$ \\
\hline \multirow{5}{*}{$\begin{array}{l}\text { Incrementar el } \\
\text { porcentaje de } \\
\text { trabajadores } \\
\text { calificados }\end{array}$} & $\begin{array}{l}\mathrm{N}^{\circ} \text { de horas } \\
\text { hombre } \\
\text { ejecutivos / Año }\end{array}$ & $\begin{array}{c}45 \\
\text { horas }\end{array}$ & $\begin{array}{c}60 \\
\text { horas }\end{array}$ & $\begin{array}{c}92 \\
\text { horas }\end{array}$ & $\begin{array}{c}150 \\
\text { horas }\end{array}$ & $\begin{array}{c}160 \\
\text { horas }\end{array}$ & $\begin{array}{c}180 \\
\text { horas }\end{array}$ & $\begin{array}{r}180 \\
\text { horas }\end{array}$ \\
\hline & $\begin{array}{l}\mathrm{N}^{\circ} \text { de horas } \\
\text { hombre } \\
\text { capacitación a } \\
\text { operarios / Año }\end{array}$ & $\begin{array}{c}800 \\
\text { horas }\end{array}$ & $\begin{array}{l}920 \\
\text { horas }\end{array}$ & $\begin{array}{l}920 \\
\text { horas }\end{array}$ & $\begin{array}{l}1000 \\
\text { horas }\end{array}$ & $\begin{array}{l}1015 \\
\text { horas }\end{array}$ & $\begin{array}{l}1080 \\
\text { horas }\end{array}$ & $\begin{array}{l}1080 \\
\text { horas }\end{array}$ \\
\hline & $\begin{array}{l}\text { Porcentaje de } \\
\text { trabajadores } \\
\text { capacitados / } \\
\text { Año }\end{array}$ & $78 \%$ & $79 \%$ & $81 \%$ & $95 \%$ & $97 \%$ & $100 \%$ & $100 \%$ \\
\hline & $\begin{array}{l}\mathrm{N}^{\circ} \text { trabajadores } \\
\text { usando } \\
\text { tecnología / Total } \\
\text { de trabajadores }\end{array}$ & $88 \%$ & $90 \%$ & $92 \%$ & $94 \%$ & $96 \%$ & $96 \%$ & $96 \%$ \\
\hline & $\begin{array}{l}\text { Porcentaje de } \\
\text { trabajadores } \\
\text { satisfechos / Año }\end{array}$ & $77 \%$ & $78 \%$ & $80 \%$ & $80 \%$ & $85 \%$ & $87 \%$ & $89 \%$ \\
\hline \multirow{4}{*}{$\begin{array}{l}\text { Mejorar el } \\
\text { clima } \\
\text { organizacional }\end{array}$} & $\begin{array}{l}\mathrm{N}^{\circ} \text { de solicitudes } \\
\text { atendidas / } \mathrm{N}^{\circ} \\
\text { solicitudes }\end{array}$ & $62 \%$ & $65 \%$ & $68 \%$ & $70 \%$ & $80 \%$ & $85 \%$ & $90 \%$ \\
\hline & $\begin{array}{l}\mathrm{N}^{\circ} \text { de } \\
\text { trabajadores } \\
\text { satisfechos con el } \\
\text { trato / Total de } \\
\text { trabajadores }\end{array}$ & $72 \%$ & $76 \%$ & $79 \%$ & $80 \%$ & $85 \%$ & $87 \%$ & $89 \%$ \\
\hline & $\begin{array}{l}\text { Porcentaje de } \\
\text { aprobación de los } \\
\text { proyectos } \\
\text { realizados por la } \\
\text { empresa }\end{array}$ & $81 \%$ & $85 \%$ & $87 \%$ & $87 \%$ & $92 \%$ & $94 \%$ & $96 \%$ \\
\hline & $\begin{array}{l}\% \text { consumo } \\
\text { bobinas de papel }\end{array}$ & $82 \%$ & $86 \%$ & $88 \%$ & $90 \%$ & $92 \%$ & $92 \%$ & $92 \%$ \\
\hline
\end{tabular}




\begin{tabular}{|c|c|c|c|c|c|c|c|c|}
\hline $\begin{array}{c}\text { Objetivos } \\
\text { Específicos }\end{array}$ & Indicadores & 2015 & 2016 & 2017 & $\begin{array}{l}\text { Meta } \\
2018\end{array}$ & $\begin{array}{c}\text { Meta } \\
2019\end{array}$ & $\begin{array}{l}\text { Meta } \\
2020\end{array}$ & $\begin{array}{l}\text { Meta } \\
2021\end{array}$ \\
\hline \multirow{4}{*}{$\begin{array}{l}\text { Innovar los } \\
\text { procesos y } \\
\text { productos }\end{array}$} & $\begin{array}{l}\text { propio/ Total } \\
\text { consumido }\end{array}$ & & & & & & & \\
\hline & $\begin{array}{l}\text { \% de tubos y } \\
\text { esquineros } \\
\text { malos/ Total } \\
\text { producido }\end{array}$ & $8 \%$ & $7 \%$ & $4 \%$ & $3 \%$ & $2 \%$ & $1 \%$ & $1 \%$ \\
\hline & $\begin{array}{l}\text { M3/TM } \\
\text { producidas }\end{array}$ & $\mathrm{s} / \mathrm{d}$ & $\mathrm{s} / \mathrm{d}$ & 29 & 40 & 60 & 120 & 120 \\
\hline & $\begin{array}{l}\text { Unidades } \\
\text { Reclamadas } \mathrm{x} \\
\text { cada } 1000 \\
\text { Unidades }\end{array}$ & 10.36 & 7.63 & 4.75 & 4.5 & 3 & 2.5 & 2 \\
\hline \multirow{4}{*}{$\begin{array}{l}\text { Optimizar los } \\
\text { procesos }\end{array}$} & $\begin{array}{l}\text { \% total horas } \\
\text { trabajadas/ Total } \\
\text { horas } \\
\text { presupuestadas }\end{array}$ & $62.50 \%$ & $58.70 \%$ & $75.00 \%$ & $80.00 \%$ & $85 \%$ & $92 \%$ & $94 \%$ \\
\hline & $\begin{array}{l}\text { Metros Lineales } \\
8 \text { horas. }\end{array}$ & 26,200 & 25,729 & 26,500 & 27,000 & 32,000 & 35,000 & 35,000 \\
\hline & $\begin{array}{l}\% \text { de pedidos } \\
\text { producidos/ Total } \\
\text { pedidos del mes }\end{array}$ & $68.25 \%$ & $87.28 \%$ & $92 \%$ & $95 \%$ & $97 \%$ & $97 \%$ & $97 \%$ \\
\hline & $\begin{array}{l}\% \text { de } \\
\text { Desperdicios } \\
\text { TM bobinas de } \\
\text { Papel }\end{array}$ & $6.94 \%$ & $6.91 \%$ & $6.40 \%$ & $6.20 \%$ & $6 \%$ & $5.8 \%$ & $5.8 \%$ \\
\hline \multirow{2}{*}{$\begin{array}{l}\text { Planificar las } \\
\text { actividades } \\
\text { eficientemente }\end{array}$} & $\begin{array}{l}\% \text { (Tiempo de } \\
\text { Paro/Tiempo } \\
\text { Disponible) }\end{array}$ & $4.67 \%$ & $3.89 \%$ & $2.05 \%$ & $2.00 \%$ & $1.5 \%$ & $1.5 \%$ & $1.5 \%$ \\
\hline & $\begin{array}{l}\text { \% de Pedidos } \\
\text { cumplidos }\end{array}$ & $76.96 \%$ & $84.29 \%$ & $90.21 \%$ & $95.00 \%$ & $97 \%$ & $98 \%$ & $98 \%$ \\
\hline \multirow{2}{*}{$\begin{array}{l}\text { Ser el } \\
\text { proveedor } \\
\text { líder }\end{array}$} & $\begin{array}{l}\text { Porcentaje de } \\
\text { participación de } \\
\text { mercado }\end{array}$ & $22 \%$ & $35 \%$ & $43 \%$ & $61 \%$ & $75 \%$ & $80 \%$ & $80 \%$ \\
\hline & $\begin{array}{l}\text { Ventas anuales } \\
\text { expresado en } \\
\text { toneladas } \\
\text { métricas }\end{array}$ & 3,089 & 3,397 & 3,952 & 7,109 & 9,066 & 10,921 & 12,118 \\
\hline
\end{tabular}




\begin{tabular}{|c|c|c|c|c|c|c|c|c|}
\hline $\begin{array}{c}\text { Objetivos } \\
\text { Específicos }\end{array}$ & Indicadores & 2015 & 2016 & 2017 & $\begin{array}{r}\text { Meta } \\
2018\end{array}$ & $\begin{array}{l}\text { Meta } \\
2019\end{array}$ & $\begin{array}{c}\text { Meta } \\
2020\end{array}$ & $\begin{array}{l}\text { Meta } \\
2021\end{array}$ \\
\hline & $\begin{array}{l}\text { Número de } \\
\text { nuevos clientes }\end{array}$ & 123 & 169 & 240 & 300 & 305 & 305 & 305 \\
\hline \multirow{2}{*}{$\begin{array}{l}\text { Fidelizar a los } \\
\text { clientes }\end{array}$} & $\begin{array}{l}\text { Volumen de } \\
\text { Compra }\end{array}$ & $31 \%$ & $41 \%$ & $45 \%$ & $50 \%$ & $70 \%$ & $75 \%$ & $80 \%$ \\
\hline & $\begin{array}{l}\text { Valoración del } \\
\text { producto }\end{array}$ & $82 \%$ & $87 \%$ & $89 \%$ & $90 \%$ & $92 \%$ & $95 \%$ & $95 \%$ \\
\hline \multicolumn{2}{|c|}{$\begin{array}{lc}\text { Incrementar } & \text { la Número de } \\
\text { satisfacción } & \text { de clientes } \\
\text { clientes } & \text { satisfechos }\end{array}$} & $82 \%$ & $87 \%$ & $89 \%$ & $95 \%$ & $95 \%$ & $97 \%$ & $98 \%$ \\
\hline $\begin{array}{l}\text { Reducir los } \\
\text { costos } \\
\text { operativos }\end{array}$ & $\begin{array}{l}\text { Costos } \\
\text { operativos/ } \\
\text { Ventas }\end{array}$ & 0.147 & 0.17 & 0.164 & 0.15 & 0.21 & 0.24 & 0.24 \\
\hline \multirow{3}{*}{$\begin{array}{l}\text { Optimizar el } \\
\text { uso de activos }\end{array}$} & $\begin{array}{l}\text { Rotación de } \\
\text { inventarios }\end{array}$ & 87 días & 89 días & 87 días & 85 días & $\begin{array}{c}85 \\
\text { días }\end{array}$ & $\begin{array}{c}85 \\
\text { días }\end{array}$ & $\begin{array}{c}85 \\
\text { días }\end{array}$ \\
\hline & \multirow{2}{*}{$\begin{array}{l}\text { Capacidad } \\
\text { utilizada/capacid } \\
\text { ad instalada }\end{array}$} & $257 / 300$ & $283 / 300$ & $329 / 520$ & $592 / 800$ & $\begin{array}{l}755 / \\
800\end{array}$ & $\begin{array}{l}910 / \\
1000\end{array}$ & $\begin{array}{l}1009 / \\
1000\end{array}$ \\
\hline & & 0.86 & 0.94 & 0.63 & 0.74 & 0.94 & 0.91 & 1 \\
\hline \multirow{2}{*}{$\begin{array}{l}\text { Incrementar } \\
\text { los ingresos }\end{array}$} & TM Vendidas & $\begin{array}{c}3,089 \\
\mathrm{TM}\end{array}$ & $\begin{array}{c}3,397 \\
\mathrm{TM}\end{array}$ & $\begin{array}{c}3,952 \\
\mathrm{TM}\end{array}$ & $\begin{array}{c}7,109 \\
\text { TM }\end{array}$ & $\begin{array}{c}9,066 \\
\text { TM }\end{array}$ & $\begin{array}{l}10,92 \\
1 \mathrm{TM}\end{array}$ & $\begin{array}{l}12,11 \\
8 \mathrm{TM}\end{array}$ \\
\hline & $\begin{array}{l}\text { Ratio de cuentas } \\
\text { por cobrar }\end{array}$ & $\begin{array}{c}113.92 \\
\text { días }\end{array}$ & $\begin{array}{l}110 \\
\text { días }\end{array}$ & $\begin{array}{l}105 \\
\text { días }\end{array}$ & 90 días & $\begin{array}{l}75 \\
\text { días }\end{array}$ & $\begin{array}{l}75 \\
\text { días }\end{array}$ & $\begin{array}{l}75 \\
\text { días }\end{array}$ \\
\hline
\end{tabular}




\subsection{Iniciativas (acciones a llevar a cabo para cada uno de los objetivos específicos)}

Estrategias, programas, políticas, reglas, procedimiento

Tabla 110

Iniciativas para los Objetivos específicos

\section{Objetivos Específicos \\ Iniciativas}

\begin{tabular}{|c|c|}
\hline \multirow{2}{*}{$\begin{array}{l}\text { Incrementar el porcentaje } \\
\text { de trahaiadnres calificadns }\end{array}$} & Capacitaciones brindadas por personal interno. \\
\hline & Lapacitaciones brindadas por personal externos. \\
\hline \multirow{2}{*}{$\begin{array}{l}\text { Mejorar el clima } \\
\text { oroanizarinnal }\end{array}$} & $\begin{array}{l}\text { Apertura de una oficina de Asistencia Social para la UEN } \\
\text { Tubos y Esquineros. }\end{array}$ \\
\hline & $\begin{array}{l}\text { rlanıticacion y ejecucion de una actıvidad campestre anuaı en } \\
\text { el mes de Setiembre entre todas las áreas. }\end{array}$ \\
\hline \multirow[t]{2}{*}{ Incrementar los activos } & $\begin{array}{l}\text { Desarrollar máquinas tuberas } \mathrm{N}^{\circ} 7 \text { y } 8 \text {, cortadoras automáticas } \\
\mathrm{N}^{\circ} 3 \text { y } 4 \text {, Cortadoras manuales y Slitter } \mathrm{N}^{\circ} 4 \text { y ampliar } \\
\text { edificaciones y almacenes. }\end{array}$ \\
\hline & $\begin{array}{l}\text { Creación de área de Investigación y desarrollo de nuevos } \\
\text { productos. }\end{array}$ \\
\hline \multirow{2}{*}{$\begin{array}{l}\text { Innovar los procesos y } \\
\text { productos }\end{array}$} & $\begin{array}{l}\text { Adquisición de una cámara de frío, con el fin de hacer pruebas } \\
\text { de resistencias a la humedad. }\end{array}$ \\
\hline & Instalación de gas natural para los hornos. \\
\hline \multirow{2}{*}{ Optimizar los procesos } & Desarrollo de un ERP Integrado. \\
\hline & Adquisición de una máquina de Compresión. \\
\hline $\begin{array}{l}\text { Planificar las actividades } \\
\text { eficientemente }\end{array}$ & $\begin{array}{l}\text { Disminuir los mantenimientos correctivos de las máquinas de } \\
\text { tubos y esquineros. }\end{array}$ \\
\hline \multirow[b]{2}{*}{ Ser el nroveednr líder } & Contratación de una persona para el área de despacho. \\
\hline & $\begin{array}{l}\text { Incorporar certı11caciones de Lalıdad ISU YUUI para Ia UEIN } \\
\text { Tubos y Esquineros. }\end{array}$ \\
\hline
\end{tabular}

Fidelizar a los clientes

Elaboración y ejecución de programas de visitas a clientes

Incrementar la satisfacción de clientes

Optimización del sistema de gestión de reclamos

\begin{tabular}{ll}
\hline $\begin{array}{l}\text { Reducir los costos } \\
\text { operativos }\end{array}$ & $\begin{array}{l}\text { Elaboración de planes de trabajo semanales para justificación } \\
\text { de horas extras }\end{array}$ \\
\hline
\end{tabular}




\section{Objetivos Específicos}

Optimizar el uso de activos

Monitorear nivel de Inventarios a partir de la Planificación de las ventas.

\section{Revisar las políticas de créditos para lograr una eficiente}

Incrementar los ingresos

Evaluar la rentabilidad por cliente

A continuación, se detalla el cálculo del presupuesto de las capacitaciones enfocadas a los ejecutivos de venta y a los operarios, así como también el cálculo del total de horas anuales las cuales fueron consideradas como metas.

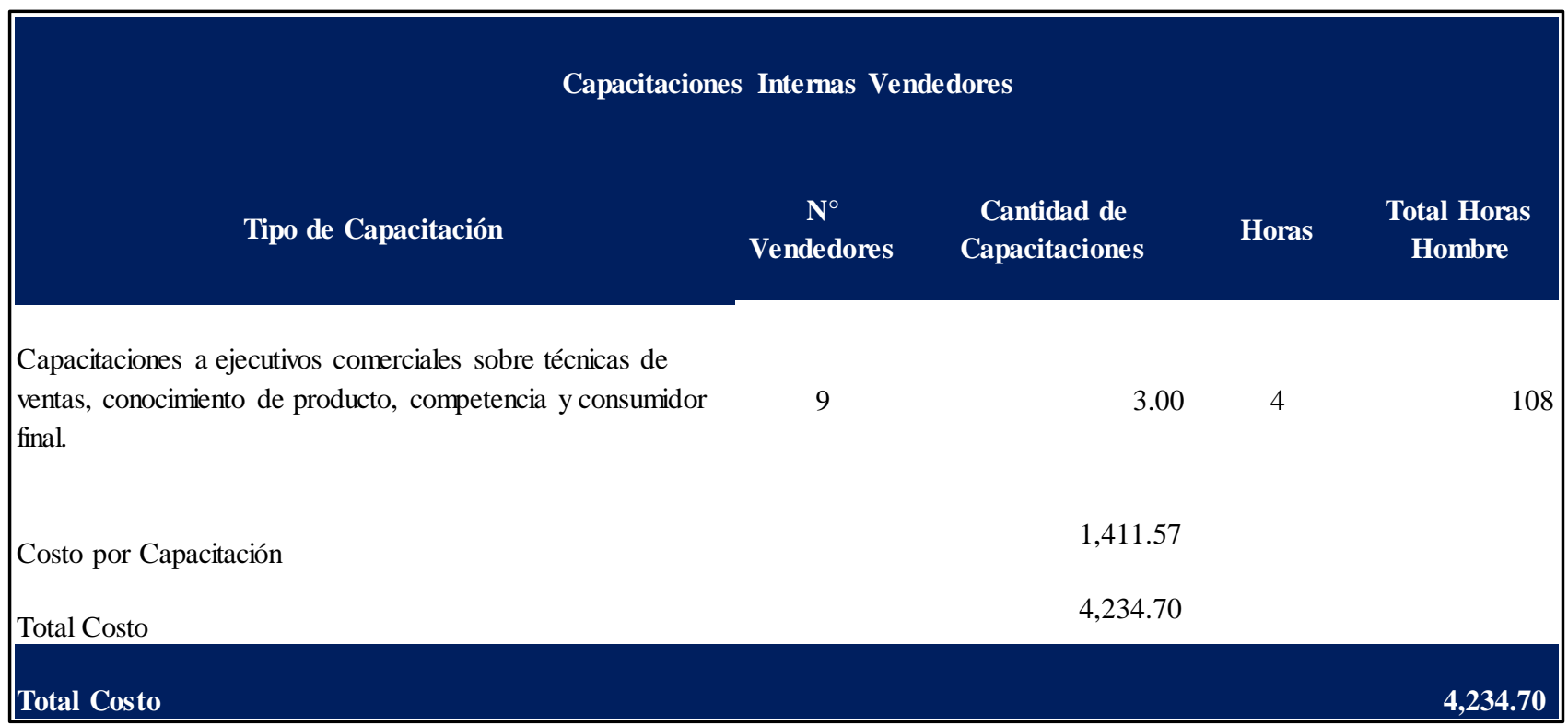

Figura 117. Capacitaciones Internas a los Ejecutivos de ventas 
Capacitaciones Extemas Vendedores

Tipo de Capacitación
$\mathbf{N}^{\circ}$

Vendedores
Cantidad de

Capacitaciones
Horas

Total Horas

Hombre

Capacitaciones a ejecutivos comerciales sobre técnicas de ventas, conocimiento de producto, competencia y consumidor final.

9
9

Costo por Capacitación

Total Costo

$15,217.50$

Total Costo

Figura 118. Capacitaciones Externas a los Ejecutivos de ventas

\begin{tabular}{|c|c|c|c|c|}
\hline $\begin{array}{l}\text { Total Horas Hombre Ejecutivos de } \\
\text { Venta }\end{array}$ & 2018 & 2019 & 2020 & 2021 \\
\hline Capacitaciones Internas y Externas & 150 & 160 & 180 & 180 \\
\hline
\end{tabular}

Figura 119. Total de Horas Hombre Capacitaciones Ejecutivos de Venta

\begin{tabular}{|c|c|c|c|c|}
\hline \multicolumn{5}{|c|}{ Capacitaciones Seguridad y Salud en el Trabajo } \\
\hline Tipo de Capacitación & $\begin{array}{c}\mathbf{N}^{\circ} \\
\text { Colaboradores }\end{array}$ & $\begin{array}{c}\text { Cantidad de } \\
\text { Capacitaciones }\end{array}$ & Horas & $\begin{array}{c}\text { Total Horas } \\
\text { Hombre }\end{array}$ \\
\hline $\begin{array}{l}\text { El área de Seguridad } \\
\text { Industrial, deberá generar } \\
\text { capacitaciones a los nuevos } \\
\text { operarios de planta, sobre } \\
\text { el uso adecuado de los } \\
\text { EPP. }\end{array}$ & 90 & 4.00 & 2 & 720 \\
\hline Costo por Capacitación & & 300.00 & & \\
\hline Total Costo & & $1,200.00$ & & \\
\hline Total Costo & & $1,200.00$ & & \\
\hline
\end{tabular}

Figura 120. Capacitaciones Seguridad y Salud en el Trabajo (SST) 


\begin{tabular}{|c|c|c|c|c|}
\hline \multicolumn{5}{|c|}{ Capacitaciones Gestión Ambiental } \\
\hline Tipo de Capacitación & $\begin{array}{c}\mathbf{N}^{\circ} \\
\text { Colaboradores }\end{array}$ & $\begin{array}{c}\text { Cantidad de } \\
\text { Capacitaciones }\end{array}$ & Horas & $\begin{array}{c}\text { Total Horas } \\
\text { Hombre }\end{array}$ \\
\hline $\begin{array}{l}\text { El área de Seguridad Industrial, } \\
\text { deberá generar capacitaciones a } \\
\text { los nuevos operarios de planta, } \\
\text { sobre el impacto Ambiental }\end{array}$ & 90 & 4.00 & 1 & 360 \\
\hline Costo por Capacitación & & 245.00 & & \\
\hline Total Costo & & 980.00 & & \\
\hline Total Costo & & 980.00 & & \\
\hline
\end{tabular}

Figura 121. Capacitaciones Gestión Ambiental

\begin{tabular}{|l|r|r|r|r|}
\hline Total Horas Hombre Operarios & $\mathbf{2 0 1 8}$ & $\mathbf{2 0 1 9}$ & $\mathbf{2 0 2 0}$ & $\mathbf{2 0 2 1}$ \\
\hline Capacitaciones Internas y Externas & 1,000 & 1,015 & 1,080 & 1,080 \\
\hline
\end{tabular}

Figura 122. Total de Horas Hombre Capacitaciones Operarios 


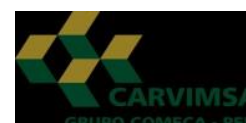

PROYECTO

Capacitaciones en Gestión Ambiental

Aprendizaje y Crecimiento

\begin{tabular}{|c|c|c|c|c|c|c|}
\hline \multirow[t]{2}{*}{ Estado General } & \multirow{2}{*}{\multicolumn{2}{|c|}{\begin{tabular}{|l|} 
Objetivo \\
Brindar información a los colaborares en temas de impacto en el \\
medio ambiente, por ello la empresa necesita colaboradores \\
especializados en estos temas. Asegurar la interiorización y \\
concientización del personal en las obligaciones ambientales \\
exigidas a Carvimsa de acuerdo a las necesidades de la \\
empresa, normas legales y compromisos asumidos por \\
Carvimsa.
\end{tabular}}} & \multicolumn{4}{|c|}{ Indicador del proyecto } \\
\hline & & & \multicolumn{2}{|c|}{$\begin{array}{l}\text { Para la medición del presente } \\
\text { programa, se ha establecido el } \\
\text { indicador de horas hombres de } \\
\text { capacitación, el } \\
\text { cual se obtiene mediante la } \\
\text { siguiente formula } N^{\circ} \text { de } \\
\text { Asistentes } \times 60 \text { minutos (1 hora) }\end{array}$} & \multicolumn{2}{|c|}{$\begin{array}{c}3000 \\
2000 \\
1000 \\
\end{array}$} \\
\hline \multicolumn{3}{|c|}{ Alcance } & \multicolumn{4}{|c|}{ Métrica del proyecto } \\
\hline \multicolumn{3}{|c|}{$\begin{array}{l}\text { Este proyecto de capacitación es aplicable a todos los colabradores (90) de la UEN Tubos y } \\
\text { Esquineros de Carvimsa. Duración aproximada de } 60 \text { minutos. Modalidad Presencial para } \\
\text { los colaboradores }\end{array}$} & \multicolumn{2}{|c|}{ Indice de participantes } & \multicolumn{2}{|c|}{ Año — Numero de Participantes } \\
\hline Auspiciante & Coordinador & \multicolumn{2}{|l|}{ Fecha de inicio } & \multicolumn{3}{|c|}{ Fecha de ciemre } \\
\hline Flavia Meza & Angela Alegría & \multirow{2}{*}{\multicolumn{2}{|c|}{$\begin{array}{c}\text { 15-Mar } \\
\text { Eventos Principales }\end{array}$}} & \multicolumn{3}{|c|}{ 15-Nov } \\
\hline \multicolumn{2}{|c|}{ Equipo del Proyecto } & & & Fecha Pla & ada & Fecha Real \\
\hline \multirow{3}{*}{\multicolumn{2}{|c|}{$\begin{array}{l}\text { Jefe de Gestión de Medio Ambiente } \\
\text { Jefe de Producción } \\
\text { Jefe de Ventas Jefe } \\
\text { de Despacho Jefe } \\
\text { de Calidad Jefe de } \\
\text { RRHH }\end{array}$}} & \multirow{5}{*}{\multicolumn{2}{|c|}{$\begin{array}{l}\text { Información general de CARVIMSA } \\
\text { Sistema Integrado de Gestión: Seguridad, Salud } \\
\text { Ocupacional y Medio Ambiente } \\
\text { Política Integrada de Seguridad, Salud Ocupacional y } \\
\text { Medio Ambiente. } \\
\text { Normatividad sobre Seguridad y Salud Ocupacional } \\
\text { Gestión Ambiental de Carvimsa } \\
\text { Programa de Manejo Ambiental } \\
\text { Manejo de Residuos Sólidos } \\
\text { Sistema BASC }\end{array}$}} & \multicolumn{2}{|c|}{ 15-Mar } & 20-Mar \\
\hline & & & & \multicolumn{2}{|c|}{ 15-May } & 22-May \\
\hline & & & & \multicolumn{2}{|c|}{ 15-Ago } & 19-Ago \\
\hline \multicolumn{2}{|c|}{ Areas Involucradas } & & & \multirow{2}{*}{\multicolumn{2}{|c|}{ 15-Nov }} & \multirow[b]{2}{*}{ 20-Nov } \\
\hline Medio Ambiente, Produ & $\begin{array}{l}\text { n, Ventas, Despacho, Calidad } \\
\text { RHH }\end{array}$ & & & & & \\
\hline \multicolumn{2}{|c|}{ Información } & \multicolumn{2}{|l|}{ Inversiones en } & \multicolumn{2}{|c|}{ Aprobado } & Real \\
\hline Actualizado en: & $31 / 12 / 2018$ & \multirow{2}{*}{\multicolumn{2}{|c|}{$\begin{array}{l}\text { Las Inversiones se relacionan con el material y coffe } \\
\text { break, sala de capacitaciones de Carvimsa, no se } \\
\text { considera el pago al expositor ya que la capacitación } \\
\text { será realizada por el área de Gestión del } \\
\text { Medioambiente. }\end{array}$}} & \multirow{2}{*}{\multicolumn{2}{|c|}{$\mathrm{s} / 980.00$}} & \multirow[b]{2}{*}{$\mathrm{s} / 980.00$} \\
\hline Por: & Angela Alegría & & & & & \\
\hline
\end{tabular}

\begin{tabular}{|c|r|}
\hline \multicolumn{1}{|c|}{ Año } & \% de personal capacitado \\
\hline 2017 & $11 \%$ \\
\hline $2020-2021$ & $100 \%$ \\
\hline \multicolumn{2}{|c|}{} \\
\hline Año & Numero de Participantes \\
\hline 2017 & 10 \\
\hline $2020-2021$ & 90 \\
\hline Operarios & 7 \\
\hline Jefaturas & 4 \\
\hline Ventas & 9 \\
\hline Despacho & 1 \\
\hline
\end{tabular}

Figura 123. Ficha técnica del Proyecto "Capacitaciones en Gestión ambiental." 


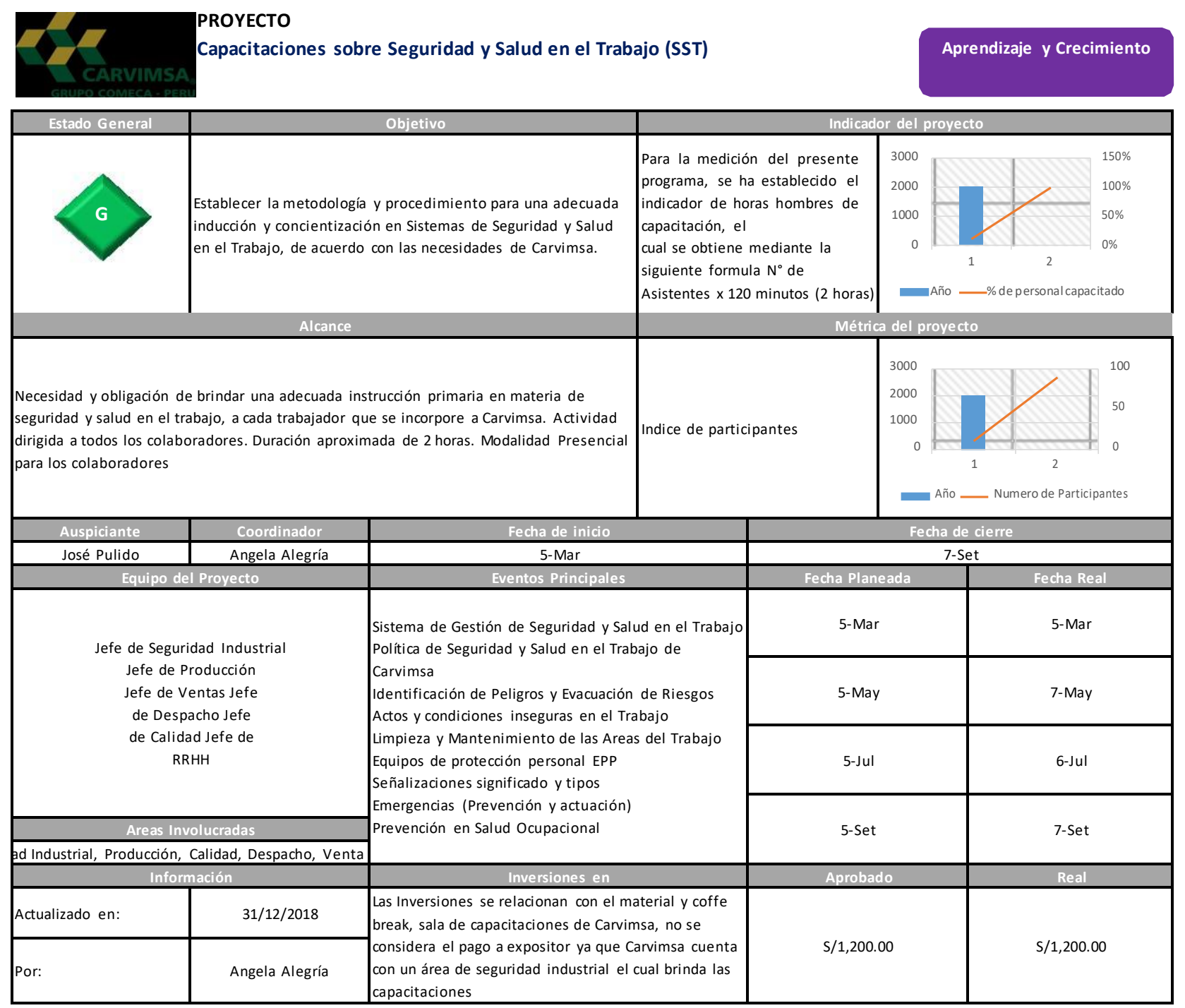

\begin{tabular}{|c|c|}
\hline Año & \% de personal capacitado \\
\hline 2017 & $11 \%$ \\
\hline 2020-2021 & $100 \%$ \\
\hline Año & Numero de Participantes \\
\hline 2017 & 10 \\
\hline 2020-2021 & 90 \\
\hline Operarios & 76 \\
\hline Jefaturas & 4 \\
\hline Ventas & c \\
\hline Despacho & \\
\hline
\end{tabular}

Figura 124. Ficha técnica del Proyecto "Capacitaciones sobre Seguridad y Salud en el Trabajo (SST)." 


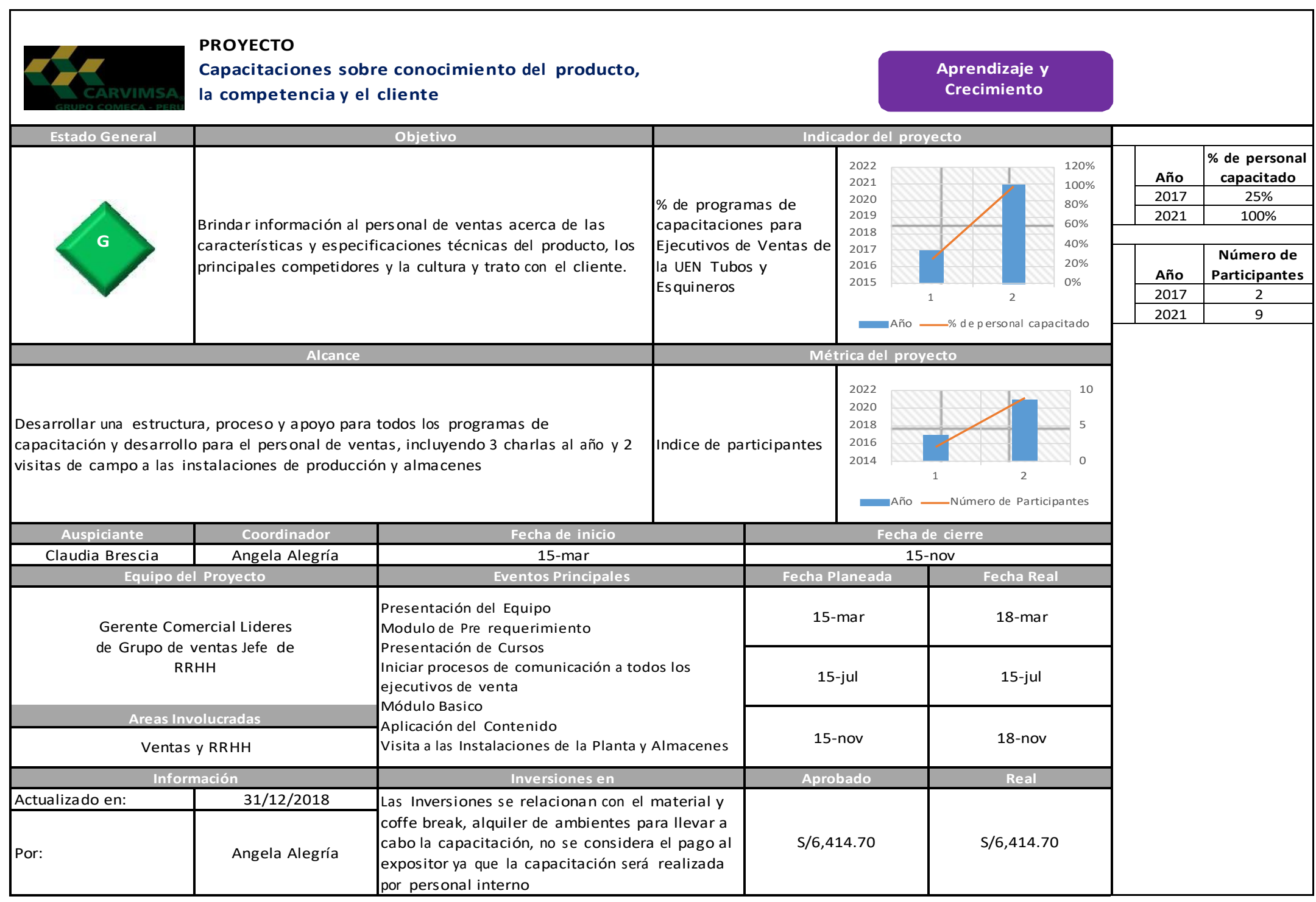

Figura 125. Ficha técnica del Proyecto "Capacitaciones sobre conocimiento del producto, la competencia y el cliente." 


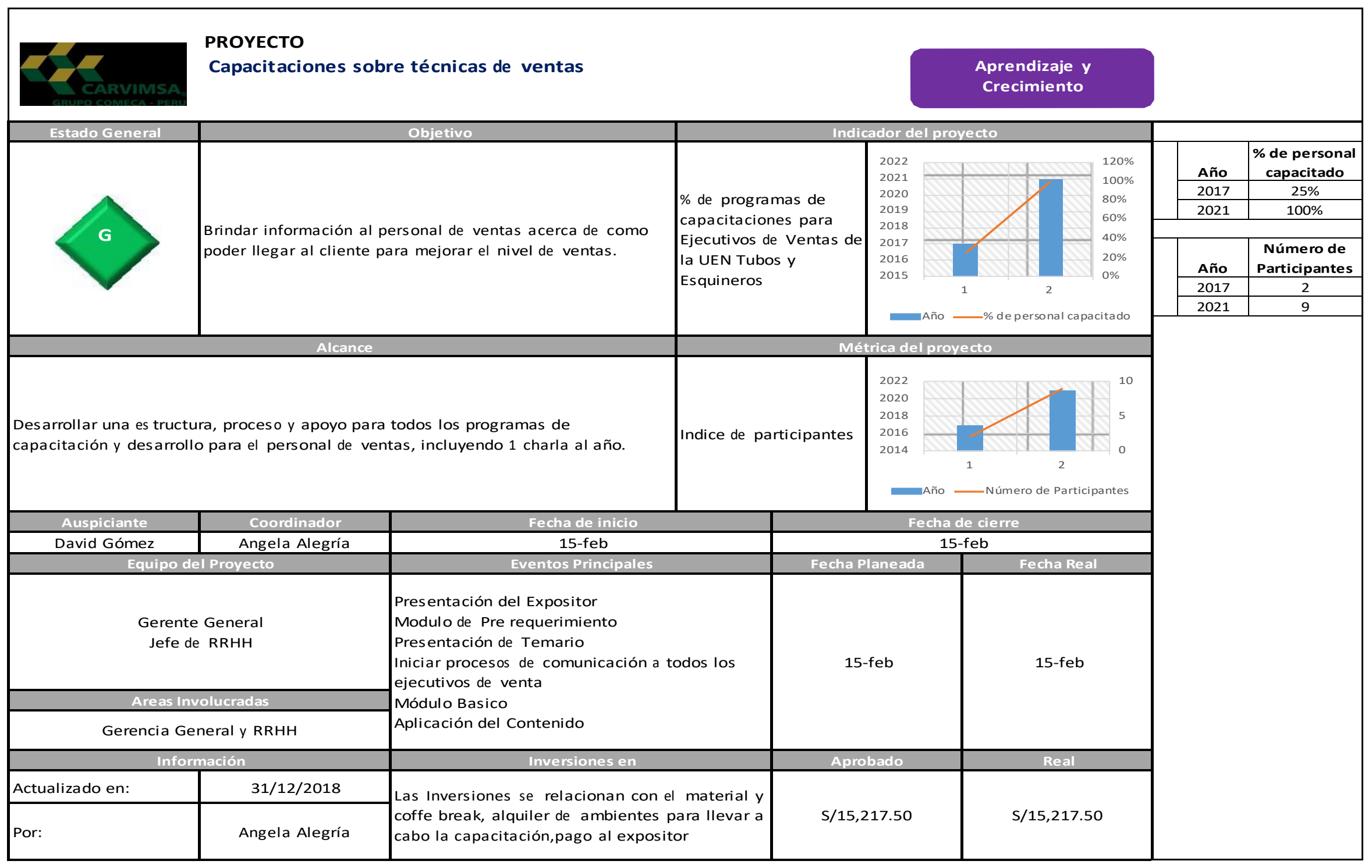

Figura 126. Ficha técnica del Proyecto "Capacitaciones sobre técnicas de ventas" 


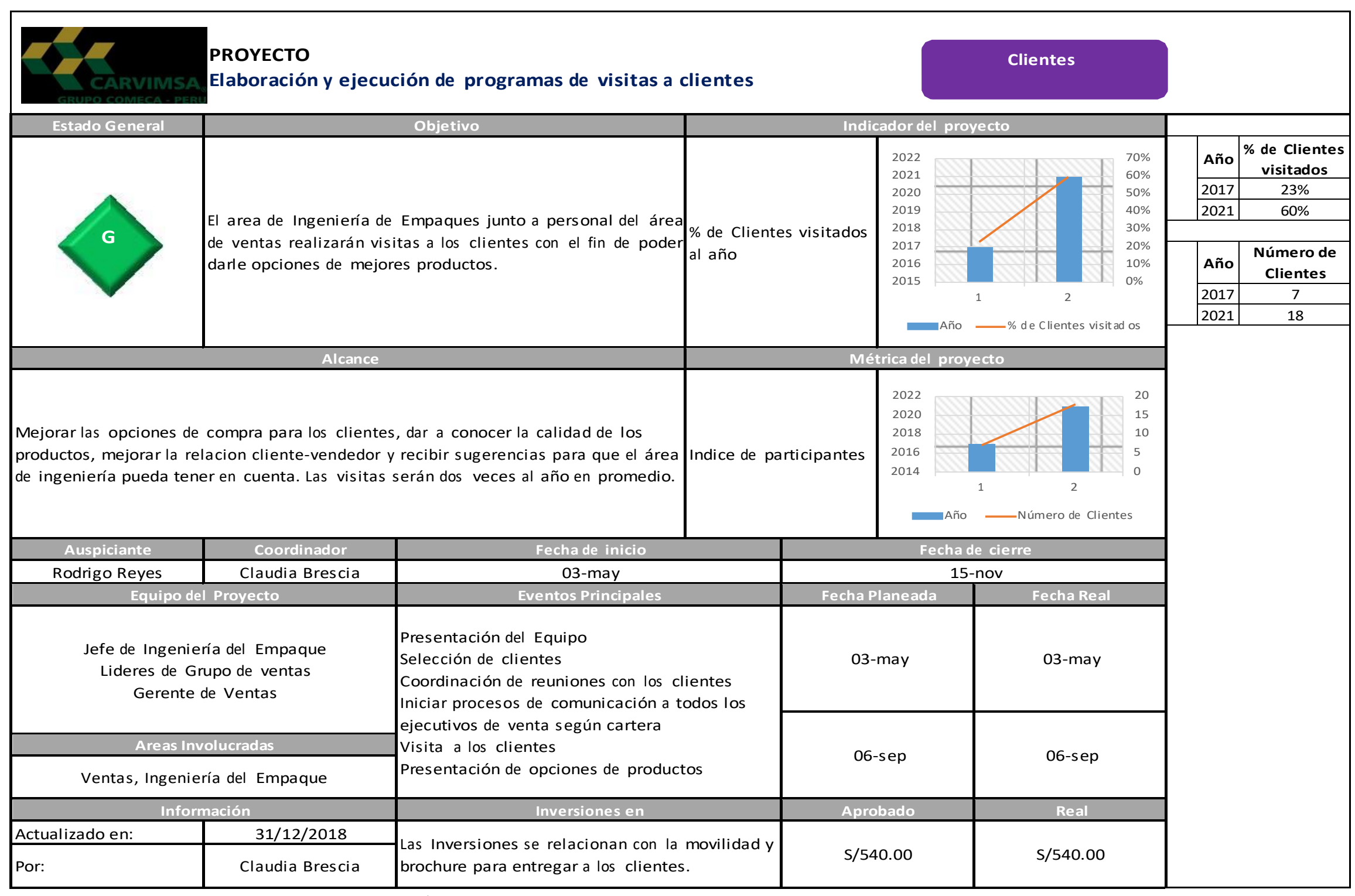

Figura 127. Ficha técnica del Proyecto "Elaboración y ejecución de programas de visitas a clientes" 


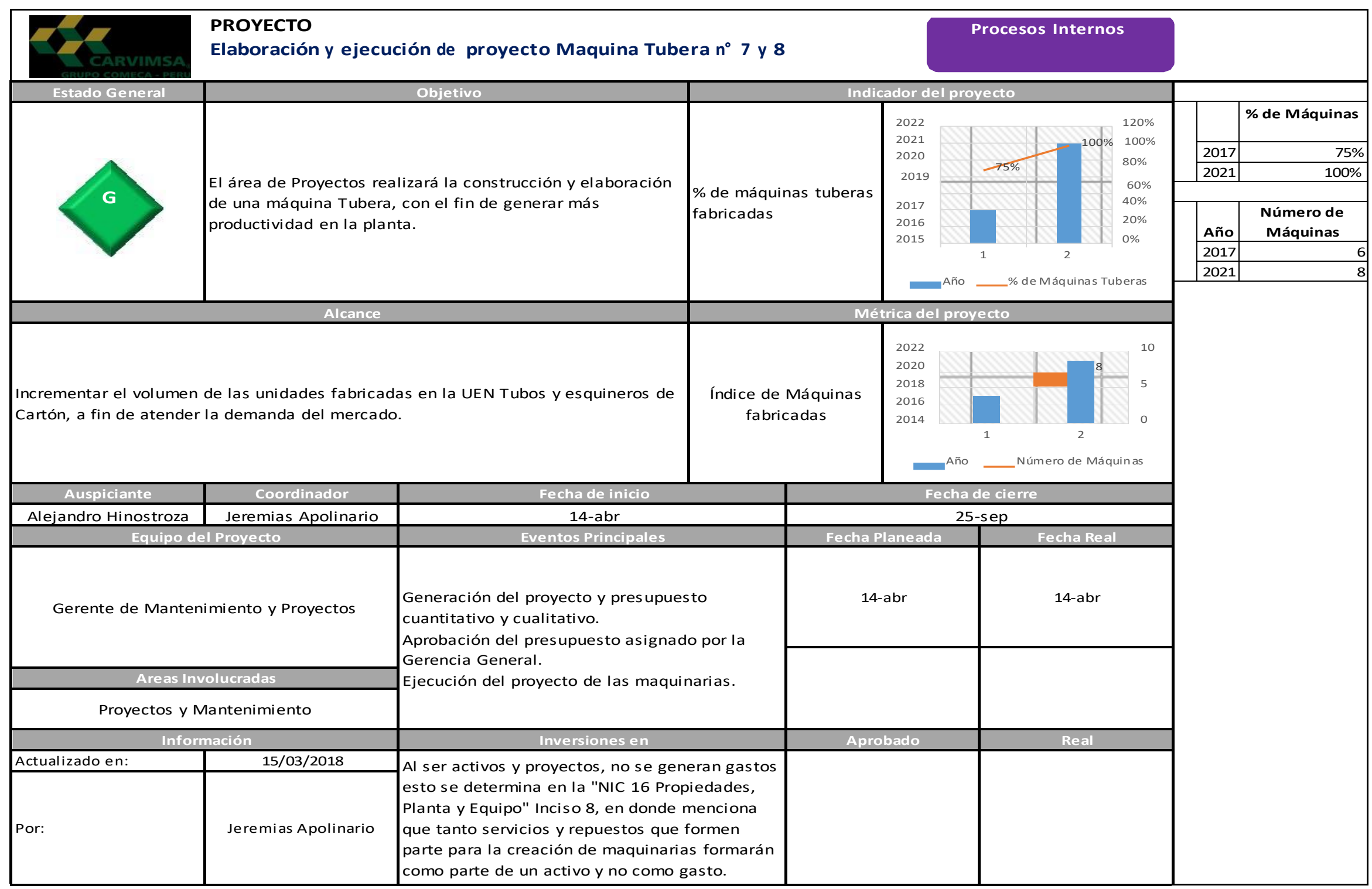

Figura 128. Ficha técnica del Proyecto "Elaboración y ejecución de proyecto Máquina Tubera N 7 y 8 " 


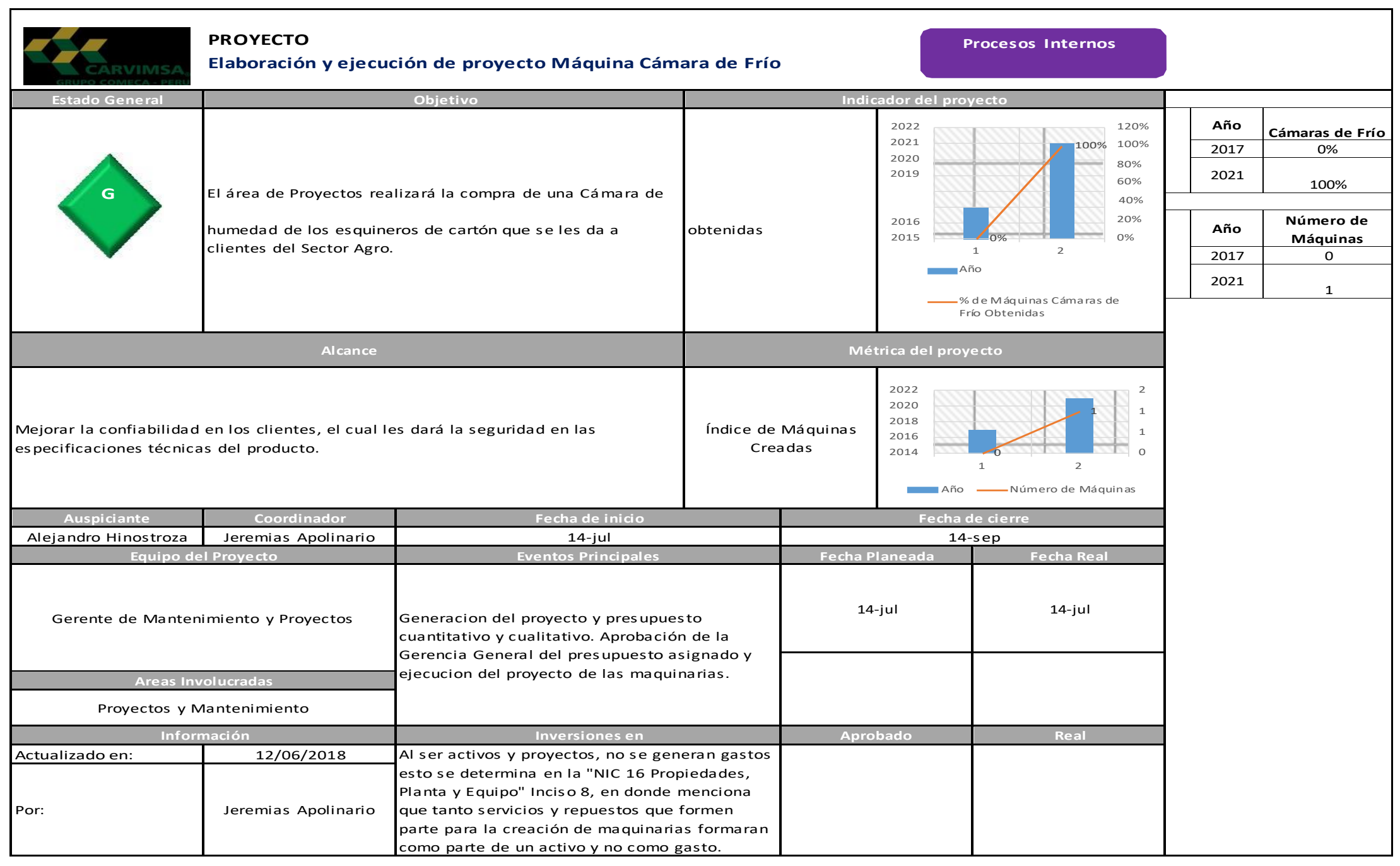

Figura 129. Ficha técnica del Proyecto "Elaboración y ejecución de proyecto Máquina Cámara de Frío." 


\subsection{Responsable de cada una de las iniciativas}

Los responsables para la UEN Tubos y Esquineros de cartón - CARVIMSA, estarán dadas por áreas, las cuales se encargarán del cumplimiento de los objetivos y el seguimiento de estos. La finalidad de tener responsables para las iniciativas de los objetivos es que estos se cumplan al $100 \%$ para el éxito de la unidad estratégica. 
Tabla 111

Responsables de cada una de las iniciativas propuestas para la UEN Tubos y Esquineros de cartón.

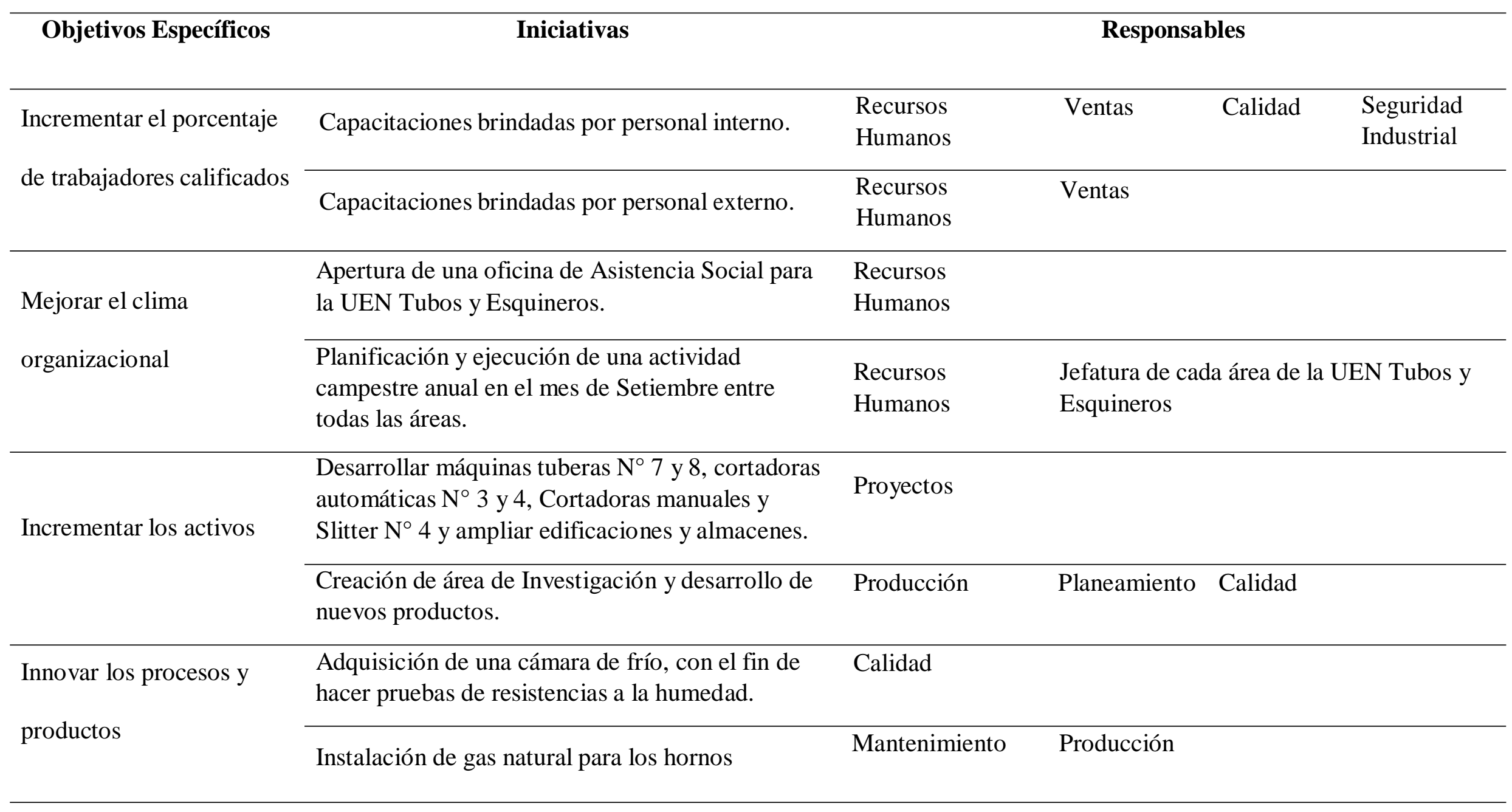




\begin{tabular}{|c|c|c|c|}
\hline Objetivos Específicos & Iniciativas & & Responsables \\
\hline \multirow{2}{*}{ Optimizar los procesos } & Desarrollo de un ERP Integrado. & G. General & Sistemas \\
\hline & Adquisición de una máquina de Compresión. & Ing. Empaques & Producción \\
\hline $\begin{array}{l}\text { Planificar las actividades } \\
\text { eficientemente }\end{array}$ & $\begin{array}{l}\text { Disminuir los mantenimientos correctivos de las } \\
\text { máquinas de tubos y esquineros }\end{array}$ & Mantenimiento & Producción \\
\hline \multirow{2}{*}{ Ser el proveedor líder } & $\begin{array}{l}\text { Contratación de una persona para el área de } \\
\text { despacho. }\end{array}$ & Ventas & Despacho \\
\hline & $\begin{array}{l}\text { Incorporar certificaciones de Calidad ISO } 9001 \\
\text { para la UEN Tubos y Esquineros. }\end{array}$ & Calidad & \\
\hline \multirow{2}{*}{ Fidelizar a los clientes } & Campañas publicitarias semestrales & Ventas & \\
\hline & $\begin{array}{l}\text { Elaboración y ejecución de programas de visitas a } \\
\text { clientes }\end{array}$ & $\begin{array}{l}\text { Ing. De } \\
\text { Empaques }\end{array}$ & \\
\hline $\begin{array}{l}\text { Incrementar la } \\
\text { satisfacción de clientes }\end{array}$ & Optimización del sistema de gestión de reclamos & $\begin{array}{l}\text { Servicio al } \\
\text { Cliente }\end{array}$ & \\
\hline $\begin{array}{l}\text { Reducir los costos } \\
\text { operativos }\end{array}$ & $\begin{array}{l}\text { Elaboración de planes de trabajo semanales para } \\
\text { justificación de horas extras }\end{array}$ & Administración & \\
\hline $\begin{array}{l}\text { Optimizar el uso de los } \\
\text { activos }\end{array}$ & $\begin{array}{l}\text { Monitorear nivel de Inventarios a partir de la } \\
\text { Planificación de las ventas }\end{array}$ & Ventas & Planeamiento Producción \\
\hline
\end{tabular}




\section{Objetivos Específicos}

Iniciativas

Responsables

Revisar las políticas de créditos para lograr una eficiente gestión de cobranzas

Créditos y

Cobranzas

Ventas

Incrementar los ingresos

Evaluar la rentabilidad por cliente
Costos 


\subsection{Presupuesto de cada una de las iniciativas}

Se muestra los presupuestos anuales para cada una de las iniciativas planteadas para la UEN Tubos y Esquineros de cartón. Los costos principales se concentran en la implementación en la fuerza de aprendizaje y crecimiento ya que conlleva a poder dar identificación al factor humano, este factor es primordial ya que aportara directamente en la productividad. 
Tabla 112

Presupuesto de implementación de la fuerza de aprendizaje y crecimiento

\begin{tabular}{|c|c|c|c|c|}
\hline Año & Iniciativas & Detalle & Presupuesto & Total \\
\hline \multirow{6}{*}{2018} & \multirow{3}{*}{ Capacitaciones brindadas por personal interno. } & $\begin{array}{l}\text { El área de Recursos humanos en conjunto el área } \\
\text { comercial coordinará capacitaciones internas con el } \\
\text { área de producción, sobre conocimiento del } \\
\text { producto, la competencia y el cliente. } \\
\text { Capacitaciones a operarios nuevos sobre el uso de } \\
\text { máquinas. }\end{array}$ & $4,234.70$ & \multirow{6}{*}{$47,257.72$} \\
\hline & & $\begin{array}{l}\text { El área de Recursos humanos en conjunto con el } \\
\text { área de Seguridad Industrial coordinará } \\
\text { capacitaciones internas, sobre conocimiento sobre } \\
\text { seoguridad v salıd en el trahain. }\end{array}$ & $1,200.00$ & \\
\hline & & $\begin{array}{l}\text { El área de Recursos humanos en conjunto con el } \\
\text { área de Gestión Ambiental coordinará } \\
\text { capacitaciones internas, sobre concientización del } \\
\text { Impacto Medioambiental y de la gestión de riesgos. }\end{array}$ & 980.00 & \\
\hline & Capacitaciones brindadas por personal externo. & $\begin{array}{l}\text { El área de Recursos humanos contratará un asesor, } \\
\text { para capacitaciones sobre técnicas de ventas. }\end{array}$ & $15,217.50$ & \\
\hline & $\begin{array}{l}\text { Apertura de una oficina de Asistencia Social } \\
\text { para la UEN Tubos y Esquineros }\end{array}$ & $\begin{array}{l}\text { Recursos Humanos planifica contar con una } \\
\text { Asistenta Social para la UEN Tubos y Esquineros }\end{array}$ & $16,440.00$ & \\
\hline & $\begin{array}{l}\text { Planificación y ejecución de una actividad } \\
\text { campestre anual en el mes de Setiembre entre } \\
\text { todas las áreas. }\end{array}$ & $\begin{array}{l}\text { Recursos Humanos fomentará una actividad anual, } \\
\text { en el mes de Setiembre, entre todas las áreas. }\end{array}$ & $9,185.52$ & \\
\hline
\end{tabular}




\begin{tabular}{|c|c|c|c|c|}
\hline Año & Iniciativas & Detalle & Presupuesto & Total \\
\hline \multirow[t]{2}{*}{2019} & Capacitaciones brindadas por personal interno. & $\begin{array}{l}\text { El área de Recursos humanos en conjunto el área } \\
\text { comercial coordinará capacitaciones internas con el } \\
\text { área de producción, sobre conocimiento del } \\
\text { producto, la competencia y el cliente. } \\
\text { Capacitaciones a operarios nuevos sobre el uso de } \\
\text { máquinas. }\end{array}$ & $2,117.35$ & \multirow[t]{2}{*}{$11,302.87$} \\
\hline & $\begin{array}{l}\text { Planificación y ejecución de una actividad } \\
\text { campestre anual en el mes de Setiembre entre } \\
\text { todas las áreas. }\end{array}$ & $\begin{array}{l}\text { Recursos Humanos fomentará una actividad anual, } \\
\text { en el mes de Setiembre, entre todas las áreas. }\end{array}$ & $9,185.52$ & \\
\hline \multirow[t]{2}{*}{2020} & Capacitaciones brindadas por personal interno. & $\begin{array}{l}\text { El área de Recursos humanos en conjunto el área } \\
\text { comercial coordinará capacitaciones internas con el } \\
\text { área de producción, sobre conocimiento del } \\
\text { producto, la competencia y el cliente. } \\
\text { Capacitaciones a operarios nuevos sobre el uso de } \\
\text { máquinas. }\end{array}$ & $2,117.35$ & \multirow[t]{2}{*}{$11,302.87$} \\
\hline & $\begin{array}{l}\text { Realización de actividades no relacionadas al } \\
\text { trabajo }\end{array}$ & $\begin{array}{l}\text { Recursos Humanos fomentará una actividad anual, } \\
\text { en el mes de Setiembre, entre todas las áreas. }\end{array}$ & $9,185.52$ & \\
\hline \multirow[t]{2}{*}{2021} & Capacitaciones brindadas por personal interno. & $\begin{array}{l}\text { El área de Recursos humanos en conjunto el área } \\
\text { comercial coordinará capacitaciones internas con el } \\
\text { área de producción, sobre conocimiento del } \\
\text { producto, la competencia y el cliente. } \\
\text { Capacitaciones a operarios nuevos sobre el uso de } \\
\text { máquinas. }\end{array}$ & $2,117.35$ & \multirow[t]{2}{*}{$11,302.87$} \\
\hline & $\begin{array}{l}\text { Realización de actividades no relacionadas al } \\
\text { trabajo }\end{array}$ & $\begin{array}{l}\text { Recursos Humanos fomentara una actividad anual, } \\
\text { en el mes de Setiembre, entre todas las áreas. }\end{array}$ & $9,185.52$ & \\
\hline
\end{tabular}


Tabla 113

Presupuesto de implementación de la fuerza de procesos internos

\begin{tabular}{|c|c|c|c|c|}
\hline Año & Iniciativas & Detalle & Presupuesto & Total \\
\hline \multirow{8}{*}{2018} & $\begin{array}{l}\text { Desarrollar máquinas tuberas } \mathrm{N}^{\circ} 7 \text { y } \\
8 \text {, cortadoras automáticas } \mathrm{N}^{\circ} 3 \text { y } 4, \\
\text { Cortadoras manuales y Slitter } \mathrm{N}^{\circ} 4 ; \mathrm{y} \\
\text { ampliar edificaciones y almacenes }\end{array}$ & $\begin{array}{l}\text { Para lograr el objetivo de la capacidad instalada de la planta, se } \\
\text { desarrollará maquinarias como tuberas, cortadoras y slitters, así } \\
\text { como la ampliación de la nave de planta y almacenes. }\end{array}$ & 0 & \multirow{8}{*}{$41,430.00$} \\
\hline & $\begin{array}{l}\text { Creación de área de Investigación y } \\
\text { Desarrollo de nuevos productos. }\end{array}$ & $\begin{array}{l}\text { El área de Planeamiento en conjunto con Producción y Calidad, } \\
\text { buscarán alternativas de Materias Prima, previo análisis del caso. }\end{array}$ & 270.00 & \\
\hline & Adquisición de una cámara de frío, & El área de Calidad planifica la compra de una cámara de frio de & & \\
\hline & $\begin{array}{l}\text { con el fin de hacer pruebas de } \\
\text { resistencias a la humedad }\end{array}$ & prueba, el cual le permitirá verificar la resistencia del producto. & $6,700.00$ & \\
\hline & $\begin{array}{l}\text { Instalación de gas natural para los } \\
\text { hornos }\end{array}$ & $\begin{array}{l}\text { El área de Mantenimiento ejecutará la instalación del Gas Natural } \\
\text { en las Salas de Horno. }\end{array}$ & $17,200.00$ & \\
\hline & $\begin{array}{l}\text { Adquisición de una máquina de } \\
\text { Compresión. }\end{array}$ & $\begin{array}{l}\text { El área de Ing. de Empaques adquirirá una máquina de Compresión } \\
\text { para poder medir la resistencia de la máquina y minimizar los } \\
\text { anchos de refile de los tubos y esquineros. }\end{array}$ & $4,450.00$ & \\
\hline & $\begin{array}{l}\text { Disminuir los mantenimientos } \\
\text { correctivos de las máquinas de tubos } \\
\text { y esquineros }\end{array}$ & $\begin{array}{l}\text { El área de mantenimiento deberá minimizar las horas de paro de } \\
\text { máquinas. }\end{array}$ & 0 & \\
\hline & $\begin{array}{l}\text { Desarrollar maquinas tuberas } \mathrm{N}^{\circ} 7 \mathrm{y} \\
8 \text {, cortadoras automáticas } \mathrm{N}^{\circ} 3 \text { y } 4 \\
\text { Cortadoras manuales y Slitter } \mathrm{n}^{\circ} 4 \mathrm{y}\end{array}$ & $\begin{array}{l}\text { Para lograr el objetivo de la capacidad instalada de la planta, se } \\
\text { desarrollará maquinarias como tuberas, cortadoras y slitters, así } \\
\text { como la ampliación de la nave de planta y almacenes. }\end{array}$ & 0 & \\
\hline
\end{tabular}




\begin{tabular}{lllll}
\hline Año & Iniciativas & Detalle & Presupuesto & Total \\
\hline 2019 & $\begin{array}{l}\text { Creación de área de Investigación y } \\
\text { Desarrollo de nuevos productos. }\end{array}$ & $\begin{array}{l}\text { El área de Planeamiento en conjunto con Producción y Calidad, } \\
\text { buscarán alternativas de Materias Prima, previo análisis del caso. }\end{array}$ & 270.00 & 270.00 \\
\hline 2020 & $\begin{array}{l}\text { Creación de área de Investigación y } \\
\text { Desarrollo de nuevos productos. }\end{array}$ & $\begin{array}{l}\text { El área de Planeamiento en conjunto con Producción y Calidad, } \\
\text { buscarán alternativas de Materias Prima, previo análisis del caso. }\end{array}$ & 270.00 & 270.00 \\
\hline 2021 & $\begin{array}{l}\text { Creación de área de Investigación y } \\
\text { Desarrollo de nuevos productos. }\end{array}$ & $\begin{array}{l}\text { El área de Planeamiento en conjunto con Producción y Calidad, } \\
\text { buscarán alternativas de Materias Prima, previo análisis del caso. }\end{array}$ & 270.00 & 270.00 \\
\hline
\end{tabular}


Tabla 114

Presupuesto de implementación en la fuerza de clientes

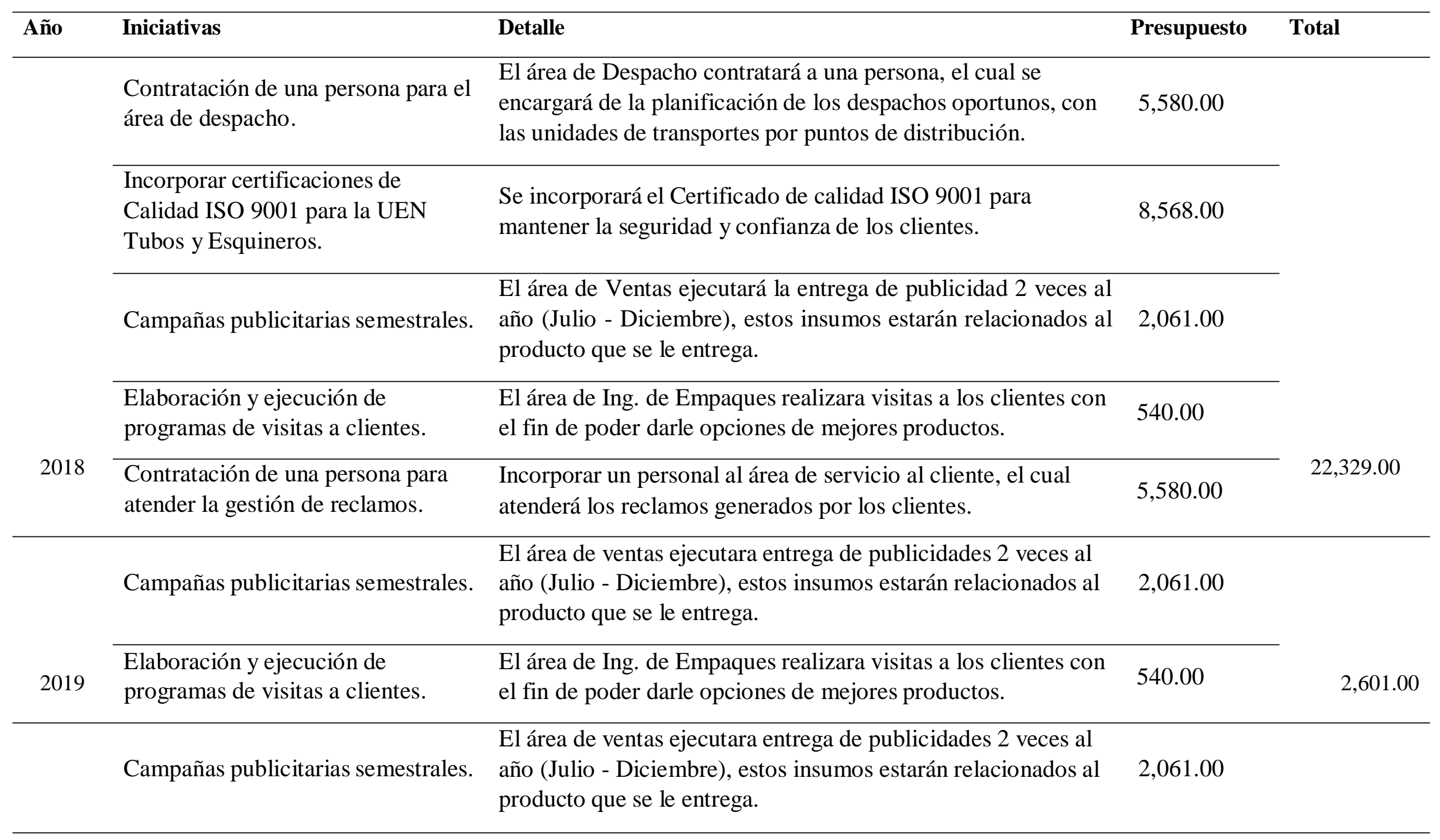




\begin{tabular}{|c|c|c|c|c|}
\hline Año & Iniciativas & Detalle & Presupuesto & Total \\
\hline 2020 & $\begin{array}{l}\text { Elaboración y ejecución de } \\
\text { programas de visitas a clientes. }\end{array}$ & $\begin{array}{l}\text { El área de Ing. de Empaques realizara visitas a los clientes con } \\
\text { el fin de poder darle opciones de mejores productos. }\end{array}$ & 540.00 & $2,601.00$ \\
\hline & Campañas publicitarias semestrales. & $\begin{array}{l}\text { El área de ventas ejecutara entrega de publicidades } 2 \text { veces al } \\
\text { año (Julio - Diciembre), estos insumos estarán relacionados al } \\
\text { producto que se le entrega. }\end{array}$ & $2,061.00$ & \\
\hline 2021 & $\begin{array}{l}\text { Elaboración y ejecución de } \\
\text { programas de visitas a clientes. }\end{array}$ & $\begin{array}{l}\text { El área de Ing. de Empaques realizara visitas a los clientes con } \\
\text { el fin de poder darle opciones de mejores productos. }\end{array}$ & 540.00 & $2,601.00$ \\
\hline
\end{tabular}

Tabla 115

Presupuesto de implementación en la fuerza financiera

\begin{tabular}{|c|c|c|c|c|}
\hline Año & Iniciativas & Detalle & Presupuesto & Total \\
\hline \multirow{4}{*}{2018} & $\begin{array}{l}\text { Elaboración de planes de trabajo } \\
\text { semanales para justificación de horas } \\
\text { extras. }\end{array}$ & $\begin{array}{l}\text { El jefe administrativo, medirá las funciones de sus trabajadores y } \\
\text { los capacitará a fin de que realicen sus funciones de forma eficiente; } \\
\text { para lo cual tendrán una reunión semanal, el cual permita mostrar sus } \\
\text { avances de la semana. }\end{array}$ & 160.00 & \multirow{4}{*}{160.00} \\
\hline & $\begin{array}{l}\text { Monitorear nivel de inventarios a } \\
\text { partir de la planificación de las ventas. }\end{array}$ & $\begin{array}{l}\text { El área de Almacén en conjunto con producción deberá planificar la } \\
\text { rotación de los inventarios. }\end{array}$ & 0.00 & \\
\hline & $\begin{array}{l}\text { Revisar las políticas de créditos para } \\
\text { lograr una eficiente gestión de } \\
\text { cobranzas. }\end{array}$ & $\begin{array}{l}\text { El área de Créditos y Cobranzas deberá mejorar sus procedimientos } \\
\text { de análisis crediticio a los clientes. }\end{array}$ & 0.00 & \\
\hline & Evaluar la rentabilidad por cliente. & $\begin{array}{l}\text { El área de Costos deberá ejecutar el costeo de productos por clientes } \\
\text { y además mostrar el valor neto de realización (VNR). }\end{array}$ & 0.00 & \\
\hline
\end{tabular}




\begin{tabular}{|c|c|c|c|c|}
\hline Año & Iniciativas & Detalle & Presupuesto & Total \\
\hline \multirow{3}{*}{2019} & $\begin{array}{l}\text { Elaboración de planes de trabajo } \\
\text { semanales para justificación de horas } \\
\text { extras. }\end{array}$ & $\begin{array}{l}\text { El jefe administrativo, medirá las funciones de sus trabajadores y } \\
\text { los capacitará a fin de que realicen sus funciones de forma eficiente; } \\
\text { para lo cual tendrán una reunión semanal, el cual permita mostrar } \\
\text { sus avances de la semana. }\end{array}$ & 160.00 & \multirow{3}{*}{160.00} \\
\hline & $\begin{array}{l}\text { Monitorear nivel de inventarios a } \\
\text { partir de la planificación de las ventas. }\end{array}$ & $\begin{array}{l}\text { El área de Almacén en conjunto con producción deberá planificar la } \\
\text { rotación de los inventarios. }\end{array}$ & 0.00 & \\
\hline & Evaluar la rentabilidad por cliente. & $\begin{array}{l}\text { El área de Costos deberá ejecutar el costeo de productos por clientes } \\
\text { y además mostrar el valor neto de realización (VNR). }\end{array}$ & 0.00 & \\
\hline \multirow{3}{*}{2020} & $\begin{array}{l}\text { Elaboración de planes de trabajo } \\
\text { semanales para justificación de horas } \\
\text { extras. }\end{array}$ & $\begin{array}{l}\text { El jefe administrativo, medirá las funciones de sus trabajadores y } \\
\text { los capacitará a fin de que realicen sus funciones de forma eficiente; } \\
\text { para lo cual tendrán una reunión semanal, el cual permita mostrar } \\
\text { sus avances de la semana. }\end{array}$ & 160.00 & \multirow{3}{*}{160.00} \\
\hline & $\begin{array}{l}\text { Monitorear nivel de inventarios a } \\
\text { partir de la planificación de las ventas. }\end{array}$ & $\begin{array}{l}\text { El área de Almacén en conjunto con producción deberá planificar la } \\
\text { rotación de los inventarios. }\end{array}$ & 0.00 & \\
\hline & Evaluar la rentabilidad por cliente. & $\begin{array}{l}\text { El área de Costos deberá ejecutar el costeo de productos por clientes } \\
\text { y además mostrar el valor neto de realización (VNR). }\end{array}$ & 0.00 & \\
\hline \multirow[t]{2}{*}{2021} & $\begin{array}{l}\text { Elaboración de planes de trabajo } \\
\text { semanales para justificación de horas } \\
\text { extras. }\end{array}$ & $\begin{array}{l}\text { El jefe administrativo, medirá las funciones de sus trabajadores y } \\
\text { los capacitará a fin de que realicen sus funciones de forma eficiente; } \\
\text { para lo cual tendrán una reunión semanal, el cual permita mostrar sus } \\
\text { avances de la semana. }\end{array}$ & 160.00 & \multirow[t]{2}{*}{160.00} \\
\hline & $\begin{array}{l}\text { Monitorear nivel de inventarios a } \\
\text { partir de la planificación de las ventas. }\end{array}$ & $\begin{array}{l}\text { El área de Almacén en conjunto con producción deberá planificar la } \\
\text { rotación de los inventarios. }\end{array}$ & 0.00 & \\
\hline
\end{tabular}


Año Iniciativas

Detalle

Presupuesto

Total

Evaluar la rentabilidad por cliente.

El área de Costos deberá ejecutar el costeo de productos por clientes y además mostrar el valor neto de realización (VNR).

0.00 


\subsection{Cronograma de cada una de las iniciativas}

En la siguiente figura se muestra las fechas tentativas, los cuales se ejecutarán las iniciativas que se proponen para los siguientes cuatro años para la UEN Tubos y Esquineros de cartón. 


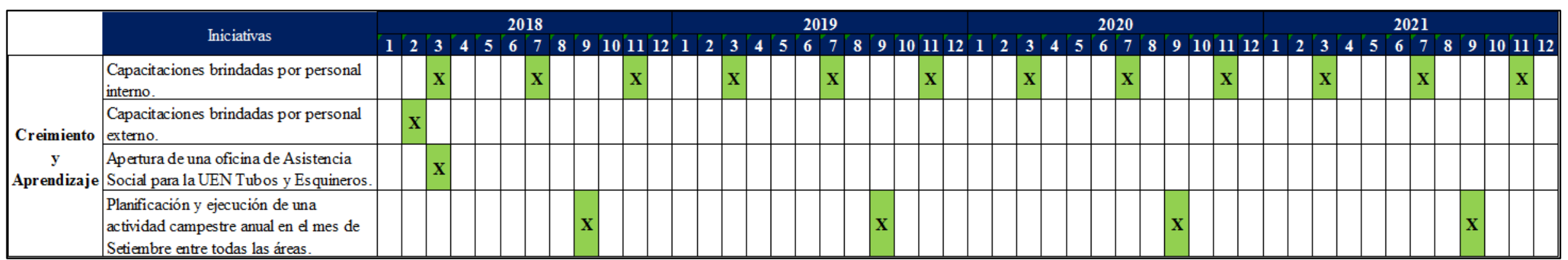

Figura 130. Cronograma de iniciativas de la fuerza de Crecimiento y Aprendizaje de la UEN Tubos y Esquineros - CARVIMSA.

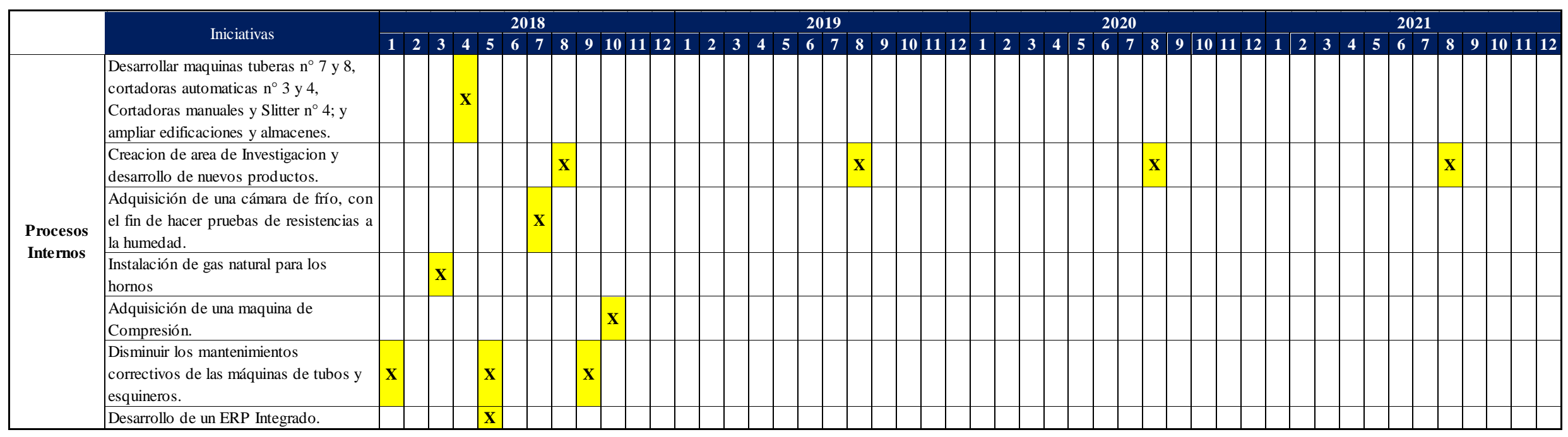

Figura 131. Cronograma de iniciativas de la fuerza de Procesos Internos de la UEN Tubos y Esquineros - CARVIMSA. 


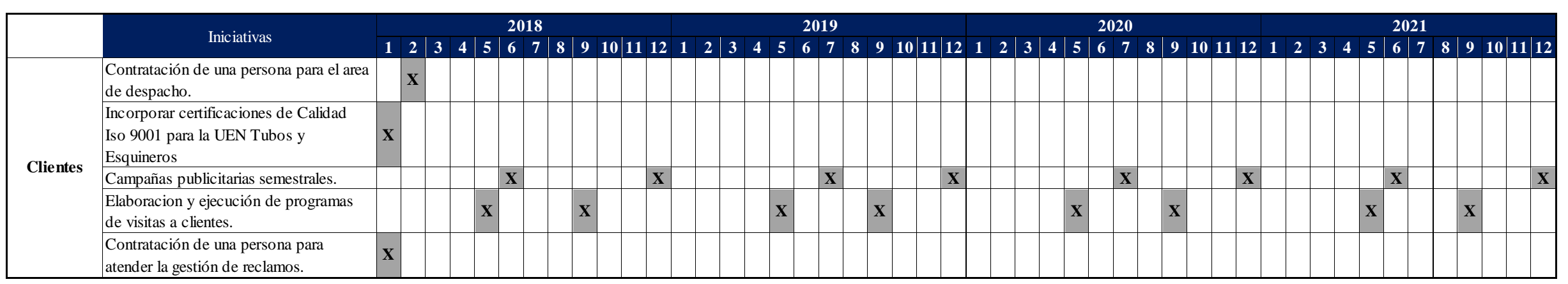

Figura 132. Cronograma de iniciativas de la fuerza de Clientes de la UEN Tubos y Esquineros - CARVIMSA.

\begin{tabular}{|c|c|c|c|c|c|c|c|c|c|c|c|c|c|c|c|c|c|c|c|c|c|c|c|c|c|c|c|c|c|c|c|c|c|c|c|c|c|c|c|c|c|c|c|c|c|c|c|}
\hline & \multirow{2}{*}{ Iniciativas } & \multirow{2}{*}{\multicolumn{12}{|c|}{ 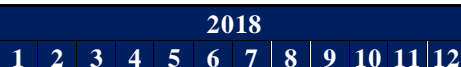 }} & \multicolumn{11}{|c|}{2019} & \multicolumn{11}{|c|}{2020} & \multicolumn{12}{|c|}{2021} \\
\hline & & & & & & & & & & & & & 12 & $1 \mid$ & 2. & $\begin{array}{ll}3 & 4 \\
\end{array}$ & $4 \mid 5$ & 6 & 7 & 8 & 9 & 10 & 111 & 12 & 1 & 2 & 3 & 4 & 5 & 67 & 78 & 9 & & 11 & 12 & 1 & 2 & 3 & 4 & 5 & 6 & & 8 & 91 & & & 12 \\
\hline \multirow{4}{*}{ Financiero } & $\begin{array}{l}\text { Reducción de horas extras en el } \\
\text { personal administrativo }\end{array}$ & $\mathbf{X}$ & $\mathbf{X}$ & $\mathbf{X}$ & $\mathbf{x}$ & $\mathbf{X}$ & $\mathbf{x}$ & $\mathbf{X}$ & $\mathbf{x}$ & $\mathbf{X}$ & $\mathbf{x}$ & $\mathbf{x}$ & $\mathbf{X}$ & $\mathbf{x}$ & $\mathbf{x}$ & \begin{tabular}{l|l}
$\mathbf{x}$ & $\mathbf{x}$
\end{tabular} & $\mathbf{X} \mathbf{X}$ & $\mathbf{x}$ & $\mathbf{x}$ & $\mathbf{X}$ & $\mathbf{x}$ & $\mathbf{x}$ & $\mathbf{x}$ & $\mathbf{x}$ & $\mathbf{X}$ & $\mathbf{x}$ & $\mathbf{x}$ & $\mathbf{X}$ & $\mathbf{X}$ & $\mathbf{x} \mid \mathbf{x}$ & $\mathbf{X} X$ & $\mathbf{X}$ & $\mathbf{x}$ & $\mathbf{x}$ & $\mathbf{x}$ & $\mathbf{x}$ & $\mathbf{x}$ & $\mathbf{x}$ & $\mathbf{x}$ & $\mathbf{x}$ & $\mathbf{X}$ & $\mathbf{x}$ & $\mathbf{x}$ & $\mathbf{x}$ & $\mathbf{x}$ & $\mathbf{x}$ & $\mathbf{x}$ \\
\hline & $\begin{array}{l}\text { Monitorear nivel de Inventarios a partir } \\
\text { de la Planificación de las ventas }\end{array}$ & & & & $\mathbf{x}$ & & & & $\mathbf{x}$ & & & & $\mathbf{X}$ & & & & $\mathbf{X}$ & & & $\mathbf{x}$ & & & & $\mathbf{X}$ & & & & $\mathbf{X}$ & & & $\mathrm{x}$ & & & & $\mathbf{x}$ & & & & $\mathbf{X}$ & & & & $\mathbf{x}$ & & & & $\mathbf{x}$ \\
\hline & $\begin{array}{l}\text { Revisar las políticas de créditos para } \\
\text { lograr una eficiente gestión de cobranzas }\end{array}$ & $\mathbf{X}$ & & & & & & & & & & & & & & & & & & & & & & & & & & & & & & & & & & & & & & & & & & & & & \\
\hline & Evaluar la rentabilidad por cliente & & & & & & $\mathbf{x}$ & & & & & & $\mathbf{x}$ & & & & & $\mathbf{X}$ & & & & & & $\mathbf{x}$ & & & & & & $\mathbf{X}$ & & & & & $\mathbf{x}$ & & & & & & $\mathbf{X}$ & & & & & & $\mathbf{x}$ \\
\hline
\end{tabular}

Figura 133. Cronograma de iniciativas de la fuerza Financiera de la UEN Tubos y Esquineros - CARVIMSA 


\section{Capítulo X. Evaluación}

\subsection{Evaluación Cualitativa}

David (2013) sostiene que la evaluación de la estrategia es necesaria independientemente del tipo y tamaño de empresa, la cual se enfoca en tres actividades esenciales: i) el examen de las bases subyacentes de la estrategia de una empresa; ii) la comparación de los resultados esperados con los resultados reales; y iii) la toma de medidas correctivas para avalar que el rendimiento tenga concordancia con los planes.

\subsubsection{Criterios de Evaluación}

David (2013) propuso cuatro criterios para evaluar una estrategia, basados en la evaluación externa e interna de la empresa: i) la congruencia, ii) la concordancia, iii) la viabilidad y iv) la ventaja.

- Congruencia: Una estrategia no debe presentar metas ni políticas incongruentes, para ellos es necesario tener en cuenta indicadores que permitan monitorear si las estrategias son adecuadas.

- Concordancia: Los estrategas deben examinar una serie de tendencias del ambiente externo, de modo que la estrategia debe adaptarse a este ambiente, así como los cambios importantes que puedan surgir en él.

- Viabilidad: Se refiere a determinar si la estrategia se puede aplicar con los recursos físicos, humanos y financieros de la empresa.

- Ventaja: La estrategia debe garantizar la creación y el mantenimiento de la ventaja competitiva de la empresa. 


\subsubsection{Comparación de la estrategia con los criterios}

\section{- Congruencia}

La estrategia seleccionada es la de penetración de mercado, ya que nada garantiza que la estrategia que se ha determinado sea óptima, es importante evaluar posibles deficiencias. Dentro del criterio de congruencia, se encuentran temas del clima organizacional y discusiones entre departamentos, en el caso de la UEN Tubos y Esquineros muchos de los actuales colaboradores iniciaron en otras unidades y adquirieron experiencia que les permitió formar parte de la UEN de Tubos y Esquineros y capacitar a los nuevos que se integraron. La estrategia busca la captación de nuevos clientes y el aumento de volúmenes de venta a clientes actuales entre otras acciones, por lo que en vez de generar diferencias entre los departamentos y unidades se apoyará para trabajar en conjunto.

El aspecto que podría generar un posible conflicto, si no se controla oportunamente, es el crecimiento no planificado de las ventas que puede traer consigo una desorganización en la producción y los despachos. Como alternativa para evitar estas señales de incongruencia se recomienda realizar un plan de ventas asociado a un planeamiento de la producción y un cronograma de prioridades para los despachos. Si nos enfocamos en el tema de la presión por aumentar el nivel de ventas y si no se cuenta con una política consistente de créditos, se podría generar un conflicto con el área de créditos y cobranzas ya que al presentarse un mayor número de evaluaciones para nuevos clientes y si éstos no aprueban el crédito podría ser un motivo para el fracaso en el cumplimiento de las proyecciones del área comercial. Otra posible incongruencia de la estrategia podría ser que no se llegue a cumplir con las proyecciones de penetración de mercado y que a pesar de que se cambie al personal de ventas esta estrategia continúe sin 
dar resultado y subsistan los problemas, se tendría que evaluar la congruencia de la estrategia.

- Viabilidad

Al implementarse la estrategia de penetración de mercado dentro de la UEN de Tubos y Esquineros se requiere de recursos físicos, humanos y financieros. Dentro de estos recursos se encuentran la implementación del área de mercadotecnia e investigación de mercados, la contratación del gerente de producción y la inversión en máquinas de esquineros y armado de máquinas tuberas. Cabe resaltar, que CARVIMSA cuenta con los recursos financieros propios y no es necesario incurrir en financiamiento externo, por lo que la estrategia es hasta el momento viable. También es importante mencionar que CARVIMSA ha demostrado en el pasado que posee las capacidades, habilidades y competencias para desarrollar sus actividades con éxito.

\section{- Consonancia}

La estrategia de penetración de mercado está condicionada a un conjunto de tendencias del ambiente externo, como el crecimiento de los sectores de manufactura, construcción, agroindustrial y a una serie de aspectos económicos como el tipo de cambio, la inflación y las exportaciones. Si bien es cierto, las tendencias económicas parecen estables y proyectan buenos resultados de las variables influyentes en la estrategia, podría ocurrir un evento exógeno como el huaico ocurrido en el verano del 2017 que afectaría a los agricultores, teniendo impacto directo en las exportaciones de los productos agroindustriales que es donde se usan los esquineros. 
- Ventaja

La ventaja que trae consigo la implementación de la estrategia es la posición superior de la UEN Tubos y Esquineros de CARVIMSA y su consolidación en el mercado en cuanto a participación, cartera de clientes y posicionamiento. Esta posición será sustentable siempre y cuando los factores internos y externos permanezcan estables. Una posible complicación con la estrategia sería la complejidad del entorno lo que no ayudaría a pronosticar con precisión cifras con relación a las ventas. Un reto para los gerentes de CARVIMSA es inculcar en sus colaboradores la flexibilidad y la innovación para adaptarse a los cambios.

Tabla 116

Comparación de la estrategia con los criterios

Criterio Posibles deficiencias Alternativas de solución

\begin{tabular}{lll}
\hline Congruencia & $\begin{array}{l}\text { El crecimiento no planificado de las } \\
\text { ventas podría traer consigo una } \\
\text { desorganización en la producción y los } \\
\text { despachos }\end{array}$ & $\begin{array}{l}\text { Realizar un plan de ventas } \\
\text { asociado a un planeamiento de la } \\
\text { producción y un cronograma de } \\
\text { prioridades para los despachos }\end{array}$ \\
\cline { 2 - 3 } & $\begin{array}{l}\text { Conflicto con el área de créditos y } \\
\text { nuevos clientes }\end{array}$ & Política consistente de créditos \\
& $\begin{array}{l}\text { Incumplimiento de las proyecciones de } \\
\text { ventas y que a pesar de que se cambie al } \\
\text { personal esta estrategia continúe sin dar } \\
\text { resultado }\end{array}$ & $\begin{array}{l}\text { Selección adecuada de los } \\
\text { ejecutivos comerciales y } \\
\text { evaluación de la congruencia de la } \\
\text { estrategia }\end{array}$ \\
\hline & $\begin{array}{l}\text { Insuficiencia de recursos financieros para } \\
\text { concretar la implementación del área de } \\
\text { mercadotecnia e investigación de } \\
\text { mercados, la contratación del gerente de } \\
\text { producción y la inversión en máquinas de } \\
\text { esquineros y armado de máquinas } \\
\text { tuberas. }\end{array}$ & $\begin{array}{l}\text { Financiamiento de los accionistas } \\
\text { y financiamiento externo }\end{array}$ \\
\hline $\begin{array}{l}\text { Ocurrencia de un evento exógeno como } \\
\text { el huaico en el verano del 2017 que } \\
\text { afectaría a los agricultores, teniendo } \\
\text { impacto directo en las exportaciones de }\end{array}$ & $\begin{array}{l}\text { Potenciar las ventas de Tubos para } \\
\text { amortiguar las bajas en las ventas }\end{array}$ \\
\hline
\end{tabular}




\begin{tabular}{|c|c|c|}
\hline Criterio & Posibles deficiencias & Alternativas de solución \\
\hline & $\begin{array}{l}\text { los productos agroindustriales que es } \\
\text { donde se usan los esquineros. }\end{array}$ & $\begin{array}{l}\text { de esquineros ya que los eventos } \\
\text { naturales no se pueden controlar }\end{array}$ \\
\hline Ventaja & $\begin{array}{l}\text { Complejidad del entorno que dificultaría } \\
\text { pronosticar con precisión las ventas para } \\
\text { mantener la ventaja de posición } \\
\text { consolidada. }\end{array}$ & $\begin{array}{l}\text { Inculcar en los colaboradores de } \\
\text { CARVIMSA la flexibilidad y la } \\
\text { innovación para adaptarse a los } \\
\text { cambios }\end{array}$ \\
\hline
\end{tabular}

\subsection{Evaluación Financiera de la Estrategia}

\subsubsection{Proyección de estados financieros (situación actual y con la nueva estrategia)}

Gitman y Zutter (2016) sostienen que los cuatro estados financieros clave son: i) Estado de pérdidas y ganancias, ii) Balance general, iii) Estado de patrimonio de los accionistas y iv) Estado de flujos de efectivo.

Para realizar las proyecciones, se tuvo que ejecutar una estructura de costos y gastos. A continuación, se presenta una Matriz consolidada, Matriz de Tubos y una Matriz de Esquineros.

La matriz de resultados de la UEN Tubos y Esquineros se elaboró bajo las premisas de las proyecciones de ventas, las cuales fueron brindadas por el área comercial. 


\begin{tabular}{|c|c|c|c|c|c|c|c|c|c|c|}
\hline \multirow[b]{3}{*}{ Line a } & \multirow[b]{3}{*}{ Clientes } & \multicolumn{9}{|c|}{ Pre s upue stos } \\
\hline & & \multicolumn{9}{|c|}{ (Acumulado en Tm) } \\
\hline & & 2,017 & 2,018 & Var \% & 2,019 & Var \% & 2,020 & Var \% & 2,021 & Var \% \\
\hline Tubos & Solpack S.A. & 1,659 & 2,400 & $45 \%$ & 3,430 & $43 \%$ & 4,459 & $30 \%$ & 4,949 & $11 \%$ \\
\hline Tubos & Surpack & 840 & 600 & $-29 \%$ & 630 & $5 \%$ & 630 & $0 \%$ & 680 & $8 \%$ \\
\hline Tubos & Filmpack S.A.C. & 360 & 360 & $0 \%$ & 400 & $11 \%$ & 460 & $15 \%$ & 511 & $11 \%$ \\
\hline Tubos & Peruplast S.A. & 360 & 510 & $42 \%$ & 638 & $25 \%$ & 733 & $15 \%$ & 814 & $11 \%$ \\
\hline Tubos & TDM Ge osinteticos & 216 & 240 & $11 \%$ & 288 & $20 \%$ & 331 & $15 \%$ & 358 & $8 \%$ \\
\hline Tubos & Envolturas Flexibles Huachipa S.A.C. & 180 & 300 & $67 \%$ & 360 & $20 \%$ & 414 & $15 \%$ & 447 & $8 \%$ \\
\hline Tubos & Union Plast S.A. & 168 & 144 & $-14 \%$ & 180 & $25 \%$ & 207 & $15 \%$ & 230 & $11 \%$ \\
\hline Tubos & Opp Film S.A. & 425 & 1,050 & $147 \%$ & 1,550 & $48 \%$ & 1,938 & $25 \%$ & 2,199 & $14 \%$ \\
\hline Tubos & Megapack Group S.A.C. & - & 60 & & 70 & $17 \%$ & 77 & $10 \%$ & 85 & $11 \%$ \\
\hline Tubos & Resinplast S.A. & - & 120 & & 140 & $17 \%$ & 154 & $10 \%$ & 166 & $8 \%$ \\
\hline Tubos & Linea Plastica Perú S.A. & 85 & 120 & $41 \%$ & 134 & $12 \%$ & 148 & $10 \%$ & 160 & $8 \%$ \\
\hline Tubos & Peruana De Papeles Y Cartones S.A.C & - & 60 & & 80 & $33 \%$ & 88 & $10 \%$ & 95 & $8 \%$ \\
\hline Tubos & Polinplast S.AC. & 35 & 60 & $71 \%$ & 70 & $17 \%$ & 77 & $10 \%$ & 85 & $11 \%$ \\
\hline Esquineros & Avocado Packing Company S.A.C. & - & 380 & & 400 & $5 \%$ & 480 & $20 \%$ & 533 & $11 \%$ \\
\hline Esquineros & Procesadora Laran S.A.C. & - & 120 & & 140 & $17 \%$ & 168 & $20 \%$ & 186 & $11 \%$ \\
\hline Esquineros & Huaral Fruit Export S.A.C. & - & 84 & & 90 & $7 \%$ & 108 & $20 \%$ & 120 & $11 \%$ \\
\hline Esquineros & Sociedad Agricola Drokasa S.A. & 80 & 85 & $6 \%$ & 180 & $112 \%$ & 216 & $20 \%$ & 240 & $11 \%$ \\
\hline Esquineros & Agro Victoria S.A.C & - & 60 & & 80 & $33 \%$ & 96 & $20 \%$ & 107 & $11 \%$ \\
\hline Esquineros & Prcesadora Torre Blanca S.A. & - & 96 & & 116 & $21 \%$ & 128 & $10 \%$ & 142 & $11 \%$ \\
\hline Esquineros & Agricola Cerro Prieto S.A. & - & 40 & & 60 & $50 \%$ & 66 & $10 \%$ & 73 & $11 \%$ \\
\hline Esquineros & Sociedad Anonima Papelsa & - & 120 & & 140 & $17 \%$ & 154 & $10 \%$ & 171 & $11 \%$ \\
\hline \multirow[t]{2}{*}{ Esquineros } & Tal S.A. & 56 & 60 & $7 \%$ & 80 & $33 \%$ & 88 & $10 \%$ & 98 & $11 \%$ \\
\hline & Sub - Total (86.20\%) & 4,464 & 7,069 & $58 \%$ & 9,256 & $31 \%$ & 11,219 & $21 \%$ & 12,449 & $11 \%$ \\
\hline \multirow[t]{2}{*}{ Tubos } & Resto de Clientes (13.80\%) & 1,032 & 1,085 & $5 \%$ & 1,096 & $1 \%$ & 1,205 & $10 \%$ & 1,338 & $11 \%$ \\
\hline & Total & 5,496 & 8.154 & $48 \%$ & 10,352 & $27 \%$ & 12,425 & $20 \%$ & 13.787 & $11 \%$ \\
\hline
\end{tabular}

Figura 134. Presupuesto de Ventas de la UEN Tubos y Esquineros - CARVIMSA

Aprobado el Presupuesto de Ventas expresado en Tm, se envía al área de producción para la elaboración y planificación del presupuesto de producción de dichas toneladas.

El área productiva calcula en base a las referencias de cada cliente, el espesor, longitud y ancho de cada producto, posterior a eso se elabora la receta de materiales, asignando los costos.

Como resultado se obtiene la siguiente Matriz de Costos: 


\begin{tabular}{|c|c|c|c|c|c|c|c|c|c|c|}
\hline \multirow[b]{2}{*}{ EMPRESA 95: Division Tubos y Esquineros } & & \multirow[b]{2}{*}{2017} & \multicolumn{8}{|c|}{ ESTRUCTURA DE COSTOS Y GASTOS CON LA NUEVA ESTRATEGIA } \\
\hline & & & & 2018 & & 2019 & & 2020 & & 2021 \\
\hline DESCRIPCION & & REAL & & REAL & & REAL & & REAL & & REAL \\
\hline Producción (TM) & & 5,496 & & 8,154 & & 10,352 & & 12,425 & & 13,787 \\
\hline Ventas TM & & 5,251 & & 8,154 & & 10,352 & & 12,425 & & 13,787 \\
\hline Ventas Brutas $\$$ & & $3,695,279$ & & $5,756,567$ & & $7,307,016$ & & $8,769,155$ & & $9,730,591$ \\
\hline TOTAL VENTAS NETAS \$ & $\$$ & $3,695,279$ & $\$$ & $5,756,567$ & $\$$ & $7,307,016$ & $\$$ & $8,769,155$ & $\$$ & $9,730,591$ \\
\hline TOTAL VENTAS \$ (ACUM) & $\$$ & $3,695,279$ & $\$$ & $5,756,567$ & $\$$ & $7,307,016$ & $\$$ & $8,769,155$ & $\$$ & $9,730,591$ \\
\hline Precio Promedio / TM & $\$$ & 704 & $\$$ & 706 & $\$$ & 706 & $\$$ & 706 & $\$$ & 706 \\
\hline TOTAL REGALIAS C & $\$$ & 321,780 & $\$$ & 858,052 & $\$$ & $1,282,036$ & $\$$ & $1,667,337$ & $\$$ & $1,960,037$ \\
\hline TOTAL REGALIAS R & $\$$ & 321,780 & $\$$ & 858,052 & $\$$ & $1,282,036$ & $\$$ & $1,667,337$ & $\$$ & $1,960,037$ \\
\hline Cintas & & $1,708,282$ & & $2,433,598$ & & $3,065,786$ & & $3,663,005$ & & $4,050,876$ \\
\hline Adhesivos & & 467,943 & & 716,301 & & 909,732 & & $1,092,266$ & & $1,212,013$ \\
\hline TOTAL COSTOS MATERIAS PRIMAS & $\$$ & $2,176,225$ & $\$$ & $3,149,899$ & $\$$ & $3,975,518$ & $\$$ & $4,755,270$ & $\$$ & $5,262,889$ \\
\hline Mano de Obra Directa & & 560,812 & & 744,323 & & 918,055 & & $1,058,013$ & & $1,118,810$ \\
\hline Mano de Obra Indirecta & & 70,953 & & 75,903 & & 76,671 & & 79,311 & & 80,271 \\
\hline Combustible 1 (bunker + D2 + gas) & & 21,036 & & 5,332 & & 6,799 & & 8,191 & & 9,088 \\
\hline Suministros 1 & & 94,450 & & 142,937 & & 181,146 & & 216,557 & & 237,947 \\
\hline Suministros 2 & & 22,495 & & 14,410 & & 14,410 & & 14,410 & & 14,410 \\
\hline Reparaciones y Mantenimiento & & 69,364 & & 48,000 & & 10,400 & & 10,400 & & 10,400 \\
\hline Depreciación y Amortización & & 58,869 & & 94,144 & & 94,144 & & 94,144 & & 94,144 \\
\hline Otros & & 27,721 & & 35,117 & & 35,117 & & 35,117 & & 35,117 \\
\hline TOTAL COSTOS CONVERSION & $\$$ & 925,699 & $\$$ & $1,160,165$ & $\$$ & $1,336,742$ & $\$$ & $1,516,143$ & $\$$ & $1,600,187$ \\
\hline TOTAL COSTOS PRODUCCION & $\$$ & $3,101,924$ & $\$$ & $4,310,064$ & $\$$ & $5,312,260$ & $\$$ & $6,271,413$ & $\$$ & $6,863,076$ \\
\hline Gastos Administración & & 61,138 & & 61,376 & & 61,376 & & 61,376 & & 61,376 \\
\hline Gastos Ventas sin Fletes & & 51,040 & & 66,370 & & 65,988 & & 65,988 & & 65,988 \\
\hline TOTAL G.A.V.F sin Fletes & $\$$ & 112,178 & $\$$ & 127,746 & $\$$ & 127,364 & $\$$ & 127,364 & $\$$ & 127,364 \\
\hline Fletes & & 302,770 & & 460,706 & & 585,355 & & 703,040 & & 780,113 \\
\hline TOTAL GAVF + FLETES & 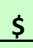 & 414,948 & $\$$ & 588,451 & $\$$ & 712,720 & $\$$ & 830,405 & $\$$ & 907,477 \\
\hline TOTAL CONVERSION +GAVF+FLETES & $\$$ & $1,340,647$ & $\$$ & $1,748,616$ & $\$$ & $2,049,462$ & $\$$ & $2,346,547$ & $\$$ & $2,507,664$ \\
\hline Variación Inventarios y Gastos Diversos & & $-11,948$ & & $-11,065$ & & $-10,242$ & & $-9,715$ & & $-7,320$ \\
\hline TOTAL COSTOS Y GASTOS DEL PERIODO & $\$$ & $3,504,924$ & $\$$ & $4,887,451$ & $\$$ & $6,014,737$ & $\$$ & $7,092,103$ & $\$$ & $7,763,233$ \\
\hline Cintas / TM & $\$$ & 310.83 & $\$$ & 298.45 & $\$$ & 296.16 & $\$$ & 294.82 & $\$$ & 293.82 \\
\hline Adhesivos / TM & $\$$ & 85.14 & $\$$ & 87.85 & $\$$ & 87.88 & $\$$ & 87.91 & $\$$ & 87.91 \\
\hline TOTAL COSTO MATERIA PRIMA / TM & $\$$ & 395.97 & $\$$ & 386.30 & $\$$ & 384.04 & $\$$ & 382.73 & $\$$ & 381.73 \\
\hline Mano de Obra Directa / TM & $\$$ & 102.04 & $\$$ & 91.28 & $\$$ & 88.69 & $\$$ & 85.15 & $\$$ & 81.15 \\
\hline Mano de Obra Indirecta / TM & $\$$ & 12.91 & $\$$ & 9.31 & $\$$ & 7.41 & $\$$ & 6.38 & $\$$ & 5.82 \\
\hline Combustible 1/ TM & $\$$ & 3.83 & $\$$ & 0.65 & $\$$ & 0.66 & $\$$ & 0.66 & $\$$ & 0.66 \\
\hline Suministros $1 / \mathrm{TM}$ & $\$$ & 17.19 & $\$$ & 17.53 & $\$$ & 32.96 & $\$$ & 39.40 & $\$$ & 43.30 \\
\hline Suministros $2 / \mathrm{TM}$ & $\$$ & 4.09 & $\$$ & 2.62 & $\$$ & 2.62 & $\$$ & 2.62 & $\$$ & 2.62 \\
\hline Reparaciones y Mantenimiento / TM & $\$$ & 12.62 & $\$$ & 5.89 & $\$$ & 1.00 & $\$$ & 0.84 & $\$$ & 0.75 \\
\hline Depreciación y Amortización / TM & $\$$ & 10.71 & $\$$ & 11.55 & $\$$ & 9.09 & $\$$ & 7.58 & $\$$ & 6.83 \\
\hline Otros / TM & $\$$ & 5.04 & $\$$ & 4.31 & $\$$ & 3.39 & $\$$ & 2.83 & $\$$ & 2.55 \\
\hline TOTAL COSTO CONVERSION / TM & $\$$ & 168.43 & $\$$ & 143.14 & $\$$ & 145.82 & $\$$ & 145.46 & $\$$ & 143.68 \\
\hline TOTAL COSTO PRODUCCION /TM & $\$$ & 564.41 & $\$$ & 529.44 & $\$$ & 529.87 & $\$$ & 528.19 & $\$$ & 525.41 \\
\hline TOTAL GAV sin Fletes / TM & $\$$ & 20.41 & $\$$ & 15.67 & $\$$ & 12.30 & $\$$ & 10.25 & $\$$ & 9.24 \\
\hline Flete / TM & $\$$ & 55.09 & $\$$ & 56.50 & $\$$ & 56.55 & $\$$ & 56.58 & $\$$ & 56.58 \\
\hline TOTAL COSTO CON FLETE/ TM & $\$$ & 639.91 & $\$$ & 601.60 & $\$$ & 598.72 & $\$$ & 595.02 & $\$$ & 591.23 \\
\hline Variación Inventarios y Gastos Diversos / TM & $\$$ & 27.61 & $\$$ & (2.21) & $\$$ & (17.68) & $\$$ & (24.22) & $\$$ & $(28.14)$ \\
\hline TOTAL COSTOS Y GASTOS DEL PERIODO TM & $\$$ & 667.52 & $\$$ & 599.39 & $\$$ & 581.04 & $\$$ & 570.81 & $\$$ & 563.09 \\
\hline
\end{tabular}

Figura 135. Matriz Consolidada de Estructura de Costos y Gastos de la UEN Tubos y

Esquineros - CARVIMSA 


\begin{tabular}{|c|c|c|c|c|c|c|c|c|c|c|}
\hline \multirow{2}{*}{$\begin{array}{r}\text { EMPRESA } 95: \text { UEN TUBOS } \\
\text { DESCRIPCION }\end{array}$} & \multicolumn{2}{|r|}{2017} & \multicolumn{2}{|r|}{2018} & \multicolumn{2}{|r|}{2019} & \multicolumn{2}{|r|}{2020} & \multicolumn{2}{|r|}{2021} \\
\hline & & REAL & & ESUPUESTO & & RESUPUESTO & & RESUPUESTO & PR & ESUPUESTO \\
\hline Producción (TM) & & 4,139 & & 7,109 & & 9,066 & & 10,921 & & 12,118 \\
\hline Ventas TM & & 3,953 & & 7,109 & & 9,066 & & 10,921 & & 12,118 \\
\hline Ventas Brutas \$ & & $2,796,209$ & & $4,993,717$ & & $6,368,236$ & & $7,671,527$ & & $8,512,224$ \\
\hline TOTAL VENTAS NETAS \$ & & $2,796,209$ & $\$$ & $4,993,717$ & $\$$ & $6,368,236$ & $\$$ & $7,671,527$ & $\$$ & $8,512,224$ \\
\hline Precio Promedio / TM & $\$$ & 707 & $\$$ & 702 & $\$$ & 702 & $\$$ & 702 & $\$$ & 702 \\
\hline TOTAL REGALIAS $\mathbf{R}$ & $\$$ & 189,919 & $\$$ & 733,678 & $\$$ & $1,107,321$ & $\$$ & $1,446,497$ & $\$$ & $1,703,495$ \\
\hline Cintas & & $1,182,975$ & $\$$ & $2,024,856$ & $\$$ & $2,564,066$ & $\$$ & $3,077,894$ & $\$$ & $3,403,072$ \\
\hline Adhesivos & $\$$ & 361,236 & $\$$ & 632,701 & $\$$ & 806,852 & $\$$ & 971,978 & $\$$ & $1,078,494$ \\
\hline TOTAL COSTOS MATERIAS PRIMAS & & $1,544,210$ & $\$$ & $2,657,557$ & $\$$ & $3,370,918$ & $\$$ & $4,049,872$ & $\$$ & 4,481,566 \\
\hline Mano de Obra Directa Mano de & $\$$ & 529,369 & $\$$ & 719,495 & $\$$ & 893,227 & $\$$ & $1,033,185$ & $\$$ & $1,093,982$ \\
\hline Obra Indirecta Combustible 1 & $\$$ & 56,682 & $\$$ & 61,632 & $\$$ & 62,400 & $\$$ & 65,040 & $\$$ & 66,000 \\
\hline (bunker + D2 + gas) Suministros 1 & $\$$ & 21,036 & $\$$ & 5,332 & $\$$ & 6,799 & $\$$ & 8,191 & $\$$ & 9,088 \\
\hline Suministros 2 & $\$$ & 77,159 & $\$$ & 132,298 & $\$$ & 168,260 & $\$$ & 201,822 & $\$$ & 221,758 \\
\hline Reparaciones y Mantenimiento & $\$$ & 21,239 & $\$$ & 13,260 & $\$$ & 13,260 & $\$$ & 13,260 & $\$$ & 13,260 \\
\hline Depreciación y Amortización & $\$$ & 63,590 & $\$$ & 42,000 & $\$$ & 4,400 & $\$$ & 4,400 & $\$$ & 4,400 \\
\hline Otros & $\$$ & 49,860 & $\$$ & 84,829 & $\$$ & 84,829 & $\$$ & 84,829 & $\$$ & 84,829 \\
\hline & $\$$ & 22,265 & $\$$ & 29,117 & $\$$ & 29,117 & $\$$ & 29,117 & $\$$ & 29,117 \\
\hline TOTAL COSTOS CONVERSION & $\$$ & 841,201 & $\$$ & $1,087,963$ & $\$$ & $1,262,293$ & $\$$ & $1,439,843$ & $\$$ & $1,522,434$ \\
\hline TOTAL COSTOS PRODUCCION & & $2,385,411$ & $\$$ & $3,745,521$ & $\$$ & $4,633,210$ & $\$$ & $5,489,715$ & $\$$ & $6,003,999$ \\
\hline Gastos Administración & $\$$ & 48,910 & $\$$ & 49,101 & $\$$ & 49,101 & $\$$ & 49,101 & $\$$ & 49,101 \\
\hline Gastos Ventas sin Fletes & $\$$ & 40,832 & $\$$ & 53,096 & $\$$ & 52,791 & $\$$ & 52,791 & $\$$ & 52,791 \\
\hline TOTAL G.A.V.F sin Fletes & $\$$ & 89,742 & $\$$ & 102,196 & $\$$ & 101,891 & $\$$ & 101,891 & $\$$ & 101,891 \\
\hline Fletes & & 241,475 & & 412,322 & & 525,814 & & 633,424 & & 702,839 \\
\hline TOTAL GAVF + FLETES & $\$$ & 331,217 & $\$$ & 514,518 & $\$$ & 627,705 & $\$$ & 735,315 & $\$$ & 804,730 \\
\hline TOTAL CONVERSION +GAVF+FLETES & & $1,172,418$ & $\$$ & $1,602,482$ & $\$$ & $1,889,997$ & $\$$ & $2,175,159$ & $\$$ & $2,327,164$ \\
\hline TOTAL COSTOS Y GASTOS DEL PERIODO & & $2,606,290$ & $\$$ & $4,260,039$ & $\$$ & $5,260,915$ & $\$$ & $6,225,030$ & $\$$ & $6,808,729$ \\
\hline Cintas / TM & $\$$ & 285.82 & $\$$ & 284.83 & $\$$ & 282.83 & $\$$ & 281.83 & $\$$ & 280.83 \\
\hline Adhesivos / TM & $\$$ & 87.28 & $\$$ & 89.00 & $\$$ & 89.00 & $\$$ & 89.00 & $\$$ & 89.00 \\
\hline TOTAL COSTO MATERIA PRIMA / TM & $\$$ & 373.10 & $\$$ & 373.83 & $\$$ & 371.83 & $\$$ & 370.83 & $\$$ & 369.83 \\
\hline Mano de Obra Directa / TM & $\$$ & 127.90 & $\$$ & 101.21 & $\$$ & 98.53 & $\$$ & 94.60 & $\$$ & 90.28 \\
\hline Mano de Obra Indirecta / TM & $\$$ & 13.70 & $\$$ & 8.67 & $\$$ & 6.88 & $\$$ & 5.96 & $\$$ & 5.45 \\
\hline Combustible 1 / TM & $\$$ & 5.08 & $\$$ & 0.75 & $\$$ & 0.75 & $\$$ & 0.75 & $\$$ & 0.75 \\
\hline Suministros 1 / TM & $\$$ & 18.64 & $\$$ & 18.61 & $\$$ & 18.56 & $\$$ & 18.48 & $\$$ & 18.30 \\
\hline Suministros 2 / TM & $\$$ & 5.13 & $\$$ & 1.87 & $\$$ & 1.46 & $\$$ & 1.21 & $\$$ & 1.09 \\
\hline Reparaciones y Mantenimiento / TM & $\$$ & 15.36 & $\$$ & 5.91 & $\$$ & 0.49 & $\$$ & 0.40 & $\$$ & 0.36 \\
\hline Depreciación y Amortización / TM & $\$$ & 12.05 & $\$$ & 11.93 & $\$$ & 9.36 & $\$$ & 7.77 & $\$$ & 7.00 \\
\hline Otros / TM & $\$$ & 5.38 & $\$$ & 4.10 & $\$$ & 3.21 & $\$$ & 2.67 & $\$$ & 2.40 \\
\hline TOTAL COSTO CONVERSION / TM & $\$$ & 203.24 & $\$$ & 153.04 & $\$$ & 139.24 & $\$$ & 131.84 & $\$$ & 125.64 \\
\hline TOTAL COSTO PRODUCCION / TM & $\$$ & 576.34 & $\$$ & 526.87 & $\$$ & 511.07 & $\$$ & 502.67 & $\$$ & 495.47 \\
\hline Flete / TM & $\$$ & 58.34 & $\$$ & 58.00 & $\$$ & 58.00 & $\$$ & 58.00 & $\$$ & 58.00 \\
\hline TOTAL COSTO CON FLETE/ TM & $\$$ & 656.37 & $\$$ & 599.25 & $\$$ & 580.31 & $\$$ & 570.00 & $\$$ & 561.87 \\
\hline TOTAL COSTOS Y GASTOS DEL PERIODO TM & $\$$ & 659.40 & $\$$ & 599.25 & $\$$ & 580.31 & $\$$ & 570.00 & $\$$ & 561.87 \\
\hline
\end{tabular}

Figura 136. Matriz de Tubos de Estructura de Costos y Gastos de la UEN Tubos y

Esquineros - CARVIMSA 


\begin{tabular}{|c|c|c|c|c|c|c|c|c|c|}
\hline EMPRESA 95 : Linea Esquineros & 2017 & & 2018 & & 2019 & & 2020 & & 2021 \\
\hline DESCRIPCION & REAL & & ESUPUESTO & PR & ESUPUESTO & PRE & ESUPUESTO & & RESUPUESTO \\
\hline Producción (TM) & 1,357 & & 1,045 & & 1,286 & & 1,504 & & 1,669 \\
\hline Ventas TM & 1,298 & & 1,045 & & 1,286 & & 1,504 & & 1,669 \\
\hline Ventas Brutas \$ & $\$ 899,070$ & $\$$ & 762,850 & $\$$ & 938,780 & $\$$ & $1,097,628$ & $\$$ & $1,218,367$ \\
\hline TOTAL VENTAS NETAS \$ & $\$ 899,070$ & $\$$ & 762,850 & $\$$ & 938,780 & $\$$ & $1,097,628$ & $\$$ & $1,218,367$ \\
\hline TOTAL VENTAS \$ (ACUM) & $\$ 899,070$ & $\$$ & 762,850 & $\$$ & 938,780 & $\$$ & $1,097,628$ & $\$$ & $1,218,367$ \\
\hline Precio Promedio / TM & 693 & $\$$ & 730 & $\$$ & 730 & $\$$ & 730 & $\$$ & 730 \\
\hline TOTAL REGALIAS C & $\$ 131,861$ & $\$$ & 124,374 & $\$$ & 174,715 & $\$$ & 220,840 & $\$$ & 256,543 \\
\hline TOTAL REGALIAS R & $\$ 131,861$ & $\$$ & 124,374 & $\$$ & 174,715 & $\$$ & 220,840 & $\$$ & 256,543 \\
\hline Cintas & $\$ 525,307$ & $\$$ & 408,741 & $\$$ & 501,720 & $\$$ & 585,111 & $\$$ & 647,804 \\
\hline Adhesivos & $\$ 106,708$ & $\$$ & 83,600 & $\$$ & 102,880 & $\$$ & 120,288 & $\$$ & 133,520 \\
\hline TOTAL COSTOS MATERIAS PRIMAS & $\$ 632,015$ & $\$$ & 492,341 & $\$$ & 604,600 & $\$$ & 705,399 & $\$$ & 781,324 \\
\hline Mano de Obra Directa & $\$ 31,443$ & $\$$ & 24,828 & $\$$ & 24,828 & $\$$ & 24,828 & $\$$ & 24,828 \\
\hline Mano de Obra Indirecta & $\$ 14,271$ & $\$$ & 14,271 & $\$$ & 14,271 & $\$$ & 14,271 & $\$$ & 14,271 \\
\hline Suministros 1 & $\$ 17,291$ & $\$$ & 10,638 & $\$$ & 12,886 & $\$$ & 14,735 & $\$$ & 16,189 \\
\hline Suministros 2 & $\$ \quad 1,256$ & $\$$ & 1,150 & $\$$ & 1,150 & $\$$ & 1,150 & $\$$ & 1,150 \\
\hline Reparaciones y Mantenimiento & 5,774 & $\$$ & 6,000 & $\$$ & 6,000 & $\$$ & 6,000 & $\$$ & 6,000 \\
\hline Depreciación y Amortización & $\$ 9,009$ & $\$$ & 9,315 & $\$$ & 9,315 & $\$$ & 9,315 & $\$$ & 9,315 \\
\hline Otros & $\$ \quad 5,455$ & $\$$ & 6,000 & $\$$ & 6,000 & $\$$ & 6,000 & $\$$ & 6,000 \\
\hline TOTAL COSTOS CONVERSION & $\$ 84,498$ & $\$$ & 72,202 & $\$$ & 74,450 & $\$$ & 76,299 & $\$$ & 77,753 \\
\hline TOTAL COSTOS PRODUCCION & $\$ 716,513$ & $\$$ & 564,543 & $\$$ & 679,050 & $\$$ & 781,698 & $\$$ & 859,077 \\
\hline Gastos Administración & $\$ 12,228$ & $\$$ & 12,275 & $\$$ & 12,275 & $\$$ & 12,275 & $\$$ & 12,275 \\
\hline Gastos Ventas sin Fletes & $\$ 10,208$ & $\$$ & 13,274 & $\$$ & 13,198 & $\$$ & 13,198 & $\$$ & 13,198 \\
\hline TOTAL G.A.V.F sin Fletes & $\$ 22,436$ & $\$$ & 25,549 & $\$$ & 25,473 & $\$$ & 25,473 & $\$$ & 25,473 \\
\hline Fletes & $\$ 61,295$ & $\$$ & 48,384 & $\$$ & 59,542 & $\$$ & 69,617 & $\$$ & 77,275 \\
\hline TOTAL GAVF + FLETES & $\$ 83,731$ & $\$$ & 73,933 & $\$$ & 85,015 & $\$$ & 95,090 & $\$$ & 102,747 \\
\hline TOTAL CONVERSION +GAVF+FLETES & $\$ 168,229$ & $\$$ & 146,135 & $\$$ & 159,464 & $\$$ & 171,389 & $\$$ & 180,501 \\
\hline Variación Inventarios y Gastos Diversos & $\$$ & $\$$ & - & $\$$ & - & $\$$ & - & $\$$ & - \\
\hline TOTAL COSTOS Y GASTOS DEL PERIODO & $\$ 800,244$ & $\$$ & 638,476 & $\$$ & 764,065 & $\$$ & 876,788 & $\$$ & 961,825 \\
\hline Cintas / TM & $\$ 387.11$ & $\$$ & 391.14 & $\$$ & 390.14 & $\$$ & 389.14 & $\$$ & 388.14 \\
\hline Adhesivos / TM & $\$ 78.63$ & $\$$ & 80.00 & $\$$ & 80.00 & $\$$ & 80.00 & $\$$ & 80.00 \\
\hline TOTAL COSTO MATERIA PRIMA / TM & $\$ 465.74$ & $\$$ & 471.14 & $\$$ & 470.14 & $\$$ & 469.14 & $\$$ & 468.14 \\
\hline Mano de Obra Directa / TM & $\$ \quad 23.17$ & $\$$ & 23.76 & $\$$ & 19.31 & $\$$ & 16.51 & $\$$ & 14.88 \\
\hline Mano de Obra Indirecta / TM & 10.52 & $\$$ & 13.66 & $\$$ & 11.10 & $\$$ & 9.49 & $\$$ & 8.55 \\
\hline Suministros 1 / TM & 12.74 & $\$$ & 10.18 & $\$$ & 10.02 & $\$$ & 9.80 & $\$$ & 9.70 \\
\hline Suministros 2 / TM & 0.93 & $\$$ & 1.10 & $\$$ & 0.89 & $\$$ & 0.76 & $\$$ & 0.69 \\
\hline Reparaciones y Mantenimiento / TM & 4.25 & $\$$ & 5.74 & $\$$ & 4.67 & $\$$ & 3.99 & $\$$ & 3.59 \\
\hline Depreciación y Amortización / TM & 6.64 & $\$$ & 8.91 & $\$$ & 7.24 & $\$$ & 6.20 & $\$$ & 5.58 \\
\hline Otros / TM & 4.02 & $\$$ & 5.74 & $\$$ & 4.67 & $\$$ & 3.99 & $\$$ & 3.59 \\
\hline TOTAL COSTO CONVERSION / TM & $\$ \quad 62.27$ & $\$$ & 69.09 & $\$$ & $\mathbf{5 7 . 8 9}$ & $\$$ & 50.74 & $\$$ & 46.59 \\
\hline TOTAL COSTO PRODUCCION / TM & $\$ 528.01$ & $\$$ & 540.23 & $\$$ & 528.03 & $\$$ & 519.88 & $\$$ & 514.73 \\
\hline TOTAL GAV sin Fletes / TM & $\$ \quad 16.53$ & $\$$ & 24.45 & $\$$ & 19.81 & $\$$ & 16.94 & $\$$ & 15.26 \\
\hline Gastos Financieros / TM & $\$$ & $\$$ & - & $\$$ & - & $\$$ & - & $\$$ & - \\
\hline Flete y Seguros Exterior / TM & $\$$ & $\$$ & - & $\$$ & - & $\$$ & - & $\$$ & - \\
\hline Flete / TM & $\$ 45.17$ & $\$$ & 46.30 & $\$$ & 46.30 & $\$$ & 46.30 & $\$$ & 46.30 \\
\hline TOTAL COSTO CON FLETE/ TM & $\$ 589.71$ & $\$$ & 610.98 & $\$$ & 594.14 & $\$$ & 583.13 & $\$$ & 576.29 \\
\hline Variación Inventarios y Gastos Diversos & $\$ 26.73$ & $\$$ & - & $\$$ & 0.00 & $\$$ & 0.00 & $\$$ & 0.00 \\
\hline TOTAL COSTOS Y GASTOS DEL PERIODO TM & $\$ 616.44$ & $\$$ & 610.98 & $\$$ & 594.14 & $\$$ & 583.13 & $\$$ & 576.29 \\
\hline
\end{tabular}

Figura 137. Matriz de Esquineros de Estructura de Costos y Gastos de la UEN Tubos y

Esquineros - CARVIMSA 
10.2.2. Estado de resultados (situación actual y con la nueva estrategia)

Gitman y Zutter (2016) mencionan que:

El estado de pérdidas y ganancias (o estado de resultados) presenta un resumen financiero de los resultados operativos de la empresa a lo largo de un periodo especifico. Lo más común es que abarquen un año con término en una fecha preestablecida, casi siempre el 31 de diciembre (p.61). 
Tabla 117

Estado de Resultado proyectado Sin Estrategia de la UEN Tubos y Esquineros - CARVIMSA

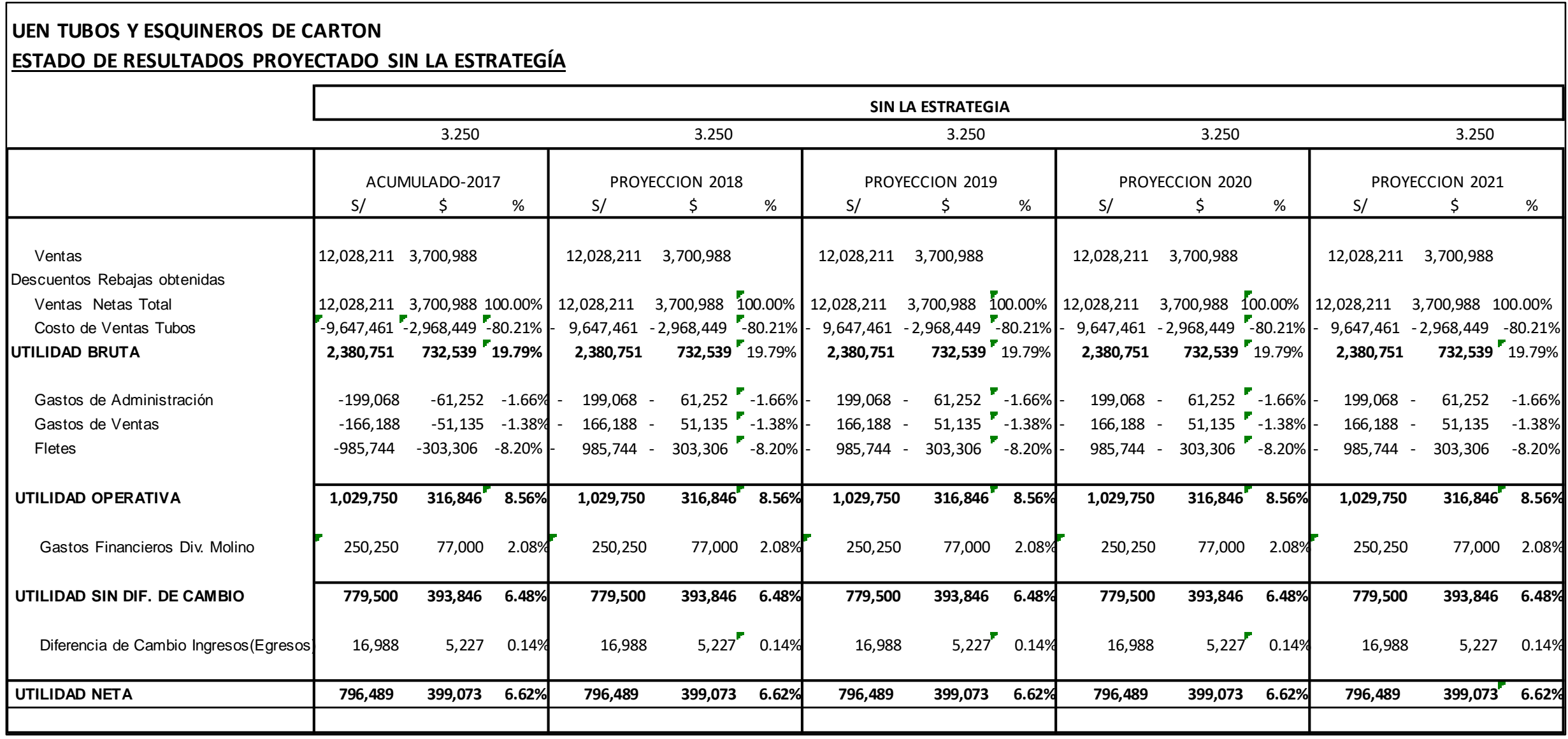


Tabla 118

Estado de Resultado proyectado con la Nueva Estrategia de la UEN Tubos y Esquineros - CARVIMSA

\begin{tabular}{|c|c|c|c|c|c|c|c|c|c|c|c|c|}
\hline \multicolumn{13}{|c|}{$\begin{array}{l}\text { UEN TUBOS Y ESQUINEROS DE CARTON } \\
\text { ESTADO DE RESULTADOS SITUACION ACTUAL Y PROYECTADO CON ESTRATEGIA }\end{array}$} \\
\hline & \multicolumn{12}{|c|}{ CON LA NUEVA ESTRATEGIA } \\
\hline & \multicolumn{3}{|c|}{3.250} & \multicolumn{3}{|c|}{3.250} & \multicolumn{3}{|c|}{3.250} & \multicolumn{3}{|c|}{3.250} \\
\hline & \multicolumn{3}{|c|}{ PROYECCION 2018} & \multicolumn{3}{|c|}{ PROYECCION 2019} & \multicolumn{3}{|c|}{ PROYECCION 2020} & \multicolumn{3}{|c|}{ PROYECCION 2021} \\
\hline & s/ & $\$$ & $\%$ & s/ & $\$$ & $\%$ & s/ & $\$$ & $\%$ & s/ & $\$$ & $\%$ \\
\hline $\begin{array}{l}\text { Ventas } \\
\text { Descuentos Rebajas obtenidas }\end{array}$ & $18,708,843$ & $5,756,567$ & & $23,747,802$ & $7,307,016$ & & $28,499,753$ & $8,769,155$ & & $31,624,421$ & $9,730,591$ & \\
\hline Ventas Netas Total & $18,708,843$ & $5,756,567$ & $100.00 \%$ & $23,747,802$ & $7,307,016$ & $100.00 \%$ & $28,499,753$ & $8,769,155$ & $100.00 \%$ & $31,624,421$ & $9,730,591$ & $100.00 \%$ \\
\hline Costo de Ventas Tubos & $-14,007,708$ & $-4,310,064$ & $-74.87 \%$ & $-17,264,846$ & $-5,312,260$ & $-72.70 \%$ & $-20,382,093$ & $-6,271,413$ & $-71.52 \%$ & $-22,304,998$ & $-6,863,076$ & $-70.53 \%$ \\
\hline UTILIDAD BRUTA & $4,701,135$ & $1,446,503$ & $25.13 \%$ & $6,482,957$ & $1,994,756$ & $27.30 \%$ & $8,117,660$ & $2,497,742$ & $28.48 \%$ & $9,319,423$ & $2,867,515$ & $29.47 \%$ \\
\hline Gastos de Administración & $-199,472$ & $-61,376$ & $-1.07 \%$ & $-199,472$ & $-61,376$ & $-0.84 \%$ & $-199,472$ & $-61,376$ & $-0.70 \%$ & $-199,472$ & $-61,376$ & $-0.63 \%$ \\
\hline Gastos de Ventas & $-1,267,405$ & $-389,971$ & $-6.77 \%$ & $-1,266,166$ & $-389,589$ & $-5.33 \%$ & $-1,266,166$ & $-389,589$ & $-4.44 \%$ & $-1,266,166$ & $-389,589$ & $-4.00 \%$ \\
\hline Fletes & $-1,497,293$ & $-460,706$ & $-8.00 \%$ & $-1,902,405$ & $-585,355$ & $-8.01 \%$ & $-2,284,882$ & $-703,040$ & $-8.02 \%$ & $-2,535,368$ & $-780,113$ & $-8.02 \%$ \\
\hline UTILIDAD OPERATIVA & $1,736,965$ & 534,451 & $9.28 \%$ & $3,114,914$ & 958,435 & $13.12 \%$ & $4,367,141$ & $1,343,736$ & $15.32 \%$ & $5,318,417$ & $1,636,436$ & $16.82 \%$ \\
\hline Gastos Financieros Div. Molino & $-233,567$ & $-71,867$ & $-1.25 \%$ & $-216,883$ & $-66,733$ & $-0.91 \%$ & $-200,200$ & $-61,600$ & $-0.70 \%$ & $-183,517$ & $-56,467$ & $-0.58 \%$ \\
\hline UTILIDAD SIN DIF. DE CAMBIO & $1,503,398$ & 462,584 & $8.04 \%$ & $2,898,031$ & 891,702 & $12.20 \%$ & $4,166,941$ & $1,282,136$ & $14.62 \%$ & $5,134,901$ & $1,579,969$ & $16.24 \%$ \\
\hline Diferencia de Cambio Ingresos(Egresos) & 0 & 0 & $0.00 \%$ & 0 & 0 & $0.00 \%$ & 0 & 0 & $0.00 \%$ & 0 & 0 & $0.00 \%$ \\
\hline UTILIDAD NETA & $1,503,398$ & 462,584 & $8.04 \%$ & $2,898,031$ & 891,702 & $12.20 \%$ & $4,166,941$ & $1,282,136$ & $14.62 \%$ & $5,134,901$ & $1,579,969$ & $16.24 \%$ \\
\hline
\end{tabular}




\subsubsection{Balance general (situación actual y con la nueva estrategia)}

El balance general presenta la situación financiera de la empresa en un momento determinado, el cual se enfoca en realizar un balance entre los activos que posee la empresa frente al endeudamiento, ya sea por deuda adquirida o capital aportado por los accionistas. (Gitman y Zutter, 2016) 
Tabla 119

Balance general de la Sin la Nueva Estrategia de la UEN Tubos y Esquineros - CARVIMSA

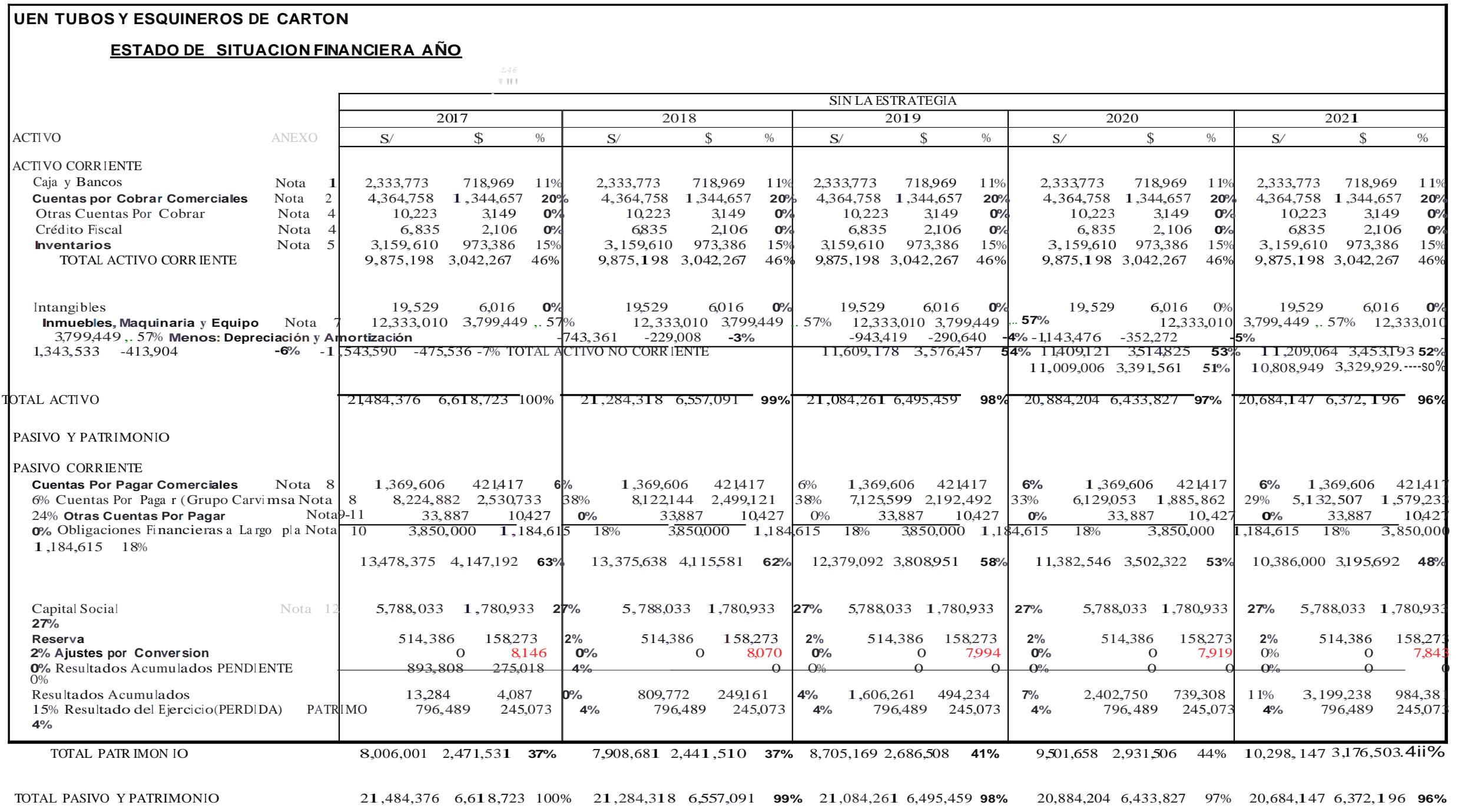


Tabla 120

Balance general de la Con la Nueva Estrategia de la UEN Tubos y Esquineros - CARVIMSA

\begin{tabular}{|c|c|c|c|c|c|c|c|c|c|c|c|c|c|}
\hline \multicolumn{14}{|c|}{ UEN TUBOS Y ESQUINEROS DE CARTON } \\
\hline \multicolumn{14}{|c|}{ ESTADO DE SITUACION FINANCIERA CON LA ESTRATEGIA } \\
\hline \multirow[b]{3}{*}{ ACTIVO } & \multirow[b]{3}{*}{ ANEXO } & \multirow{2}{*}{\multicolumn{3}{|c|}{2018}} & \multirow{2}{*}{\multicolumn{6}{|c|}{ CON LA NUEVA ESTRATEGIA }} & & & \\
\hline & & & & & & & & & & & \multicolumn{3}{|c|}{2021} \\
\hline & & $\mathrm{s} /$ & $\$$ & $\%$ & $\mathrm{~s} /$ & $\$$ & $\%$ & $\mathrm{~s} /$ & $\$$ & $\%$ & $\mathrm{~s} /$ & $\$$ & $\%$ \\
\hline \multicolumn{14}{|l|}{ ACTIVO CORRIENTE } \\
\hline Caja y Bancos & Nota & $2,737,063$ & 843,211 & $12 \%$ & $4,729,570$ & $1,457,045$ & $20 \%$ & $7,835,265$ & $2,413,822$ & $29 \%$ & $12,469,801$ & $3,841,590$ & $40 \%$ \\
\hline Cuentas por Cobrar Comerciales & Nota & $4,676,698$ & $1,440,757$ & $21 \%$ & $4,063,151$ & $1,251,741$ & $17 \%$ & $4,682,548$ & $1,442,560$ & $17 \%$ & $4,763,591$ & $1,467,526$ & $15 \%$ \\
\hline Otras Cuentas Por Cobrar & Nota & 10,223 & 3,149 & $0 \%$ & 10,223 & 3,149 & $0 \%$ & 10,223 & 3,149 & $0 \%$ & 10,223 & 3,149 & $0 \%$ \\
\hline (-) Cobranza Dudosa & Nota & $-1,051,704$ & $-324,000$ & & $-1,051,704$ & 324,000 & $-4 \%$ & $-1,051,704$ & $-324,000$ & $-4 \%$ & $-1,051,704$ & $-324,000$ & $-3 \%$ \\
\hline Crédito Fiscal & Nota & 8,746 & 2,694 & $0 \%$ & 10,245 & 3,156 & $0 \%$ & 10,258 & 3,160 & $0 \%$ & 11,146 & 3,434 & $0 \%$ \\
\hline Inventarios & Nota & $3,595,951$ & $1,107,810$ & $16 \%$ & $3,771,778$ & $1,161,977$ & $16 \%$ & $4,261,812$ & $1,312,943$ & $16 \%$ & $4,176,229$ & $1,286,577$ & $13 \%$ \\
\hline TOTAL ACTIVO CORRIENTE & & $9,976,977$ & $3,073,622$ & $49 \%$ & $11,533,263$ & $3,553,069$ & $49 \%$ & $15,748,403$ & $4,851,634$ & $58 \%$ & $20,379,285$ & $6,278,276$ & $65 \%$ \\
\hline Intangibles & & 19,529 & 6,016 & $0 \%$ & 19,529 & 6,016 & $0 \%$ & 19,529 & 6,016 & $0 \%$ & 19,529 & 6,016 & $0 \%$ \\
\hline Inmuebles, Maquinaria y Equipo & Nota & $13,502,360$ & $4,159,692$ & $60 \%$ & $13,502,360$ & $4,159,692$ & $57 \%$ & $13,502,360$ & $4,159,692$ & $49 \%$ & $13,502,360$ & $4,159,692$ & $43 \%$ \\
\hline \multirow{2}{*}{\multicolumn{2}{|c|}{$\begin{array}{l}\text { Menos: Depreciación y Amortización } \\
\text { TOTAL ACTIVO NO CORRIENTE }\end{array}$}} & $-1,046,378$ & $-322,359$ & $-5 \%$ & $-1,455,936$ & $-448,532$ & $-6 \%$ & $-1,970,243$ & $-606,976$ & $-7 \%$ & $-2,589,300$ & $-797,689$ & $-8 \%$ \\
\hline & & $12,475,511$ & $3,843,349$ & $56 \%$ & $12,065,954$ & $3,717,176$ & $51 \%$ & $11,551,647$ & $3,558,733$ & $42 \%$ & $10,932,589$ & $3,368,019$ & $35 \%$ \\
\hline TOTAL ACTIVO & & $22,452,488$ & $6,916,971$ & $100 \%$ & $23,599,216$ & $7,270,245$ & $100 \%$ & $27,300,049$ & $8,410,366$ & $100 \%$ & $31,311,874$ & $9,646,295$ & $100 \%$ \\
\hline \multicolumn{14}{|l|}{ PASIVO Y PATRIMONIO } \\
\hline \multicolumn{14}{|l|}{ PASIVO CORRIENTE } \\
\hline Cuentas Por Pagar Comerciales & Nota & $1,459,590$ & 449,105 & $7 \%$ & $1,343,460$ & 413,372 & $6 \%$ & $1,539,704$ & 473,755 & $6 \%$ & $1,582,963$ & 487,066 & $5 \%$ \\
\hline Cuentas Por Pagar (Grupo Carvimsa & Nota 8 & $7,853,907$ & $2,416,587$ & $35 \%$ & $6,472,863$ & $1,991,650$ & $27 \%$ & $6,063,298$ & $1,865,630$ & $22 \%$ & $5,149,363$ & $1,584,419$ & $16 \%$ \\
\hline Otras Cuentas Por Pagar & Nota 9-11 & 36,259 & 11,157 & $0 \%$ & 38,797 & 11,938 & $0 \%$ & 42,677 & 13,131 & $0 \%$ & 46,945 & 14,444 & $0 \%$ \\
\hline \multirow[t]{2}{*}{ Obligaciones Financieras a Largo pla } & Nota 10 & $3,593,333$ & $1,107,003$ & $16 \%$ & $3,336,667$ & $1,026,667$ & $14 \%$ & $3,080,000$ & 947,692 & $11 \%$ & $2,823,333$ & 868,718 & $9 \%$ \\
\hline & & $12,943,089$ & $3,983,851$ & $58 \%$ & $11,191,787$ & $3,443,627$ & $47 \%$ & $10,725,679$ & $3,300,209$ & $39 \%$ & $9,602,604$ & $2,954,647$ & $31 \%$ \\
\hline Capital Social & Nota 12 & $5,788,033$ & $1,780,933$ & $26 \%$ & $5,788,033$ & $1,780,933$ & $25 \%$ & $5,788,033$ & $1,780,933$ & $21 \%$ & $5,788,033$ & $1,780,933$ & $18 \%$ \\
\hline Reserva & & 514,386 & 158,273 & $2 \%$ & 514,386 & 158,273 & $2 \%$ & 514,386 & 158,273 & $2 \%$ & 514,386 & 158,273 & $2 \%$ \\
\hline Ajustes por Conversion & & 0 & 7,151 & $0 \%$ & 0 & 8,948 & $0 \%$ & 0 & 10,351 & $0 \%$ & 0 & $11,872.36$ & $0 \%$ \\
\hline Resultados Acumulados PENDIENTE & & 893,808 & 275,018 & $4 \%$ & 893,808 & 275,018 & $4 \%$ & 893,808 & 275,018 & $3 \%$ & 893,808 & 275,018 & $3 \%$ \\
\hline Resultados Acumulados & & 809,772 & 249,161 & $4 \%$ & $2,313,170$ & 711,745 & $10 \%$ & $5,211,201$ & $1,603,446$ & $19 \%$ & $9,378,142$ & $2,885,582$ & $30 \%$ \\
\hline Resultado del Ejercicio(PERDIDA) & PATRIMO & $1,503,398$ & 462,584 & $7 \%$ & $2,898,031$ & 891,702 & $12 \%$ & $4,166,941$ & $1,282,136$ & $15 \%$ & $5,134,901$ & $1,579,969$ & $16 \%$ \\
\hline TOTAL PATRIMONIO & & $9,509,399$ & $2,933,120$ & $42 \%$ & $12,407,429$ & $3,826,619$ & $53 \%$ & $16,574,370$ & $5,110,157$ & $61 \%$ & $21,709,270$ & $6,691,648$ & $69 \%$ \\
\hline TOTAL PASIVO Y PATRIMONIO & & $22,452,488$ & $6,916,971$ & $100 \%$ & $23,599,216$ & $7,270,245$ & $100 \%$ & $27,300,049$ & $8,410,366$ & $100 \%$ & $31,311,874$ & $9,646,295$ & $100 \%$ \\
\hline
\end{tabular}




\subsubsection{Flujo de efectivo (situación actual y con la nueva estrategia)}

El estado de flujos de efectivo provee información relacionada a los flujos de efectivo operativos, de inversión y financieros de la empresa durante un periodo determinado.

(Gitman y Zutter, 2016)

\subsubsection{Proyección de flujos (situación actual y con la nueva estrategia)}

A continuación, se presenta la proyección de flujos de la situación actual y con la nueva estrategia:

Tabla 121

Estado de Flujos Directo Sin estrategia de la UEN Tubos y Esquineros - CARVIMSA

\begin{tabular}{|c|c|c|c|c|}
\hline $\begin{array}{r}\text { UEN TUBOS Y ESQUINERO } \\
\text { ESTADO DE FLUJOS DE EFE } \\
(\text { Notas 1, 2 y 3) } \\
(\text { Expresado en Nuevos }\end{array}$ & $\begin{array}{l}\text { CARTON } \\
\text { O DIRECTC }\end{array}$ & & & \\
\hline & & Sin & strategia & \\
\hline & & $\begin{array}{r}\text { Por los a } \\
\text { el } 31 \text { c }\end{array}$ & $\begin{array}{l}\text { s terminado } \\
\text { ciembre de }\end{array}$ & \\
\hline & 2018 & 2019 & 2020 & 2021 \\
\hline ACTIVIDADES DE OPERACIÓN & & & & \\
\hline Utilidad (pérdida) del año & 796,489 & 796,489 & 796,489 & 796,489 \\
\hline Más (menos) & & & & \\
\hline Depreciación de propiedades, planta y equipo & 200,057 & 200,057 & 200,057 & 200,057 \\
\hline Disminución (aumento) de cuentas por cobrar comerciales & 0 & 0 & 0 & 0 \\
\hline Disminución (aumento) de otras cuentas por cobrar & 0 & 0 & 0 & 0 \\
\hline Disminución (aumento) de inventarios & 0 & 0 & 0 & 0 \\
\hline Aumento (disminución) de cuentas por pagar comerciales & 0 & 0 & 0 & 0 \\
\hline Aumento (disminución) de cuentas por pagar a partes relacionadas & $-102,737$ & $-996,546$ & $-996,546$ & $-996,546$ \\
\hline Aumento (disminución) de otras cuentas por pagar & 0 & 0 & 0 & 0 \\
\hline Efectivo y equivalentes de efectivo provisto (aplicado) en actividades de operación & 893,808 & 0 & $(0)$ & (0) \\
\hline $\begin{array}{l}\text { ACTIVIDADES DE INVERSIÓN } \\
\text { Venta de propiedad, planta y equipo }\end{array}$ & & & & \\
\hline Adquisición de propiedad, planta y equipo & 0 & 0 & 0 & 0 \\
\hline Intangible & 0 & 0 & 0 & 0 \\
\hline Efectivo y equivalentes de efectivo aplicado en actividades de inversión & - & - & - & - \\
\hline ACTIVIDADES DE FINANCIAMIENTO & & & & \\
\hline Obligaciones financieras, neto de amortizaciones & 0 & 0 & 0 & 0 \\
\hline Dividendos & $-893,808$ & 0 & 0 & 0 \\
\hline Efectivo y equivalente de efectivo provisto en actividades de financiamiento & $(893,808)$ & - & - & - \\
\hline Aumento de efectivo y equivalente de efectivo & $(0)$ & 0 & $(0)$ & (0) \\
\hline Efectivo y equivalentes de efectivo al inicio del año & $2,333,773$ & $2,333,773$ & $2,333,773$ & $2,333,773$ \\
\hline Efectivo y equivalentes de efectivo al final del año & $2,333,773$ & $2,333,773$ & $2,333,773$ & $2,333,773$ \\
\hline
\end{tabular}


Tabla 122

Estado de Flujos Directo Con estrategia de la UEN Tubos y Esquineros - CARVIMSA

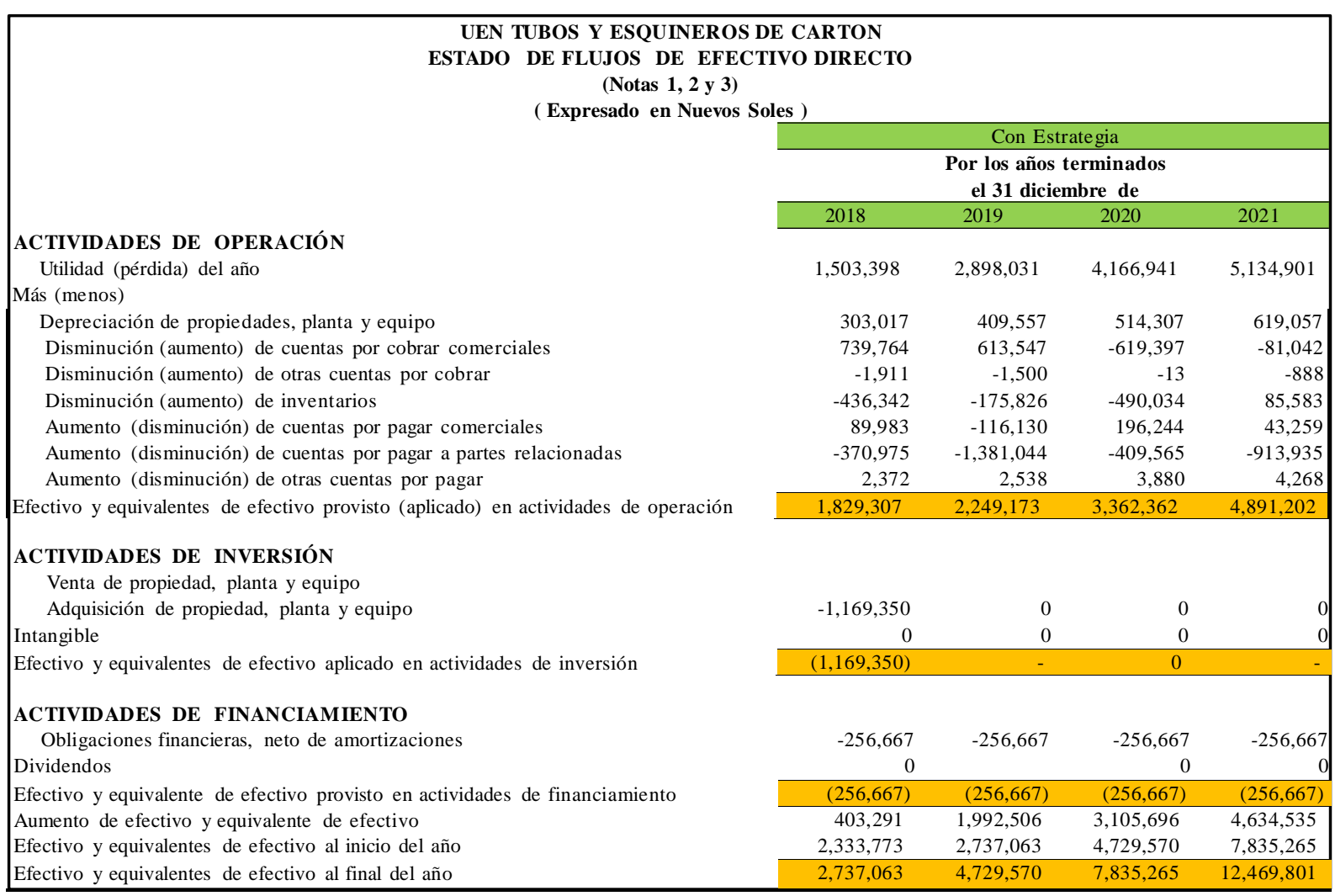




\section{Valorización de la Inversión Inicial}

Tabla 123

Listado de los Activos como inversión de la UEN Tubos y Esquineros - CARVIMSA

\begin{tabular}{|c|c|}
\hline INMUEBLES MAOUINARIAS Y EOUIPOS & $\frac{\text { UN TUBOS Y ESOUINEROS }}{2018}$ \\
\hline Adquisición de Activos & $\mathrm{S} / \mathrm{.}$ \\
\hline ERP & 18,000 \\
\hline Camara de Frio & 8,700 \\
\hline Gas Natural & 25,200 \\
\hline Box Compressión & 6,450 \\
\hline Ampliacion Nave de Planta & 80,000 \\
\hline Ampliacion de Almacen de Productos en Proceso & 15,000 \\
\hline Ampliacion de Almacen de Materias Prima & 15,000 \\
\hline Ampliacion de Almacen de Sub Productos & 15,000 \\
\hline Ampliacion de Almacen de Producto Terminado Tubos & 15,000 \\
\hline Ampliacion de Almacen de Producto Terminado Esquineros & 15,000 \\
\hline Sala de Horno $\mathrm{N}^{\circ} 4$ & 30,000 \\
\hline Tubera $\mathrm{N}^{\circ} 7$ y $\mathrm{N}^{\circ} 8$ & 380,000 \\
\hline Cortadoras Automaticas $\mathrm{N}^{\circ} 3 \mathrm{y} \mathrm{N}^{\circ} 4$ & 125,000 \\
\hline Cortadoras Manuales & 128,000 \\
\hline Slitter $N^{\circ} 4$ & 293,000 \\
\hline Total Activos & $1,169,350$ \\
\hline
\end{tabular}


Tabla 124

Estado de Flujos Directo Incrementado de la UEN Tubos y Esquineros - CARVIMSA

\begin{tabular}{|c|c|c|c|c|}
\hline \multicolumn{5}{|c|}{$\begin{array}{l}\text { UEN TUBOS Y ESQUINEROS DE CARTON } \\
\text { ESTADO DE FLUJOS DE EFECTIVO DIRECTO } \\
(\text { Notas } 1,2 \text { y } 3) \\
\text { ( Expresado en Nuevos Soles ) }\end{array}$} \\
\hline & \multicolumn{4}{|c|}{$\begin{array}{r}\text { Proyecto (Incremental) } \\
\end{array}$} \\
\hline & \multicolumn{4}{|c|}{$\begin{array}{c}\text { Por los años terminados } \\
\text { el } 31 \text { diciembre de }\end{array}$} \\
\hline & 2018 & 2019 & 2020 & 2021 \\
\hline \multicolumn{5}{|l|}{ ACTIVIDADES DE OPERACIÓN } \\
\hline Utilidad (pérdida) del año & 706,909 & $2,101,542$ & $3,370,452$ & $4,338,412$ \\
\hline \multicolumn{5}{|l|}{ Más (menos) } \\
\hline Depreciación de propiedades, planta y equipo & 102,960 & 209,500 & 314,250 & 419,000 \\
\hline Disminución (aumento) de cuentas por cobrar comerciales & 739,764 & 613,547 & 619,397 & 81,042 \\
\hline Disminución (aumento) de otras cuentas por cobrar & 1,911 & 1,500 & 13 & 888 \\
\hline Disminución (aumento) de inventarios & 436,342 & 175,826 & 490,034 & 85,583 \\
\hline Aumento (disminución) de cuentas por pagar comerciales & 89,983 & 116,130 & 196,244 & 43,259 \\
\hline Aumento (disminución) de cuentas por pagar a partes relacionadas & 268,237 & 384,498 & 586,981 & 82,611 \\
\hline Aumento (disminución) de otras cuentas por pagar & 2,372 & 2,538 & 3,880 & 4,268 \\
\hline Efectivo y equivalentes de efectivo provisto (aplicado) en actividades de operación & 935,499 & $2,249,173$ & $3,362,362$ & $4,891,202$ \\
\hline \multicolumn{5}{|l|}{$\begin{array}{l}\text { ACTIVIDADES DE INVERSIÓN Venta de } \\
\text { propiedad, planta y equipo Adquisición de }\end{array}$} \\
\hline Intangible & - & - & 0 & - \\
\hline Efectivo y equivalentes de efectivo aplicado en actividades de inversión & $(1,169,350)$ & - & - & - \\
\hline \multicolumn{5}{|l|}{ ACTIVIDADES DE FINANCIAMIENTO } \\
\hline Obligaciones financieras, neto de amortizaciones & 256,667 & 256,667 & 256,667 & 256,667 \\
\hline Dividendos & 893,808 & - & 0 & - \\
\hline Efectivo y equivalente de efectivo provisto en actividades de financiamiento & 637,142 & $(256,667)$ & $(256,667)$ & $(256,667)$ \\
\hline Aumento de efectivo y equivalente de efectivo & 403,291 & $1,992,506$ & $3,105,695$ & $4,634,535$ \\
\hline Efectivo y equivalentes de efectivo al inicio del año & $2,333,773$ & $2,737,063$ & $4,729,570$ & $7,835,265$ \\
\hline Efectivo y equivalentes de efectivo al final del año & $2,737,063$ & $4,729,570$ & $7,835,265$ & $12,469,801$ \\
\hline
\end{tabular}

Cabe mencionar, que por política de los directores del Grupo Comeca, la empresa no repartirá Dividendos en los próximos 10 años, ya que piensas en reinvertir, por ello no se ha considerado en el flujo de caja proyectado.

\subsubsection{Evaluación Financiera (VAN, TIR, WACC, COK, PRC y ratios financieras)}

Gitman y Zutter (2016) precisan que:

El valor presente neto (VPN) es una técnica más desarrollada de elaboración de presupuesto de capital; se calcula restando la inversión inicial de un proyecto del 
valor presente de sus flujos de entrada de efectivo, descontados a una tasa equivalente al costo de capital de la empresa (p.403).

La tasa interna de rendimiento (TIR) es un indicador de la rentabilidad de un proyecto, el cual hace referencia a la tasa constante a la que se tendría que descontar un proyecto para hacer que el valor presente neto sea igual a cero. (Gitman y Zutter. 2016)

\section{Cálculo del COK}

Para calcular el COK se ha utilizado el modelo CAPM, para lo cual se ha aplicado la fórmula detallada en la figura 138. Así mismo los valores empleados para calcular el COK se muestran en la figura 139.

$$
\mathrm{COK}=\mathrm{RF}+\text { Beta apalancada }(\mathrm{Rm}-\mathrm{RF})+\mathrm{RP}
$$

Figura 138. Fórmula de cálculo del COK

\begin{tabular}{|l|r|}
\hline Año & 2017 \\
\hline Tasa Impuesto a la renta (t) & $29.5 \%$ \\
Beta Desapalancado & 0.74 \\
\hline Estructura de capital & \\
\hline Deuda (D) & $13,478,375$ \\
Patrimonio (E) & $8,006,001$ \\
\hline D+E & $21,484,376$ \\
\hline D/E & 1.68 \\
Beta Apalancado & 1.62 \\
Tasa Libre de Riesgo (RF) & $2.08 \%$ \\
Prima Riesgo de Mercado (Rm - RF) & $6.26 \%$ \\
Riesgo País (RP) & $1.72 \%$ \\
\hline COK (tasa mínima del accionista) & $13.94 \%$ \\
\hline
\end{tabular}

Figura 139. Valores para el cálculo del COK. Valores tomados de SUNAT, Damodaran y BCRP.

Los valores empleados, así como la fuente para cada variable se describen a continuación: 
- Tasa libre de riesgo (RF): La tasa libre de riesgo considerado es de $2.08 \%$, el cual representa el promedio de los dos (02) últimos años del valor del bono del tesoro a un plazo de 10 años. La información fue obtenida de la página web de Banco Central de Reserva del Perú.

- Beta Apalancada: Para el cálculo de la beta apalancada se ha considerado la siguiente fórmula:

Beta Apalancada $=$ Beta Desapalancada $\times(1+(\mathrm{D} / \mathrm{E}) \times(1-\mathrm{t}))$

Figura 140. Fórmula de cálculo del Beta Apalancada

Los valores empleados para cada variable se describen a continuación:

- Beta Desapalancada: La beta desapalancada ha sido considerado debido a que el inversionista (Grupo Comeca) se encuentra diversificado dado que opera en diferentes sectores. El valor de 0.74 se ha obtenido de la página web de Damodaran.

- Deuda (D): Esta variable se ha obtenido del Balance General de la UEN Tubos y Esquineros de CARVIMSA. El valor es S/ 13,478,375

- Patrimonio (E): Esta variable se ha obtenido del Balance General de la UEN Tubos y Esquineros de CARVIMSA. El valor es S/ 8,006,001

- Tasa de Impuesto a la Renta (t): El valor se ha obtenido de la página web de SUNAT y corresponde a $29.5 \%$.

- Prima Riesgo de Mercado (RM - RF): El valor $6.26 \%$ obtenido se ha calculado de la serie histórica de la página web de Damodaran.

- Riesgo País (RP): El valor de $1.72 \%$ representa el promedio de los dos (02) últimos años del valor de riesgo país de Perú. La información fue obtenida de la página web de Banco Central de Reserva del Perú. 
Finalmente, la aplicación de los valores antes mencionados revela un resultado del

COK de $13.94 \%$, la cual se muestra en la figura 141:

\begin{tabular}{|c|}
\hline $\mathrm{COK}=\mathrm{RF}+$ Beta apalancada $(\mathrm{RM}-\mathrm{RF})+\mathrm{RP}$ \\
\hline $13.94 \%=2.08 \%+1.62(6.26 \%)+1.72 \%$ \\
\hline
\end{tabular}

Figura 141. Aplicación de los valores para el cálculo del COK

\section{Cálculo del WACC}

El Weighted Average Cost of Capital (WAAC) o también conocido como Costo Promedio Ponderado de Capital, es el costo de las fuentes de capital, que se utilizaron en financiar los activos estructurales (permanentes o de largo plazo) de la empresa. Para calcular el WACC se ha empleado la fórmula que se muestra en la figura 142. Así mismo los valores empleados para calcular se muestran en la figura 143.

$\mathrm{WACC}=\mathrm{COK} \times(\mathrm{E} /(\mathrm{D}+\mathrm{E}))+\mathrm{Rd} \times(1-\mathrm{t}) \times(\mathrm{D} /(\mathrm{D}+\mathrm{E}))$

Figura 142. Fórmula del WACC

\begin{tabular}{|l|r|}
\hline Variables & Valores \\
\hline Costo de la deuda (Rd) & $6.00 \%$ \\
D/ (D+E) & 0.63 \\
E/(D+E) & 0.37 \\
Tasa Impuesto a la renta (t) & $29.50 \%$ \\
\hline WACC (tasa mínima para la empresa) & $7.85 \%$ \\
\hline
\end{tabular} Figura 143. Valores para el cálculo del WACC.

Los valores empleados, así como la fuente para cada variable se describen a continuación: 
- Costo de la Deuda (Rd): El costo de la deuda de CARVIMSA se ha obtenido del promedio de las tasas de interés que tiene la empresa con los bancos. El valor resultante es del $6 \%$.

- Deuda (D): Esta variable se ha obtenido del Balance General de la UEN Tubos y Esquineros de CARVIMSA. El valor es S/ 13,478,375

- Patrimonio (E): Esta variable se ha obtenido del Balance General de la UEN Tubos y Esquineros de CARVIMSA. El valor es S/ 8,006,001

- Tasa Impuesto a la renta (t): El valor se ha obtenido de la página web de SUNAT y corresponde a $29.5 \%$.

Finalmente, la aplicación de los valores antes mencionados revela un resultado del WACC de $7.85 \%$, la cual se muestra en la figura 144 :

\begin{tabular}{|c|}
\hline WACC $=$ COK $\times(\mathrm{E} /(\mathrm{D}+\mathrm{E}))+\mathrm{Rd} \times(1-\mathrm{t}) \times(\mathrm{D} /(\mathrm{D}+\mathrm{E}))$ \\
\hline $7.85 \%=13.94 \% \times 0.37+6 \% \times(1-29.5 \%) \times 0.63$ \\
Figura 144. Aplicación de los valores para el cálculo del WACC
\end{tabular}

\section{Cálculo VAN}

Para calcular el VAN, se descuenta los flujos de efectivo a una tasa que hace referencia al costo de capital de la empresa (COK), el cual es del $13.94 \%$ para CARVIMSA.

\begin{tabular}{|c|c|c|c|c|c|}
\hline \multicolumn{6}{|c|}{ Valor Actual Neto (VAN) - UEN Tubos y Esquineros de Cartón } \\
\hline COK & $13.94 \%$ & 2018 & 2019 & 2020 & 2021 \\
\hline Periodo & & 1 & 2 & 3 & 4 \\
\hline Valor Actual $(\mathrm{VA})=$ & & $\mathrm{S} / .821,075$ & S/.1,732,616 & $\mathrm{S} / .2,273,335$ & $\mathrm{~S} / .2,902,514$ \\
\hline Valor Actual Total (VAT) & & & & & S/.7,729,540 \\
\hline Valor Actual Neto $(\mathrm{VAN})=$ & Propiedades & & & & $\mathrm{S} / .6,560,190$ \\
\hline
\end{tabular}

Figura 145. Cálculo del VAN 
Como se puede observar, el VAN es positivo $(+6,560,190)$; de modo que el proyecto es rentable.

\section{Cálculo de la TIR}

El resultado de la TIR, empleando la función de Excel +TIR, dio como resultado $140 \%$. Lo que quiere decir que es mayor que el costo de capital de la empresa.

\begin{tabular}{|ccccccc|}
\hline & \multicolumn{2}{c|}{ Tasa Interna de Retorno (TIR) - UEN Tubos y Esquineros de Cartón } \\
\hline TIR & 2017 & & 2018 & 2019 & 2020 & 2021 \\
\hline & - & $1,169,350$ & 935,499 & $2,249,173$ & $3,362,362$ & $4,891,202$ \\
\hline Tasa Interna de Retorno (TIR) & \multicolumn{7}{c}{} & & & $140 \%$ \\
\hline
\end{tabular}

Figura 146. Cálculo de la TIR

\section{Cálculo del PRC}

El resultado del cálculo del periodo de recuperación del capital se obtuvo sumando la inversión y el flujo del año 2018, a este resultado se le obtiene el valor absoluto y se divide entre el flujo del año 2019 ya que en dicho periodo el flujo acumulado deja de ser negativo. El resultado se multiplica por 365, para obtener la fracción adicional al año, como resultado final obtenemos 1 año y 140 días.

\begin{tabular}{|c|c|c|c|c|c|}
\hline PRC & Inversion & 2018 & 2019 & 2020 & 2021 \\
\hline Aumento de efectivo y equivalente de efectivo & - $1,169,350$ & 403,291 & $1,992,506$ & $3,105,695$ & $4,634,535$ \\
\hline Flujos Acumlados al 2018 & - $\quad 766,059$ & & & & \\
\hline Valor Absoluto & 766,059 & & & & \\
\hline Fracción de año & 0.38 & & & & \\
\hline Periodo de Recuperación de la Inversión PRC & 1 Año + 140 días & & & & \\
\hline
\end{tabular}

Figura 147. Cálculo del PRC 


\section{Ratios de Liquidez}

○ Razón Corriente

$$
\text { Razón corriente }=\frac{\text { Activo } C P}{\text { Pasivo } C P}
$$

Figura 148. Fórmula de Razón corriente

Tabla 125

Resultados de la Razón Corriente

\begin{tabular}{ccccc}
\hline $\mathbf{2 0 1 7}$ & $\mathbf{2 0 1 8}$ & $\mathbf{2 0 1 9}$ & $\mathbf{2 0 2 0}$ & $\mathbf{2 0 2 1}$ \\
\hline 1.03 & 1.07 & 1.47 & 2.06 & 3.01 \\
\hline
\end{tabular}

Se observa que la disponibilidad de la UEN Tubos y Esquineros de CARVIMSA de los últimos cuatro años son sostenibles, por lo cual puede afrontar sus deudas en el corto plazo.

\section{○ Prueba ácida}

$$
\text { Prueba ácida }=\frac{\text { Activo } C P-\text { Inventario }}{\text { Pasivo } C P}
$$

Figura 149. Fórmula de la prueba ácida.

Tabla 126

Resultados de la Prueba ácida

\begin{tabular}{ccccc}
\hline $\mathbf{2 0 1 7}$ & $\mathbf{2 0 1 8}$ & $\mathbf{2 0 1 9}$ & $\mathbf{2 0 2 0}$ & $\mathbf{2 0 2 1}$ \\
\hline 0.70 & 0.68 & 0.99 & 1.50 & 2.39 \\
\hline
\end{tabular}

Los resultados muestran que la empresa a partir del año 2019 en adelante tiene disponibilidad de efectivo para poder afrontar sus deudas en el corto plazo. 


\section{- Prueba defensiva}

$$
\text { Prueba defensiva }=\frac{\text { Caja }+ \text { Equivalentes de efectivo }}{\text { Pasivo } C P}
$$

Figura 150. Fórmula de la prueba defensiva

Tabla 127

Resultados de la Prueba defensiva

\begin{tabular}{ccccc}
\hline $\mathbf{2 0 1 7}$ & $\mathbf{2 0 1 8}$ & $\mathbf{2 0 1 9}$ & $\mathbf{2 0 2 0}$ & $\mathbf{2 0 2 1}$ \\
\hline 0.24 & 0.29 & 0.60 & 1.02 & 1.84 \\
\hline
\end{tabular}

Al comparar el resultado del año 2017 y el del año 2021 se refleja una mejora en los indicadores, ya que este ratio considera únicamente los activos registrados en caja y bancos, el aumento de este ratio se da por la disminución de días de crédito a los clientes, de esta manera la capacidad de la UEN para operar con sus activos es más líquidos.

\section{Ratios de actividad}

○ Rotación de inventarios

$$
\text { Rotación de inventarios }=\frac{\text { Costo de Ventas }}{\text { Existencias }}
$$

Figura 151. Fórmula de la rotación de inventarios.

Tabla 128

Resultados de la rotación de inventarios(días)

\begin{tabular}{ccccc}
\hline $\mathbf{2 0 1 7}$ & $\mathbf{2 0 1 8}$ & $\mathbf{2 0 1 9}$ & $\mathbf{2 0 2 0}$ & $\mathbf{2 0 2 1}$ \\
\hline 119.54 & 93.70 & 79.94 & 76.32 & 68.34 \\
\hline
\end{tabular}

Al implementar las estrategias recomendadas como la penetración de mercado, se observa que el número de veces al año que se vende el inventario disminuye, es decir 
rota más rápido y eso es algo positivo, pero también es una alerta para que el área de planificación esté atenta con el requerimiento de las importaciones de insumos.

\section{○ Rotación de cuentas por cobrar}

$$
\text { Rotación cuentas por cobrar }=\frac{\text { Ventas Netas }}{\text { Cuentas por Cobrar comerciales }}
$$

Figura 152. Fórmula de la rotación de cuentas por cobrar

Tabla 129

Resultados de la rotación de cuentas por cobrar(días)

\begin{tabular}{ccccc}
\hline $\mathbf{2 0 1 7}$ & $\mathbf{2 0 1 8}$ & $\mathbf{2 0 1 9}$ & $\mathbf{2 0 2 0}$ & $\mathbf{2 0 2 1}$ \\
\hline 132.45 & 91.24 & 62.45 & 59.97 & 54.98 \\
\hline
\end{tabular}

Se observa que se cumple uno de los objetivos que es reducir el tiempo en que se cobra y se vuelve a dar crédito, este ratio permite deducir la edad promedio en días de las cobranzas.

\section{○ Rotación de cuentas por pagar}

Rotacion de Cuentas por Pagar $=$ Costo de Ventas

Cuentas por Pagar Comerciales

Figura 153. Fórmula de la rotación de cuentas por pagar .

Tabla 130

Resultados de la rotación de cuentas por pagar(días)

\begin{tabular}{ccccc}
\hline $\mathbf{2 0 1 7}$ & $\mathbf{2 0 1 8}$ & $\mathbf{2 0 1 9}$ & $\mathbf{2 0 2 0}$ & $\mathbf{2 0 2 1}$ \\
\hline 363.00 & 242.68 & 165.25 & 136.15 & 110.17 \\
\hline
\end{tabular}

Muestra que se ha logrado mejorar los plazos de pago a los proveedores, este ratio permite deducir la edad promedio en días de los pagos, además al replantear las líneas de crédito, pudieron liberar en partes intereses generados por los proveedores 
externos. En la composición a los proveedores tenemos a los externos como a sus vinculadas.

\section{Ratios de Solvencia}

\section{○ Endeudamiento total}

\section{Endeudamiento total $=\frac{\text { Pasivo Total }}{\text { Activo Total }}$}

Figura 154. Fórmula de endeudamiento total.

Tabla 131

Resultados de endeudamiento total

\begin{tabular}{lllll}
\hline $\mathbf{2 0 1 7}$ & $\mathbf{2 0 1 8}$ & $\mathbf{2 0 1 9}$ & $\mathbf{2 0 2 0}$ & $\mathbf{2 0 2 1}$ \\
\hline $63 \%$ & $58 \%$ & $47 \%$ & $39 \%$ & $31 \%$ \\
\hline
\end{tabular}

El grado de endeudamiento de la UEN tiende a disminuir respecto a los activos totales que harán frente a las obligaciones contraídas. El ratio de endeudamiento ideal se sitúa entre $40 \%$ y $60 \%$. En este caso la UEN podría estar incurriendo en un exceso de capitales ociosos, el cual deberían replantear aumento de inversiones (Deudas a Largo Plazo).

\section{○ Deuda Capital}

$$
\text { Deuda a capital }=\frac{\text { Pasivo } \text { Total }}{\text { Patrimonio }}
$$

Figura 155. Fórmula de deuda a capital

Tabla 132

Resultados de deuda a capital

\begin{tabular}{lllll}
\hline $\mathbf{2 0 1 7}$ & $\mathbf{2 0 1 8}$ & $\mathbf{2 0 1 9}$ & $\mathbf{2 0 2 0}$ & $\mathbf{2 0 2 1}$ \\
\hline $168 \%$ & $136 \%$ & $90 \%$ & $65 \%$ & $44 \%$ \\
\hline
\end{tabular}


En este caso muestra el grado de endeudamiento con relación al patrimonio, este ratio disminuye considerablemente. La UEN adquiriría una deuda para crecer y ganar mercado, investigar y desarrollar nuevos mercados, para ello debe mantener vigilada la deuda con relación a su capital a fin de generar el efectivo que se requiera para operar y cumplir con sus obligaciones.

\section{Ratios de Rentabilidad}

○ Margen de Utilidad

$$
\text { Margen de utilidad }=\frac{\text { Utilidad Neta }}{\text { Ventas Netas }}
$$

Figura 156. Fórmula de margen de utilidad.

Tabla 133

Resultados de margen de utilidad (\%)

\begin{tabular}{ccccc}
\hline $\mathbf{2 0 1 7}$ & $\mathbf{2 0 1 8}$ & $\mathbf{2 0 1 9}$ & $\mathbf{2 0 2 0}$ & $\mathbf{2 0 2 1}$ \\
\hline $7 \%$ & $8 \%$ & $12 \%$ & $15 \%$ & $16 \%$ \\
\hline
\end{tabular}

Se observa la eficiencia final de la UEN, se proyectó un incremento del margen de utilidad lo cual se ve reflejado en los resultados, incrementándose en el 2021 a más del 100\% respecto al 2017. Mientras mayor sea el incremento económico esto nos señalará la capacidad que tendría para aumentar su rentabilidad.

\section{○ Return on Assets (ROA)}

$$
\text { ROA }=\frac{\text { Utilidad Neta }}{\text { Activos Totales }}
$$

Figura 157. Fórmula de ROA. 
Tabla 134

Resultados de ROA

\begin{tabular}{ccccc}
\hline $\mathbf{2 0 1 7}$ & $\mathbf{2 0 1 8}$ & $\mathbf{2 0 1 9}$ & $\mathbf{2 0 2 0}$ & $\mathbf{2 0 2 1}$ \\
\hline $7 \%$ & $12 \%$ & $24 \%$ & $36 \%$ & $45 \%$ \\
\hline
\end{tabular}

Los activos muestran una tendencia a incrementar su valor y paralelamente las utilidades siguen esa tendencia, lo cual nos indica que los costos están bien controlados.

\section{○ Return on Equity (ROE)}

$$
R O E=\frac{\text { Utilidad Neta }}{\text { Patrimonio }}
$$

Figura 158. Fórmula de ROE.

Tabla 135

Resultados de ROE

\begin{tabular}{lllll}
\hline $\mathbf{2 0 1 7}$ & $\mathbf{2 0 1 8}$ & $\mathbf{2 0 1 9}$ & $\mathbf{2 0 2 0}$ & $\mathbf{2 0 2 1}$ \\
\hline $10 \%$ & $16 \%$ & $23 \%$ & $25 \%$ & $24 \%$ \\
\hline
\end{tabular}

Esta razón señala la tasa de rendimiento que obtienen los propietarios respecto a la inversión representada en el patrimonio. Esta tasa tiene un incremento a partir del 2018. 


\section{Conclusiones y Recomendaciones}

\section{Conclusiones}

1. CARVIMSA al ser una empresa en marcha ya contaba con una misión, visión y valores corporativos los cuales forman parte de su identidad institucional, tras una revisión de su composición se encontraron elementos que no fueron considerados y que son relevantes para la industria en que se desarrolla, se realizaron nuevas propuestas.

2. Al realizar el análisis de la Matriz Interna Externa, se ha determinado que la posición de la UEN Tubos y Esquineros está el cuadrante de las estrategias intensivas de penetración de mercado, desarrollo de mercado y desarrollo de producto.

3. El análisis de portafolio de productos actuales de CARVIMSA realizado mediante la matriz BCG permite concluir que la UEN Tubos y Esquineros se encuentra en el cuadrante de las estrellas, por ello debe aprovechar el rápido crecimiento como potencial para ganar aún más cuota de mercado.

4. Luego de tomar en cuenta los criterios para la selección de la estrategia y el método de escenarios, se determinó que la estrategia principal es la penetración de mercado. Se han determinado los siguientes objetivos estratégicos a) Incrementar de forma simultánea el volumen de venta en un 55\% para el 2018, 27\% para el 2019, 20\% para el 2020 y $11 \%$ para el 2021 , b) Incrementar en un $9 \%$ de utilidad neta sobre las ventas proyectadas al año 2021 y c) Incrementar en un $42 \%$ la participación en el mercado con medición a fines del año 2021. Actualmente CARVIMSA tiene una participación 
del $43 \%$. Incrementar un $42 \%$ la facturación al año 2021, logrando el objetivo de los \$ 10,425,794 anuales.

5. El análisis financiero, luego de la implementación de la estrategia planteada en el Plan Estratégico 2018-2021, permite concluir que es rentable obtener un VAN de S/. $4,997,214.02$ y una TIR de $151 \%$. Al tener un VAN y una TIR por encima del costo de capital se recomienda la implementación del Plan Estratégica.

\section{Recomendaciones}

1. Implementar el plan estratégico partiendo de los hallazgos en el análisis interno y externo de la unidad estratégica de negocio "Tubos y Esquineros" de la empresa CARVIMSA

1.1.La Unidad Estratégica Tubos y Esquineros, requiere de una reestructuración organizacional, que le permita afrontar el crecimiento y las acciones que se plantean en el plan estratégico.

1.2. Deben planificar con tiempo tener inventarios efectivos, ya que se está suscitando una crisis en las industrias papeleras internacionales (Estados Unidos y Japón), el cual les provee de manera directa e indirecta las materias primas y los insumos de materias auxiliares (costos variables), por ende, deben hacer simulaciones o proyecciones de la situación económica de la empresa, con el fin de replantear estos insumos en el mercado local.

2. Llevar a cabo las iniciativas para el cumplimiento de los objetivos estratégicos para la unidad estratégica del negocio "Tubos y Esquineros" de la empresa CARVIMSA. 
2.1.Para poder llegar con el plan estratégico recomendado se debe cumplir con los objetivos estratégicos dados, como:

2.1.1. Adquisición de nuevas maquinarias planteadas, ampliación de planta y almacenes, con el objetivo de poder llegar a la producción y venta proyectada.

2.1.2. Tener una Gerencia comercial consolidada, con áreas claves que aporten a mantener y aumentar los volúmenes de ventas, tanto el mercado nacional como internacional. Estas áreas que se plantean son: Servicio al Cliente, Diseño de Empaques, Vendedores y Diseño Gráfico.

2.1.3. La mejora en la rentabilidad es uno de los puntos más importantes en el plan estratégico, para llegar a los valores planteados, se necesita que exista la comunicación y la interacción de la Gerencia de Planta y de la Gerencia Comercial, con el fin de planificar con tiempo la producción de los clientes, realizar pruebas de nuevos productos solicitados por la nueva de cartera de clientes que se propone esta unidad estratégica y sobre todo que la Gerencia de planta y Calidad puedan desarrollar nuevos tipos de papeles, que les permitirá a mejorar sus costos pero manteniendo la calidad y resistencia de los productos. Teniendo todos estos puntos dados, se podrá llevar un control adecuado de los costos y gastos operativos de la unidad, el cual les permitirá tener una mejora en la utilidad neta.

2.1.4. El área comercial deberá tener definido y claro los sectores que les son más rentables, con el fin de poder aumentar su participación de mercado, para llegar a eso la Gerencia comercial planteara la cartera de clientes por ejecutivos y dar metas de ventas anuales tanto en toneladas métricas vendidas como en dólares realizados, para eso deben tener indicadores y tener mínimos, promedio y máximo. 


\section{Implementar la estrategia seleccionada para la unidad estratégica de negocio} "Tubos y Esquineros" CARVIMSA.

3.1.Se analizó y seleccionó la estrategia de penetración de mercado, debido a que la UEN Tubos y Esquineros proyecta un crecimiento sostenido en las ventas, es por ello que se debe consolidar las actividades como mercadotécnica, publicidad, relaciones con los clientes y el servicio post venta.

3.2.Con la finalidad de que la estrategia sea eficiente, es preciso mantener o mejora las fortalezas que tiene la UEN, como: i) materia prima obtenida del Molino propio, ii) competitividad de precios, iii) mayor participación del mercado, iv) sin antecedentes de contaminación ambiental y v) hornos con conexión a gas natural.

3.3.Por último, para lograr los resultados dados en la estrategia seleccionada, es necesario tomar acciones para hacer frente a la amenazas y debilidades, es por ellos que resulta necesario e indispensable la contratación del Gerente de Producción que se encargue de gestionar y analizar los costos de forma eficiente a fin de maximizar el margen de utilidad.

\section{Determinar la implementación de la estrategia}

4.1.Se determinó que, para poder implementar la estrategia, es necesario que la UEN Tubos y Esquineros debe enfocarse en la gestión de cuatro procesos internos claves: i) aprendizaje y crecimiento, ii) Procesos Internos, iii) Clientes y iv) Financiero, si cumplen con los lineamientos planteados por cada uno de estas, podrán tener un rendimiento superior a otras empresas similares al rubro.

4.2. Se le mostrará y planteará a la UEN Tubos y esquineros cada punto por estrategia que deberá realizar, para así llegar a los ideales económicos planteados.

\subsubsection{Objetivo de Aprendizaje y crecimiento: Este objetivo se enfoca al recurso} humano que debe tener la UEN, el cual deberá estar basado en la información, 
motivación y calidad de trabajo que se le dará al personal, es por ello por lo que para cumplir lo propuesto, se deberá mejorar el porcentaje de trabajadores calificados y mejorar el clima organizacional.

4.2.2. Objetivos de Procesos Internos: se planteó mejorar y optimizar aún más la calidad de los productos, teniendo de la mano tecnología de punta, para llegar a ello se deberá innovar los procesos, planificar las actividades eficientemente y optimizar los procesos.

4.2.3. Objetivos de Clientes: se concluyó que, para lograr este objetivo, se debe cumplir con la mayor parte de las expectativas que tiene el cliente. Los objetivos que deberá trabajar la UEN es demostrar que la UEN es el proveedor líder en el sector de envases de tubos y esquineros, fidelizar a los clientes e incrementar la satisfacción de los clientes.

4.2.4. Objetivos Financieros: como recomendación a esta UEN, se pide mucho control de los márgenes de rentabilidad, incrementar el ROA, reducir los costos operativos y optimizar el uso de los activos, cumpliendo con estos ratios de indicadores financieros, podrán llegar con éxito a los valores presupuestados.

\section{Realizar la comparación de la evaluación económica - financiera real con la} proyectada del proyecto con la nueva estrategia.

5.1.Dado todos los metas y estrategias dadas con el plan estratégico, tanto de manera cuantitativa como cualitativa, se recomienda que esta unidad aumenta sus inversiones dadas en activos (maquinarias y equipos), ya que cuenta con una alta rentabilidad el cual les puede permitir sacar productos de tubos y esquineros flexo gráficas, la inversión es mayor, pero tendría aun mayor participación en el mercado internacional, el cual sería reconocido no solo de manera nacional sino internacional, por los demás ratios o estados financieros, se muestran sostenibles en el tiempo. 


\section{Referencias}

Arthur, A., Thompson, M., Peteraf, J. Gamble, A \& Strickland, III. (2014). Administración Estratégica teoría y casos decimonovena edición. México: Mc Graw Hill Education

Banco Central de Reserva del Perú. (2016). Perú obtiene la mejor calificación en Libertad Monetaria en América Latina (Nota informativa 2016-09-18). Recuperado de http://www.bcrp.gob.pe/docs/Transparencia/Notas-Informativas/2016/nota-informativa-201609-18.pdf

Banco Central de Reserva del Perú (2017). Resumen Informativo Semanal $N^{\circ} 14$. Recuperado de http://www.bcrp.gob.pe/docs/Publicaciones/Nota-Semanal/2017/resumeninformativo-14-2017.pdf

Banco Mundial (2017). Informe del Panorama Mundial. Recuperado del Sitio de Internet del Banco Mundial: http://www.bancomundial.org/es/country/peru/overview

Briceño, O. (diciembre, 2016). Latinoamérica: coyuntura económica y perspectivas 2017. Revista Oficial de la Asociación de Corrugadores del Caribe, Centro y Suramérica (ACCCSA) Edición N $N^{\circ} 6$. Recuperado de http://pdf.corrugando.com/CORRUGANDO-56.pdf

Brenes, P. (2015) Técnicas de Almacén Ciclos Formativos. España: Editex.

Cabrera, J. (diciembre, 2016). Desarrollo Sostenible y Economía Circular y no le demos más vueltas. Revista Oficial de la Asociación de Corrugadores del Caribe, Centro y Suramérica (ACCCSA) Edición No56. Recuperado de http://pdf.corrugando.com/CORRUGANDO-56.pdf

Campodónico, J. (2002). Análisis del Reciclaje de Papel y Cartón en la Ciudad de Chiclayo (tesis de pregrado), Universidad de Piura,

Corrugated Packaging Alliance (2017). History of corrugated. Recuperado de http://www.corrugated.org/?l=history_of_corrugated

D'Alessio, F. (2008). El proceso estratégico: Un enfoque de gerencia. México: Pearson Educación.

David, F. (2013). Conceptos de Administración Estratégica. México: Pearson Educación.

Diez, T. (2017). El arte de la construcción en papel de Shigeru Ban. Código Diez. Recuperado de http://www.codigodiez.mx/textosarquitectoura/shigeruban.html

El mercado de empaque de Cartón Corrugado en Desaceleración. (febrero, 2017). Revista

Oficial de la Asociación de Corrugadores del Caribe, Centro y Suramérica

(ACCCSA) Edición N $N^{\circ}$ 7. Recuperado de http://pdf.corrugando.com/CORRUGANDO-57.pdf 
El Niño costero: Daños ya suman US\$3,124 millones según Macroconsult (24 de marzo de 2017). RPP Noticias. Recuperado de http://rpp.pe/economia/economia/el-ninocostero-danos-ya-suman-s--noticia-1039319

Estudio de Precios de Transferencia (2015). Cartones Villa Marina SA

European Federation of Corrugated Board Manufacturers (2017). History of corrugated. Recuperado de http://www.fefco.org/corrugated-packaging/history-corrugated

Fondo Monetario Internacional. (2017). Perspectivas de la economía mundial (Informe WEO). Recuperado del sitio de Internet de Fondo Monetario Internacional:

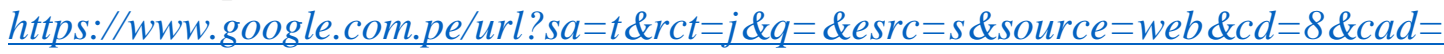
rja\&uact $=8 \& v e d=0 a h U K E$ wibkLv09LXTAhUDKiYKHQ6IBv4QFghLMAc \&url=http s\%3A\%2F\%2Fwww.imf.org $\% 2 F$ external $\% 2 F$ spanish $\% 2 F$ pubs $\% 2 F f t \% 2 F$ weo $\% 2 F 20$ $15 \% 2 F 02 \% 2 \mathrm{Fpdf} \% 2$ Ftexts.pdf\&usg=AFQjCNG12_cjgnYF26OluWcDeyC10WGrQA \&sig2 $=u \quad 04 q 96 g F Q z q F-O 9 M V d 3 b w$

Gálvez, C. V. (17 de febrero de 2015). SNI: Manufactura crecerá 2,5\% en el 2017. Diario El Comercio. Recuperado de http://elcomercio.pe/economia/peru/sni-manufacturacrecera-25-2017-noticia-1969267

Gonzales, T. (31 de marzo de 2017). Niño Costero deja daños severos en la agricultura de regiones de Perú. Mercados \& Regiones. Recuperado de http://mercadosyregiones.com/nino-costero-deja-danos-severos-en-la-agricultura-deregiones-de-peru/

Hernández, A. (diciembre, 2016). Innovación y Tecnología de punta sorprendieron en el 2016. Revista Oficial de la Asociación de Corrugadores del Caribe, Centro y Suramérica (ACCCSA) Edición N ${ }^{\circ} 56$. Recuperado de http://pdf.corrugando.com/CORRUGANDO-56.pdf

Hitt, M., Duane, R. \& Hoskisson, R. (2015). Administración Estratégica. Competitividad y globalización: Conceptos y casos Decimo onceava edición. México: Cergage Learning Editores, SA de CV.

Kaplan, R. \& Norton D. (2004). Strategy maps: converting intangible assets into tangible outcomes. Boston: Harvard Business School Press

Maximixe Consult S.A. (2017). Perú Proyecciones 2016-2018: El futuro de la economía peruana hoy.

Ministerio del Ambiente. (2005). La Ley General del Ambiente $N^{\circ} 28611$. Recuperado de http://cdam.minam.gob.pe/novedades/leygeneralambiente2.pdf

Ministerio de Economía y Finanzas. (2016). Marco Macroeconómico Multianual 2017-2019 Revisado. Recuperado de https://www.mef.gob.pe/contenidos/pol_econ/marco_macro/MMM_2017_2019_Revi sado.pdf 
Ministerio de Producción. (2015). Reglamento de Gestión Ambiental para la Industria Manufacturera y el Comercio Interno. Recuperado de http://www.produce.gob.pe/documentos/mype-industria/diggam/ds017-2015produce.pdf

Perú es el tercer mejor país para hacer negocios en la región. (marzo, 2015). Diario Gestión. Recuperado de http://gestion.pe/noticia/283455/peru-tercer-mejor-pais-hacernegocios-region

Porter, M. (enero, 2008). The Five Competitive Forces That Shape Strategy (Harvard Business Review Analytic Services). Recuperado de https://hbr.org/product/the-fivecompetitive-forces-that-shape-strategy-hbr-bestseller/R0801E-PDF-ENG

Real Academia Española (2005). Recuperado de http://lema.rae.es/dpd/srv/search?key=commodity

Robbins, S., \& Judge, T. (2013). Comportamiento organizacional Decimoquinta edición. México: Pearson Education

Thompson, A. (2015). Administración estratégica Decimonovena edición. México: Mc Graw-Hill Interamericana

Twede, D. (2016). The History of Corrugatd Fiberboard Shipping Contaners. USA: Michigan State University, East Lansing MI.

Unesco (2015). Informe Resumen Analítico del Perú. Recuperado de http://www.infoartes.pe/wp-content/uploads/2014/12/libro-22-Indicadores-deCultura-para-el-Desarrollo2.pdf

Vásquez, G. R. (26 de diciembre de 2016). Entrevista: Magaly Robalino. Diario El Comercio. Recuperado de http://www.unesco.org/new/fileadmin/MULTIMEDIA/FIELD/Lima/pdf/elcomercio.p $\underline{\mathrm{df}}$

Zumbado, S., Briceño C. (diciembre, 2016). El futuro del mercado corrugador es hoy. Revista Oficial de la Asociación de Corrugadores del Caribe, Centro y Suramérica (ACCCSA) Edición N ${ }^{\circ} 56$. Recuperado de http://pdf.corrugando.com/CORRUGANDO-56.pdf 
ANEXOS 


\section{ANEXO 1. Ficha de Entrevistas a Profundidad}

\begin{tabular}{|c|c|}
\hline Método & Cualitativo \\
\hline $\begin{array}{l}\text { Técnica de } \\
\text { recolección de } \\
\text { datos }\end{array}$ & Entrevista a Profundidad \\
\hline $\begin{array}{l}\text { Número de } \\
\text { Entrevistados }\end{array}$ & Siete Personas \\
\hline Participantes & $\begin{array}{l}\text { 1. Gerente General de CARVIMSA SA } \\
\text { 2. Asistente de Compras de OPP Film SA } \\
\text { 3. Coordinador de Logística de Resinplast Holding SAC } \\
\text { 4. Asistente de Compras de Solpack SAC } \\
\text { 5. Jefe de Almacén de Film Pack SAC } \\
\text { 6. Coordinadora de Logística de Peruplast SAC } \\
\text { 7. Gerente de Comercio Exterior de la Cámara de Comercio de Lima }\end{array}$ \\
\hline Reclutamiento & Se convocó a personas con alta experiencia en el rubro. \\
\hline Duración & $15-60$ minutos por entrevista \\
\hline $\begin{array}{l}\text { Fecha de } \\
\text { Levantamiento }\end{array}$ & De 19 al 23 de agosto \\
\hline $\begin{array}{l}\text { Equipo de } \\
\text { Trabajo }\end{array}$ & $\begin{array}{l}\text { Entrevistadores } \\
\quad \text { - } \text { Ingeniero Leniza Llanos } \\
\text { - } \quad \text { Contador Público Colegiado Yanine Casanova } \\
\text { - } \quad \text { Licenciada Angela Rodríguez } \\
\text { Guía de entrevista } \\
\quad \text { - Ingeniero Henry Santa Cruz }\end{array}$ \\
\hline
\end{tabular}




\section{ANEXO 2. Entrevista a Profundidad al Gerente General de CARVIMSA}

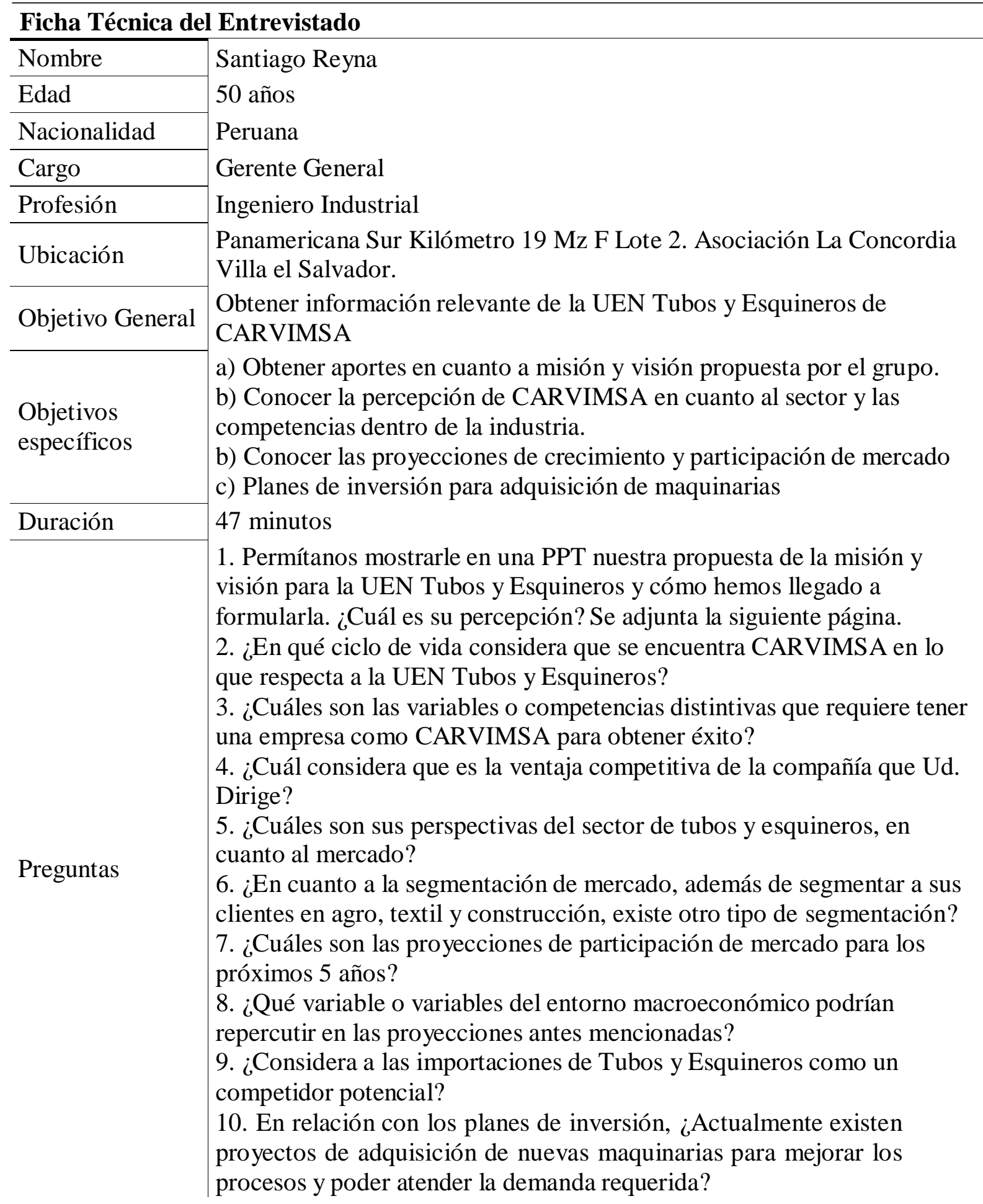


ANEXO 3. Presentación para la Entrevista al Gerente General de CARVIMSA Ci,cll"'"

\section{VISIÓN ACTUAL DE CARVIMSA}

"7i-abajamos con una visión colporativa de manera que en el plazo de cinco a ios habremos alcanzado. El lidemzgo en sei'Vicio al cliente y elz la solución integral de sus necesidades de envases.

Una sólida y creciente presencia en el mercado agroindustrial.

La consolidación de rwestro crecimiento y participación en el segmento domestico del merr;ado naci01zal de enm ses de cartón cormgado."

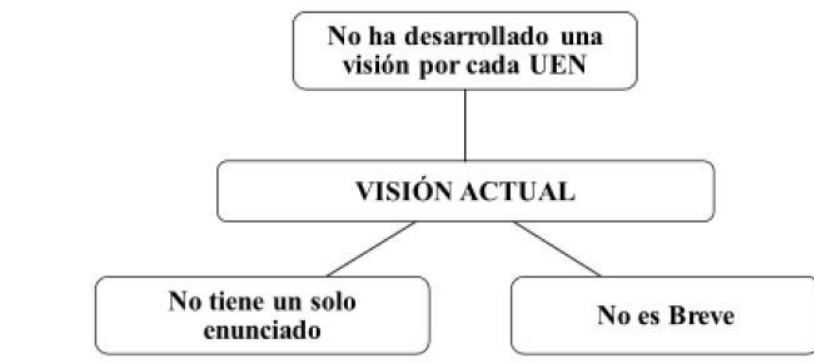

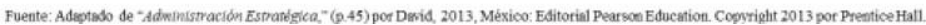

clalMM"'

\section{VISIÓN PROPUESTA PARA LA UEN "TUBOS Y ESQUINEROS"}

"Ser la empresa líder en el Perú en la fabricación y distribución de productos de wbas y esquineros de canón. concemrándose en los sectores de embalaje. agroilzdustrial, colzstmcción y textil."

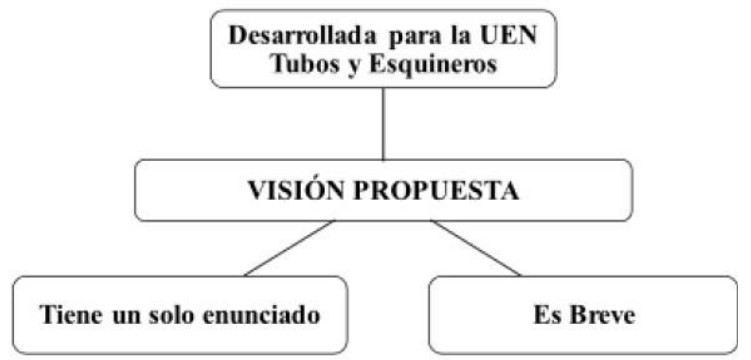




\section{ANEXO 4. Transcripción de la Entrevista al Gerente General de CARVIMSA}

\section{Permítame mostrarle en una PPT nuestra propuesta de la misión y visión para la UEN Tubos y Esquineros y cómo hemos llegado a formularla. ¿Cuál es su percepción? Aportes.}

La misión actual está orientada a cartón corrugado, totalmente, no revela responsabilidad ambiental, justo estamos en la etapa haciendo el planeamiento estratégico de la empresa, entonces vamos en estos meses que quedan antes del fin de año haciendo el próximo planeamiento estratégico para los próximos tres años y la misión y la visión de la empresa va a ser analizada nuevamente, porque esta misión y visión fueron dadas en un momento estamos hablando hace dieciocho años y ya las cosas han cambiado muchísimo, entonces nuestra participación, nuestra presencia, nuestro tamaño de operación.

No revela responsabilidad ambiental. La responsabilidad ambiental es una de las cosas que vamos a tener porque nosotros tenemos un sistema ISO 14000 en la planta, entonces el hecho de tener un sistema ISO 14000 hace que podamos mostrar que estamos preocupados por el medio ambiente, es más, en esta operación la fábrica de cajas y el molino son unidades de negocio que tienen que tener mucho cuidado con el medio ambiente porque se genera desperdicios, nosotros obviamente aprovechamos todos los desperdicios pero hay algunas cosas que tienes que considerar a la hora de hacer algo a largo plazo.

No revela responsabilidad social. Yo creo que más que no revela responsabilidad social, sí, responsabilidad social estamos hablando con respecto a nuestros stakeholders externos, porque en el interno si están, sobre la base del desarrollo humano y una actitud positiva frente al cambio, eso está revelando lo que son nuestros colaboradores en el interno, pero en el externo obviamente la responsabilidad social no la tenemos, pero debería estar contemplada con el tema medioambiental.

La utilidad de los productos. Para hacer una misión que tenga identificado cada producto, claro nosotros no tenemos una misión y visión para lo que es la división tubos, la división molino y la división cartón corrugado sino una sola porque en realidad somos una sola empresa con tres unidades de negocio y entonces el concepto de una empresa para nosotros tiene que ser que todos piensen lo mismo, no podemos dentro de la misma empresa tres grupos de personas pensando diferente porque personas que trabajan en la unidad de corrugad, en papel, pueden ser trasladadas como ha pasado. Para nosotros formar una nueva división sacamos de, en este caso, la división donde estamos en este momento a los profesionales que pueden ayudarnos a formar, a colonizar, a culturizar nuevas empresas. Entonces los que se van de aquí tienen que tener una filosofía bien clara de que eso mismo que acá se quiere esté dado en el otro lado, entonces la cuantificación es un poco más detallada y ya no podría la misión como concepto mío tiene que ser algo simple, que se entienda, porque mientras más se detalle es más grande y mientras más grande es, la gente menos lo entiende. 
No toma en cuenta nuevos componentes del producto, mercado, tecnología, rentabilidad. El mismo concepto, yo creo que como cuando hicimos la misión y la visión es contemplar y decir: ¿Realmente lo entiende nuestra gente? Podemos hacer una misión a veces y uno lee las misiones que son enormes de las empresas, entren a internet y se pueden dar cuenta que hay misiones y visiones que son de una página, pero cuando le preguntas a la gente que es lo que quiere, no lo entiende. Mientras más concisa, más detallada y más puntual sea la misión y la visión es más fácil para todos poder seguirla. Como nuestros valores también, nuestros valores son cinco: desarrollo humano, compromiso, atención al cliente, respeto y rentabilidad. Rentabilidad como un Factor de austeridad para poder hacer las cosas pensando en que también todo debe hacerse rentablemente porque si no, no hay sostenibilidad en el tiempo. Esas son cosas muy puntuales, pero a la pregunta de ustedes si estos, los comentarios de ustedes van, si es correcto para mí que no se revela responsabilidad ambiental y social que deben estar incluidas en la nueva misión.

CARVIMSA no ha desarrollado una misión para cada UEN. No considero porque sería formar tres empresas en una sola porque al formar tres empresas estamos formando tres grupos que piensas diferente o que no deben estar orientados, por lo menos la forma de pensar mía, yo veo todas las operaciones, Yanine también ve las operaciones, entonces el pensamiento, la forma de trabajo de cada uno tiene que estar orientado a poder participar en cada una de las unidades de negocio, hoy el gerente de planta de la corrugadora vino del molino, y antes el del molino vino de latas, y la gente que va trabajando ahorita como operadores como supervisores van cambiando pero van con una filosofía, el de mantenimiento también, el de calidad también, entonces yo creo que el pensamiento tiene que ser uno solo, es mi opinión, y creo que ustedes han venido también mi opinión, quizá es como un ejército que no tenga claro a donde ir y tengas una sección de la tropa que piense tengo una misión, otra que piense otra y otra que piense otra entonces ¿Cómo puedes unir? Somos más de 650 personas entonces tenemos que tener claro cuáles son las normas y los ideales y a donde queremos llegar por eso que hacemos algo en forma consolidada.

Ustedes han propuesto una adicional, a ver, me parece bien, ahí habría algunos otros sectores, por ejemplo, en qué sector podemos al papel higiénico no es embalaje, no es agroindustria, no es construcción y no es textil, entonces cuando tenemos una misión con tanto detalle estamos quitando, por ejemplo, donde ponemos el sector de las geomembranas, ¿saben lo que es una geomembrana? La geomembrana es una cuando ustedes están en el campo o en algún lugar una zona desértica, la geomembrana reemplaza a una piscina, ustedes hacen un hueco y ponen telas de plástico a lo largo del hueco, las pegan una con otra con un pegamento especial a esa temperatura y ustedes pueden echar agua y no filtra, son pozos de almacenamiento de agua que se pueden llenar cada cierto tiempo como una piscina sin goteo ni filtración. La geomembrana también la pueden ver en la costa verde cuando ustedes pasan y ven el cerro que tienen unas láminas para evitar que las piedras se vengan, encima unas mallas, esas mallas son geomembranas, la UEN de tubos hace los tubos para los rollos. Entonces, si me parece interesante, yo le ajustaría de repente un poco el tema de los sectores tendrían que poner todos los sectores y son muchos cada vez son más, por ejemplo, embalaje, agroindustria también está la de alimentos, por ejemplo, ustedes compran una galleta, esa envoltura viene en un rollo, ese rollo viene sobre un tuco, hay mucho es muy amplio. Me parece interesante salvo eso sería mi apreciación. 
La visión actual de CARVIMSA, igual ya lo hemos dicho, según ustedes es correcto no hay un desarrollo por cada área, también se debe revisar porque una sola presencia en el mercado agroindustrial si es importante pero no es la única tenemos que desarrollar otros productos.

Propuesta. Me parece bien, ya somos los líderes, ya no es una visión, somos los líderes en este momento, mantener el liderazgo seria quizá la misión porque con la cantidad de producción que tenemos somos los líderes. Un poco el tema de concentración, igual que en la misión si nosotros ponemos detalles estamos limitando un poco lo que queremos hacer, si ahorita queremos hacer, por ejemplo en la feria expo alimentaria, por ejemplo hay productos se van haciendo muebles o sillas sobre la base de tucos o tubos porque el tubo tiene mucha resistencia, yo puedo hacer esta mesa y puedo ponerle tubos de parantes y la va a aguantar sin problemas, es una resistencia mecánica muy alta, entonces limitamos, porque si uno hace una visión teóricamente esto tiene que ser algo a lo que queremos llegar entonces si nosotros limitamos o cortamos nuestra visión de repente estos son los clientes pero acá hay sectores que puedo entrar, si yo ya de por sí mi visión la corto para ir solamente para allá estoy perdiendo oportunidades de negocio, esa sería mi apreciación, se perdería eso, entonces ahí podrían ser más amplios todos los sectores que se necesite.

Una de las cosas que se va a hacer también en la revisión del planeamiento es también revisar los valores, yo estoy planteando la inclusión de un nuevo valor que es la innovación, esto nos permite avanzar en el tiempo, innovar en muchas cosas, en productos como lo hemos hecho, nosotros al introducirnos en el mercado de Tubos y Esquineros y darle a nuestros clientes cosas adicionales, le estamos dando productos que satisfacen una necesidad que no estaba satisfecha, porque le podemos dar tubos, le podemos cajas, le podemos dar papel a nuestros clientes. Nuestros tubos tienen una ventaja están hechos de esos Side roll que les dije, esos pedazos de bobina, esos Side roll son papeles que van a producción de cajas de exportación, entonces tienen una resistencia y calidad superior a la que hace la competencia, especialmente la competencia hace un papel para tubos, nosotros no hacemos un papel para tubos, tomamos lo que está en el mercado, lo que nos sobra, entonces le damos a la competencia un producto que es $30 \%$ más resistente.

\section{2. ¿En qué ciclo de vida considera que se encuentra CARVIMSA en lo que respecta a la UEN Tubos y Esquineros?}

Yo creo que estamos recién empezando, hemos sembrado mucho a lo largo de estos años y no es fácil, ¿creciendo? Claro estamos creciendo, pero yo soy más ambicioso, yo creo que todavía no hemos visto ni el $20 \%$ de lo que puede hacer la división. Entonces digo que estamos empezando recién, me dices más o menos cuando sentiré que estamos creciendo, el próximo año porque si vamos de 500 a 700 a 800 toneladas ya sentiré que estanos creciendo porque mi meta es llegar a 1000 toneladas el próximo año, entonces ahí seguimos creciendo, tenemos todavía mercado de países vecinos, tenemos que apuntar, pero primero hay que consolidarse en el mercado local.

\section{3. ¿Cuáles son las variables o competencias distintivas que requiere tener una empresa como CARVIMSA para obtener éxito?}

Yo creo que lo más importante es el servicio técnico, el servicio, tenemos que ser una empresa que le facilite al cliente desarrollo de nuevos productos, un gran servicio pre y post 
venta, un gran servicio de atención al cliente porque hacer tubos lo puede hacer cualquiera. El cliente más valora es el servicio, si te digo que el precio no es el primero, en este tipo de productos cuando nosotros hemos hecho encuestas, uno dice ¿qué es lo primero que quiere el cliente? uno por ahí piensa que es precio, pero nunca es precio, es entrega a tiempo, uno puede estar un centavo o dos centavos más abajo, pero si no le llega el producto y bloquea una exportación de un cliente, ¿Cuánto le cuesta? Es igual ¿por qué van a comprar a una tienda preferida de ustedes? porque van a encontrar una prenda que les guste. Yo creo que el servicio para mí es importante, pero un servicio como debe ser no de la boca para fuera, no sotros tenemos un área de servicio grande en la corrugadora, es grande porque justamente necesitamos que los clientes estén bien atendidos con respecto a sus solicitudes entonces el servicio es importante, la innovación también, porque las fechas de entrega y el precio y otras cosas más son replicables, el servicio y la innovación no porque eso es cultural, eso es de una organización. Precio cualquiera lo baja, producir un tipo de tubo de una manera también, haces la formulación, el tipo de papel, el tipo de pegamento y sale el tubo, pero el servicio no.

\section{4. ¿Cuál considera que es la ventaja competitiva de la compañía que Ud. Dirige?}

La ventaja competitiva de la división tubos es que puede disponer de una materia prima como es parte de la misma empresa, una materia prima a precio muy competitivo que le permite hacer un producto, a ver vamos al caso, si yo no utilizaría el papel sino lo residuo yo trasladaría un papel que me costaría mandarlo nuevamente al reproceso 200 dólares y lo estoy mandando al mercado a 700 dólares, eso es un aporte que tiene. La ventaja que tiene la división tubos es primero que tiene materia prima disponible, segundo que tiene un área técnica bastante buena que le permite desarrollar productos que tienen una diferencia importante con respecto a los del mercado.

En un tubo, si mi tubo es $30 \%$ más resistente, puedo hacer mi tubo con menos espesor, este es el tubo, si mi tubo es $30 \%$ más resistente que el de la competencia y la competencia está acostumbrada a usar este diámetro, entonces yo puedo decirle, puedo reducir el espesor porque tiene más resistencia, si yo le reduzco el espesor él puede poner más material, y si él exporta está aprovechando el flete, dando más producto pagando el mismo flete, entonces yo le estoy dando un beneficio adicional, un valor agregado, porque mi producto me permite darle eso. Además de la innovación que podemos tener con respecto a la fabricación del tubo, antes de nosotros, yo vi personalmente como se hacía, agarraba y veía el tubo, a ver ¿cuál es la prueba de calidad? Se hacía así, se hacía así y se pesaba, y eso es muy informal.

\section{5. ¿Cuáles son sus perspectivas del sector de tubos y esquineros, en cuanto al mercado?}

Cuando ingresamos al sector Tubos y Esquineros, encontramos en el mercado competidores familiares, es decir empresas familiares, con señores que algunos hacían las cosas porque lo habían hecho así siempre y cambiarles el chip es complicado. No lo han hecho y algunos ya están desapareciendo porque obviamente el crecimiento de CARVIMSA es en perjuicio de alguien. La competencia no se ha podido adecuar, entre otros aspectos, por inversión porque obviamente una máquina para medir la compresión axial no es barata y CARVIMSA la tiene.

Además, cuando hay una variación del precio del papel en el mercado internacional como la que hay, esas empresas que compran papel a terceros se ven perjudicadas también 
porque no pueden mantener un precio como CARVIMSA si lo puede hacer. El éxito de la operación de la división tubos y esquineros no solamente está en la rentabilidad si no en la eficiencia que le da al molino para que todo el side roll pueda ser usada, esa es la gran ventaja que tenemos.

Ahora el antiguo líder del mercado ya prácticamente está saliendo y nos está dejando, estamos creciendo justamente estas toneladas que les estoy diciendo, son toneladas de nuestros clientes, pero todavía hay toneladas que vienen de la competencia que vamos a agarrar. Entonces yo creo que no se adecuaron, nosotros hemos entrado a hacer una revolución, como concepto siempre me ha gustado hacer eso, siempre me ha gustado como las empresas que he dirigido ver qué cosa necesita el mercado. En relación con las perspectivas, comenzamos con 20 o 30 toneladas al mes y hoy estamos en 500. Y a partir de septiembre estamos en 700 y esperamos llegar a fin de año a 800 u 850 toneladas.

\section{6. ¿En cuanto a la segmentación de mercado, además de segmentar a sus clientes en agro, textil y construcción, existe otro tipo de segmentación?}

Normalmente los esquineros van para la exportación que en este caso es agroexportación sin embargo se usa en otros sectores también, es decir cualquier producto que sea paletizado. Entonces el abanico es más grande que agroindustria, puede ser textil, cosmético, industrial, pesca. Los tubos van a otro sector, donde van los Films o los plásticos, las cintas adhesivas, papel, polipropileno, celofán, plástico o lo que sea. Entonces es un mercado muy grande porque ocho de cada diez productos vienen en una caja de cartón. También segmentamos por volumen de compra. Los clientes grandes son los que tienen mayor volumen de compra que amerita mayores esfuerzos, en tema logístico y atención. Un cliente que consume dos toneladas al mes es diferente al que consume 100. Entonces el de 100 te va a exigir muchos más cambios, va a estar sujeto a mayores oscilaciones en la demanda.

\section{7. ¿Cuáles son las proyecciones de participación de mercado para los próximos cinco años?}

A cinco años todavía no la tenemos. Es muy complicado hacer una proyección a cinco años porque yo creo que nosotros entendemos muy bien que esto nos ayuda como empresa porque ayuda a la división molino. Hay otros molinos de papel en Lima y que pueden ver esa opción también interesante porque, así como nosotros tenemos remanentes o side roll o sobras, lo que quieran ustedes denominar, también ellos lo tienen. Y entonces que les costaría invertir para hacer eso, estamos hablando de empresas grandes, el líder del mercado no somos nosotros, somos el segundo. El líder del mercado también puede hacer esto, pero el líder del mercado tiene un gran problema: que su área de servicio es bastante limitado, limitado no porque no tenga gente, si no que no tiene el concepto que quizás tenemos nosotros aquí.

\section{8. ¿Qué variable o variables del entorno macroeconómico podrían repercutir en las proyecciones antes mencionadas?}

Se tienes dos variables de las cuales podrían repercutir en las proyecciones ya dadas por CARVIMSA: 
- Competencia: porque quizás en el corto plazo el líder del mercado de empaques de cartón podría hacerle atractivo esta operación, ya que este a su vez tiene un molino de papel, los cuales les generan bobinas Side Roll, lo cual en la actualidad lo reprocesan, si desearan optimizar sus procesos y costos lo podrían hacer.

- PBI: a menor consumo de la población podría afectarse la demanda local de lo que es Tubos, ya que la mayoría de los productos pasan por un embalado, y estos embalados tienen como insumo principal un tubo de cartón, pero a corto plazo no prevén variaciones, ya que sus dos clientes potenciales tienen plantas en Perú como en el exterior.

\section{9. ¿Considera a las importaciones de Tubos y Esquineros como un competidor potencial?}

En lo que es los productos de Tubos de cartón es muy difícil que existe competidor potencial, ya que estos productos generan volumen, por lo cual en un contenedor solo podrían entrar un aproximado de $3 \mathrm{tm}$ de tubos, el cual los importadores se verían afectados por los altos costos de fletes y gastos por nacionalización, ya que estos se cobran por contenedor y estos no serían rentables.

En los productos de esquineros de cartón si podría darse, pero CARVIMSA, quito mercado a Chile, por los mismo que pasa con los tubos, el cual son los costos altos de fletes y gastos de nacionalización, al no importar se ahorran en gastos por financiamiento y no tendrían que recurrir en solicitudes de cartas de créditos, ya que al importar, tienes que generar un pedido general y este tiene que pedir a los bancos aprobación de las cartas de créditos, el cual garantizan que las operaciones de la negociación sean realizadas, pero si ha mediado de su campaña le surgen contratiempos (Desastres Naturales) si podrían verse afectados, llegando al punto de no necesitar todos los esquineros pedidos, ya que al generar cartas de créditos no puedes romper el contrato dado, pero si trabaja con proveedores locales como CARVIMSA, podría hacer pedidos y despachos paulatinamente a los consumos que necesiten.

\section{En relación con los planes de inversión, ¿Actualmente existen proyectos de adquisición de nuevas maquinarias para mejorar los procesos y poder atender la demanda requerida?}

$\mathrm{Si}$, básicamente en lo que es inversiones se prevé adquirir fabricar dos máquinas tuberas, ya que nos proyectamos cerrar con un promedio de $850 \mathrm{tm}$, el cual nos va a demandar la fabricación de los tubos de cartón, la otra inversión es tener área, espacio, ampliar la planta y almacenamiento, ya que los tubos generan volúmenes, y al proyectarse para este año necesitamos mayor almacenamiento de los inventarios. 


\section{ANEXO 5. Transcripción de la Entrevista a la Asistente de Compras de OPP Film SA (Empresa no cliente)}

\begin{tabular}{|c|c|}
\hline \multicolumn{2}{|r|}{ Ficha Técnica del Entrevistado } \\
\hline Nombre & Melani Medina \\
\hline Edad & \\
\hline Nacionalidad & Peruana \\
\hline Cargo & Asistente de Compras de OPP Film SA \\
\hline Profesión & Ingeniera Industrial \\
\hline Ubicación & Av. San Pedro Mz. B Lote 40 Urb. San Vicente. Lurín \\
\hline Objetivo & $\begin{array}{l}\text { Obtener información de la percepción del cliente sobre la empresa } \\
\text { CARVIMSA. }\end{array}$ \\
\hline Preguntas & $\begin{array}{l}\text { 1. Coméntenos sobre el producto ¿Cuántas toneladas de Tubos consume su } \\
\text { empresa al mes? } \\
\text { 2. ¿Con cuántos proveedores de Tubos trabaja actualmente, podría nombrar } \\
\text { algunos de ellos? } \\
\text { 3. ¿Ha recibido la asesoría de una visita técnica? } \\
\text { 4. ¿Ha recibido charlas de capacitación sobre el uso y manipuleo de los Tubos } \\
\text { de cartón? } \\
\text { 5. ¿Ha visitado la planta de Tubos de Tubos de su proveedor CARVIMSA que } \\
\text { queda en Huachipa? } \\
\text { 6. A continuación, le presentamos una tabla con algunos factores importantes al } \\
\text { momento de comprar. Por favor indique su percepción del proveedor en cada } \\
\text { factor es muy bueno (1), bueno (2), regular (3) o malo (4). }\end{array}$ \\
\hline
\end{tabular}




\section{Cuestionario:}

1. Coméntenos sobre el producto ¿Cuántas toneladas de Tubos consume su empresa al mes?

\section{Rpta:}

\section{Toneladas}

1

2. ¿Con cuántos proveedores de Tubos trabaja actualmente, podría nombrar algunos de ellos?

Rpta:

Proveedores

Acinsa

CARVIMSA

\section{3. ¿Ha recibido la asesoría de una visita técnica por parte de CARVIMSA?}

\section{Rpta:}

$\mathrm{Si} \quad$ No

$\mathrm{x}$

Que comentarios le da a CARVIMSA por las cualidades ofrecidas.

Se adjunta cuadro de homologación:

\section{Cualidades}

Calidad del producto

Entrega de cantidades completas

Cumplimiento de fecha de entrega

Conocimiento técnico del ejecutivo de ventas

\section{Puntaje}

La calidad de los productos que brinda CARVIMSA son buenos ya que muestran resistencia en todos los tubos de cartón.

En lo particular siempre nos entregan cantidades exactas, es buena la entrega de cantidades.

Es regular las entregas a tiempo, les falta aún perfeccionar como por ejemplo la entrega inmediata.

Es bueno el conocimiento técnico del vendedor, demuestra que tiene conocimiento de las especificaciones de los productos. 
Comunicación de su ejecutivo de ventas

Respuesta para la solución de reclamos

Atención del área del servicio al cliente

Atención del personal de transporte

Atención del área de créditos y cobranzas

Emisión y entrega de certificados de calidad
Es buena la comunicación que se tiene con el vendedor, nos brinda ayuda y le da seguimiento hasta el día que se hace la entrega.

Es buena la reacción que tiene CARVIMSA, ya que nos dan soluciones.

La atención post venta es regular, aun no tenemos mucha comunicación con esa área.

Es buena, su atención ya que demuestran conocimiento de la entrega de documentación que nos brinda.

Es buena, ya que no ayudan con los saldos de nuestras cuentas.

Es buena, ya que nos entregan a tiempo.

4. ¿Ha recibido charlas de capacitación sobre el uso y manipuleo de los Tubos de cartón por parte de CARVIMSA?

\section{Rpta:}

$\mathrm{Si} \quad \mathrm{No}$

$\mathrm{X}$

5. ¿Ha visitado la planta de Tubos de Tubos de su proveedor CARVIMSA que queda en Huachipa?

\section{Rpta:}

$\mathrm{Si} \quad \mathrm{No}$

$\mathrm{X}$ 


\section{ANEXO 6. Transcripción de la Entrevista al Coordinador de Logística de Resinplast Holding SAC (Empresa Cliente de CARVIMSA)}

\begin{tabular}{|c|c|}
\hline \multicolumn{2}{|r|}{ Ficha Técnica del Entrevistado } \\
\hline Nombre & Carlos Salazar \\
\hline Edad & \\
\hline Nacionalidad & Peruana \\
\hline Cargo & Coordinador de Logística de Resinplast Holding SAC \\
\hline Profesión & Ingeniero Industrial \\
\hline Ubicación & Av. Benjamín Franklin Nº 233 ZI Santa Rosa. Ate \\
\hline Objetivo & $\begin{array}{l}\text { Obtener información de la percepción del cliente sobre la empresa } \\
\text { CARVIMSA. }\end{array}$ \\
\hline Preguntas & $\begin{array}{l}\text { 1. Coméntenos sobre el producto ¿Cuántas toneladas de Tubos consume su } \\
\text { empresa al mes? } \\
\text { 2. ¿Con cuántos proveedores de Tubos trabaja actualmente, podría nombrar } \\
\text { algunos de ellos? } \\
\text { 3. ¿Ha recibido la asesoría de una visita técnica? } \\
\text { 4. ¿Ha recibido charlas de capacitación sobre el uso y manipuleo de los Tubos } \\
\text { de cartón? } \\
\text { 5. ¿Ha visitado la planta de Tubos de Tubos de su proveedor CARVIMSA que } \\
\text { queda en Huachipa? } \\
\text { 6. A continuación, le presentamos una tabla con algunos factores importantes al } \\
\text { momento de comprar. Por favor indique su percepción del proveedor en cada } \\
\text { factor es muy bueno (1), bueno (2), regular (3) o malo (4). }\end{array}$ \\
\hline
\end{tabular}




\section{Cuestionario:}

1. Coméntenos sobre el producto ¿Cuántas toneladas de Tubos consume su empresa al mes?

Rpta:

Toneladas

1.30

2. ¿Con cuántos proveedores de Tubos trabaja actualmente, podría nombrar algunos de ellos?

Rpta:

Proveedores

CARVIMSA

Acinsa

3. ¿Ha recibido la asesoría de una visita técnica por parte de CARVIMSA?

Rpta:

$\mathrm{Si} \quad$ No

$\mathrm{X}$

Que comentarios le da a CARVIMSA por las cualidades ofrecidas.

Se adjunta cuadro de homologación:

\section{Cualidades}

Calidad del producto

Entrega de cantidades completas

Cumplimiento de fecha de entrega

\section{Puntaje}

La calidad de los productos que brinda CARVIMSA es buena ya que muestran resistencia.

Es buena ya que las unidades de medida que manejamos es kilos y a veces tienen pequeñas variaciones de peso, pero no muchas.

Es regular las entregas a tiempo, ya que han tenido retrasos por temas de congestión vehicular. 
Conocimiento técnico del ejecutivo de ventas

Comunicación de su ejecutivo de ventas

Respuesta para la solución de reclamos

Atención del área del servicio al cliente

Atención del personal de transporte

Atención del área de créditos y cobranzas

Emisión y entrega de certificados de calidad
Es bueno el conocimiento técnico del vendedor, demuestra que tiene conocimiento de las especificaciones de los productos.

Es muy buena la comunicación que se tiene con el vendedor, nos brinda mucha ayuda.

Es buena la reacción que tiene CARVIMSA, ya que nos dan soluciones.

La atención post venta es buena, escucha nuestros reclamos y les dan seguimiento.

Es buena, su atención ya que demuestran conocimiento de la entrega de documentación que nos brinda.

Es buena, ya que no ayudan con los saldos de nuestras cuentas.

Es buena, ya que nos entregan a tiempo.

4. ¿Ha recibido charlas de capacitación sobre el uso y manipuleo de los Tubos de cartón por parte de CAR VIMSA?

\section{Rpta:}

Si No

$\mathrm{X}$

5. ¿Ha visitado la planta de Tubos de Tubos de su proveedor CARVIMSA que queda en Huachipa?

\section{Rpta:}

$\mathrm{Si} \quad \mathrm{No}$

$\mathrm{X}$ 


\section{ANEXO 7. Transcripción de la Entrevista al Asistente de Compras de Solpack SAC (Empresa Cliente de CARVIMSA)}

\begin{tabular}{|c|c|}
\hline \multicolumn{2}{|r|}{ Ficha Técnica del Entrevistado } \\
\hline Nombre & Karina Paredes \\
\hline Edad & \\
\hline Nacionalidad & Peruana \\
\hline Cargo & Asistente de Compras de Solpack SAC \\
\hline Profesión & Ingeniera Industrial \\
\hline Ubicación & $\begin{array}{l}\text { Calle Los Cedros Mz C Lote } 20 \text { Urb. Bajo el Fundo Huachipa - San Juan de } \\
\text { Lurigancho }\end{array}$ \\
\hline Objetivo & $\begin{array}{l}\text { Obtener información de la percepción del cliente sobre la empresa } \\
\text { CARVIMSA. }\end{array}$ \\
\hline Preguntas & $\begin{array}{l}\text { 1. Coméntenos sobre el producto ¿Cuántas toneladas de Tubos consume su } \\
\text { empresa al mes? } \\
\text { 2. ¿Con cuántos proveedores de Tubos trabaja actualmente, podría nombrar } \\
\text { algunos de ellos? } \\
\text { 3. ¿Ha recibido la asesoría de una visita técnica? } \\
\text { 4. ¿Ha recibido charlas de capacitación sobre el uso y manipuleo de los Tubos } \\
\text { de cartón? } \\
\text { 5. ¿Ha visitado la planta de Tubos de Tubos de su proveedor CARVIMSA que } \\
\text { queda en Huachipa? } \\
\text { 6. A continuación, le presentamos una tabla con algunos factores importantes al } \\
\text { momento de comprar. Por favor indique su percepción del proveedor en cada } \\
\text { factor es muy bueno (1), bueno (2), regular (3) o malo (4). }\end{array}$ \\
\hline
\end{tabular}




\section{Cuestionario:}

1. Coméntenos sobre el producto ¿Cuántas toneladas de Tubos consume su empresa al mes?

Rpta:

Toneladas

100

2. ¿Con cuántos proveedores de Tubos trabaja actualmente, podría nombrar algunos de ellos?

Rpta:

Proveedores

CARVIMSA

3. ¿Ha recibido la asesoría de una visita técnica por parte de CARVIMSA?

Rpta:

$\mathrm{Si} \quad$ No

$\mathrm{X}$

Que comentarios le da a CARVIMSA por las cualidades ofrecidas.

Se adjunta cuadro de homologación:

\section{Cualidades}

Calidad del producto

Entrega de cantidades completas

\section{Puntaje}

La calidad de los productos que brinda CARVIMSA es buena ya que muestran resistencia.

Es buena ya que las unidades de medida que manejamos es kilos y a veces tienen pequeñas variaciones de peso, pero no muchas. 
Cumplimiento de fecha de entrega

Conocimiento técnico del ejecutivo de ventas

Comunicación de su ejecutivo de ventas

Respuesta para la solución de reclamos

Atención del área del servicio al cliente

Atención del personal de transporte

Atención del área de créditos y cobranzas

Emisión y entrega de certificados de calidad
Es regular las entregas a tiempo, ya que han tenido retrasos por temas de congestión vehicular.

Es bueno el conocimiento técnico del vendedor, demuestra que tiene conocimiento de las especificaciones de los productos.

Es regular la comunicación ya que sentimos que no le da el seguimiento de nuestros productos hasta el día de entrega.

Es regular la reacción que tiene CARVIMSA, ya que se demoran para dar soluciones a nuestros problemas.

La atención post venta es buena, escucha nuestros reclamos y les dan seguimiento.

Es buena, su atención ya que demuestran conocimiento de la entrega de documentación que nos brinda.

Es buena, ya que no ayudan con los saldos de nuestras cuentas.

Es buena, ya que nos entregan a tiempo.

4. ¿Ha recibido charlas de capacitación sobre el uso y manipuleo de los Tubos de cartón por parte de CAR VIMSA?

\section{Rpta:}

$\mathrm{Si} \quad \mathrm{No}$

$\mathrm{X}$

5. ¿Ha visitado la planta de Tubos de Tubos de su proveedor CARVIMSA que queda en Huachipa?

\section{Rpta:}

$\mathrm{Si} \quad$ No




\section{ANEXO 8. Transcripción de la Entrevista al Jefe de Almacén de Film Pack SAC (Empresa Cliente de CARVIMSA)}

\begin{tabular}{l|l}
\hline \multicolumn{1}{l}{ Dombre } & \multicolumn{1}{c}{ Ficha Técnica del Entrevistado } \\
\hline Edad & $\begin{array}{l}\text { Peruana } \\
\text { Jefe de Almacén de Film Pack SAC }\end{array}$ \\
\hline Nacionalidad & $\begin{array}{l}\text { Ingeniero Industrial } \\
\text { Avargo }\end{array}$ \\
\hline Profesión & $\begin{array}{l}\text { Huachipa. Huachipa } \\
\text { Obtener información de la percepción del cliente sobre la empresa } \\
\text { CARVIMSA. }\end{array}$ \\
\hline Ubicación & $\begin{array}{l}\text { 1. Coméntenos sobre el producto ¿Cuántas toneladas de Tubos consume su } \\
\text { empresa al mes? } \\
\text { 2. ¿Con cuántos proveedores de Tubos trabaja actualmente, podría nombrar } \\
\text { algunos de ellos? } \\
\text { 3. ¿Ha recibido la asesoría de una visita técnica? } \\
\text { 4. ¿Ha recibido charlas de capacitación sobre el uso y manipuleo de los Tubos } \\
\text { de cartón? } \\
\text { 5. ¿Ha visitado la planta de Tubos de Tubos de su proveedor CARVIMSA que } \\
\text { queda en Huachipa? } \\
\text { 6. A continuación, le presentamos una tabla con algunos factores importantes al } \\
\text { momento de comprar. Por favor indique su percepción del proveedor en cada } \\
\text { factor es muy bueno (1), bueno (2), regular (3) o malo (4). }\end{array}$ \\
\hline
\end{tabular}




\section{Cuestionario:}

1. Coméntenos sobre el producto ¿Cuántas toneladas de Tubos consume su empresa al mes?

Rpta:

Toneladas

20

2. ¿Con cuántos proveedores de Tubos trabaja actualmente, podría nombrar algunos de ellos?

Rpta:

Proveedores

CARVIMSA

Acinsa

3. ¿Ha recibido la asesoría de una visita técnica por parte de CARVIMSA?

\section{Rpta:}

$\mathrm{Si} \quad$ No

$\mathrm{X}$

Que comentarios le da a CARVIMSA por las cualidades ofrecidas.

Se adjunta cuadro de homologación:

\section{Cualidades}

Calidad del producto

Entrega de cantidades completas

\section{Puntaje}

La calidad de los productos que brinda CARVIMSA es buena ya que muestran resistencia.

Es regular ya que a veces no nos llegan las cantidades completas en los pallets. 
Cumplimiento de fecha de entrega

Conocimiento técnico del ejecutivo de ventas

Comunicación de su ejecutivo de ventas

Respuesta para la solución de reclamos

Atención del área del servicio al cliente

Atención del personal de transporte

Atención del área de créditos y cobranzas

Emisión y entrega de certificados de calidad
Es regular las entregas a tiempo, ya que han tenido retrasos por temas de congestión vehicular.

Es bueno el conocimiento técnico del vendedor, demuestra que tiene conocimiento de las especificaciones de los productos.

Es buena la comunicación ya que no brinda apoyo y le da seguimiento de nuestros productos hasta el día de entrega.

Es regular la reacción que tiene CARVIMSA, ya que se demoran para dar soluciones a nuestros problemas.

La atención post venta es buena, escucha nuestros reclamos y les dan seguimiento.

Es buena, su atención ya que demuestran conocimiento de la entrega de documentación que nos brinda.

Es buena, ya que no ayudan con los saldos de nuestras cuentas.

Es buena, ya que nos entregan a tiempo.

4. ¿Ha recibido charlas de capacitación sobre el uso y manipuleo de los Tubos de cartón por parte de CAR VIMSA?

\section{Rpta:}

$\mathrm{Si} \quad$ No

$\mathrm{X}$

5. ¿Ha visitado la planta de Tubos de Tubos de su proveedor CARVIMSA que queda en Huachipa?

\section{Rpta:}

$\mathrm{Si} \quad$ No




\section{ANEXO 9. Transcripción de la Entrevista al Coordinadora de Logística de Peruplast SAC (Empresa Cliente de CARVIMSA)}

\begin{tabular}{l|l}
\hline & \multicolumn{1}{c}{ Ficha Técnica del Entrevistado } \\
\hline Nombre & Nadhia Pérez \\
\hline Edad & Peruana \\
Nacionalidad & Coordinadora de Logística de Peruplast SAC \\
\hline Cargo & $\begin{array}{l}\text { Ingeniera Industrial } \\
\text { Jirón Santa Clorinda } N^{\circ} 1136 \text { Urbanización Palao. San Martín de Porres }\end{array}$ \\
\hline Profesión & $\begin{array}{l}\text { Obtener información de la percepción del cliente sobre la empresa } \\
\text { CARVIMSA. }\end{array}$ \\
\hline Objetivo & $\begin{array}{l}\text { 1. Coméntenos sobre el producto ¿Cuántas toneladas de Tubos consume su } \\
\text { empresa al mes? } \\
\text { 2. ¿Con cuántos proveedores de Tubos trabaja actualmente, podría nombrar } \\
\text { algunos de ellos? } \\
\text { 3. ¿Ha recibido la asesoría de una visita técnica? } \\
\text { 4. ¿Ha recibido charlas de capacitación sobre el uso y manipuleo de los Tubos } \\
\text { de cartón? } \\
\text { 5. ¿Ha visitado la planta de Tubos de Tubos de su proveedor CARVIMSA que } \\
\text { queda en Huachipa? } \\
\text { 6. A continuación, le presentamos una tabla con algunos factores importantes al } \\
\text { momento de comprar. Por favor indique su percepción del proveedor en cada } \\
\text { factor es muy bueno (1), bueno (2), regular (3) o malo (4). }\end{array}$ \\
\hline
\end{tabular}




\section{Cuestionario:}

1. Coméntenos sobre el producto ¿Cuántas toneladas de Tubos consume su empresa al mes?

Rpta:

\section{Toneladas}

29

2. ¿Con cuántos proveedores de Tubos trabaja actualmente, podría nombrar algunos de ellos?

Rpta:

Proveedores

CARVIMSA

Acinsa

3. ¿Ha recibido la asesoría de una visita técnica por parte de CARVIMSA?

Rpta:

$\begin{array}{ll}\mathrm{Si} & \text { No } \\ & \mathrm{X}\end{array}$

Que comentarios le da a CARVIMSA por las cualidades ofrecidas.

Se adjunta cuadro de homologación:

\section{Cualidades}

Calidad del producto

Entrega de cantidades completas

Cumplimiento de fecha de entrega

Conocimiento técnico del ejecutivo de ventas

Comunicación de su ejecutivo de ventas

\section{Puntaje}

La calidad de los productos que brinda CARVIMSA es buena ya que muestran resistencia.

Es buena ya que siempre nos llegan las cantidades correctas.

Es regular las entregas a tiempo, ya que han tenido retrasos por temas de congestión vehicular.

Es bueno el conocimiento técnico del vendedor, demuestra que tiene conocimiento de las especificaciones de los productos.

Es buena la comunicación ya que no brinda apoyo y le da seguimiento de nuestros productos hasta el día de entrega. 
Respuesta para la solución de reclamos

Atención del área del servicio al cliente

Atención del personal de transporte

Atención del área de créditos y cobranzas

Emisión y entrega de certificados de calidad
Es buena la reacción que tiene CARVIMSA, ya que nos ayudan con las soluciones lo más pronto posible.

La atención post venta es buena, escucha nuestros reclamos y les dan seguimiento.

Es regular su atención ya que no demuestran conocimiento de la entrega de documentación que nos brinda.

Es buena, ya que no ayudan con los saldos de nuestras cuentas.

Es buena, ya que nos entregan a tiempo.

4. ¿Ha recibido charlas de capacitación sobre el uso y manipuleo de los Tubos de cartón por parte de CARVIMSA?

\section{Rpta:}

$\mathrm{Si} \quad \mathrm{No}$

$\mathrm{X}$

5. ¿Ha visitado la planta de Tubos de Tubos de su proveedor CARVIMSA que queda en Huachipa?

\section{Rpta:}

$\mathrm{Si} \quad$ No

$\mathrm{X}$ 
ANEXO 10. Análisis de los resultados de las entrevistas realizadas del 19 al 31 de julio de 2017

1. Clientes Encuestados

\begin{tabular}{|r|l|l|l|}
\hline \multicolumn{1}{|c|}{ CLIENTE } & CONT ACTO & CARGO \\
\hline 1 & OPP FILM S.A. & Srta. Melani Medina & ASISTENTE DE COMPRAS \\
\hline 2 & RESINPLAST S.A.C & Sr. Carlos Salazar & COORDINADORA DE LOGISTICA \\
\hline 3 & SOLPACK S.A.C. & Srta. Karina Paredes & ASISTENTE DE COMPRAS \\
\hline 4 & FILM PACK S.A.C. & David Heredia & JEFE DE ALMACEN \\
\hline 5 & PERUPLAST & Nadhia Perez / Wendy Nicho & COORDINADORA DE LOGISTICA \\
\hline
\end{tabular}

2. Desarrollo de Pregunta 1: ¿Cuántas toneladas de tubos consume su empresa al mes?

\begin{tabular}{|r|l|l|l|r|}
\hline \multicolumn{1}{|c|}{ CLIENTE } & CONT ACTO & CARGO & $\begin{array}{l}\text { Toneladas } \\
\text { Consumidas }\end{array}$ \\
\hline 1 & OPP FILM S.A. & Srta. Melani Medina & ASISTENTE DE COMPRAS & 1.00 \\
\hline 2 & RESINPLAST S.A.C & Sr. Carlos Salazar & COORDINADORA DE LOGISTICA & 1.30 \\
\hline 3 & SOLPACK S.A.C. & Srta. Karina Paredes & ASISTENTE DE COMPRAS & 100.00 \\
\hline 4 & FILM PACK S.A.C. & David Heredia & JEFE DE ALMACEN & 20.00 \\
\hline 5 & PERUPLAST & Nadhia Perez / Wendy Nicho & COORDINADORA DE LOGISTICA & 29.00 \\
\hline
\end{tabular}

3. Desarrollo de Pregunta 2: ¿Con cuántos proveedores de tubos trabaja actualmente?

\begin{tabular}{|l|c|c|c|}
\hline Cliente & Prove edor 1 & Prove edor 2 & Total Prove edores \\
\hline OPP FILM S.A. & Cavimsa & Acinsa & 2 \\
\hline RESINPLAST S.A.C & Cavimsa & Acinsa & 2 \\
\hline SOLPACK S.A.C. & Cavimsa & & 1 \\
\hline FILM PACK S.A.C. & Cavimsa & Acinsa & 2 \\
\hline PERUPLAST & Cavimsa & Acinsa & 2 \\
\hline
\end{tabular}

4. Desarrollo de Pregunta 3: ¿Ha recibido la asesoría de una visita técnica?

\begin{tabular}{|c|c|}
\hline \multicolumn{2}{|c|}{ Puntuacion } \\
\hline Muy Bueno & 1 \\
\hline Bueno & 2 \\
\hline Regular & 3 \\
\hline Malo & 4 \\
\hline
\end{tabular}

\begin{tabular}{|c|c|c|c|c|c|c|c|}
\hline No & cliente & Fecha & $\begin{array}{c}\text { Calidad del } \\
\text { Producto }\end{array}$ & $\begin{array}{c}\text { Entrega de } \\
\text { Cantidades } \\
\text { Completas }\end{array}$ & $\begin{array}{c}\text { Cumplimiento } \\
\text { de la } \\
\text { Fecha de } \\
\text { Entrega }\end{array}$ & $\begin{array}{c}\text { Conocimiento } \\
\text { técnico del } \\
\text { Ejecutivo de } \\
\text { ventas }\end{array}$ & $\begin{array}{c}\text { Comunicacion } \\
\text { con su } \\
\text { Ejecutivo de } \\
\text { ventas }\end{array}$ \\
\hline & OPPFILMS.A. & 2 & 2 & 3 & 2 & 2 \\
\hline 2 & RESINPLAST S.A.C & $24 / 07 / 2017$ & 2 & 2 & 3 & 2 & 1 \\
\hline 3 & SOLPACK S.A.C. & $26 / 07 / 2017$ & 2 & 2 & 3 & 2 & 3 \\
\hline 4 & FILMPACK S.A.C. & $28 / 07 / 2017$ & 2 & 3 & 3 & 2 & 2 \\
\hline 5 & PERUPLAST & $31 / 07 / 2017$ & 2 & 2 & 3 & 2 & 2 \\
\hline
\end{tabular}




\begin{tabular}{|c|l|c|c|c|c|c|c|c|}
\hline No & cliente & Fecha & $\begin{array}{c}\text { Respuesta para } \\
\text { la solución de } \\
\text { reclamos }\end{array}$ & $\begin{array}{c}\text { Atención del Area } \\
\text { de Servicio al } \\
\text { Cliente }\end{array}$ & $\begin{array}{c}\text { Atención de } \\
\text { Personal de } \\
\text { Transporte }\end{array}$ & $\begin{array}{c}\text { Atención del Area } \\
\text { de Créditos y } \\
\text { Cobranza }\end{array}$ & $\begin{array}{c}\text { Emisión y } \\
\text { Entrega de } \\
\text { Certificados de } \\
\text { Calidad }\end{array}$ & $\begin{array}{c}\text { Nivel de satisfacciòn } \\
\text { respecto al servicio y } \\
\text { producto que brinda } \\
\text { CARVIMSA }\end{array}$ \\
\hline 1 & OPP FILM S.A. & $19 / 07 / 2017$ & 2 & 3 & 2 & 2 & 2 & SATISFECHO \\
\hline 2 & RESINPLAST S.A.C & $24 / 07 / 2017$ & 2 & 2 & 2 & 2 & 2 & SATISFECHO \\
\hline 3 & SOLPACK S.A.C. & $26 / 07 / 2017$ & 3 & 2 & 2 & 2 & 2 \\
\hline 4 & FILM PACK S.A.C. & $28 / 07 / 2017$ & 3 & 2 & 2 & 2 & 2 \\
\hline 5 & PERUPLAST & $31 / 07 / 2017$ & 2 & 2 & 3 & 2 & 2 & SATISFECHO \\
\hline
\end{tabular}

5. Desarrollo de Pregunta 4: ¿Ha recibido alguna charla de capacitación por parte de la empresa CARVIMSA, sobre el uso y manipuleo de los tubos de cartón?

\begin{tabular}{|r|l|l|}
\hline & \multicolumn{1}{|c|}{ CLIENTE } & Pregunta 4 \\
\hline 1 & OPP FILM S.A. & NO \\
\hline 2 & RESINPLAST S.A.C & NO \\
\hline 3 & SOLPACK S.A.C. & NO \\
\hline 4 & FILM PACK S.A.C. & NO \\
\hline 5 & PERUPLAST & NO \\
\hline
\end{tabular}

6. Desarrollo de Pregunta 5: ¿Ha visitado la planta de tubos de proveedor CARVIMSA que queda en Huachipa?

\begin{tabular}{|r|l|l|}
\hline & \multicolumn{1}{|c|}{ CLIENTE } & Pregunta 5 \\
\hline 1 & OPP FILM S.A. & SI \\
\hline 2 & RESINPLAST S.A.C & SI \\
\hline 3 & SOLPACK S.A.C. & NO \\
\hline 4 & FILM PACK S.A.C. & NO \\
\hline 5 & PERUPLAST & NO \\
\hline
\end{tabular}




\begin{tabular}{|c|c|c|}
\hline \multicolumn{3}{|c|}{ Clientes en General } \\
\hline Calidad del producto & Cantidad & $\%$ \\
\hline Muy Bueno & 0 & $0 \%$ \\
\hline Bueno & 5 & $100 \%$ \\
\hline Regular & 0 & $0 \%$ \\
\hline Malo & 0 & $0 \%$ \\
\hline Total & $\mathbf{5}$ & $100 \%$ \\
\hline
\end{tabular}

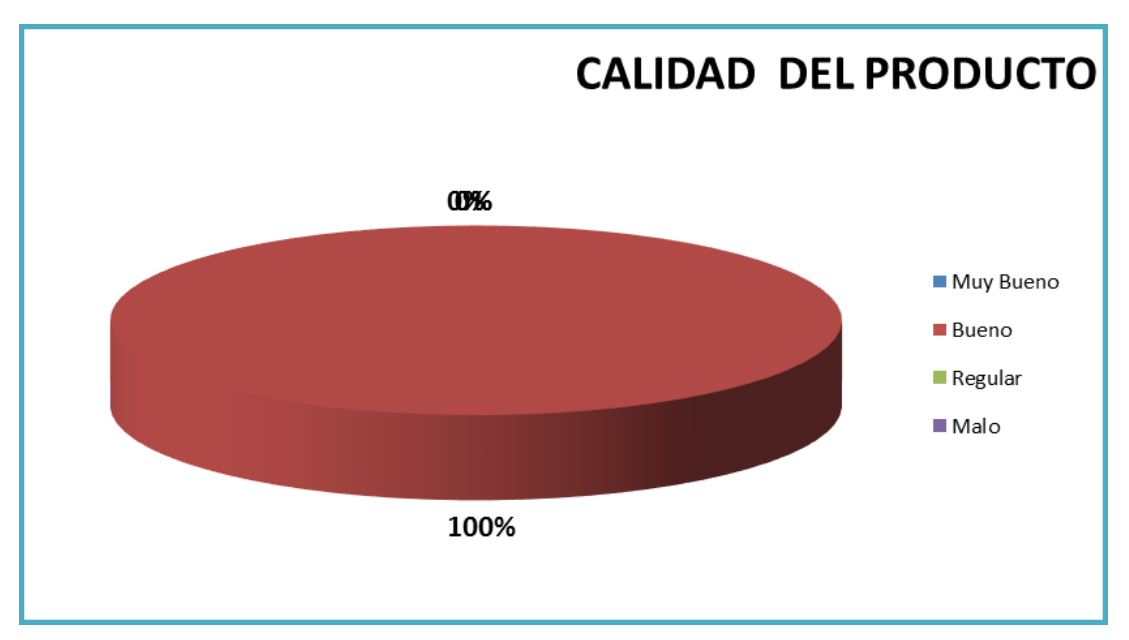

\begin{tabular}{|c|c|c|}
\hline \multicolumn{3}{|c|}{ Clientes en General } \\
\hline & & \\
\hline $\begin{array}{c}\text { Entrega de Cantidades } \\
\text { Completas }\end{array}$ & Cantidad & $\%$ \\
\hline Muy Bueno & 0 & $0 \%$ \\
\hline Bueno & 4 & $80 \%$ \\
\hline Regular & 1 & $20 \%$ \\
\hline Malo & 0 & $0 \%$ \\
\hline Total & $\mathbf{5}$ & $\mathbf{1 0 0} \%$ \\
\hline
\end{tabular}

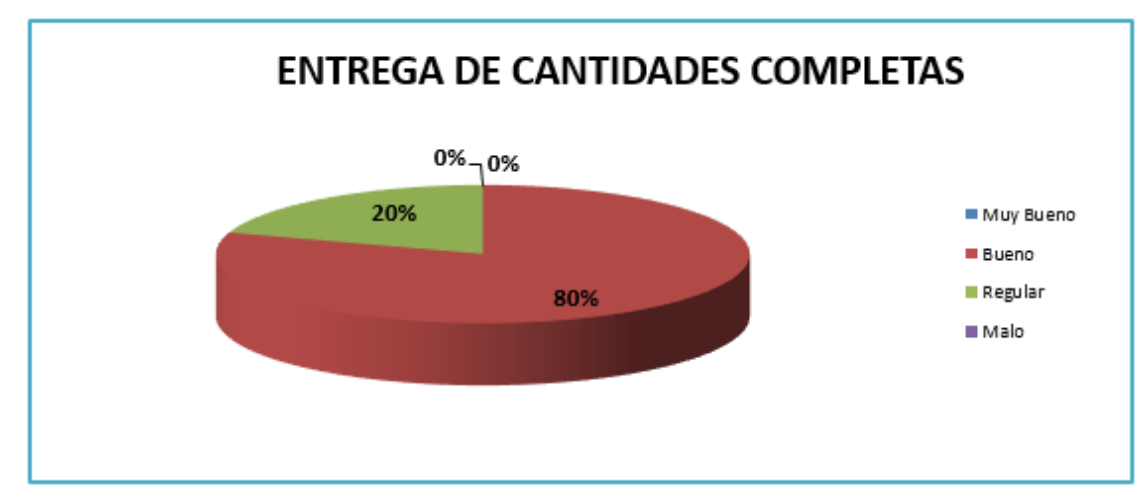




\begin{tabular}{|c|c|c|}
\hline \multicolumn{2}{|c|}{ Clientes en General } \\
\hline $\begin{array}{c}\text { Cumplimiento de Fecha de } \\
\text { entrega }\end{array}$ & Cantidad & $\%$ \\
\hline Muy Bueno & 0 & $0 \%$ \\
\hline Bueno & 0 & $0 \%$ \\
\hline Regular & 5 & $100 \%$ \\
\hline Malo & 0 & $0 \%$ \\
\hline Total & $\mathbf{5}$ & $\mathbf{1 0 0} \%$ \\
\hline
\end{tabular}

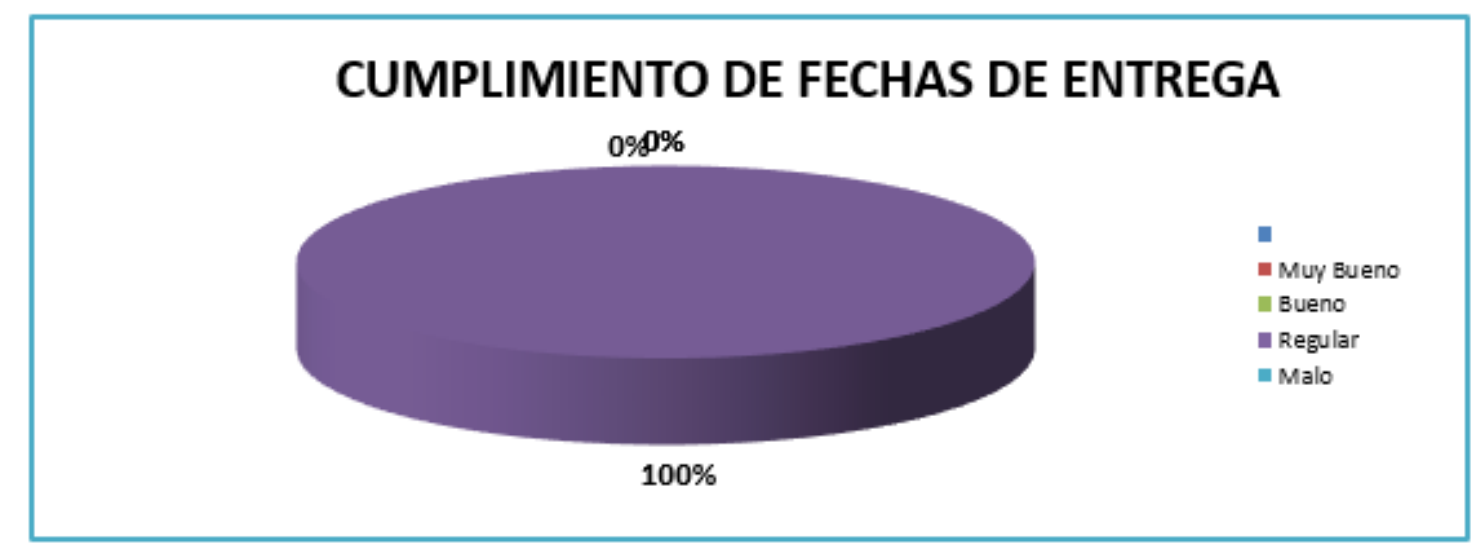

\begin{tabular}{|c|c|c|}
\hline \multicolumn{2}{|c|}{ Clientes en General } \\
$\begin{array}{c}\text { Conocimiento Técnico de su } \\
\text { Ejecutivo de ventas }\end{array}$ & Cantidad & $\%$ \\
\hline Muy Bueno & 0 & $0 \%$ \\
\hline Bueno & 5 & $100 \%$ \\
\hline Regular & 0 & $0 \%$ \\
\hline Malo & 0 & $0 \%$ \\
\hline Total & $\mathbf{5}$ & $\mathbf{1 0 0} \%$ \\
\hline
\end{tabular}

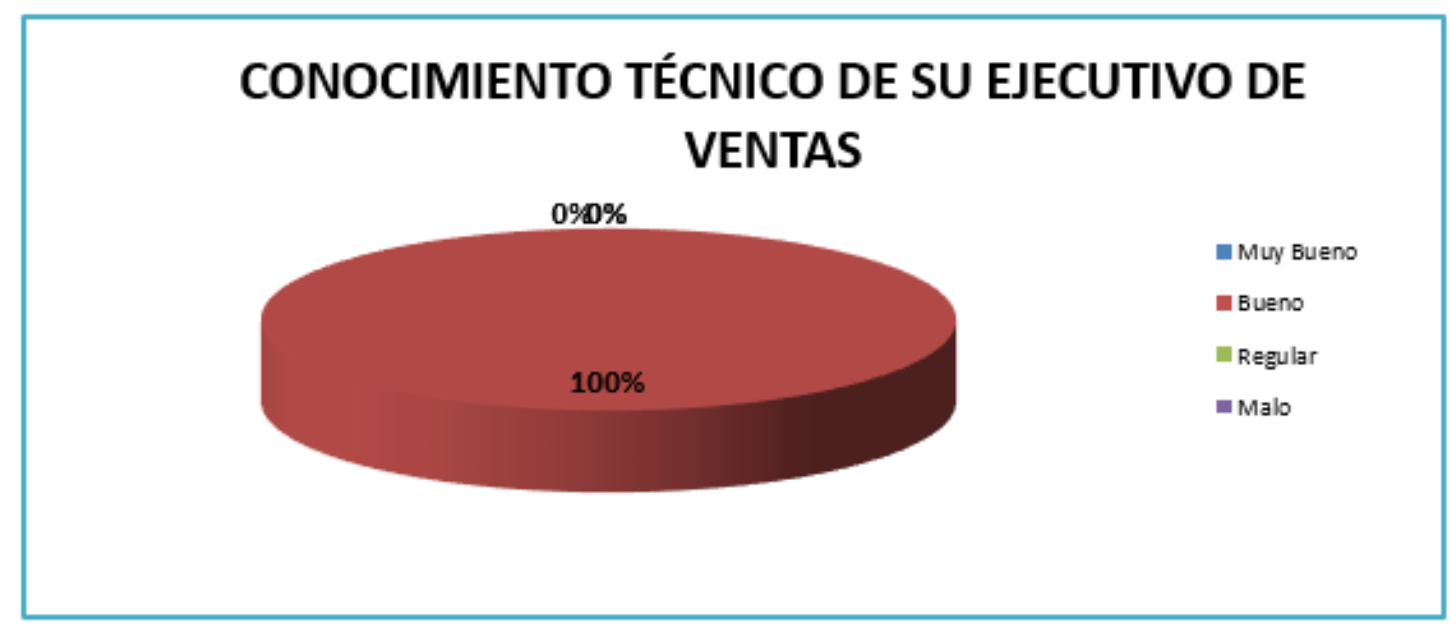




\begin{tabular}{|c|c|c|}
\hline \multicolumn{3}{|c|}{ Clientes en General } \\
\hline $\begin{array}{c}\text { Comunicación con su Ejecutivo } \\
\text { de ventas }\end{array}$ & Cantidad & $\%$ \\
\hline Muy Bueno & 1 & $20 \%$ \\
\hline Bueno & 3 & $60 \%$ \\
\hline Regular & 1 & $20 \%$ \\
\hline Malo & 0 & $0 \%$ \\
\hline Total & $\mathbf{5}$ & $\mathbf{1 0 0} \%$ \\
\hline
\end{tabular}

\section{COMUNICACIÓN CON SU EJECUTIVO DE VENTAS}

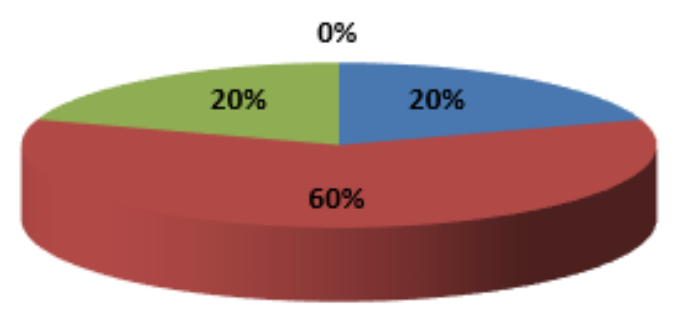

\begin{tabular}{|c|c|c|}
\hline \multicolumn{2}{|c|}{ Clientes en General } \\
$\begin{array}{c}\text { Respuesta para la solución de } \\
\text { reclamos }\end{array}$ & Cantidad & $\%$ \\
\hline Muy Bueno & 0 & $0 \%$ \\
\hline Bueno & 3 & $60 \%$ \\
\hline Regular & 2 & $40 \%$ \\
\hline Malo & 0 & $0 \%$ \\
\hline Total & $\mathbf{5}$ & $\mathbf{1 0 0} \%$ \\
\hline
\end{tabular}

\section{RESPUESTA PARA LA SOLUCIÒN DE RECLAMOS}

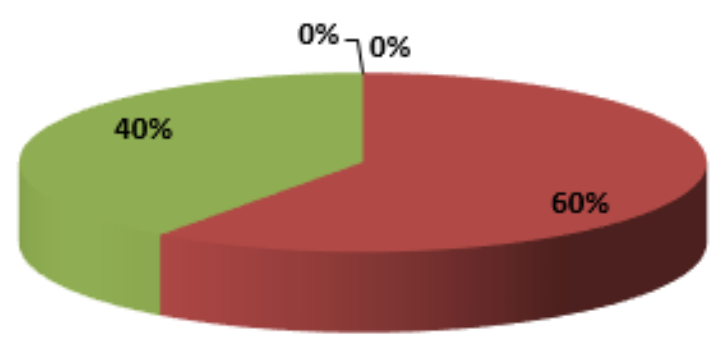




\begin{tabular}{|c|c|c|}
\hline \multicolumn{3}{|c|}{ Clientes en General } \\
\hline $\begin{array}{c}\text { Atención del Área de Servicio al } \\
\text { Cliente }\end{array}$ & Cantidad & $\%$ \\
\hline Muy Bueno & 0 & $0 \%$ \\
\hline Bueno & 4 & $80 \%$ \\
\hline Regular & 1 & $20 \%$ \\
\hline Malo & 0 & $0 \%$ \\
\hline Total & $\mathbf{5}$ & $\mathbf{1 0 0} \%$ \\
\hline
\end{tabular}

\section{ATENCIÓN DEL AREA DE SERVICIO AL CLIENTE}

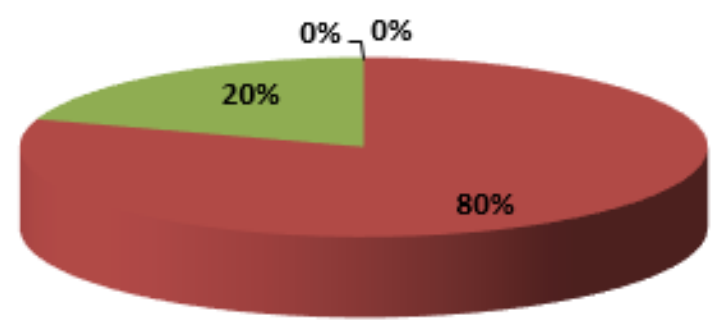

\section{Clientes en General}

Atención de Personal de

Transporte Cantidad

$\%$

Muy Bueno

Bueno

Regular

Malo

Total

\begin{tabular}{|c|c|}
\hline 0 & $0 \%$ \\
\hline 4 & $80 \%$ \\
\hline 1 & $20 \%$ \\
\hline 0 & $0 \%$ \\
\hline $\mathbf{5}$ & $\mathbf{1 0 0} \%$ \\
\hline
\end{tabular}

\section{ATENCIÓN DEL PERSONAL DE TRANSPORTE}

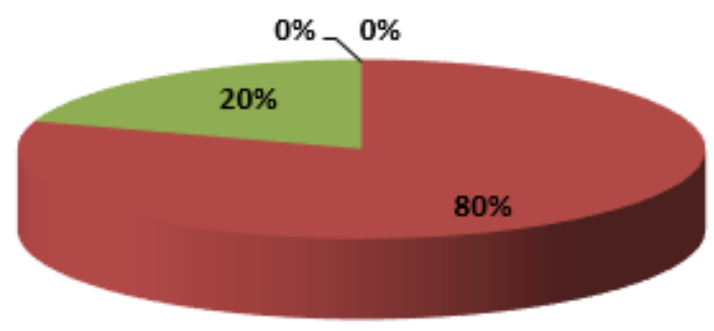




\begin{tabular}{|c|c|c|}
\hline \multicolumn{2}{|c|}{ Clientes en General } \\
\hline $\begin{array}{c}\text { Atención del Área de créditos y } \\
\text { cobranzas }\end{array}$ & Cantidad & $\%$ \\
\hline Muy Bueno & 0 & $0 \%$ \\
\hline Bueno & 5 & $100 \%$ \\
\hline Regular & 0 & $0 \%$ \\
\hline Malo & 0 & $0 \%$ \\
\hline Total & $\mathbf{5}$ & $100 \%$ \\
\hline
\end{tabular}

\section{ATENCIÓN DEL ÁREA DE CRÉDITOS Y COBRANZAS}

0\%\%

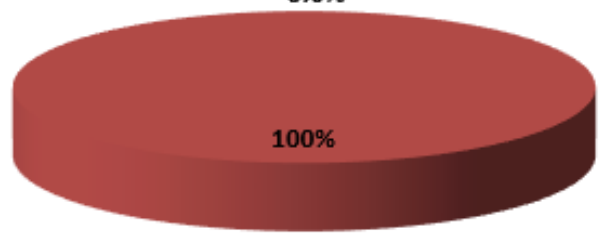

\begin{tabular}{|c|c|c|}
\hline \multicolumn{2}{|c|}{ Clientes en General } \\
\hline $\begin{array}{c}\text { Emisión y entrega de certificados } \\
\text { de calidad }\end{array}$ & Cantidad & $\%$ \\
\hline Muy Bueno & 0 & $0 \%$ \\
\hline Bueno & 5 & $100 \%$ \\
\hline Regular & 0 & $0 \%$ \\
\hline Malo & 0 & $0 \%$ \\
\hline Total & $\mathbf{5}$ & $\mathbf{1 0 0} \%$ \\
\hline
\end{tabular}

\section{EMISIÓN Y ENTREGA DE CERTIFICADOS DE}

\section{CALIDAD}

$09 \%$

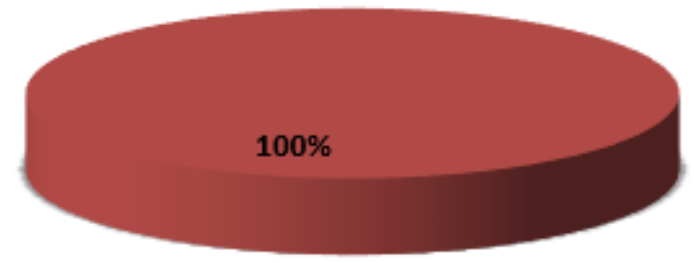




\begin{tabular}{|c|c|c|}
\hline \multicolumn{3}{|c|}{ Clientes en General } \\
\hline $\begin{array}{c}\text { Nivel de satisfacciòn respecto al } \\
\text { servicio y producto que brinda } \\
\text { CARVIMSA }\end{array}$ & Cantidad & $\%$ \\
\hline MUY SATISFECHO & 0 & $0 \%$ \\
\hline SATISFECHO & 5 & $100 \%$ \\
\hline REGULARMENTE SATISFECHO & 0 & $0 \%$ \\
\hline NADA SATISFECHO & 0 & $0 \%$ \\
\hline Total & $\mathbf{5}$ & $\mathbf{1 0 0} \%$ \\
\hline
\end{tabular}

Nivel de satisfacciòn respecto al servicio y producto que brinda CARVIMSA $0 \% \%$

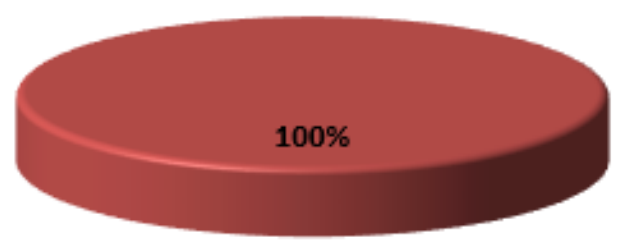

MUY SATISFECHO

GSATISFECHO 


\begin{tabular}{|c|c|c|c|}
\hline \multirow{4}{*}{ Pregunta 3 } & $\begin{array}{c}\text { ¿Ha recibido la asesoría de una } \\
\text { visita técnica ? }\end{array}$ & Cantidad & $\%$ \\
\cline { 2 - 4 } & $\mathrm{Si}$ & 2 & $40.0 \%$ \\
\cline { 2 - 4 } & No & 3 & $60.0 \%$ \\
\cline { 2 - 4 } & Total & 5 & $100.0 \%$ \\
\hline
\end{tabular}

\section{¿Ha recibido la asesoría de una visita técnica ?}

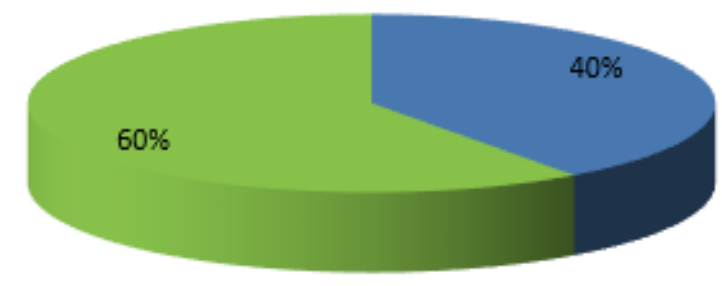

\begin{tabular}{|c|l|c|c|}
\hline \multirow{4}{*}{ Pregunta 4 } & $\begin{array}{l}\text { ¿Ha recibido alguna charla de } \\
\text { capacitación sobre el uso y } \\
\text { manipuleo del papel? }\end{array}$ & Cantidad & $\%$ \\
\cline { 2 - 4 } & $\mathrm{Si}$ & 0 & $0 \%$ \\
\cline { 2 - 4 } & $\mathrm{No}$ & 5 & $100 \%$ \\
\cline { 2 - 4 } & Total & 5 & $100 \%$ \\
\hline
\end{tabular}

\section{¿Ha recibido alguna charla de capacitación sobre el uso y manipuleo del papel?}

$0 \%$

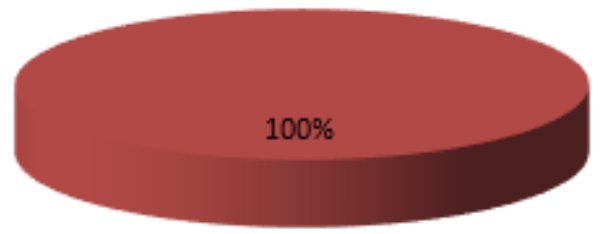

\begin{tabular}{|c|l|c|c|}
\hline \multirow{4}{*}{ Pregunta 5 } & $\begin{array}{l}\text { ¿Ha visitado nuestra División } \\
\text { Molino en Huachipa? }\end{array}$ & Cantidad & $\%$ \\
\cline { 2 - 4 } & $\mathrm{Si}$ & 2 & $40 \%$ \\
\cline { 2 - 4 } & $\mathrm{No}$ & 3 & $60 \%$ \\
\cline { 2 - 4 } & Total & 5 & $100 \%$ \\
\hline
\end{tabular}


362

¿Ha visitado nuestra División Molino en

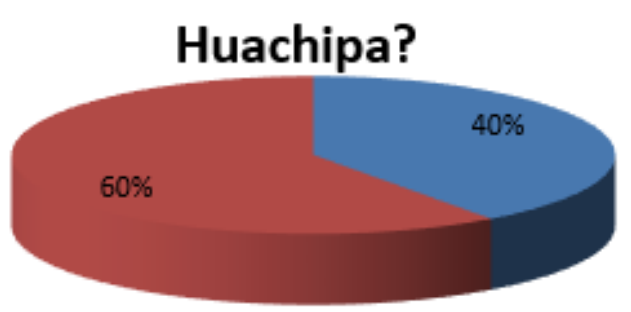

$=5 \mathrm{i}$
$=$ No 


\section{ANEXO 11. Transcripción de la Entrevista al Gerente de Comercio Exterior de la Cámara de Comercio de Lima}

\begin{tabular}{ll}
\hline \multicolumn{1}{c}{ Ficha Técnica del Entrevistado } \\
\hline Nombre & Carlos García Jerí \\
\hline Nacionalidad & Peruana \\
\hline Cargo & Gerente de Comercio Exterior de la Cámara de Comercio de Lima \\
\hline Objetivo & Obtener información sobre el sector manufacturero (Cartón y Envases) \\
\hline & 1. ¿Cuáles son las proyecciones de crecimiento para el sector manufacturero? \\
& 2. ¿Qué variable o variables del entorno macroeconómico considera claves para \\
& el crecimiento del sector cartonero? \\
& 3. ¿Cuál ha sido la tendencia en los últimos años de las exportaciones \\
& agroindustriales? \\
& 4. ¿Cuáles son las perspectivas para las exportaciones textiles, existe data sobre \\
& las exportaciones de telas en forma tubular? \\
& 5. ¿Qué iniciativas gubernamentales existen para promover el desarrollo del \\
& comercio exterior de las industrias que se encuentran en el sector cartonero? \\
\hline
\end{tabular}


1. ¿Cuáles son las proyecciones de crecimiento para el sector manufacturero?

La Cámara de Comercio esperaba un crecimiento de 3.9\% en el 2017, aunque es posible un ajuste a la baja.

2. ¿Qué variable o variables del entorno macroeconómico considera claves para el crecimiento del sector cartonero?

El desarrollo del comercio exterior será clave, sobre todo las industrias con potencial de crecimiento como las agroexportaciones. Otros sectores manufactureros vinculados a la industria cartonera no tienen potencial de crecimiento en el 2017.

Las variables que pueden impactar en el crecimiento son las inversiones (pública y privada) y la recaudación tributaria vía la formalización y el incremento de productividad.

3. ¿Cuál ha sido la tendencia en los últimos años de las exportaciones agroindustriales?

$\mathrm{Al}$ alza, con tasas altas gracias al incremento de áreas habilitadas, el incremento de inversiones en el sector, el ingreso de nuevos cultivos y la aceleración de los protocolos sanitarios con importantes países compradores.

4. ¿Cuáles son las perspectivas para las exportaciones textiles, existe data sobre las exportaciones de telas en forma tubular?

Perú exporta muy pocos textiles, el fuerte está en confecciones. En los dos casos la tendencia es a la baja, cayendo de forma sostenida desde el 2011.

5. ¿Qué iniciativas gubernamentales existen para promover el desarrollo del comercio exterior de las industrias que se encuentran en el sector cartonero? 
Las medidas de promoción del comercio exterior q se vienen dando no son sectoriales, son transversales a la industria, buscando promover el valor agregado y los servicios.

PROMPERU tienen programas de promoción comercial por sectores, pero no son "medidas". 


\section{ANEXO 12. Focus Group Clima Organizacional de la UEN Tubos y Esquineros de CARVIMSA}

La parte operativa de la UEN está conformada por 76 trabajadores, el área administrativa lo conforman cuatro jefaturas: el jefe de producción, el jefe de calidad, el jefe de despacho y el jefe de ventas todos a nivel de jefaturas, actualmente no existen gerencias para la UEN. En total la UEN está conformada por 80 trabajadores.

Cabe mencionar, que debido a los trabajos de característica manual todos los trabajadores operativos son hombres y las jefaturas no cuentan con personal de género femenino.

Como se observa en la siguiente figura, la concentración de trabajadores se encuentra en el rango de edad de 26 a 33 años y en un menor porcentaje, se encuentran los trabajadores entre un rango de edad de 42 años a más. Para efectos de la realización del focus group se organizó en 3 sesiones cada una con trabajadores de rango de edad distinto para que la muestra sea variada.

\section{CANTIDAD DE TRABAJADORES POR RANGO DE EDAD}

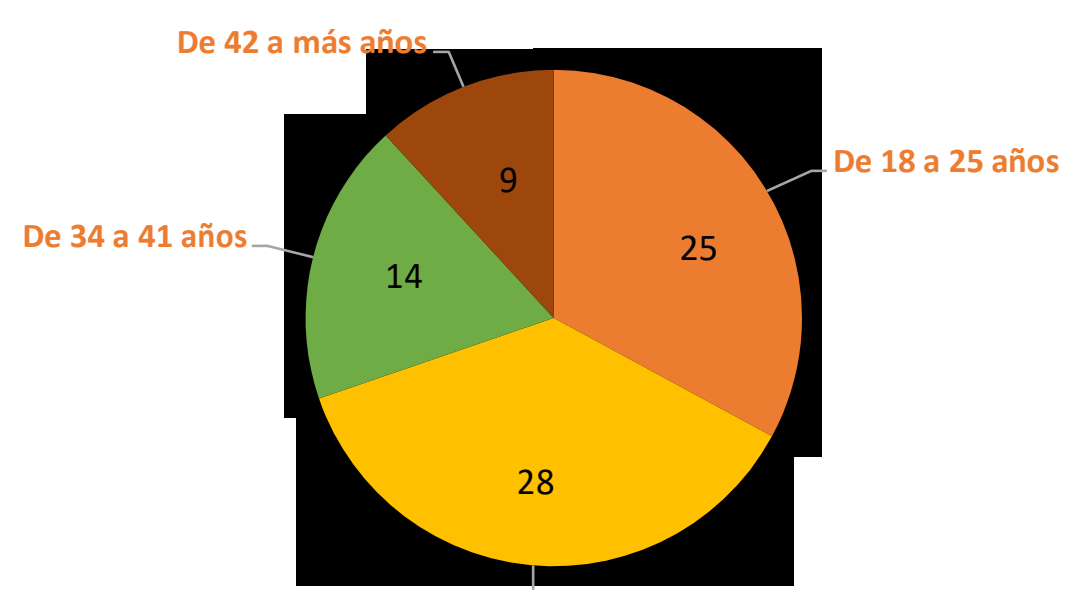

De 26 a 33 años 
Así mismo, en esta UEN, la mayoría de los trabajadores no cuentan con estudios superiores como se observa en el siguiente gráfico solo 2 de ellos tienen estudios universitarios y 2 tienen estudios técnicos. En este caso también se trabajó con grupos de diferente grado de instrucción.

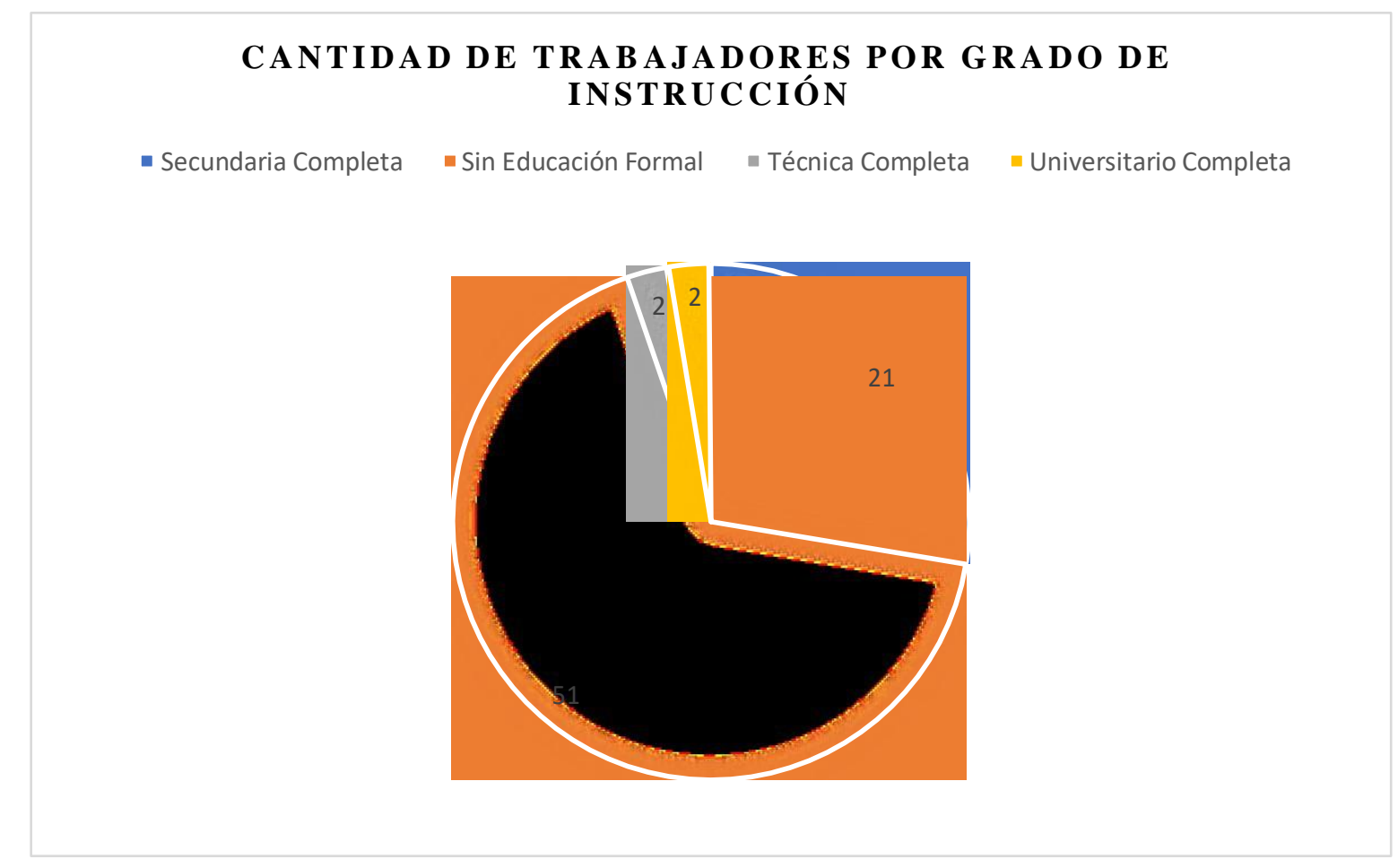

Las variables y dimensiones abordadas en el focus group en relación con las encuestas proporcionadas por la empresa respecto al año 2017, son las siguientes:

\section{Variable Comunicación}

Relaciones Sociales internas

Confianza en el Grupo de Trabajo

Comunicación con los superiores

Relación con otros compañeros

\section{Variable Condiciones de trabajo}

Ambiente físico del puesto de trabajo

Higiene y Seguridad Laboral

Remuneraciones, compensaciones y beneficios

Uniformes y ropa de trabajo

Horario de Trabajo y conciliación vida personal laboral 


\begin{tabular}{ll}
\hline Variable Liderazgo & Variable Capacitación \\
\hline Dimensión Dirección & Capacitaciones mejoran el desempeño laboral \\
Dimensión Estímulo a Excelencia & Capacitaciones internas \\
Dimensión Estímulo de Trabajo en & \\
Equipo & Capacitaciones externas \\
Dimensión Solución de Conflictos & Titulo o certificación por las capacitaciones \\
Retroalimentación & Capacitaciones presenciales \\
Delegación & Capacitaciones virtuales
\end{tabular}

\begin{tabular}{ll}
\hline Variable Identificación y Compromiso & Variables Demográficas \\
\hline Identificación con el puesto de trabajo & Género \\
Estabilidad & Formación \\
Identificación con la Organización & Área \\
& Edad
\end{tabular}

Ficha Técnica - Estudio Cualitativo

\begin{tabular}{|c|l|}
\hline Metodología & $\begin{array}{l}\text { Se utilizó la técnica del Focus Group que consistió en } \\
\text { dinámicas de grupo efectuadas con } 6 \text { personas con } \\
\text { características homogéneas, dirigidas por una persona del } \\
\text { área de RRHH con experiencia en la moderación. }\end{array}$ \\
\hline $\begin{array}{l}\text { Las sesiones se desarrollaron sobre la base de una guía de } \\
\text { pautas elaborada por el grupo y previamente aprobadas } \\
\text { por RRHH }\end{array}$ \\
\hline Universo & $\begin{array}{l}\text { Hombres de edades comprendidas entre los } 18 \text { años y } 42 \\
\text { años a más }\end{array}$ \\
\hline Realización de Dinámicas & $\begin{array}{l}\text { Las dinámicas de grupo se realizaron en el mes de } \\
\text { diciembre del año 2018, en la planta de Carvimsa } \\
\text { localizada en Huachipa }\end{array}$ \\
\hline
\end{tabular}

Para la selección de los grupos se tomaron en cuenta las variables de edad, el área en la cual laboran que son 4 área de producción, despacho, calidad y ventas, por último se consideró el grado de instrucción. 

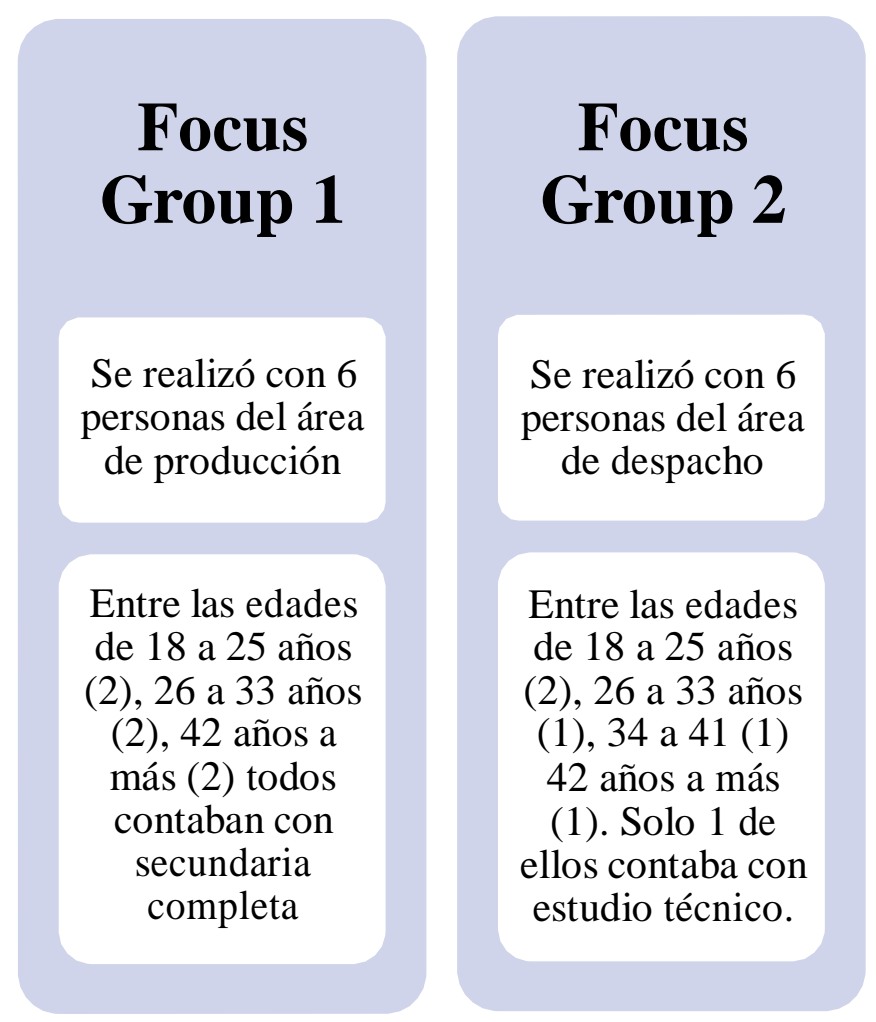

\section{Focus Group 3}

Se realizó con 6 personas del área de calidad

Entre las edades de 18 a 25 años (1), 26 a 33 años (2), 34 a 41 (2) 42 años a más (1). Solo 1 de ellos contaba con estudio universitario.

\section{Focus Group 4}

Se realizó con 6 personas del área de ventas

Entre las edades de 18 a 25 años (3), 26 a 33 años (3). En este grupo 1 persona contaba con estudio técnico y 1 con estudio universitario. 